UNIVERSIDAD NACIONAL DE LA PLATA

FACULTAD DE HUMANIDADES Y CIENCIAS DE LA EDUCACIÓN

SECRETARIA DE POSGRADO

DOCTORADO EN CIENCIAS SOCIALES

\title{
“HACER PARTOS Y PARIR: HACIA UNA SOCIOLOGÍA DE LA ATENCIÓN MÉDICA DE EMBARAZOS Y PARTOS.
}

EXPERIENCIAS DE MUJERES-MADRES, VARONES-PADRES Y PROFESIONALES DE LA SALUD DE LA PLATA (2013-2019)".

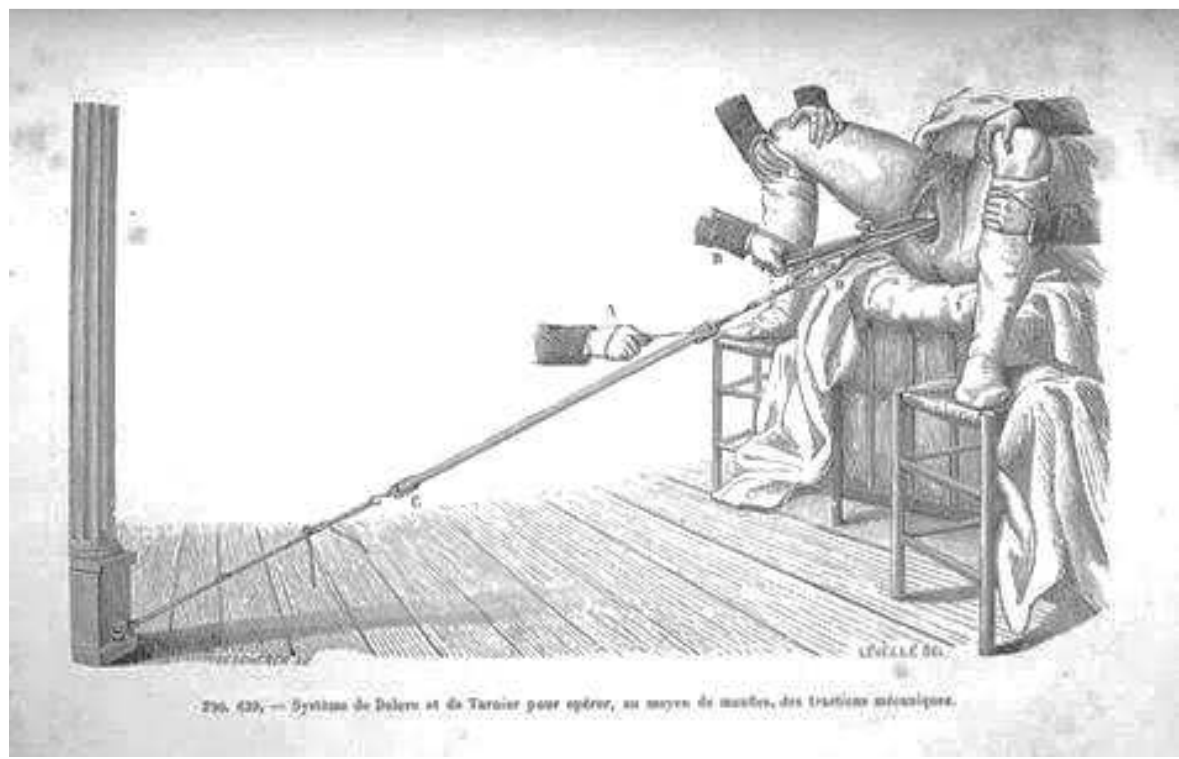

\section{BELÉn CASTRILLO}

-TESIS PARA OPTAR POR EL GRADO DE DOCTORA EN CIENCIAS SOCIALES-

DiRECTORA: DRA. LICIA PAGNAMENTO (UNLP)

MAYO DE 2019 
Imagen de portada: Método de tracción axial de Delore. El método de tracción axial de Delore empleando poleas y cuerdas atadas al fórceps de Tarnier en un parto. Estos métodos tan agresivos son de una época en que una cesárea era una muerte casi segura, y se usaban principalmente para intentar salvar a la mujer. "Histoire des accouchements chez tous les peuples" por G. J. Witkowski. 1890. 
A Juana y Clara, cuyos nacimientos gestaron esta tesis. 


\section{INDICE}

AGRADECIMIENTOS

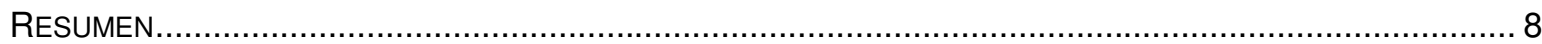

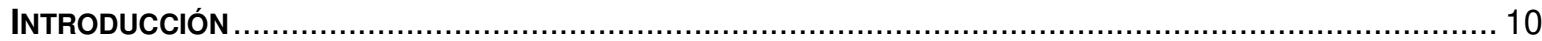

Capítulo 1. Gestando una sociología de la atención médica de embarazos y partos. estado

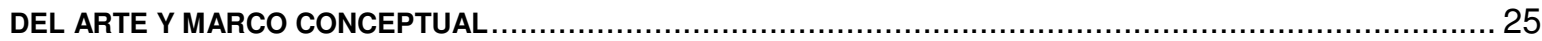

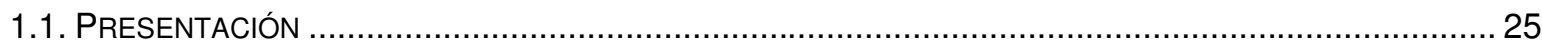

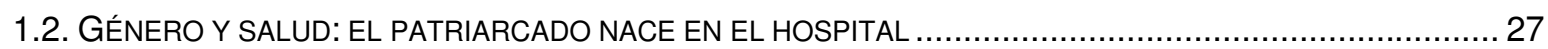

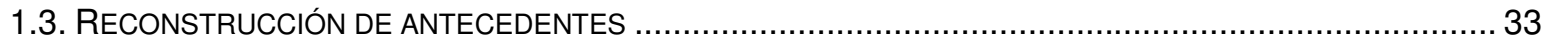

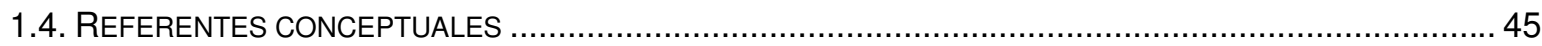

1.5. SOCIOLOGÍA DE LA ATENCIÓN MÉDICA DE EMBARAZOS Y PARTOS .............................................. 51

CAPÍtULO 2. MARCO METOdOLÓGICO. DECISIONES METOdOLÓGICAS Y EJERCICIO DE REFLEXIVIDAD ....... 73

2.1. EL QUÉ: OBJETIVOS Y PREGUNTAS DE INVESTIGACIÓN......................................................... 73

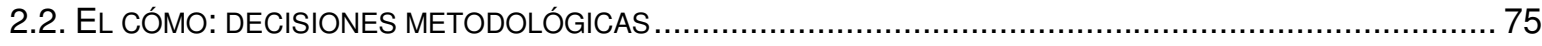

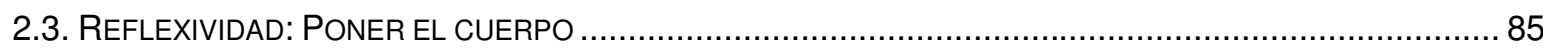

Capítulo 3. Las políticas del parto. Marco regulatorio y contextual. Sistema de salud y POLÍTICAS PÚBLICAS DE ATENCIÓN AL EMBARAZO Y PARTO PARA EL CASO DE ESTUDIO......................... 93

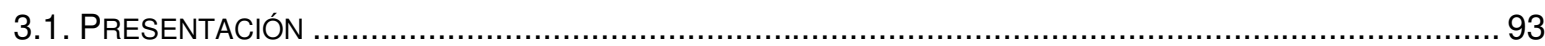

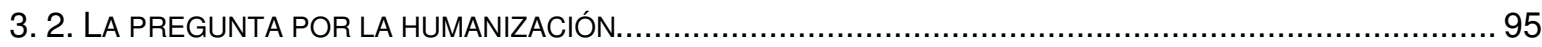

3.3. LAS GUÍAS Y LOS LINEAMIENTOS DE LA POLÍTICA DE HUMANIZACIÓN ............................................ 96

3.4. CARACTERÍSTICAS DE LA IMPLEMENTACIÓN DE LA POLÍTICA DE HUMANIZACIÓN DEL PARTO EN LA PLATA 104

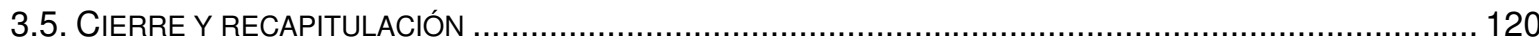

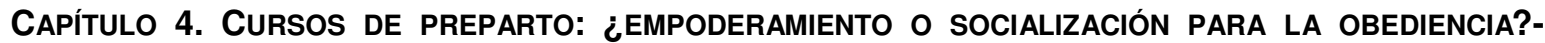
INTERVENCIONES MÉDICAS EN LOS PROCESOS DE EMBARAZO ................................................ 122

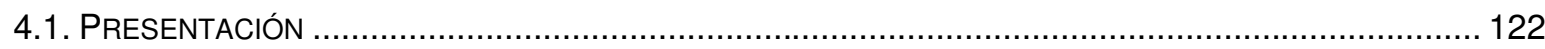

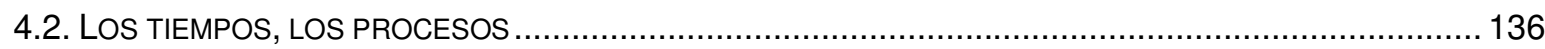

4.3.“¿CÓMO SÉ QUE ESTOY EN TRABAJO DE PARTO?”: CONOCIMIENTO DEL CUERPO MEDIADO POR EL SABER

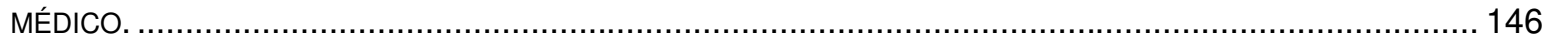

4.4. SOCIALIZACIÓN PARA LA OBEDIENCIA O EMPODERAMIENTO PARA LA AUTONOMÍA .......................... 154

4.5. EL CASO ATÍPICO: ENCUENTROS PRENATALES DEL “GRUPO DE PARTO DOMICILIARIO”...................... 168

4.6. A MODO DE CIERRE Y RECAPITULACIÓN: LAS EXPERIENCIAS CONCRETAS …............................. 176 
Capítulo 5. HACER (O ACOMPAÑAR) PARTOS. INTERVENCIONES MÉdicAS EN LOS PROCESOS DE PARTO

5.1. PRESENTACIÓN 179

5.2. CONSTRUCCIÓN DEL HABITUS MÉDICO OBSTÉTRICO: APRENDER A HACER PARTOS. 181

5.3. EL CAMPO PROFESIONAL OBSTÉTRICO COMO CAMPO DE DISPUTA 204

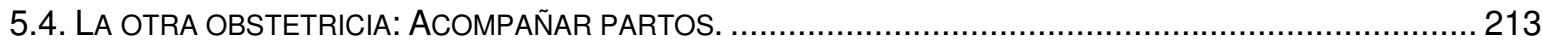

5.5. A MODO DE CIERRE Y RECAPITULACIÓN: HACER PARTOS RESPETADOS. 222

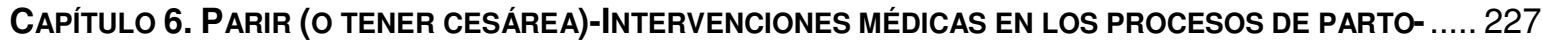

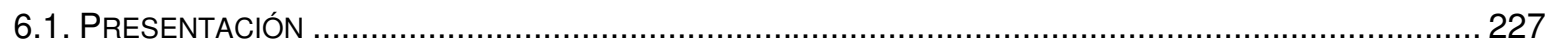

6. 2. PARIR/TENER CESÁREA Y PONER EL CUERPO: VISIÓN DE LAS MUJERES-MADRES ........................... 232

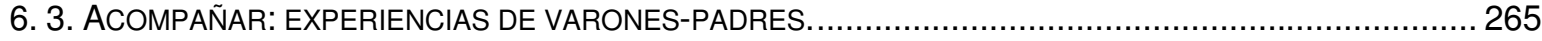

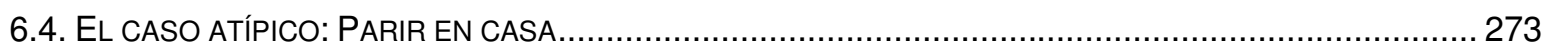

6.5. VIOLENCIA OBSTÉTRICA: EL NACIMIENTO DEL ACTIVISMO POR EL PARTO RESPETADO .....................2279

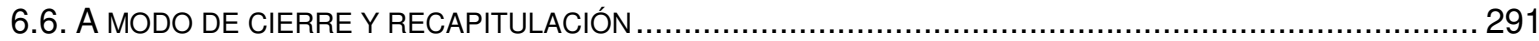

CONCLUSIONES.GRISES Y PUENTES EN LAS EXPERIENCIAS DE ATENCIÓN DE EMBARAZOS Y PARTOS..... 293

REFERENCIAS BIBLIOGRÁFICAS .303

\section{NOTA DE LA AUTORA: \\ MI TEXTO, MI DECISIÓN}

Como se trata de una tesis eminentemente feminista, busqué devolver el lugar central a las mujeres en este trabajo, a partir del uso del lenguaje inclusivo. En este caso en particular, escribi con " $x$ " suplantando las vocales que asignan género a algunos sustantivos (por ejemplo la masculinización masiva con la "e" en trabajadores o la "o" en médicos). Asimismo, utilicé las comillas para todos aquéllos fragmentos textuales y en ellos no intervine su utilización del lenguaje masculino "universal". Es decir, no modifiqué el lenguaje utilizado por Ixs entrevistadxs ni intervine la transcripción de las entrevistas.

Además, escribí esta tesis en primera persona del singular, como un modo de asumir el compromiso académico y político de ser la persona que dice y afirma, sin por ello desconocer o renunciar a que el conocimiento es una producción colectiva. 


\section{AgRAdeCIMIENTOS}

Aunque esta tesis lleve mi firma, hay en ella condensado años de apoyo, aporte, contribuciones, lectura y sostén de muchas personas y espacios de trabajo e intercambio. A todxs ellxs quiero expresarles mi agradecimiento.

A Licia, mi directora, amiga, compañera, referente. Esta tesis no podría haberse hecho sin este equipo-dúo de trabajo que formamos hace ocho años, en el que establecimos que la principal prioridad es el bienestar, el disfrute y la coherencia. Gracias por tus lecturas, comentarios, el apoyo constante y el espacio perfecto entre la autonomía y la guía académica y afectiva. Mi partera de lujo desde que se gestó esta tesis, que apostó por un tema poco conocido, resistido e invisibilizado. Hacer ciencia con vos es un lujo para mí.

A nivel institucional quiero agradecer a todxs Ixs que conforman el CIMeCS, mi lugar de trabajo desde el 2011. A Amalia Eguía por recibirme en su casa, y en su proyecto/equipo de investigación con Susana Ortale en mis comienzos. A Eugenia Rausky y Leticia Muñiz Terra, actuales directoras del centro y grandes compañeras. A Corina, por todas las mañanas de catarsis en la secretaria juntas. A todxs Ixs que compartieron seis años de almuerzos hablando de partos y embarazos, a quienes me leyeron, me escucharon, me acompañaron y me dejaron ser la aparata que soy.

Menciones especiales a Flor por prestarme su casa como casa de partos de esta tesis; a Sabri por el cariño, la lectura, el acompañamiento y la seguridad; y a Sil, por ser tan generosa conmigo y una amiga tan hermosa y referente para mí a nivel laboral pero, sobre todo, personal y afectivo.

Gracias particularmente a dos amigas que me dio el centro: Lau y Magda, gracias por el apoyo constante, la fuerza y el sostén afectivo dentro y fuera de la cancha de la academia. ¡Las quiero!

Al equipo de investigación sobre salud que formamos hace cinco años con Licia, Cintia, Hernán, Diana, Jime, Ludmila y Nati. Gracias por la lectura y por este equipo amistoso, placentero y de disfrute.

Al IdlHCS y con él al CONICET por financiar mi última etapa de la tesis y acogerme en su seno. Gracias también a la UNLP y a la CIC-PBA por financiar los comienzos de esta investigación y apostar a hacer ciencias sociales.

Finalmente, en lo institucional, gracias al Doctorado en Ciencias Sociales de la FaHCE y la Secretaria de Posgrado, en particular a Martin y Marina, por allanarme los caminos para que esta tesis salga a la luz.

En lo estrictamente personal, gracias a mi familia: a mi vieja por parirme y por la hermosa cicatriz vertical que mi venida al mundo por cesárea le dibujó en su cuerpo; a mi viejo por ser el mejor compañero que me pudo haber tocado. A los dos: gracias por la crianza libre pero responsable, por dejarme elegir siempre, por desafiarme, por acompañarme incondicionalmente y por alentarme siempre con amor. A mis hermanas, 
mis mejores amigas de la vida: a Nati por ser una madre para mí también y, junto a Edu, por traer al mundo a Juana y Clara, y darme sin querer, un objeto de estudio y una pasión/vocación militante y profesional. A Flor por apoyarme y ser mi compañera desde que nací.

A mis sostenes afectivos. A Ramiro por haber aprendido a acompañarme y desestresarme y hacerlo tan bien. A mis amigas por bancarse cenas, mates, cervezas y noches enteras hablando de partos, embarazos, cuerpos, mujeres y hospitales. A Nana (quien fue la primera en darme un sobrino, Isidro), Tatu, Jime, Isa, Vale, Caro y Ana. A mis apoyos terapéuticos, Patri y Emi.

A la Asociación Civil Vos Podés, en especial a Lore y Ro y en ellas a todas mis compañeras. Ustedes me enseñaron todo lo que sé sobre derechos del parto, embarazo y crianza. Fue un honor para mí construir con ustedes. Espero que esta tesis contribuya a seguir militando por esta causa tan necesaria.

Finalmente pero en modo central gracias a todxs Ixs participantes de esta tesis: entrevistadxs y asistentes a cursos de preparto. Gracias también a quienes facilitaron algunos de los datos estadísticos y quienes permitieron mi ingreso a instituciones y equipos sanitarios. Asimismo, gracias a las colegas, por su lectura, por los ámbitos de intercambio académico, por las relaciones y redes tejidas en torno al estudio de la salud y el género. Por último, gracias a las jurados que leerán y evaluarán este trabajo.

Esta tesis fue mi pilar y mi cable a tierra en seis años difíciles de mi vida. Mi estabilidad en la inestabilidad. Una gran fuente de placer y de goce. Quise transmitir eso y desterrar la idea de que "hacer una tesis es un parto" de esos hegemónicos. Hacer una tesis puede ser uno de esos partos orgásmicos de los que habla la gran Casilda Rodrigañez. En mi caso la gestación y el trabajo de parto de esta este trabajo incluyeron disfrute, alegría, militancia, empatía, sororidad, seguridad, vocación. En fin: pasión y emociones por doquier (de las positivas). Si además del pretendido aporte cognitivo, teórico/metodológico y político de esta tesis, pudiera sumar una contribución del quehacer científico sería esa: romper el mítico del Síndrome de Burnout en Ixs becarixs doctorales y poder mostrar un testimonio de placer y gozo en relación a un trabajo elegido y buscado. Terminar una tesis (nunca mejor dicho), es de los mayores placeres que se pueden imaginar. Mi deseo es que sea una fuente de disfrute también su lectura. 


\section{RESUMEN}

La presente tesis se inserta en los estudios sobre las construcciones sociales de la salud, la medicalización de la reproducción humana y del proceso perinatal, y la salud sexual-reproductiva, desarrollados por la sociología y la antropología principalmente. En particular, se orienta al estudio de las experiencias y representaciones sociales de mujeres-madres, varones-padres y profesionales de la salud obstétricxs respecto a las intervenciones médicas sobre los procesos de embarazo y parto.

"Hacer partos y parir" refiere a las relaciones, roles y acciones sociales principales que se implican en los nacimientos de las personas. En este sentido, la tesis analiza diversas instancias de la atención médica del proceso perinatal en la ciudad de La Plata, con técnicas metodológicas complementarias: observaciones con distintos grados de participación en cursos de preparto y salas de espera; entrevistas en profundidad a mujeres-madres, varones-padres y profesionales de la salud; y un extenso corpus de charlas informales y presencias en el campo, desde 2013 a 2019.

La tesis de la tesis se asienta en que, a partir de una mirada sociológica, relacional y con perspectiva de género de este proceso/evento cotidiano y trascendental a la vez, es posible advertir modos de intervención médica justificados no ya clínicamente, sino por cuestiones morales, sociales, culturales, económicas y simbólicas. Esto es, la constitución de este problema social como objeto de estudio sociológico permite analizar la atención médica de los procesos de embarazos y partos (PEP) como campo de disputa en el que diversxs actorxs construyen legitimaciones o cuestionamientos a las formas de concebir, tratar, asistir e intervenir dichos PEP.

En este sentido, esta tesis reconstruye una disputa principal que recoge actorxs, posiciones asimétricas de poder, prácticas y representaciones, entre dos modelos de atención médica de PEP: el intervencionista/medicalizado y el humanizado/respetado. A lo largo de los capítulos, iré mostrando cómo la construcción de estos dos modelos (no sólo analítica sino, principalmente, como categorías del campo) articula diversas tensiones y ante la cual propongo pensar los grises entre los dos polos. Si puede decirse que estamos en una época de transición entre los dos modelos o crisis del primero (impulsada desde el Estado, organizaciones de la sociedad civil y algunos movimientos médicos), es relevante también reponer las resistencias, muchas veces propugnadas por las parturientas, sujetas a una socialización médica tradicional que reproduce el modelo intervencionista. 
Para mostrar este campo de disputas y relaciones la tesis se estructura en seis capítulos: en el primero reconstruyo el estado de la cuestión y el marco teórico que moldea la investigación; en el segundo establezco las decisiones metodológicas y presento un ejercicio de reflexividad; en el tercero analizo la política de humanización y el marco contextual regulatorio. Ya en términos de análisis de las experiencias de Ixs sujetxs, en el capítulo cuarto expongo el tránsito por los cursos de preparto y la tensión entre obediencia y autonomía que tienden a (re)producir; en el quinto me enfoco en las representaciones y prácticas de profesionales médicxs sobre su quehacer profesionales; $y$, finalmente, en el sexto capítulo retomo experiencias de mujeres-madres y varonespadres. Para todos los casos la búsqueda es captar la heterogeneidad de modelos y ámbitos de atención obstétrica e ir reconstruyendo tensiones, grises y puentes.

Palabras Claves: ATENCIÓN MÉdica - Embarazos y PARTOS - MODELOS de atención OBSTÉTRICA - GÉNERO Y SALUD - EXPERIENCIAS. 


\section{INTRODUCCIÓN}

\section{PRESentación Y PLANTEO PRELIMINAR DEL PROBLEMA de INVESTIGACIÓN}

En las últimas décadas tomaron escena pública los cuestionamientos de diversxs sujetxs y organizaciones (de la sociedad civil, profesionales, de derechos humanos y feministas) respecto a la medicalización, la patologización y la consolidación del intervencionismo médico en la atención de los procesos de embarazo y parto. En paralelo, se asiste a la construcción de un conjunto de normativas ${ }^{1}$ que procuran dar tratamiento a estas cuestiones proponiendo la humanización de la atención médica de dichos procesos. Este nuevo paradigma apunta a despatologizar el evento perinatal, considerando que el embarazo y parto no son a priori hechos médicos, sino sexuales, íntimos y privados de las mujeres y sus familias. Apunta también a re-centrarlo en una dinámica médica no intervencionista, que garantice el respeto de los derechos humanos de las mujeres y sus familias. Se trata, entonces, de un escenario en el cual distintxs sujetxs, acciones e instituciones impugnan las prácticas de violencia obstétrica que pueden darse en la relación médicx-paciente y frente a la cual se presenta el modelo de parto respetado como contrapropuesta, en el marco de la defensa de los derechos sexuales y reproductivos de las mujeres y las familias en general a elegir cómo, dónde y con quién parir.

Considero que en este contexto son precisos estudios y abordajes desde las ciencias sociales que problematicen y complejicen los análisis en torno a las intervenciones médicas y que apunten a reconstruir las experiencias de Ixs sujetxs implicadxs en el entramado de las relaciones sociales que las sustentan, por tratarse de un tema resonante y relevante. En este sentido, la presente tesis se inserta en el campo de estudios socio-antropológicos sobre las construcciones sociales de la salud, la medicalización de la reproducción humana, del proceso perinatal, de los cuerpos y de la salud sexual-reproductiva. En particular, se presenta el análisis de las experiencias y

\footnotetext{
${ }^{1}$ Me refiero al entramado compuesto por la actual política nacional y provincial que propugna el "Modelo de Maternidades Seguras y Centradas en la Familia” (Ministerio de Salud de la Nación, UNICEF, Maternidad Sardá y Fundación Neonatológica: 2011) y las guías procedimentales específicas para la atención médica de embarazos y partos, trabajadas en el capítulo 3. Asimismo, en el plano legislativo la Ley 25929/04 de Derechos de padres e hijos durante el proceso de nacimiento en la Argentina (conocida como "Ley de parto respetado", reglamentada recientemente tras once años de su sanción), la Ley 26485/o9 de Violencia contra las mujeres (que define legalmente la violencia obstétrica) y la actual discusión sobre la Ley 17132 de incumbencias profesionales de las parteras.
} 
representaciones sociales de mujeres-madres, varones-padres ${ }^{2}$ y profesionales de la salud obstétricxs respecto a las intervenciones médicas sobre los procesos de embarazo y parto.

El título de la tesis refiere al protagonismo de unx u otrx sujetx de la relación médicx-paciente en la atención obstétrica. "Hacer partos y parir" no sólo refiere a una diversidad de prácticas sino a la heterogeneidad de representaciones construidas por Ixs actorxs claves sobre el proceso perinatal y la atención médica que requiere. "Hacer partos y parir" refiere a las relaciones, roles y acciones sociales principales que se implican en los nacimientos de cada persona. En este sentido, la presente tesis analiza diversas instancias de la atención médica del proceso perinatal en la ciudad de La Plata, con técnicas metodológicas complementarias: observaciones con distintos grados de participación en cursos de preparto y salas de espera; entrevistas en profundidad a mujeres-madres, varones-padres y profesionales de la salud; y un extenso corpus de charlas informales y presencias en el campo, desde 2013 a 2018.

La tesis de la tesis se asienta en que, a partir de una mirada sociológica, relacional y con perspectiva de género y derechos humanos de este proceso/evento cotidiano y trascendental a la vez, es posible advertir modos de intervención médica justificados no ya clínicamente, sino por cuestiones morales, sociales, culturales, económicas y simbólicas. Esto es, la constitución de este problema social como objeto de estudio sociológico permite analizar la atención médica de los procesos de embarazos y partos (PEP) como campo de disputa en el que diversxs actorxs construyen legitimaciones o cuestionamientos a las formas de concebir, tratar, asistir e intervenir dichos PEP. Al mismo tiempo, el análisis que propongo se interna en un contexto sociohistórico de disputa entre dos paradigmas asistenciales opuestos. Por ello otra de las tesis de la tesis es que en este momento coyuntural, normativo y sociocultural es posible advertir idas y vueltas, convivencias y grises/puentes entre estos dos modelos de atención obstétrica, en el marco de una disputa general y de transición asistencial y rearticulación hegemónica de la profesión médica obstétrica.

En este sentido, esta tesis reconstruye una disputa principal que recoge actorxs, posiciones asimétricas de poder, prácticas y representaciones, entre dos modelos de atención médica de PEP: el intervencionista/medicalizado y el humanizado/respetado. A lo largo de los capítulos, iré mostrando cómo la construcción de estos dos modelos (no

\footnotetext{
${ }^{2}$ He decidido referirme así a lxs sujetxs en tanto hay momentos del proceso (de investigación y perinatal) en el que no son madres/padres aún y por ende son mujeres/varones. Sobre el posible reduccionismo binario de trabajar con parejas heteroparentales, me refiero más adelante.
} 
sólo analítica sino, principalmente, como categorías del campo) articula diversas tensiones y ante las cuales propongo pensar los grises entre los dos polos. Si puede decirse que estamos en una época de transición entre los dos modelos o crisis del primero (impulsada desde el Estado, organizaciones de la sociedad civil y algunos movimientos médicos), es relevante también reponer las resistencias, muchas veces propugnadas por las mujeres, sujetas a una socialización médica tradicional que reproduce el modelo intervencionista.

Esta tesis sobre nacimientos nació en 2013 a raíz de una concatenación de cuestiones. Primero, una vez concluida mi tesina de licenciatura sobre participación comunitaria en salud, en la que uno de los resultados fue la confirmación de la conocida feminización de los cuidados que implica que de las problemáticas de salud/enfermedad/atención son protagonistas, responsables, destinatarias y ejecutoras, en su mayoría, las mujeres; el devenir natural de los temas doctorales me llevaban a cuestiones ligadas a la salud femenina, sexual, reproductiva y materna. Segundo, a fines de 2012 nació mi primera sobrina a través de lo que luego pudimos tipificar como una cesárea innecesaria. Supimos luego que en nueve ocasiones los jueves el mismo obstetra y el mismo anestesista realizaban cesáreas sin indicación correcta (innecesarias) y dormían con anestesia total a las mujeres (eso pasó con mi hermana), culpabilizándolas por el miedo y la incertidumbre de ese desenlace inesperado. Tercero, en un curso que daba un instituto provincial sobre transversalizacón de la perspectiva de género, conocí a la presidenta de una ONG que lucha por los derechos perinatales en la ciudad. En mayo de 2013, la ley de parto respetado en Argentina ya tenía 8 años sancionada pero sin reglamentar y hacía 4 años que el Estado había tipificado la violencia obstétrica como una de las seis modalidades de violencia contra las mujeres. En ese mes asistí por primera vez a un evento en el marco de la Semana Mundial por el Parto Respetado de ese año y en ese acto concluyeron mi interés personal, mi implicancia política y mi inquietud académica. Allí descubrí la urgencia de estudiar la violencia obstétrica, y aunque en los siguientes seis años, y tal como mostrará el recorrido de esta tesis, el foco ha ido variando, creo relevante presentar en esta introducción cómo me introduje en este camino, cómo se gestó esta tesis.

\section{$>$ LA URGENCIA DE ESTUDIAR LA VIOLENCIA OBSTÉTRICA}

Dos leyes de avanzada, el reconocimiento estatal e internacional de la problemática, la evidencia científica disponible para hacer un llamado urgente a 
desmedicalizar y desintervenir los nacimientos, y de todos modos la cesárea convertida en epidemia, el parto construido como un trauma, y la idea de que quien "hace" los partos es el/la médicx y no la mujer y el/la recién nacidx. El propio proceso de deconstrucción me llevó a preguntarme cómo había sido posible que se naturalizara, internalizara y deseara parir con vías, hormonas sintéticas, maniobras externas, sin el mínimo poder de decisión sobre cómo, dónde, con quién. Sin duda se trata de una problemática social en la que hay una tensión entre las nominaciones objetivas y externas y las apropiaciones subjetivas, la autoidentificación como víctimas, y la posibilidad de cuestionar la autoridad médica y su definición, cimentada histórica y socioculturalmente, de cómo es nacer y parir en nuestra sociedad.

De todos modos, el proceso de construcción del problema de investigación a partir de este problema social, me llevó a abrir el juego a pensar la heterogeneidad de modelos y ámbitos de atención obstétrica, a incluir relaciones de poder, sujetxs, escenarios diversos y así, que la VO sea un punto de llegada y no de partida, o un elemento transversal que acompaña el camino, aunque no esté puntualmente enfatizado. Así está escrita esta tesis: en el último apartado del último capítulo recién vuelvo a pensar cómo en mi trabajo de campo, en mi caso de estudio, emergieron expresiones de $\mathrm{VO}$, aunque eso no implicara que las mujeres-madres, los varones-padres o Ixs profesionales de la salud identificaran esos hechos como violentos. En esta tensión descansa la mirada sobre la VO que he desarrollado y asentado en estos seis años, y que describo a continuación, a modo de un primer aporte de la tesis.

Partí y parto del supuesto que sostiene que subyace en la definición de VO un campo de disputa por las legitimidades (de su definición), es decir, un ida y vuelta constante entre las nominaciones objetivas y las significaciones subjetivas sobre ciertas prácticas obstétricas definidas como violentas. Sostengo que el cambio en las sensibilidades sociales sobre diversas formas de violencia generó cambios en las legitimidades, y éstos, a su vez, expandieron el cambio en las sensibilidades. Estos procesos son catalizadores de las actuales disputas en la definición de la VO, donde lo "objetivo" y lo "subjetivo" generan diferentes interpretaciones y legitimaciones, que son ejes de mi trabajo.

En este marco propongo pensar un sistema tripartito, interrelacionado y en tensión de definiciones de la VO compuesto por las legislativas/de políticas públicas, las académicas y las "nativas"/subjetivas. A los dos primeros tipos los considero definiciones "objetivas" o externas en tanto apuntan a definir un fenómeno social desde perspectivas 
más amplias que la mera experiencia personal. Con objetivas aquí no quiero decir neutrales, sino que utilizo el término para oponerlas a las subjetivas. En este sentido, las definiciones que aquí considero objetivas vinculan la VO a la violencia de género. La más importante es, en Argentina, la que produce la Ley $26485^{3}$ que incluye a la VO como una de las modalidades de las violencias contra las mujeres y la define como

"aquella que ejerce el personal de salud sobre el cuerpo y los procesos reproductivos de las mujeres, expresada en un trato deshumanizado, un abuso de medicalización y patologización de los procesos naturales, de conformidad con la Ley 25.929 [“De derechos de padres e hijos durante el proceso de parto y nacimiento"]".

Esta definición legal va en consonancia con otras legislaciones internacionales ${ }^{4}$ y genera un marco normativo circular que se da entre esta ley y la ley de parto respetado (25.929), que, en complementación, expone los derechos de "padres e hijos" en la atención del proceso de parto/nacimiento. Esto es: el no cumplimiento de los derechos que enmarca la ley 25929 constituye VO en tanto lo delimita la ley 26485.

Y en conjunto, la Organización Mundial de la Salud clasifica la VO en cinco tipos, que sirven para operacionalizar aquella definición legal: 1.Intervenciones y medicalización innecesarias y de rutina (sobre la madre o el/la bebé); 2. Maltrato, humillaciones y agresión verbal o física; 3. Falta de insumos, instalaciones inadecuadas; 4. Ejercicios de residentes y practicantes sin la autorización de la madre con información completa, verdadera y suficiente; 5. Discriminación por razones culturales, económicas, religiosas, étnicas.

En paralelo, las ciencias sociales han producido y producen definiciones académicas de la VO que tienen como punto de partida pensar que la práctica médica en tanto práctica social (y no técnico-inocua) expresa relaciones de poder, posiciones de clase, jerarquías, incluso sujeción y formas de violencia, y supone, entre otras cosas, a Ixs pacientes como sujetxs subalternizadxs y pasivxs. En esas relaciones de poder asimétricas se dan condiciones para que se ejerzan violencias sobre las mujeres-madres, los varones-padres y Ixs recién nacidxs. Se trata de formas específicas de violencia que se dan en la atención obstétrica, que algunxs analistas entienden como:

\footnotetext{
3 "Ley de Protección Integral para Prevenir, Sancionar y Erradicar la Violencia contra las Mujeres en los ámbitos en que desarrollen sus relaciones interpersonales”.

${ }^{4}$ Por ejemplo, violencia obstétrica es, según la primer definición legal venezolana de 2007: "toda conducta, acción u omisión, realizada por personal de la salud que de manera directa o indirecta, tanto en el ámbito público como en el privado, afecte el cuerpo y los procesos reproductivos de las mujeres, expresada en un trato deshumanizado, un abuso de medicalización y patologización de los procesos naturales” (Ley orgánica sobre el derecho de las mujeres a una vida libre de violencia).

${ }^{5} \mathrm{El}$ universal masculino viene de la ley.
} 
"violaciones a los derechos humanos y reproductivos de las mujeres, incluyendo los derechos a la igualdad, a la no discriminación, a la información, a la integridad, a la salud y a la autonomía reproductiva. Se genera en el ámbito de la atención del embarazo, parto y puerperio en los servicios de salud - públicos y privados-, y es producto de un entramado multifactorial en donde confluyen la violencia institucional y la violencia de género" (Medina; 2010, p. 120-121).

Retomando a Villanueva Egan (2010), se puede pensar la VO en un continuo que va desde regaños, burlas, humillaciones, manipulación de la información y negación al tratamiento, hasta daños mayores a la salud de las mujeres. Incluye, además, la no consulta (ni la posibilidad de participación) sobre decisiones que se toman en el curso del trabajo de parto, su utilización como recurso didáctico sin autorización y el manejo del dolor durante el proceso como castigo. Todo esto enmarcado en la imposibilidad de negarse, dado que "desde el momento en que ingresan a la sala de labor, las mujeres reciben una serie de mensajes, que las instruyen sobre la conveniencia de someterse a las órdenes de los médicos" (Villanueva Egan, 2010, p. 148). Así, las formas de VO asociadas a las intervenciones médicas en los PEP, implican mujeres pariendo solas (sin acompañantes), en lugares pretendidamente asépticos, en una posición física (litotomía) conveniente al/la médicx, constantemente regulados, controlados y acelerados los tiempos y ritmos fisiológicos. Arguedas Ramírez (2014) lo resume del siguiente modo: la VO es aquel "conjunto de prácticas que degrada, intimida y oprime a las mujeres y a las niñas en el ámbito de la atención en salud reproductiva y, de manera mucho más intensa, en el período del embarazo, parto y posparto" (p. 3). En efecto, las definiciones académicas permiten vincular la cuestión de la violencia de género que enmarca la VO a la violencia institucional en salud, y explican, como Magnone Aleman, que ambas violencias "son posibles porque las sostienen sistemas de poder jerárquicos de género y de salud, respectiva e interconectadamente" (Magnone Aleman, 2011, p. 3) ${ }^{6}$.

Tal como establece la ley argentina que tipifica la VO como una violencia contra las mujeres (conocida popularmente como "ley de violencia de género", 26.485), hay dos niveles básicos de definición que yo nomino como formas evidentes y sutiles de violencia.

\footnotetext{
${ }^{6} \mathrm{Su}$ argumentación parte de que: "En la historia de occidente el avance en las igualdades formales fue acompañado por el perfeccionamiento de dispositivos de discriminación, marginalización, exclusión, represión, y exterminio. Para sostener la discriminación de género las instituciones generaron estrategias y dispositivos de violencia represiva y simbólica. De forma naturalizada, imponen la arbitrariedad cultural de la inferiorización femenina mediante diversos discursos, mitos sociales, explicaciones religiosas y científicas (Fernández, 2004: 6). Por su parte, la violencia generada por las prestadoras de servicios se asienta en un sistema de salud altamente jerarquizado, en un contexto de relaciones médico-paciente caracterizadas por las asimetrías de poder y por la apropiación del sistema sobre las decisiones vitales sobre el cuerpo de sus usuarios/as. Esto crea condiciones específicas sobre la concepción sobre el cuerpo para la clínica obstétrica” (Magnone Aleman, 2011, p. 4).
} 
En las primeras ubico los actos que cualquier testigo podría pensar como agresivo o violento y se relacionan a cuestiones de maltrato o destrato, y claramente aquellos casos que desencadenan en muertes perinatales o graves daños a la salud de la madre o Ixs recién nacidxs. La mayor dificultad política y simbólica se relaciona a nominar como violento las formas más sutiles. En ellas están las prácticas médicas, con aparente justificación clínica-científica lo que parece volverlas inevitables o innecesarias, pero como constituyen excesos de medicalización y patologización del proceso (tanto de su comprensión como de su forma de abordarlo) son pasibles de ser significadas como violencias. Así los tactos repetidos, las cesáreas innecesarias, las episiotomías (cortes en el periné) didácticas o "por prevención", la obligación de no moverse ni comer ni beber durante el trabajo de parto, la obligatoriedad de parir acostadas, la vía con suero de rutina y, el monitoreo fetal constante, son solo algunas de las prácticas médicas, que responden a un quehacer profesional que vulnera derechos humanos de las mujeres y por ello constituyen VO. Disputar que un modo de trabajar, pensar e intervenir un proceso puede ser significado como violencia, es el quid de la cuestión y la disputa de la definición. Finalmente lo visible es que la VO tiene su eje (y la posibilidad de su reproducción) en las prácticas masivas, revestidas de cientificidad. Se trata de un ejemplo más del "iceberg de la violencia de género": lo visible es el maltrato, lo invisible y que está por debajo son las intervenciones médicas ${ }^{7}$.

En suma, mi perspectiva se nutre de las argumentaciones de Castro y Erviti (2014, 2015) quienes entienden la VO no como una cuestión de calidad en la atención médica, como se sostiene desde una mirada de la salud pública, sino como una violación a derechos sexuales y reproductivos de las mujeres ${ }^{8}$ inherente a la estructura del campo médico. En este sentido, entiende la violación de estos derechos humanos a las mujeres durante la atención obstétrica "como un epifenómeno del campo médico que se manifiesta en las prácticas cotidianas que resultan del rutinario encuentro entre la estructura de poder de dicho campo y el habitus de los médicos" (Castro y Erviti, 2014, p. 40). O, en otras palabras, como "un efecto de la estructura de poder del campo médico y de la

\footnotetext{
${ }^{7}$ Canevari Bledel (2016) hace un interesante análisis retomando la definición que hace la ley de violencia de género (25.485) de las seis modalidades de violencia contra las mujeres (obstétrica, doméstica, institucional, contra la libertad reproductiva y mediática) que a su vez pueden asumir cinco tipos cada una. Así, la VO puede ser física, psicológica, sexual, económica/patrimonial y simbólica.

${ }^{8}$ Espinosa Pérez (2006) sostiene que se puede resumir "el universo de los derechos reproductivos así: derecho a la vida, derecho a la salud incluyendo salud reproductiva, derecho a la integridad física y a estar libre de violencia, derecho a estar libre de explotación sexual, derecho a decidir el número e intervalo de hijos, derecho a la intimidad, derecho a la igualdad y a la no discriminación, derecho al matrimonio y a fundar una familia, derecho al empleo y a la seguridad social, derecho a la educación" (2006, p. 300). Luego cita otro listado posible producido por Londoño (p. 300-301).
} 
lógica-práctica que caracteriza el habitus de los prestadores de servicios" (Castro, 2014, p. 176). Esto quiere decir que hablar de calidad de atención reduce el problema y supone soluciones técnicas y de recursos humanos, y en cambio hablar de vulneraciones a derechos humanos requiere conceptos sociológicos, políticos y cambios de paradigma.

Este marco conceptual le aporta relevancia sociológica al estudio que propongo, que busca reponer el origen de la VO en una articulación entre la violencia de género y la relación asimétrica médicx-paciente, que, a su vez, está atravesada o tiene expresiones diversas según la clase. Así, son más probables las cesáreas innecesarias en el sector privado (donde los índices llegan al 85\%, mientras que en los públicos al 40\%) pero en el público el hecho de tratarse de hospitales escuelas, los cuerpos de las mujeres son objetos pedagógicos y las mujeres sufren tactos repetidos o episiotomías innecesarias (para que Ixs residentes practiquen las técnicas de sutura), entre otras expresiones de VO. Este aspecto relacional implica interacciones de poder, hegemonía, consensos y violencias entre médicxs y pacientes, teniendo como punto de partida que las violencias obstétricas se dan en un contexto de naturalización de la inequidad de poder. Así, son bases comunes a muchos estudios las conceptualizaciones sobre el poder y violencia simbólicos, que podrían explicar la dinámica por la cual dominantes y dominadxs del campo médico comparten una cosmovisión general y la creencia de la necesidad de intervenir los PEP sin cuestionar al/la detentorx de ese saber específico. Se trata de un poder producto de un saber constitutivo, legitimado y exclusivo/excluyente. Castro (2014) y otros autores se centran en los análisis de Foucault sobre el poder disciplinario como red y las instituciones de control y vigilancia y la construcción de relaciones de poder que traducen tecnologías del yo, es decir, formas de intervención sobre el cuerpo y la mente de los individuos que impactan en aprendizajes. Son útiles estas conceptualizaciones para entender la atención médica de PEP y la VO como mecanismos de disciplinamiento, control y producción de subjetividad.

Situada la VO en el marco del entrecruzamiento entre violencias contra las mujeres que se dan en el desarrollo del proceso de parto/nacimiento y de la violencia institucional (simbólica, administrativa, sexual, etc.) que se da en la atención en salud, es importante poner el acento en que dicha definición externa u objetiva aún está en proceso de apropiación social y subjetiva, lo que es visible en los bajos números de denuncia y en la invisibilización de este tipo de vulneración a derechos humanos. Por ello, sostengo que la definición de violencia es un campo de disputa por la legitimidad de dicha definición, de quien la enuncia y de la misma práctica violenta. No hay definición estática, la violencia es 
un concepto social e históricamente cambiante en relación a las posiciones de poder de Ixs sujetxs involucradxs, sus posiciones estructurales y las definiciones de lo legítimo. Partiendo de que van cambiando las legitimidades, en tanto cambian las posiciones estructurales y de poder de estxs sujetxs y así cambia la definición de violencia, el núcleo de mi posición sostiene que la "invención" y definición de la VO se asienta sobre cambios en las sensibilidades sociales (a partir de la nueva ley, por ejemplo) que han operado y operan cambios en el régimen de legitimidades. Es clave cómo en los últimos años y a través del movimiento feminista, muchas violencias contra las mujeres han comenzado a nominarse como tal (noviazgos violentos, violencia mediática, violencia sexual, etc.). La expansión de las etiquetas de violencias se vincula, según Elías, al mismo proceso de civilización. Esto es, se expanden las etiquetas en tanto "comienzan a calificarse como "violentas" prácticas que, unas décadas atrás, eran rutinarias (o, al menos, moralmente indiferentes)" (Garriga Zucal y Noel, 2010, p. 100). El cambio de sensibilidades, entonces, implica una "modificación de nuestros umbrales de sensibilidad moral, que van corriendo, constantemente, la frontera entre lo aceptable y lo inaceptable" (Garriga Zucal y Noel, 2010, p. 100). Simiao (2011) vincula esta modificación al discurso de gender:

"La invención de la violensia domestika amplía considerablemente la suma de situaciones que podrían ser denominadas conflictos. La nueva moralidad que acompaña el discurso de gender crea condiciones para que situaciones antes percibidas como normales, pasen a ser vistas como ilegítimas $y$, por tanto, se transformen en casos de justicia [o de violencia]" (Simiao, 2011, p.202).

El recorrido por el trabajo de Checa y Rosenberg (1998), aporta claves en este sentido, ya que suma al discurso de género otra variable explicativa:

"La creciente universalización del reconocimiento y promoción de los derechos humanos que cada vez con más fuerza incorporan aspectos de la vida que estaban silenciados en la insignificancia de lo cotidiano, produce movimientos de reapropiación expresados en conductas que pueden ser interpretadas como formas de resistencia" (Checa y Rosenberg, 1998, p. 69) ${ }^{9}$.

En este marco, la emergencia de las demandas por los derechos reproductivos explica este cambio de sensibilidades y de cuestionamientos a diversxs sujetxs de poder que actúan en ese ámbito.

"El concepto de derechos reproductivos es pues, el resultado de un movimiento que nombra el desplazamiento de los procesos reproductivos que tienen lugar en el cuerpo de las mujeres, desde el ámbito de lo biológico naturalizado y/o medicalizado, al del derecho

${ }^{9}$ Sin embargo, las autoras se pronuncian críticas respecto a poder considerar hoy el papel de la reproducción de las mujeres como "un campo de ejercicio de derechos sociales", a raíz de los condicionamientos económicos, políticos y sociales. 
y el ejercicio de la ciudadanía -ámbito eminentemente relacional- en el que los hechos son pasibles de ser juzgados de acuerdo a criterios de justicia o injusticia. Lugar de elaboración de diferencias (diferencia sexual, por un lado, y diferencias entre mujeres, sobre todo económicas, por otro), para conseguir la realización de la igualdad que dé acceso a los beneficios médicos y sociales que actualmente tienen el carácter de privilegios" (Checa y Rosenberg, 1998, p. 74).

En suma, a partir de las luchas sociales, cambia la agenda y cambian las legitimidades; los dispositivos institucionales de control del cuerpo (Míguez, 2002) comienzan a ser cuestionados y las prácticas que los articulan, a ser significadas como violentas. En este sentido, es válido reconocer que la actuación médica en el proceso de embarazo y parto, cuyo principal fin se inscribe en la necesidad de disminuir los índices de mortalidad materno-infantil, no conlleva necesariamente y en todos los casos intimidaciones ni prácticas violentas. Por ello considero que la VO es un aspecto, consecuencia o dimensión de los distintos grados de intervención médica en los PEP y que su estudio debe vincularse a las significaciones y representaciones de las prácticas como violentas, y no en definiciones a priori. Representaciones que se construyen en el entramado de relaciones sociales que las sustentan, producen, reproducen y transforman.

Finalmente, antes de establecer cómo construí el problema de investigación y presentar la estructura de la tesis, ofrezco una posible respuesta a la pregunta que encabeza este apartado. Probablemente sigamos naciendo y pariendo en contextos de vulneración de derechos por el efecto de la violencia y poder simbólicos.

"Las violencias analizadas se dan en un contexto de naturalización de la inequidad de poder, tomando sentido traer parte de los conceptos creados por Bourdieu (2000) para analizar la dominación en las relaciones sociales. Específicamente la noción de poder y violencia simbólica. <El poder simbólico como poder de constituir lo dado por la enunciación, de hacer ver y de hacer creer, de confirmar o de transformar la visión del mundo, por lo tanto el mundo; poder casi mágico que permite obtener el equivalente de lo que es obtenido por la fuerza (física o económica), gracias al efecto específico de movilización (...) La violencia simbólica, de la mano del poder simbólico, resulta del acuerdo inmediato de las estructuras objetivas con las estructuras cognoscitivas. Se aprende como natural lo dado en el mundo objetivo. Es ejercida con el consenso y el desconocimiento de quien la padece, y esconde las relaciones de fuerza que están debajo de la relación en la que se configura" (Magnone Aleman, 2011, p. 5-6).

\section{LA CONSTRUCCIÓN SOCIOLÓGICA DE ESA URGENCIA}

Como se deduce del apartado anterior, la producción de esa propuesta conceptual o teórico-metodológica sobre cómo pensar la VO fue transversal a todo el trabajo de investigación, pero fue diseminándose para transformarse en eje el análisis de las intervenciones médicas en los embarazos y partos. Al respecto, fue y es necesario contextualizar el proceso de medicalización del proceso perinatal, a partir del cual se 
fueron desplegando las prácticas, representaciones, experiencias y relaciones de poder que son objeto de esta tesis.

"Desde finales del siglo XIX la ciencia biomédica ha ido elaborando modelos mecanicistas de la salud y de la enfermedad que paulatinamente se han ido implantando en la atención sanitaria. Este contexto explica cómo el proceso del parto comienza a ser atendido en los hospitales cuyo perfil estructural estaba configurado por discursos médicos en los que se representa a la gestante como una mujer enferma que necesita de asistencia médica. Es la etapa en la que se inicia la medicalización del parto. Progresivamente se impone un dominio absoluto del proceso por parte del aparato médico con la consiguiente desposesión del control de la mujer sobre su propio cuerpo. El poder y la autoridad de los médicos legitiman con sus discursos esa práctica y subordinan la maternidad al modelo biomédico. De esta manera, la medicina construye el proceso reproductivo desde una perspectiva médica hegemónica patologizante. Impone una comprensión de la vida, la salud y la enfermedad así como la muerte basadas en causas exclusivamente biológicas, cognoscibles y manejables a través de los avances técnicos" (Arnau Sánchez y otros, 2012, p. 227).

La literatura sobre historia de la medicina y de sociología de la salud permite ubicar el objeto de estudio en el cruce de diversos procesos sociales que se centran en la medicalización del proceso perinatal y de la salud femenina desde el siglo XIX. Así, Nari (2004) explica cómo el "aparato sanitario fue uno de los instrumentos significativos para la formación de la nacionalidad" (p. 103) y repone los debates higienistas y poblacionistas para situar esta problemática. En paralelo, Belli sostiene:

"Estas políticas higienistas, impulsadas por los Estados de mediados de siglo diecinueve, logran a comienzos del siglo veinte la hegemonía en torno de las prácticas correctas durante el proceso del parto. El parto intervenido, medicalizado, es sólo un aspecto de la nueva concepción fuertemente biologista de la reproducción humana y de la salud humana en general. Y son las instituciones de la salud espacios en los cuales estos procesos encuentran su lugar. No es casual que sea entonces cuando la obstetricia campo en el cual necesariamente resulta más evidente la subordinación de las mujeres al saber médico- surge como especialidad, desarrollando un conjunto de prácticas y saberes tendientes a regular y controlar la experiencia de la maternidad" (Belli, 2013, p. 25-26).

La obligatoriedad de parir en instituciones con asistentes profesionalizadxs, la pérdida de autonomía de las mujeres, las disputas internas a la obstetricia y a la constitución de la atención médico-científica de los nacimientos y el rol del Estado en estos planos son otros de los ejes que diversas autoras han desarrollado (Bellli, 2013; Nari, 2004; Felitti, 2011a; Ramacciotti y otros, 2008; Biernat y Ramacciotti, 2014, Ledesma Prieto, 2012a, 2014).

En suma, los procesos de embarazo y parto se han convertido en eventos médicos (plausibles de ser objeto de política estatal y de intervención clínica) durante el siglo XIX cuando se dieron dos hechos conexos: la profesionalización de la atención, que pasó de parteras a médicxs, y su institucionalización, al trasladarse del hogar y el contexto familiar 
hacia el hospital (Camacaro Cuevas, 2008a; 2008 b; 2009). El objetivo de estas dos ocurrencias estuvo ligado a disminuir las altas tasas de mortalidad materno-infantil, con la incorporación de principios como la asepsia, los controles prenatales y el seguimiento del trabajo de parto y posparto, entre otros. Posteriormente, se consolidó la tendencia general hacia la medicalización que construye a los embarazos y partos como eventos sanitariohospitalarios, homogéneos, estandarizados, controlados y regulados por el personal de salud, con un aumento del uso de la tecnología entre sus intervenciones ${ }^{10}$. Esto se expresa, por ejemplo, en la construcción médica del riesgo en los eventos perinatales que permite que ciertas intervenciones médicas se presenten como "necesarias, justificables y basadas en criterios exclusivamente médicos y por tanto científicos y neutrales" (Erviti, 2010, p. 7), en tanto se las considera "como una necesidad orientada a controlar los riesgos reproductivos" (Erviti, 2010, p. 11).

En este marco es que me pregunté por las maneras en las que se pare y se nace en el contexto local, y más particularmente incorporando una mirada sociológica y relacional del asunto, por cómo se atienden e intervienen desde la medicina estos procesos. Me centré en los embarazos y partos identificados como de bajo riesgo ${ }^{11}$, en tanto considero que allí es posible advertir modos de intervención médica sustentados en variadas justificaciones más allá de las estrictamente médicas (morales, sociales, culturales, económicas, simbólicas) y pensarlos como campos en disputa en el que diversxs actorxs construyen legitimaciones o cuestionamientos en torno a dichas intervenciones y sus recortes como objeto médico o de la intimidad de las personas. Esta

\footnotetext{
10 Al respecto, Larguía (2000, p. 180) establece los efectos colaterales de dicha institucionalización: "La institucionalización del parto persiguió un fin válido e indiscutible, proteger a madre e hijo. Disminuir sus riesgos de enfermar o morir. Ofrecer tecnologías más complejas, infraestructuras, servicios auxiliares, especialistas, etc. El objetivo válido se logró pero con un costo impensado. La institucionalización del parto, especialmente en las mega maternidades amputó el grupo familiar y no reprodujo la ambientación del hogar. Las antes dueñas de casa, esposas-madres, son ahora pacientes. Las familias son extranjeros con horarios restringidos. Los hermanos no conocen al nuevo. Los abuelos deben esperar por su nieta/o. Las instituciones, aterrorizantes hospitales, mal diseñados para enfermos, se han apropiado de madres e hijos antes y después de nacer, y creen ser generosos por ello y motivo de reconocimiento y agradecimiento. Las mega maternidades no escuchan las necesidades de quienes asisten y por ende no las reconocen ni satisfacen. No saben quiénes son los verdaderos dueños de casa y creen serlo ellos. Ellos, es decir nosotros los agentes de salud, a quienes nos pagan por servir a la gente sólo pensamos en nuestras necesidades. Aún creemos con omnipotencia que nuestra misión es curar".

11 Según la OMS, el embarazo de bajo riesgo es "aquel que transcurre sin que factores desfavorables (biológicos, psicológicos, sociodemográficos, etc.) y/o patologías maternas previas o adquiridas en el transcurso del embarazo evidentes o no, interfieran en su normal evolución llegando a término con feto sano, en presentación cefálica y proporción céfalo-pélvica adecuada, posibilitando un parto de bajo riesgo y un puerperio normal". Según el mismo organismo, el parto de bajo riesgo es "aquel de comienzo espontáneo, de bajo riesgo desde el comienzo del trabajo de parto, hasta la finalización del nacimiento. El niño nace en forma espontánea, en presentación cefálica, entre las 37 y 42 semanas completas de edad gestacional. Luego, tanto la madre como el niño están en buenas condiciones”.
} 
tesis propone comprender cómo se dan los procesos de (re)producción, (des)legitimación, cuestionamiento o resistencia de las intervenciones médicas en los procesos de embarazo y parto, a través de la reconstrucción de las experiencias y sentidos asociados a éstas por parte de mujeres-madres, varones-padres y profesionales de la salud que asisten partos en la ciudad de La Plata. Se tomó como recorte espacial para la investigación empírica los límites de dicha ciudad y como marco temporal se analizaron experiencias de partos/nacimiento ocurridos en la última década (2010-2019), siguiendo en ambos casos criterios de accesibilidad y factibilidad. De todos modos, se busca que las conclusiones y resultados de la presente investigación pueden servir para pensar procesos similares o que rebasen este recorte seguido.

Sobre el objeto de estudio, la propuesta es pensar las intervenciones médicas en Ios PEP en plural para romper con lecturas monolíticas que piensan en extremos la medicalización y la humanización de estos procesos, tendiendo un puente entre esos polos, buscando captar debates, contradicciones y sentidos compartidos. Con el fin de comprender la complejidad de las experiencias y la heterogeneidad de los entramados relacionales médicx-pacientes que se dan durante la atención de embarazos y partos de bajo riesgo. Considero que esto permite captar más ampliamente de qué modos se interviene sin caer en una caracterización negativa o simplista de las intervenciones al centrarnos en cómo las experimentan estxs sujetxs, y pensando que esa experimentación está atravesada por múltiples factores, como la clase, el género y la edad, entre muchos otros. A los fines analíticos propongo una caracterización típica ideal de los dos paradigmas asistenciales (medicalizado y humanizado) para luego ir deconstruyendolo, criticándolo y atravesándolo con las experiencias concretas de puentes y grises.

Se pueden pensar, por tanto, las intervenciones médicas prácticas y técnicoclínicas en los procesos de embarazo y parto (como por ejemplo el uso de técnicas de inducción, la cesárea, la episiotomía ${ }^{12}$ y la administración de oxitocina); tanto como las intervenciones simbólicas en el y del proceso, esto es, su construcción en términos de riesgo obstétrico, que requiere prácticas clínicas para evitar desviaciones de la norma. $\mathrm{O}$, en otros términos, su medicalización, vigilancia y control, que actúa reproduciendo cierto orden social. De todos modos este desglose es sólo analítico, en tanto las intervenciones prácticas son simbólicas de por sí. Se apunta, por tanto, a comprender las significaciones

\footnotetext{
12 "La episiotomía es una incisión quirúrgica de la vagina y el periné. Practicada a más del 80\% de las primíparas en América Latina, constituye un grave problema de salud, por constituir una lesión quirúrgica y hemorrágica que violenta la integridad anatómica y funcional del canal blando del parto (Cárdenas, et al, 2008)" (Magnone Aleman, 2011, p. 17).
} 
que Ixs sujetxs asignan a las intervenciones en términos tanto de los aspectos clínicotécnicos como simbólicos que conlleva, produce y reproduce, y a las relaciones médicxpacientes que se dan durante el embarazo y parto de bajo riesgo.

El horizonte de esta investigación es aportar al conocimiento general sobre los modos de (re)producir, (des)legitimar y disputar el modelo médico obstétrico, asentado en un saber-poder médico hegemónico. Esto es, conocer a raíz de una investigación cualitativa, de qué modos se da el proceso de construcción de hegemonía (con cruces de consenso y cuestionamiento por parte de los sujetos) alrededor de las intervenciones médicas en los procesos de los PEP, y cómo actúa el saber-poder médico hegemónico para instalar las pautas de normalidad y contribuir a la naturalización de un modelo particular de parir y nacer.

Quedan excluidas de esta indagación las parejas homoparentales y las madres y los padres solterxs, por dos motivos. Primero, porque se piensa como aporte principal de esta investigación al campo de conocimiento la inclusión de la perspectiva de los varonespadres en tanto padres en parejas heterosexuales (construido como vacancia en el estado de la cuestión); y, segundo, porque se considera que las dimensiones de las intervenciones a esxs sujetxs aquí excluidxs se complejizan y no es propósito de este estudio abordarlas.

Finalmente, teniendo en cuenta los recaudos tomados a la hora de construir sociológicamente la VO como estudio y de pensar en dimensiones de análisis prósperas, fructíferas y políticamente relevantes, sigo el consejo de Menéndez sobre estudiar lo obvio, lo cotidiano: nace un/x bebé por minuto en Argentina.

"Plantearse el estudio de lo obvio, de lo que está tan cerca que no lo vemos, de externar nuestra interioridad para poder observarla desde dentro y desde fuera, y en consecuencia hacer surgir las obviedades que vemos pero que no observamos. Lo cual (...) se convierte en una regla metodológica fundamental para que nuestros trabajos no se conviertan en profecías autocumplidas, y para que sigamos descubriendo en los procesos de salud/enfermedad/atención-prevención aspectos que las otras disciplinas no ven" (Menéndez, 2012, s/p)

La tesis se estructura en tres partes: marcos, hallazgos y conclusiones. En la primera se presentan los marcos de la investigación: la reconstrucción de los antecedentes que aportaron al campo de estudios de reciente formación y el marco conceptual, en el que refiero las principales perspectivas teóricas a partir de las cuales construí y analicé mi objeto de estudio y presento mi propuesta analítica con la categoría intervenciones médicas en los procesos de embarazo y parto (capítulo 1). En un segundo momento de esta primera parte, se presenta el marco metodológico, en el que desarrollo 
las decisiones tomadas en el proceso de investigación y realizo un ejercicio de reflexividad sobre mi propio rol en el campo (capítulo 2).

En la segunda parte de la tesis se exponen "la(s) tesis de la tesis", presentando los hallazgos en el campo a partir de la reconstrucción del diálogo de actorxs y relaciones (Estado, profesionales de la salud, mujeres-madres y varones-padres) en la disputa por los modos de parir y atender los PEP. Así, en el capítulo 3 se expone el marco contextual o regulatorio en torno a cuáles son las políticas de atención médica de PEP para el caso de estudio: normativas ministeriales y guías de atención. En este sentido, se reconstruye la primera disputa en términos hegemónicos sobre dos modelos de atención obstétrica: intervencionista y humanizado, teniendo éste último la particularidad de ser validado por el Estado a través de diversas normativas, pero aun así, constituyéndose como alternativo al dominante en el espacio médico.

En el capítulo 4 se abordan las intervenciones médicas que se dan durante el embarazo, particularmente durante los cursos de preparto (CPP). A través de la observación con distintos grados de participación en 30 encuentros, reconstruyo diferentes elementos que muestran la disputa entre los modelos de atención y respondo al interrogante acerca de si dichos CPP, que en lo discursivo afirman aportar al empoderamiento de las mujeres, en realidad incentivan la socialización para la obediencia al poder médico. $\mathrm{O}$, en otras palabras, (re)producen las relaciones de asimetría y poder entre médicxs y pacientes, que se construyen en las intervenciones médicas analizadas.

En los siguientes dos capítulos, me enfoco en el evento de parto/nacimiento desde dos ópticas diferentes. En el capítulo 5 se describe y problematiza la práctica profesional obstétrica en el marco de una apropiación particular de la disputa por los modelos de atención. En este caso, se trata de "hacer o acompañar partos" dando cuenta de cómo la formación y las relaciones al interior del campo obstétrico delinean/condicionan el trabajo en una o en "la otra obstetricia". En el capítulo 6 se reconstruyen las experiencias de las mujeres-madres y varones-padres de itinerarios asistenciales obstétricos de la ciudad de La Plata. Finalmente cierro el círculo presentando de qué modos ha sido posible pensar la VO en este caso de estudio y proponiendo algunas dimensiones para pensar el activismo por los derechos del parto.

A modo de cierre, en la última parte de la tesis, se presentan las principales conclusiones, en tono de recapitulación de los hallazgos, y posibles líneas de indagación futura. 


\title{
CAPÍTULO 1
}

\section{GESTANDO UNA SOCIOLOGÍA DE LA ATENCIÓN MÉdICA DE EMBARAZOS Y PARTOS.}

\author{
ESTADO DEL ARTE Y MARCO CONCEPTUAL
}

\subsection{Presentación}

En este capítulo se presentan articuladamente los dos pasos de la construcción teórica de la tesis: la constitución de un estado del arte, a partir de la reconstrucción de antecedentes; y la explicitación del andamiaje teórico-conceptual que sostiene la investigación. El resultado de dicha articulación es la construcción de algunos ejes de análisis de una sociología de la atención médica de embarazos y partos, sirviéndome de la construcción analítica de dos modelos de atención y la propuesta de pensar las intervenciones médicas en los PEP como matices de ambos extremos.

Para ello, comienzo estableciendo la perspectiva de género en los estudios de salud como el enfoque general de trabajo, problematizando de qué modos éste es clave para criticar al modelo de atención obstétrica hegemónica (1.2). A continuación, presento el estado de la cuestión describiendo las principales dimensiones de análisis de la atención médica de los procesos de embarazo y parto (PEP) que se han privilegiado en los trabajos de cientistas sociales (1.3). En tercer lugar, construyo el marco teórico a partir del desarrollo de las principales categorías analíticas que sostienen la tesis (1.4). Finalmente, y a modo de resumen de los hallazgos y aportes reconstruidos, desarrollo la cimentación de mi propuesta de modelo teórico, gestado a partir de los tres pasos anteriormente expresados y de las áreas de vacancia encontradas. Se trata de una sociología de la atención médica de los PEP, que descansa en dos elementos principales: la construcción analítica de dos modelos de partos (medicalizados-intervenidos y humanizados-fisiológicos) y una caja de herramientas conceptuales que los pasos anteriores proveyeron para analizar el objeto de estudio (1.5).

Tal como se estableció en la introducción, una tesis sociológica sobre la atención médica de embarazos y partos nace en el marco del cruce entre los estudios sociales sobre los procesos de salud/enfermedad/atención, los estudios de género y los estudios culturales sobre la construcción de hegemonía y contrahegemonía, en el marco de relaciones de poder médicx-pacientes generizadas. En este sentido, este capítulo es un recorrido minucioso por los aportes de los distintos campos cuya relación y 
entrecruzamiento permitió gestar una sociología que busca responder cómo parimos y nacemos en la actualidad.

En ese sentido, una categoría que atraviesa el capítulo y que por tal requiere una definición introductoria, es el concepto de modelo médico hegemónico $(\mathrm{MMH})$ definido por Menéndez (1988) como el conjunto de prácticas, saberes y teorías generados por el desarrollo de la medicina científica, que desde fines del siglo XVIII ha ido logrando establecer como subalternas al conjunto de prácticas, saberes e ideologías hasta entonces dominantes, hasta lograr identificase como la única forma de atender la enfermedad legitimada tanto por criterios científicos, como por el Estado. "La legitimación central de esta hegemonía la constituyen las denominadas 'presunciones de cientificidad' de la biomedicina" (Esteban, 2001, p. 35). Ángel Martínez (1996, citado por Esteban) menciona las siguientes: la definición de la enfermedad como desviación de una norma biológica; la doctrina de que existe una etiología específica de las enfermedades (unicausalidad); la noción de que las enfermedades son universales; la idea de neutralidad de la teoría y práctica biomédicas; la dicotomía mente/cuerpo; la autonomía de la biología de la conciencia humana; el atonomismo anatómico; la independencia de lo natural frente a lo social; el biologicismo; el mecanicismo; el mercantilismo; la asociabilidad; la ahistoricidad; la eficacia pragmática ${ }^{13}$.

"La ciencia médica, acota María González (2005, p. 27) 'es un conocimiento cerrado, eminentemente biologicista, individualista y ahistórico. Un modelo patriarcal de poder, con categoría de dogma ya que el médico es el único que sabe y la intervención tecnológica es lo único que puede curar'. La concepción biologicista del discurso privilegia la biología del cuerpo, además de una visión mecanicista de la relación de éste con el entorno, disimulando los acontecimientos sociales como determinantes de la salud y la enfermedad" (Camacaro Cuevas, 2008a, p. 102).

Este es el paradigma central desde el que se construye la sociología de la salud y, específicamente, una forma de pensar y abordar la atención médica de los PEP, porque permite vincular los procesos sociales, políticos, biopolíticos, culturales y económicos al estudio de los cuerpos, procesos reproductivos y relaciones médicx-paciente. En este punto y antes de dar comienzo al capítulo, es prudente recordar el llamado de Illich respecto al proceso de normalización y moralización que es inherente a la medicina, ya

\footnotetext{
13 "También llamada medicina occidental, científica, alopática, cosmopolita o etnomedicina fisiológicamente orientada. Designa al sistema médico desarrollado en Occidente desde la Ilustración, el cual se caracteriza por asumir la distinción cartesiana entre cuerpo y mente y por su comprensión de las enfermedades en tanto que entidades definidas producidas por causas únicas. Se le ha llamado también Modelo Médico Hegemónico $(\mathrm{MMH})$ con el fin de designar el tipo de práctica médica característica de la biomedicina: biologismo, ahistoricidad, a-socialidad, mercantilismo y eficacia pragmática. El apellido hegemónico proviene de la teoría de Gramsci y se opone al de subalterno (Comelles y Martínez 1993: 85-87)” (Sadler, 2004, p. 1).
} 
que son procesos que se ven en constante performance en el objeto de estudio de esta tesis.

"Como indica Illich (1978, p. 18), la medicina es una empresa moral y en cada sociedad define lo que es normal o deseable. De este modo, la profesión médica resulta una manifestación del control adquirido en base a la estructura del poder de clase de las elites universitarias. Los usuarios del sistema de salud con una actitud pasiva no tienen control sobre la percepción, clasificación y toma de decisiones médicas" (Schwartz, 2010, p. 102).

\subsection{GÉNERO Y SALUD: EL PATRIARCADO NACE EN EL HOSPITAL}

"¿Cómo es que esos poderes de los cuerpos femeninos se trastocan en subordinaciones?" (De Barbieri, 1993, p. 154)

La presente tesis se ubica en las preguntas por los cruces entre género y salud. El análisis de la atención médica de embarazos y partos implica el estudio de un entramado de relaciones de poder que incluye a diversxs sujetxs e instituciones. En torno a la atención específica, las relaciones asimétricas, de poder y subordinación son características de la práctica médica y de las relaciones de género, por lo que asumo una doble perspectiva relacional (de género y de subordinación médicxs-pacientes). La adopción de un enfoque de género y salud, contribuye a identificar las prácticas médicas en atención del embarazo y parto con instituciones o procesos sociales atravesados por la desigualdad de género, vinculados al control de las mujeres, sus cuerpos y sus procesos reproductivos.

En este sentido, asumo una perspectiva de género feminista, en tanto retomo las ideas de Facio (2009) respecto a que todxs tenemos un enfoque de género pero algunos de éstos (la mayoría) responden al androcentrismo y reproducen la desigualdad de las mujeres. Entiendo el género como un "sistema de prácticas, símbolos, representaciones, normas y valores en torno a la diferencia sexual entre los seres humanos, que organiza las relaciones entre las mujeres y los varones de manera jerárquica, asegurando la reproducción humana y social” (Ariza y De Oliveira, 2000, p. 2). En este sentido, el llamamiento de las teóricas feministas que inspiran mi trabajo es a utilizar conceptos y dimensiones relacionales y multidimensionales que "englobe las desigualdades económicas, socioculturales y de poder, entre hombres y mujeres, por un lado; y entre las propias mujeres y los propios hombres, por otro" (lbídem, p. 2). No obstante, esta autora reconoce el reduccionismo de pensar en términos binarios los géneros, pero, como he expresado anteriormente, se trata de una decisión arbitraria teórica metodológica. En 
suma, retomo el género como "un concepto multidimensional que articula aspectos de carácter socio-estructural y socio-simbólico e incluye tanto determinantes macro como microestructurales" (Ibídem, p. 3).

Ahora bien, en particular esta tesis se concentra en las desigualdades de género en los procesos de salud/enfermedad/atención, y específicamente de los procesos reproductivos, las maternidades y los cuerpos de las mujeres.

"Hablar desde el feminismo y seguir la vía metodológica del género (...) significó develar que desde el nacimiento de la medicina moderna hasta nuestros días (...) las mujeres han sido pensadas como objetos, no como sujetos, y que el poder médico se ha adjudicado progresivamente el derecho de establecer quiénes son las mujeres y cómo deben ser tratados sus cuerpos y sus vidas. El modelo dominante occidental de atención a la reproducción humana, se sustenta en una ideología que impregna de significados patriarcales los distintos momentos, como el embarazo, parto y puerperio. Esta ideología además se reproduce constantemente, manteniéndose así una determinada concepción social del embarazo y de la maternidad como funciones esenciales de las mujeres" (Camacaro cuevas, 2009, p. 150).

La perspectiva de género en salud permite estudiar la subordinación de las mujeres en el ámbito médico en el análisis de relaciones de dominación que se consideran patriarcales. En palabras de Fornes (2011, p. 134), este enfoque "contribuye a comprender cómo la experiencia subjetiva puede abrirnos a un conocimiento cualitativo de estas prácticas, en que las mujeres ponen literalmente el cuerpo dentro de un sistema de desigual distribución del poder".

"No es ingenuo que en la mayoría de las sociedades occidentales, a partir de mediados del siglo antepasado, la atención del embarazo, parto y del puerperio le es quitado a las mujeres de sus manos, pasando a ser un acto sanitario-hospitalario, aislado, homogéneo para todas las mujeres, donde es el personal de salud quienes controlan, deciden y son los/as únicos/as presentes, quedando privilegiado el uso de la tecnología y medicalización. Desmitificar ésta sustitución de protagonismos, es vital para comprender la justa dimensión de la necesidad de la obstetricia del control sobre el cuerpo sexualreproductivo y psíquico de las mujeres, control que se ejecuta, no para la perpetuación de la especie humana, como aparenta la representación social que lo soporta, sino para la perpetuación de la especie social patriarcal” (Camacaro Cuevas, 2008, p. 294).

En suma, este enfoque ubica el estudio de la atención médica de embarazos y partos en el marco de relaciones de subordinación genéricas, coincidentes con un modelo médico hegemónico patriarcal, que reproduce una asignación social de roles en base a diferencias sexuales y genéricas. Al analizar las intervenciones médicas de los PEP desde una perspectiva de género, se capitaliza su carácter relacional, multidimensional, micro y macro social, socio-estructural y socio-simbólico, lo que permite pensar las desigualdades económicas, socioculturales y de poder, inter e intra géneros, alrededor de este fenómeno. Esta perspectiva supone un modo de mirar los procesos y hechos 
sociales, poniendo el acento en las desigualdades y/o exclusiones resultantes de valores existentes en relación a la condición femenina y/o masculina. En el caso del análisis del estudio de la atención obstétrica es necesaria en tanto permite:

"desentrañar las relaciones de las mujeres con su cuerpo y derechos reproductivos; categorías que descubren la concepción del mundo patriarcal en torno a la mujer; así como un cuerpo marcado por el sistema de poder y vivenciado por las mujeres como objeto de representación, sometido a diferentes valoraciones en un territorio minado de códigos sociales y culturales (Camacaro Gómez, 2009, p. 218).

Además, contribuye a identificar las prácticas médicas en atención al parto con instituciones o procesos sociales atravesados por la desigualdad de género, vinculados al control de las mujeres.

"La teoría y metodología [de género] posibilitó captar el sentido de muchas prácticas y conductas que se aplican normalmente en las salas de parto, y son reproducidas tanto por las/os profesionales de salud, como por la institución hospitalaria, las cuales legitiman que [éstos] despojen a las mujeres de su papel activo en tanto que ellos/ellas saben y controlan el proceso de embarazo, parto, y puerperio, quedando el papel de la mujer reducido al de paciente. La perspectiva de género nos permitió acercarnos a la realidad de esa vivencia desde una postura que parte de preguntarse por qué la mujer no es una sujeta activa de esos procesos, sino que su autonomía ha sido secuestrada por la práctica médica. El género nos llevó a cuestionar el valor, supuestamente "natural", de éstas prácticas, construcciones e instituciones" (Camacaro Cuevas, 2009, p. 151).

Al respecto, sobre la pérdida de protagonismos, García Jordá et al (2012) sostienen que

"a través de la poca información que reciben las mujeres, la poca capacidad de acción y decisión y la legitimación de su rol de pacientes durante todo el proceso, lo que consolida su subordinación hacia las indicaciones médicas. Las mujeres carecen de poder y de autonomía para decidir sobre sus propios partos, pierden protagonismo al ser descalificados sus conocimientos y al no crear condiciones para que ellas y sus parejas tomen decisiones y sean sustituidas por las de un equipo de expertos, que además excluye a los padres del trabajo de parto y el parto y separa a las madres de las criaturas" (p. 1900).

La intersección de género y salud se asienta en la consideración de que la salud es una de las parcelas de poder de la sociedad. Así, en torno a la salud sexual y reproductiva, por vincularse a uno de los ámbitos esenciales de la reproducción social, se producen, reproducen y manifiestan relaciones desiguales y jerárquicas entre varones y mujeres (y expectativas comportamentales diferenciales) así como de clase, culturales, económicas y políticas fundacionales para el entramado social y constitutivas o constituyentes de su estructuración histórica. 
En el estudio del tema hay varias dimensiones de análisis que encuentran una mayor potencialidad al ser analizadas desde una perspectiva de género. En tal sentido: la dinámica del saber-poder autorizado y el desacreditado (en la que entre otros elementos interviene la construcción de género), la maternidad como función social natural de la mujer, el lugar del cuerpo femenino apropiado por la práctica médica, las construcciones legítimas y contrahegemónicas de lo femenino y lo masculino, la relación de dominación médicx-paciente, las posibilidades de resistencia y lucha vinculadas a formas respetuosas de parir, y el lugar del varón-padre en el proceso de parto/nacimiento intervenido. Un pasaje de una de las tesis retomadas describe estas potencialidades:

"En la atención obstétrica institucionalizada, los/as profesionales de la salud, específicamente obstetras, residentes, ocupan a través de su saber, el lugar del poder. Las mujeres, por su condición de pacientes, aun cuando en la mayoría de los casos buscan atención para un proceso de salud y no de enfermedad, como (...) un parto de bajo riesgo, ocupan el lugar pasivo e incluso de sumisión (...) El enfoque que utilizamos posibilitó captar el sentido de muchas prácticas y conductas, que se aplican normalmente en las salas de parto y son reproducidas tanto por las/os profesionales de salud, como por la institución hospitalaria (...) El género como herramienta de análisis (...) nos permitió develar que el discurso y la práctica médica obstétrica se sustentan en concepciones sexistas sobre el cuerpo sexuado, la salud y la capacidad reproductiva de las mujeres, y más que eso, nos proporcionó las herramientas teóricas para deconstruir lo que la mujer es y ha sido para la lógica patriarcal, y obviamente para el discurso médico oficial" (Camacaro Cuevas, 2008b, p. 296-297).

Junto a la cuestión del entramado saber-poder en disputa, el cuerpo es un núcleo conceptual clave para esta tesis, desde la intersección de género y salud, en tanto es ineludible considerar que "el cuerpo como territorio de control y disputa, espacio de subordinación y agencia a su vez, ha sido objeto de vigilancia de saberes, representaciones y prácticas" (Colanzi, 2014, p. 2). Se trata de un territorio disputado por el discurso médico "incorporando tecnologías diversas" (ibídem) ${ }^{14}$.

"En el devenir histórico, como ha señalado el pionero trabajo de Marcela Nari, la permeabilidad de estos discursos en el discurso cotidiano y en las políticas públicas dispuso que la capacidad reproductiva parezca ser solo cosa de mujeres. Sin embargo, con ello únicamente se hace referencia a su capacidad de gestar en su cuerpo al embrión, que no es lo mismo que capacidad reproductiva. Así pues, las mujeres se convirtieron en sujetos de algunos derechos, y otros les fueron vedados debido a su capacidad potencial de ser madres: en este caso, el derecho a decidir sobre su cuerpo" (Ledesma Prietto, 2012, p. 1).

\footnotetext{
${ }^{14}$ Sobre este discurso médico eminentemente pariarcal, Camacaro Gómez (2009, p. 222) afirma: "El discurso médico se traduce en acciones que han sido sistemáticamente aceptadas como verdades absolutas e irrefutables, que impide ver las consecuencias físicas, psicológicas y emocionales de la mujer, dentro de este contexto el cuerpo de la mujer sólo evoca enfermedad. Todos los testimonios nos hablan de la instauración del discurso médico en el imaginario colectivo”.
} 
La articulación entre discurso(s) médico(s), cuerpo(s) y derechos que propone Ledesma Prietto es central para esta tesis. Al mismo tiempo contribuye a visibilizar el esencialismo de género en el que es posible caer si pensamos el género en forma binaria. Tal vez la propuesta de July Cháneton sirva para seguir ubicando la centralidad en los cuerpos de las mujeres, aunque no permita salvar el reduccionismo binario.

"Es porque lo viven con el cuerpo. Se plantea el problema desde su especificidad de género. Los varones pueden compartir el momento si las mujeres lo habilitan, pero están afuera del proceso. Se necesitan de dos partes para procrear, pero es sólo el cuerpo de la mujer el que sostiene física y psíquicamente ese embarazo" (July Cháneton, $2011^{15}$ ).

Uno de los nudos conceptuales del estudio de la atención obstétrica radica en qué intereses, ideologías, visiones del mundo y roles (de género, clase, edad, familiares) produce y reproduce. Para abordarlo, los trabajos que recupero se centran en el aspecto relacional de dicha intervención, que supone relaciones asimétricas de poder y vinculadas a lógicas societarias e institucionales que consideran patriarcales. Es decir, tal como afirma Sadler (2004), los modos en que una sociedad organiza el comportamiento reproductivo de sus miembros refleja sus valores nucleares y principios estructurales. El punto clave que se quiere establecer es que el estudio de estas temáticas ligadas al embarazo/parto (pensadas como específicas de las mujeres) puede ser un medio valioso a través del cual analizar procesos sociales generales. El análisis de la atención obstétrica, entonces, implica el estudio de un entramado de relaciones de poder que incluye a mujeres-madres, varones-padres y profesionales de salud. Estas relaciones asimétricas implican relaciones de poder/subordinación características de la práctica médica y de las relaciones de género.

"La intervención del modelo médico hegemónico se sostiene sobre una asimetría de poder entre médico y paciente. El médico detenta el poder del saber, la autorización legal y la legitimidad que la sociedad le otorga cotidianamente para intervenir en los cuerpos de las personas. Cuando el médico es varón y la paciente es mujer esta asimetría de poder se yuxtapone a otra más antigua y profundamente arraigada en el imaginario y prácticas de nuestra sociedad, la estructura de poder de las relaciones de género, en la que la mujer la posición subordinada" (Schwartz, 2010, p.101-102).

Asumiendo una doble perspectiva relacional (de género y de subordinación médicx-paciente) un hecho que se destaca entre los estudios del campo, es que no se ha incluido a los varones-padres como sujetos claves del proceso. La perspectiva de género contribuye en la inclusión de una visión que incorpora a los varones en el análisis de la

${ }^{15}$ En entrevista "La culpa ante el aborto tiene que ver con una moral burguesa". 20 de marzo de 2011. 
situación de las mujeres ${ }^{16}$, en tanto relaciona los aspectos biológicos y los sociales y que permite analizar las diferencias (inter e intragénero/sexo) pero también las similitudes entre ambos colectivos en cada contexto (Valls Llobet, 2009). De todos modos, tal como argumenta Sadler (2007), la mayoría de los estudios reprodujeron "una visión fragmentada donde género aparecía en la mayoría de los casos como sinónimo de mujeres, y en muy pocos casos vinculados a lo masculino (...) [y así] "pecaron" por omisión, al centrarse principalmente en las mujeres y sus condiciones” (p. 437).

Esta carencia de estudios sobre los varones-padres en el embarazo, parto y puerperio de sus parejas, el nacimiento de sus hijxs y sobre las paternidades en general, puede estar ligado a la falta de investigaciones sobre las masculinidades y cierta invisibilidad de los varones como dotados de género ${ }^{17}$. Esta vacancia dio lugar a un grupo de investigaciones recientes que específicamente se dedicaron a "indagar en las características identitarias esenciales de los varones; reconocer la importancia que tiene su presencia en la configuración del orden patriarcal; abrir la posibilidad de redefinir las formas de asumir sus roles y de resituar su participación social" pública y privada; y buscar promover nuevas formas de relación consigo mismo y con otros y otras (Sadler; 2007, p. 438).

En suma, la perspectiva de género permea el abordaje sociológico de la atención obstétrica, sus condiciones de posibilidad, las dimensiones y variables que la atraviesan, el lugar de Ixs sujetxs y su carácter eminentemente relacional. En un nudo conceptual que vincula el modelo médico hegemónico al género y al patriarcado, se proponen otras variables explicativas vinculadas a la clase de lxs sujetxs implicadxs, la constitución y las dinámicas del saber-poder médico, el enfrentamiento entre saberes y prácticas populares y el saber científico, el análisis de las prácticas médicas gineco-obstétricas, el manejo de la información como elemento de poder simbólico, las determinaciones económicas,

\footnotetext{
16 "Es muy reciente que los varones entran a ser estudiados desde esta perspectiva [la de género] (...) los hombres, sus cuerpos, sus subjetividades, sus comportamientos, aquello denominado "lo masculino" ha sido sometido al escrutinio científico. En la medida en que las identidades masculinas- "masculinidades"- desde una perspectiva de género son consideradas construcciones sociales y no datos naturales, son culturalmente específicas, histórica y especialmente situadas” (de Keijzer, 2001, p. 1-2).

17 Este vacío pudo deberse a dos causas principales: "por el hecho de que las teorías sobre La Mujer habían reificado una imagen de Hombre dada por el uso del concepto de patriarcado como sistema universal y omnipresente, dibujando una silueta masculina estereotipada e idéntica para todas las sociedades; por el otro, el hecho de que desde muchas disciplinas como el psicoanálisis, la propia filosofía, la historia, "el hombre" aparecía como un sujeto incuestionable; preguntarse por qué ser un hombre contenía a toda la humanidad, con lo cual era imposible plantearse el asunto como un problema de género, y más aún la propia pregunta no podía siquiera modularse" (Sadler, 2007,p. 438).
} 
institucionales, culturales y políticas del contexto estudiado, y aspectos vinculados a la dimensión emocional y afectiva de mujeres y varones en el proceso de parto (miedo al dolor, incertidumbre, acompañamiento y sostén, entre otros). Se trata de pensar sociológicamente las intervenciones médicas en los PEP, a través de la mirada de profesionales de la salud, de mujeres-madres y, como aporte novedoso, de los varonespadres implicados en el proceso.

"El desplazamiento de esta red femenina por parte del poder médico y la institucionalización del parto en los hospitales han sido denunciados recurrentemente por el feminismo como otra manifestación del patriarcado en su afrenta contra la autonomía de las mujeres. No obstante, algunos estudios históricos realizados sobre estos procesos en Europa y en los Estados Unidos han permitido visibilizar a las mujeres en un rol más activo" (Felitti, 2011a, p. 115).

Siguiendo esta consideración de Felitti, propongo entonces pensar las disputas de poder en la atención de los procesos de embarazo y parto en nuestro caso de estudio, visibilizando estrategias de resistencia y de (re)producción hegemónica, en una constante interrelación.

\subsection{RECONSTRUCCIÓN DE ANTECEDENTES}

Para estudiar la atención médica de PEP históricamente se ha prestado especial atención a los procesos de medicalización/institucionalización/patologización del parto, el saber y el poder médico vinculados al patriarcado, el discurso médico, el modelo médico hegemónico, y el análisis del poder en tanto relación de dominación y violencia simbólica, biopolítica, hegemonía y autonomía, mecanismos de desautorización de las mujeres; y diversos modos de entender las relaciones médicx-pacientes como relaciones de poder. Otros estudios se enfocaron en reflexiones sobre la maternidad, la paternidad y el fenómeno del parto en sus múltiples consideraciones.

En este apartado, propongo reconstruir el mapa actual de los estudios de las ciencias sociales sobre la atención médica de embarazos y partos a partir de la selección de un corpus de una decena de tesis doctorales y de maestría, y un conjunto de más de cien artículos académicos. La construcción de ese corpus (que comenzó en 2013) cumple con los criterios de saturación y relevancia temática. La elaboración del estado de arte contribuye a mi trabajo en tanto permite mostrar cómo esta tesis se inserta en un área de vacancia, por el caso y por la perspectiva teórica-metodológica, y asimismo, pretende ubicarla (en diálogo, tensión, complementariedad) en un campo de saber emergente y en amplio desarrollo en el último lustro. Esto en el sentido de que uno de los objetivos 
cognitivos de la tesis es aportar a la sistematización de las perspectivas y aportes de los estudios del campo de estudios sociales sobre los PEP. Con dicho objetivo, a continuación se presentan las conceptualizaciones principales a partir de las cuales se produjeron/producen y situaron/sitúan los distintos saberes sobre el tema, con el fin de contextualizar una nueva investigación sociológica sobre los sentidos y prácticas asociadas a la intervención médica en el proceso de parto/nacimiento por parte de mujeres-madres, varones-padres y profesionales de la salud en la actualidad.

El proceso de construcción de los antecedentes supuso dos etapas: en primer lugar, el ordenamiento de los trabajos en algunos corpus etiquetados previamente: atención obstétrica, ma/paternidades, medicalización y profesión médica, políticas públicas y derechos sexuales y reproductivos, y salud y género. En un segundo momento, y tras la lectura y análisis de los mismos, se organizaron en tres conjuntos (que no son excluyentes entre sí): a) Medicalización y patologización del proceso de embarazo y parto; b) Género y derechos sexuales y reproductivos; y, c) El aspecto relacional de la atención médica de partos: violencia obstétrica en la relación médicx-paciente; ma/paternidades; y la perspectiva de los sujetos: profesionales de la salud, mujeres-madres y varonespadres. A continuación expondré algunas líneas centrales de estos tres ejes.

\subsection{A. I- MEDICALIZACIÓN Y PATOLOGIZACIÓN DEL PROCESO DE EMBARAZO Y PARTO.}

"Con el término medicalización, las ciencias sociales suelen referirse a los procesos de expansión de los parámetros tanto ideológicos como técnicos dentro de los cuales la medicina produce saberes e interviene en las áreas de la vida social que exhibían en el pasado un mayor grado de exterioridad respecto a sus tradicionales dominios (Menéndez,1985)" (Mitjavila, 1998, p. 2) ${ }^{18}$.

Para estudiar las intervenciones médicas en los procesos de embarazo y parto se ha prestado especial atención a los procesos de medicalización, institucionalización y patologización del parto (Camacaro Cuevas, 2008a, 2008b y 2009; Camacaro Gómez, 2009; García Jordá ét al, 2012; Mitjavila, 1998; Gainza et al, 2013); y se han analizado junto a éstas, otras cuestiones macro y procesos generales vinculadas al análisis del modelo médico hegemónico (Arnau Sánchez y otros, 2012; Romerio y Díaz, 2001; Sadler, 2004; Cáceres Manrique y Molina Martin, 2010). Así, se han estudiado la constitución de los discursos, saberes y poder médicos (Giberti, 2003; Sadler, 2004), la relación médicx-

\footnotetext{
${ }_{18}$ En su “documento de trabajo” para la carrera de Sociologia de la UdelaR, Mitjavila (1998) realiza un profundo trabajo de reflexión sobre la medicalización, la función normalizadora del saber médico, la economía política de la medicina, la constitución de la biopolítica y una serie de argumentaciones riquísimas que han inspirado este trabajo.
} 
paciente en tanto relación de dominación y violencia simbólica (Magnone Aleman, 2011); la constitución hegemónica de la medicina, vinculada a la biopolítica y autonomía del campo médico (Goberna Trías, 2012); y el fenómeno del parto en sus múltiples consideraciones: fisiológico, medicalizado, intervenido, humanizado, respetado, natural y normal (Arnau Sánchez y otros, 2012; Castro et al, 1991; García Jordá et al, 2012).

Un punto de partida común a varios trabajos es el análisis del proceso de institucionalización de la atención del embarazo, parto y puerperio que a fines del siglo XIX pasó a ser un acto sanitario-hospitalario, homogéneo, estandarizado, controlado y regulado por el personal de salud, con un aumento del uso de la tecnología en el marco de un proceso simultáneo de medicalización. Este doble proceso de institucionalizaciónmedicalización encuentra su origen, según Camacaro Cuevas (2008a) en dos ocurrencias históricas que impactan en la vida reproductiva de las mujeres: la trastocación de los protagonismos provocada por la atención médico-obstétrica que pasó de manos de las parteras a manos de profesionales de la salud, y el concomitante traslado de los partos del hogar a los hospitales. Una de las consecuencias de la hospitalización se entiende como que "la institucionalización de los procesos reproductivos no contempla la relación protagónica de y entre las mujeres durante la vivencia del embarazo, el parto o el puerperio. Las mujeres son desplazadas por la autoridad del saber médico" (Camacaro Cuevas, 2009, p. 148).

"Cuando la medicina empezó a usurpar los hogares y los tiempos de la vida humana, una de las primeras críticas a esa medicalización giraron hacia el parto en el hospital; esto dejaba sola a la mujer para sufrir con las manipulaciones de técnicas extrañas y desconocidas le impedía su participación como sujeto activo en la extraordinaria experiencia del nacimiento y del primer contacto con el hijo, quien inmediatamente sería transferido a otro lugar; la medicina pretende en suma, dictar los horarios y las modalidades de esta relación que debe ser lo más espontánea posible, íntima y natural. (Berlinguer, 1996, p. 40 en Camacaro Cuevas, 2009, p. 154).

Tomando esta matriz, se pueden pensar los dos procesos interrelacionados. Burgo (s/f) y otros autores (Sadler, 2004; Villanueva Egan, 2010) sostienen que el modelo de la medicalización, que transforma el hecho afectivo, familiar y social de parir y nacer en un acto médico, se basa en la despersonalización de la parturienta convertida en paciente y en la des-sexualización del parto. A su vez, Magnone Aleman (2011) sostiene que se dio una radicalización de la medicalización en las mujeres, atendiendo a la relación entre la dominación del sistema de salud en el parto y las condiciones de sostenimiento del sistema patriarcal, prevaleciendo, además, un discurso científico médico asociado a un discurso moral. Dicha relación intrínseca entre el discurso médico hegemónico y la 
episteme patriarcal, se vincula, según Camacaro Cuevas (2008a), a que la medicina construyó su apreciación de la anatomía y la fisiología femenina tomando como patrón de referencia al hombre, lo que Carme Valls Llobet (2013) denomina "androcentrismo de la ciencia". Además, Villegas Poljak (2009) sostiene que la ciencia médica se sustenta y a la vez invisibiliza el discurso patriarcal. Junto a este aspecto ideológico se sitúan las dimensiones biologicista, ahistórica, individualista y focalizada en la enfermedad que modelan la atención médica del parto representándose como un proceso patológico que hay que tratar (Arnau Sánchez et al, 2012).

Este discurso medicalizador es producto de un sistema médico, entendido en las ciencias sociales como un conjunto organizado de creencias y acciones, de conocimientos científicos y habilidades de los miembros de un grupo perteneciente a una determinada cultura, relativas a la salud, la enfermedad y sus problemas asociados ${ }^{19}$. Siendo que no es el único posible, el sistema médico oficial hegemoniza el control sobre los conocimientos que se refieren al cuerpo humano, en este caso al cuerpo femenino y sus procesos fisiológicos patologizándose las etapas del ciclo vital de las mujeres: la menstruación, gestación, parto y menopausia son consideradas enfermedades a tratar y controlar (Sadler; 2004; Valls Llobet, 2013).

La segunda ocurrencia que se destaca entre los trabajos antecedentes que se han preguntado por los procesos de construcción de parto como evento médico, tiene que ver con la hospitalización del proceso de parto y los estudios que se ocuparon del tema destacan principalmente: la problematización del nacimiento en un lugar de enfermedad (Camacaro Cuevas, $2009^{20}$ ); el auge de la medicina perinatal; la consolidación del control, medicación y regulación del trabajo de parto en vinculo a la revolución industrial (Arguedas Ramírez, 2014, p. 164); la posibilidad de pensar la sala de parto y el

\footnotetext{
${ }^{19}$ En este marco, se sitùan los aportes de la medicina social latinoamericana y los estudios del enfoque de la salud colectiva. Asimismo, las apropiaciones de Foucault quien "sitúa el surgimiento de la medicina social en el desarrollo del modelo de sistema médico seguido en Occidente a partir del siglo XVIII, que -en su opinión- se basa en tres aspectos: la biohistoria, la medicalización y la economía de la salud. La biohistoria, entendida como efecto de la intervención médica a nivel biológico, el trazo que pueda dejar en la historia de la especie humana la fuerte intervención médica que comenzó en el siglo XVIII. La medicalización, como la extensión de las prácticas médicas a las áreas de la conducta y el comportamiento humano realizadas de manera intensa y extensa. La economía de la salud, como un área que se desarrolla a partir del mejoramiento y el consumo de servicios de salud que comienzan a producir y reproducir económicamente (Foucault, 1978)” (Laplacette y Vignau, 2008, p. 53).

20 "La preeminencia del hospital como el espacio apto para el proceso obstétrico, nos obliga a escudriñar los intereses sublimados por el poder de la ciencia, que llevan a crear una conciencia colectiva que acepta como natural y normal que niños y niñas nazcan en un lugar de enfermedad. La construcción de esta enajenación colectiva conlleva a una encrucijada dramática frente a esta mentira que se funda como verdad social; es preciso inquirir su posibilidad de consolidación como realidad” (Camacaro Cuevas, 2009, p. 149).
} 
consultorio ginecológico como una institución total en términos de Goffman anclada en el control del tiempo, los ritmos, movimientos y la imposición de decisiones médicas frente a mujeres y cuerpos dóciles. En síntesis, los estudios han concluido que se impone un dominio absoluto del proceso por parte del aparato médico con la consiguiente desposesión del control de la mujer sobre su propio cuerpo (Arnau Sánchez et al, 2012) y del grupo familiar sobre el evento del nacimiento de un nuevo miembro (Larguía, 2000).

En este marco general de análisis de la institucionalización del parto, un aporte original es la propuesta de Sadler (2004) respecto a pensar los mecanismos de desautorización que se interrelacionan para despojar de poder (de decisión, de regulación, de control) a las mujeres-madres y varones-padres, y entregarle la autoridad a los profesionales de la salud, en el marco de la atención médica del parto. Se trata de los mencionados en la siguiente figura vinculados a las lógicas de infantilización, dessexualización y des-personalización antes mencionadas ${ }^{21}$.

FIGURA 1: ESQUEMA DE MECANISMOS DE DESAUTORIZACIÓN PROPUESTO POR SADLER (2004, P. 26)

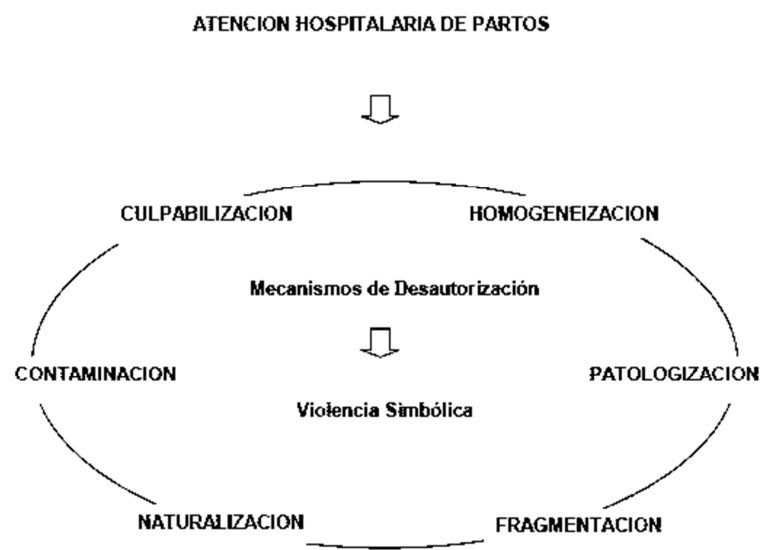

En la misma sintonía, Arguedas Ramírez (2014), propone una nueva categoría para estudiar el objeto propuesto a la que denomina "poder obstétrico", entendido como un poder disciplinario enmarcado en el ámbito de la capacidad reproductiva de las mujeres que se ejerce en un territorio-género específico: los cuerpos que se embarazan y paren. Esta microfísica del poder dispone de ciertas tecnologías disciplinarias como la vigilancia, la observación minuciosa, la documentación estadística que establece la

\footnotetext{
${ }^{21}$ Es necesario destacar que estos mecanismos de desautorización no son exclusivos de las mujeres sino que responden a una lógica institucional que atraviesa a todxs lxs usuarixs del sistema de salud. El resumen de qué implica cada uno se encuentra en las páginas 27 y 28 del texto citado.
} 
normalidad y las técnicas para la administración médico-jurídica del embarazo y el parto. El objetivo del poder obstétrico sería la producción de cuerpos dóciles femeninos que permitan maximizar la efectividad de los embarazos, los partos y del cuidado de Ixs recién nacidxs, lo que sólo es posible si estos procesos son construidos subjetiva y socialmente como problemas sociales y de alteración/desorden que deben ser vigilados.

De este modo, institucionalización y medicalización son los dos ejes ineludibles y puntos de partida que la construcción del estado del arte permite visualizar. Junto a estos, los dos ejes siguientes completan el mapa conceptual general establecido en el campo de estudio.

\subsection{A.II. GÉNERO Y DERECHOS SEXUALES Y REPRODUCTIVOS.}

Muchos estudios analizaron el parto y su medicalización desde una perspectiva de género y derechos humanos, marco en el cual sitúo "lo canónico" del estado del arte de la temática. Me refiero a tesis doctorales de ciencias sociales actuales como son las de Sadler (2003), Montes Muñoz (2007), Blázquez Rodríguez (2009), Canevari Bledel (2011) y Magnone Aleman (2011), que se asientan en perspectivas de género y clase para pensar el objeto, aunque con distinta pregunta de investigación. Esto es, pertenecen a otros recortes espacio-temporales, y al mismo tiempo se concentran en unx solx de Ixs sujetxs que aquí considero (mujeres o médicxs), y se restringen sólo a la atención hospitalaria pública o concentran su análisis en los discursos o en otras aristas. En este marco, es que se analizaron las intervenciones médicas en vinculación a los derechos sexuales y reproductivos, su garantía estatal y demanda social (Camacaro Cuevas, 2009; Magnone Aleman, 2011).

\subsection{A.III. EL ASPECTO RELACIONAL DE LA ATENCIÓN MÉDICA DE EMBARAZOS Y PARTOS.}

Algunxs autorxs analizaron las intervenciones médicas y las relaciones médicxpaciente en el proceso de parto desde su correlato en violencias obstétricas: así, se han estudiado sus definiciones y tipos, incluidas las definiciones legales (Arguedaz Ramírez, 2014; Camacaro Gómez, 2009; Farías, 2013; Medina, 2010; Villanueva Egan, 2010; Villegas Poljak, 2009) y se han problematizado las prácticas consideradas como violentas (Mitjavila, 1998; Camacaro Cuevas, 2008b; Burgo, s/f). De igual modo, otros estudios se 
centraron en comprender las dinámicas, posibilidades y limitaciones del parto respetado (Baranchuk, 2009; García Zeferino et al, 2010; Larguía, 2000; Pujadas Ríos et al, 2011).

En este mismo eje, distintos trabajos recuperan el hecho de que estas intervenciones médicas en los PEP se sustentan en entramados relacionales médicxpaciente entre profesionales de la salud, mujeres-madres y varones-padres, y por ello dirigieron sus interrogantes hacia el análisis y comprensión de las perspectivas de Ixs sujetxs, sus experiencias, significaciones y singularidades.

>>PROFESIONALES DE LA SALUD, MÉDICXS, PARTERAS ${ }^{22}$

Por el lado de Ixs médicxs, se ha analizado el saber médico vinculado a las nociones de patriarcado y a un conocimiento autoritativo (Camacaro Cuevas, 2008b; Villegas Poljak, 2009); la exclusión de otros saberes no-científicos; las características del discurso médico (Camacaro Cuevas, 2008a); la formación de lxs médicxs entendida como una socialización instructiva (Arnau Sánchez y otros, 2012) y generadora de un habitus médico autoritario (Castro, 2014); el/la médicx como empresarix moral y el lugar de las parteras en la atención obstétrica (Pelcastre et al, 2005; García Zeferino et al, 2010).

El poder de Ixs médicxs emana de un saber específico legitimado socialmente. Sadler (2004) utiliza el concepto de conocimiento autoritativo (que retoma de Jordan, 1993) para referirse a ese conjunto de saberes que adquieren el más alto poder y legitimidad para explicar los fenómenos en un contexto determinado. Su constitución es un proceso social continuo que construye y refleja las relaciones de poder al interior de una comunidad, que en la atención de partos hospitalarios, toma la forma de supresión activa de todo lo que la mujer pueda saber, sentir o imaginar acerca de sí misma durante el proceso. Junto a su análisis de los mecanismos de desautorización puede explicar por qué el poder de la toma de decisiones y la autoridad son automáticamente transferidos desde la paciente hacia el personal médico y administrativo del hospital cuya competencia profesional es alópata, por lo que se ocupa del tratamiento de la patología a través de medios quirúrgicos, farmacológicos y técnicos. Al preguntarse, entonces, por las condiciones de posibilidad y la legitimación de este conocimiento autoritativo sostiene que las mujeres invisibilizan su percepción subjetiva y hablan desde la normatividad médica

\footnotetext{
${ }_{22}$ El género de lxs sujetxs agentes de salud responde a la generalización del campo: diversidad de géneros
} entre lxs médicxs y feminización completa en la rama de las parteras. 
que han internalizado haciéndola propia, lo que las transforma en cómplices de su propia subordinación. Castro (2014) aporta también un concepto sumamente original y relevante para estudiar a estxs sujetxs: entiende que existe un habitus médico autoritario, que comienza a fundarse durante la formación universitaria en las facultades de medicina y que se consolida durante la especialización en los hospitales, y que tiene una vinculación estructural con los rasgos autoritarios que eventualmente exhiben durante su práctica profesional. Se refiere así al conjunto de mensajes, enseñanzas, recriminaciones, clasificaciones, descalificaciones, regulaciones y jerarquías (de clase, de género, etarias, etc.), que Ixs estudiantes de medicina y Ixs médicxs viven en carne propia o atestiguan de cerca durante los años de formación. Se trata de "tecnologías del yo" por cuanto constituyen prácticas pautadas a través de las cuales el campo médico se legitima y se reproduce.

A estas dos conceptualizaciones se suma Giberti (2003) quien sostiene que quienes participan de los sectores de poder hegemónicamente instalados, con escasa posibilidades de ser contrariados o juzgados, manipulan sus conocimientos para mantener su posición. $Y$ de hecho, que Ixs participantes principales de las relaciones en el hospital sean personal médico especializado hace que las interacciones sean "puramente médicas". En mi interpretación, esto implica decir que como el ethos de Ixs profesionales se asocia a la neutralidad valorativa, moral y afectiva (cercana a la asepsia), esos planos de lo propiamente humano se ocultan, desconocen y no promueven. En este sentido, el lugar de las parteras cumple aquí un rol clave: existe un sentido común construido en torno a su relación afectiva con las mujeres embarazadas, su función de apoyo, sostén emocional, abogacía e incluso su rol de líderes naturales (como señala Pelcastre et al, 2005). En nuestro trabajo se toma una posición crítica sobre dicho sentido común y se indaga sobre el lugar de las parteras hoy en la atención obstétrica.

>> MUJERES-MADRES, CORPORALIDAD EN EL PROCESO DE NACIMIENTO.

Por el lado de las mujeres-madres, se ha profundizado en la experiencia de la maternidad en instituciones de salud (Arvelo Arregui, 2004; Genolet et al, 2009; Marcús, 2006; Palomar Verea, 2005; Posso Quiceno, 2010; Schwartz, 2010a y b); como conflicto y acto político (Romerio y Diaz, 2001; Boichux, 2012) y vinculada a 
mitos (Espinoza Pérez, 2006). También el lugar de la embarazada como enferma/paciente (Villanueva Egan, 2010; Sadler, 2004), los procesos de infantilización y dominación (Giberti, 2003) y mecanismos de desautorización (Sadler, 2004) que ejerce la institución médica sobre ellas. En paralelo se desarrollaron conceptualizaciones sobre el cuerpo (García: 2009) en tanto al cuerpo gestante y cuerpo pariendo (Magnone Aleman, 2013), el cuerpo sospechoso y responsable (Montes Muñoz, 2008), el lugar simbólico del útero en la mujer y la sociedad (Camacaro Gómez, 2009; Camacaro Cuevas y Camacaro Gómez, 2010; Rodrigañez Bustos, 2000); y los procesos de fragmentación/reintegración (Larguía, 2000) y de dysappearance en el yo materno (Goberna Trías, 2012) como fenómenos corporales vinculados al proceso de nacimiento.

Respecto al foco en las mujeres, Villanueva-Egan (2010) y Sadler (2004) hacen una extensa problematización de la condición mujer-paciente antes mencionada. Por ello destaco los estudios que se centran en explicar y describir cómo la corporalidad de las mujeres es vivida y (re)significada en el proceso de embarazo y parto. Diversxs autorxs sostienen que en el marco de la fragmentación que el sistema médico ejerce sobre la mujer, se escinde el cuerpo de la mente, las emociones y los saberes, y se producen procesos de (re)integración, y analizan el dolor y sus experiencias y significados. Así, García (2009) refiere al proceso de fragmentación en el marco del pasaje de cuerpo-sujeto a cuerpo-objeto médico y entiende que el tránsito entre uno y otro es fundamentalmente negociado y no el producto del control unilateral ejercido por la medicina, pero en él el/la paciente negocia desde una posición de desigualdad, disrupción e incertidumbre, y ve condicionado los modos en que pueda realizarse la (re)integración. Goberna Tricas (2012) sostiene que el parto es un proceso en que las vivencias corporales deben objetivarse en el "yo materno" y lo que sucede es que se da un proceso de disociación cuerpo-mente durante el trabajo de parto, siendo que durante el proceso de dilatación las mujeres desarrollan fases de dysappearance en las cuales el cuerpo se manifiesta como autónomo, es decir, que el cuerpo "en estado de parto" aparece disociado del "yo" de la mujer. En sintonía, Magnone Aleman (2013) se centra en la imposibilidad de integrar el saber racional (médico) con el saber instintivo y corporal (femenino), y analiza el cuerpo gestante y el cuerpo pariendo. Asimismo, Montes Muñoz (2008) refiere a cómo el modelo médico hegemónico clasifica los cuerpos en torno al parto: cuerpo sospechoso (que engloba el cuerpo 
deficiente, el cuerpo como generador de riesgos y el cuerpo imprevisible) y el cuerpo responsable. Por último, y en referencia a la corporalidad, Camacaro Gómez (2009), Camacaro Cuevas y Camacaro Gómez (2010) y Rodrigañez Bustos (2000) analizan el proceso por el cual la ciencia médica y los mitos religiosos construyeron problemáticamente al útero como el órgano principal de la reproducción, y así pasó a ser objeto de control del saber-poder masculino.

En relación a los modos de pensar la maternidad, aparecen dos visiones principales. En primer lugar, desde un enfoque sociológico, se la ve como un complejo proceso social de empoderamiento y/o incapacitación de las mujeres, que acontece en la encrucijada entre la biología y la cultura humanas, que está estructurada según las relaciones de poder entre los géneros, las generaciones, las clases sociales y las etnias (Informe del Ministerio de Salud de España, 2012). En segundo lugar, vinculadas a mitos que han configurado modos de ser y de pensar los roles de madre, como analiza Espinosa Pérez (2006). Y por último, el llamamiento de Boichuk (2012) a analizar las vivencias de la maternidad ya no como una institución (funcional al status quo, producida desde el sistema médico moral) sino como un acto político y como experiencia apoderada.

>>VARONES-PADRES EN EL PROCESO DE PARTO/NACIMIENTO.

Finalmente, sobre los varones-padres, hay una menor cantidad de estudios, que han analizado principalmente la paternidad en tensión/relación con la masculinidad hegemónica (De Keijzer, 2001; Velázquez, 2004; Sadler, 2007; Arvelo Arregui, 2004) y la participación de los varones-padres en el proceso de embarazo, parto y puerperio (Maroto Navarro et al, 2009; Sadler, 2007, Hacisic, 2012, 2018).

Respecto a la paternidad, o las paternidades como sugiere tratarlas De Keijzer (2001), los pocos estudios se han centrado en considerarlas en su relación con los modelos de masculinidad y a señalar la carencia de referencias lingüísticas para nombrar la experiencia del embarazo, parto y nacimiento por parte de los varones padres; situación impulsada por las instituciones de salud, que se han centrado en el binomio madre/hijx sin dar lugar a la posibilidad de un trinomio que los incluya. En este sentido este autor sostiene que la paternidad es una posición y función situada histórica y culturalmente, y que es necesario estudiar la conexión entre reproducción 
y paternidad ya que para los varones la paternidad se constituye en la principal (y a veces única) objetivación de su participación en el fenómeno de la reproducción (De Keijzer, 2001). Velázquez (2004) sostiene que la paternidad integra aspectos subjetivos, simbólicos y valorativos, motivaciones, prácticas sexuales, reproductivas y de crianza en los varones y que sólo es posible comprenderla de manera amplia a partir de su carácter relacional con la maternidad ${ }^{23}$. Además, sostiene que por ser una construcción sociocultural está influida por la formación de la identidad genérica, y aporta una perspectiva para estudiarla en el marco de la trayectoria de vida de los varones ${ }^{24}$. Por último, Maroto Navarro et al (2009) realizan un estudio de campo con varones-padres y presentan sus conclusiones en torno a cinco ejes principales que destacan estos sujetos de su vinculación con la atención médica del parto: una crítica al modelo asistencial dominante que no los incluye pero tampoco considera protagonista a las mujeres; la conclusión de que como el proceso está corporalmente mediado y acceden a él por un conocimiento de segunda mano, sólo les cabe dar apoyo y luchar por su relevancia; la afirmación de que los servicios sanitarios hacen invisibles a los hombres ("eternos secundarios") por la exclusiva atención a las madres; el hecho de que los protocolos sanitarios coartan su participación y les excluyen; $y$, por último, que como el sistema sanitario reproduce la asignación de roles de género en materia reproductiva, los servicios los prejuzgan y no les asignan espacio cuando quieren participar.

Sadler (2007) sostiene que la mayoría de los estudios sobre paternidad han sido abordados generalmente desde una perspectiva negativa, marcando los problemas que genera la ausencia del padre y no planteando una reflexión en torno a su presencia, los valores, actitudes y expectativas de los varones respecto a esta experiencia. "Poco sabemos de los padres presentes en los hogares, de las condiciones bajo las cuales aceptan o rehúsan las obligaciones y tareas que llevan al desempeño de su rol paterno, y de los significados que le atribuyen a la paternidad" (Sadler, 2007, p. 439).

\footnotetext{
${ }^{23}$ Establece que "la perspectiva de género en su carácter relacional aporta elementos válidos para abordar las diferencias en los procesos de construcción como mujeres y como varones, la manera como se va construyendo una madre o un padre, los diferentes momentos como serían la formalización de la relación de pareja, la decisión y planeación de los hijos, la participación en el embarazo, nacimiento y crianza, así como los cambios en las prácticas en la trayectoria de vida no sólo de los hijos e hijas, sino de ellos como padres y ellas como madres" (Velázquez, 2004, p. 441-442).

24. Velázquez (2004, p. 436) retoma el estudio de Rojas (2000) para ejemplificar diferentes ejercicios de paternidad atravesados por la dimensión de clase y edad.
} 
Por último, y a los fines de situar en el campo de conocimiento esta propuesta de inclusión, retomo algunas de las conclusiones del trabajo de Sadler (2007) en el que realiza una etnografía sobre varones-padres en la sala de espera de un hospital durante el trabajo de parto de "sus" parejas, y en la que analiza tanto su participación como acompañantes, el manejo de la información por parte de Ixs médicxs como medio de poder simbólico y el desafío de la promoción de paternidades más afectivas, equitativas y comprometidas ${ }^{25}$. Entre las conclusiones a las que arriba Sadler se destaca:

"Consideramos que la participación en el parto se transforma en una instancia privilegiada para fomentar estas transformaciones, pues es un espacio donde a los hombres se les permite expresar sus emociones. En el contexto del fomento de prácticas que humanicen la atención de salud reproductiva, es un momento propicio para reflexionar acerca de las formas en que la participación del varón en el parto se lleva a la práctica. A nuestro juicio, el foco para un verdadero parto humanizado debe estar en la familia, sea cual sea su configuración, en un paso por dejar de reducir la salud reproductiva a la mujer/madre. Sin negar que su cuerpo es el que vive el proceso fisiológico de la gestación y el parto, se debe considerar que su pareja también vive el proceso, en un nivel que por ser intangible, queda invisibilizado. Tanto la gestación como el nacimiento deben ser considerados de la competencia y responsabilidad tanto de la mujer como de su pareja y redes de apoyo. La presencia del padre debe ser vista como parte integral de la atención de salud reproductiva. Las maneras en que esto se pueda implementar pueden constituirse en un importante elemento para hablar de la salud sexual y reproductiva de la familia y de los varones" (Sadler, 2007, p. 449).

He señalado la carencia de estudios sobre Ixs varones-padres en el embarazo, parto y puerperio de sus parejas, el nacimiento de sus hijxs y sobre las paternidades en general. Es propósito de mi investigación incluirlos al estudio sobre la atención médica de PEP, en tanto se trata de un proceso sociocultural diverso.

"La reproducción humana, no es un asunto meramente biológico, sino que es una actividad social, que está determinada por diferentes condiciones como son políticas, materiales y socioculturales, que establecen un modelo de atención basado en una ideología de la reproducción que dota de significación a todos sus elementos como el embarazo, parto, puerperio, y produce unas determinadas ideologías de la maternidad y la paternidad" (Blázquez Rodríguez, 2005, p. 4).

Centrarse en el análisis de los sujetos y sus relaciones ha sido una alternativa para iluminar algunos de los componentes del proceso de atención médica de PEP que es

\footnotetext{
${ }_{25}$ "Siguiendo las ideas vertidas en la Conferencia de El Cairo (1994), podemos decir que este desafío se formula no sólo a los hombres sino también a la sociedad en su conjunto, en términos de las condicionantes culturales que establecen roles y estereotipos sexuales, y que jerarquizan las relaciones entre los sexos; al Estado, en lo que concierne a su voluntad política, para operar cambios a nivel legislativo, económico, educacional y de servicios, que posibiliten el ejercicio de los derechos antes mencionados" (Sadler, 2007, p. $449)$.
} 
fundamentalmente relacional y cuyas interacciones se dan en el marco de lógicas desiguales y asimétricas de poder.

De este modo he presentado las principales líneas de análisis que constituyen mi estado del arte y a partir del cual he establecido algunas áreas de vacancia, algunos aportes fundamentales y ciertxs "clásicxs" del campo de estudio. A continuación expongo las principales categorías analíticas que hacen de referentes conceptuales de la tesis, para finalmente establecer la propuesta de una sociología de la atención médica de embarazos y partos que dialoga con los estudios del campo y articula el marco teórico propuesto.

\subsection{REFERENTES CONCEPTUALES}

Los referentes teóricos de esta tesis se encuentran en la antropología y sociología médicas/de la salud, en tanto a nivel macro (de las teorías generales) se centra en las discusiones de las ciencias sociales sobre el proceso de medicalización de ciertos problemas sociales construidos como eventos médicos ${ }^{26}$. Recupero algunas conceptualizaciones de la medicina social latinoamericana, en tanto esta perspectiva aporta herramientas para pensar integralmente el objeto de estudio, desde la problematización de las relaciones médicx-paciente hasta la consolidación de saberes y formas de atención biomédicas hegemónicas y alternativas, profundizando en conceptualizaciones sobre el poder y la dominación (Menéndez, 1988, 1992, 2009; Castro et al, 1991; Castro, 2011, 2014). Por detrás están las referencias a teorías generales de la estructura social como son las de Bourdieu (campo, habitus, capitales) y Foucault (medicalización, biopolítica, saber-poder), aunque con apropiaciones particulares por parte de los referentes específicos del campo.

A nivel micro, propongo la articulación de una serie de conceptualizaciones más cercanas, por su recorte, sobre las expresiones particulares que aquel proceso de medicalización encuentra en el embarazo y el parto. Esto es, las miradas sociológicas y antropológicas sobre la atención obstétrica, centradas en los factores materiales, ideológicos y simbólicos que rodean las intervenciones médicas en el embarazo y parto, teniendo como premisa que "la manera en que se desarrollan los partos da cuenta de

\footnotetext{
${ }_{26}$ En el trabajo de Fornes (2010) es posible rastrear los cuatro elementos claves de la antropología de la reproducción constituida desde los 70: a) entender la reproducción como un proceso sociocultural, b) controlado por profesionales médicos, c) sujeto a un proceso de mercantilización y d) atrávesado por las desigualdades de género.
} 
cómo se socializa y se reproducen los modelos culturales y sus estructuras de poder" (Jerez, 2014, p. 5). Aquí pienso la cultura como tramas de significaciones que los sujetos construyen y a partir de los cuales hacen cosas, una urdimbre que busco comprender e inscribir apelando a las perspectivas que, en este caso, distintxs actorxs erigen sobre su experiencia de las intervenciones médicas en los PEP. Me paro sobre este concepto semiótico de la cultura que propone Geertz (1987) y en la idea del estudio empírico para analizar en la acción social su articulación y el grado de patronización producto de procesos y relaciones sociales específicos, en los que interrogando la cultura se puede saber algo del poder y la desigualdad. Esto porque considero la cultura como resultado de desacuerdos que no expresa una totalidad: la cultura como campo de disputa por la ordenación simbólica del mundo, y en este caso, de los modos de nacer.

En términos de mediaciones conceptuales y categorías analíticas específicas, se destacan tres que atraviesan todo el estudio: intervenciones médicas en los procesos de embarazo y parto; hegemonía y experiencia.

La noción de intervenciones médicas no ha sido definida de un modo unívoco, por lo que aquí la pienso en torno a cómo y de qué modos la medicina interviene, se entromete, actúa sobre, piensa, simboliza y construye los procesos de embarazo y parto. Para ello será clave pensar el enfoque de riesgo médico obstétrico y las relaciones de poder médicx-paciente. De todos modos, esta categoría se construye y delimita en el siguiente apartado.

Entiendo la hegemonía retomando la argumentación gramsciana que reconstruye Williams (1997) y parto de la distinción entre dominio y hegemonía, ya que ésta "incluye y va más allá" de los conceptos de cultura e ideología, y a partir de ella podemos pensar desigualdades en una sociedad total, porque "no se reduce la conciencia a las formaciones de la clase dominante, sino que comprende las relaciones de dominación y subordinación" (Williams, 1997, p. 131).

"La hegemonía constituye todo un cuerpo de prácticas y expectativas en relación con la totalidad de la vida: nuestros sentidos y dosis de energía, las percepciones definidas que tenemos de nosotros mismos y de nuestro mundo. Es un vívido sistema de significados y valores-fundamentales y constitutivos-que en la medida en que son experimentados como prácticas parecen, confirmarse recíprocamente. Por lo tanto, es un sentido de la realidad para la mayoría de las gentes de la sociedad, un sentido de lo absoluto debido a la realidad experimentada más allá de la cual la movilización de la mayoría de los miembros de la sociedad-en la mayor parte de las áreas de sus vidas- se torna sumamente difícil. Es decir que, en el sentido más firme, es una "cultura», pero una cultura que debe ser considerada asimismo como la vívida dominación y subordinación de clases particulares" (Williams, 1997, p.131-2). 
¿Cuál es el modo hegemónico de intervenir médicamente en procesos de parto y embarazo? Medicalizándolos, institucionalizándolos, estableciendo un deber ser que convierte en un hecho médico un evento de la sexualidad de Ixs sujetxs, y lo hace factible de interpelaciones políticas, técnicas, económicas. Construyendo el polo "parto medicalizado", que puede ser caracterizado como una tecnocratización del nacimiento (Davis-Floyd, 1994), enfocando en "cómo el parto-nacimiento bajo el paradigma médico es el resultado de una cadena "fabril" compuesta por procedimientos que deben respetarse estrictamente para lograr una "calidad" de parto esperada" (Merino y Fornes, 2008). En este tipo de conceptualizaciones se da una gran relevancia al paradigma médico obstétrico hegemónico, vinculado a la construcción y reproducción del $\mathrm{MMH}$, anclado en concepciones biomédicas, ahistóricas, patologizantes y centradas en controles médicos autorizados. Así, se sostiene que en este modelo de parto se nace en instituciones sanitarias, con médicxs profesionales que intervienen el proceso fisiológico y sin protagonismo de la mujer (despersonalizada y devenida en "paciente"). ¿De qué modos las intervenciones médicas en los procesos de embarazo y parto expresan, producen y son producto de articulaciones hegemónicas? Al plantear modos unívocos de concebir las relaciones médicx-pacientes, de representar y actuar sobre estos procesos y de justificarse, al asentarse en una medicalización e institucionalización creciente de la sexualidad y reproducción que construye concepciones particulares del cuerpo femenino, de la maternidad, del nacimiento, del parto.

El análisis de la medicina en términos de la categoría hegemonía ha sido desplegado por varios autores (Menéndez y su concepto "modelo médico hegemónico" principalmente) y es posible afirmar que "sus formas de dominación y subordinación se corresponden más estrechamente con los procesos normales de la organización y el control social en las sociedades desarrolladas" (Williams, 1997, p. 132). Se tamizó el análisis a través de la lente de la hegemonía de las intervenciones médicas en tanto permite ver de qué modos suponen procesos de legitimación y de consenso y de resistencia y disputa.

"Una hegemonía dada es siempre un proceso. $Y$ excepto desde una perspectiva analítica, no es un sistema o una estructura. Es un complejo efectivo de experiencias, relaciones y actividades que tiene límites y presiones específicas y cambiantes. En la práctica, la hegemonía jamás puede ser individual. Sus estructuras internas son sumamente complejas (...) no se da de modo pasivo como una forma de dominación. Debe ser continuamente renovada, recreada, defendida y modificada. Asimismo, es continuamente resistida, limitada, alterada, desafiada por presiones que de ningún modo le son propias. Por tanto debemos agregar al concepto de hegemonía los conceptos de 
contra hegemonía y de hegemonía alternativa, que son elementos reales y persistentes de la práctica" (Williams, 1997, p. 134).

Pensar las intervenciones médicas obstétricas desde la lente de la hegemonía, entonces, tiene la ventaja de develar las relaciones de poder-dominación-desigualdad y su disputa, a través de la creación de hegemonías alternativas, que actualmente se vincula a la construcción del referente "parto respetado/humanizado", que ha sido caracterizado como aquel en el que se respetan las necesidades fisiológicas del parto y las necesidades sociales y subjetivas de la mujer y no hay intervenciones "innecesarias" que obstaculicen su desarrollo. Por tanto, se sostiene que en este modelo se elige cómo, dónde y con quién parir: elección de la mujer sobre las posiciones de parto, el lugar de ocurrencia (la casa, el hospital) y el acompañamiento de parteras, doulas ${ }^{27}$, médicxs obstetras, etc. En este sentido, si afirmamos que "todo proceso hegemónico debe estar en un estado especialmente alerta y receptivo hacia las alternativas y la oposición que cuestiona o amenaza su dominación" (Williams, 1997, p.135), es posible comprender cómo varias clínicas privadas de la ciudad ofrecen una atención bajo este paradigma (con el pago de un plus). Es posible, también, pensar los modos en que se reactualiza la hegemonía en tanto el mismo Estado Nacional lanza una ley de "parto respetado" en 2004 retomando un significante construido socialmente, y aquí puedo preguntarme si no hay un "enroque" de hegemonías dominantes y subalternas. O porqué la asociación de parteras de Argentina (en sintonía con lo que sucede en otras partes del mundo) exige acciones estatales para excluir a las doulas acusándolas de ejercicio ilegal de la medicina y de intrusión profesional ${ }^{28}$. Disputas, contradicciones, negociaciones, son posibles captarlas a través de esta perspectiva conceptual.

Asimismo, y siendo que la argumentación de Williams es una lente analítica principal de la tesis, si se piensa en cómo la hegemonía se asienta sobre tradiciones, instituciones y formaciones, sobran referencias en el tema de las intervenciones médicas en el PEP. ¿Acaso en la construcción de hegemonías alternativas no hay una acción selectiva del parto en casa de nuestras abuelas o la referencia a las mujeres de siglos pasados como apelación legitimante a lo natural/tradicional, como resistencia al parto medicalizado? Del mismo modo, la construcción de la hegemonía dominante ¿no se

\footnotetext{
27 Una "doula" es una asistente sin titulación oficial que proporciona apoyo físico y emocional a las mujeres durante el embarazo, el parto y el posparto.

${ }^{28}$ Se vuelve relevante para análisis futuro, pensar la disputa parteras-doulas desde la idea de "establecidosoutsiders” de Norbert Elías (1998, p.9).
} 
asienta en la institución sanitaria principal de nuestra sociedad, el hospital, y en el referente del acceso a la salud y en la construcción hegemónica del riesgo? Y más aún, ¿no existe $\mathrm{o}$ es comprobable la emergencia de formaciones pro-parto respetado encarnados por grupos de mujeres, varones y profesionales de la salud de clase media urbana en distintos lugares del mundo? Incluso, ¿no es posible aplicar los conceptos de residual y emergente para pensar, por ejemplo, la presión familiar para el parto hospitalizado y los controles prenatales, y la incorporación de las doulas a la atención perinatal, correspondientemente? Esta tormenta de ideas desordenada es sólo un ejemplo de las herramientas que ofrecen los estudios culturales para interrogar, literalmente, a nuestro objeto.

Finalmente, experiencia es una categoría analítica central, que retomo a través de la vinculación que Williams hace de la hegemonía con la experiencia vivida, como "economía de la experiencia" y conciencia práctica. Aunque exceden a esta tesis las argumentaciones que hacen del concepto Williams y Thompson, referenciadas por Hall (1994) y Scott (1999), rescato la apelación a las formas de vivir, lo articulado y lo vivido, la conciencia, las condiciones objetivas, la subjetividad, el discurso, el conocimiento y la estructura de sentimiento para analizar la experiencia.

"Se trata, en última instancia, de dónde y cómo la gente experimenta sus condiciones de vida, las define y responde a ellas, lo cual, para Thompson, define por qué cada modo de producción es también una cultura, y porqué todo conflicto de clases es también una lucha entre modalidades culturales y qué es, para Williams, lo que un análisis cultural debería entregar en última instancia. En la experiencia hay una intersección de las diferentes prácticas, aun sobre una base desigual y de mutuas determinaciones" (Hall, 1994, p. 80-1).

En este marco, elegí la perspectiva de Scott porque propone darle historicidad a la experiencia, ver cómo produce sujetos, su carácter discursivo, la política de su construcción y la necesaria creación de genealogías para su estudio; en tanto "la experiencia es, en este acercamiento, no el origen de nuestra explicación, sino aquello que queremos explicar" (Scott, 1999, p. 73).

"Para eso necesitamos dirigir nuestra atención a los procesos históricos que, a través del discurso, posicionan a los sujetos y producen sus experiencias. No son los individuos los que tienen la experiencia, sino los sujetos los que son constituidos por medio de la experiencia (...) Pensar de esta manera en la experiencia es darle historicidad, así como dar historicidad a las identidades que produce" (Scott, 1999, p. 49-50). 
Y esta idea es central para la tesis, en tanto las experiencias (colectivas e individuales) de embarazo y parto y de la atención médica que de éstos producen sujetxs e identidades heterogéneas ${ }^{29}$.

"La experiencia [escribe Teresa de Lauretis] es el proceso por el cual se construye la subjetividad para todos los seres sociales. A través de ese proceso uno se ubica o es ubicado en la realidad social y de ese modo percibe y comprende como subjetivas (referidas a y originadas en uno mismo) esas relaciones -materiales, económicas e interpersonales- que de hecho son sociales y, en una perspectiva más amplia, históricas" (Scott, 1999, p. 53).

Entonces es a raíz de las propias experiencias que lxs sujetxs pueden construir conceptualizaciones de las relaciones médicx-paciente, de las intervenciones médicas, de los modos institucionales de parir y de los atravesamientos de poder y desigualdad que dejan marcas en estos procesos y relaciones. Se trata de "explorar los procesos de producción de la diferencia en un mundo de espacios cultural, social y económicamente interconectados e interdependientes" (Gupta y Ferguson, 2008, p. 12), de la heterogeneidad de experiencias y significaciones respecto de las intervenciones médicas en los PEP, de la construcción discursiva de éstas como legitimantes, (re)productoras, resistentes y/o cuestionadoras de tales acciones de la medicina.

Los estudios culturales han propuesto a esta tesis tres modos de formular la pregunta por la cultura: en términos de significados, los estudios culturales tienen mucho para aportarle al objeto, en tanto la pregunta de investigación se centra en ellos; en términos de posiciones y la vinculación entre clase y cultura, las reflexiones sobre las posiciones de clase de Ixs sujetxs que incluí en el estudio urgen y son completamente ineludibles; $y$, respecto a las relaciones, el estudio de las intervenciones médicas en los PEP tienen su pilar principal en la construcción de relaciones médicx-pacientes especiales. En resumen, los significados, las posiciones y las relaciones son tres perspectivas desde las cuales interpelar el objeto y de ahí la utilidad de interrogarlo desde los estudios culturales, en el marco del despliegue de un uso estratégico de la teoría (Grosberg, 2006).

\footnotetext{
${ }^{29}$ Se destacan, en tal caso, aquellas mujeres-madres y varones-padres que posterior a atravesar embarazos y partos intervenidos, medicalizados y autoasumiéndose víctimas de violencia obstétrica, se enrolan en actividades y grupos pro-parto respetado y de lucha por los derechos del parto. O dicho de otro modo, estas asociaciones civiles que actualmente están en auge y se multiplican en distintos puntos del país, están formadas por sujetos que, a partir de sus experiencias, decidieron participar activa y políticamente para producir un cambio de paradigma en la atención obstétrica. La experiencia los ha constituido en determinados sujetos políticos
} 
Finalmente, a modo de cierre del marco teórico, vuelvo a la sociología de la salud para retomar el ineludible aporte de Grimberg (2003) acerca de cómo pensar la experiencia

\begin{abstract}
"como un proceso variable, situado en una trama de relaciones intersubjetivas, construido y reconstruido histórica y socialmente en una diversidad de dimensiones (cognitivas, normativo-valorativas, emotivas, etc.). Como unidad tensa entre acción y simbolización, la experiencia constituye la base de la construcción y el cambio de identificaciones y prácticas sociales, cuya comprensión requiere un contexto conceptual que articule las relaciones entre poder, cuerpo, género, sexualidad, emoción, reflexividad, en las distintas áreas de la vida cotidiana, ya que se trata de una activa construcción intersubjetiva, sujeta al mismo tiempo a procesos estructurales históricos" (p. 81).
\end{abstract}

Es desde esta tensión constructiva, articuladora de relaciones de poder, sujeta y activa, que pienso la construcción de las experiencias de atención médica de PEP por parte de mujeres-madres, varones-padres y profesionales de la salud obstétrica de la ciudad de La Plata, que son el eje de análisis de la presente tesis.

\title{
1.5. SOCIOLOGÍA DE LA ATENCIÓN MÉdICA DE EMBARAZOS Y PARTOS ${ }^{30}$
}

La ciencia avanza por acumulación, diálogo, crítica. Con esta premisa, en el marco de este capítulo de la tesis que reconstruye el marco conceptual, considero relevante a partir de una lectura crítica de los estudios del campo de estudio, su problematización y (re)valorización, construir una caja de herramientas y proponer una sociología de la atención médica de embarazos y partos. Para ello propongo tres pasos: primero, un recorrido a modo de resumen por los aportes de algunas tesis del campo de estudio de la socioantropología de la atención obstétrica ${ }^{31}$; segundo, la construcción de dos tipos/modelos de atención; y, finalmente, la noción de intervenciones médicas en los PEP y sus potenciales para el objeto de estudio.

¿Por y para qué pensar sociológicamente un proceso "eminentemente biológico y médico"? Justamente para desnaturalizar esa idea, y reponer su carácter sociocultural y

\footnotetext{
30 Nobleza obliga, Hernández Garré y Echevarría Pérez (2016) propusieron una sociología del parto, en relación a los conflictos asistenciales en el parto intervenido, que llaman parto tecnocrático. Su principal conclusión es que "estamos ante un ritual medicalizado impregnado de vivencias de obediencia pasiva, en el que el miedo al peligro siembra la desconfianza corporal, a la vez que la voluntad de la mujer es moldeada por los expertos. Realidad que las parturientas asumen como inevitable, e incluso demandan, como consecuencia de la seguridad que les aporta el control biotecnológico, una vez asumidos los discursos clínicos que representan al parto como un proceso patológico y de riesgo” (p. 1).

${ }^{31}$ Esta presentación aparte de las constribuciones de un conjunto de tesis, descansa en una mera cuestión cronológica y esquemática de encuentro con el material. Es posible que esto implique una repetición de algunos conceptos, pero la decisión arbitraria apunta también a visibilizar las tesis o a establecer "lo canónico” del área, como propósito cognitivo. He decidido emparentar la antropología con la sociología del parto, en tanto la mayoría de lxs autorxs provienen de la primera.
} 
los procesos ideológico-político-morales y socioeconómicos por los cuales un proceso cuya dimensión fisiológica y sexual ha sido convertido en un evento médico. En este sentido, el abordaje y construcción sociológica de la atención médica de embarazos y partos, tiene como objetivo "descubrir las estructuras de dominación que subyacen a la práctica médica y que explican tanto la conducta del personal de salud como de las usuarias de los servicios" (Castro y Erviti, 2015, p. 22). Así, las preguntas sociológicas al objeto de estudio permiten, por un lado, reconstruir los esquemas de percepción y apreciación de mujeres y médicxs, los patrones de interacción y las lógicas prácticas (re)producidas en la atención médica obstétrica, elementos de la formación, estructura jerárquica y condiciones laborales de la "clase médica" (Castro y Erviti, 2015), y, por otro, dar cuenta de procesos sociales más generales, como se ha mostrado anteriormente.

Tanto sea que se concentre en lo micro o se quieran reconstruir miradas macrosociales, la sociología de la atención médica de embarazos y partos permite pensar los procesos, las experiencias, las prácticas y representaciones, y las relaciones entre Ixs sujetxs, e incluso problematizar el conjunto en torno a las desigualdades (de género, edad, ámbito de atención, posición socioeconómica), las heterogeneidades o puntos de encuentro, las cuestiones de poder, dominación y las estrategias de resistencia, como en tantos otros objetos sociológicos. Porque finalmente, el parto es "fruto de la internalización de las normas sociales que lo apuntan en cada contexto particular" (Sadler, 2003, p. 6), por lo que aunque el proceso perinatal es un proceso fisiológico universal, existe una diversidad cultural en su atención (Sadler, 2003). En este sentido es que Montes Muñoz (2007) se refiere a las culturas del nacimiento, como aquellos universos simbólicos ( $p$. 175) o sistemas de prácticas y representaciones sobre la concepción, la gestación, los partos/nacimientos en los distintos grupos culturales; sistemas que a su vez determinan las acciones y conductas de Ixs sujetxs, y señalan expectativas comportamentales uniformes.

"Las investigaciones antropológicas sobre embarazo, parto y puerperio tuvieron auge en el contexto de la segunda oleada de movimientos feministas, en la búsqueda de la diversidad de roles, sentidos y prácticas referentes a la maternidad. Desde los años ochenta los estudios sobre reproducción se enfocaron directamente a investigar la atención obstétrica en la sociedad occidental, poniendo énfasis en las representaciones y prácticas relacionadas al incremento de la tecnologización y medicalización del parto. A través de la producción teórica y la investigación empírica algunas antropólogas vienen sosteniendo desde abordajes particulares que el parto-nacimiento es un proceso cultural además de biológico, enmarcado en tramas de significación y relaciones de poder específicas a cada sociedad" (Fornes, 2009, p. 1). 
Esta diversidad cultural en la atención de los PEP es el principal eje de la antropología/sociología del parto $^{32}$, que se apoya y surge en la intersección entre los estudios de género y la sociología de la salud. Entendemos a ésta última emparentada a la antropología médica crítica, que problematiza cómo "las diferencias de poder moldean las diferencias sociales, postulando que las ideologías dominantes y los patrones sociales en el cuidado médico están íntimamente relacionados a ideologías hegemónicas y patrones externos a la biomedicina" (Sadler, 2003, p. 59).

En el abordaje sociológico que construyo en este diálogo con el estado de la cuestión, resulta fundamental la consideración de la doble dimensión de la práctica médica que desarrollan Castro y Erviti (2015)

"por el grado de acumulación de conocimientos clínicos logrados, por su nivel de especialización técnica, y por el manejo de tecnologías modernas en el diagnóstico y tratamiento de los pacientes, es una práctica profesional orientada a brindar servicios de salud a la población, y por la forma en que estas jerarquías se expresan y se reproducen en el encuentro entre médicos y pacientes, la práctica médica es una estructura de dominación a la búsqueda permanente de los medios de su propia legitimación y perpetuación" (Castro y Erviti, 2015, p. 158-159, las cursivas son del original).

Estos dos "frentes activos" de la profesión médica, esto es, "la prestación" y "la producción y reproducción de su legitimidad" (Castro y Erviti, 2015, p. 137) son lo que Schraiber (2015) llama acción técnica y acción moral de la medicina. La primera refiere a la intervención práctica, a la dimensión clínica y técnica, supuestamente inocua y neutral de la acción médica; mientras que la segunda apela a la dimensión política, normativa e

\footnotetext{
32 Sadler (2003, p. 62-63) sitúa como clásicos anglosajones de la antropología del parto a Jordan, DavisFloyd y Kitzinger. Blázquez Rodríguez hace una enumeración más extensa (2005, p. 2): "Es a partir del trabajo de Margaret Mead y Niles Newton en 1967 (citado en Browner and Sargent, 1990:221) de comparación ntercultural de distintos sistemas de parto, cuando se empiezan a producir etnografías acerca del tema. De manera que en la década de los 70 encontramos lo que se empieza a denominar Antropología del Parto con una veintena de publicaciones que son las siguientes: Nancy Stoller Shaw (1974), Carol McClain (1975), Sheila Cosminsky (1977), Brigitte Jordan (1977), Shelia Kitzinger (1978) y Linda Annis (1978). Y posteriormente Ann Oakley (1980), Soheir Morsy (1981), Carol MacCormack (1982), Carolyn Sargent (1982 y 1996), Margarita Kay (1982), Carol Laderman (1983), Lucille Newman (1985), Dana Raphael (1985), Pamela Eakins (1986), Robert Hahn (1996), Patricia Jeffery, Roger Jeffery y Andrew Lyon (1989), Faye Ginsburg y Rayna Rapp (1991 y 1995), Robbie Davis Floyd (1992, 1994, 2000 y 2001), Shirley Lindendaum y Margaret Lock (1993), Sara Franklin y Helena Ragone (1997) y Iris López (1998). A partir de estos estudios se pone de manifiesto que siendo el embarazo y el parto, procesos universales en cuanto a la fisiología del cuerpo femenino, sin embargo, nunca ocurren como un mero proceso biológico, sino que se encuentran culturalmente moldeados, dándose de diferentes maneras en cada sociedad y en los diferentes grupos sociales. A partir de los ochenta surgen también otra veintena de etnografías que se dirigen a la atención obstétrica, dónde se incluye el estudio del incremento de la medicalización en la atención al embarazo y el parto en las sociedades industrializadas como Shelly Romalis (1981), William Arney (1982), Audrey Eccles (1982), Rita Arditti, Renate Klein y Shelley Minden (1984), Rosalind Pollack Petchesky (1984 y 1987), Paola Tabet (1985), Ann Oackley (1986 y 1987), Barbara Rothman (1982 y 1986), Judith Leavitt (1986 y 1987), Emily Martin (1987), Susan Irwin y Brigette Jordan (1987), Ellen Lazarus (1988 y 1994), Karen Michaelson (1988), Carolyn Sargent y Nancy Stark (1989), Brigitte Jordan (1993), Hency Goer (1995), Carole Browner y Nancy Press (1995), y Rayna Rapp (2000).
} 
ideológica de la misma acción. Se trata de "una descripción clínica montada sobre una práctica normativa" (Schraiber en Castro y Erviti, 2015, p. 160).

Blázquez Rodríguez (2007, p. 99) los nomina como los dos planos de la asistencia sanitaria: uno de la praxis y otro ideológico; y es justamente en este segundo en el que se puede construir y aplicar la pregunta sociológica que propuse. En resumen, si se entiende que la concepción del embarazo/parto como evento médico responde a una construcción política e ideológica clara y situada históricamente, y que justificadas en esa concepción se aplican las intervenciones prácticas-clínicas que tanto se discuten actualmente (epidemia de cesáreas, inducciones y episiotomías); se puede entonces entender la relevancia de des-naturalizar, des-cubrir y reponer las ontologías de la estructura de dominación que supone la práctica profesional médica obstétrica. Estructura de dominación que, desde mi lente sociológica y feminista, responde a subordinaciones de género y estructuras de poder androcéntricas y patriarcales del poder médico.

"La relación que existe entre el orden social generizado y los discursos producidos por los profesionales médicos en el ámbito reproductivo, en tanto es en ese orden social en el que estos discursos se enmarcan y adquieren sentido. En este orden social y corporal se han legitimado y construido regulaciones y controles corporales y simbólicos que mediante distintos mecanismos sociales contribuyen a mantener y reproducir las desigualdades (no sólo de género) en el área de la reproducción. Por ello, se vuelve pertinente dimensionar los cuerpos como territorios de las políticas, prácticas y representaciones específicas de las regulaciones de su uso reproductivo" (Erviti, 2010, p. 19).

Sobre esta doble implicancia de la práctica clínica, en el caso de los PEP, diversos autores señalan de qué modos las intervenciones implican acciones pedagógicas y "forman parte de mecanismos a través de los cuales se propugna la aceptación de una estructura de relaciones de poder entre médicos y pacientes y entre hombres (significando el androcentrismo de la ciencia) y mujeres" (Fornes, 2009, p. 4). En este sentido, Davis-Floyd (1994) piensa a las prácticas obstétricas como "rituales" que sirven a la aceptación por parte de la mujer de un orden social establecido, tomando como premisa que "la forma en que se da lugar al nacimiento implica una forma de socialización y reproducción de un modelo cultural y sus estructuras de poder"33. Al respecto y en coincidencia con esta argumentación, Fornes (2011, p. 143) sostiene que lo relevante

\footnotetext{
33 "En las diferentes situaciones, las mujeres confirman que su cuerpo pasa por un proceso de medicalización, imposición que aceptan porque históricamente han venido aprendiendo que los eventos fisiológicos como la menstruación, el embarazo, la menopausia, entre otros, son tratados como enfermedades y que su cuerpo constituye un espacio para la aplicación de un conocimiento normatizado y donde la pauta es patologizar. El poder que la sociedad le ha atribuido a la institución médica hace que cualquier mensaje emitido por ésta, se instituya como declarativo y resolutivo, de algo que ha de cumplirse” (Camacaro Gómez, 2009, p. 226).
} 
entonces es "focalizar en su eficacia simbólica más que en lo obsoleto de su efectividad clínica”, en referencia a las intervenciones obstétricas. Así, vincula, por ejemplo, la inmovilización en silla de ruedas con la incapacidad o el reposo en la camilla para el trabajo de parto con la enfermedad, incluso la posición de litotomía -acostadas- para el parto con la sujeción y la sumisión ${ }^{34}$.

Del mismo modo, Sadler (2004) analiza diversos mecanismos de desautorización que se interrelacionan en la institucionalización de embarazos y partos, entre ellos la infantilización, des-sexualización y des-personalización aplicada a mujeres como efecto de ciertas intervenciones comunes que hacen a la relación médicx-paciente. En congruencia, Jerez (2014) concibe las intervenciones como "ritos de pasaje" a través de los cuales la mujer asume los dictados sociales y las demandas institucionales. Entre estas perspectivas antro-sociológicas sobre la atención médica de embarazos y partos, también se han desarrollado visiones sobre el despliegue de un poder disciplinario médico, a través de la sanción normalizadora, la vigilancia y el control social de los cuerpos y la normalización del proceso de parto (Erviti, 2010). Asimismo, pensando esta estructura de dominación que conllevan las intervenciones médicas, Grimberg (1995) propone el concepto de micropolítica de la medicina, que refiere a la reproducción y refuerzo de las relaciones políticas macro en el nivel micro de las relaciones médicxpaciente. Aquí agrego que se da también a través de procesos de negociación propios de la construcción hegemónica. En este sentido, el espacio de la consulta médica y de todas las instancias de contacto entre el personal de salud y las mujeres en el proceso de parto es territorio de reactualización de sentidos hegemónicos vinculados a la medicina como forma legítima de tratar la salud y la enfermedad, y es a la vez, "la performance del acto de legitimación de un saber excluyente, y una instancia de control normativo sobre los cuerpos de un agente por sobre otros" (Marton y Echazu, 2010, p.130). En suma, uno de los principales ejes para pensar estas intervenciones médicas en el PEP es inherente a los procesos de medicalización: esto es, la legitimación y potenciación de saberes médicos biomédicos, y procesos de exclusión/inclusión y reconocimiento/desconocimiento

\footnotetext{
34 Burgo (s/f) sostiene -y coincido- que "la posición de la madre es un procedimiento médico, una intervención médica”. Arguedas Ramírez (2014, p. 164) da más detalles del proceso de constitución de la litotomía: "Durante los últimos 300 años, la opinión médica ha favorecido el cambio a la posición de decúbito, sin embargo, esto se ha implementado sin el aval de evidencia científica. Los cambios que condujeron al parto en decúbito iniciaron con el advenimiento de los cirujanos obstetras durante el siglo XVII en Francia. Estos cambios se pueden rastrear hasta el Hotel Diêu, donde Amboise Paré y sus seguidores iniciaron con estos procedimientos. Cincuenta años después, el parto en decúbito se generalizó por la influencia de Francois Mauriceau en la corte de Luis XIV. Al parecer, además, el Rey prefería esta posición para poder observar el nacimiento de sus hijos”.
} 
de otros saberes como el conocimiento experiencial femenino o el que aporten las mujeres sobre el estado de su cuerpo; así como el conocimiento de colectivos de mujeres o referidos al uso de terapias alternativas para aliviar dolores o resolver problemas clínicos.

Tomando como punto de partida esta "doble verdad de la práctica médica" me he concentrado en ver la atención médica de embarazos y partos como una práctica de dominación, tratando de desentrañar los pilares ideológicos que son núcleo de las intervenciones clínicas supuestamente inocuas.

\subsection{A. MODELOS DE ATENCIÓN AL PROCESO DE EMBARAZO Y PARTO}

Partiendo de que "las dicotomías medicalización/no medicalización y trato humanizado/deshumanizado estructuran en gran medida el campo simbólico de la atención del parto" (Arosteguy y otras, 2017, p. 4) resumo en este apartado esos dos modelos de atención obstétrica que articulan la tesis. La decision de trabajar con modelos conjuga lo emergente del campo de estudio y del trabajo empírico con un modo de trabajo analítico propio que propone pensar en paradigmas extremos para ir deconstruyéndolos a partir de la explicitación de los grises y matices. Retomo la concepción de Menéndez (1992) sobre los modelos y su utilización para las ciencias sociales de la salud, como un instrumento metodológico construido por el/la investigador/a, con fines heurísticos, que exige la "referencia a situaciones históricamente determinadas" para poder actuar como medio de explicación de los problemas específicos.

"Los modelos están planteados a partir de una perspectiva metodológica relacional, que supone procesos de hegemonía/subalternidad entre los mismos, y que halla en el términos "transacciones" el concepto con el cual se puede describir y explicar al conjunto de relaciones que operan potencialmente. Las transacciones suponen siempre procesos de reapropiación y rearticulación generados desde los grupos subalternos" (Menéndez, 1992, p. 86).

La conceptualización que hace el autor de esta herramienta metodológica es completamente coherente con mi propuesta de investigación: mi búsqueda es usar los modelos y conocer los grises, cruces y tensiones (lo que él llama "transacciones") entre los diferentes modos que ofrecen de concebir y abordar la atención de los PEP.

Para completar la construcción conceptual que estructura la tesis, presentaré algunos rasgos principales del modelo de atención obstétrica "hegemónico" (intervencionista y medicalizado) y otros de la propuesta del paradigma de humanización o parto respetado, contruídos a partir del corpus de tesis analizado. Finalmente 
presentaré la idea de las intervenciones médicas en los PEP que permite operar a explicitación de los grises mencionados.

>> LO HEGEMÓNICO: PARTOS MEDICALIZADOS E INTERVENIDOS.

Una parada obligatoria para una sociología de la atención médica de embarazos y partos es la caracterización que asume esta atención obstétrica en sus modos hegemónicos, dominantes, frecuentes: hospitalarios y medicalizados. El punto en partida común implica la reconstrucción dos ocurrencias históricas, mencionadas anteriormente, situadas en el siglo XIX, que explican la emergencia y consolidación de dicha hegemonía: la institucionalización de los partos y la profesionalización de su atención. Esta doble dinámica se imbrica con los elementos aquí abajo reseñados, para dar forma a la atención hegemónica nominadas por Ixs autorxs de diversos modos: "control biomédico del parto"35 (Blázquez Rodríguez, 2009), "parto hospitalario" (Montes Muñoz, 2007) o "sistema médico oficial o imperante" (Sadler, 2003). Aquí me refiero a ella como modelo hegemónico de atención obstétrica (o de embarazos y partos).

Estas seis herramientas conceptuales (cuadro 1) que incluyo en la caja de abordaje sociológico que construí a partir de las lecturas y que permiten pensar la atención médica de los PEP como expresión de procesos sociales generales, están interrelacionadas, imbricadas y suponen una heterogeneidad de relaciones de precedencia o causa-efecto, por lo que más bien se trata de una red de categorías explicativas.

\section{CUADRO 1: HeRRAMIENTAS CONCEPTUALES PARA UNA SOCIOLOGía dE LA ATENCIÓN MÉdICA HEGEMÓNICA DE LOS PEP}

ATENCIÓN OBSTÉTRICA HEGEMÓNICA
>>HEGEMONÍA MÉDICA $<<$
>>SABER EXPERTO $<<$
>>MEDICALIZACIÓN Y PATOLOGIZACIÓN $<<$
>>ENFOQUE DE RIESGO REPRODUCTIVO $<<$
>>TECNOLOGIA, PRODUCCIÓN Y TIEMPOS $<<$
>>MECANISMOS DE DOMINACIÓN Y DESAUTORIZACIÓN $<<$

$\checkmark$ Hegemonía mÉdicA. Al analizar la práctica médica en términos de hegemonía, se vuelve relevante e ineludible la referencia al concepto de modelo médico hegemónico

\footnotetext{
${ }_{35}$ Blázquez Rodríguez (2009, p. 90) sostiene, citando a Stoller, que este control biomédico del parto tiene cinco elementos principales: medicalización/monopolio medico; institucionalización; especialización y rutinización de la atención; confianza en la tecnología y uso del poder/jerarquía médica.
} 
$(\mathrm{MMH})$ que designa al conjunto de prácticas, saberes y teorías generados históricamente por la medicina científica, la cual logró identificarse en Occidente como la única forma legítima de atender la enfermedad. Esta categoría, construida por Eduardo Menéndez en el seno de la corriente de la medicina social latinoamericana que es el marco teórico de nuestra indagación, permite dar cuenta de la relevancia cognitiva de la construcción de modelos de atención a la salud.

"El MMH constituye una construcción teórica que manejo en varios niveles de abstracción (...) La construcción de este modelo suponen detectar una serie de rasgos considerados como estructurales, los cuales deben ser entendidos como modelo a partir de la estructura de relaciones que opera entre los mismos. Los principales rasgos estructurales son: biologismo, individualismo, ahistoricidad, asociabilidad, mercantilismo, eficacia pragmática, asimetría, autoritarismo, participación subordinada y pasiva del paciente, exclusión del conocimiento del consumidor, legitimación jurídica, profesionalización formalizada, identificación con la racionalidad científica, tendencias inductivas al consumo médico" (Menéndez, 1988, p. 2).

En este sentido, se verá que las características que Menéndez identifica en la construcción de su modelo de $\mathrm{MMH}$, son claves en la construcción de un modelo de atención médica obstétrica hegemónica, con los elementos que describimos a continuación.

$\checkmark$ SABER EXPERTO. Blázquez Rodríguez (2009) sostiene que uno de los principales pilares del control biomédico de partos es su presunción de cientificidad, amparada en cinco elementos: la determinación de la desviación y la normalidad a través de la construcción estadística (p. 83-84); la universalización y uniformización (p. 86); la (pretendida) neutralidad (p. 87); la legitimación de la tecnología (p. 88); y su constitución como saber experto (p.90) o conocimiento autorizado ${ }^{36}$.

"El sistema médico oficial hegemoniza el control sobre los conocimientos que se refieren al cuerpo humano, en este caso al cuerpo femenino y sus procesos fisiológicos: podríamos hablar de un conocimiento autorizado, como el conjunto de saberes que adquieren el más alto poder y legitimidad para explicar los fenómenos en un contexto determinado (Jordan 1993: 152). El conocimiento autorizado que se impone en occidente es uno que patologiza las etapas del ciclo vital de las mujeres, concibiéndose la menstruación, gestación, parto y menopausia como enfermedades que deben ser tratadas y controladas (...) Esta propensión ha significado que el parto se haya transformado en un problema médico aislado, separado del resto de las experiencias de vida de la mujer y por ello, que la mujer gestante se conciba como una pasiva y dependiente paciente" (Sadler, 2003, p. 9).

\footnotetext{
${ }^{36} \mathrm{El}$ concepto fue acuñado por la antropóloga norteamericana Brigitte Jordan como authoritative knowledge. "La constitución del conocimiento autorizado es un proceso social continuo que construye y refleja las relaciones de poder al interior de una comunidad. Y llega a ocurrir que los participantes ven el orden social así construido como el orden natural de las cosas. De este modo, se puede decir que el conocimiento autorizado es persuasivo porque parece natural, razonable y construido consensualmente, por tanto, su poder radica no en que sea el conocimiento correcto, sino el que cuenta" (Sadler, 2003, p. 6).
} 
Sadler (2003) centraliza en este elemento para analizar la atención del proceso perinatal y sostiene que este conocimiento autoritativo, a partir de las relaciones de poder médicx-paciente, se establece como régimen particular de verdad. Además, explicita que la reproducción de este tipo de saber se asienta en tres procesos: la desproporción de poder de Ixs participantes, la organización de la atención obstétrica y las prescripciones institucionales. Marton y Echazú (2010, p.130) dan una sentencia interesante al respecto: "la puesta en escena del ritual terapéutico es también la performance del acto de legitimación de un saber excluyente, y una instancia de control normativo sobre los cuerpos de un agente por sobre otros".

Así, la atención obstétrica hegemónica se materializa/visibiliza en relaciones médicx-paciente, definiendo como pacientes a mujeres-parturientas, varones-padres y recién nacidxs, en un tipo de relación de dominación que se asienta en la subordinación del/lxs paciente/s por la figura del/la médicx, portador del saber-poder. Por tanto, para Villanueva Egan (2010) este modelo de atención se asienta sobre un control simbólico del saber: esto es, por un lado, la descalificación de la información y el conocimiento que poseen las mujeres sobre su proceso de parto; y, por el otro, un control riguroso de la información que posee el personal sanitario sobre su estado de salud (estructurándose ésta como una forma de poder simbólico en el marco de un orden jerárquico). "Las dos condiciones anteriores (...) sirven de base para un tercer patrón de interacción de consecuencias más graves: se trata de la desacreditación de las mujeres como sujetos que sufren" (Villanueva Egan, 2010, p. 148-9).

"El conocimiento de las mujeres era (¿o es?) descartado por ser supuestamente acientífico y por considerarse producto de la irracionalidad. Lo anterior resulta en la ironía de que, al parecer, todo el mundo puede conocer sobre las mujeres y su cuerpo excepto ellas mismas. No se les considerada "adecuadas" para producir conocimiento por diferentes razones; por ejemplo, el ser juzgadas por estereotipos y prejuicios acerca de qué y cómo pueden conocer; su experiencia no equivale a conocimiento y a esa misma experiencia tampoco se le atribuye su valor total diferenciándola de la experiencia masculina" (Cárdenes y Ugarte, 2002, p. 131)

La relación médicx-paciente en la atención obstétrica supone la legitimación del/la portador/a del saber y excluye la posibilidad de otras voces autorizadas, en este caso las mujeres que paren. Considero que este elemento del saber es núcleo y motor de los procesos de medicalización, de las relaciones de poder y hegemonía médicx-paciente, en tanto el lugar de saber-poder y el de saber-hacer son los ladrillos que dan firmeza a la autoridad y jerarquía médica tanto para definir como para intervenir los embarazos y partos. Lo que la sociología de la atención obstétrica puede aportar, entre otras cosas, es 
el análisis de esa "ciencia" pretendidamente neutral, como resultado y productor de procesos de dominación patriarcales, elitistas y excluyentes de otros tipos de saberes.

$\checkmark$ MEDICALIZACIÓN Y PATOLOGIZACIÓN. Entiendo la medicalización de los partos como un proceso histórico social basado en intervenciones sobre los procesos reproductivos: algunas de tipo simbólico, que han permitido construir el parto como un evento médico, y otras intervenciones prácticas y clínicas que han reafirmado dicha construcción. El proceso de medicalización general de la sociedad, encuentra expresiones particulares en los modos en que se efectúa en el proceso de nacimiento ${ }^{37}$. Esto es, la consolidación de discursos médicos que a través de su poder legitimado socialmente, realiza interpretaciones sobre los cuerpos femeninos y la reproducción social humana que pretenden ser únicas en función de un criterio de validación científico que recorta lo biológico como elemento central en la explicación y que devienen hegemónicas, transformando los procesos de embarazo y parto (tanto como la sexualidad, el cuerpo y la subjetividad femeninas) en pasibles focos de un control activo y normalizador.

"Esta visión patológica de los cuerpos y procesos de las mujeres es muy influyente en el modo actual de concebir los partos. En vez de partir de la evidencia científica aportada por la medicina y basada en evidencia que sustenta que más de $85 \%$ de los partos y nacimientos pueden desarrollarse de forma fisiológica y casi sin intervención externa a las mujeres, se organiza un sistema de atención al parto que pretende llegar a $100 \%$ de las mujeres basado en la concepción patológica del parto, obligando a las mujeres a parir en centros de segundo y tercer nivel de atención, asistidas por la medicina e invadidas por la tecnología y por intervenciones muchas veces injustificadas que van quitándole la posibilidad de reconocer y responder a las necesidades de su cuerpo. Negándoles así la posibilidad de experimentar que son ellas las que paren a sus hijos e hijas, y al contrario, presentando al hospital como el dispositivo que "logró" que su bebé naciera" (Gainza et al., 2014, p. 188-189).

Montes Muñoz (2007) analiza la definición médica del parto y sostiene que su construcción como problema (que se acompaña de la definición de las mujeres como sujetxs asistibles), legitima la intervención profesional. Esto es efecto de la medicalización, un conjunto de prácticas, ideologías y saberes utilizados básicamente por la institución médica, la cual refiere a una extensión de las funciones curativas y preventivas hacia funciones de control y normatización (Menéndez, 1988).

Magnone Aleman (2010) analiza la medicalización de la vida social (y de los procesos vitales) retomando las tres tesis de Illich que sostienen que la medicalización es

37 "La medicalización del parto y su construcción como una condición patológica están ligados en sus orígenes a las nociones acerca de la mujer decente (era victoriana). Los partos fueron cada vez más atendidos sólo por médicos, y en esta situación los familiares eran excluidos físicamente y las mujeres anestesiadas y relegadas corporalmente del proceso del parto. El resultado fue que los médicos ganaron el control sobre el proceso y la consignación de las mujeres a las salas de parto" (Erviti, 2010, p. 4). 
iatrogénica (produce efectos negativos en la salud), que impide el ejercicio del autocuidado (por el monopolio médico, que desestima también otros modos de atención) y que se expande y penetra todo el tejido social (por la estandarización del conocimiento y de las intervenciones sanitarias). La iatrogenia, entendida en términos simples como los daños que produce la intervención médica que se realiza para evitar o tratar daños, tiene a su vez tres dimensiones en la argumentación de Illich ${ }^{38}$. Es clínica, porque supone la sustitución de capacidades orgánicas por la administración de drogas sintéticas; es social, porque implica una pérdida de control por parte de Ixs sujetxs; y es cultural, en tanto se basa en que no se acepta el sufrimiento como parte de la vida. En el caso del proceso de nacimiento, Magnone Aleman sostiene que la medicalización (re)produce nuevas concepciones del dolor y la muerte y una educación y socialización maternal a partir de disciplinas secundarias como la puericultura, que señalan la necesidad de la profesión médica para concebir, gestar, parir, amamantar, criar, expandiendo su poder y jurisprudencia. Así, la autora establece el vínculo entre medicalización, iatrogenia y enfoque de riesgo:

"el paradigma de atención al parto basado en el enfoque de riesgos, se trata de adelantar a cualquier complicación realizando intervenciones preventivas, cuestión que en la mayoría de las situaciones es la causa del 'intervencionismo obstétrico'. En donde una intervención crea una necesidad de otra intervención y así sucesivamente; lo cual transforma un parto que podría haber sido liderado por los tiempos y requerimientos de la que pare, en un parto intervenido o una cesárea, protagonizado por la institución de salud" (Magnone Aleman, 2010, p.77).

En paralelo, Camacaro Cuevas (2000) sostiene que la iatrogenia se corporiza en "consecuencias biomédicas del acto técnico (...) [esto es,] condiciones clínicas en las que los agentes patógenos son medicamentos, médicos o las instituciones hospitalarias" ( $p$. $124)^{39}$.

Como sostiene Schwartz "la redefinición del parto como un evento médico depende del carácter potencialmente problemático del mismo, justificando así la intervención médica" (Schwartz; 2010, p. 98). Esto se da en el marco de lo que Esteban (2001) considera que es una medicalización particular de las mujeres, que se realiza "específicamente a través del control de procesos corporales y reproductivos" (p. 35). Es justamente la definición del proceso perinatal como evento médico que exige, por ende, el

\footnotetext{
${ }^{38}$ Camacaro Cuevas (2009, p. 155) cita un fragmento de Illich (1975, p. 23) quien sostiene que: "la nueva epidemia de enfermedades producidas por el doctor, son enfermedades yatrogénicas clínicas y comprenden todos los estados clínicos respecto de los cuales son agentes patógenos o enfermantes, los medicamentos, los médicos o los hospitales, causando una serie de efectos secundarios terapéuticos”.

${ }^{39}$ En obstetricia se habla de "cascada de intervenciones": una intervención (la analgesia epidural para reducir el dolor de las contracciones) exige otra (oxitocina para reactivar las contracciones).
} 
seguimiento/ control/ vigilancia/ cuidado/ asistencia/ atención/ e /intervención por parte de la profesión médica hegemónica como única capaz por su saber experto, siendo esta la expresión más clara del proceso de medicalización de los nacimientos.

$\checkmark$ ENFOQUE DEL RIESGO REPRODUCTIVO. Este elemento, al igual que el precedente y el siguiente, son centrales en la mayoría de las tesis, y están completamente concatenados. Tal como he establecido en trabajos previos (Castrillo, 2016a, 2016 b) y desarrollaré más adelante, creo que en la atención hegemónica obstétrica, todos los embarazos y partos son riesgosos hasta que se demuestre lo contrario, amparado ésto incluso en las definiciones médicas y estatales del bajo y alto riesgo para el proceso perinatal: el establecimiento del score de riesgo es postfáctico, una vez concluido el embarazo o el parto, razón por la cual se actuará con presunción de riesgo. Mitjavila (1998, p. 15) sostiene que la lógica del riesgo es una "justificación de la intervención médica en nombre de la probabilidad y no de la certeza de que ocurra un daño en la salud". Esta presunción, que pasa de probabilidad a certeza/condena, constituye una acción política-ideológica propia del modelo médico en tanto se trata de "elaboraciones socioculturales realizadas por el saber biomédico" (Blázquez Rodríguez, 2009, p. 192). Me refiero a la construcción/expansión de factores de riesgo y el exceso de etiquetas de riesgo, que individualizan procesos sociales, culpabilizan y responsabilizan a Ixs sujetxs y que permiten la patologización del proceso, justifican las intervenciones médicas y determinan los itinerarios asistenciales de las mujeres usuarias, razones por las cuales el enfoque de riesgo reproductivo es nodal en la caja de herramientas que aquí describo. En este sentido, Magnone Aleman (2010) entiende el enfoque de riesgo reproductivo como un "dispositivo biopolítico de dominación" en tanto "las formas como una sociedad produce y enfrenta los riesgos siempre dependen de los mecanismos de poder hegemónico" (p. 78).

Los discursos del riesgo, a su vez, consolidan la idea de que el parto es un evento explosivo y urgente, lo que produce la redención y entrega al saber-poder médico. Es así que "un parto que no progresa según la norma médica se torna peligroso y debe ser intervenido" (Sadler, 2004, p. 15). En el mismo sentido, Sadler (2003, p. 61) sostiene que el parto se define como una "experiencia trágica del mundo (...) [a partir de una] concepción desde la biomedicina como un proceso patológico, dramático, peligroso, que necesita ser intervenido". 
"La amenaza de catástrofes, afirma Douglas (1996:93), se activa para renovar el compromiso de los sujetos con los objetivos de las instituciones. Ante la duda del incumplimiento, el mecanismo se dispara. Las mujeres deben aceptar los dictados médicos en un discurso que se expresa en poder de la verdad y en base a un saber absoluto desde el que se fomenta la amenaza moral del riesgo, ingredientes que aumentan el dominio de la institución médica (Bensaid, 1986:88), y el consentimiento y obediencia de las mujeres" (Montes Muñoz, 2007, p. 221).

El enfoque del riesgo reproductivo, asimismo, potencia la uniformización y estandarización de los cuerpos, procesos reproductivos y la forma de atenderlos ${ }^{40}$ : "independientemente de la situación en que ellas lleguen al hospital, siempre sean sometidas a una rutina que pretende cubrir los riesgos obstétricos que puedan presentarse" (Camacaro Cuevas, 2000, p. 123). El riesgo es un apriorismo indiscutible y se construye a partir de una escala de factores de riesgo en la que la iatrogenia que produce no aparece: los riesgos son de los cuerpos, no de las intervenciones.

Finalmente, la lógica del riesgo impide que lxs profesionales de la salud obstétrica visibilicen los derechos sexuales y reproductivos de las mujeres, es decir que anula la perpectiva de derechos en la atención (Erviti, 2010).

$\checkmark$ TECNOLOGÍA, PRODUCTIVISMO Y GESTIÓN DE LOS TIEMPOS. En la atención hegemónica, los partos se han convertido en "trances tecnológicos" (Hernández Garré y Echevarría Pérez, 2016, p. 2).

"La manera como la sociedad concibe y utiliza la tecnología refleja y perpetúa el sistema de valores y de creencias que la sustenta (...) El sistema de valores fundamentales de la sociedad occidental está fuertemente orientado hacia la ciencia, la alta tecnología, el beneficio económico y las instituciones dirigidas patriarcalmente" (Davis-Floyd, 2001, p.1).

Aunque podrían considerarse por separado, creo que los tres procesos que aquí retomo conforman un núcleo problemático clave, en tanto la concepción productivista, industrializada y mercantilizada del parto se retroalimenta con el uso de tecnología para acelerar y gestionar los tiempos. Magnone Aleman (2010) sostiene que la construcción de la asistencia intervencionista se asienta en tres elementos: el uso abusivo de la tecnología, la aceleración de los tiempos y la imposición de tiempos límites (de embarazo, de trabajo de parto, de parto).

Quien mayormente analizó este fenómeno fue la antropóloga Robbie Davis-Floyd (2001), quien tituló como "modelo tecnocrático" el modelo actual de atención obstétrica

\footnotetext{
${ }^{40} \mathrm{Al}$ respecto, Magnone Aleman (2013, p. 84) sostiene: "el parto es concebido de forma estandarizada, con una pauta temporal que no se adapta a las particularidades de cada proceso".
} 
(retomado en la mayoría de las tesis aquí reseñadas). Lo fundamental es considerar que la tecnología "no actúa en el vacío social sino que refuerza y reproduce su ideología" (Montes Muñoz, 2007, p. 156). Esta confianza exacerbada en la tecnología implica que el conocimiento de los procesos reproductivos (tanto para los profesionales como para las mujeres) se asienta en datos científicos emitidos por instrumentos de tecnología médica, sujetos a interpretación de Ixs agentes de salud, y no en las sensaciones y saberes femeninos (se confirma el embarazo por un análisis clínico, la vivacidad del feto por una ecografía, la presencia de latidos o movimientos del bebé por un monitoreo fetal, la progresión del trabajo de parto por intervenciones como el tacto). Sobre el productivismo, Hernández Garré y Echevarría Pérez (2016) sostienen que

"a veces, se da mayor prelación a las rutinas clínicas que a las propias necesidades maternas. Control y mecanización asistencial que aporta, no obstante, una mayor seguridad a las mujeres investigadas, sirviendo de basamento para la perpetuación de un modelo asistencial que, a veces, es resignificado desde su propia óptica, al haber asumido como positivo el férreo control al que son sometidas durante el itinerario asistencial. Parece que estamos ante unas perspectivas asistenciales impregnadas por la "biopolítica", mecanismo estatal para garantizar la reproducción de ciudadanos sanos y productivos" (p. 10).

En este marco, la gestión de los tiempos aparece tanto como representación ideológica así como exigencia institucional hospitalaria (la necesidad de desocupar camas o "limpiar guardias"). Asimismo,

"la centralidad de los tiempos en la definición de los partos constituye una construcción del proceso del parto, propia del modelo biomédico, donde los tiempos se elevan como un instrumento para guiar la actuación profesional (si debe intervenir la obstetra o no, y qué hacer), a la vez que para distinguir lo que son las desviaciones de la normalidad (los riesgos)" (Blázquez Rodríguez, 2009, p. 222).

Canevari Bledel (2011) analiza cómo se puede generar disciplinamiento a partir del uso del espacio y del tiempo (en este último, tanto la obligación a la espera de turnos, estudios, atención; como al aceleramiento del periodo dilatante, expulsivo y de alumbramiento del parto). Tecnología y tiempos se unen a una concepción productivista del parto, que implica que en el binomio madre/hijx, la centralidad está en el producto (el/la recién nacidx). "De la mujer se espera que ocupe su lugar en esta cadena de producción y que acepte las pautas y cumpla con el rol específico" (Blázquez Rodríguez, 2009, p. 232). En este sentido Montes Muñoz sostiene que la mujer aparece como una "fábrica de bebés" sin ser propietaria de los medios de producción ${ }^{41}$.

\footnotetext{
${ }^{41}$ La metáfora de la mujer y el hospital como fábrica de bebés nace con la teoría de Emily Martin quien "encuentra una analogía entre la producción industrial capitalista y la producción de niños en Occidente" (Schwartz, 2010a, p. 97). Blázquez Rodríguez (2005, p. 11-12) refiere a este proceso como la "taylorización
} 
"En este contexto tecnocrático, el parto es definido como un proceso estandarizado en donde se obtiene el producto de la gestación. Siempre plausible de complicarse hacia el desarrollo de patologías, se impone el enfoque de riesgos y la intervención médicotecnológica continua para introducir las correcciones necesarias a un fenómeno inherentemente <defectuoso>" (Magnone Aleman, 2010, p. 33).

\section{MECANISMOS DE DOMINACIÓN/DESAUTORIZACIÓN SOBRE LAS MUJERES, SUS}

CUERPOS Y SUS PROCESOS. Para cerrar la descripción de la caja de herramientas conceptuales, es central retomar la lectura de los antecedentes filtrando cómo analizan los efectos de dominación de la práctica médica obstétrica.

La propuesta que desencadena este filtro especial es la de los ya citados mecanismos de desautorización de los saberes de las mujeres que propone Sadler (2003), en tanto su tesis busca conocer cómo se construye y legitima el conocimiento autorizado biomédico. Establece como dispositivos propios de la violencia simbólica que permite la reproducción del sistema hegemónico: la homogenización (a partir de la pacientización de todas las mujeres), la patologización (que implica la estandarización de los procedimientos), la fragmentación (del proceso perinatal, del cuerpo de la mujer ${ }^{42}$ ), la infantilización y des-sexualización del EPP, y la culpabilización y responsabilización de las mujeres por lo que sucede ${ }^{43}$ (con la contradicción de que Ixs únicxs capacitadxs para actuar son Ixs profesionales).

Este proceso, Arguedas Ramírez (2014) lo piensa en términos foucaultianos de saberes subyugados, en tanto sostiene que "todo ejercicio de poder conlleva también una producción de saber" (p. 175). Así, afirma que el saber femenino

"está doblemente subyugado, además, en razón del lugar social que las mujeres ocupan de acuerdo con la dominante estructura social de género que privilegia lo masculino sobre lo femenino. Frente al poder/saber ejercido por parte de los profesionales en salud (especialistas en medicina y enfermería), las mujeres embarazadas o en proceso de parir no son interlocutoras válidas" (p. 166).

del parto" que implica "la progresiva reducción de los tiempos normales para las fases del parto según los conocimientos científicos disponibles”.

${ }_{42}$ Blázquez Rodríguez (2009, p. 97) afirma que el embarazo-parto-puerperio es un continuum que ha sido desagregado por la medicina.

${ }^{43}$ Camacaro Cuevas (2009) lo expresa del siguiente modo: "Ahora bien, si el médico/a es la autoridad, es a la vez quien sabe qué se debe hacer y cómo se debe hacer en relación a la salud y la enfermedad, la vida y la muerte. Partiendo de allí, todo lo que ocurra fuera de lo esperado, fuera de la norma médica, se considera que no es responsabilidad del cuerpo médico, sino en nuestro caso de la mujer, quien tal vez: no sea obediente y deje de cumplir los tratamientos, o sea desaseada y se infecte, o sea ignorante y no entienda las indicaciones médicas” (p. 159). Y Sadler (2004, p. 24) lo resumen así: "como parte de la violencia simbólica, las mujeres introyectan la culpa, sintiéndose responsables por el curso de los eventos”. 
A esto se anexa la tesis principal de Canevari Bledel (2011) vinculada al doble proceso de enajenación de las mujeres y de expropiación de los cuerpos ${ }^{44}$. En paralelo, Montes Muñoz (2007) sostiene que en la atención obstétrica hegemónica existen dos representaciones claves que estructuran las prácticas: una afirma que "las mujeres no saben" lo que sienten y sucede en sus cuerpos, lo que legitima su pacientización, el protagonismo tecnológico y la expropiación progresiva de sus saberes, y la otra que "el embarazo-parto son de Ixs profesionales", consolidando su cosificación y enajenación.

"La invalidación de las mujeres para poder conducir sus partos y para poder decidir libremente sobre su salud sexual y reproductivas es cultural y está fuertemente anclada en la mirada biomédica que ha marcado la autopercepción que las mujeres tenemos de nuestro cuerpo" (García Fernández, 2014, p. 6).

En suma, una de las principales particularidades por las cuales analizo el objeto de estudio desde una perspectiva de género en salud, se da porque "la atención biomédica del parto es una poderosa metáfora de la opresión que el sistema patriarcal ejerce sobre las vidas femeninas, lo cual es a su vez símbolo de la supresión de todas las maneras de conocer no hegemónicas" (Sadler, 2003, p. 154). De este modo, en la atención hegemónica de embarazos y partos muchas veces el derecho a la decisión sobre cómo, dónde y con quién parir (que en Argentina están establecidos por ley desde hace más de una década), es sustituido por los efectos del tutelaje médico, que se explica por los elementos de la caja de herramientas conceptuales que propongo ${ }^{45}$.

"En las prácticas médicas el tutelaje se expresa a través de la idea de que las mujeres no están en condiciones de tomar decisiones sobre su propio cuerpo. Entonces no se les brinda toda la información que precisan y la decisión queda en manos del profesional que la atiende" (Canevari Bledel, 2011, p. 132).

Considero que estas seis herramientas conceptuales, por un lado, reúnen las principales perspectivas y dimensiones de análisis del campo de estudios de la socioantropología de la atención obstétrica; y, por el otro, abren las puertas para la crítica, lectura y análisis de cómo se nace y se pare actualmente en el paradigma hegemónico.

\footnotetext{
44 "En este sentido, Marcela Lagarde (1994) se refiere a la expropiación de los cuerpos femeninos, sintetizada en la prohibición de decidir sobre el uso de sus cuerpos preservando su propia integridad y su desarrollo personal. El cuerpo femenino está destinado para funciones y usos que implican la negación de la primera persona; es simbolizado como cuerpo para otros y las decisiones sobre éste son tomadas por terceros a través de restricciones, dogmas, mandatos, prohibiciones, controles y tabúes” (Sadler, 2004, p. 5-6)

${ }_{45}$ Marton y Echazu profundizan el análisis del tutelaje y lo vinculan a una cuestión de clase: "dos lógicas radicalmente diferentes que orientan la práctica médica en cada uno de estos sistemas: la de la tutela y la del contrato. El contrato se orienta a la obtención de lucros a partir de la elección de los servicios; la tutela se orienta a cubrir la demanda de sujetos sociales considerados como una masa pobre, indiferenciada, inevitablemente creciente en el marco del progresivo achicamiento del Estado nacional (Álvarez, 2003). Tutela y contrato se definen, así, a partir de la variable de clase, definida en este trabajo en términos de una tipología de relaciones sociales históricamente constituidas (Donzelot, 1991)” (2010, p. 132).
} 
De todos modos, es necesario a los fines del modelo teórico sociológico propuesto, presentar el otro polo de este continuum asistencial: el parto respetado.

>> LO ¿ALTERNATIVO?: HUMANIZACIÓN DE LA ATENCIÓN OBSTÉTRICA.

La humanización de la atención médica se vincula a un paradigma que propugna cambios en la relación médicx-paciente y en la intervención clínica, que tiene raigambre en diversas áreas de la salud. En la atención de partos de bajo riesgo, específicamente, pone el acento en que durante el proceso perinatal, se garanticen una serie de derechos humanos, sexuales y reproductivos de las mujeres y las familias, se lo entienda como un proceso integral (que adquiere significaciones psicoafectivas, emocionales, culturales y sociales) y se modifiquen las prácticas profesionales clínicas y, por tanto, las relaciones médicas. De este modo, la humanización de la asistencia del parto implica una transformación tanto de la comprensión del parto como del hacer médico (Porto et al, 2015). En este sentido, la humanización aparece como alternativa al exceso de intervencionismo médico, patologización y medicalización construida alrededor de estos procesos, que ha tendido a generar una cultura del nacimiento estandarizada, homogénea, tecnologizada, supeditada a protocolos clínicos e institucionales, y desvinculada de los derechos y necesidades de las mujeres que paren.

En los estudios sobre el tema, se piensa la humanización del parto como una retórica (Jerez, 2015), ideario (Tornquist, 2003) o término estratégico (Porto et al, 2015), que combina dos dimensiones centrales: la garantía de los derechos sexuales y reproductivos de las mujeres y, por ende, de la ciudadanía y autonomía de las mujeres a decidir sobre su propio cuerpo, y la crítica y transformación de las prácticas médicas obstétricas para apuntar al cumplimiento de esos derechos. Algunos de los estudios han privilegiado uno $u$ otro aspecto, $y$ aquí he decidido tomarlos como partes interrelacionadas, en tanto comprendo que la garantía de los derechos a la salud, y específicamente, a la salud sexual y reproductiva de las mujeres-madres que paren, exige cambios en las prácticas médicas durante el proceso de parto. Este será el eje de análisis del capítulo 3.

Este círculo vicioso conceptual y práctico se explica porque al cuestionarse, desde diversos organismos internacionales y nacionales gubernamentales ligados a la salud (OMS, OPS, UNICEF, CEDAW, etc.) y desde distintas organizaciones sociales feministas y de derechos humanos, las prácticas médicas que se rutinizaron durante el proceso 
perinatal en el marco de un $\mathrm{MMH}$ patologizador, basado en la construcción del riesgo reproductivo como un universal, se han construido instrumentos y dispositivos legales y de política pública para garantizar su revisión, estableciendo los derechos sexuales y reproductivos de las mujeres como fundamento. Estos últimos, a su vez, invitan a repensar y modificar la práctica profesional, para lo cual se crearon guías procedimentales que apuntan a marcar nuevas orientaciones en la atención médica de partos. Estos procesos implican y reconocen disputas entre la sociedad civil, el Estado (en sus diversos ámbitos), las corporaciones médicas y las distintas formas de institucionalidad del sistema de salud. Por tanto, aquí es visible cómo el Estado genera diferentes normativas o documentos para cada eje (la ley para el primero, las guías para el segundo). Esto es, el Estado garantiza derechos y a la vez interviene en la profesión médica.

"En el movimiento por la humanización del parto coexisten diferentes soportes discursivos y también diferentes acciones consecuentes con éstos. Todos confluyen en considerar vital el proceso de parto-nacimiento dentro de la experiencia femenina y para un nacimiento saludable de su bebé. La humanización entonces sería la contrapartida de la actual tecnificación y medicalización que ha enajenado a la mujer de protagonizar esta experiencia pese a que existen recomendaciones internacionales (OMS), evidencia científica internacional (COCHRANE) y local (IECS) y dos leyes nacionales: una específica de parto (25929) y una de violencia que incluye en su artículo 6 a la violencia obstétrica (26485)" (Fornes, 2010, p. 3).

Más allá de la disputa política por cómo pensar y abordar médicamente los PEP, en términos de la atención profesional implica una concepción fisiológica del proceso, entendiéndolo como eventos sexuales, privados, de salud (y no de enfermedad), que asumen características socioculturales específicas. Implica abandonar la centralidad de los elementos de la caja de herramientas del modelo hegemónico antes presentado e ir hacia otro paradigma, como se ve en el cuadro 2.

CUADRO 2: HERRAMIENTAS CONCEPTUALES PARA UNA SOCIOLOGÍA DE LA ATENCIÓN MÉDICA HUMANIZADA DE LOS PEP

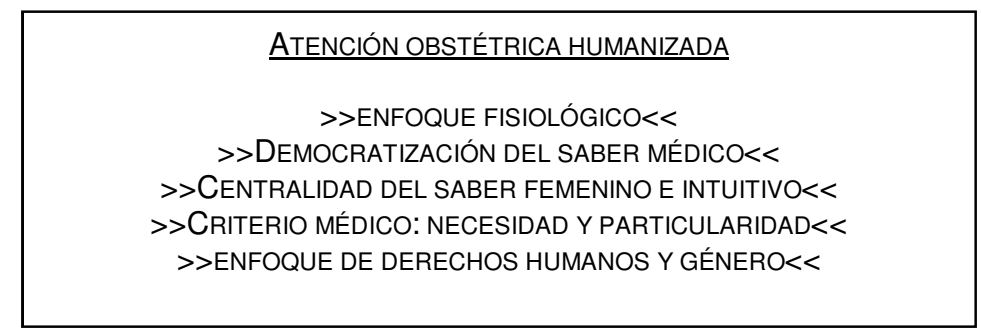

Cuando me refiero al enfoque fisiológico, asigno una especial importancia a la confianza en el cuerpo, su conocimiento y el proceso reproductivo, que en el caso de la 
atención hegemónica es totalmente distinto (como se verá más adelante, se basa en una desconfianza y en una concepción completamente defectuosa del cuerpo femenino).

"Trabajar desde una conceptualización fisiológica del parto significa asistirlo bajo el supuesto de que el evento se va a desarrollar de forma satisfactoria sin necesidad de alta tecnología, bajo la supervisión de profesionales calificados/as, con un control adecuado de los riesgos" (Magnone Aleman, 2013, p. 81).

Los otros elementos incluidos en el cuadro responden a la oposición con el modelo intervencionista y suponen una atención personalizada en cada caso, un abandono del enfoque de riesgo, la garantía y el acceso a los derechos sexuales y reproductivos de las mujeres y sus familias, y la posibilidad de elegir cómo, dónde y con quién parir.

> GRISES Y PUENTES: "INTERVENCIONES MÉDICAS EN LOS PROCESOS DE EMBARAZO Y PARTO"

El origen de esta propuesta conceptual es considerar que los dos modelos/ enfoques del parto implican concepciones distintas de la mujer, del cuerpo, del proceso de embarazo, parto y puerperio, de cómo intervenirlo, de cómo pensar el debate naturaleza cultura, entre muchos otros. Y sin embargo, la certeza de que hay tensiones, cruces, complementariedad y un continuum entre ambos, que es identificable a partir de las intervenciones médicas en los PEP. Esto se basa en dos hipótesis centrales que he construido: a) las intervenciones por sí mismas no constituyen un modelo de atención, aunque a mayor intervencionismo, mayor cercanía con el modelo medicalizado obstétrico; y, b) Ixs sujetxs implicadxs y sus acciones tienden puentes entre esos modelos, y en una misma experiencia conviven prácticas y representaciones aparentemente contradictorias entre sí. En otras palabras: una misma intervención, por ejemplo la cesárea, puede ser significada como parte de una atención hegemónica o una humanizada y particularizada, según las experiencias y significaciones atribuidas por Ixs sujetxs.

Considero que pensar las intervenciones médicas en plural permite captar más ampliamente de qué modos se interviene sin caer en una caracterización negativa o simplista de las intervenciones al centrarme en cómo las experimentan mujeres-madres, varones-padres y profesionales de la salud, y pensando que esa experimentación está atravesada por múltiples factores, como la clase, el género y la edad. Propongo pensar, por tanto, las intervenciones médicas prácticas y técnico-clínicas en los PEP (como por ejemplo el uso de técnicas de inducción, la cesárea, la episiotomía y la administración de oxitocina); tanto como las intervenciones simbólicas en el y del proceso, esto es, su medicalización que actúa reproduciendo un orden social desigual y de jerarquías médicas hegemónicas sobre mujeres construidas como objetos médicos. De todos modos este 
desglose es sólo analítico, en tanto las intervenciones prácticas son simbólicas de por sí; de hecho, Fornes (2009) sostiene que dichas prácticas deben comprenderse más en su eficacia simbólica que en su efectividad clínica. Así, por ejemplo, Magnone Aleman (2011, p. 17) establece (y coincido) que la episiotomía es una "expresión de la misoginia institucional". A ello hacen referencia Erviti, Castro y Sosa (2006) cuando afirman que la práctica clínica se sustenta sobre una doble verdad objetiva, tal como mostré anteriormente.

Estas lecturas habilitan preguntas sobre los mecanismos de control y disciplinamiento sobre el cuerpo y la subjetividad de las mujeres a partir de las intervenciones médicas (con estas prácticas que dejan a las mujeres sometidas a la intervención de terceros) y una posible hipótesis sobre la implicancia que tienen estos "rituales obstétricos" como ritos de fijación de las reglas y los roles sociales atribuidos sexo-genéricamente a las mujeres. Además, en tanto considero las intervenciones médicas en términos de construcciones hegemónicas y no únicamente de dominación, apunto a pensar los modos en que, entonces, se legitiman y reproducen dichas prácticas, a raíz de los sentidos heterogéneos que involucra (que pueden o no naturalizarlos, legitimarlos, cuestionarlos, reproducirlos). Por ello, apunto a tender puentes entre las visiones dicotomizadas y dicotomizantes para poder captar la heterogeneidad de sentidos y experiencias que se tejen en torno a estas intervenciones, a las relaciones médicxpaciente, a la propia experiencia de maternidad y paternidad. Asimismo, pensar las intervenciones médicas permite incorporar la dimensión de la agencia y las posibilidades de resistencia y cuestionamiento de Ixs sujetxs, para romper la visión que reifica el saberpoder médico y encontrar algunas válvulas de escape en la que efectivamente se introducen estrategias de cambio. Esto es, las intervenciones médicas no son sólo producidas y "llevadas a cabo" por profesionales de la salud, sino que, por efecto de los procesos de medicalización social, Ixs sujetxs sociales también intervienen médicamente en los PEP: por ejemplo, realizando controles prenatales extras, presionando a "la embarazada de la familia" para que actúe de algún modo. A su vez, no todas las experiencias de embarazos y partos responden al marco hegemónico.

El marco conceptual que busco (re)construir se centra en pensar las intervenciones médicas que se dan en los PEP, para poder dar cuenta de la heterogeneidad de prácticas y representaciones que las constituyen y que buscan constituir. La propuesta es pensar las intervenciones en plural para romper con lecturas 
monolíticas que piensan en extremos la medicalización y la humanización de estos procesos, tendiendo un puente entre esos polos, buscando captar debates, contradicciones y sentidos compartidos. En síntesis, para poder comprender la complejidad tanto de dichas intervenciones como de las experiencias que construyen Ixs mujeres-madres, varones-padres y profesionales de la salud. Pienso las experiencias como resultantes de prácticas y representaciones construidas socialmente, y que pueden pensarse como legitimantes y/o cuestionadoras de tales intervenciones, y que permiten caracterizar la construcción de entramados relacionales médico-pacientes heterogéneos.

"Es a través de estas técnicas y prácticas, que se cristalizan relaciones de poder: el que interviene, ve, palpa, decide, corta y la que tiene que obedecer, no tiene dominio de su propio cuerpo y debe "dejar hacer". Es por todo esto que los distintos autores conciben a la gineco-obstetricia como un dispositivo de poder que busca controlar y patologizar el cuerpo de las mujeres (Butler, 2007; Foucault, 2005; Jornadonova, 1989; López Sánchez, 2010)" (Pozzio, 2013, p.8)

En suma, entiendo las intervenciones médicas en dos sentidos. Primero, como la actividad profesional práctica sobre los PEP, y, segundo, la construcción social particular que hace la medicina del PEP como un proceso médico/patológico/institucional. En el cuadro 3 se resume la perspectiva explicitada en este apartado, con categorías cuyas interrelaciones, cruces, tensiones y disputas dan cuerpo al objeto de esta tesis.

CUADRO 3: RESUMEN SOCIOLOGÍA DE LA ATENCIÓN MÉDICA DE EMBARAZOS Y PARTOS (ELAB. PROPIA)

Modelo Hegemónico INTERVEncionista

INTERVENCIONES MÉDICAS EN LOS PROCESOS DE EMBARAZOS Y PARTOS

Ideológica/simbólica/política

Sobre la concepción del PEP
Modelo alternativo hUMANIZADO

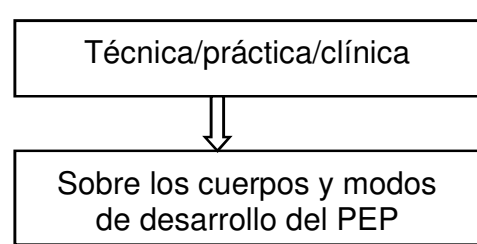

Finalmente estas intervenciones médicas y estos modelos de atención obstétrica se imbrican con normativas y derechos sexuales y reproductivos de las mujeres, cuya garantía, como se explicó anteriormente, exige que se modifiquen dichas intervenciones 
tanto prácticas como simbólicas: tanto cómo se concibe el proceso perinatal como la forma de abordarlo. En ese entramado se halla el aporte de esta tesis para la gestación de una sociología de la atención médica de embarazos y partos.

\subsection{RECAPITULACIÓN Y CIERRE}

Expuesto el estado de la cuestión construido sobre el tema de investigación, a través de las principales claves interpretativas que han desarrollado las ciencias sociales respecto al problema de investigación propuesto, establecí algunas áreas de vacancia que busqué cubrir con la propia indagación. En primer lugar, la propuesta conceptual de pensar las intervenciones médicas en los procesos de embarazo y parto (en plural), es destacable en tanto se busca captar la heterogeneidad de experiencias y sentidos. Asimismo, la propuesta de incluir la perspectiva de tres sujetxs claves es novedosa, en tanto se ha tendido a privilegiar a médicxs o a mujeres y se ha relegado la voz de los varones-padres. Por último, no hay estudios sobre el tema en las mismas coordenadas espacio-temporales propuestas. En estos ejes descansa la originalidad de la propuesta.

En el marco de una clasificación arbitraria que permitió presentar las dimensiones del proceso iluminadas por la bibliografía, se expusieron conceptualizaciones generales (vinculadas a la institucionalización y medicalización del proceso de parto/nacimiento, en el marco de relaciones de poder desiguales) y otras más específicas que se propusieron problematizar aspectos particulares de la intervención médica de los PEP. Reflexiones sobre maternidad, paternidad y parto y el análisis de Ixs sujetxs que entran en esas relaciones de dominación son algunos de los tópicos que recorren la producción de conocimiento científico sobre la temática.

Establecí dos modelos de atención obstétrica, desarrollando los elementos principales de cada uno, y finalmente propuse pensar que entre estos modelos es posible distinguir puentes a través de las intervenciones médicas en los PEP y las experiencias que de ellas construyen Ixs sujetxs implicadxs. Se trató de, no solo presentar el estado de la cuestión y el marco teórico de la tesis, sino también de articularlos en una sociología de la atención médica de embarazos y partos entendida a partir de una doble dimensión técnica y moral de la práctica médica y de la reconstrucción de disputas y relaciones de poder centrales. 


\section{CAPÍtULO 2}

\section{MARCO METODOLÓGICO}

-DECISIONES METODOLÓGICAS Y EJERCICIO DE REFLEXIVIDAD-

En este capítulo se exponen tres elementos que hacen/hicieron al marco metodológico de la tesis y la explicitaciones de los objetivos que la guiaron. En primer lugar, las decisiones metodológicas tomadas en torno a la selección de casos, la producción de datos (técnicas y procedimientos) y análisis de la información producida. En segundo lugar, las características del trabajo de campo: cómo fueron construidos esos datos en forma concreta. $\mathrm{Y}$, finalmente, un ejercicio de reflexividad que emerge como necesario en torno a mi rol como investigadora y activista por el parto respetado (y sus implicancias en la realización de la tesis), y a mi inserción de género pero en situación diferencial en el trabajo de campo: una mujer no embarazada en los cursos de preparto, una mujer no madre en las entrevistas a parturientas, una mujer no médica en las entrevistas a profesionales.

\subsection{EL QUÉ: OBJETIVOS Y PREGUNTAS DE INVESTIGACIÓN}

A modo esquemático presento el objetivo general, los específicos y las preguntas de investigación que guiaron esta tesis.

\section{OBJeTIVo General}

Comprender y describir la heterogeneidad de experiencias y representaciones sobre las intervenciones médicas en los procesos de embarazo y parto que construyen mujeres-madres, varones-padres y profesionales de la salud que asisten partos, en la ciudad de La Plata. Analizar cómo esas experiencias apuntan a la legitimación o cuestionamiento de dichas intervenciones.

\section{OBJETIVOS ESPECÍFICOS:}

1) Conocer, describir y analizar las principales características de las intervenciones médicas en los procesos de embarazo a partir de la experiencia de lxs sujetxs.

- Describir las modalidades hegemónicas de seguimiento y atención del embarazo, a través de dispositivos como los controles prenatales, las consultas médicas y los cursos de preparación para el parto. 
- Conocer otros modos alternativos de seguimiento y atención del embarazo.

- Describir y analizar las representaciones sociales que se despliegan sobre el proceso de embarazo y su proceso asistencial.

- Analizar las relaciones que se establecen entre mujeres-madres y profesionales de la salud y con sus parejas durante la temporalidad del embarazo.

2) Conocer, describir y analizar las principales características de las intervenciones médicas en los procesos de parto a partir de la experiencia de Ixs sujetxs.

- Describir las modalidades hegemónicas de atención del parto, a través del análisis de las intervenciones médicas protocolizadas en la atención institucional.

- Conocer modos alternativos de atención del parto (humanizado, domiciliario).

- Describir y analizar las representaciones sociales que se despliegan sobre el proceso de parto y su proceso asistencial.

- Analizar las relaciones que se establecen entre mujeres-madres y profesionales de la salud y con sus parejas durante el proceso de parto.

3) Problematizar las experiencias construidas a partir de:

a) Variables que afectan la experiencia de Ixs sujetxs: clase (en relación al ámbito institucional privado o público -o domicilio -de atención), edad y género.

b) Dimensiones de los procesos de embarazo y parto y su atención: instituciones de ocurrencia, tipo de parto, saberes, etc.

c) En lo específico de la experiencia de las mujeres-madres:

- Situar el análisis de las experiencias en torno a los procesos de embarazo y parto, la puesta en juego de saberes (biomédicos o no), los roles asumidos y las representaciones construidas en torno al proceso asistencial, y a las relaciones que se construyen.

d) En lo específico de las experiencias de los varones-padres:

- Situar el análisis de las experiencias en torno a los roles, los márgenes de participación, las representaciones y las relaciones que se construyen.

e) En lo específico de las experiencias de Ixs profesionales de la salud:

- Situar el análisis de las experiencias en torno a las relaciones internas a la práctica profesional (obstetras y parteras e instituciones de salud) y externas 
(con las mujeres-madres y los varones-padres), las representaciones sobre la "normalidad" y patología en torno a los procesos de embarazo y parto, la preeminencia del enfoque de riesgo en la atención, los roles asumidos y las representaciones sobre las intervenciones médicas obstétricas en general.

4) Analizar las formas de (re)producción, (des)legitimación, cuestionamiento y resistencia de las intervenciones médicas en los procesos de embarazo y parto por parte de los sujetos a partir de la reconstrucción de sus experiencias.

- Describir algunas formas asociativas de mujeres de la ciudad que apuntan a su cuestionamiento y conocer con qué discursos argumentan su acción.

- Describir vulneraciones a derechos sexuales y reproductivos (en forma de VO) en las experiencias analizadas.

\section{PREgunTAS DE INVESTIGACIÓN}

a) ¿Cuáles son las principales características que asumen las intervenciones médicas en los procesos de embarazo y parto en el contexto de estudio? ¿Cómo es posible caracterizar al modelo hegemónico de atención médica a los procesos de embarazo y parto en dicho contexto?

b) ¿Cómo experimentan y qué sentidos asignan las mujeres-madres, los varones padres y Ixs profesionales de la salud a dichas intervenciones?

c) ¿Cómo se construyen esas experiencias y sentidos según el género, la clase, la edad y otras dimensiones que afectan las experiencias de esxs sujetxs? ¿Y en relación a características de los embarazos, partos y su atención, como el tipo de parto o la institución de ocurrencia?

d) ¿De qué modos esas experiencias y sentidos representan/aluden a formas de (re)producción, (des)legitimación, cuestionamiento y resistencia de las intervenciones médicas en los PEP?

\subsection{EL CÓMO: DECISIONES METODOLÓGICAS}

En este apartado se presentan diversas instancias del proceso del diseño y la ejecución del cómo investigar aquello que se propuso. Se trata de las decisiones 
metodológicas en constante redefinición, vinculadas al recorte del objeto de estudio, a la selección de los casos y a la producción de datos, completamente interrelacionadas.

\subsection{A) DISEÑO}

Se realizó un estudio de tipo analítico-descriptivo asentado en un abordaje cualitativo, con un diseño de investigación flexible (en términos de Valles, 2000) e interactivo (Maxwell, 1996), en tanto tiene una intención explicativa de los fenómenos sociales en proceso, analizando cómo Ixs actorxs sociales configuran el marco significativo y simbólico de sus prácticas y representaciones.

Sobre el recorte espacio-temporal, las decisiones del proyecto de investigación se centraron en la accesibilidad y la significatividad respecto al problema. La necesidad de aportarle un marco que aporte factibilidad y coherencia al trabajo, me ha llevado a pensar en límites temporales que se vincularan a algún hito en el campo, por lo que en primera instancia tomé como parámetro inicial el año 2004 porque en ese momento se sancionó la ley nacional 25.929 de "Derechos de Padres e Hijos durante el proceso de nacimiento", que apunta hacia la atención respetuosa del embarazo, parto y puerperio. Aunque la ley aún no estaba reglamentada cuando comencé el trabajo de campo en 2013 (se reglamentó en 2015, once años después de su sanción), y ello podía implicar que no hubiera cambios en los protocolos institucionales de atención obstétrica, sí se verificaba que diversos movimientos sociales de impugnación de la violencia obstétrica y de defensa del parto respetado emergieron y se constituyeron en estos últimos veinte años. De hecho en la ciudad de La Plata, contexto espacio-territorial de la investigación, existen ONG's y acciones extendidas en este sentido. Es decir, el marco espacio-temporal se funda, además, en la emergencia de sectores sociales que disputan los modos normalizados y naturalizados de parir/nacer en la actualidad. Mediante dicho recorte se busca garantizar la construcción de un campo heterogéneo de la atención médica de embarazos y partos en La Plata. En la selección concreta de los casos, se trata de la re-construcción de experiencias de partos/nacimientos ocurridos en los últimos años (2013-2019), a partir del testimonio de Ixs tres actorxs principales señaladxs: experiencias sobre las intervenciones médicas obstétricas de mujeres-madres, varones-padres y profesionales de la salud (gineco-obstetras y parteras principalmente) platenses. Finalmente, a raíz de la emergencia de una doble etapa de investigación que surgió por la combinación de observaciones con distintos grados de participación en cursos de preparto y entrevistas de seguimiento, la mayorías de las entrevistas a mujeres-madres y varones-padres se 
remitieron a procesos de parto ocurridos en los últimos 5 años; y a profesionales en actividad.

Otra de las decisiones teórico-metodológicas que atraviesan la investigación es el basamento en la perspectiva de mujeres-madres y varones-padres, en tanto parejas. La inclusión de éstos tiene raíces teóricas en tanto se ha demostrado, en el estado del arte, que existe una carencia de estudios que problematicen las paternidades y sus experiencias y representaciones sobre la atención médica del PEP de sus compañeras y del nacimiento de sus hijxs. Decidir trabajar con parejas heteroparentales implicó excluir parejas de homosexuales madres-padres y las voces de mujeres-madres solteras y varones-padres solteros, tal como se expresó en la introducción.

Finalmente, partiendo de que toda investigación se basa en un recorte temático específico, se asumió aquí que el tratamiento de los partos institucionalizados no excluía la posibilidad de que se incluyera el parto domiciliario. Esto es, la inclusión del parto en casa como escenario/hecho propio de esa heterogeneidad buscada en la presentación de distintas modalidades de intervención/atención del embarazo y parto.

\subsection{B) SELECCIÓN / MUESTRA / RECORTE}

Sobre la selección de casos, las decisiones en relación al plan de muestreo estuvieron en continua revisión justamente por la flexibilidad que permite el enfoque. En base a un muestreo oportunista e intencional por bola de nieve (es decir no probabilístico), se apuntó a incorporar en dicha muestra la expresión de diversas posiciones y experiencias sobre la atención de los procesos de embarazo y parto de mujeres-madres, varones-padres y profesionales de la salud.

Se utilizó la técnica de bola de nieve considerando incluir la mayor diversidad posible de voces para la construcción de un campo complejo de la atención médica del PEP en la ciudad. Por el tipo de muestreo elegido, se contó con la posibilidad de incorporar unidades no previstas. En este sentido, tratándose de una investigación cualitativa, la selección de los casos tuvo como criterio rector la significatividad, la relevancia respecto del tema de investigación y la saturación de la información. Dicha selección estuvo guiada por algunos criterios arbitrarios y construidos en torno a los objetivos y la rentabilidad en la investigación (Stake, 1998).

¿Cómo justificar y garantizar la heterogeneidad de casos? Uno de los propósitos de la investigación fue dar cuenta de un campo social en disputa alrededor de los modos legítimos, habituales y buscados de parir/nacer. En tal sentido, la construcción de ese 
campo implicó visibilizar las diversas experiencias de intervención médica en el PEP, incluyendo diversxs actorxs, discursos y concepciones y tipos de institución sanitaria donde se dieron (públicas y privadas) y otros no institucionales. Dichas experiencias en algunos casos se han convertido en fundamento de militancias: así, algunas mujeres que sufrieron violencia obstétrica decidieron transformar su situación en una acción política de denuncia y prevención y de visibilización y búsqueda de modos respetuosos de parir. En otros casos, las experiencias han sido significadas como positivas, "correctas" o simplemente no han conllevado reflexiones profundas ni críticas de la atención médica. Por lo tanto la búsqueda apunta a incluir las voces sin que unas solapen a las otras, esto es: dando cuenta de la heterogeneidad, con miras a la construcción de un abanico de experiencias de la atención médica de embarazos y partos en el marco específico propuesto.

\subsection{C) PRODUCCIÓN DE DATOS}

El trabajo de campo se realizó desde mayo de 2013 hasta marzo de 2019, y se sustentó en tres fuentes de producción de datos empíricos completamente interrelacionadas: entrevistas en profundidad a informantes claves, observaciones con distintos grados de participación en cursos de preparto y ámbitos relevantes, y análisis documental de diversas fuentes secundarias.

Sobre las técnicas de producción de datos, las decisiones tomadas previeron la constitución de una caja de herramientas metodológicas heterogénea y abierta a las posibilidades del campo. El instrumento principal fue la entrevista en profundidad, orientada a la producción de narrativas del embarazo, parto y nacimiento (y de su atención médica) a fines de conocer las experiencias y sentidos asignados a las intervenciones médicas, por parte de Ixs tres sujetxs claves de este fenómeno relacional: mujeres-madres, varones-padres y profesionales de la salud. En un nivel secundario pero interrelacionado, se utilizaron técnicas complementarias: el análisis documental y la observación con distintos grados de participación.

\section{$>$ ENTREVISTAS EN PROFUNDIDAD}

Respecto a la entrevista en profundidad o abierta, los trabajos de Alonso (1998) y de Giarraca y Bidaseca (2001), permitieron expandir la perspectiva sobre este instrumento metodológico y asegurar la justificación de su elección. El primero caracteriza la entrevista como un proceso comunicativo con carácter directo, no mediado e hipersubjetivo, basado 
en discursos de la experiencia, donde el yo biográfico y la biografía implican que "la información ha sido experimentada y absorbida por el entrevistado y que será proporcionada con una orientación e interpretación significativas de la experiencia del entrevistado" (Alonso, 1998, p. 1). Es justamente esta orientación la que enriquece el trabajo con técnicas cualitativas y lo que busqué fue la interpretación inserta en la experiencia de la atención médica de embarazos y partos narrada por Ixs sujetxs. Asimismo se refiere a que mis informantes son "individuos concretos que por su situación social nos interesan para localizar discursos que cristalizan, no tanto los metalenguajes de colectivos centralmente estructurados, sino las situaciones de descentramiento y de diferencia expresa" (Alonso, 1998, p. 2). Es decir, se procuró, a través de las entrevistas hallar lo sedimentado en torno a los modos de parir/nacer, las resistencias y legitimidades de las intervenciones médicas en esos modos y las posibles articulaciones con discursos sociales más ampliamente reconocidos. Finalmente, su perspectiva es relevante para mi reflexión metodológica, en tanto afirma que "la técnica de la entrevista abierta se presenta útil para obtener informaciones de carácter pragmático, es decir, de cómo los sujetos diversos actúan y reconstruyen el sistema de representaciones sociales en sus prácticas individuales" (Alonso, 1998, p. 5), en concreto, un decir del hacer. No interesaron, por tanto, los discursos como hechos aislados sino su vinculación con las prácticas, su performatividad. Por otro lado, el artículo de Giarraca y Bidaseca (2001) aporta a la problematización de la "plurivocidad específica" propia de las voces de las entrevistas, y a la asunción de la multiplicidad de eventos, opiniones, concepciones y sentidos que esos discursos de la experiencia biográfica y personal conllevan.

"Se trata de captar discontinuidades, fracturas, contradicciones, los aspectos inexplicados, y de lograr una representación compleja y múltiple, fundada en la expresión de las mismas realidades en discursos diferentes, a veces irreconciliables y abandonar el punto de vista único en beneficio de la pluralidad de puntos de vista coexistentes y a veces irreconciliables" (Bourdieu, 1999, p. 9; citado por Giarraca y Bidaseca, 2001, p.14).

Sostengo que otra de las potencialidades de trabajar con narrativas es que permiten conocer "realidades y experiencias silenciadas o tergiversadas por las "versiones oficiales", que suele ser el caso de las experiencias de mujeres, muchas veces silenciadas, invisibilizadas o transmitidas desde perspectivas masculinas" (Bocco y otros, 2012, p. 333).

"El relato biográfico permite tender un puente entre el conocimiento de lo particular, en términos de lo vivido y relatado por el actor social, y el conocimiento de lo general, es decir, las características, condiciones y eventos del contexto social e histórico en el cual transcurre la vida del que narra su historia" (Villarroel, 1999:14). Al mismo tiempo que cuenta su historia personal, quien construye un relato muestra su trayectoria conjugada 
con la de otro/as que son sus contemporáneos en tanto miembros de una familia, de una comunidad, de una adscripción de clase, étnica, de género o pertenencia generacional (Barbieri, 2008). Estos relatos, a su vez, reflejan los cambios y continuidades en las experiencias de sujetos/as de distinta pertenencia social, genérica y generacional, permitiéndonos así acceder no sólo a lo común y compartido en un colectivo sino también a lo particular y diverso, pues "los relatos de vida, recuperan los saberes particulares surgidos de experiencias muchas veces compartidas, pero no por ello vividas como comunes" (Kornblit, 2007:19)" (Bocco y otros; 2012, 333-334)".

En lo concreto, se entrevistaron a 12 (doce) profesionales de la salud (ginecoobstetras, parteras, psicólogas, trabajadoras sociales y neonatólogas) que atienden embarazos y partos en instituciones públicas y privadas de salud de la ciudad y asisten partos domiciliarios. Entre estas 12, cinco ocupaban al momento de la entrevista cargos jerárquicos en las maternidades o en el Ministerio de Salud Provincial. En paralelo, se realizaron 7 (siete) entrevistas en profundidad a mujeres-madres, siendo tres de ellas en conjunto con sus parejas (varones-padres). El objetivo de estas entrevistas, que en general duraron en promedio una hora con las profesionales y dos horas o más con las mujeres y parejas, fue conocer qué discursos emergen del diálogo, atendiendo y problematizando los sentidos genéricos asignados a la experiencia del embarazo y el parto, en particular las vinculadas a los contactos con equipos de salud (consultas y estudios prenatales, parto hospitalizado o con médicxs, puerperio).

A tal fin se construyeron dos guiones de entrevista: uno para guiar la indagación a profesionales de la salud y otro para direccionar la conversación con las mujeres-madres y varones-padres ${ }^{46}$. Siguiendo a Suarez (2008), considero que el trabajo de recolección y producción de datos (como todo el que acompaña el proceso de investigación), tiene una cuota importante de artesanía por parte del/ de la investigador/a, por lo cual la explicitación de los guiones de entrevista no incorpora tonalidades y modos directos de conversación (lo que Alonso -1993, p. 8- menciona como "fraseología"). Es decir, se propusieron tópicos de trabajo, sabiendo que las expresiones reales y el orden secuencial de tales ítems dependerían de cada entrevista en particular, de la situación dialógica y del ambiente en el que se diera la entrevista. De hecho, la experiencia tenida en campo, corrobora esta idea. De todos modos, la ventaja principal de los guiones radicó en la posibilidad de comparar las distintas voces.

\footnotetext{
${ }^{46}$ La realización de los guiones fue sólo tentativa y admitió (e incluso exigió) reformulaciones afines a la experiencia empírica del trabajo de campo y su aplicación. De tal manera, ya en la realización de la primera entrevista surgieron cuestiones a modificar.
} 
CuAdro 4. GuION DE ENTREVISTAS A PROFESIONALES DE LA SALUD

\begin{tabular}{|l|l|}
\hline \multicolumn{1}{|c|}{ Tópico } & \multicolumn{1}{c|}{ Profundizaciones } \\
\hline 1.Sobre el propio nacimiento & Elección de la carrera: por qué (influencias), dónde la estudió, cómo lo vivió. \\
\hline $\begin{array}{l}\text { 2.Historia personal- } \\
\text { profesional }\end{array}$ & \\
\hline Atención médica en el parto & \\
\hline $\begin{array}{l}\text { 3.Relato del primer y último } \\
\text { parto }\end{array}$ & $\begin{array}{l}\text { Descripción médica de los dos partos. } \\
\text { Sus sentimientos, expectativas, sensaciones. } \\
\text { Relación con lxs otrxs miembros del equipo: relación con pares y superiores. } \\
\text { Relación con mujer-madre y acompañante (varón-padre). } \\
\text { Relación con recién-nacidx. }\end{array}$ \\
\hline $\begin{array}{l}\text { 4.Equipo de trabajo actual } \\
\text { que trabaja }\end{array}$ & $\begin{array}{l}\text { Conformación por función, sexo y edad. Relaciones. } \\
\text { experiencia mixta generar comparaciones. }\end{array}$ \\
\hline $\begin{array}{l}\text { 6.Seguimiento pre y post } \\
\text { parto }\end{array}$ & Consultas y estudios pre-natales: cuáles, cuántos, dónde. \\
\hline 7.Rutinas en el parto & $\begin{array}{l}\text { Acciones de cada integrante del equipo. Justificaciones médicas a cada } \\
\text { intervención. }\end{array}$ \\
\hline
\end{tabular}

CUADRO 5: GUIÓN DE ENTREVISTAS A MUJERES-MADRES Y VARONES-PADRES

\begin{tabular}{|l|l|}
\hline \multicolumn{1}{|c|}{ Tópico } & \multicolumn{1}{|c|}{ Profundizaciones } \\
\hline 1.Sobre el propio nacimiento & \\
\hline Embarazo & $\begin{array}{l}\text { Si fue buscado o no. Uso de métodos anticonceptivos. } \\
\text { Llegada: primera acción y contacto con médicx, profesional o } \\
\text { institución de salud: quién, cómo, dónde. }\end{array}$ \\
\hline 2.Búsqueda de embarazo & $\begin{array}{l}\text { Interacción médicx-paciente. Qué estudios, compañía, informaciones } \\
\text { sobre el bebé, etc. }\end{array}$ \\
\hline 3.Controles y estudios pre-natales \\
\hline 4.Dimensión emocional & $\begin{array}{l}\text { Sensaciones de ambos durante los meses de embarazo: inquietudes, } \\
\text { miedos, expectativas. }\end{array}$ \\
\hline Parto & $\begin{array}{l}\text { Explicación médica. } \\
\text { Valoración. } \\
\text { Reevaluación. }\end{array}$ \\
\hline 5.Intervenciones médicas & Temores, expectativas, lo real y lo esperado. \\
\hline 6.Relato del parto (libre) & \\
\hline Postparto/Puerperio/Crianza & \\
\hline $\begin{array}{l}\text { 7.Salud física y emocional de la } \\
\text { parturienta }\end{array}$ & Lactancia, sueño, alimentación. \\
\hline $\begin{array}{l}\text { 8.Consejos/indicaciones médicas de } \\
\text { crianza }\end{array}$ &
\end{tabular}

En este puno, es relevante marcar algunas características que tuvo el proceso de entrevistas. En primer lugar, los encuentros con profesionales de la salud y funcionarias ministeriales fueron más breves, aunque en algunos casos llegaron a durar más de dos horas (en el caso de profesionales humanistas con quienes realicé las entrevistas en el seno del hogar). Con las jefas de los servicios de tocoginecología de tres de las maternidades públicas de la ciudad, me encontré en sus despachos, por lo que tuve que esperar en los pasillos del hospital las horas necesarias para poder conversar en el 
ámbito de un trabajo muy demandante. En ese marco las charlas fueron poco íntimas y marcadas por la jerarquía, la distancia física del escritorio y simbólica del ambo.

En el caso de las entrevistas a mujeres-madres, de las siete sólo tres asistieron solas: ellas eligieron hacerlo así. Como se ve en el cuadro 6, puse los nombres de los varones entre paréntesis porque fueron referenciados constantemente en la entrevista pero no estaban presentes. Las otras variaron entre más duales o momentos en que las mujeres monopolizaban la palabra, y se daba una dinámica muy interesante de construcción colectiva del relato de parto. Por ejemplo, entre ambxs rellenaban huecos temporales que unx u otrx no recordaban. Así, en las entrevistas duales, fue posible ver un interesante diálogo entre ellxs, diferentes versiones de la historia o registros del tiempo. Estas entrevistas fueron seis en hogar (cuatro en el suyo, dos en el mío) y una en un bar. Fueron amenas y duraron, entre hora y media y dos horas cada una.

Todas las entrevistas fueron desgrabadas y analizadas pormenorizadamente a partir de categorías y ejes de lectura. Los datos construidos se exponen en los capítulos 3,5 y 6 .

CUADRO 6. RESUMEN DE ENTREVISTAS REALIZADAS SEGÚN “TIPO DE SUJETXS"47

\begin{tabular}{|c|c|c|c|}
\hline & Profesionales & & Mujeres-madres/Varones-padres \\
\hline 1 & Bárbara (partera) & 1 & Natalia y Lito \\
\hline 2 & Equipo de psicología de Maternidad & 2 & Sabrina (y Agustín) \\
\hline 3 & Equipo de trabajo social de Maternidad & 3 & Valeria y Santiago \\
\hline 4 & Rocío (obstetra/tocoginecologa) & 4 & Johana y Damián \\
\hline 5 & Sandra (partera) & 5 & Mariana (y Leandro) \\
\hline 6 & Andrea (neonatóloga) & 6 & Anabel y Dimitri \\
\hline 7 & Adela (obstetra, Jefa de servicio de tocoginecología) & \multirow[t]{5}{*}{7} & \multirow[t]{5}{*}{ Emilia (y Marco) } \\
\hline 8 & Alicia (obstetra, Jefa de servicio de tocoginecología) & & \\
\hline 9 & Marta (obstetra, Jefa de servicio de tocoginecología) & & \\
\hline 10 & Elina (pediatra, funcionaria) & & \\
\hline 11 & Fernanda (neonatóloga, funcionaria) & & \\
\hline
\end{tabular}

\section{>OBSERVACIONES CON DISTINTOS GRADOS DE PARTICIPACIÓN}

En la realización de este trabajo, asumí que si bien no era una decisión explícita, estaba realizando observaciones con distintos grados de participación en diversos espacios de reunión de mujeres-madres, varones-padres y profesionales de la salud que atienden partos desde una perspectiva humanizada y fisiológica. Se trata de la

\footnotetext{
${ }^{47}$ En los capitulos 5 y 6 hay cuadros con información más detalla de cada entrevista.
} 
participación en actividades emprendidas por organizaciones de la sociedad civil y organismos estatales que apuntaron a visibilizar y difundir los derechos vinculados a la asistencia al embarazo, parto y nacimiento y a la denuncia de la violencia obstétrica: obras de teatro, proyección de documentales, asambleas de una ONG, actividades en el marco de la "Semana Mundial del Parto Respetado" y de la "semana contra la violencia hacia las mujeres", participación (como coordinadora) en mesa de debate sobre nacimiento respetado en el décimo Encuentro Nacional por la Niñez. De todos modos, es relevante marcar que aunque sí realicé observaciones participantes en estos espacios (donde me contacté con informantes claves y ocasionales, que motorizaron el muestreo como bola de nieve), decidí no participar en los espacios donde se concretizan los distintos modos de atención al parto: es decir, tomé la decisión de no asistir a ningún nacimiento y no realizar etnografía en salas de parto y de posparto en instituciones sanitarias $^{48}$.

En la salida al campo, el principal imponderable que surgió fue sumamente beneficioso para la investigación: tramitando contactos de entrevistas, tuve acceso a participar como observadora de un curso de preparto. Al presenciar estas reuniones semanales durante un mes, concluí que tenía muchas potencialidades para mi trabajo. Entre otras, me permitía ampliar la mirada hacia la temporalidad del embarazo, conocer cómo se preparan las mujeres y sus parejas/acompañantes para los partos, qué discursos (re)producen Ixs profesionales de la salud y ver en ellos un montón de dispositivos simbólicos que implican modos de concebir los procesos reproductivos, los cuerpos, a las mujeres, etc.

Luego de esta primera experiencia, decidí incluir la participación en cursos como incursión fundamental en el campo ya que me permitía cubrir las experiencias de las mujeres y sus parejas, las interacciones con profesionales médicxs, los discursos médicos, y todo esto con las particularidades del contexto o tipo de institución sanitaria (público, privado, particular). La participación en cursos de preparto, como fuente de información fundamental no anticipada o no considerada en la etapa de proyecto, implicó la adaptación a nuevos espacios, nuevas técnicas, nuevos informantes. Además de la información en sí misma que aportaba cada participación en cada curso, servía a modo

\footnotetext{
48 Dicha decisión responde a una concepción ideológica más que a las posibilidades reales de hacerlo: estar presente en una sala de parto me parece que implica violaciones a derechos sexuales y reproductivos de las mujeres, como la privacidad y la intimidad. De hecho autoras como Blázquez Rodríguez y Sadler, especialistas en el tema en España y Chile respectivamente, realizaron etnografías situadas en instituciones sanitarias para estudiar la temática.
} 
de contacto con parejas y profesionales para ser entrevistadxs, por lo que se constituyó en un medio y un fin en sí mismo para la investigación.

Participé en seis cursos de preparto, asistiendo a un total de 30 encuentros, de entre una y cuatro horas de duración cada uno. Las diferencias principales entre cada uno se dieron por quién ofrecía el campo: uno de una obra social, otro de un gimnasio, otro de un hospital público, otro de una clínica privada, otro de un hospital privado y uno ofrecido por un grupo de profesionales que asisten partos domiciliarios. Cada curso a su vez tenía dinámicas particulares, tiempos diferentes y equipos profesionales diversos entre sí. Otra vez, el criterio de heterogeneidad fue el rector en la elección de estos espacios. El desarrollo de esta experiencia de campo se presenta en el capítulo 4 . En lo práctico tomé notas a modo de diario de campo al salir de cada encuentro, tanto del núcleo de cada uno como de la previa y el post. Trabajé con esas notas, dibujos y gráficos para armar dicho capítulo.

\section{>ANÁLISIS DOCUMENTAL}

Se analizaron documentos escritos de fuentes públicas y privadas. Considerando que a los documentos también se los observa y se los entrevista, se trabajó con un corpus documental heterogéneo compuesto por leyes/normativas, protocolos y declaraciones médicas (colegios de obstetricia, ginecología y partería); guías ministeriales, relatos de parto (en grupos y páginas de internet y redes sociales; declaraciones de ONGs pro parto respetado). Se decidió incorporar esta técnica para complementar la producción de datos, contextualizarla y otorgarle mayor base empírica a la investigación.

\subsection{D) ANÁLISIS}

En cuanto al proceso de análisis de los datos, se realizó una lectura reiterada y cuidadosa de la información recogida en diarios de campo y transcripción de entrevistas, intentando ver su relación con lo esperado en base al conocimiento previo, viendo coincidencias entre distintos casos, analizando relaciones entre conceptos, alentando la generación de nuevas categorías, conceptos, relaciones e interrogantes. Se concibió este análisis como un proceso de codificación, categorización y construcción interpretativa de los discursos en "significados", es decir, en explicaciones teóricamente consistentes de lo dicho, con el fin de reconstruir los hallazgos en relación con el marco teórico y los objetivos de la investigación. 


\subsection{RefLeXIVIDAD: PONER EL CUERPO}

Durante todo el extenso y profundo trabajo de campo, fui realizando diversos ejercicios de autocrítica y vigilancia epistemológica sobre cómo era investigar el PEP, cómo investigar la atención médica, cómo me sentía yo, qué lugar ocupaba en el campo, qué tensiones encontraba con mi militancia política, cómo me relacionaba poniendo el cuerpo en un proceso eminentemente corporal, entre otras muchas cuestiones. Por ello, finalizo el apartado metodológico con tres ejes principales para mí que surgieron de este ejercicio de reflexividad: la negociación de roles en el campo, el compromiso político con el tema investigado y el poner el cuerpo como un elemento de unión entre Ixs sujetxs de estudio y la sujeta que estudia.

>>QUÉ SOY Y QUÉ NO SOY EN EL CAMPO: NEGOCIACIÓN DE ROLES

Durante mi trabajo de campo asumí una diversidad de roles y posiciones, principalmente en los cursos de preparto: acomodadora de colchonetas/sillas, impresora y distribuidora de listas de materiales para internación; organizadora de campaña de donación de ropa, pañales y sacaleches; community manager; coordinadora del curso en caso de tardanza de la partera ${ }^{49}$; la no-embarazada, la no-profesional, la informante o cara del curso para Ixs asistentes, mano de obra, chivo expiatorio, fotógrafa, humorista, confidente, asistente, portadora de saber experto/voz autorizada, agenda humana de las clases que faltan y que se dieron, militante, referente, miembro de una organización, evaluadora, cebadora de mate, participante al igual que ellxs, cadete intrainstitucional, modelo de masajes, "visitante" socióloga/ la de la universidad, entre otras muchas.

En los seis cursos y en las entrevistas me presenté como "una socióloga que estudia la atención médica de embarazos y partos en La Plata". A veces mencionaba "eso de la violencia obstétrica y el parto respetado" para ubicarlo en un contexto más coloquial. Respondí las preguntas de Ixs interesadxs siempre que me lo refirieron, me comprometí explícitamente a mantener el anonimato y no obtuve resistencias a participar. En los cursos tomaba en general el rol de cebadora de mates, porque además de ser algo que

\footnotetext{
${ }^{49}$ Ocurrio en el hospital público, donde estuve dos meses ininterrumpidos y Sandra me pidió que "les hablara de algo" mientras ella terminaba unos trabajos administrativos: les hablé de la ley de parto respetado y los derechos que las asisten

${ }^{50}$ En el curso del hospital privado me obligaron a colgarme un cartelito en el pecho que decía "visitante" para distinguirme del resto de lxs participantes (que incluía embarazadas, varones, padres, amigas, etc).
} 
me gusta hacer, me da cierta comodidad en el habitar el espacio: tengo una función asignada y se naturaliza más rápido mi presencia, que, al mismo tiempo, es "deseada" por el hecho de que doy algo a cambio. Desconozco si se han hecho reflexiones sobre el rol del mate en las ciencias sociales, pero en esta tesis fue central en todas las instancias: proyecto, trabajo de campo (entrevistas y CPP) y escritura final.

Por mis "habilidades sociales" no tuve dificultades para relacionarme con cada una de las personas y supe ser flexible, improvisar y adaptarme a dicha heterogeneidad. Esa es tal vez una capacidad que desarrollé en mis años de tallerista ad honorem en la Comisión por la Memoria, con adolescentes tan distintxs que iban desde habitantes de comunidades rurales hasta alumnxs de un Liceo Militar. Estas habilidades han hecho no sólo que el trabajo de campo fluyera sino también y, principalmente, que fuera una fuente de placer, disfrute y hasta de comienzo de amistades y vínculos más estrechos.

Seguramente los roles que más me incomodaron fueron al momento de entrevistar a las tres jefas de los servicios de tocoginecología de maternidades públicas de la ciudad: cada una en su despacho del hospital correspondiente, luego de hacerme esperar en algún caso tres horas y dedicándome como máximo treinta minutos, mirando el reloj a cada rato. Me refería a ello en mis charlas con colegas y amigxs como "me aplicaron todos los mecanismos de poder posibles": espera, ambo, escritorio, distancia. De todos modos me dieron las entrevistas, respondieron cosas muy interesantes y aproveché los ratos de espera para observar y conocer la dinámica hospitalaria, tomar nota, asociar ideas y hasta pactar entrevistas. Por ejemplo gracias a esas observaciones pude ver que las mujeres son nominadas como un número (de la habitación, en el caso de las dobles) y una ubicación (ventana/pasillo), que todas se llaman "mami" y que en los hospitales públicos la mayoría están solas con sus bebés.

El ejercicio reflexivo fue constante e integral de la investigación, problematizando cuestiones como las expectativas de rol bilaterales (del/la entrevistador/a y del/la entrevistadx); los rediseños de los guiones de entrevistas post- realización de las primeras conversaciones (a modo de pre-test); la necesidad de desarrollar una capacidad de adaptación y ajustes pertinentes a situaciones no esperadas y no controladas, la negociación constante del rol de la investigadora en el trabajo de campo; y la búsqueda de un control de calidad, en tanto la construcción de relatos disciplinados e intelectualmente controlados; entre otros. 
La plasticidad y la posibilidad de ir generando contactos desde cero (gracias a la capacidad del caradurismo, infravalorada socialmente), golpeando puertas, enviando mails y llamando por teléfono a desconocidxs, me permitió realizar un extenso y profundo trabajo de campo, cuya producción de datos se presenta en esta tesis. Quizás el rol que más tensiones me ha generado y me sigue generando es mi rol en tanto investigadora y militante de la causa del parto respetado, que desarrollo a continuación.

\subsection{B. ¿UNA MILITANTE INVESTIGANDO O UNA INVESTIGADORA MILITANDO?}

Me acerqué a la temática con un interés sociológico en 2013, y en la medida en que me adentré y construí relaciones con distintxs sujetxs, me convertí en una militante por los derechos del parto y nacimiento. Soy socióloga y militante de la causa: socióloga de la causa porque me mueve un interés por pensarla sociológicamente, reponer sus ontologías y pensar modos de intervención; militante de la causa desde que fui miembro de una ONG de mi ciudad orientada a promover y defender los derechos del embarazo, parto y puerperio. De dicha ONG, también fui productora de su programa radial sobre el tema y luego hacia 2015 decidí salir de la participación orgánica por el tiempo que me insumía y porque comprendí que necesitaba distancia para poder realizar esta tesis. De todos modos desde el primer momento y aprovechando mi capacidad y mi gusto por la divulgación científica y política, doy charlas a distintos públicos en distintos ámbitos ${ }^{51}$. Pero esto es: soy socióloga y militante de la causa, en paralelo, imbricadas, actuando como socióloga en mi campo de militancia; y buscando mantener una posición crítica cuando la militancia quiso/quiere dirigir mi estudio.

En este apartado quiero pensar mi lugar como investigadora de un campo social en el que a la vez participo políticamente. Para ello, leí debates vinculados a los compromisos y la implicación del/de la investigador/a con su tarea (Rivas, 1994); a la posibilidad de una posición excéntrica del/ de la analista (Esteban, 2001) o a la idea de un sujeto excéntrico al género (Valls Llobet, 2009); la posición refugio de Mauger (Pestaña y García, 2006); la apuesta del/de la intelectual colectivo de Bourdieu (analizado por Suarez, 2008) y las propuestas de extrañamiento y descotidianizar de Lins Ribeiro (1989). Este autor retoma la noción de conciencia práctica de Giddens, entendida como la

\footnotetext{
${ }^{51}$ He tenido el placer de dar charlas de prevención de la violencia obstétrica y difusión de derechos al parto respetado desde un sindicato, una unidad básica barrial hasta la Facultad de Medicina de la ciudad o el Senado de la provincia.
} 
"fijación de los elementos constitutivos de los contextos significantes para las interacciones, [que] está dada por la rutinización de los encuentros sociales en el cotidiano de los agentes sociales" (Lins Ribeiro, 1989, p. 195-6), para nombrar qué situaciones debemos descotidianizar y de cuáles debemos extrañarnos cuando estudiamos la propia sociedad. Aquí encuentro un elemento que me aporta un lugar particular en el campo de estudio en el que además participo políticamente, ya que el hecho de no ser madre y no haber atravesado la experiencia de embarazo/parto constituye un diferencial de capitales con Ixs sujetxs que son parte de mi indagación.

En el marco de esta revisión, hallé una reflexión de la socióloga argentina Maristella Svampa (2008) en la que propone la figura del investigador-intelectual como anfibio que me resulta útil y sumamente positiva para pensar mi práctica investigativa. La autora analiza la figura del intelectual militante ${ }^{52}$ y del experto (y dentro de éste al intelectual intérprete ${ }^{53}$ y al intelectual ironista ${ }^{54}$ ) y ve la "necesidad de construir un nuevo paradigma del investigador e intelectual comprometido". Por ello propone la figura antes mencionada, partiendo de la hipótesis de que es posible conjugar ambas figuras en ese solo paradigma.

"El intelectual-investigador como anfibio, a saber, una figura capaz de habitar y recorrer varios mundos, y de desarrollar, por ende, una mayor comprensión y reflexividad sobre las diferentes realidades sociales y sobre sí mismo. Así, a la manera de esos vertebrados que poseen la capacidad de vivir en ambientes diferentes, sin cambiar por ello su naturaleza, lo propio del investigador- intelectual anfibio es su posibilidad de generar vínculos múltiples, solidaridades y cruces entre realidades diferentes. En este sentido, no se trata de proponer una construcción de tipo camaleónica, a la manera de un híbrido que se adapta a las diferentes situaciones y según el tipo de interlocutor, sino de poner en juego y en discusión los propios saberes y competencias, reafirmando su lugar en tanto intelectual-investigador crítico. Asimismo, hay que agregar que la naturaleza anfibia y por ende, los niveles de reflexividad que está en condiciones de desarrollar el intelectualinvestigador militante (...) Esta forma de militancia expresa una vocación por el cruce social y la multipertenencia, en el marco del desarrollo de relaciones de afinidad y redes de solidaridad con otras organizaciones" (Svampa, 2008, p. 14).

\footnotetext{
52 "El intelectual militante suele convertirse en un activista a tiempo completo, cuyo nivel de involucramiento dificulta una reflexión crítica, obturando la producción de un tipo conocimiento que vaya más allá de la visión de los actores" (Svampa, 2008, p. 10).

53 "El intelectual-intérprete estaría orientado, más modestamente, a la comprensión y la comunicación de saber, sin pretensión legislativa alguna (...) [siendo] el lugar del investigador como una suerte de traductor sofisticado de la experiencia de los actores" (Svampa, 2008, p. 11).

54“ [Los intelectuales ironistas $]$ adoptan como principio epistemológico y político la distancia irónica y provocativa respecto de la realidad social, proponiendo de entrada la imposibilidad de una articulación entre investigación académica y compromiso militante (...) el ironista rechaza toda posibilidad de intervención, acantonándose en un modelo epistemológico-narcisista y un escepticismo político” (Svampa, 2008, p. 12)
} 
Se refiere a la posibilidad de hacer uso y politizar el habitus académico, buscar un lugar dentro del espacio militante en tanto investigadorxs comprometidxs y críticxs, capaces de "producir un conocimiento que vaya más allá de la visión y el discurso de los actores y, al mismo tiempo, capaz de interpelar críticamente a quienes dice acompañar" (Svampa, 2008, p. 15).

"La aportación del feminismo a las ciencias sociales y a las ciencias de la salud no se ha limitado sólo a hacer visibles las relaciones ocultas o desenmascarar conclusiones tendenciosas, sino que la forma de investigar también se ha puesto en cuestión (...) la investigación feminista ha demostrado que el observador está por necesidad implicado en el proceso de producción de datos (...) en el contexto de una ciencia androcéntrica, los datos relacionados con las mujeres y los temas de género permanecen ampliamente invisibles, como ha ocurrido en la ciencia de la medicina en la que las mujeres han sido tradicionalmente invisibles" (Valls Llobet, 2009, p. 12b).

Es decir, en el centro de la perspectiva de género también hay una respuesta a mi segundo interrogante: allí encuentra unx como investigador/x e intelectual una conexión estrecha con su compromiso político y sociológico.

"El carácter riguroso de la metodología de género, y la novedad epistemológica que representa, es que la aproximación a la realidad no la realizamos de manera neutra ni arropada bajo la bandera de una universalidad sin signos distintivos, por el contrario, asumimos esta metodología afirmando que existe una problemática de las relaciones de poder entre mujeres y varones, partiendo de que la mujer es subordinada en el espacio social, y que esa desigualdad entre los géneros no es consecuencia de hechos naturales, sino históricos, y por ello se habla de posibilidades reales de cambio. Este cambio se producirá, precisamente, mediante la producción de conocimiento desde la metodología de género, la cual entre sus primeras consecuencias, deja al desnudo la pretendida neutralidad, objetividad y universalidad de la ciencia dominante, rigores "científicos" que presentan al sujeto masculino como único referente válido de lo humano" (Camacaro Cuevas, 2009, p. 151).

Sobre la cuestión de mi doble rol como investigadora y militante por la causa del parto respetado, desde mediados de 2015 me aparté de mi tarea en la ONG que integraba y adopté una distancia crítica tanto con algunos conceptos como con ciertas prácticas, que repercutían en mi modo de abordar sociológicamente la problemática. En este sentido, busqué a través de una constante vigilancia epistemológica y un ejercicio de reflexividad, evitar los posibles sesgos propios de la selección de casos en el caso particular de mi participación política en el tema. En tal sentido, intenté no sobredimensionar aquellos casos cercanos de militantes por el parto respetado para generar y garantizar igual participación a las distintas significaciones y experiencias de la atención obstétrica.

"Mi punto de partida ha sido adoptar una posición que Didier Fassin (1999: 54) denomina antropología implicada que interviene y quiere contribuir con el objeto de estudio, 
mediante la mejora de los servicios sanitarios, la praxis sanitaria, la promoción de un mayor control de la población sobre su salud, pero manteniendo una distancia epistemológica que le permita una actitud crítica tanto sobre su objeto de estudio, como sobre su propia práctica antropológica” (Blázquez Rodríguez, 2008, p. 26).

De todos modos y para finalizar, he advertido que en mi inserción en campo me ha sido difícil apagar el chip de la militante y convertirme en solo una oyente. Cuando advertía que en los relatos de Ixs entrevistadxs aparecían cuestiones que constituían claras violaciones a sus derechos sexuales y reproductivos, me era muy difícil no decir nada. Por ejemplo en una entrevista, terminé por confirmarle a uno de los varones-padres que tenía derecho a entrar al nacimiento de su hijo y ver que a partir de mi información él comenzó a identificarse como víctima de VO, fue algo que no había tenido en cuenta. Del mismo modo que en muchos casos durante la presencia en los cursos, cuando las personas me asignaban el rol de "la militante" o "la voz autorizada" solían preguntarme o contarme situaciones que incluían desde indicar cesáreas innecesarias o no satisfacer algunas de sus necesidades, y yo tendí a dar la información más imparcial posible, más clara y concisa. De ningún modo creo que saberse violentadxs en la experiencia del nacimiento de sus hijxs sea algo que esperaban quienes me daban su entrevista, por ello solo hablé de ello cuando lo creí correcto y si era interrogada al respecto. En general me preguntaban “¿se puede eso?”, “¿es así en todos lados?” y se daba un interesante proceso de deconstrucción, por ejemplo, de la medicalización del parto. Sin dudas en la mayoría de los casos las entrevistas constituyeron encuentros horizontales (dentro de lo que la situación de entrevista permite), relajados y abiertos a la interrogación constante: lo que vale es la experiencia que cada unx tenía para compartir(me).

\subsection{PONER EL CUERPO}

"Poner el cuerpo" es un excelente modo de cerrar la parte de los marcos de la investigación para pasar a presentar los resultados y hallazgos. Hablo de poner el cuerpo porque es esa la característica distintiva de este tipo de abordajes, ese "estar ahí", pero que además, en el estudio de procesos que suceden en el cuerpo de las mujeres, como el embarazo y el parto, poner el cuerpo es un diferencial no sólo de la investigadora sino de Ixs sujetxs de investigación.

Ese poner el cuerpo salta a la vista concreta y simbólicamente en los cursos de preparto, situándome en tanto investigadora como una "tercera en discordia", un sujeto híbrido en tanto no soy embarazada porque no tengo panza (que a las 30 semanas de 
gestación, que es cuando comienzan a participar de estos espacios, es sumamente visible) y tampoco tengo ambo o chaqueta médica (elementos que hacen a la distinción simbólica desde lo corporal), por lo que no soy profesional de la salud ${ }^{55}$. Esta posición híbrida me impulsó a explicitar mi objetivo de participación en los espacios desde el principio. Este lugar intermedio, gris, me ubicó a veces como público raso (oyente del curso, participante activa en las clases de actividad física), a veces como voz autorizada (quienes dictaban el curso muchas veces apelaban a mis conocimientos y me pedían que participara dando mi opinión) y otras veces, bastante seguido, como una especie de asistente del curso, con todo tipo de actividades extras: ordenar sillas o colchonetas, tomar nota de los presentes, repartir volantes, cerrar y abrir ventanas, entre otras. Además, ese lugar intermedio, me permitió mantener relaciones cercanas tanto con las mujeres y acompañantes que participaban (al no identificarme con la autoridad y jerarquía médica) como con Ixs profesionales médicxs, en tanto me consideraban alguien distinto a Ixs participantes, más cercano a ellos.

Poner el cuerpo realizando los cursos fue un espacio de placer investigativo para mí: no implicó violaciones a la intimidad como sí creía que podía implicar la etnografía sanitaria en salas de parto e implicó, en mayor o menor medida, dinámicas participativas y de intercambio de saberes, la pertenencia a un grupo, cierta horizontalidad y espacios de expresión de emociones, miedos e inquietudes, que, por los relatos de las entrevistadas, difieren mucho de lo que ocurre en las consultas particulares. Me refiero al placer y al disfrute, además y principalmente, por mis propias cualidades personales para la sociabilidad, que pude desplegar con creces en este trabajo de campo. $Y$ me permito hablar de disfrute porque creo que es un punto clave a tener en cuenta en la reflexividad metodológica.

Así como hubo puntos de encuentro con todos los miembros de los cursos, hubo situaciones que marcaron la distinción principal que pasaba, sobre todo, por poner el cuerpo. Por ejemplo en los momentos de actividad física (solo los dos cursos de preparto de entidades sanitarias privadas no lo contemplaban) tanto de relajación como de desinhibición corporal, en los que participé activamente, entendí que estar embarazada y poner el cuerpo es un diferencial sumamente ineludible en la experiencia de los cursos. La fatiga, la dificultad para estar acostadas boca arriba o para sentarse o pararse que

\footnotetext{
55 Sólo en uno de los cursos (el del hospital público, donde participé mas tiempo, cerca de dos meses), la partera que dictaba el curso me sugirió que utilizara una chaqueta, en lo que entendí, era una disputa de distinción interna al hospital. De todos modos, eludí esa sugerencia y seguí participando “de civil”, aunque el no portar panza marcaba mi posición distintiva en el espacio del curso.
} 
ellas sentían, me recordaba siempre que aunque me sintiera muy cercana, éramos diferentes. $Y$ que ese poner el cuerpo también separaba a las embarazadas de sus acompañantes y de Ixs profesionales médicxs, en tanto es el distintivo de la experiencia perinatal.

En síntesis, toda esta experiencia en los cursos me hizo volver al cuerpo, al obvio y visible cuerpo gestante y cuerpo paridor, porque es el territorio en el que se despliegan las intervenciones médicas que estudio y es la frontera que ubica a esas mujeres en un espacio en el que otras mujeres y varones no estamos.

El campo y poner el cuerpo hicieron reformular la estrategia metodológica y algunas aristas conceptuales, hacia formas que me resultaron más productivas y más placenteras. A partir de haber puesto el cuerpo seis años a esta tesis, es que puedo presentar los siguientes resultados. 


\title{
CAPÍTULO 3
}

\section{LAS POLÍTICAS DEL PARTO. MARCO REGULATORIO Y CONTEXTUAL}

\author{
SISTEMA DE SALUD Y POLÍTICAS PÚBLICAS DE ATENCIÓN AL EMBARAZO Y PARTO PARA EL \\ CASO DE ESTUDIO
}

\subsection{Presentación}

En este capítulo se expone una visión macro del problema de estudio: el marco regulatorio actual, las tensiones y los obstáculos de la implementación de los cambios legislativos y protocolares en la atención. En este sentido, aquí se describe y analiza lo que nomino como política de humanización de la atención médica de los embarazos y partos de bajo riesgo, que constituye el modelo de asistencia promovido desde el Estado y en proceso de implementación. Considero que la humanización de este tipo de atención se asienta sobre dos ejes interrelacionados: la consagración de derechos sexuales y reproductivos de las mujeres y la revisión y cuestionamiento de las prácticas médicas obstétricas hegemónicas.

En vistas de una breve contextualización de las preocupaciones estatales por la salud materno-infantil en Argentina, retomo el trabajo de Biernat y Ramacciotti "Crecer y multiplicarse" (2013) que da cuenta de cómo se ha ido constituyendo la política argentina en esta materia en la primera mitad del siglo XX. En una ponencia presentada en 2014, en la mesa de Estudios Comparados de América Latina (GESHAL) explican por qué el Estado interviene en esta área:

"Tanto para garantizar la reproducción cuantitativa y cualitativa de la población como para buscar una respuesta a la disolución del tejido social se apela a la participación del Estado. En este sentido, el cuidado de la salud de las mujeres, en tanto procreadoras, y la de su prole se sitúa en su horizonte de prioridades a la hora de realizar diagnósticos y proponer estrategias de intervención pública. Se trata de intervenciones que entrelazan propósitos económicos, demográficos y sociales y que van construyendo el entramado de la política social argentina" (2014, p. 2).

De este modo "la salud de las mujeres en relación a su capacidad reproductiva se constituye en preocupación de Estado en la Argentina desde las últimas décadas del siglo XIX" ( $p$ 11). A modo de resumen y pantallazo general de dicho contexto de constitución de la política materno-infantil argentina, establecen:

"La asistencia sanitaria materno-infantil en la Argentina durante la primera mitad del siglo XX está guiada por el debate poblacionista y por el intento de dar respuestas a la "cuestión social". Frente a las dudas que deja el proyecto inmigratorio, la preocupación por la cantidad y/o la calidad de la población nativa, presente y futura, comienza a tener 
un papel protagónico en las políticas sociales. Es en este sentido que la salud de las madres, en tanto su capacidad reproductiva, y la de sus hijos cobran mayor relevancia. Las mujeres son visualizadas con un lugar protagónico en la sociedad en la medida que pueden motorizar el "vigor racial" y, de este modo, construir una comunidad nacional moderna, homogénea, sana y exenta de conflictos. Esta creencia va de la mano de otro debate ideológico: el crecimiento poblacional deja de asociarse predominantemente con el aporte extranjero, en su doble función de mano de obra y agente de civilización, y el aumento del factor humano endógeno comienza a ser pensado como deseable y necesario. Estas ideas se desprenden, con variados matices, de una densa polifonía de voces que se registran en la prensa periódica, en los debates parlamentarios, en las demandas obreras y en las voces profesionales y que se plasman, muchas veces, en proyectos legislativos y en políticas concretas" (2014, p. 31).

Al respecto, López Gómez (2016) sostiene que en las últimas décadas se da un cambio "de un enfoque materno-infantil hacia otro centrado en la salud y los derechos sexuales y reproductivos" (p. 23). Es en este contexto en el que se inserta la emergencia y disputa por la política de humanización.

"La salud y los derechos sexuales y reproductivos son un campo de disputa moral, ideológica, política, religiosa, simbólica y económica y, a la vez, de creciente legitimación y reconocimiento a nivel social. El aborto, como componente de la salud sexual y reproductiva, permite analizar una constelación de asuntos vinculados a la sexualidad, la (no) reproducción, el amor y la libre disposición y control del cuerpo de las mujeres -las principales involucradas-; cuestiones que remiten, en definitiva, a los conflictos entre lo individual y lo colectivo, lo público y lo privado, la universalidad y la particularidad, lo laico y lo confesional, la subordinación y la dominación, que se expresan en la atención de los servicios de salud y en el contrato entre profesionales y mujeres usuarias" (López Gómez, 2016, p. 24).

El capítulo consta de cuatro partes: en la primera se analizan los significados e implicancias de la humanización de la atención del parto ${ }^{56}$. En la segunda, se propone una lectura crítica de tres guías ministeriales (dos nacionales y una específica de la provincia de Buenos Aires) que operativizan los lineamientos de la política de humanización a la luz de los dos ejes mencionados: garantía de derechos humanos y revisión de prácticas. En la tercera, se abordan los lineamientos particulares de las guías sobre la humanización en atención de los partos de bajo riesgo. En la cuarta parte, y a través de lo recorrido en las anteriores, se expone un análisis de su implementación a partir de entrevistas a funcionarias del área de Maternidad e Infancia del ministerio de salud de la provincia de Buenos Aires y a las jefas de los servicios de tocoginecología de tres maternidades de Hospitales públicos de la ciudad de La Plata realizadas en $2015^{57}$. El abordaje es cualitativo, basado en el análisis de documentos y entrevistas.

\footnotetext{
${ }^{56}$ Quedan excluidas de este capítulo las reflexiones sobre las regulaciones en torno al embarazo, puerperio, lactancia y cuidados del recién nacido, ejes en los que las guías analizadas intervienen.

${ }_{57}$ Estas entrevistas se realizaron en 2015 y culminaron, casualmente, el día que se reglamentó la ley de parto respetado en Argentina, en octubre de dicho año.
} 


\section{2. LA PREGUNTA POR LA HUMANIZACIÓN}

"La humanización comprende por lo menos dos aspectos fundamentales. El primero, respecto a la convicción de que es deber de las unidades de salud recibir con dignidad a la mujer, a sus familiares y al [/a la] recién nacido [/a], es decir, acogerlas y tratarlas como personas. Esto requiere actitud ética y solidaria por parte de los/as profesionales de la salud y la organización de la institución con la finalidad de crear un clima agradable y a instituir rutinas hospitalarias que rompan con el tradicional aislamiento impuesto a la mujer. El otro se refiere a la adopción de medidas y procedimientos que son beneficiosos para el acompañamiento del parto y del nacimiento, evitando prácticas intervencionistas innecesarias, que aunque tradicionalmente han sido realizadas, no benefician a la mujer ni al [/a la] recién nacido [/a], y que con frecuencia acarrean mayores riesgos para ambos. Además dignificaría a la mujer pues tendría en cuenta sus deseos y necesidades a la hora de parir que contribuiría a aumentar su grado de satisfacción" (Sánchez, 2012, p. 232).

La humanización de la atención médica se vincula a un paradigma que propugna cambios en la relación médicx-paciente y en la intervención clínica, que tiene arraigo en diversas áreas de la salud. En la atención de partos, específicamente, pone el acento en que durante el proceso de embarazo, parto y puerperio, se respeten y adquieran protagonismo los derechos de las mujeres, lo que implica cambios y adaptaciones de las prácticas médicas. En este sentido, la humanización aparece como reacción a la patologización e intervencionismo médico instalados alrededor de estos procesos, con la intención de combinar el progreso de la tecnomedicina con un trato y una relación médicopaciente particular, respetuosa, centrada en los aspectos psicoafectivos, emocionales, culturales y sociales del evento del nacimiento. De este modo, la humanización de la asistencia al parto implica una transformación tanto de la comprensión del parto como del hacer médico (Porto et al., 2015) y combina dos dimensiones centrales: la garantía de los derechos sexuales y reproductivos de las mujeres, y, por ende, de la ciudadanía y autonomía de las mujeres con el derecho a decidir sobre su propio cuerpo, y la críticatransformación de las prácticas médicas obstétricas para apuntar al cumplimiento de esos derechos.

Hablo de una "política de humanización" en tanto constituye el horizonte estatal de la atención médica de partos, y analizo solo un instrumento de dicha política al tomar tres guías que recogen parte de sus lineamientos principales. El supuesto básico del presente capítulo es que a través de estos instrumentos (las guías mencionadas y otros dispositivos de la política de humanización) el Estado legitima ciertas intervenciones médicas en los procesos de parto (o su reevaluación o la incorporación de nuevas) al tiempo que cuestiona mitos instalados en la práctica clínica y da nuevas orientaciones para el trabajo profesional. Entiendo aquí la humanización como un horizonte, vinculado a 
una política de salud que se traduce en intervenciones protocolizadas y guías de procedimientos que apuntan al cambio de la actividad asistencial, de las relaciones médicx-paciente y del acceso a derechos sexuales y reproductivos de la sociedad. En este sentido, la pregunta sociológica es sobre las relaciones de poder que se dan en la atención médica del parto y en los modos en que el Estado viabiliza, obstaculiza, propone y disputa las formas en que se dan.

\subsection{LAS GUÍAS Y LOS LINEAMIENTOS DE LA POLÍTICA DE HUMANIZACIÓN}

Los lineamientos centrales de la humanización del parto derivan de la Declaración de Fortaleza producida por la OMS en 1985, titulada "Tecnología apropiada para el parto". Retomo el resumen de Fornes (2010) sobre estas recomendaciones internacionales que apuntan a:

"Informar a la comunidad sobre los diversos procedimientos que constituyen la atención del parto, a fin de que cada mujer pueda elegir el tipo de atención que prefiera; realizar más de un 10 al $15 \%$ de los nacimientos por cesárea es injustificable en cualquier región geográfica; favorecer los partos vaginales después de cesáreas; evitar pruebas de monitoreo durante el trabajo de parto normal ya que no está probado que tenga efectos positivos en el resultado del embarazo; no colocar a las embarazadas en posición de litotomía (acostadas con las piernas en alto); animarlas a caminar durante el trabajo de parto y posibilitar que cada mujer pueda decidir libremente la posición que quiera asumir durante el parto; no realizar episiotomía (incisión para ampliar la abertura vaginal) en forma rutinaria; no inducir (iniciarse por métodos artificiales) los partos por conveniencia en un porcentaje mayor a un 10\%; evitar durante el parto la administración por rutina de fármacos analgésicos o anestésicos que no se requieran específicamente para corregir o evitar una complicación en el parto; ningún procedimiento de observación del recién nacido justifica la separación de su madre; fomentar el inicio inmediato del amamantamiento, inclusive antes de que la madre salga de la sala de partos" (p. 3-4).

En este sentido, el plan 10-10-10 es el resumen del ideal OMS sobre atención del parto: $10 \%$ de cesáreas, $10 \%$ de episiotomías y $10 \%$ de inducciones como índices máximos de trabajo. Junto a estas indicaciones sobre la práctica médica específica, que ya tienen 34 años, los Estados nacionales de algunos países han establecido complejos normativos para alcanzar dicho ideal.

La política de humanización de la atención médica de partos, encuentra en Argentina un punto de partida en la Ley 25929 de "Derechos de padres e hijos durante el proceso de nacimiento", sancionada en 2004 y reglamentada once años después. Este instrumento legal condensa y responde a años de demandas de grupos sociales y es de los primeros dispositivos a través de la cual el Estado instituye formas de concebir la 
atención obstétrica humanizada, a través de la explicitación de los derechos de las mujeres-madres durante el proceso de nacimiento ${ }^{58}$.

En el caso de las mujeres madres, la ley 25.929 establece los derechos a: la información sobre la evolución de su trabajo de parto y estado de salud y sobre las intervenciones disponibles para optar libremente por realizarlas o no (decisión informada); al trato respetuoso individual y personalizado; a ser consideradas personas sanas; al parto natural (es decir, al respeto de los tiempos biológicos y psicológicos, evitando prácticas invasivas y suministro de medicación que no estén justificados por el estado de salud de ella y su bebé); a no ser objeto de estudio sin su consentimiento; al acompañamiento por la persona que elija; y a no ser separada de su bebé, principalmente. Si bien la apuesta simbólica es por la garantía y el acceso a derechos sexuales y reproductivos, en algunos pasajes y nociones de esta ley, se reproducen y generan idealizaciones de los procesos de parto y de los modos de ser mujeres y madres. La propuesta es analizar la política de humanización a partir de lo que considero como dos de sus dimensiones centrales: el acceso a derechos sexuales y reproductivos de las mujeres y la revisión de las intervenciones médicas (a través del criterio de la medicina basada en la evidencia ${ }^{59}$ ). Algunos de los estudios (Jerez, 2015; Porto et al., 2015; Gainza et al., 2013) han privilegiado uno u otro aspecto, y aquí he decidido tomarlos como partes interrelacionadas, en tanto comprendo que el acceso a los derechos a la salud, y específicamente, a la salud sexual y reproductiva de las mujeres-madres en el PEP, exige cambios en las intervenciones médicas obstétricas. Esto es, con relación a la redefinición de las prácticas médicas, las guías valoran la utilización de prácticas demostradas científicamente como beneficiosas y alertan sobre las que se evidencian como perjudiciales. Por ejemplo, el acceso a la libre elección de la posición para parir o el derecho al acompañamiento, remiten a la modificación de prácticas e intervenciones de Ixs profesionales durante la atención del parto. De hecho, las normativas insisten en que Ixs mismxs profesionales médicxs deben dar conocimiento a las mujeres de los derechos que las asisten, en el marco del horizonte humanizador y de la revisiones y cuestionamientos a las prácticas médicas que, basada en la evidencia científica, se postulan como aconsejadas y desaconsejadas.

\footnotetext{
${ }_{58}$ La ley también establece los derechos del recién nacido sano, los derechos de los padres y madres alrededor de las posibles internaciones neonatológicas, y de los varones-padres durante el proceso de nacimiento.

59 Sobre las críticas a la Medicina Basada en la Evidencia ver Fernández Sacasas (2011); Gómez de la Cámara (2003); Gracia (2009); Ortega Calvo y Cayuela Domínguez (2002).
} 
En consonancia con esta ley, se generan una serie de lineamientos que se expresan en tres guías producidas por los ministerios de salud de nación ${ }^{60}$ y de la provincia de Buenos Aires en la última década, que aquí retomo para analizar la política general de humanización. Se trata de las guías: "Maternidad segura y centrada en la familia con enfoque intercultural: conceptualización e implementación del modelo" (en adelante, Guía 1), producido por UNICEF y ministerio de salud de la nación en 2011; la "Guía para la atención del parto normal en maternidades centradas en la familia" (en adelante, Guía 2), con autoría de la Dirección Nacional de Maternidad e Infancia del ministerio de salud de la nación de 2012; y la "Guía de procedimientos para el control del embarazo y la atención del parto y puerperio de bajo riesgo" (en adelante, Guía 3) del ministerio de salud de la provincia de Buenos Aires publicada en 2012. Este conjunto de guías, como se puede apreciar en el cuadro $N^{\circ} 7$, se concentra en distintos aspectos de la atención médica del proceso perinatal, y se orienta a promover cambios y a regularizar aspectos institucionales y de la atención médica.

CuAdRO 7: SÍNTESIS DE LAS GUÍAS SOBRE HUMANIZACIÓN DE LA ATENCIÓN MÉDICA DEL PEP — ELAB. PROPIA

\begin{tabular}{|c|c|c|c|c|c|}
\hline & \multirow{2}{*}{$\begin{array}{l}\text { Autoría } \\
\text { y año }\end{array}$} & \multirow{2}{*}{$\begin{array}{l}\text { Cambio } \\
\text { institucional }\end{array}$} & \multicolumn{3}{|c|}{ Atención médica } \\
\hline & & & Embarazo & Parto & $\begin{array}{l}\text { Puerperio } \\
\text { y neonatal }\end{array}$ \\
\hline $\begin{array}{l}\text { Guía 1:"Maternidad segura y centrada } \\
\text { en la familia con enfoque intercultural: } \\
\text { conceptualización e implementación } \\
\text { del modelo" }\end{array}$ & $\begin{array}{l}\text { Mrio de Salud } \\
\text { Nación (2011) }\end{array}$ & $\sqrt{ }$ & & $\sqrt{ }$ & $\sqrt{ }$ \\
\hline $\begin{array}{l}\text { Guía 2: "Guía para la atención del } \\
\text { parto normal en maternidades } \\
\text { centradas en la familia" }\end{array}$ & $\begin{array}{l}\text { Mrio de Salud } \\
\text { Nación (2012) }\end{array}$ & & $\sqrt{ }$ & $\sqrt{ }$ & $\sqrt{ }$ \\
\hline $\begin{array}{l}\text { Guía 3: "Guía de procedimientos para } \\
\text { el control del embarazo y la atención } \\
\text { del parto y puerperio de bajo riesgo" }\end{array}$ & $\begin{array}{l}\text { Mrio de Salud } \\
\text { Pcia Bs As. } \\
\text { (2012) }\end{array}$ & & & $\sqrt{ }$ & $\sqrt{ }$ \\
\hline
\end{tabular}

En términos generales, la guía que opera en la práctica profesional es la que establece el cambio hacia el modelo "Maternidades seguras y centradas en la familia" (MSCF, Guía 1) basado en la experiencia de las prácticas en la Maternidad Sardá desde 1980 y busca replicarla.

"Una MSCF tiene una cultura organizacional que reconoce a los padres y a la familia, junto al equipo de salud, como protagonistas de la atención de la mujer embarazada, la madre y el recién nacido y define la seguridad de la atención como una de sus prioridades; estimula el respeto y la protección de los derechos de la mujer y del bebé por parte del equipo de salud; promueve la participación y la colaboración del padre, la familia y la comunidad en la protección y el cuidado de la mujer y el recién nacido; implementa

${ }^{60}$ Durante la mayor parte de mi trabajo de tesis existió el Ministerio de Salud de la Nación hasta 2018, que fue reducido a categoría de Secretaria en el marco de la política de ajuste neoliberal macrista. 
prácticas seguras y de probada efectividad, y fortalece otras iniciativas, como la iniciativa Hospital Amigo de la Madre y del Niño, que promueve fuertemente la lactancia materna" (Guía 1, 2011, p.11).

La primera guía propone reevaluar las prácticas médicas en la atención del PEP y modificarlas teniendo como criterios la efectividad, la seguridad, la cultura del error basada en el sistema ${ }^{61}$, el cambio espacial y la medicina centrada en el paciente, todos vinculados a la política de humanización. Respecto al enfoque de derechos, esta guía retoma los derechos explicitados en la ley 25929 (aunque no la menciona), y en términos de derechos humanos alude al derecho a la vida y a recibir atención médica, pero no a los derechos sexuales y reproductivos de las personas. En distintos pasajes, las guías hacen referencia a los derechos tratándolos como necesidades, decisiones o deseos, sin tener en cuenta que sus significados difieren ampliamente. Asimismo, sostiene que el equipo de salud debe llevar adelante "comportamientos y prácticas sustentadas en los derechos de la embarazada y su bebé" (Guía 1, 2011, p. 68), mientras que en otros pasajes, se refiere a "la decisión de la embarazada sobre la posición, disposición y tiempos durante el trabajo de parto y parto" (Guía 1, 2011, p. 40).

Considero que esta serie de postulaciones idealizan la relación médicx-paciente, en tanto supone que Ixs médicxs y la estructura organizacional hospitalaria están dispuestos a negociar (y respetar) esas decisiones/necesidades/derechos, y que las familias pueden hacerlo, sin tener en cuenta variadas constricciones estructurales, como así también los desiguales recursos simbólicos, culturales o sociales que permiten negociar en el marco de relaciones de dominio/subordinación médicx-pacientes.

La segunda guía analizada, producida en 2012 también con autoría del ministerio de salud de la nación y de UNICEF, se deriva de la primera, al sentar las bases para la "atención del parto normal en las MSCF" (Guía 2). Las particularidades radican en que está destinada a los equipos de salud (obstétricas, tocoginecólogxs, neonatólogxs, médicxs generalistas, enfermerxs, etc.) y que se apoya en la medicina basada en la evidencia para argumentar y sostener la revisión de las prácticas profesionales.

Un elemento destacable de esta segunda guía es que su punto de partida es un diagnóstico de situación sobre el proceso histórico de medicalización del parto y de su construcción como acto médico, en un acto de reflexividad sumamente interesante; al

\footnotetext{
${ }^{61}$ Se vincula el error a una cuestión del sistema y no a cuestiones de mala praxis o de errores humanos del personal de salud, en un movimiento en el que "se sustituye una concepción moral punitiva por una concepción de perfeccionamiento humano en que el error no es castigado” (Guía 1, p. 46). Considero que si bien esto tiene aspectos positivos, en tanto implica pensar estructuralmente los errores, también responde a una medicina corporativa defensiva.
} 
tiempo que refiere a varias acciones político-estatales internacionales que buscaron humanizar la atención, con lo cual permite instalar este entramado en un marco mayor. Da cuenta de los procesos de institucionalización y patologización del parto y la entrada de mujeres y recién nacidxs sanxs a la lógica hospitalaria:

"Pasaron a hacer largas colas, internarse para el parto separados de su familia, en ambientes intimidantes, con horarios restringidos de visitas, con recién nacidos colocados detrás de vidrios aislantes y a recibir, en general, un trato despersonalizado, desvalorizante y poco afectuoso con consecuencias iatrogénicas como la lesión del vínculo madre-hijo [/a]y la introducción de otros líquidos y sucedáneos en la alimentación del recién nacido sano, con graves consecuencias para la lactancia materna (...) El parto se transformó en un acto médico cuyos significados científicos dejaron de lado los otros aspectos. Dejó de ser privado y femenino para ser vivido de manera pública, con presencia de otros [/as] actores [/as] sociales" (Guía 2, 2012, p. 15).

Aunque la mayoría de los estudios sobre el tema comparten esta visión sobre la institucionalización y medicalización del parto, considero que aquí puede pensarse que se utiliza el argumento con fines de construir un estereotipo negativo que permite legitimar la nueva política de humanización con los cambios que implica. Esto es visible en el hecho de que se reproduce una visión idílica de un pasado en el que el parto era "privado y femenino", desconociendo que en realidad en el pasado los partos eran tal vez aún más públicos que ahora por tratarse de hechos de la comunidad, de los que participaban mujeres, actorxs comunitarixs y matronas, entre otrxs.

Esta guía da cuenta, a su vez, de cómo el eje de las decisiones pasó a ser el equipo de salud y cómo se extendió el uso de tecnologías y procedimientos destinados a los PEP de alto riesgo a todos los casos (incluidos los de bajo riesgo), rutinizando las prácticas médicas en la atención del parto. 'Se consideró conveniente 'gobernar o dirigir' el parto, aún los normales, extendiendo prácticas hoy desaconsejadas, pero que en algunas instituciones se siguen realizando" (Guía 2, 2012, p. 15).

Finalmente, la tercera guía, producida desde la cartera de salud de la provincia de Buenos Aires, analiza los tres subperíodos de este proceso general: embarazo (y controles prenatales), parto y puerperio de bajo riesgo. Sus postulaciones se insertan en la búsqueda del "cuidado integral de la mujer" y en un enfoque de derechos, centrado principalmente en los derechos de salud.

"La intervención planteada desde los procedimientos aquí descriptos se apoya en un enfoque de derechos. Esta perspectiva aplicada a la atención de la salud, concibe a la misma como una responsabilidad de los gobiernos, de carácter obligatorio en lo moral y lo legal, para cubrir las demandas de la población y garantizar un buen estado de salud integral a largo plazo. El enfoque de derechos no sólo hace hincapié en la responsabilidad de las autoridades, sino en la concepción de sujeto como persona empoderada que ha tomado conciencia de los derechos y puede exigir su cumplimiento y 
garantía. Por otra parte, una perspectiva de derechos contribuye también a una atención más completa y equitativa, ya que los derechos, en tanto normas universales, estandarizan y benefician a todos los sujetos por igual" (Guía 3, 2012, p. 13).

En líneas generales, se puede afirmar que la letra de estas guías que referencian la política de humanización de la atención médica de PEP, expresa visiones progresistas que tensionan la realidad en la que se los atienden hoy. Sin embargo, proponen un horizonte que no ve constricciones estructurales del sistema sanitario y hospitalario y de la profesión médico-obstétrica general, y desatiende disputas, (des)acuerdos, condiciones y posibilidades de Ixs sujetxs, colectivos e instituciones implicados; al tiempo que se presenta como una alternativa de cambio, reevaluación y redefinición de prácticas médicas con el fin de garantizar derechos.

\subsection{A. LOS LINEAMIENTOS ESPECÍFICOS PARA LA ATENCIÓN DE PARTOS DE BAJO RIESGO}

La propuesta es considerar que hay tres cuestiones principales para tener en cuenta en el análisis de los lineamientos de la política de humanización para la atención de los partos de bajo riesgo. Primero, el enfoque de riesgo reproductivo utilizado para ponderar los partos ya mencionado; segundo, la cuestión de las prácticas médicas aconsejadas y desaconsejadas para la intervención en estos casos; y, tercero, el foco en los derechos sexuales y reproductivos de las mujeres que buscan garantizarse en este período del proceso perinatal.

"Según la OMS, el parto normal es aquel de comienzo espontáneo, de bajo riesgo desde el comienzo del trabajo de parto, hasta la finalización del nacimiento. El [/la] niño [/a] nace en forma espontánea, en presentación cefálica, entre las 37 y 41 semanas completas de edad gestacional. Luego, tanto la madre como el [/la] niño [/a] están en buenas condiciones" (Guía 2, 2012, p. 23).

Sobre el enfoque de riesgo, sólo mencionaré algunas reflexiones que emergen en el análisis y que considero prudente retomar y profundizar. Es significativo que la definición del bajo riesgo es posterior al evento, por lo que se actuará con presunción de riesgo y las decisiones clínicas se tomarán en conformidad con dicha presunción: todo parto es riesgoso hasta que se demuestre lo contrario. Esta forma de proceder se tensiona con la idea humanizadora que estipula que "en el parto normal deben existir razones muy válidas para interferir con el proceso natural (OMS, 1996)" (Guía 2, 2012, p. 23). Considero que la cuestión de la construcción del riesgo, de las etiquetas de riesgo reproductivo y de las ideas de normalidad/desviación constituye uno de los núcleos más problemáticos en la política de humanización. En efecto, mientras que por un lado se 
discuten las intervenciones innecesarias en el marco de una concepción fisiológica del parto ${ }^{62}$; por el otro se propugna la evaluación y control constante del proceso de nacimiento. Este nodo conflictivo aún requiere de trabajos de articulación y reflexión para no descartar ni reificar la cuestión del riesgo reproductivo.

En torno a esas intervenciones médicas que se revisan, las guías establecen cuáles se aconsejan, según la evidencia clínica y científica disponible, y cuáles no, según su rutinización y sus consecuencias iatrogénicas (ver cuadro 8).

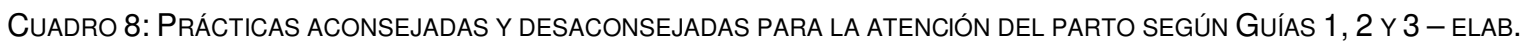
PROPIA

\begin{tabular}{|c|c|c|}
\hline Período del parto ${ }^{63}$ & Prácticas Aconsejadas & Prácticas Desaconsejadas \\
\hline DILATANTE & $\begin{array}{l}\text { - Manejo activo del trabajo de parto } \\
\text { - Acompañamiento y apoyo psicofísico } \\
\text { - Ingesta de líquidos y alimentos } \\
\text { - Analgesia no farmacológica } \\
\text { - Monitoreo fetal intermitente } \\
\text { - Libre de ambulación } \\
\text { - Elección de posición } \\
\text { - Partograma }\end{array}$ & $\begin{array}{l}\text { - Venoclisis (vía) } \\
\text { - Enema } \\
\text { - Rasurado púbico } \\
\text { - Medicación e inducción con oxitocina } \\
\text { - Monitoreo fetal continuo } \\
\text { - Tactos frecuentes } \\
\text { - Amniotomia (rotura artificial de } \\
\text { membranas) }\end{array}$ \\
\hline EXPULSIVO & $\begin{array}{l}\text { - Acompañamiento y apoyo psicofísico } \\
\text { - Ambientación de sala de parto: cálida y } \\
\text { aséptica } \\
\text { - Elección de posición } \\
\text { - Pujo espontáneo } \\
\text { - Criterio conservador, expectante y } \\
\text { fisiológico } \\
\text { - Recurrencia a saberes de curso preparto } \\
\text { - Clampeo tardío del cordón } \\
\text { - Contacto piel a piel (COPAP) y no } \\
\text { separación de madre-recién nacidx }\end{array}$ & $\begin{array}{l}\text { - Episiotomía de rutina } \\
\text { - Pujo dirigido } \\
\text { - Cateterización vertical } \\
\text { - Maniobra de kristeller } \\
\text { - Más de una hora de expulsivo. } \\
\text { - Rutinización de cesáreas }\end{array}$ \\
\hline ALUMBRAMIENTO & $\begin{array}{l}\text { - Manejo activo del alumbramiento } \\
\text { (administración de oxitocina para } \\
\text { acelerar la expulsión de la placenta). } \\
\text { - Examen de membranas y placenta } \\
\text { - Procedimientos de rutina al RN }\end{array}$ & $\begin{array}{l}\text { - Manejo fisiológico del alumbramiento } \\
\text { (respeto del tiempo fisiológico de } \\
\text { expulsión de la placenta). }\end{array}$ \\
\hline
\end{tabular}

Cabe resaltar que el horizonte humanizador de estas guías, que buscan promover la desmedicalización y evitar intervenciones médicas innecesarias durante el proceso de nacimiento, se anula durante el período de alumbramiento. Es decir, ya que la hemorragia postparto es la primera causa de muerte materna, se propugna una intervención total a través del "manejo activo" de la expulsión de la placenta (aplicando oxitocina sintética),

62 "En el 90\% de los casos el parto es un proceso fisiológico, espontáneo y saludable. La mujer y el bebé poseen la sabiduría inherente necesaria para el parto” (Guía 3, 2012, p. 90, cursivas propias).

${ }^{63} \mathrm{El}$ parto supone tres sub-periodos: el de dilatación (conocido como trabajo de parto), el expulsivo (el momento propio del parto/nacimiento) y el de alumbramiento (en el que se expulsa la placenta y concluye el parto). 
erigiéndose como una de las prácticas aconsejadas, por sus justificaciones médicas y epidemiológicas explícitas.

La modificación de prácticas consideradas ya sea perjudiciales o beneficiosas, en base a evidencia científica, se relaciona con el acceso a los derechos a la salud, sexuales y reproductivos de las mujeres, y la vinculación de ambos ejes es el pilar sobre el que se asienta la política de humanización. Entonces, retomando el eje del enfoque de derechos, en las guías se establece cómo la atención médica puede ligarse con el respeto de los derechos de la mujer, el/la bebé y su familia, en una clara búsqueda de humanización:

“l) Asegurar que el parto se realice en instituciones, de manera segura y bajo las pautas de MSCF, evitando el uso rutinario de fármacos innecesarios y de prácticas y procedimientos sin un fundamento científico. II) Permitir el acceso de la persona que la parturienta elija para que le brinde apoyo físico y emocional durante el trabajo de parto y parto. III) Respetar el derecho de la mujer a elegir la posición que le resulte más placentera para parir. IV) Respetar la privacidad, confidencialidad y dignidad de la parturienta. V) Lograr que el progreso del parto y la condición materno-fetal se mantengan dentro de límites fisiológicos. VI) Fomentar la internación conjunta a fin de fortalecer el vínculo madre-hijo [/a]" (Guía 3, 2012, p. 84).

Por otro lado, se sostiene que el contexto institucional y la relación médicxpaciente intervienen favorable o desfavorablemente sobre el proceso de parto, razón por la cual es posible generar preguntas de investigación referidas a este marco.

"La confianza de la mujer [y] su capacidad para dar a luz (...) se ven aumentadas (maternidades amigables) o disminuidas (maternidades expulsoras) por todo el personal que le proporcione o no cuidados, así como por el entorno en donde se produce el parto y el nacimiento" (Guía 3, 2012, p. 84).

Esta premisa es fundamental para entender la justificación de la necesidad de humanizar la atención, de proporcionar cierta división interna de trabajo, en la que las obstétricas se encarguen de la atención integral del parto normal, y que Ixs médicxs se encarguen de la patología obstétrica.

A continuación, analizaré cómo se materializan estas recomendaciones que establecen las guías, y qué elementos favorecen u obstaculizan la implementación de dicha política en el contexto local, para el caso de las instituciones públicas de la ciudad ${ }^{64}$.

${ }^{64} \mathrm{El}$ acceso a datos estadísticos sobre las instituciones de salud privado fue difícultoso y se privilegió analizar el ámbito público para poder analizar las obligaciones estatales en salud materno-fetal. Respecto al alcance de la política de humanización en la atención privada, existe disonancia en las experiencias conocidas, pero el universo legal es el marco desde el que las mujeres y las asociaciones de activistas accionan para reclamar que se garanticen los derechos en estos ámbitos donde prima la libertad de empresa. 


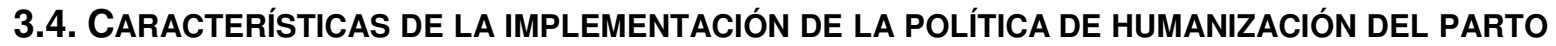 EN LA PLATA}

La información estadística a la que tuve acceso ${ }^{65}$ consigna la cantidad de nacimientos, distinguidos entre parto y cesárea de las cuatro maternidades públicas de la ciudad, correspondientes al período que va desde 2013 a 2017 (cuadros 9 al 13) .

CUADRO 9: TOTAL DE PARTOS Y CESÁREAS EN MATERNIDADES PÚBLICAS DEL PARTIDO DE LA PLATA - 2013.

\begin{tabular}{|l|l|l|l|l|}
\hline & Partos & Cesáreas & Índice cesáreas & Total nacimientos \\
\hline Htal. Zonal Gral. De Ag. San Roque & 2055 & 515 & $20 \%$ & 2570 \\
\hline Htal. Interz. Gral. De Ag. Y Cron. Dr. A. Korn & 1696 & 384 & $18,4 \%$ & 2080 \\
\hline Htal. Zonal Gral. De Ag. Dr. R. Gutierrez & 1258 & 313 & $19,9 \%$ & 1571 \\
\hline Htal. Interz. Gral. De Ag. Gral San Martin & 3253 & 1100 & $25,2 \%$ & 4353 \\
\hline La Plata & $\mathbf{8 2 6 2}$ & $\mathbf{2 3 1 2}$ & $\mathbf{2 1 , 8 \%}$ & $\mathbf{1 0 5 7 4}$ \\
\hline \multicolumn{5}{|c|}{ Elaboración propia en base a datos SIP, PBA, 2013 } \\
\hline
\end{tabular}

CUADRO 10: TOTAL DE PARTOS Y CESÁREAS EN MATERNIDADES PÚBLICAS DEL PARTIDO DE LA PLATA - 2014

\begin{tabular}{|l|l|l|l|l|}
\hline & Partos & Cesáreas & Indice cesáreas & Total nacimientos \\
\hline Htal. Zonal Gral. De Ag. San Roque & 1229 & 369 & $23,5 \%$ & 1598 \\
\hline Htal. Interz. Gral. De Ag. Y Cron. Dr. A. Korn & 1447 & 384 & $20,9 \%$ & 1831 \\
\hline Htal. Zonal Gral. De Ag. Dr. R. Gutierrez & 728 & 222 & $23,3 \%$ & 950 \\
\hline Htal. Interz. Gral. De Ag. Gral San Martin & 2224 & 1182 & $34,7 \%$ & 3406 \\
\hline La Plata & $\mathbf{5 6 2 8}$ & $\mathbf{2 1 5 7}$ & $\mathbf{2 7 , 7 \%}$ & $\mathbf{7 7 8 5}$ \\
\hline \multicolumn{5}{|c|}{ Elaboración propia en base a datos SIP, PBA, 2014 } \\
\hline
\end{tabular}

CUADRO 11: TOTAL DE PARTOS Y CESÁREAS EN MATERNIDADES PÚBLICAS DEL PARTIDO DE LA PLATA - 2015

\begin{tabular}{|l|l|l|l|l|}
\hline & Partos & Cesáreas & Indice cesáreas & Total nacimientos \\
\hline Htal. Zonal Gral. De Ag. San Roque & 1610 & 449 & $27,9 \%$ & 2059 \\
\hline Htal. Interz. Gral. De Ag. Y Cron. Dr. A. Korn & 1667 & 319 & $19,1 \%$ & 1986 \\
\hline Htal. Zonal Gral. De Ag. Dr. R. Gutierrez & 1230 & 297 & $24,1 \%$ & 1527 \\
\hline Htal. Interz. Gral. De Ag. Gral San Martin & 3395 & 1231 & $36,3 \%$ & 4626 \\
\hline La Plata & $\mathbf{7 9 0 2}$ & $\mathbf{2 2 9 6}$ & $\mathbf{2 9 , 1 \%}$ & $\mathbf{1 0 1 9 8}$ \\
\hline \multicolumn{5}{|c|}{ Elaboración propia en base a datos SIP, PBA, 2015 } \\
\hline
\end{tabular}

CUADRO 12: TOTAL DE PARTOS Y CESÁREAS EN MATERNIDADES PÚBLICAS DEL PARTIDO DE LA PLATA - 2016

\begin{tabular}{|l|l|l|l|l|}
\hline & Partos & Cesáreas & Indice cesáreas & Total nacimientos \\
\hline Htal. Zonal Gral. De Ag. San Roque & 1559 & 504 & $32,3 \%$ & 2063 \\
\hline Htal. Interz. Gral. De Ag. Y Cron. Dr. A. Korn & 1704 & 464 & $27,2 \%$ & 2168 \\
\hline Htal. Zonal Gral. De Ag. Dr. R. Gutierrez & 1652 & 417 & $25,2 \%$ & 2069 \\
\hline Htal. Interz. Gral. De Ag. Gral San Martin & 2349 & 937 & $39,9 \%$ & 3286 \\
\hline La Plata & $\mathbf{7 2 6 4}$ & $\mathbf{2 3 2 2}$ & $\mathbf{3 2 \%}$ & $\mathbf{9 5 8 6}$ \\
\hline \multicolumn{5}{|c|}{ Elaboración propia en base a datos SIP, PBA, 2016 } \\
\hline
\end{tabular}

${ }^{65}$ Con el cambio de gobierno de 2015, ocurrieron dos hechos en relación a la disponibilidad de estadísticas perinatalaes para el caso de estudio. Por un lado, se publicaron en la página web (hasta 2017) los datos producidos por el Sistema Informático Perinatal (SIP) en relación a partos y cesáreas, y por otro, se perdieron o no me facilitaron el acceso a datos que en 2013 existían sobre índice de acompañamientos, inducciones, episiotomías y hasta deseo del embarazo consignados por región sanitaria y hospital. 
CUADRO 13: TOTAL DE PARTOS Y CESÁREAS EN MATERNIDADES PÚBLICAS DEL PARTIDO DE LA PLATA - 2017

\begin{tabular}{|l|l|l|l|l|}
\hline & Partos & Cesáreas & Indice cesáreas & Total nacimientos \\
\hline Htal. Zonal Gral. De Ag. San Roque & 1507 & 503 & $33,4 \%$ & 2010 \\
\hline Htal. Interz. Gral. De Ag. Y Cron. Dr. A. Korn & 1360 & 252 & $18,5 \%$ & 1612 \\
\hline Htal. Zonal Gral. De Ag. Dr. R. Gutierrez & 1683 & 436 & $25,9 \%$ & 2119 \\
\hline Htal. Interz. Gral. De Ag. Gral San Martin & 2404 & 1078 & $44,8 \%$ & 3482 \\
\hline La Plata & $\mathbf{6 9 5 4}$ & $\mathbf{2 2 6 9}$ & $\mathbf{3 2 , 6 \%}$ & $\mathbf{9 2 2 3}$ \\
\hline \multicolumn{5}{|c|}{ Elaboración propia en base a datos SIP, PBA, 2017 } \\
\hline
\end{tabular}

Aunque el listado de cuadros puede entorpecer la lectura, estos datos permiten ver cómo el índice de cesáreas ha ido aumentando progresivamente en el promedio de la atención pública de la ciudad: de 21, 6\% en 2013 a 32, 6\% en 2017. Justo en el medio de estos cinco años que cubren los cuadros, se dieron dos hechos relevantes para la investigación: las entrevistas de evaluación de la implementación que presento en este apartado, y en simultáneo la reglamentación de la ley de parto respetado de 2015, que busca justamente reducir esos índices de cesárea por ejemplo, para acercarlos al ideal OMS de 10-15\%. De algún modo es posible advertir que, con los datos duros, se confirma que la reglamentación de la ley generó un retroceso en los índices o, por lo menos, no produjo el impacto deseado. En vistas de comprender la profundidad de esta realidad, presento a continuación la indagación cualitativa que realicé en 2015.

Para analizar la implementación de la política de humanización de la atención de partos y los lineamientos propuestos en las guías reseñadas, en hospitales públicos del partido, realicé, durante octubre de 2015, entrevistas a funcionarias de la Dirección de Maternidad e Infancia (DMI) del Ministerio de Salud de la provincia de Buenos Aires y a las jefas de los servicios de tocoginecología de tres de las cuatro maternidades públicas ${ }^{66}$. Considero que su doble condición, como profesionales de la salud con cargos jerárquicos (en unos casos en el gobierno y en otros en la estructura hospitalaria), le asigna sentidos particulares a la perspectiva desde la que analizan dicha implementación.

Se organizó la información obtenida de las entrevistas reconstruyendo inicialmente algunas reflexiones generales realizadas por las funcionarias ministeriales, para luego desarrollar el análisis de la implementación de la política de humanización desde la perspectiva de las profesionales de la salud de las maternidades en torno a los tópicos siguientes: los significados que construyen sobre la humanización, las modificaciones de

\footnotetext{
${ }^{66}$ Se trata de una maternidad de bajo riesgo que recuenta menos de 1500 partos anuales, y dos maternidades de alto y bajo riesgo, de las cuales una, por asistir aproximadamente el doble de nacimientos anuales, es considerada una "megamaternidad".
} 
las prácticas (en relación a los derechos consagrados) y las condiciones estructurales que influyen en la implementación.

En términos de la propuesta ministerial, la política de humanización de la atención médica del parto tiene como horizonte lograr partos "con calidad y calidez".

"Lo que ahora tenemos que lograr es el mejor parto para cada mujer, y entonces sí: la posición que ella quiera, estar acompañada, un cambio de paradigma del momento del parto y que esté acompañada, que pueda moverse y eso también estamos, las obstétricas, con el banquito, están como abriendo el juego y capacitando también a los equipos (...) Para nosotros el camino es mejorar los partos, bajar las cesáreas, no al parto domiciliario y seguir avanzando en trabajar, en buscar alternativas, en fomentar el trabajo con las obstétricas, en mejorar el rol de la enfermería, en poner a los médicos más en la patología, que somos formados más para la patología, y que haya otros que puedan acompañar mejor los partos, que por ahí están más formados para acompañar los partos normales" (Entrevista funcionaria de la DMI).

Dicha informante sugiere que hay que considerar tres niveles para esta implementación: en primer lugar, un nivel macro, referido a "la política", haciendo mención al modelo MSCF, que incluye acuerdos internos del Ministerio (con el propio Ministro, con la Dirección de Hospitales), con organismos internacionales (UNICEF, OMS, OPS), con otras provincias y otros tipos de acuerdos político-institucionales. Por otro lado, un nivel meso, referido a las articulaciones con las direcciones de cada hospital provincial y con Ixs jefxs de Servicios de Tocoginecología de cada uno de ellos. Finalmente, un nivel micro referido al trabajo con los equipos de salud (obstétricas, médicxs, enfermerxs) y las comunidades. Sobre los tres niveles, la funcionaria sostuvo que se había trabajado fuertemente en el primero y que se estaban dedicando a generar cambios en el ámbito hospitalario, buscando articular con Ixs directorxs de hospitales y Ixs jefxs de servicio, y que era ahí donde se encontraban grandes resistencias y dificultades.

Sobre esto último, las dos funcionarias de la DMI entrevistadas reflexionaron sobre las dificultades para el cambio institucional e individual en medicina, señalando el "miedo al cambio" de profesionales "aferrados a sus prácticas", que ahora resultaban desacreditadas (por las guías y la evidencia científica en la que se basaban) lo que produce desarticulaciones y resistencias corporativas ${ }^{67}$. Ambas coinciden en representar a los planteles obstétricos de los hospitales como comandados por profesionales viejxs, "anquilosados", y en posicionar a las obstétricas/parteras como las promotoras reales de los cambios. Asimismo, las funcionarias describen la situación de Ixs médicxs como amenazadxs, solxs, con miedo a los juicios de mala praxis y a las exposiciones públicas. Una de las funcionarias entiende que la atención médica de los partos se asienta en un

\footnotetext{
67 "Le estamos yendo a decir a los médicos que trabajaron mal 30 años" (Entrevista 1, funcionaria DMI.
} 
"mecanismo de desconexión" entre el/la profesional y el evento del nacimiento y los "paquetes emocionales" de Ixs pacientes en él. Desconexión, rutinización de prácticas y desconocimiento de las necesidades de las mujeres que van a parir, irían de la mano. Tal caracterización de Ixs profesionales reduce a una actitud o decisión individual y volitiva, cuestiones que también se vinculan a constricciones estructurales, condiciones de trabajo, culturas hospitalarias y otros aspectos que analizaré más adelante.

En paralelo, las entrevistadas reflexionaron sobre dos dimensiones centrales para enfrentar el cambio e implementar la política de humanización de la atención médica de partos en hospitales provinciales. En primer lugar, se refirieron a la dimensión emocional que se viene mencionando, sosteniendo que al igual que las mujeres que van a parir, Ixs médicxs necesitan un fuerte y continuo acompañamiento durante la transición y el aprendizaje del nuevo paradigma de humanización. Mi propuesta es considerar que es necesario pensar ésto en términos de la socialización profesional médica, de esquemas aprehendidos, en torno a los habitus médicos (Castro, 2009) y no en términos puramente emocionales, que se vuelven reduccionistas. En segundo lugar, las entrevistadas pusieron énfasis en el problema de la falta de autoridad ("que no es lo mismo que autoritarismo"), como una inquietud relevante, reflexionando sobre los diversos niveles de ejercicio de la autoridad, esto es: autoridad profesional del/ de la médicx sobre el/la paciente, autoridad política del ministerio sobre Ixs efectorxs de salud. Habría que, según esta visión, acompañarlxs en el proceso de transición hacia el modelo de atención humanizada y pensar la cuestión de la pérdida de autoridad que este modelo implica. Si cambian los protagonismos de la escena del parto, cambian los roles, las relaciones de poder, los privilegios, entre otras cuestiones.

Habiendo planteado las principales cuestiones referidas por las funcionarias ministeriales sobre la humanización del parto, me detendré en conocer cómo se lleva a cabo en la práctica, considerando las referencias brindadas por las jefas del servicio de tocoginecología de las maternidades. Sus reflexiones se organizan alrededor de los significados de la humanización, las modificaciones de las prácticas, las condiciones estructurales que influyen en la implementación, y aspectos relevantes en la atención médica de partos.

\subsection{A. SIGNIFICADOS DE LA HUMANIZACIÓN}

En primer lugar, indagué qué sentidos asignan las jefas del Servicio de Tocoginecología a la humanización de la atención médica de partos. En líneas generales 
las respuestas giraron alrededor de tres cuestiones: la idea de que las nuevas prácticas y derechos explicitados no son nuevas, y la posición crítica al sentirse consideradxs como médicxs "inhumanxs"; las perspectivas y acciones respecto a las prácticas aconsejadas y desaconsejadas; y a la división del trabajo profesional entre parteras y médicxs ${ }^{68}$.

En primer lugar, entonces, hablar de humanización interpela a las jefas del servicio (quienes entienden como pares idénticos el parto humanizado y el modelo MSCF) que responden con una actitud cuestionadora y defensiva: pensar que hay que humanizar algo que está deshumanizado les resulta "ofensivo". De todos modos, en el desarrollo de su argumentación, vinculan la humanización con aspectos tales como la formación del equipo de salud, las condiciones de trabajo, el financiamiento y la infraestructura.

"Primero que filosóficamente no creemos que esté deshumanizado. A ver, es un concepto ideológico. O sea, la humanización del parto como si ya fuera deshumanizado, como si fuera con un látigo, como si fuera en un chiquero, como si fuera con una mujer atada con grilletes a la camilla y no es así. No lo vemos así nosotros. Entendemos que sí, que la participación de la familia está bueno, que se le permita caminar y que no se la ate a una vía de suero, está todo perfecto. Pero para eso hay que dar otras condiciones. Como dijo acá muy bien el doctor [que está presente en la entrevista] los cambios se hacen cuando se construyen desde los cimientos. Y nosotros tenemos que cambiar la formación, tenemos que cambiar un montón de cosas pero el ministerio tiene que cambiar también la infraestructura y adecuar los lugares para que eso se pueda hacer. Cambiando el techo no se logra todo, se cambia el techo" (Entrevista 3, jefa de servicio de tocoginecología).

En este verbatim es posible advertir un corrimiento de la responsabilidad profesional hacia la infraestructura y otros factores que entiende como condicionantes. Este desplazamiento del eje de discusión permite alejarse de revisar o cuestionar las propias prácticas, poniendo como paso previo otras modificaciones que no le competen.

"Mirá el tema de la humanización del parto, yo no sé cómo será en otros hospitales, yo te cuento mi historia. Yo me formé hace treinta y pico de años en el hospital [anonimizado], de todas maneras capaz que antes se utilizaba más el intervencionismo médico, porque era más de poner suero, en general, pero siempre con una indicación. O sea, si la paciente tenía dinámica espontánea, uno le respetaba esa dinámica. Nunca fue tan estricto y nunca fuimos inhumanos, por eso esto de la humanización me suena muy como que fuéramos inhumanos (...) eso de humanización yo no lo entiendo o el término está mal usado, capaz, yo lo pondría más como volver un poco más a la fisiología" (Entrevista 5, jefa de servicio de tocoginecología).

\footnotetext{
68“En el contexto de la humanización del parto, la praxis obstétrica llevada a cabo por los/as profesionales generalmente está condicionada por las representaciones simbólicas que éstos/as poseen respecto a los conceptos de parto normal, natural y humanizado. Estas representaciones se construyen a partir de las creencias, valores, actitudes, habilidades, hábitos, prácticas que se tiene sobre un aspecto determinado. Por otro lado, el proceso de socialización laboral durante la formación del equipo de salud va a determinar los valores, las normas y los conocimientos que éste adquirirá a lo largo de su formación profesional (Hughes, 1958: 57; Walker et al, 2009: 469)” (Arnau Sánchez y otros, 2012, p. 228).
} 
En segundo lugar, y con relación a las prácticas aconsejadas y desaconsejadas, sostienen que esas son las normas que utilizan comúnmente, y que se garantizan.

"El parto humanizado de no poner oxitocina, de no romper la bolsa, sí, nosotros somos conscientes de esa propuesta. Ahora bien, cuando vos tenés siete u ocho trabajos de parto a la vez, y cuatro personas o tres personas para atender todo lo que te dije, ¿podés tomarte el tiempo de darle a ese trabajo de parto ocho, nueve, diez horas, las que requiera y no colaborar en que algunas etapas se organicen y se aceleren para que vos puedas terminar con este parto y seguir dedicándote al otro? Porque está muy bueno lo de que no se rompa la bolsa, que no se use oxitocina, está perfecta la teoría, están mostrados los beneficios. Eso es cuando una paciente en trabajo de parto está acompañada por un profesional, que le vigila los latidos, que la contiene, que la ayuda, que la vigila y que va evaluándolo. Si vos tenés una persona para atender a cuatro, esa persona a la fuerza se tuvo que organizar para vigilar intensamente un trabajo de parto, terminarlo y agarrar otro, terminarlo y así" (Entrevista 3, jefa de Servicio de Tocoginecología).

Se trata de la falta de personal como justificación a la atención intervencionista, el aceleramiento de los tiempos y control permanente e individual que no siempre es necesario y continúa reproduciendo la centralidad de Ixs profesionales, siendo Ixs médicxs Ixs garantes exclusivxs del éxito del parto. En la construcción de los relatos, además, los casos mencionados no necesariamente son las situaciones típicas, sino que son casos que permiten justificar el status quo. De hecho en el siguiente verbatim, una de las jefas de servicio da ejemplos que rememoran a la tortura, con ejemplos extremos que, lógicamente, se construyen desde un discurso médico autoevidente y autojustificatorio.

"Me da la impresión que esta cosa de la humanización tiene que ver, capaz, con no ponerle suero a todas las pacientes, que acá nunca ocurre. Porque realmente acá si la paciente es una paciente que dilata espontáneamente, se la deja que dilate. Se corrige como son todas las normas, incluso las de la MSCF, si vos la lees y dice que la paciente tiene una hipodinamia, hay que corregirla. No es que el cien por cien tiene que tener por abajo aunque tarde tres días, porque hay cosas que vos sí o sí tenés que corregir, no podés dejar a una mujer que esté en trabajo de parto con contracciones tres días porque se le termina rompiendo el útero si realmente tiene dinámica de trabajo de parto. Nosotros respetamos eso" (Entrevista 5, jefa de servicio de tocoginecología).

Por último los sentidos asignados a la humanización se vinculan al trato y a la relación médicx-paciente, y al rol particular de la partera como la punta de lanza del cambio hacia la humanización.

"Acá tenemos por suerte muchas obstétricas y las obstétricas tienen un manejo con el paciente diferente al médico. Nosotros estamos como mucho más estructurados, estamos con la medicina metida y con los pro, los contra, las enfermedades, las patologías, cómo se resuelven, qué se hace, qué no se hace, somos mucho más pragmáticos" (Entrevista 4, jefa de Servicio de Tocoginecología).

La fisiología del parto y el nacimiento, aparece como un significante clave, vinculado a la naturalidad de dichos eventos, opuesto al intervencionismo. En este 
sentido, la humanización como vuelta a la fisiología se vincula a esta idea de respetar la dinámica del trabajo de parto y del parto (los tiempos biológicos que menciona la ley 25929) y no intervenir médicamente más que para corregir posibles desviaciones o patologías. Asimismo, es relevante la crítica a la política de humanización como vanguardia. En esta dirección, dado que hay una clara referencia a las prácticas aconsejadas y desaconsejadas, analizamos cómo se dan algunas de ellas, en vinculación a los derechos que implican para las mujeres y sus familias.

Los fragmentos coinciden con lo afirmado por Arnau Sánchez y otros (2012) en el sentido de que:

"El equipo médico posee una confusión manifiesta sobre el concepto de humanización, en tanto que para algunos el intervencionismo deshumaniza el proceso mientras que para otros la intervención es compatible con la humanización. Esta divergencia en las posturas sobre el entendimiento del término puede ser debido a que reciben una formación tecnocrática basada en una ideología técnico-científica y centrada en la fragmentación del individuo, aspecto que les conducen a tener dificultades en la visualización holística de la mujer en la atención asistencial de la secuencia reproductiva" (p. 244).

\subsection{B. PRÁCTICAS MÉdICAS Y DERECHOS DE MUJERES.}

$>$ ACOMPAÑAMIENTO.

El acompañamiento de la persona que elija la mujer durante el proceso de parto, es uno de los indicadores de la implementación real de la política de humanización. Es importante el hecho de que en las maternidades públicas de la ciudad de La Plata este derecho está garantizado parcialmente en el caso de los varones: en el parto sí, en la internación no. En general, el acompañamiento se encuentra feminizado, reproduciendo el lugar de las mujeres de la familia o allegadas de la embarazada como encargadas del cuidado, legitimando roles y estereotipos de género. Entonces la feminización de los cuidados se reproduce en la internación, con la excusa de que como las parturientas comparten habitación con otras mujeres, no debería haber varones.

"Siempre mujeres eh, yo trato que las acompañantes sean femeninas por una cuestión de delicadeza, de intimidad, las mujeres están con camisón, hay muchas que están con las piernas abiertas, dan de amamantar y no me gusta que haya varones porque hay de todo, tenes buenas personas y otras no (...) también permitimos que estén hermanas o madres o lo que fueren durante todo el trabajo de parto, que acompañen el puerperio (...) Siempre están acompañadas, en general por familiares. Así que bueno, eso se revirtió y eso también genera mejores respuestas también en los trabajos de parto y un montón de cosas" (Entrevista 4, jefa de servicio de tocoginecología).

En este caso, uno de los derechos (a la intimidad) se privilegia por encima del derecho al acompañamiento, sólo por razones institucionales. Contrariando un concepto de las guías, algunas maternidades restringen el acceso de los varones/padres debido a 
la falta de recursos que aseguran adecuadas condiciones de higiene en la sala de parto, por ejemplo, apelando a la falta de recursos hospitalarios:

"Entonces yo no quiero que entren varones excepto si van al parto y tenemos la ropa adecuada para que entren, fantástico, generalmente no la tenemos (...) Las parteras siempre les dicen [a los varones-padres] que si pueden se compren el camisolín, el barbijo, el gorro y las botas que son descartables para poder ingresar, porque muchas veces ni nosotros tenemos" (Entrevista 4, jefa de servicio de tocoginecología).

La carencia de recursos es real y generalizada en los hospitales provinciales de la ciudad, pero en estos casos, en los que los partos no son quirúrgicos y por tanto no se requieren estas prendas especiales, puede estar actuando a modo de excusa para impedir el acompañamiento real, o al menos, como dispositivo desalentador para su participación. En tal sentido, también se suma como impedimento la apelación a las condiciones estructurales, siendo que varones en una sala donde se tactan y evalúan a mujeres, posiblemente desnudas, no son aceptados.

"O sea yo acá tengo que meter a vos, a tu marido, a tu mamá, a tu papá, todo, porque una ley me dice. Yo hago un esfuerzo sobrehumano, ahora, ¿eso es humano para vos? Yo te pregunto, vos me lo contestás. Para mí no. Una sala común, dos millones de mujeres desnudas delante de tu marido, de mí, que soy médico, soy varón y está expuesta a mí, que nada, para mí es un trabajo, pero te imaginás para el resto de las personas no. ¿Eso es humanizado para vos? Entonces el concepto es qué es humanizado para cada uno, ¿sí? Yo creo que siempre hay que empezar por la base, nunca por el techo (...) Nosotros, la infraestructura hospitalaria tiene cien años con lo cual no podemos incorporar a toda la familia sin invadir la intimidad y la privacidad de la que está al lado. Son salas de internación conjunta" (Entrevista 3, jefa de servicio de tocoginecología).

Como testimonia la entrevistada, las restricciones de la infraestructura, donde las mujeres están internadas en salas conjuntas con otra decena de parturientas, también dificulta la garantía del derecho al acompañamiento. Esa cita de entrevista, además, permite destacar esa visión casi inmediata que vincula el modelo de maternidad segura y centrada en la familia a una invasión de familiares en las salas de preparto, parto y puerperio; lo que implica en la opinión de Ixs profesionales diversas dificultades, principalmente, en el desarrollo de la tarea médica y la dinámica hospitalaria.

"La política es que entre todo el mundo pero, ¿sabes qué pasa? Todo el mundo, hay ciertas restricciones que hay que tener, sobre todo, mirá, por ejemplo, yo intento que de 7 , yo vengo a las 7 y cuarto de la mañana, de 7 a 10 de la mañana no haya nadie. ¿Por qué? Porque hay que pasar sala, porque están los enfermeros que tienen que tomar la presión, que tienen que cambiar, que tienen que y cuando hay gente, molesta la gente, no permite el desenvolvimiento común de lo que es la actividad hospitalaria" (Entrevista 4 , jefa de servicio de tocoginecología).

"Le permitimos que entre el familiar siempre y cuando esto en una sala general no intercepte 0 no complique la atención de otra paciente o, más bien, no va a estar el 
familiar mirando cuando se tacta a otra paciente (...) O sea, respetando eso, la intimidad de la paciente" (Entrevista 5, jefa de servicio de tocoginecología).

Conviven, además, en las distintas entrevistas, conceptualizaciones sobre los familiares como agentes potencialmente problemáticxs que invaden la institución, y que demandan determinadas acciones a Ixs profesionales, en una clara disputa de posiciones y saberes en la relación médicx-paciente-familiar.

"Si la paciente es una paciente tranquila, que lleva bien su trabajo de parto y tiene un acompañante sea su pareja, su mamá, su hermana, que la contiene, que yo recuerde, siempre se le permitió estar con esa persona, incluso te estoy hablando de treinta y pico de años atrás en el hospital [anonimizado]. Si la familia es una familia que en vez de contenerla la desborda y que te quiere manejar las indicaciones 0 te pide cesárea a los dos minutos, entonces la limitamos, porque el criterio médico si queremos justamente bajar el índice de cesáreas y hacer el parto más fisiológico posible no podemos, porque no le duela el trabajo de parto, entendés, hacer lo que dice la familia" (Entrevista 5, jefa de servicio de tocoginecología).

La garantía del derecho al acompañamiento, entonces, adquiere una lógica condicional: si la situación se da, si tienen la ropa, si no invaden los derechos de otrxs y la dinámica hospitalaria, si la paciente y Ixs familiares son "tranquilxs", si las acompañantes son mujeres, porque son más delicadas, y, si la infraestructura lo permite, es posible el acompañamiento de quien la mujer elija. Todo ello por supuesto evaluado, tutelado y permitido o no por Ixs profesionales médicxs.

\section{>LIBRE ELECCIÓN DE LA (IM)POSICIÓN PARA PARIR}

"Lo que el tema de la posición en el parto muestra es cómo, en el proceso de su medicalización, se dio prioridad al médico gineco-obstetra en detrimento de la mujer, ya que -salvo la cuestión de las hemorragias, que pueden ser controladas en una institución asistencial debidamente equipada- la única justificación de la posición horizontal y a la francesa, es la comodidad del médico. Por eso, la discusión, que por momentos pareciera ir por canales científicos, muestra que lo que está por detrás es otra cosa: el poder, es decir, quién decide qué está bien, cómo se hace una práctica, cómo se pare, cómo se

nace. Es a través de estas técnicas y prácticas, que se cristalizan relaciones de poder: el que interviene, ve, palpa, decide, corta y la que tiene que obedecer, no tiene dominio de su propio cuerpo y debe "dejar hacer"' (Pozzio, 2013, p. 7-8)

El acceso a este derecho se encuentra, en las tres maternidades analizadas, limitado por la infraestructura. Esto es, existe una vinculación entre la elección de la posición con la disponibilidad de equipamiento que permita dicha postura, sin considerar la posibilidad del parto vertical o en cuclillas en las camillas existentes. La posición del parto se encuentra atada al mobiliario del que disponen en la sala de partos, por lo que la carencia de sillones de parto de última generación, impide el acceso a este derecho y la 
innovación en la práctica: "que la mujer adopte la posición que se pueda si la infraestructura está preparada" (Entrevista 3, jefa de servicio de tocoginecología) ${ }^{69}$.

De todos modos, en dos de las tres maternidades las entrevistadas mencionaron la necesidad del cambio en la posición para parir, mientras que en la megamaternidad justifican la posición de litotomía (acostadas con cierta reclinación) ya que "el útero tiene la fuerza para empujar un auto" (Entrevista 3, jefa de servicio de tocoginecología), relegando importancia de la fuerza de gravedad. Esta concepción extravagante del útero no tiene en cuenta los derechos y necesidades de las mujeres, como busca concertar la política de humanización.

"No tenemos otro método, tenemos el sillón de parto, la camilla de parto y usamos una posición que también resulta, no sé si tan cómoda para la madre, pero sí anatómicamente favorable para el parto. Es la mamá acostada con las piernas flexionadas en las pierneras, que si vos [representa con una hoja de papel], que está acostada con las patas así, vos la ponés en el piso y está en cuclillas. La posición del arco anterior de la pelvis cambia lo mismo que si estuviera en cuclillas. No es tan fácil pujar pero si en una maternidad de alto riesgo se hacen 2500 partos por año en esta posición y si los tienen los pibes, no será que..." (Entrevista 3, jefa de servicio de tocoginecología).

A través de esta cita se puede vislumbrar la centralidad de la eficacia en la lógica hospitalaria, que recuerda la idea de la tecnocratización del nacimiento (Davis-Floyd: 1994), que explica "cómo el parto-nacimiento bajo el paradigma médico es el resultado de una cadena "fabril" compuesta por procedimientos que deben respetarse estrictamente para lograr una "calidad" de parto esperada" (Merino y Fornes, 2008).

\section{>PRÁCTICAS DESACONSEJADAS Y CESÁREAS}

Un indicador clave sobre el acceso al derecho al parto natural ${ }^{70}$ es el índice de cesáreas que consignan las maternidades, que debe vincularse al score de riesgo de los partos que atienden. Por ello, la megamaternidad que atiende partos de bajo y alto riesgo tiene un índice de 33\%; la segunda que también tiene el tipo de riesgo mixto reporta entre 25 y $29 \%$ de cesáreas y la maternidad de bajo riesgo alcanza $22 \%$, al momento de las entrevistas (octubre de 2015). Las recomendaciones de la OMS estipulan que los índices no deben superar el 10-15\%, y en los últimos años alertó sobre un exceso de cesáreas en

\footnotetext{
69 Los mismos resultados encuentra Patricia Schwartz (2010) y sostiene: "La totalidad de los obstetras consultados respondieron no practicar ningún método diferente al "convencional" (en una camilla, en posición semi-horizontal). Manifestaron que en Argentina no existía la tecnología necesaria para practicar otras modalidades de parto” (p. 99).

${ }^{70}$ Existen muchas discusiones sobre la noción de parto "natural" en tanto categoría conflictiva, discutida y re-pensada en el marco de la antropología y sociología médica. Para abordar tales discusiones puede ser interesante revisar Arnau Sánchez et al (2012).
} 
todo el mundo, siendo que en América Latina superan el 35\% de los nacimientos. En comparación con estos datos, las tasas que existen en las maternidades de La Plata son bajas, y más aún en comparación con los hospitales privados donde se alcanzan índices cercanos al $70 \%{ }^{71}$.

"Nosotros a las primerizas estamos en un índice bajo, la primer cesárea estamos en un índice bajo; al segundo bebé recontra bajo, casi ninguna mamá que tuvo un parto vuelve a tener el segundo en el hospital y se le hace cesárea. Se le hace muchas cesáreas a la mamá que tiene bebé prematuro. Entonces si vos analizás fríamente el dato, se le hace cesárea a quien hay que hacérsela, a quien está recomendado hacérsela. $Y$ al otro grupo de pacientes estamos en un índice, alguno más bajo que la media. Estamos en niveles más bajos que hospitales que están propagandeados como que bajaron el índice de cesáreas" (Entrevista 3, jefa de servicio de tocoginecología).

Respecto a las cesáreas, es interesante una reflexión de una de las jefas del servicio de tocoginecología en torno al "parto transmitido" como evento doloroso, lo que ha llevado a que cada vez más mujeres demanden la realización de una cesárea.

Sobre el resto de prácticas desaconsejadas, las tres jefas de servicio refieren a la episiotomía como una práctica que entienden que no debe utilizarse de rutina, aunque sus índices no lo demuestren así: la megamaternidad reporta un 90\% de episiotomías a primerizas, según su jefa de tocoginecología.

"La episiotomía no se hace, se intenta no hacer más, pero qué pasa, también hay muchos más desgarros. Lo de la episiotomía sirvió porque se intentó respetar lo de no ser tan agresivos con el tema del corte a todas y prácticamente no se hace, pero también hay muchos más desgarros porque uno tiene que controlar mucho más el periné y a veces no es tan fácil controlar y que salga el chico, entonces hay más desgarros que antes" (Entrevista 4, jefa de servicio de tocoginecología).

Finalmente, hay un reconocimiento de prácticas desaconsejadas ("estamos intentando que bajen" -entrevista 3, jefa de servicio de tocoginecología-) pero se resiste a caracterizarlas de rutinarias, ya que se encuentra una justificación médica para su aplicación.

"Es que nunca se hacen prácticas rutinarias. Eso yo creo que quedó en la historia, no sé por qué se sigue, no sé si habrá hospitales... O sea, vos en una nulíparas, que es una primeriza, hasta incluso en esas si se puede, nosotros tratamos de esperar. En general, la práctica demuestra que si la dejás se te desgarra, y se te va a desgarrar hacia abajo, hacia el recto. Entonces entre un desgarro que te involucra el recto y un tajito que vos lo dirigís, es preferible, capaz, hacerle eso a una primeriza, y no a todas. A veces hay algunas que no se les hace. No es que de rutina se sigue trabajando (...) siempre es en pos de la paciente, nada es de rutina. Porque cada paciente es especial y cada trabajo de parto es diferente, ¿entendes? No se les hace, a todas no se les pone suero, no se les hace episio, no, no, no, se trata de hacer lo más natural que se pueda, e

\footnotetext{
71 Ver la nota periodística disponible en http://tiempo.infonews.com/nota/149809/la-oms-alerto-por-elcrecimiento-de-las-cesareas-en-el-mundo que referencia un informe de la OMS de 2015.
} 
individualizado porque cada paciente es especial y es diferente y cada mujer en cada trabajo de parto es diferente" (Entrevista 5, jefa de servicio de tocoginecología).

Las intervenciones desaconsejadas, por tanto, siguen asumiendo el carácter de necesarias, en tanto tienden a "corregir" o "ayudar" los procesos de parto.

"A lo sumo lo podemos ayudar con una intervención con un fórceps o con un vacum para acortarles el expulsivo. Pero en ese caso no es no-humanizado el parto porque hay casos donde hay que intervenir, y eso está marcado hasta en las guías de la maternidad, viste, de la familia" (Entrevista 5, jefa de servicio de tocoginecología).

La revisión de las prácticas médicas rutinizadas en la atención obstétrica de partos es precisa, necesaria y requiere acompañamiento, capacitación y formación constantes. Desaprender lo aprendido y relativizar lo sabido para dar lugar a la emergencia de nuevas formas de trabajar y de asistir partos es un proceso multifactorial que aún no se ha iniciado completamente.

\section{> VÍNCULO MADRE-RECIÉN NACIDX}

Con relación a lo anterior, una de las prácticas aconsejadas desde las guías es la del clampeo tardío del cordón umbilical, esto es, la espera de aproximadamente un minuto desde el parto hasta el corte del cordón dado que se entiende que es el tiempo necesario para que el/la recién nacidx reciba "cargas" importantes de sangre, hierro y nutrientes. En dos de las tres maternidades se realiza este procedimiento.

"En cuanto nace el bebé se le apoya en la panza de la mamá, no está todavía cortado el cordón que ya se le apoya a la mamá, ¿entendés? Para que enseguida tenga lazo con su mamá, escucha el corazón de la madre, después lo llevan, lo revisan y vuelve a su mamá" (Entrevista 5, jefa de servicio de tocoginecología).

Respecto a la no separación madre-recién nacidx, lo que en las guías aparece como "contacto piel a piel" (COPAP) no obtuve referencias, aunque es posible advertir, en la cita, que la separación existe aunque luego el/la recién nacidx vuelve con su madre, pero no se sabe cuánto tiempo trascurre entre cada acción.

\subsection{LAS CONDICIONES ESTRUCTURALES DE LA MATERNIDAD}

Como se viene señalando, las jefas de los servicios de tocoginecología consideran que las condiciones estructurales en las que llevan a cabo su práctica profesional influyen de diversos modos sobre la implementación de la atención humanizada del parto. Al hablar de condiciones estructurales se piensa en la infraestructura hospitalaria y en los 
recursos humanos con los que cuenta y a las diversas situaciones que atraviesan su práctica.

Una de estas condiciones se relaciona a la violencia: se Ixs acusa de ejercer la violencia en su práctica profesional y al mismo tiempo se sienten víctimas de violencia tanto de Ixs usuarixs y familiares como desde el sistema de salud. Así, hacen referencia a la violencia de la que son víctimas Ixs profesionales médicxs, vinculándola a la "deshumanización que hay de la sociedad hacia el equipo de salud" (Entrevista 3, jefa de servicio de tocoginecología). Aluden a la violencia social que sufren diariamente en su contexto laboral, y se refieren a la violencia obstétrica de la que son acusadxs por algunos sectores sociales, lo que vislumbra que el tema de la violencia penetra desde varias aristas su labor profesional.

"La falta de educación de la población, la falta de respeto por las instituciones que toda la gente tiene hoy, no se respeta el guardapolvo del maestro, el guardapolvo del médico, el uniforme de la policía, ninguna institución tiene el respeto de la sociedad entendido como que todos son libres de avasallar a cualquiera. Y los servidores públicos, de los que nosotros somos partes, somos ya sirvientes públicos o esclavos públicos. Se me saltó la chaveta" (Entrevista 3, jefa de servicio de tocoginecología).

"Entonces vos decís, sí hay violencia de, a veces, de lo que es el personal de salud hacia los pacientes, pero es mucho más al revés que del personal de salud hacia los pacientes" (Entrevista 4, jefa de servicio de tocoginecología).

En segundo lugar, las condiciones de trabajo aparecen como una variable estructural que dificulta la implementación de la política de humanización, en particular en referencia a la falta de personal y de nombramientos de cargos. Otra vez aparece la "deshumanización", en este caso del trabajo obstétrico, como complemento a la búsqueda de humanización de la atención.

"Es multifactorial la cuestión, la humanización es de todos, del paciente y del equipo de salud. Si van a humanizar la atención del parto, tienen que humanizar también el rol del equipo de salud. ¿Qué es humano para nosotros? Planteles que no están completos, falta de recursos humanos, físicos y de insumos, por más que se hacen esfuerzos denodados por mantener la calidad de atención de parte de la dirección, que quede claro, de parte de las instancias que nos competen, de parte del servicio: optimización de recursos, atar con alambre, arreglar como se pueda pero que la cosa siga caminando y no estancarse, no decir "yo no hago más nada porque en estas condiciones no se puede". Seguimos con la premisa de que hay una respuesta a las madres, hay que dar una respuesta a las madres, hay que dar una respuesta a las madres. Eso es nuestro caballito de batalla todos los días. Ahora bien, no es fácil tampoco para nosotros venir al lugar al que uno viene por vocación a recibir cachetazos. Hay demanda de la gente, hay demanda de resultados" (Entrevista 3, jefa de servicio de tocoginecología).

Condiciones de trabajo negativas, precarias, empleos mal remunerados y una constante vulnerabilidad al estrés laboral propio de la actividad, obstaculizan y desalientan 
los cambios actitudinales, la necesaria capacitación y formación en el nuevo paradigma y la revisión de las prácticas rutinizadas en el hacer obstétrico.

En tercer lugar, y adquiriendo importancia en las entrevistas realizadas, se mencionan los déficits infraestructurales que impiden que se garanticen derechos y se cambien y adecúen las prácticas médicas. La infraestructura aparece como un gran determinante de la atención médica de partos y como un obstaculizador de su humanización (o de la modificación de ciertas prácticas que se considera que humanizan el acto médico), y llega a sostenerse que dicha infraestructura deficiente es ejemplo de la "violencia institucional" que se ejerce desde el hospital hacia Ixs pacientes, visible en prácticas cotidianas, como la falta de sábanas en la sala de preparto. "Nosotros tenemos una infraestructura deshumanizada para nosotros, así que te imaginarás para el paciente" (Entrevista 3, jefa de servicio de tocoginecología) o "la situación cambiará cuando cambiemos de edificio" (Entrevista 5, jefa de servicio de tocoginecología) son algunas de las citas textuales que refieren que la humanización de la atención debe vincularse principalmente a los cambios estructurales y no tanto a la modificación de la tarea profesional. Esto marca un contrapunto con la visión de las funcionarias ministeriales que sostienen que las dificultades para implementar el cambio hacia el paradigma de la humanización se basa en una resistencia profesional y hasta generacional.

Con relación a esto, y en cuarto lugar, emergió con énfasis en las entrevistas la referencia a "el" ejemplo real de la implementación del MSCF, esto es, el caso de la maternidad Estela de Carlotto de Moreno ${ }^{72}$. Se lo toma como un "ejemplo bueno pero imposible de replicar" (Entrevista 3, jefa de servicio de tocoginecología) y se argumenta que su "propagandeada" como maternidad respetuosa no tiene en cuenta que los inmejorables índices de cesáreas y la adopción de prácticas obstétricas alineadas al enfoque de la humanización, se pueden realizar por el sesgo de la población que atienden.

"Tiene una población muy selectiva, no atienden primerizas, no atienden prematuros, no atienden pacientes con cesáreas anteriores, ni pacientes con embarazos pasados de fecha. (...) Entonces en esa maternidad hay un grupo de pacientes muy selectas en donde ellos tiene un 10 a $11 \%$ de cesáreas y nosotros tenemos menos en ese grupo de pacientes. ¿Está claro? Si vos elegís una población que no va a ir a cesárea, tener un $10 \%$ de cesárea no es el mérito. ¿Está claro? ¿Qué estás haciendo de maravilloso? Si el número de cesáreas en esa franja es de ese número o menos" (Entrevista 3, jefa de servicio de tocoginecología).

\footnotetext{
${ }^{72}$ Fue la primera maternidad construida física y conceptualmente con el propósito de replicar el modelo MSCF en la provincia de Buenos Aires.
} 
En este caso, el de la maternidad de Moreno, las referencias de las entrevistadas sostienen que, en buena medida, la implementación de la humanización de la atención del parto es posible por la estructura edilicia, el equipamiento disponible, los recursos (económicos, humanos, simbólicos), la "selección" de mujeres gestantes a atender y la formación específica de Ixs profesionales para la aplicación de ese modelo.

\subsection{OTROS ASPECTOS RELEVANTES EN LA ATENCIÓN MÉDICA DE PARTOS.}

Finalmente, decidí retomar otros aspectos que las jefas del servicio vinculan a la atención médica de partos, porque contribuyen a comprender su concepción sobre su propio trabajo y dar cuenta de otros elementos que influyen en la implementación de la política de humanización.

Así, es contundente cómo en todas las entrevistas se repite la imagen del parto como un evento de emergencia, patológico, una bomba de tiempo que se desarrolla bien o con normalidad y se puede complicar de un instante al otro, lo cual contribuye a aquella referencia que hice en la primera parte sobre que todo parto es riesgoso hasta que se demuestre lo contrario. Esto tiene dos implicancias en el trabajo profesional: en primer lugar, la particularidad de la obstetricia como especialidad médica en constante alerta.

"Una especialidad que tiene sus particularidades: no tiene horario, no tiene aviso de la urgencia, las cosas pueden presentarse súbitamente sin aviso previo, algo que venía muy bien puede terminar muy mal; una paciente normal, sin ningún tipo de agresión por parte del equipo de salud puede terminar en una hemorragia porque el equipo no se contrae 0 porque la placenta no se desprende; un feto que venía bien puede tener los latidos y requerir una cesárea de urgencia. Digamos, el quehacer nuestro de cada día tiene ese timing, [un alerta constante], constantemente. La gente reclama siempre un buen resultado de eso y no entiende que algún resultado adverso en obstetricia no es porque se hayan hecho las cosas mal, sino porque es inherente a la especialidad. Entonces, este grado de estrés y de compromiso con el trabajo y el reclamo global al especialista hace que no elijan esta especialidad como base de su formación futura" (Entrevista 3, jefa de servicio de tocoginecología).

En segundo lugar, señalan la división de tareas entre parteras y médicxs obstetras, que vincula a las primeras a la atención del parto fisiológico y normal, y a Ixs segundxs al trabajo sobre la patología.

"Pero pasa en general que las obstétricas van [a la sala de partos] y los médicos van porque, bueno, la obstétrica tiene sus limitaciones. Ellas pueden atender los partos normales, pero nunca uno sabe cuándo el parto deja de ser normal para ser patológico. Entonces ahí tiene que estar el médico para actuar en ese momento, para una cesárea, para un fórceps, para lo que fuera" (Entrevista 4, jefa de servicio de tocoginecología). 
Y con relación a esto, se hace referencia a que existe una responsabilidad diferente entre el/la médicx obstetra y las parteras, en tanto Ixs primerxs deben responder por partida doble, esto es, por la salud de la mamá y del/la bebé (Entrevista 4, jefa de servicio de tocoginecología), mientras que las segundas aparecen como auxiliares en la atención. La política de humanización supone una división del trabajo ideal entre parteras y médicxs, en relación a la valoración del riesgo del embarazo/parto a atender, y entiendo que este modelo desconoce pujas corporativas históricas del trabajo en las salas de parto: el monopolio de la atención de médicxs obstetras de la mayoría de los PEP.

En simultáneo, resultó llamativo que dos de las jefas de servicio refirieran al imaginario popular (sic) "de que cualquiera puede atender un parto" (Entrevista 4, jefa de servicio de tocoginecología) o de que todos los partos salen bien (Entrevista 3, jefa de servicio de tocoginecología), como un elemento de distinción de su práctica médica y de conocimiento autoritativo (Sadler, 2004).

"¿Pero la cultura popular qué dice? Que vos entrás sonriente a que te saquen a tu bebe de la panza o que puedas parirlo y todos nos vamos sonrientes a casa. $Y$ a veces no siempre es así y todos hicieron lo técnicamente bien, científicamente avalado y la vida no hizo que el resultado sea... la naturaleza se torció" (Entrevista 3, jefa de servicio de tocoginecología).

Por último, en ocasiones permea a las concepciones de las jefas de servicio, una representación de las mujeres pacientes como irresponsables, en relación a que suelen llegar con menos de los controles prenatales esperados/obligatorios (cinco en caso de los PEP de bajo riesgo). Irresponsabilidad y falta de compromiso con el cuidado de su salud y la de su hijx que se explica sólo por una falta de voluntad, esto es, no se controlan durante el embarazo "no porque no tengan acceso al control sino porque no quieren, porque no les importa" (Entrevista 4, jefa de servicio de tocoginecología). Este elemento es importante, ya que la política de humanización de la atención médica de partos también abarca el embarazo y los controles prenatales, y propone una red de cuidados, cursos y consultas en el primer nivel de atención, para garantizar su acceso.

A lo largo de este apartado se han visto distintos testimonios de la brecha entre los postulados de las guías y la realidad de la asistencia de partos en maternidades públicas de la ciudad de La Plata. El contrapunto es evidente y emerge en diversas aristas alrededor de las prácticas, las percepciones y valoraciones de Ixs profesionales y Ixs funcionarixs. El trabajo hacia el cambio de paradigma en la asistencia de partos requiere 
atender a negociaciones, disputas, sentidos heterogéneos y aprendizajes consolidados en varios sectores del sistema hospitalario.

\subsection{Cierre y Recapitulación}

Se describieron los lineamientos de la política de humanización de la atención médica de partos a través de una lectura crítica de tres guías ministeriales y de analizó el proceso de implementación en maternidades públicas de la ciudad de La Plata a partir de entrevistas a funcionarias ministeriales y jefas de servicios de tocoginecología. Se puso el énfasis en analizar cómo esta política se asienta sobre dos ejes fundamentales: los derechos de mujeres y familias respecto al proceso de parto, y la revisión de las prácticas médicas.

Recapitulando, considero que los lineamientos de las guías analizadas permiten sugerir que si bien se propone incorporar y consolidar el horizonte humanizador, garantizando derechos sexuales, reproductivos y de acceso a la salud, y señalando cambios en las intervenciones y en ciertas aristas de la relación médicx-paciente, pasa por alto disputas y constricciones estructurales que emergieron como insoslayables en las reflexiones de las jefas de servicio y de Ixs trabajadorxs de la salud.

En términos del análisis del proceso de implementación, los contrapuntos entre las visiones de las funcionarias ministeriales y las jefas de los servicios de tocoginecología son destacables al mismo nivel que la brecha que se evidencia entre la letra de las guías y las interpretaciones y análisis de la práctica concreta hospitalaria.

De las entrevistas con las funcionarias se destaca la caracterización y percepción estereotipada de la planta profesional de los servicios obstétricos de los hospitales, que limitan el análisis de la implementación a actitudes, voluntades y limitaciones generacionales sin considerar algunos elementos que sobresalen en la perspectiva de las jefas hospitalarias.

De las entrevistas con las jefas de los servicios de tocoginecología, se destacaron varios elementos que articulé en torno a cuatro ejes: 1) los significados de la humanización; 2) la revisión de las prácticas médicas en relación a los derechos de las mujeres; 3) las condiciones estructurales que afectan la implementación; y 4) otros aspectos que consideran relevantes en la atención médica de partos. Así, llama la atención que en torno a la humanización y al modelo MSCF hay una interpretación lineal o literal que los vincula al trato cariñoso y a la idea de "toda la familia adentro". De igual 
modo, existen perspectivas que profundizan y hacen referencia al reconocimiento de derechos y cuestionamientos al intervencionismo médico en el parto. Asimismo, es relevante la posición defensiva o crítica con la que las jefas de servicio recogen esta política, en términos de no sentirse interpeladas por no considerar que su práctica sea "deshumanizada" y no encontrar novedad en prácticas que consideran que "ya existían".

En la indagación sobre los derechos (que implican la revisión de las prácticas), es visible que su garantía es limitada, parcial o nula según de cuál se trate, y que se explica esta situación en relación a cuestiones estructurales heredadas, en condiciones de trabajo negativas y deficitarias, y en un status médico amenazado por la violencia social. Una de las entrevistadas refirió, a propósito de su inaplicabilidad, que esta política busca "meter un cuadrado en un redondo" (Entrevista 3, jefa de servicio de tocoginecología).

Porto et al (2015) sostienen que hay cuatro factores fundamentales que implican dificultades para la implementación del modelo de humanización del parto: la cultura hospitalaria, la infraestructura sanitaria, las prácticas médicas sanitarias y la acción profesional. En este capítulo he advertido que en nuestro contexto se identifican estas dificultades que obstaculizan la aplicación de la política de humanización.

Estoy de acuerdo con Pozzio (2013) en que las posiciones médicas son heterogéneas y que es importante considerar la tensión entre la voluntad de cambio y las condiciones estructurales hospitalarias y sanitarias que las frenan, pero que de igual modo éstas no impiden la autocrítica y la revisión de ciertas prácticas y formas de las relaciones médicx-paciente que pueden modificarse. Que tal vez deba reforzarse el puente entre los dos ejes que aquí se consideran como los pilares de la humanización de la atención del parto, esto es: el acceso a los derechos a la salud, sexuales y reproductivos de mujeres y familias y la revisión de las prácticas médicas ${ }^{73}$.

Retomar testimonios de las distintas posiciones de poder en la disputa estatallaboral y de las diversas experiencias, permitió captar lo común, lo sedimentado. Y permitió concluir que, así como la medicina "corrige" los trabajos de parto para que no se desvíen de la normalidad inyectando oxitocina, el Estado ha lanzado una ley en el mismo sentido: para "corregir" a las instituciones y profesionales médicxs que se desvían. Los resultados de dichos cambios aún se están gestando.

\footnotetext{
${ }^{73}$ Se destaca, a su vez, que tanto en las guías como en las entrevistas, no hay mención ni reconocimiento a los saberes previos, femeninos, populares. El único saber válido es el médico científico, es desde allí desde donde se propugnan los cambios y, al mismo tiempo, se justifica el status quo.
} 


\section{CAPÍTULO 4}

\section{CURSOS DE PREPARTO: ¿EMPODERAMIENTO O SOCIALIZACIÓN PARA LA OBEDIENCIA? -INTERVENCIONES MÉDICAS EN LOS PROCESOS DE EMBARAZO-}

\subsection{Presentación}

Entre octubre de 2016 y diciembre de 2017 participé de 30 encuentros de "cursos de preparto" (CPP), dictados por seis grupos profesionales o institucionales distintos. Si bien surgió como estrategia metodológica para realizar seguimientos y hacer contactos para entrevistas posteriores a los partos/nacimientos, las observaciones en los CPP se erigieron en uno de los dos pilares principales del trabajo de campo de esta tesis. La propuesta es analizar las intervenciones médicas en los procesos de embarazo a través de su expresión, relación e impronta en los contenidos, formatos y ofertas de los cursos. O dicho de otro modo, a partir de lo visible en los CPP, vislumbrar y desentrañar las representaciones y prácticas sobre los embarazos y partos en general que se (re)producen en estos ámbitos.

Para ello y respetando el criterio de heterogeneidad que guió la investigación, accedí a seis cursos de preparto diversos en cuanto a su oferta, abordaje, metodología y pertenencia institucional. Se trató de un curso dictado por una obra social de trabajadorxs estatales (4 encuentros); un curso de un hospital público (12 encuentros); un curso dictado por un gimnasio (3 encuentros); un curso de un hospital privado (2 encuentros); un curso ofertado por una clínica privada (3 encuentros); y, un curso dictado por un grupo de profesionales que asisten partos en domicilio (4 encuentros).

El criterio de heterogeneidad vino dado no sólo por el ámbito de atención sino también por el modelo de atención (re)producido y promovido. Concepciones más o menos intervencionistas y medicalizantes o más o menos humanizantes y fisiológicas y un eterno cruce de grises nos permiten vislumbrar cómo en estos espacios de los cursos que "actúan" durante la temporalidad del embarazo, se van desarrollando, estableciendo y legitimando diversos modos de intervenir y asistir los PEP.

Esto es, tomo aquí los CPP como expresión de modos de atender/intervenir/acompañar y concebir los PEP, y creo que a partir de los contenidos y las formas que pude identificar en la participación en los CPP, es que se pueden analizar, estudiar y problematizar las significaciones y las prácticas que se van estableciendo alrededor de la atención médica de embarazos y partos 
Teniendo dicho horizonte, como punto de partida y a modo de primera aproximación, presento un cuadro comparativo (Cuadro 14) con características generales de los CPP. A continuación, comienzo el análisis dando cuenta de algunos otros elementos globales: metodología, objetivos explícitos, sujetxs a cargo y sujetxs participantes, principalmente. El resto del capítulo se articula en cinco partes. Con el objetivo de responder la pregunta que titula este capítulo, pondré luz en cinco dimensiones que permiten ver de qué modo las representaciones y prácticas que (re)producen los CPP en torno a la atención médica de los PEP tienden a generar/promover/propiciar la obediencia o emancipación/autonomía reproductiva de las mujeres. Las cinco partes son:

1. La cuestión de los tiempos y los procesos en la atención médica de los PEP, con centralidad en su abordaje y expresión en los CPP.

2. La mediación (y necesariedad) médica en el conocimiento del propio cuerpo de las mujeres y sus procesos fisiológicos.

3. Los discursos de los cursos: obediencia a reglas institucionales y profesionales o autonomía y libertad de elección en vínculo con derechos sexuales y reproductivos.

4. El caso atípico: sobre los cuidados prenatales para el parto en domicilio.

5. El análisis de las experiencias concretas: la reconstrucción de las experiencias de quienes participaron en los CPP (a partir del seguimiento de algunas parejas entrevistadas y mi propia evaluación /devolución).

Es importante ubicar la emergencia y desarrollo de los cursos de preparto en un proceso que comienza a mediados del siglo XX en Argentina, con la llegada de las ideas de Read, Lamaze y Leboyer sobre "parto sin temor", "parto sin dolor" y "parto sin violencia", que a partir de las tareas del doctor Gavensky en los 50 tomaron carne en la psicoprofilaxis obstétrica. Karina Felitti $(2011 a, 2012)$ describe profundamente este proceso:

"Los cambios que se dieron a partir de los años 1950 en la atención del parto se inscribieron en un contexto de transformaciones sociales y culturales amplias que afectaron los roles y relaciones de género y los modelos familiares. A la vez respondieron a un renovado interés médico por mejorar la atención y minimizar sus complicaciones, aprovechando la difusión de nuevos conocimientos y herramientas tecnológicas que habían vuelto al parto menos peligroso. El parto sin dolor, parto sin temor, parto psicoprofiláctico, parto vertical, parto sin violencia, fueron diferentes modos de denominar y pensar la atención obstétrica que pusieron en evidencia diferentes concepciones sobre la relación médico/paciente y entre varones y mujeres. Todos ellos tuvieron en común el considerar a las mujeres en un rol más activo, ya no como 'enfermas' sino como sujetos 
capaces de protagonizar la experiencia. En algunos casos, los padres fueron también interpelados y llamados a ocupar un lugar más comprometido y cercano en el nacimiento de sus hijos" (2011a, p. 125-126).

Este contexto de "cambios en las relaciones de género", que implicaron cuestionamientos a los roles de los varones-padres, también impactaron en las relaciones médicx-paciente y en los modos de pensar formas alternativas de parir y nacer de las mujeres

"Las formas tradicionales de atención del embarazo y el parto comenzaron a cuestionarse. Considerar que las mujeres tenían el derecho de estar informadas sobre lo que iba a acontecer en su propio cuerpo durante la gestación y al momento de parir, respondía a estos cambios socio-culturales y al propio desarrollo de la obstetricia. Los adelantos científicos y técnicos en este campo facilitaron los diagnósticos y los tratamientos, y permitieron pensar los partos no solo desde sus potenciales peligros sino como un acontecimiento que podía vivirse de mejor modo, sin acatar necesariamente el mandato bíblico de 'parirás con dolor'” (Felitti, 2011a, p. 114-115).

Sin duda el escenario macro cambió, pero los procesos que describe Felitti se encuentran potenciados y profundizados en el de este caso de estudio, como se verá a continuación. Si este fue el origen de los CPP, es interesante ver cómo funcionan en el siglo XXI. 
CUADRO 14: CUADRO COMPARATIVO DE CURSOS DE PREPARTO - ELABORACIÓN PROPIA

\begin{tabular}{|c|c|c|c|c|c|c|}
\hline & 1-Curso Obra Social & 2-Curso Htal Público & 3- Curso Gimnasio & 4-Curso Htal Privado & 5-Curso Clínica Privada & 6-Curso Parto en casa. \\
\hline $\begin{array}{l}\text { Autodenominación } \\
\text { del curso }\end{array}$ & $\begin{array}{l}\text { "Curso de psicoprofilaxis } \\
\text { para el embarazo, parto, } \\
\text { puerperio y lactancia" }\end{array}$ & $\begin{array}{l}\text { "Taller de preparación para } \\
\text { el parto, lactancia y } \\
\text { cuidados de bebés" }\end{array}$ & $\begin{array}{l}\text { "Taller de contacto } \\
\text { para un parto } \\
\text { consciente" }\end{array}$ & "Curso de preparto" & $\begin{array}{l}\text { "Curso de preparación para } \\
\text { la maternidad" }\end{array}$ & $\begin{array}{l}\text { "Encuentros de cuidados } \\
\text { prenatales" }\end{array}$ \\
\hline $\begin{array}{l}\text { Grado de } \\
\text { observación } \\
\text { participante }\end{array}$ & $\begin{array}{l}\text { Mayoritaria (no participé en } \\
\text { la parte física). } \\
\text { Participé de } 4 \text { encuentros } \\
\text { (de un total de 4) }\end{array}$ & $\begin{array}{l}\text { Mayoritaria (no participé en } \\
\text { la parte de psicología, } \\
\text { aunque en esos momentos } \\
\text { realicé etnografía en la sala } \\
\text { de espera) } \\
\text { Participé de } 12 \text { encuentros } \\
\text { (no hay número establecido } \\
\text { total, pero podrían ser 8) }\end{array}$ & $\begin{array}{l}\text { Total. } \\
\text { Participé de } 3 \\
\text { encuentros (de un total } \\
\text { de 3) }\end{array}$ & $\begin{array}{l}\text { Total. } \\
\text { Participé de } 2 \\
\text { encuentros (de un total } \\
\text { de 2) }\end{array}$ & $\begin{array}{l}\text { Participé de } 3 \text { encuentros } \\
\text { (de un total de } 4 \text { ) }\end{array}$ & $\begin{array}{l}\text { Parcial: participé de } 4 \\
\text { encuentros: corporal, } \\
\text { binomio madre-hijx } \\
\text { (lactancia-crianza); } \\
\text { despedida del embarazo y } \\
\text { posparto (de un total de } \\
\text { 11) }\end{array}$ \\
\hline Estructura & $\begin{array}{l}4 \text { encuentros, uno por tema } \\
\text { (embarazo, parto, } \\
\text { puerperio, lactancia). Cada } \\
\text { encuentro subdividido en } \\
\text { tres momentos: uno a cargo } \\
\text { de la médica obstetra; otro } \\
\text { a cargo de la psicóloga y } \\
\text { uno de actividad física con } \\
\text { la profesora de educación } \\
\text { física. }\end{array}$ & $\begin{array}{l}\text { Cada encuentro tiene tres } \\
\text { momentos: una primer hora } \\
\text { con el equipo de psicología, } \\
\text { la hora del medio a cargo } \\
\text { de la partera; y en la última } \\
\text { hora se ofrecen clases } \\
\text { especiales a cargo de otrxs } \\
\text { profesionales } \\
\text { especializadxs. }\end{array}$ & $\begin{array}{l}3 \text { encuentros, cada uno } \\
\text { con un tema } \\
\text { específico: los dos } \\
\text { primeros sobre trabajo } \\
\text { de parto y parto; el } \\
\text { tercero (opcional) } \\
\text { sobre lactancia y } \\
\text { crianza. }\end{array}$ & $\begin{array}{l}2 \text { encuentros, en dos } \\
\text { días seguidos: un } \\
\text { módulo obstétrico un } \\
\text { día y al día siguiente el } \\
\text { módulo pediátrico- } \\
\text { lactancia. Se repiten } \\
\text { mensualmente. }\end{array}$ & $\begin{array}{l}4 \text { encuentros, se repiten } \\
\text { mensualmente. }\end{array}$ & $\begin{array}{l}\text { 11 encuentros: } \\
\text { Introducción; hábitos; arte; } \\
\text { linaje materno; trabajo de } \\
\text { parto y parto; corporal; } \\
\text { plan de parto; binomio } \\
\text { madre-hij@ (lactancia- } \\
\text { crianza); música y canto; } \\
\text { despedida; y posparto. }\end{array}$ \\
\hline Horario y lugar & $\begin{array}{l}\text { Lunes } 17 \text { horas, sede de la } \\
\text { obra social (centro de la } \\
\text { ciudad) } \\
\text { Cada edición del curso dura } \\
\text { un mes. El primer lunes de } \\
\text { cada mes se renueva el } \\
\text { grupo y el temario vuelve a } \\
\text { comenzar. } \\
\text { Duración de cada } \\
\text { encuentro: } 1.30 \mathrm{hs}\end{array}$ & $\begin{array}{l}\text { Lunes y jueves } 9 \text { horas. } \\
\text { Aula dentro de sala de } \\
\text { puerperio, en Maternidad } \\
\text { del hospital } \\
\text { Duración de cada } \\
\text { encuentro: } 2-3 \text { hs }\end{array}$ & $\begin{array}{l}\text { Los dos primeros } \\
\text { miércoles a las } 20 \text { hs, } \\
\text { el de lactancia sábado } \\
\text { consecutivo a las } 10 \\
\text { hs. No se dictan } \\
\text { periódicamente } \\
\text { Se da en un gimnasio } \\
\text { del centro de la ciudad. } \\
\text { Duración de cada } \\
\text { encuentro: } 2 \mathrm{hs} \text {. }\end{array}$ & $\begin{array}{l}\text { Modulo obstétrico: } \\
\text { martes } 14.30 \mathrm{hs} \text { (aula } \\
\text { magna del hospital). } \\
\text { Modulo pediátrico: } \\
\text { miércoles } 9.30 \mathrm{hs} \text { (aula } \\
\text { en instituto anexo al } \\
\text { hospital) } \\
\text { Duración de cada } \\
\text { encuentro: } 2 \mathrm{hs}\end{array}$ & $\begin{array}{l}\text { Sábados } 9 \text { u } 11 \text { hs. Se } \\
\text { dicta en un consultorio } \\
\text { médico en un barrio } \\
\text { alejado de la clínica y del } \\
\text { centro de la ciudad } \\
\text { (Tolosa) } \\
\\
\text { Duración de cada } \\
\text { encuentro: } 2 \text { hs. }\end{array}$ & $\begin{array}{l}\text { Cronograma lunes, o } \\
\text { miércoles o viernes según } \\
\text { corresponda a la fase del } \\
\text { embarazo. En casa- } \\
\text { consultorio, centro de la } \\
\text { ciudad. } \\
\text { Duración de cada } \\
\text { encuentro: } 3 \text { - } 4 \mathrm{hs}\end{array}$ \\
\hline
\end{tabular}




\begin{tabular}{|c|c|c|c|c|c|c|}
\hline Coordinación & $\begin{array}{l}\text { Una médica obstetra, una } \\
\text { psicóloga y una profesora } \\
\text { de educación física. }\end{array}$ & $\begin{array}{l}\text { General: a cargo de la } \\
\text { partera. La hora de } \\
\text { psicología está a cargo de } \\
\text { una psicóloga de planta y } \\
\text { residentes de primer año. } \\
\\
\text { Clases especiales: } \\
\text { neonatóloga (lactancia), } \\
\text { pediatra (cuidados recién } \\
\text { nacidx), equipo de trabajo } \\
\text { social (métodos } \\
\text { anticonceptivos), obstetra } \\
\text { (puerperio) y residente de } \\
\text { nutrición (alimentación } \\
\text { saludable) }\end{array}$ & $\begin{array}{l}\text { Una profesora de } \\
\text { educación física, una } \\
\text { asesora en lactancia y } \\
\text { una partera. }\end{array}$ & $\begin{array}{l}\text { El módulo obstétrico } \\
\text { está a cargo de un } \\
\text { médico obstetra; el } \\
\text { modulo pediátrico- } \\
\text { lactancia a cargo de } \\
\text { una } \\
\text { pediatra/neonatologa. }\end{array}$ & $\begin{array}{l}\text { Todo el curso está a cargo } \\
\text { de una partera. }\end{array}$ & $\begin{array}{l}\text { El equipo principal está } \\
\text { compuesto por un médico } \\
\text { obstetra, dos parteras y } \\
\text { una profesora de } \\
\text { educación física. Se } \\
\text { suman según el encuentro } \\
\text { una puericultura, una } \\
\text { psicóloga, dos pediatras, } \\
\text { profesoras de arte, etc. }\end{array}$ \\
\hline Temas & $\begin{array}{l}\text { Un encuentro dedicado a } \\
\text { cada uno de los cuatro ejes } \\
\text { del título (embarazo, parto - } \\
\text { dividido en dos: trabajo de } \\
\text { parto y parto- y uno último } \\
\text { que reúne puerperio y } \\
\text { lactancia). }\end{array}$ & $\begin{array}{l}\text { Las partes a cargo del } \\
\text { equipo de psicología y de la } \\
\text { partera, son a demanda: el } \\
\text { curso responde a la } \\
\text { impronta propia del público, } \\
\text { que es heterogéneo y } \\
\text { retoma principalmente } \\
\text { temas del embarazo, } \\
\text { trabajo de parto, el parto y } \\
\text { el posparto. } \\
\text { Las clases especiales son } \\
\text { cinco (ver arriba). }\end{array}$ & $\begin{array}{l}\text { Los dos primeros } \\
\text { incluyen nociones } \\
\text { sobre trabajo de parto } \\
\text { y parto con enfoque } \\
\text { fisiológico, } \\
\text { herramientas y } \\
\text { capacidades de las } \\
\text { mujeres y sus } \\
\text { acompañantes para } \\
\text { atravesar el PEP } \\
\text { Gran desarrollo de la } \\
\text { parte física. }\end{array}$ & $\begin{array}{l}\text { Ambos módulos } \\
\text { tienden a reproducir un } \\
\text { enfoque fisiológico del } \\
\text { proceso y no } \\
\text { intervencionista. } \\
\text { No incluye una parte } \\
\text { de trabajo física. }\end{array}$ & $\begin{array}{l}\text { Aborda embarazo y trabajo } \\
\text { de parto, otro sobre parto y } \\
\text { "procedimientos } \\
\text { habituales", otro sobre } \\
\text { lactancia y otro sobre } \\
\text { cuidados posteriores al } \\
\text { parto/cesárea. } \\
\text { No incluye una parte de } \\
\text { trabajo física. }\end{array}$ & $\begin{array}{l}\text { Propone un abordaje } \\
\text { integral del PEP y } \\
\text { acompañamiento del } \\
\text { embarazo. }\end{array}$ \\
\hline Público & $\begin{array}{l}\text { Trabajadorxs de una } \\
\text { institución estatal y } \\
\text { acompañantes. Gratuito e } \\
\text { incluido/ofrecido para } \\
\text { afiliadxs. } \\
\text { La participación de varones } \\
\text { es baja, no valorada, no } \\
\text { incentivada. } \\
\text { Máximo } 8 \text { personas. }\end{array}$ & $\begin{array}{l}\text { Abierto a la comunidad y } \\
\text { gratuito (participan tanto } \\
\text { usuarixs del servicio } \\
\text { público de salud como del } \\
\text { ámbito privado). } \\
\text { Participación heterogénea } \\
\text { de varones-padres y otrxs } \\
\text { acompañantes (madres, } \\
\text { abuelas, amigas). } \\
\text { Máximo } 20 \text { personas. }\end{array}$ & $\begin{array}{l}\text { Abierto a la comunidad, } \\
\text { aunque mayormente } \\
\text { alumnas de "gimnasia } \\
\text { para embarazadas" } \\
\text { que se dicta en dicho } \\
\text { gimnasio. } \\
\text { Alta participación de } \\
\text { varones-padres. } \\
\text { Máximo } 35 \text { personas. }\end{array}$ & $\begin{array}{l}\text { Pacientes del hospital, } \\
\text { con orden de su } \\
\text { médicx obstetra. Lo } \\
\text { cubren las obras } \\
\text { sociales. } \\
\text { Amplia participación de } \\
\text { mujeres-madres y } \\
\text { varones-padres. } \\
\text { Máximo } \\
\text { aproximadamente } 20 \\
\text { personas. }\end{array}$ & $\begin{array}{l}\text { Participan exclusivamente } \\
\text { parejas. } \\
\text { Máximo } 10-12 \text { personas. }\end{array}$ & $\begin{array}{l}\text { Participan } 506 \text { parejas en } \\
\text { cada encuentro. } \\
\text { Máximo } 10 \text { - } 12 \text { personas. }\end{array}$ \\
\hline
\end{tabular}


Como muestra el cuadro, la heterogeneidad de los cursos es tal que se vislumbra en todas las áreas analizables: los grupos a cargo, el temario, la estructura de trabajo, las dinámicas, los horarios, etc.

A continuación, ampliaré algunos elementos que aparece mencionados en el cuadro, para profundizar la descripción de los cursos y pasar, luego sí, al análisis propuesto anteriormente.

\subsubsection{SOBRE LA OFERTA DE LOS CURSOS: QUIÉNES, CÓMO, PARA QUÉ.}

Quiénes los dictan. Sin duda la impronta de quienes están a cargo de los cursos, impacta en los modos y contenidos que buscan transmitir, y en el modo en que esos saberes se construyen y se ponen en común. Por ejemplo, algunas parteras o médicas apelan tanto a su saber profesional como a su condición de madres para construir su "voz autorizada". Incluso en el CPP del hospital público, por ejemplo, la partera a cargo recupera mucho de su doble experiencia: como madre y como paciente de dicha maternidad pública.

Como se ve, en general los cursos están dictados por grupos de trabajo que buscan satisfacer el principio de la interdisciplinariedad (médicxs, parteras, psicólogas, profesoras de educación física, pediatras, principalmente); salvo los de los sanatorios privados (clínica y hospital) cuyo dictado está a cargo de profesionales médicxs únicamente. Asimismo es relevante mencionar que el curso dictado en un gimnasio de la ciudad tiene lo que puedo mencionar como una "impronta militante" ya que el curso nace de un grupo de activistas por el parto respetado (cuyas integrantes profesionales son las encargadas del curso).

Cómo se dictan. Las metodologías de trabajo también varían: en algunos espacios se propicia más la participación de quienes asisten (principalmente las mujeres gestantes) estimulando la narración de experiencias o la expresión de saberes previos, miedos y emociones, y en otros se tiende más a una exposición unilateral, donde quien coordina "transmite" las saberes o conocimientos y responde "dudas" o "inquietudes" de Ixs participantes. En este sentido, registré diversos modos de trabajar con esos "saberes" en juego en los CPP: transmitirlos como datos incuestionables (cierta imposición) o aceptar que son construidos y de/co/construirlos. 
Parte de esas operaciones simbólicas que se realizan con la información que circula y se (re)produce en los CPP potencian la medicalización y necesariedad de la asistencia o intervención médica (si, por ejemplo, se establece el paradigma de riesgo, la casi seguridad de la ocurrencia de complicaciones, la obediencia a las reglas médicas e institucionales). En otros casos, promueven la re-cotidianización de los PEP, al usar frases como "ustedes van a darse cuenta que están en trabajo de parto" o "vengan a la guardia sólo si hay algo grave como una hemorragia", que tienden a ridiculizar la idea del parto como un evento explosivo e imposible de manejar por la mujer y su entorno, al ubicar el proceso como un evento que no tiene por qué ser descontrolado sino tranquilo, común, "natural" y "cotidiano".

Para qué. Por último, sobre los objetivos de los cursos (no los formales sino los que se infieren en las observaciones), existe cierto consenso que establece que la idea principal es dar información para "bajar la ansiedad" de las mujeres y su entorno.

"El doctor a cargo del curso explica el objetivo del mismo. "Mostrarles" qué está pasando en su cuerpo, en sus embarazos. Discutir la "información trágica que circula" y que "uno llega a defenderse". Se refiere al "ciclo natural de sus vida", que "todas las mujeres tienen el poder y el don de parir", que hay que hacerlo respetar: "ustedes son las que tienen que luchar". Menciona el contexto de la Semana Mundial del Parto Respetado, que hay derechos para el parto respetado que no se respetan o no se hacen valer" (Diario de campo, 16/5/2017, curso hospital privado).

"Lo que hacemos es informar, light, yo a veces me voy un poco por las ramas y las chicas me frenan, pero la idea es brindar información, que ellas tengan de dónde hablar con sus obstetras y pedir y preguntar y que no sea una exigencia tampoco, ni para ellas, que sea una exigencia un parto ni que para ellas sea una exigencia la lactancia y que puedan elegir. Osea, incluso es un curso de preparación para el parto, y siempre hablamos del parto y de la cesárea, y la cesárea como una forma de parir también" (Entrevista Carla, médica obstetra a cargo del curso de obra social)

"Mirá un poco la idea es que corte un poco con la cosa de dar clases, es un poco la lógica con la que están armados los cursos, donde la gente va esperando que se de la clase formativa, y la idea un poco de nuestro espacio es que no sea una clase, sino justamente como darles la palabra y que algo se pueda armar a partir de lo que dicen" (Equipo de psicólogas, curso maternidad pública) ${ }^{74}$

\footnotetext{
${ }_{74}$ Aunque no se refiere a un CPP observado, retomamos el testimonio que expone una partera entrevistada en relación a lo que entiende por lo que es el "verdadero" objetivo de los CPP: "Y no es que al curso vas a aprender cómo pujar, porque eso yo creo que es instintivo. Al curso vas, es como más terapéutico y pautas de alarma, por ahí para que la mujer no vaya tan rápido a la consulta y no la manoseen, la toqueteen. Y además para empoderarla, para que cuando le pongan algo en el suero diga "pará, ¿qué me estás poniendo? Si tengo contracciones como tengo que tener". Es asî" (Entrevista Barbara, partera).
} 
Asimismo, como se ve, se menciona el "empoderamiento" o el "dar herramientas" a las mujeres como otro de los propósitos de estos espacios. Y sin embargo, detrás de este objetivo que parece ser autonomista/emancipatorio, se esconde la reducción del (tiempo de) trabajo del/ de la médicx de cabecera.

"Antes de empezar la clase, la partera a cargo del curso me dijo que una obstetra le dijo que las mujeres que van al curso le preguntan menos (ya están informadas y les baja la ansiedad) y "no le rompen tanto los quinotos"' (Diario de campo, 15/7/2017, curso clínica privada).

Por último y en relación a lo anterior, los objetivos de los CPP están vinculados con lo que sucede en las consultas médicas o la atención obstétrica en servicios públicos de cada mujer.

"Damián: Yo me quedé más tranquilo con el curso. Por eso te digo, en serio. Porque la información que obtuve del curso no la tuve de ella [la médica obstetra]. Si ella me hubiera dicho las cosas que yo me enteré en el curso, por ahí el curso te diga "sí, estaba bien, como un complemento, pero tampoco es necesario". Para mí fue necesario, porque todas las cosas que te enseñan en el curso nunca me las enteré por ella" (Entrevista 17, Johana y Damián, parto en hospital privado, curso de preparto en obra social).

En tal sentido, continúan reproduciendo la relación de poder que forma parte de las relaciones asimétricas entre médicxs y pacientes, y se hace visible que la relación de desigualdad se asienta en cierta subalternidad con información, para que se favorezca o no obstaculice el desarrollo de la actividad profesional médica. Parece ser que, aunque se proclame lo contrario, en algunos espacios de atención médica, su pregunta sí molesta, y por ellos los CPP vienen a zanjar estos intersticios de la consulta con el personal médico.

\subsubsection{SOBRE LA DEMANDA -EL PÚBLICO- DE LOS CURSOS: QUIÉNES PARTICIPAN.}

No es difícil notar que de las mujeres que paren, es muy ínfima la cantidad que participa de los cursos de psicoprofilaxis, y más allá de que sólo se le recomienda a las primerizas, de éstas es también poca la participación. De hecho surge en las charlas informales y entrevistas la preocupación de los equipos coordinadores o profesionales a cargo de los CPP sobre que las mujeres no van al curso porque "los médicos no las mandan". Uno de los aspectos que le da particularidad a cada CPP es justamente "el público" al que está dirigido y el que efectivamente participa. Lo pienso en tres partes a este público: primero y fundamental las mujeres; segundo el "lugar" dado y producido a y por los varones-padres, y tercero la presencia de otrxs acompañantes. 
En relación a las mujeres gestantes que asisten (en general desde la semana 30 de embarazo), me interesa destacar algunos elementos.

¿Qué tipo de alumnas/participantes hay en los cursos? En primer lugar, destaco que aunque suelen ser abiertos en sus convocatorias, los CPP dependen de la invitación o sugerencia de participación de Ixs profesionales de la salud que atienden los embarazos de las mujeres. De hecho, una de las quejas de la partera a cargo del curso del hospital público es que "no las mandan", por lo que de 4500 parturientas al año en dicha maternidad, menos del $5 \%$ participan de este espacio.

Por otro lado, en el curso de la clínica privada, donde el público es más "cautivo" que en el hospital público, existe una cláusula tácita que limita la participación/invitación: "la partera mencionó que solo le dicta los cursos a las pacientes de algunxs doctorxs, porque con otros que son intervencionistas ella no quiere trabajar" (Diario de campo, 15/7/2017, curso clínica privada).

En cuando a la información que se tiene y se pide sobre las mujeres asistentes, existen algunos agujeros. Es decir, en algunos cursos se les interroga sobre el deseo 0 no del embarazo, las experiencias de la atención y de la relación médicx-paciente hasta el momento, el lugar de atención y de posible parto (hospital público) mientras que en otros solamente:

"La única información de las mujeres es su estado de embarazo en semanas de gestación (ni su edad, trabajo, nombre completo, situación civil, lugar de residencia, y otros). Tampoco cómo asisten su embarazo y parto, en qué institución, con qué médicx, qué tipo de parto planean, etc." (Diario de campo, 16/9/2016, curso obra social).

$\mathrm{Si}$ fuera posible, mediante las observaciones participantes y las charlas informales realizadas, establecer un perfil socioeconómico de Ixs asistentes, concluiría que, salvo en el CPP del hospital público, en los cinco restantes predominan participantes de clases medias profesionales (tal como pudo establecerse en charlas informales y en las parejas con las cuales se realizó seguimiento y entrevistas en profundidad).

En este tipo de espacios suele haber diferentes perfiles de las mujeres en tanto "alumnas" o "participantes". Y en este sentido esos dos términos no son sinónimos ni inocentes: la condición de "alumna" adhiere al paradigma del saber-poder médico y del conocimiento autoritativo (Jordan, 1993) que de allí deviene, ubicándose así a la asistente en un rol de escucha, de desconocimiento de la situación y de ausencia de saberes previos. Parte de algunas de las propuestas de los CPP con enfoque fisiológico 
(el del gimnasio, el del hospital privado, el del hospital público y el de la asistencia domiciliaria, por ejemplo) se amparan en una metodología participativa que concibe a quienes asisten como sujetxs con conocimientos, saberes y por tanto en constante coconstrucción de la información que allí circula.

De todos modos, y más allá de que es posible advertir una heterogeneidad de experiencias, deseos, necesidades, expectativas y actitudes de las mujeres en los cursos (la que sabe mucho, la que pregunta mucho, la que monopoliza la palabra, la que expresa sus miedos, la que apenas habla, etc.) destaco dos tipos ideales que fueron visibles en la mayoría de los cursos. Primero, la alumna perfecta ${ }^{75}$, aquella que pregunta, suele monopolizar la palabra, en tanto parece ser que necesita reglas, estructuras y control, sometida a la creciente medicalización de la vida cotidiana. $Y$, por otro lado, el modelo de paciente informada, visible, por ejemplo, en su conocimiento previo de diversos temas que hacen a la atención obstétrica.

"Todas tienen conocimiento del plan de parto. Las preguntas de las mujeres dan cuenta de saberes expertos en el tema del parto respetado y humanizado. Se habla mucho de las tensiones entre las exigencias institucionales, de Ixs médicxs, de las mujeres: por ejemplo, preguntan si pueden entrar con sus parejas al parto y el doctor a cargo del curso responde que eso depende del médico que las atienda, por eso menciona la idea del consenso médico-paciente y las insta a que lo hablen con ellos, mencionando que existe una ley" (Diario de campo, 16/5/2017, curso hospital privado).

"[En relación al CPP de la obra social]Y está bueno además porque se da con gente de la facu. Entonces es gente preparada, que viene con preguntas. A mí al principio era... yo pasé del hospital público de explicar siempre traduciendo, eh, a explicar a la gente de la universidad y... al principio (risas) me hizo temblar un poco. Pero está buenisimo. Y además con todas las movidas que ha habido del parto respetado, de la lactancia, de todo, está bueno. Se arma lindo" (Entrevista Carla, médica obstetra a cargo del curso de la obra social)

Aunque la caracterización de las mujeres que participan (y sus actitudes) se va a ir completando en el desarrollo de este capítulo, creo que en las preguntas que no se hacen (¿cuándo es "a término"?, ¿cuánto "te esperan”?, ¿en qué consiste la inducción?, ¿puedo entrar acompañada?, ¿tengo libertad de movimiento?) es posible también vislumbrar el nivel de consentimiento y legitimidad a cierto modelo de atención que se asienta en el saber-poder médico, y en la delegación de las decisiones de las decisiones a Ixs profesionales sanitarixs.

\footnotetext{
${ }^{75} \mathrm{La}$ exageración de la denominación de este tipo ideal es sólo a fines analíticos. Lo interesante es que no es exclusivo del género femenino: en las entrevistas a parejas, muchas mujeres mencionaron actitud de escucha atenta, toma de nota y hasta de exceso de interrogación, a modo de burla a ellos, de sus compañeros (“el alumno perfecto”).
} 
Sobre la participación de los varones-padres ${ }^{76}$. El punto de partida que construí (y expresé en el marco conceptual) a partir de numerosas lecturas y conocimiento del campo señalaba la falta de participación de los varones en el proceso perinatal en general, y en los cursos en particular. En este sentido, una de las preocupaciones principales que emergió previo a la tesis (y se profundizó en su realización) es qué roles o posibilidades de participación tienen, construyen, resisten, producen los varones-padres frente a los PEP. A través de las diversas observaciones en los cursos pude ver cómo se va delineando y tensionando dicha participación.

Así, aunque discursivamente (por ejemplo en los carteles de difusión de los cursos) se convoque a la asistencia de los varones, en la práctica en muchos de los espacios se reduce la convocatoria a mera presencia física. Si bien su participación (pasiva) como oyentes de estos temas pueden generar mayor compromiso con los PEP, sólo en algunos CPP, que considero casos atípicos, es posible vislumbrar la construcción de formas más igualitarias o más activas de participación.

"En este encuentro se trabajó particularmente en el sostén a las mujeres en trabajo de parto. Se trabajó con movimientos y diversas maniobras y masajes que los varones pueden realizar para ayudar y sostener. Yo fui modelo de masajes (Laura, la profesora de educación física, mostraba en mi cintura qué movimientos hacer). Se destaca cómo incorporan a los hombres. Se lo dije a Laura y me dijo que en general las asistentes al curso son sus alumnas de gimnasia para embarazadas y ya saben todo, lo vienen hablando en las clases, en cambio los varones no saben nada" (Diario de campo, 15/3/2017, curso gimnasio).

La participación de los varones-padres en los PEP parecería estar atravesada por la cuestión de (no) poner el cuerpo. No sienten dolor, patadas, vómitos, cambios hormonales y físicos. En tal sentido, una de las apuestas de algunos cursos es incorporarlos, como éste que se acaba de reseñar, en el que se les da una opción y tarea en el trabajo de parto, una responsabilidad y la importancia de su presencia: sostén, contención, alivio de dolores con masajes y movimientos en pareja.

En algunos casos no saben qué hacer, cómo participar y sin duda eso puede vincularse a la histórica feminización de los cuidados perinatales, en la que los PEP se establecieron como asuntos de mujeres $^{77}$ y en las actuales movidas por la democratización de los cuidados y la corresponsabilidad parental, que entran en tensión $y$ hacen entrar en escena a los varones-padres.

\footnotetext{
${ }^{76}$ Aquí solo se delinean algunas características generales, a lo largo del capítulo se van mostrando más cuestiones vinculadas a su participación.

${ }^{77}$ En todas las entrevistas, incluí una pregunta inicial acerca del propio nacimiento de lxs entrevistadxs. La amplia mayoría refirió que sus propios padres no participaban porque "era cosa de mujeres", "no se usaba", etc.
} 
Por lo señalado, los CPP como expresión de modos de atender, pensar e intervenir los PEP, también reflejan diversas concepciones y expectativas comportamentales sobre cómo deben actuar los varones en estos procesos. Y es visible tanto en lo que se dice y quién lo dice ("el doctor a cargo del curso respecto al parto sostiene "el rol del padre/acompañante es obligatorio para mis pacientes" -Diario de campo, 16/5/2017, curso hospital privado-); como en otros aspectos que hacen al dictado de los cursos ${ }^{78}$.

Los horarios, por ejemplo, pueden obstaculizar o fomentar la participación de los varones-padres. El curso del hospital público se dicta en días de semana durante la mañana, en horario laboral. Claramente esto también afecta la participación de mujeres gestantes que no cuentan con trabajos en blanco y licencias por maternidad, o que tienen otrxs niñxs o sujetxs dependientes de cuidado a cargo, o que son madres solteras. Pero si apeláramos a un modelo clásico ideal de familia nuclear con varón proveedor (sobre el que se sostienen la mayoría de las políticas públicas y modos de trabajo en estas instituciones), tampoco podría participar si así lo quisiera. Y además, asistiendo igualmente no se los suele incluir en las preguntas o actividades, o se los invita sólo a un encuentro (el de parto) o no se sabe bien, desde la coordinación, qué lugar otorgarles en el proceso de PEP. A partir de esos mecanismos se desincentiva su participación.

Así como entre las mujeres participantes puedo vislumbrar algunos tipos ideales, entre los varones que participan también encontré cierta tensión entre el comprometido con el proceso perinatal y el obligado, con tendencia machista, que busca complicidad con sus congéneres. Esta tensión me la expresó uno de los entrevistados participante del CPP de la obra social, quien autoadscribía al rol del alumno comprometido, interrogador, incluso burlado por su compañera por ser "el único que tomaba notas" (Entrevista 17, Johana y Damián). Ambos me contaron que, respecto a la presencia de varones-padres,

"Damian: Pero en uno de los grupos creo que estaba yo solo, ¿o no? Después apareció un padre

Johana: Sí nosotros lo hablábamos porque "estoy acá" como, como que fue obligado. Nosotros lo hablábamos, él me decía "no, obligado no, también es tu hijo, por más de que vos no estés poniendo el cuerpo, obviamente, es tu hijo".

Damián: Claro, no, pero sí, yo me quedé helado porque él por ahí buscaba como una complicidad conmigo porque éramos los únicos hombres y como diciendo "a ver

\footnotetext{
${ }^{78} \mathrm{Al}$ respecto vale la pena recordar los 5 elementos que expulsan a los varones padres de la participación de PEP que trabajan Maroto Navarro et al (2009) y mencioné en el capitulo 1.
} 
flaco", como diciendo "a vos te pasa lo mismo" y a mí, qué se yo, medio como que bueno, ta, me reía y no sé qué, pero no me pasaba lo mismo. Porque, escuchame, si no te interesa estar acá, digo, es raro que no te interese, para mi es raro. Que lo traigan ahí obligado eh, qué se yo, me parecía tan fuera de lo que me pasaba a mí" (Entrevista 17, Johana y Damián, parto en hospital privado, curso de preparto en obra social).

En este fragmento de entrevista es posible ver cómo se tensionan dos posturas y dos formas de transitar la gestación de los propios hijos por parte de varones, que, de un modo u otro, encuentran intersticios de participación incluso en cursos que no tienen en claro cómo incluirlos (en el curso de la obra social no se incluyó ni en preguntas ni en la actividad física, por ejemplo, a los varones participantes, por tanto la tendencia de Damián a preguntar e interrogar y querer saber fue un dato interesante).

Por último y en menor medida se advierte el acompañamiento en el curso de otrxs sujetxs (madres, abuelas, amigas) en general mujeres, ratificando la tendencia hacia la feminización de las actividades de cuidado y de salud.

\subsubsection{SOBRE EL LUGAR DE LOS CURSOS: DÓNDE}

Aunque pueda parecer un detalle, el lugar donde se dictan los cursos implica e imprime características particulares que merecen ser analizadas.

En el hospital público, por ejemplo, el lugar del curso adquirió tal politicidad que fue objeto de disputas internas durante la remodelación de la maternidad. De ser dictado en un aula visible desde la guardia obstétrica, pasó a realizarse en un espacio al final del pasillo de la sala de internación de posparto. Un lugar oculto y escondido en el primer piso que, quienes conforman el equipo interdisciplinario, sostienen que refleja la decisión política de no promover esta clase de actividades. Lo paradójico es que para ingresar al curso que se dicta dos veces por semana, Ixs asistentes deben pasar por el pasillo entre las habitaciones hacia el aula del final, rompiendo dos reglas: a) entre las 7 de la mañana y las 12 del mediodía la maternidad prohíbe la presencia de "familiares" en ese espacio porque es el momento en que Ixs profesionales "hacen sala" (el control diario habitación por habitación del estado de salud de madre e hijx); b) está prohibido también que los varones que acaban de ser padres pasen por allí más que en el horario de visita por la posible "visión" de la desnudez de las puérperas internadas (tal como establecen como excusa políticamente correcta trabajadorxs del hospital y algunas 
usuarias). Entonces se da la paradoja de que si sos varón-padre, podés entrar al curso, pero al ocurrir el nacimiento de tu hijx, no vas a poder recorrer esos pasillos porque parece que (recién) en ese momento sos "amenaza" para las otras puérperas internadas.

El CPP de la clínica privada, por otro lado, no se realiza en las instituciones del sanatorio del que depende, sino en un sitio tercerizado: un consultorio médico en el barrio de Tolosa, gestionado individualmente por la partera a cargo del curso. Asimismo, el CPP del hospital privado se dicta en el aula magna de la institución. El CPP de la obra social se realiza en la sede en horario vespertino. El curso del gimnasio se dicta en la propia sede y esto le imprime características particulares: hay otra dinámica de los cuerpos, sentadxs en el piso, con colchonetas y pelotas grandes y cierta predisposición al trabajo físico. De hecho el lugar es coherente con la propuesta desmedicalizadora.

Sostengo que al poner luz sobre los espacios físicos de los cursos, es posible problematizar las decisiones y políticas institucionales sobre la prioridad y los espacios simbólicos que les asignan a las actividades de psicoprofilaxis las instituciones sanitarias y las iniciativas ministeriales. De hecho, en relación a la atención pública, si se trasladaran los CPP a los centros de Atención Primaria (CAPS, conocidos popularmente como "salitas") donde las mujeres realizan el seguimiento de sus embarazos, la participación aumentaría. La centralización del curso en el hospital analizado, por ejemplo, choca con la descentralización de los servicios de salud pública de nuestro sistema sanitario.

Por último, y no menos importante, en relación a la dimensión espacial de los cursos, existe cierta demanda común de las mujeres y la consideración de algunxs profesionales de la salud, sobre lo positivo de conocer, previo al nacimiento, la sala de parto, para despejar dudas, erradicar miedos y "bajar la ansiedad". Si bien algunas instituciones públicas y privadas pueden realizarlo, ninguno de los cursos de los que participé incluyó esta posibilidad, a pesar de la demanda de Ixs asistentes.

Tomando como punto de partida la consideración de que los CPP pueden ser una herramienta positiva para el empoderamiento de Ixs sujetxs en el tránsito de sus PEP o de mantenimiento del status quo, luego de esta presentación general, profundizaré en algunas dimensiones de análisis específicas, que permiten responder a algunas de mis preguntas de investigación. 


\subsection{LOS TIEMPOS, LOS PROCESOS}

Los modos de atender/transitar/concebir los PEP pueden responder y ampararse en lógicas de fines, centrados únicamente en el evento del nacimiento, o en lógicas de procesos, pensando en el continuo embarazo-parto-puerperio. Esto es, en los encuentros prenatales de los que participé y en los discursos que allí y en las entrevistas se (re)producen, pueden vislumbrarse las lógicas de trabajo y de abordaje que los equipos de salud proponen y que las mujeres y sus familias esperan. En lo que respecta a los contenidos vertidos en los CPP, es mayoritaria la demanda de las mujeres por enfocarse en el momento del parto: cómo identificar el comienzo del trabajo de parto, cuáles son las técnicas y habilidades para transitar las contracciones y cuáles son los signos de alarma para concurrir a la institución o tomar contacto con el/la profesional, principalmente. El trabajo o la apuesta de estos cursos es incorporar elementos de carácter procesual y pensar no sólo la instancia del parto, sino el tránsito del embarazo, convocando a la completitud de los controles prenatales, la toma de hábitos saludables y la preparación para el parto/la crianza/la maternidad/la paternidad/ la lactancia, por ejemplo, y el puerperio, centrándose principalmente en los cuidados del/ de la recién nacidx y la promoción de la lactancia materna. De todos modos, justamente por esa demanda de Ixs participantes de los cursos de enfocarse en el nacimiento, suelen ser menos atendidos estos otros contenidos.

La diferencia radica en pensar más allá del parto, incluirlo como punto de llegada o como punto de partida, como momento (lógica sincrónica) en un proceso (lógica diacrónica $)^{79}$.

"Lara: Intentamos como abrir un poco el juego, que no quede todo situado en que el asunto es el parto, digamos sino también qué implica, que el parto en realidad es un punto de llegada y un punto de partida también, como poder justamente relativizarlo a partir de eso, digamos de que es un momento, que no deja de ser importante y demás, obviamente por eso se le da el lugar y eso pero, pero que es un momento en un proceso que lleva mucho tiempo sino procesos anteriores y posteriores.

Guillermina: De hecho, el curso se llama por eso "preparación para la maternidad y paternidad", no es "curso de parto", o sea para nosotros lo nombramos así, lo que implica también pensar lo previo, las inquietudes que hay durante el embarazo, el parto y a ver, el puerperio y el momento posterior también, lo que es la crianza" (Entrevista 13: Equipo de psicólogas de la maternidad del hospital público).

\footnotetext{
79 A veces los nombres de los cursos dan la clave, en tanto se centran en el proceso del parto o en la
} preparación para el posparto (maternidad, crianza, etc). 
En este sentido, por ejemplo, la partera del CPP del mismo hospital público tiende en sus clases a ampliar, explícitamente, los contenidos más allá del momento del parto y habla de la alimentación sana, el ejercicio espiritual, la meditación y la educación espiritual como aprendizaje en el curso "para toda la vida".

"Flor contó que le da miedo el parto, el dolor, y Sandra, la partera a cargo, enfatizó en que el parto son dos horas, que se puede pedir epidural (dice que antes no se usaba y ahora sí), que el verdadero parto es la vida, la crianza de Ixs hijxs" (Diario de campo, 16/2/2017, curso hospital público).

La consideración del embarazo y el parto entendidos como proceso integral permite ver cómo las discusiones, negociaciones y disputas en torno a la asistencia del nacimiento se trabajan y procesan durante todo el embarazo. Entonces la asistencia al nacimiento sigue siendo un punto nodal aún en la consideración procesual.

Considero que esta oferta de información enfocada en el momento del parto de la mayoría de los CPP responde principalmente a la demanda de las mujeres asistentes, que viven con una diversidad de expectativas, miedos, inquietudes y emociones el momento del parto, cargado social, familiar y culturalmente de un entrecruzamiento de elementos que lo complejizan. Al estar atravesado por una heterogeneidad de sentidos y discursos, el parto se erige como el momento disruptivo que pone a prueba todo lo conocido y lo vivido por las mujeres y sus entornos, y allí radica la demanda de enfocar los cursos en él. Esto es visible, por ejemplo, en la menor atención que reciben los encuentros o clases especiales de los cursos sobre el embarazo o el posparto (lactancia y crianza, principalmente) en tanto no resuelven la pregunta principal con la que suelen acercarse a estos espacios: "¿cómo me voy a dar cuenta que estoy en trabajo de parto?". O sea que a pesar de ciertos esfuerzos de los grupos a cargo, el parto sigue siendo el protagonista. De todos modos, como se verá a continuación, los esfuerzos de integralidad perduran.

\subsubsection{CUIDADOS PRE Y POST PARTO}

La integralidad del proceso de embarazo, parto y posparto adquiere un papel protagónico en la totalidad de los CPP, en tanto destinan clases o encuentros a cada uno de los momentos de ese continuo y de hecho son mencionados en los títulos. Mencionaré algunos emergentes sobre la temporalidad del embarazo (a) y del posparto (b) que aportan al problema de investigación. 


\subsubsection{A) EMBARAZO: HÁBITOS SALUDABLE Y CUIDADOS PRENATALES}

En general, al realizarse el curso durante el embarazo, las menciones a este momento gestacional se trabajan desde el aspecto psicológico (los CPP que tienen en sus equipos profesionales de salud mental, suelen enfocarse en esto) y sino es visible que hay mayor detenimiento en el parto, por demanda de las mujeres, y en la triada posparto/crianza/lactancia.

Lo que pude notar es la existencia de dos tendencias, no excluyentes, sobre el abordaje del embarazo: la educación para la salud (adquisición de hábitos saludables), que implica un proceso de auto-compromiso con los cuidados de salud; y otra tendencia donde el embarazo y su tránsito se vinculan a (y se mencionan como) resultados de estudios médicos/ controles prenatales (CPN).

En este sentido, en relación a los controles prenatales, en algunos de los cursos se les mencionan a Ixs participantes cuáles son los estudios médicos básicos y más usuales por trimestre y en esta enumeración es posible ver rasgos del modelo de atención (más medicalizante o más fisiologicista) que propugnan y (re)producen / indican para quienes asisten. Así, por ejemplo, en el curso de la obra social, la médica obstetra a cargo que se autonombra "opuesta al sobreintervencionismo", establece una posición equilibrada entre ambas tendencias obstétricas polares. Así, sostiene que hay estudios/análisis que "no son negociables", es decir, que deben hacerse sí o sí, y en paralelo afirma que hay que apegarse a "lo estrictamente necesario", evitando el exceso de estudios y la mercantilización ${ }^{80}$ a la que se asiste.

"La medica obstetra contó cuáles eran los controles prenatales: tres ecografías en todo el embarazo, que no es necesario hacer más. Contó, usando diminutivos algunas veces, que cada ecografía tiene un sentido, que se escuchan los latidos del bebé, que se toma la presión y que hay otros estudios más específicos que se pueden ir indicando en caso de que sea necesario (mencionó un estudio que apunta a conocer las malformaciones del bebé, u otros más específicos en caso de diabetes e hipertensión)" (Diario de campo, 19/9/2016, Curso Obra social).

Al mismo tiempo, la cuestión de los CPN es un espacio apropiado por la atención del/ de la médicx obstetra de cabecera (o del servicio, en el caso del hospital público),

\footnotetext{
${ }^{80} \mathrm{El}$ ejemplo fundamental es el de las ecografías 4d que se realizan entre el segundo y tercer trimestre de embarazo, no aportan información médica relevante, son de pago privado (rondan los 1500 pesos según sondeé en febrero de 2019 para los dos establecimientos que las ofrecen en La Plata) y se entregan con llaveros y otros souvenirs. Su éxito radica en que permiten ver/adivinar/sospechar la carita del/de la bebx.
} 
por lo que incluirlos como temario en los CPP a veces actúa como un acto contrahegemónico de información y democratización del saber médico.

"La partera se dedica un rato a hablar de la educación sexual y de la sífilis. Menciona como siempre su cruzada por la educación y que no puede ser que no sepamos qué es. Menciona la VDRL, como una de las analíticas y empieza a pedirles que le muestren estudios y análisis. Una chica que está sola le da sus estudios, y ella nos muestra a todos dónde está el resultado (en tono de reto). Llama a la responsabilización por la salud, por la propia salud. Conocer y preguntarle al médico qué es cada resultado" (Diario de campo, 2/3/2017, Curso hospital público).

En esta cita (pero más en la situación narrada) es posible advertir la tensión presente entre la entrega al saber médico, que se profesa en las experiencias concretas, y la autorresponsabilización (principalmente desde la información) que se propugna en los cursos.

De todos modos, sobre el abordaje que se realiza del embarazo, en los cursos se presupone la realización y completitud de los CPN y suele promoverse la adquisición de hábitos saludables en relación, principalmente, a la alimentación pero no se expone demasiado sobre esto, se lo da también por sentado y sin mayor desarrollo como: "evitar la sal", "no fumar", "no tomar alcohol". Este elemento que aparece como obvio y de sentido común, emerge más que nada como corroboración en los cursos de que las mujeres están haciendo las cosas bien, aunque sospecho que la educación para la salud en estos términos debe realizarse más en las consultas particulares con Ixs médicxs obstetras y por eso aquí no se despliegan.

Lo que es interesante es que la mujer pasó de ser el "receptáculo" del feto al "intermediario" con el mundo exterior: lo que le pasa (emociones, alimentos, actividad física) a la mamá, le llega a su bebx. Esta visión de la mujer gestante como responsable/culpable del desarrollo y bienestar del feto en el útero materno es otro de los a priori indiscutibles en la mayoría de los espacios. Al respecto, Montes Muñoz (2008) analiza algunas dimensiones del cuerpo de la mujer gestante en la atención obstétrica: el "sospechoso" (deficiente, generador de riesgos e imprevisible ${ }^{81}$ ) y el "responsable" o autocontrolado.

\footnotetext{
81 "La interiorización de los discursos médicos de sospecha sobre las funciones de los cuerpos gestantes mantienen el recelo de muchas mujeres, aunque cuando más tomará forma esta idea será en las últimas semanas con los acontecimientos que señalan el inicio del parto. Se sigue apreciando la afirmación que trabajó Martin (1992) de que se impone la necesidad de tener las actividades de los cuerpos femeninos controladas y reguladas según el orden que se inscribe en una concepción uniformadora del
} 
"Cuerpo responsable. Desde el inicio de la gestación, se espera que las mujeres introduzcan cambios en su forma de vida y en beneficio del embrión. Lo más habitual es poner cuidado en aquello que se introduce en el cuerpo como es el control de los alimentos y tóxicos. Pero además, debe proporcionarse un estado emocional favorable, algo que también se supone influirá en la criatura gestada" (Montes Muñoz, 2008, p.4).

En paralelo, Blázquez Rodríguez (2005) retoma los trabajos de Imaz en los que establece las "representaciones del cuerpo embarazado de la mujer, a través de las prescripciones médicas y la imposición de diferentes modelos de subjetividad en la mujer" (p. 7). Y menciona tres modelos: el modelo fusión madre-hijx, el del cuerpo invadido o modelo del parasitismo y el cuerpo escindido, en el que el cuerpo de la mujer contiene en sí a otro individuo pero diferente de él. Estas son solo algunas de las clasificaciones teóricas que se han producido para mostrar cómo la ciencia médica codifica, cosifica y piensa el cuerpo gestante, asignándole comportamientos esperados y responsabilidades.

\subsubsection{B) PUERPERIO: CUIDADOS DE LA MUJER, CUIDADOS DEL RECIÉN NACIDO.}

Existe mayor desarrollo en lo referido a la continuidad de cuidados en el posparto en relación a cinco ejes principales, que varían su desarrollo de curso a curso: i.) puerperio, cuidados de la mujer; ii.) cuidados de Ixs recién nacidxs; iii.) lactancia; iv.) crianza; y, v.) métodos anticonceptivos.

Antes de dar cuenta de algunas de estas dimensiones, diré que en estos temas advertí la convivencia y disputa de diferentes versiones y "escuelas". Me refiero, por ejemplo, a la imposición versus la libertad de elección sobre la lactancia; o al fomento o prohibición de la leche de fórmula / chupete / colecho ${ }^{82} /$ apego $^{83}$ / etc. La información y las posturas ideológicas que conlleva, son visibles en estos encuentros de temas específicos, y de acuerdo al equipo de salud, profesionales o instituciones a cargo, se

funcionamiento-máquina de todos los cuerpos. Por otro lado, entiendo que el control responde también al interés político en la necesidad de regulación y apropiación de los cuerpos (Foucault, 1990:125; Scheper Hughes y Lock, 1987:26), a los que normativiza y adoctrina, función que ejerce la medicina manteniendo y reforzando una ideología jerárquica entre quién tiene el poder y quién no y entre quién sabe y quién no. El discurso del riesgo, más allá de sus funciones de prevención, viene a reafirmar el poder médico y el control social e ideológico de las mujeres" (Montes Muñoz, 2008, p.4).

82 "Colecho" se refiere a la práctica de dormir en la misma cama con el/la bebx.

${ }^{83} \mathrm{El}$ apego se refiere a una crianza donde se carga (literalmente, a través de diversos elementos como telas, guaguas, fulares, etc) o portea a lxs bebxs, cerca del pecho de la madre mientras realiza sus tareas. Asimismo se opone a una ideología de crianza que se popularizó en la década del 90, con una tendencia que nació con el libro “Duermete niño” de Eduard Estivill de 1995, en el que se generó una imagen de lxs niñxs como "manipuladorxs", "controladorxs de los tiempos de lxs padres y madres”, etc. La crianza con apego (aquí descripta muy sucintamente) supone entonces una crianza amorosa, afectiva, cercana. 
desarrollarán de una u otra forma. Esto es, en los cursos suelen establecerse normatividades y hasta construcciones punitivas sobre las mujeres que deciden no dar la teta o que duermen con sus hijxs o que usan el chupete para calmar los llantos. Depende la posición ideológica que tenga el grupo o el/la profesional a cargo, se hablará de estos temas con una tónica moral específica: estimulando o desestimulando el uso del chupete, incentivando o desincentivando el colecho, promoviendo o dejando a la libre decisión de la mujer la lactancia, etc.

Es central remarcar que sea cual sea la elección o decisión sobre estos ejes, la responsabilidad de esta continuidad de cuidados recae fundamentalmente en la mujer, reforzando a su vez la dificultad conceptual y práctica de propiciar el involucramiento de los varones-padres también post-nacimiento ${ }^{84}$.

Sobre los cuidados de las mujeres en el posparto, no hay un igual desarrollo en todos los CPP: dado el protagonismo absoluto que se le da a Ixs recién nacidxs luego del parto, las parturientas asumen un segundo plano. La mención más clara sobre los cuidados de las puérperas se realizó en el curso de la clínica privada en relación a la limpieza de las cicatrices generadas por la intervención médica (cesárea o episiotomía).

Por otro lado, los cuidados de Ixs recién nacidxs sí adquieren importancia nodal en los cursos, y muchas veces se ofrecen clases específicas sobre el tema. Por ejemplo, en el curso del hospital privado se dedica todo el encuentro del módulo pediátrico a establecer las condiciones de "normalidad" y "no-normalidad", o sea, de alarma, para identificar en el/la recién nacidx los primeros días y concurrir, de ser necesario, a la atención sanitaria. Incluso en el libro digital que se entrega las cuestiones sobre los cuidados del/de la recién nacidx y la lactancia ocupan el $90 \%$ de su contenido. En paralelo, el hospital público ofrece una clase especial sobre estos cuidados a cargo de un neonatólogo, y el resto de los cursos suele tratar el tema en las clases de lactancia.

El eje de lactancia suele ocupar un espacio privilegiado en los cursos; espacio que resulta a veces demasiado extenso durante el tránsito del embarazo, al punto de ser menos atendido por Ixs asistentes. Durante las entrevistas en postparto que realicé a parejas (por la estrategia metodológica de seguimiento), advertí que los principales problemas que refieren, paradójicamente tienen que ver con las dificultades en la lactancia (que fueron las "clases" menos atendidas). Eso le da otra explicación al

\footnotetext{
${ }^{84} \mathrm{Al}$ respecto es ineludible la referencia a la feminización de los cuidados y las teorías al respecto, como la producida por Federici.
} 
predominio de estos temas en los CPP como esfuerzo de los equipos a cargo, aunque no sean valorizados a tiempo por Ixs participantes.

La cuestión del amamantamiento genera muchas dudas y preguntas entre Ixs asistentes, lo que me hizo reflexionar sobre lo poco que se ha transmitido sobre la lactancia, las posiciones, los dolores, las previsiones, los horarios, la demanda, etc.: ¿será que la lactancia está tan naturalizada que se ha creído que no es necesario enseñarla-aprenderla? Pareciera que se naturaliza y por ello no se la problematiza ni se la cuestiona ni se la enseña ni se la aprende, y las dificultades a la hora de amamantar son las que más frustraciones suelen provocar en las madres "yo debería saber hacerlo". ¿Deberíamos saberlo o podríamos compartirlo, hablarlo, con pares mujeres? La lactancia parece establecerse como una obligación social, convirtiéndose en otro mandato sobre las mujeres y sus procesos reproductivos y sus relaciones sociales. Así, las cuestiones acerca del saber construido que implica, son puntas para seguir pensando.

Por último, el desarrollo de los temarios de crianza y métodos anticonceptivos aparecen, aunque en menor envergadura, y a veces en clases especiales, que, como pasa con la lactancia y todos los temas que no se enfocan en el momento del parto, no reciben tanta atención por parte de Ixs asistentes.

En resumen, en lo que se trabaja en los CPP en relación a los cuidados en el pre y posparto, lo constante e ineludible es el continuum de tutela médica por el que transitan y al que son sometidas las mujeres y su entorno: pasan de la tutela del obstetra (embarazo) a la de la dupla obstetra/partera (parto y posparto) a la del pediatra. Este continuum es paralelo al itinerario asistencial, dicho de otro modo, las intervenciones médicas simbólicas de dominación son paralelas (causa y efecto, retroalimentadas) a las intervenciones práctico-clínicas sobre los procesos corporales.

\subsubsection{LA ESPERA COMO MECANISMO DISCIPLINADOR}

Durante la atención del embarazo y el momento particular de la asistencia a los cursos que se dan entre las 30 y las 35 semanas de gestación, se despliegan otros elementos que hacen a la transmisión de objetivos de la hegemonía médica institucional. Por ello, si hablamos de los tiempos y los procesos durante la atención obstétrica, es necesario dedicarle un espacio no solo a los tiempos "fisiológicos" o "de la 
naturaleza, del cuerpo", del proceso reproductivo, sino a los tiempos institucionales que moldean y "corrigen" (esa es la palabra médica) a los primeros.

Es posible mencionar entonces el límite arbitrario de "esperar" el desencadenamiento de un trabajo de parto hasta la semana 39, 40 o 41 según la institución de que se trate (siendo que el parto de bajo riesgo puede ser hasta la semana 42); y en caso de que no ocurra, recurrir a la inducción medicamentosa. Todo el arsenal farmacológico dispuesto al control de los tiempos de los períodos dilatante y expulsivo (y el alumbramiento de la placenta) de los trabajos de parto, que deben ajustarse a un partograma de evolución universal y estandarizado (cuya aplicación está desaconsejada por la OMS hace años), es otro de los ejemplos de cómo el análisis no sólo de la espacialidad, sino de la temporalidad de los PEP que producen las instituciones de abordaje hegemónico, es urgente y necesario.

Y junto a este tipo de controles, durante mi trabajo de campo, principalmente en la maternidad pública pero en todos los espacios visitados, se hizo tangible el uso de la espera como mecanismo disciplinador de las mujeres, mayoritariamente pobres. Me refiero a ese efecto de las relaciones de poder, por las cuales el tiempo y su gestión se vuelven un recurso y dispositivo para la pacientización. "La lógica institucional limita por esta vía la autonomía de la persona imponiéndole sus ritmos” (Magnone Aleman, 2010, p. 90). De hecho, en las entrevistas y charlas informales noté que algunas mujeres y su entorno realizan la búsqueda del ámbito de atención y/o de Ixs profesionales de la salud, en torno a la posibilidad de gestionar la espera, lo que puede ser interpretado como un privilegio de clase.

\begin{abstract}
"Johana: Ella [su obstetra] me atendía en el Hospital Privado pero yo me estaba atendiendo en otro lugar donde ella atiende donde hay menos gente, otro consultorio, externo, digamos, ajeno del hospital, que es donde seguí todo el embarazo. No me queda más cómodo porque claramente el Hospital privado me queda acá, más cerca, pero, me quedaba más cómodo en cuanto a espera Eh, entonces yo voy y tenés, ponele, una, dos personas adelante. No tenés tanta espera" (Entrevista 17, Johana y Damián, parto en hospital privado, curso de preparto en obra social).
\end{abstract}

Lo que emerge es que sea el ámbito que sea, las mujeres negocian el tiempo de espera: en el embarazo, el hospital te hace esperar; en el parto, el hospital te espera a vos o te apura (como si el desencadenamiento del trabajo de parto fuera una acción voluntaria de las mujeres). Esto es visible en el simple hecho de las horas que mujeres embarazadas pasan en salas de espera para hacerse estudios o para acceder a la consulta con el/la médicx obstetra. En los relatos y en las charlas informales se 
menciona como una situación "inevitable" y hasta característica de todos los sistemas de atención "tal doctor/a te da turno para dentro de dos meses", "tenés dos horas de espera siempre". Esta espera como mecanismo disciplinador que dispone la autoridad médica e institucional se da tanto en el ámbito público como en el privado (aunque en el primero está extendidamente naturalizado/normalizado y no se reduce sólo a la atención obstétrica) $)^{85}$.

"En las interacciones sociales se conforman, se negocian, se tensionan, se (re)definen y se (re)actualizan sentidos, representaciones y actividades que cristalizan relaciones sociales de poder bajo determinadas lógicas temporales. Nuestra vida cotidiana está atravesada por situaciones donde el tiempo aparece como un mecanismo de subordinación y resistencia. Una manera de comprenderlo es a través del análisis de las esperas. Éstas, según diversos autores se configuran en tanto prácticas y disposiciones como mecanismos de soportabilidad social (Scribano, 2010), y/o como mecanismos de poder (Auyero, 2013)" (Romero Marchesini, 2018, p. 5).

Entonces, si en relación al embarazo y los CPN, la autoridad médica te hace esperar; al momento del parto se invierte esa cuestión y ahora "te espera" a vos. La institución sanitaria impone tiempos límites arbitrarios al desarrollo del embarazo y somete a las embarazadas a una encrucijada un tanto irracional: "te espero hasta la semana 40 y si no te induzco o vamos a cesárea", como si ellas pudieran determinar voluntariamente la segregación de las hormonas necesarias para el comienzo del trabajo de parto. En este punto es clave recordar que, tal como expuse en el capítulo 3 , las normativas internacionales, nacionales y provinciales de la atención al PEP normal o de bajo riesgo establecen que hasta la semana 42 de gestación, se debe considerar (y en consecuencia asistir) al embarazo y parto como de bajo riesgo. ¿A qué obedece entones el límite institucional del tiempo que es diferente al fisiológico? Las respuestas que puedo esbozar en base a la inserción en campo, varían entre cuestiones

\footnotetext{
${ }_{85}$ Romero Marchesini (2018, p. 5) hace un extenso análisis de estudios que se han concentrado en las temporalidades institucionales, sociales y estructurales alrededor del proceso salud/enfermedad/atención y establece que estos "diversos estudios que destacan una lógica de rutinización médico-burocrática (Ballesteros, 2016; Margulies, 2014; García et al., 2017), estándares de atención (García, 2013), y una normalización de la atención a la salud y enfermedad (Ferrero, 2003). Estos procesos se pueden visualizar en distintas situaciones como en las demoras en la asignación de turnos para la asistencia médica, los tiempo del adentro y afuera de las consultas médicas, las salas de espera, la dilación en el ingreso a una guardia, los vaivenes y papeleos para una internación, la latencia antes de retornar a los quehaceres cotidianos, entre otros. En términos generales, los trabajos recuperados acuerdan que la rutinización y estandarización de las prácticas dentro de las instituciones médicas, relevadas principalmente en hospitales públicos, se inscriben en un entramado que evidencia la organización burocrática de la institución con el fin de regular las interacciones que allí se producen. No obstante, esas normatividades en términos de procedimientos técnico-burocráticos se presentan como una forma enmascarada y una estrategia de ocultamiento de su dimensión sociopolítica (Hernáez, 2011 )”.
} 
relacionadas al control económico y cultural-institucional, el miedo médico al "devenir de la naturaleza fisiológica", la necesidad de gestionar camas hospitalarias, etc. ${ }^{86}$.

En este sentido, la etnografía sanitaria (Blázquez Rodríguez, 2005) en la sala de espera del hospital público me permitió captar que se imprime una lógica en la que, como en la atención del parto las mujeres se atienden sin hacerlas esperar (acelerando el proceso), no se quejan de la calidad o formas de esa asistencia. Es decir, si internalizan durante (y tras) 9 meses de gestación y espera en los CPN que la atención es un privilegio o un resultado tras horas y diversos sacrificios de organización doméstica y familiar (la atención obstétrica en ese hospital es de 7 a 9 para los controles, horario escolar y laboral), al momento del parto ya habrán sido domesticadas en lo que pueden esperar/merecer/recibir. Además la atención "gratuita" del sistema público, alimenta esta idea de conformarse con la asistencia recibida, así sea tras horas de espera. Después de todo, ¿qué significa ser "paciente" sino esperar?

"Lo que define a la espera de los más desposeídos es la arbitrariedad y la incertidumbre, como efectos no intencionales de los actores estatales. Puede haber funcionarios que expresen sexismo, elitismo, racismo, pero hay más bien una estrategia sin estratega. Lo que define a esa espera es la indiferencia burocrática. Entonces, en esa espera se genera lo opuesto de la ciudadanía. En vez de ciudadanos, hay pacientes del Estado, subjetividades que saben que van a recibir algo, un subsidio, un servicio, un derecho, si aprenden a esperar y a no retobarse, a administrar la frustración del "venga mañana, venga pasado". En esa manipulación del tiempo del otro lo que se está ejerciendo es un tipo de dominación política. Los sujetos aprenden a subordinarse y lo que termina ocurriendo es que el Estado termina perpetuando el sufrimiento, cuando lo que debería hacer es dar alivio" (Auyero ${ }^{87}$ ).

En síntesis, el uso del tiempo también aquí se constituye como un capital y un elemento de poder y dominación, y por tanto su explotación, estiramiento y aceleración son claves en la atención obstétrica de los PEP.

\footnotetext{
${ }^{86}$ En su trabajo, Schwartz (2010a, p. 97) se refiere a ese miedo profesional, ligado al paradigma del riesgo obstétrico: "Los médicos entrevistados se referían a la inseguridad e imprevisibilidad que sentían frente a un parto "natural". Afirmaban que este tipo de parto era deseable, pues es la vía biológicamente determinada, pero alegaban que la cesárea era más previsible y rápida, disminuyendo de manera considerable la cantidad de horas dedicadas al parto".

87 En una entrevista al respecto de su libro "Pacientes del Estado", disponible en http://rodriguezesteban.blogspot.com/2014/11/la-espera-como-espacio-de.html
} 


\section{3.“¿CÓMO SÉ QUE ESTOY EN TRABAJO DE PARTO?”: CONOCIMIENTO DEL CUERPO MEDIADO POR EL SABER MÉDICO.}

"El modo en que la ciencia ha descrito a las mujeres, lo femenino, la sexualidad, no tiene desperdicio. Sobre todo las ciencias biomédicas nos han dicho cómo ser, cómo gozar, cómo parir, cómo sentir, cómo (no) pensar, cómo enfermar y cómo morir. Todavía hoy nos cuesta vincularnos con nuestro cuerpo sin su mediación" (Maffía, 2001, p. 408, citada en Camacaro Cuevas, 2008b, p. 300).

En el embarazo y con el primer contacto con el servicio sanitario se activan dos dispositivos o prácticas simbólicas de la hegemonía médica interrelacionados que se irán repitiendo y reforzando durante todo el PEP: el etiquetamiento del riesgo reproductivo y otra serie de decisiones médicas ajenas a la voluntad de la mujer; y el conocimiento del propio cuerpo mediado por el/la profesional o la tecnología médica. Esto es, sabemos que estamos embarazadas porque lo dice un análisis de sangre o una ecografía; y por lo mismo sabemos de cuántas semanas de gestación estamos y de ahí se definen fechas, intervenciones y el momento del nacimiento; sabemos que el/la bebé vive porque una máquina registra sus latidos; sabemos que crece por otra ecografía y hasta podemos "verle" la cara; sabemos que estamos por parir porque los dedos del tacto médico lo indican ${ }^{88}$. $Y$ todo esto es una intervención/ construcción cultural y política, con origen histórico identificado, sobre nuestros cuerpos y nuestros procesos reproductivos: los scores de riesgo refuerzan la necesidad de la asistencia médica que se justifica durante el PEP en esa mediación del conocimiento de nuestros cuerpos y de sus procesos fisiológicos.

Esta mediación médica busca hacer asequibles, mediante la interpretación (falible, construida) síntomas y datos corporales, y a veces funciona como profecía autocumplida por medio de la sugestión ${ }^{89}$. Ante esta confirmación de experiencias y conocimientos de cuerpos mediados por la interpretación médica, surge la pregunta sobre cuál tiene mayor nivel de verdad: ¿la información interpretativa médica o la experiencia corporal-emocional-física de la mujer aunque se contradigan? En las

\footnotetext{
$88 \mathrm{Al}$ respecto de los tactos, Camacaro Cuevas (2009, p. 149) sostiene que constituyen una expresión del saber-poder médico: "el tacto realizado por médicos/as y estudiantes constituye un evento significante en la interacción mujer-autoridad médica. A través del tacto técnico, el poder del saber médico dirige y controla el trabajo del parto". Junto a ello, Sadler (2004, p. 16) sostiene que "En sistemas de partos tecnologizados, como el nuestro, el conocimiento adquirido a través del tacto se encuentra subordinado a la información externa que proveen los equipos electrónicos y los tests bioquímicos, los cuales suponen la inmovilización física y penetración del cuerpo de la mujer con instrumentos de diagnóstico y tratamiento. En este contexto sólo algunos individuos pueden tocar a la mujer parturienta”.

${ }^{89}$ Con esto me refiero a cuando los ecógrafos establecen fechas límites o problemas del líquido amniótico o datos que las mujeres no "sienten en sus cuerpos" y por la autoridad médica (sostenida o avalada por equipamiento de diagnóstico), adquieren el carácter de sentencia.
} 
entrevistas y charlas informales muchas veces surgió, por ejemplo, que el peso del bebé que salía en las ecografías no era el que se comprobaba en el nacimiento, o que por lo que indicaba la fecha probable de parto (decidida por el aparato ecógrafo) ya era necesario inducir un parto y al momento del nacimiento y en el momento de medir el perímetro craneal del neonato se conocía que se había actuado anticipadamente ${ }^{90}$. Por esto sostengo que en estas intervenciones simbólicas que se van potenciando durante todo el embarazo es posible vislumbrar intersticios de poder por los que se actualiza la hegemonía médica: Ixs profesionales de la salud interpretan (interpretación como ejercicio de poder) las señales que envía el cuerpo y que se toman como dato objetivo en la práctica médica, por sobre lo que expresan las mujeres y sus interpretaciones sobre sí mismas. Y como toda hegemonía, se reproduce: la desconfianza médica en el cuerpo gestante (sustrato biológico objetivo) se materializa en estudios que la contagian a la mujer y a su entorno, y que termina desconfiando de su propio cuerpo y su capacidad fisiológica de gestar-parir.

Así, se construye sobre el cuerpo gestante una visión médica particular que lo concibe defectuoso, asequible solo por medios médicos, otorgándose y legitimándose así como voz autorizada para entenderlo y disponer las intervenciones. A su vez, socialmente se acepta y legitima esa visión. Este proceso de internalización de la visión médica del cuerpo gestante (escindido de las percepciones subjetivas que le son inherentes por ser un cuerpo humano) lleva en sí una contradicción que responde a intereses y coyunturas culturales y políticas: los cuerpos de las mujeres parecen ser potencialmente defectuosos para gestar y parir, por lo cual es necesario un riguroso control, acompañamiento y conducción médica. La metáfora cuerpo-máquina (buen/mal funcionamiento) asegura una "normalidad" estandarizada (un tipo de normalidad) de la que todo cuerpo concreto es posible que se desvíe ${ }^{91}$. En esa posibilidad de desviación, me parece, se asienta la necesariedad del control médico: una necesariedad que por un lado lo justifica pero a la vez lo habilita como posibilidad. Y junto a la idea del cuerpo

\footnotetext{
90 En palabras simples, se sabe en el campo que la fecha probable de parto que estipula el aparato de ecografía "puede fallar", sin embargo este dato se pone entre paréntesis, y se adelantan o aceleran nacimientos.

91 "La metáfora del cuerpo como máquina tiene distinción de género. Mientras el cuerpo masculino es tomado como ideal, el cuerpo femenino fue concebido históricamente como una máquina defectuosa, en consecuencia: “(...) a pesar de la creciente aceptación del parto como algo mecánico,(...), pasó a ser visto como un proceso mecánico inherentemente imperfecto y poco fiable, y la metáfora del cuerpo femeninocomo una máquina defectuosa finalmente formó la base filosófica de la obstetricia moderna”. (Davis Floyd, 2001:3)” (Magnone Aleman, 2013, p. 84).
} 
gestante defectuoso, paradójicamente, se naturaliza la capacidad (y el deseo) del cuerpo materno de amamantar, negando las dificultades en la lactancia de las mujeres amparándose en una fisiología perfecta, pero que falla para otras fases del PEP.

La mediación médica tal como la expreso aquí comienza desde la misma noticia del embarazo, se reactualiza durante todo el proceso perinatal y se potencia durante el trabajo de parto y parto, constituyéndose en un constante en el continuo de la tutela médica. Me refiero a que en el trabajo de campo, en charlas informales y hasta cotidianamente, se advierte que las mujeres, sus parejas, su entorno y su médicx "confirman" la noticia del embarazo recién cuando existe un "certificado" médico: analítico o ecografía. A pesar de que la ausencia del período menstrual o la propia percepción de las mujeres tiende a confirmar la concepción; y a pesar también de que el primer mediador de tecnología médica (test de embarazo de venta libre en farmacias) así lo indica, es recién con el aval médico que se tiene certeza. Esto que aparece como lógico y obvio, es efecto (y causa) de la naturalización de la necesariedad de la intervención y participación médica desde el principio: el conocimiento del propio cuerpo y de los propios procesos sexuales y reproductivos está mediado o depende de la interpretación (y reconocimiento) médico-tecnológica.

Cuando distintxs autorxs, como se señaló en el marco conceptual, visibilizamos y problematizamos la conquista y expropiación que (re)producen las intervenciones médicas en los PEP; nos referimos también a esto. A la desconexión que legitima que "necesitemos" que un/a otrx, portador de un saber experto, asevere / confirme / decrete lo que pasa en nuestro cuerpo, deslegitimando así los sentimientos, actitudes, percepciones. Y la expropiación de los saberes propios es la que garantiza que mediante una intervención médica (diagnóstico por imágenes, tactos, monitoreos), nos confirmen que él/la bebé/a está encajadx o prestx para salir.

Lo que me interesa destacar es que este conocimiento no experto, no académico y no científico sobre el cuerpo femenino y el proceso de embarazo que sí tienen Ixs legos, se destapa / emerge y se hace presente cuando las mujeres sienten la ausencia de movimientos fetales, por ejemplo, lo que activa una serie de acciones, que en general concluirán con la certificación médica (mediante monitoreos fetales u otros exámenes) de la confirmación del diagnóstico de la mujer gestante. O sea que sí existe un saber que puede ser confiable y genera todo un repertorio de acciones, aunque no 
esté certificado por la academia. Esto emerge en muchos relatos en los que las mujeres mencionan que ellas sintieron cambios en su cuerpo durante el proceso perinatal, que motorizaron que consultaran con su médicx, desde sentirse o saberse embarazadas hasta advertir cambios en los movimiento fetales o sentir que el/la bebx "se encajó".

Esta mediación médica se reactualiza constantemente en el embarazo, y no me refiero a los CPN regulares y básicos según la perspectiva médico-clínica, sino al exceso de ecografías que, por ejemplo, se inscriben en el proceso de mercantilización médica de la experiencia gestacional. Existe un mercado floreciente (hegemónico, por tanto, demandado y legitimado por Ixs usuarixs) de ecografías "4d" que no aportan ninguna información médica relevante, pero que permiten "espiar" la vida intrauterina. En este caso, la tecnología médica se pone al servicio o (re)produce, amparada en la lógica de mediación "profesional" del conocimiento del propio cuerpo, la mercantilización del PEP.

Como aseveré, dicha mediación comienza con la mismísima concepción, aunque en el título del apartado refiera sólo al momento del parto. Por ejemplo, Johana y Damián (con quienes realicé el curso de la obra social) conocían su ciclo menstrual, ella sintió que estaba embarazada, a pesar de que el primer test dio negativo, insistió y el segundo le dio positivo, y de todos modos, aunque ella ya lo sabía, necesitó corroborar $100 \%$ por medio de una ecografía que estaba embarazada.

"Johana: Siempre fui re regular. Entonces yo sabía cuándo me venía, cuándo estaba ovulando, todo, y esa noche nosotros tuvimos relaciones y no nos cuidamos y yo le dije "mirá que estoy ovulando". A la semana nos hicimos un test y nos dio negativo, pero a mí me tenía que venir ponele un viernes y el martes no me vino. El martes me hice el test de embarazo y me dio positivo. Eh, ya sabíamos, viste, ¿viste cuando lo sabes? Damián: Ella ya sospechaba de que, cambios en el de ella, digamos, intuía que estaba embarazada igual a pesar de que el test nos había dado negativo, digamos, ¿no? Después cuando hicimos la segunda vez que dio positivo, bueno, ta, sí. Ahí ya con todo, ¿no?

Johana: Entonces, primero en realidad fuimos a ver a una guardia, ¿te acordás que primero hicimos una ecografía primero que no se veía nada? Que se veía el saco, digamos (...) Y bueno, nos dijo que, todavía no se iba a haber nada pero nos mandaron a hacer una ecografía en la que se veía un saco, o sea para corroborar de que estaba embarazada 100\%" (Entrevista 17, Johana y Damián, parto en hospital privado, curso de preparto en obra social).

Es posible que esta cita revele uno de los principales anclajes de la hegemonía de la visión médica sobre el PEP tal como la vengo describiendo: la internalización y 
legitimación de lxs usuarixs de la necesidad de la intervención asistencial ${ }^{92}$. De todos modos, esta serie de intervenciones médicas durante el proceso de embarazo que tienden a mediar el conocimiento del cuerpo y ratificarlo, son pocas al lado de todas las que se despliegan en relación al trabajo de parto y el parto.

Tomando como base común que en la atención hegemónica es el/la profesional médicx quien decreta o certifica el comienzo del parto en términos de la admisión institucional, en las distintas observaciones que realicé, la demanda común de las mujeres en todos los cursos, transmitida como miedo principal, es a no saber cuándo están en trabajo de parto (o, mejor dicho, cuándo su proceso reproductivo encaja en las normas institucionales de aceptación e internación). Mi hipótesis sostiene que, sumado a que se trata de una experiencia nueva y desconocida para Ixs usuarixs, eso se debe a un profundo desconocimiento del propio cuerpo, de los cambios en el propio cuerpo y de los procesos fisiológicos de la reproducción, que en parte responde al proceso de construcción de hegemonía en que la medicina ocupa un lugar central, en tanto es causa y a la vez efecto de la legitimación de las intervenciones médicas en los PEP. Esto es, que los saberes legos sean infravalorados o no se les de la entidad o importancia entre las mujeres, permite/produce/obliga el control y acompañamiento médico del proceso. Lo explica y es explicado.

'Lara: Para mi hay algo de la creciente medicalización de la vida cotidiana que hace que pareciera que es el médico el que te puede decir qué te está pasando en el cuerpo; o sea hay algo de eso, el saber está puesto en el otro. Lo que nosotros también intentamos laburar con el curso es bueno, qué saberes hay con respecto a la maternidad y a la paternidad, más allá de venir a buscar el saber médico, digamos. Guillermina: Lo que se pasa entre ellas digamos" (Entrevista 13: Equipo de psicólogas de la maternidad del hospital público).

Esta "transferencia del saber", que se ampara en el proceso de medicalización, es, no deberíamos negarlo, la que sostiene la estructura de los cursos: muchas veces lo que no se sabe de antemano ni es respondido por Ixs profesionales de la salud en las consultas prenatales, se espera que se responda en los CPP. Dicho de otro modo: muchas veces Ixs médicxs delegan esa transmisión del saber (formal o informal) a otros

\footnotetext{
$92 \mathrm{Al}$ respecto, Laplacette y Vignau, 2008, p. 65 sostienen que: "los grupos socialmente más vulnerables y desplazados adoptan, total o parcialmente, representaciones sociales producidas por los grupos hegemónicos (Souza Minayo, 1995). En este sentido, algunos grupos sociales incorporan acríticamente de los discursos imperantes algunas prácticas no protectoras para su salud. Como parte de ese discurso, ampliamente difundido, la población legitima la medicalización de la salud y de su vida cotidiana sin indagar las razones científicas que la sustentan”.
} 
espacios, como éstos, lo que mencionamos anteriormente en términos de "su pregunta sí molesta”.

Este dispositivo, entonces, implica un conocimiento del cuerpo mediado por un aparato tecnológico (ecografía) o por el saber médico ("el médico me va a decir"). En este sentido, emerge como tema clave de los cursos la puesta en común, más bien la transmisión unilateral médica, de "pautas de alarma", con toda la ratificación del paradigma de riesgo que esta palabra indica, que las mujeres y su entorno deben tener en cuenta para concurrir a la institución o tomar contacto con Ixs profesionales médicxs. Esto responde a una doble demanda: la de las mujeres, que necesitan saber cómo van a darse cuenta que están en trabajo de parto (TP), y para ello consultan al "saber experto" médico-científico; y la de la institución, que busca garantizar dos objetivos. Primero, la disminución de las consultas infructuosas (o "falsas alarmas") que se dan cuando el proceso de parto no se ajusta a las normas institucionales (se internan mujeres sólo a partir de los 4 centímetros de dilatación del cuello del útero); y, segundo y simultáneamente, la transmisión de la información médica asociada al enfoque de riesgo sobre posibles patologías en el proceso.

Entonces la interpretación médica de las señales del cuerpo tiene su cúspide en el momento del comienzo del TP. Cada curso da su "formulita" (textual) o ayuda memoria para "bajar la ansiedad" de las mujeres y su pareja, llamando a cualificar y cuantificar las contracciones, que una vez que cumplen los requisitos de ser constantes, seguidas e intensas, autorizan a la mujer gestante a tomar contacto con el/la profesional o la institución.

"La partera repitió cómo reconocer que se está en trabajo de parto: "3 contracciones en 10 minutos, 9 contracciones en 30 minutos, 18 contracciones en 1 hora"' (Diario de campo, 13/2/2017, curso hospital público).

"El doctor pasa unas diapositivas y dice: Contracciones: "a partir de las 30 semanas, está dentro de lo esperado la presencia de contracciones". Cada 5 minutos y durante 30 minutos después de dos horas de estar acostadas: ir a la guardia (recomienda transitar ese tiempo en la bañera). "Contracciones dolorosas, que no ceden en reposo, que son regulares en tiempo e intensidad" = alarma para ir a la guardia" (Diario de campo, 16/5/2017, curso hospital privado).

La clínica privada ofrece un volante con las pautas de alarma (y el nombre y teléfono de la partera a cargo del curso), en lo que puede considerarse una estrategia comunicacional eficaz, dado que al momento del desencadenamiento del trabajo de 
parto o con las dudas previas, el soporte textual puede ser de mayor ayuda que la memoria.

"Pautas de alarma

- Contracciones. Al principio se pueden percibir como endurecimiento de la panza, a veces acompañados de un dolor tipo menstrual o tipo cólico tolerable. Comienzan de manera irregular y duración variable, y es probable que calmen o desaparezcan con el reposo. Lo que indica que no estás en trabajo de parto.

- Contracciones de trabajo de parto. Deben ser cada 5 minutos (o menos) durante 2 horas seguidas. Aumentan su intensidad y duración (más de $30 \mathrm{seg}$ ). No desaparecen con el reposo. IMPORTANTE: este tipo de contracciones indican el inicio de trabajo de parto, por lo que no deben estar presentes antes de la semana 37 de gestación.

- Ruptura prematura de membranas. Puede ocurrir en cualquier etapa de la gestación, sin ser el trabajo de parto o el embarazo de término una condición absoluta. La pérdida de líquido por genitales externos, es siempre motivo de consulta.

- Eliminación del tapón mucoso. Es una pérdida normal, de apariencia gelatinosa y color amarronado o con hilos de sangre. No siempre indica el inicio del trabajo de parto. Tener en cuenta que se puede eliminar el tapón mucoso y que el parto se desencadene una semana después.

- Pérdida escasa rosada o marrón. Se considera normal en un embarazo de término en el que estén empezando a aparecer las primeras contracciones. Puede estar presente también después de haber tenido relaciones sexuales o luego de un examen vaginal. HEMORRAGIA ES URGENCIA" (Volante distribuido en el curso de preparto de la clínica privada, la mayúscula es del original).

Ahora bien, históricamente la medicina se ha arrogado el control de la etiqueta / nominación de lo que pasa en el cuerpo, de los signos o síntomas. Eso no únicamente es lo que aquí busco destacar, sino enfatizar la paradoja de que la mayoría de las mujeres van buscando respuestas científicas o médicas a cómo saber que están en trabajo de parto, y la respuesta de la ciencia es "te vas a dar cuenta", apelando al sentido común o incluso a la fisiología de la que las mujeres desconfían como efecto de la medicalización. Otra paradoja: el saber médico apela al saber femenino cuando se queda sin respuestas.

"Yo les puedo asegurar mujeres que ustedes van a saber cuándo van a parir", afirma el doctor. Recomienda ir a lugar oscuro y silencioso y da el ejemplo de la perra, que comparte con las mujeres el ser una hembra. Más sueño y mejor alimentada: "el cuerpo se prepara naturalmente para el parto". Apelación a la naturaleza y el poder de parir. Les dice a las presentes: "tienen ese poder de parir y ese poder de intuir el momento" (Diario de campo, 16/5/2017, curso hospital privado).

Y esto es clave porque es un límite con el que se choca la creencia y la legitimidad de la medicina. Se trata de un pequeño margen de lo imprevisible que se vuelve ineludible, si es que no se programó una cesárea en la segunda consulta prenatal. 
Sumado a esto, advertí otra operación simbólica que potencia la mediación médica sobre el conocimiento del propio cuerpo y proceso reproductivo. En el CPP de la obra social, una de las usuarias comentó que estaba preocupada porque su bebé aún no estaba encajado (en posición cefálica, cabeza abajo, lo que sentencia si el parto será vaginal o por cesárea); y que mediante conversaciones con otras mujeres supo que existía el saber popular que estipula que poniéndose todos los días un rato en cuatro patas, eso ayudaría al encajamiento (idea que yo misma escuché en varias oportunidades). La mujer lo expuso buscando la validación médico científica que resultó, lógicamente, en la afirmación de la obstetra sobre que eso "es un mito". ¿No será que la hegemonía médica transforma en mito, y por tanto deslegitima, los saberes populares, siendo que en este caso la práctica no implicaba ningún riesgo para el "binomio", también en la atención de los PEP? Porque Menéndez y diversxs teóricxs de la salud comunitaria han dado cuenta de este proceso en otras áreas de la medicina.

Por último, la dimensión corporal aparece en algunos de los cursos como un momento especial donde, a través de técnicas de relajación y respiración, se busca brindar herramientas para el atravesamiento de las contracciones y el trabajo de parto. Adquirí un rol de observación con participación total en este aspecto, y medité en el hospital público, simulé posiciones de pujo en el curso de la obra social, trabajé con una pelota gigante en el curso del gimnasio y bailé en el curso alternativo de parto en casa. Los cursos de los sanatorios privados no incluyeron trabajo físico. Algunas de estas cuestiones que evidenciaron las diferencias entre los cuerpos gestantes y mi cuerpo o el de los varones o de lxs coordinadorxs, las retomé en el apartado metodológico.

Finalmente de lo que se trata es de los atravesamientos que soportan y se (re)producen sobre los cuerpos gestantes:

"Pocos territorios han dado lugar a debates y controversias como el del cuerpo de la mujer embarazada. Alternado y conflictivamente naturalizado, disciplinado y politizado, este escenario ha seguido un derrotero de luchas por dejar de ser objeto de cuidados y constituirse en sujeto de derechos" (Fornes, 2011, p.135). 


\subsection{SOCIALIZACIÓN PARA LA OBEDIENCIA O EMPODERAMIENTO PARA LA AUTONOMÍA: IMPOSICIÓN DE NORMAS HOSPITALARIAS VERSUS EL DERECHOS A DECIDIR}

"La característica de este poder político [el médico] reside en lo que se considera el derecho de ser obedecido. La historia de la obediencia tiene antecedentes bíblicos cuya clave es política. Su análisis nos conduce al poder hegemónico de los médicos, en paralelo con otros poderes del mismo signo y que en esta circunstancia está asociado con el parir y el nacer" (Giberti, 2003, p.1)

Uno de mis supuestos/puntos de partida es que hay una tensión principal entre las prerrogativas y normas institucionales-profesionales y los derechos y necesidades de las mujeres en la atención de sus PEP. Esa tensión aparece cuestionada, legitimada, (re)producida, interpelada y actualizada de diversas formas y a partir de distintos discursos y prácticas tanto por parte de los equipos de salud como de las mujeres (y varones) que transitan embarazos y partos en la ciudad.

Considero que el espacio de los CPP, así como en las consultas médicas y en las salas de parto, o quirófanos, si se trata de cesáreas, se dan dinámicas relacionales, atravesadas por contextos socioculturales específicos, que permiten ver ejercicios de poder, dominación y estrategias de resistencia por parte de Ixs sujetxs implicadxs. Ya que por una decisión ético-política-metodológica decidí no realizar una inserción etnográfica sanitaria total e invadir espacios de intimidad y privacidad que se dan en consultorios y en la atención particular de cada mujer y su PEP, el espacio de los cursos se erigió como un híbrido entre lo público y lo privado, lo personal y lo colectivo, y mi participación tomó un carácter de mayor comodidad para todxs, ya que aún así permitió responder mi pregunta de investigación. La pregunta que guía mi análisis de estos espacios colectivos es si el objetivo es empoderarse para parir/maternar/lactar/criar o prepararse para obedecer. Esto es, ¿refuerza la tutela médica o promueve la autonomía de las mujeres en sus PEP? La importancia de esta pregunta se encadena con el análisis previo, sobre todo si se considera que la práctica médica en el PEP está atravesada por múltiples contradicciones/ paradojas/ mitos científicos y no científicos. Creo que en los cursos se da la ambivalencia entre la socialización para la obediencia, a través de la comunicación de los lineamientos institucionales, por ejemplo, sobre la posición impuesta parir, o en el acompañamiento, y el empoderamiento de las mujeres en su capacidad de gestar y parir, desde conceptos como "son las protagonistas y dueñas de sus partos”. La tónica, aunque expuesta en términos polares, busca captar los grises, las experiencias, los discursos y las prácticas que circulan y se (re)producen y actualizan en estos espacios. 
Al referirme a polos, como ya mencioné en el marco conceptual de esta tesis, pienso en esas tendencias en la información transmitida en los CPP así como en las prácticas y representaciones que circulan, se producen y se articulan en esos espacios, que tienden justamente a la legitimación o al cuestionamiento de los preceptos y modos hegemónicos de la atención obstétrica. Lo relevante es que los enfoques no son absolutos, sino que lo que emerge en este trabajo de campo es que aunque existan tendencias generales, en los cursos conviven discursos a veces contradictorios 0 , como mínimo, en disputa y tensión. Pero siempre así: en convivencia, en tonos grises. En otras palabras, es posible advertir cursos funcionales al $\mathrm{MMH}$ y otros que representan algunas estrategias o válvulas de escape, aunque claro, cayendo en una total responsabilización de las mujeres por lo que sucede y limpiando de responsabilidad al equipo de salud. Cuando a todo esto lo pasamos por el tamiz de los derechos humanos, adquiere otro color y otra densidad. En paralelo, hay cursos empoderadores al interior de instituciones sanitarias que no dejan de ser cuatro paredes bajo la voluntad o autonomía profesional de un/a médicx. Tal vez la semilla más importante es la que germina en quienes participan, porque no pueden garantizar lo que suceda fuera de su espacio.

En este sentido puedo decir que, como vengo sosteniendo, hay cursos más proclives a (re)producir el discurso biomédico, con enfoque de riesgo, de los PEP y su intervención/atención/abordaje, y entonces sus contenidos se centran en presentar la necesariedad de la asistencia médica y, en consonancia, las pautas institucionales de atención. Esto a través de, como mostraré a continuación, la socialización tanto en las pautas de comportamiento esperadas, como en las lógicas de funcionamiento internas así como en lo que tiene que ver con el ajuste del propio proceso reproductivo a las exigencias institucionales (sobre todo en relación a los tiempos y requisitos de admisión e internación $)^{93}$. Por otro lado, y en convivencia, existen cursos que buscan generar

\footnotetext{
${ }^{93}$ Sadler lo explica del siguiente modo: "En la atención hospitalaria de partos existe un comportamiento adecuado que se espera implícitamente que las mujeres adopten y cumplen. Este comportamiento se basa principalmente en seguir las normas médicas y no interferir en el trabajo del personal de atención con actitudes que respondan a necesidades individuales. En este sentido es que la estructura de atención mantiene la definición de la situación como una en la que los conocimientos y las experiencias corporales de las mujeres no cuentan para nada. Por ejemplo, todos/as los/as participantes concuerdan en que la mujer no puede pujar hasta que esté médicamente preparada en el box o pabellón, y que el personal de atención le indique que así lo haga. En el relato del bebé nacido en pre-partos que revisamos, esto se hace evidente. En este contexto, sólo los/as especialistas pueden determinar cuándo la mujer está lista para pujar, información que se obtiene a través de la lectura del monitor fetal, de los centímetros de dilatación, y tactos o examinaciones vaginales. Lo que la mujer conozca y exprese, en base a sus experiencias
} 
otras miradas y que incluso se establecen como espacios de militancia. Lo interesante es que ambos modelos de curso-contenido-información que se transmite, muchas veces se imponen como "el modelo" de atención del parto, generando nuevas normatividades. Así, muchas veces los cursos que emergen de la conciencia y activismo militante de muchas mujeres, terminan tomando un cariz maternalista que impone parto natural, lactancia a demanda y crianza con apego, sin pensar en las elecciones/decisiones/deseos de las mujeres a las que se dirige.

La propuesta entonces es ir desmenuzando estas tensiones entre las tendencias mencionadas para poder responder la pregunta de investigación que guía este capítulo.

\subsubsection{LOS DISCURSOS DE LOS CURSOS}

El discurso, entendido en su amplitud como prácticas y representaciones, que se (re)produce en este tipo de espacios asistencialistas-pedagógicos, se vincula a demandas plurales del sistema de salud, de profesionales médicxs y de las mismas mujeres y sus entornos, en relación a informar y despejar dudas sobre "lo que ocurre" durante el proceso perinatal. En esa información y en la construcción discursiva que se hace sobre "lo que ocurre" en el proceso de nacimiento se encuentra el núcleo de las tensiones. Porque en esa concepción del PEP también se incluyen las representaciones sobre lo normal y lo patológico, sobre los cuerpos de las mujeres, sobre lo que debería ser y hacer, sobre lo que sucede en términos fisiológicos pero, y sobretodo, lo que ocurre desde que se ingresa a la institución o se toma contacto con el equipo de salud estando en trabajo de parto. Ideologías de género (Blázquez Rodríguez, 2009), de la salud, de la salud pública y del quehacer profesional se reactualizan en estos espacios, que suelen presentarse como neutrales y científicos, como toda práctica médica hegemónica.

Así, encontré diversos pilares desde los que se sustentan y construyen estos discursos: la apelación a lo natural / antinatural, al "don de parir" y al auto-conocimiento (CPP hospital privado); la apelación a "lo medicamente probado" (CPP hospital público, clase de puerperio); la apelación al sentido común (CPP hospital público); la apelación a la experiencia profesional (CPP obra social) y la intuición femenina (CPP atención

corporales, no detenta ningún grado de autoridad en dicho contexto; se transforma en un problema tanto para ella como para el personal de atención, como algo que debe ser cognitivamente suprimido y manejado a través de la imposición de un determinado tipo de comportamiento. Esta supresión de las experiencias de las mujeres se simboliza poderosamente en la figura de la mujer como contaminante" (Sadler, 2004, p. 19-20). 
domiciliaria); etc. La ciencia, la experiencia, el sentido común, lo trascendental, lo místico, en fin, la conocida tensión naturaleza-cultura como centro de la articulación discursiva sobre lo que ocurre, cómo se lo concibe y cómo se interviene el PEP. Articulación sobre la que descansan, a su vez, los objetivos de empoderamiento o subordinación mencionados.

A continuación, a través de referencias a cada curso, detallaré los grises advertidos entre ambas tendencias.

En primer lugar, en el CPP que brinda la obra social, advertí tensiones entre la presentación de un modo no sobreintervencionista de atención al PEP a partir de la descripción de la fisiología del proceso perinatal (a cargo de la obstetra); la consideración de la búsqueda de un parto respetado como una moda o una rigidez (por parte de la psicóloga); y un rol pasivo y de entrega al saber médico por parte de algunas participantes.

"La psicóloga habló de la importancia de decidir pero sin ser inflexible e introdujo peyorativamente el tema del parto respetado, como una moda, refiriéndose a personas que cuestionan todo. Una de las asistentes (que es médica) le dijo a la doctora que confiaba en ella, que ahí "Yo soy pasiva, soy paciente" (Diario de campo, 26/9/2016, curso de obra social).

"La psicóloga plantea frases un tanto ambiguas entre sí: que las mujeres decidan, pero que respeten al médico; que el hombre participe pero por ahí no les gusta" (Diario de campo, 3/10/2016, curso obra social).

Estas citas tienen la riqueza de mostrar los matices entre los dos polos o modelos de atención al parto que he venido describiendo, que complejizan el análisis de las intervenciones médicas en los PEP. Por un lado, la propuesta de la psicóloga sobre no ser inflexible y no planificar "por demás" el parto, puede ser interpretada como de resubordinación de las mujeres: la última palabra la tiene el/la médicx (o la bendita complicación). Y en consonancia la operación simbólica de la mujer (que ejerce como profesional de la salud) de igualar las condiciones de pasividad y de paciente. Su profesión no resulta irrelevante, ya que esta articulación de los términos parece responder a los parámetros de la medicina y las relaciones médicx-pacientes dominantes. $Y$ en la no pregunta o aseveración de estos preceptos encuentro algo más, no exclusivo de las asistentes a este curso en particular. La clase, el perfil socioeconómico de Ixs participantes, no es determinante; lo explicativo es la hegemonía médica: estas mujeres que tienen conocimientos $u$ oportunidades de obtenerlo, prefieren no saber. Tal vez Ixs profesionales, en su rol de alumnxs, aceptan más la profesionalización de los cuidados: el valor del saber. 
Sumado a esto, en relación a la atención del parto y a la tensión entre las prerrogativas institucionales y los derechos de las mujeres, en este curso se despliega una visión fisiológica del parto, señalando algunas de las prácticas innecesarias que la obstetricia hegemónica despliega rutinariamente. Sin embargo y en paralelo, se naturaliza la posición litotómica (acostadas, en detrimento de la fuerza de gravedad, sólo beneficiosa para el/la profesional que atiende) en los ejercicios de pujo a cargo de la profesora de educación física; lo que puede interpretarse como transmisión o internalización acrítica de esta intervención, practica y simbólica, de la atención dominante.

"Se habló de la cascada de intervenciones (en términos de riesgo) que produce la anestesia epidural. Revalorizaron la cesárea "porque a la cesárea también las mujeres le ponen el cuerpo". Se habló del alumbramiento, del dolor, de la escena del parto. No se cuestionó que se lleven al bebé. Se puede comer, puede haber libre movimiento durante el trabajo de parto. La obstetra habló de que no se puede parir en cuclillas porque no hay camillas aptas, pero algunas te permiten sentarte" (Diario de campo, 3/10/2016, curso obra social).

El curso de la obra social no tiene convenio con ninguna institución sanitaria en particular (al igual que el que ofrece el gimnasio) por lo que la información que allí circula no responde a los lineamientos de un centro de salud particular sino a los comunes o habituales en la atención y según la concepción de quienes dictan el curso. Es importante marcar esto porque en su experiencia de atención del nacimiento de sus hijxs, las mujeres referirán diferencias o incongruencias con lo expuesto en el CPP: lo que sucede en sala de partos no suele respetar/responder/reflejar lo trabajado en los cursos. Y aunque a priori parecería ser algo exclusivo de estos cursos, otro de los hallazgos de esta investigación es que esta situación se repite en todos los cursos, dado que aunque respondan al nombre de una institución o incluso sean fomentados por ella, ni los cursos ni la atención obstétrica de todo el proceso perinatal responden a un marco común. Esto es, tanto lo que ocurre dentro de las aulas de los cursos como lo que ocurre dentro de las salas de parto parece, según las experiencias analizadas, estar bajo jurisdicciones distintas de profesionales individuales. En otras palabras, el personalismo y la ausencia de una línea general de trabajo/ atención/ abordaje/ concepción de los PEP genera una distancia entre lo que se dice en los cursos y lo que finalmente sucede en los nacimientos. Esto puede producir la improbable suerte de que si el curso expresaba una tendencia más biomédica, las mujeres se encuentren en el parto un modelo humanizado y respetuoso de atención; o se lleven la decepción de que su proceso de empoderamiento en cursos con tendencia más fisiológica, choque con 
una atención intervencionista y medicalizante. Pero más allá del mero conflicto de expectativas, lo que quiero señalar es que en una misma institución puede convivir un espacio, el CPP, o algunxs profesionales que empoderen a las mujeres y su entorno hacia el ejercicio de una ciudadanía reproductiva, con otros modos de trabajo que violan esos derechos. Entonces el personalismo puede implicar tanto médicxs intervencionistas como médicxs respetuosxs, por lo que los grises y la convivencia de matices entre los polos, afecta al interior de las instituciones la garantía de derechos sexuales y reproductivos, por la falta de líneas de trabajo comunes con perspectiva de género y de derechos.

En el hospital público es donde fue más clara esta brecha entre el curso y la atención real. Durante los 12 encuentros que presencié, se desplegó una interesante dinámica de empoderamiento y responsabilización de las mujeres. Este doble proceso trae consigo/ implica/ se ampara en cierta des-responsabilización del Estado en la garantía de derechos humanos, sexuales y reproductivos y del rol de Ixs agentes de salud como funcionarixs públicxs. De este curso (que fue en el que más encuentros observé), destaco nueve ideas claves interrelacionadas que repite la partera a cargo y que permiten dar cuenta de esta dinámica y de las prácticas y representaciones sobre el PEP y su intervención/ atención médicas que se (re)producen allí.

"Algunos de los conceptos que la partera a cargo fue vertiendo y son los troncales a su propuesta, son:

- "El embarazo no es una enfermedad": no son pacientes, no hay que dramatizar, hay que cuidar y hacerse respetar el cuerpo.

- "No hablemos de dolor, hablemos de malestar": el dolor es por algo que nos hace daño, esto es por un cuerpo atravesando nuestra cadera.

- "Saben parir": tenemos un cuerpo preparado para parir, no somos un útero (el plural es porque ella hablaba como una embarazada), nuestro cuerpo es sagrado y los médicos tienen que pedirnos permiso para tactarnos porque "hay una ley que nos ampara".

- "No tirarle el cuerpo al médico": responsabilizarse de la propia salud y cuidado, exigir información sobre lo que se le hace a nuestro cuerpo.

- "Cerebro activo e informado: menor temor y menor dolor".

- El parto como un momento efímero o puntual, la importancia de generalizar estas enseñanzas (relajación, alimentación, cuidados de la salud) para toda la vida. Espacio de empoderamiento.

- Centralidad de la educación (en salud, en alimentación, en prevención, en general) como clave para "cambiar el mundo".

- "Sean libres como los pájaros, hagan lo que sientan, no lo que digo", en un afán (que me encanta) de generar autocrítica, compromiso, reflexividad, responsabilidad" (Diario de campo, diversos registros de febrero de 2017, curso hospital público) ${ }^{94}$.

\footnotetext{
${ }_{94}$ Tal como mencioné en una nota anterior, mantengo el uso del lenguaje sexista que realiza la partera, en la que se iguala médico a varón.
} 
Es interesante recordar que este curso se da en la maternidad más grande de la ciudad, cuya tasa de episiotomías es de $90 \%$ en primerizas, las cesáreas superan el $35 \%$ y la internación está completamente feminizada, por la que los varones-padres no pueden pernoctar junto a su mujer puérpera y su hijx recién nacidx. Esa es la brecha a la que me refiero.

Esas ideas reflejan una mezcla de cuestiones científicas, biomédicas y otras espirituales y "de sentido común" en la construcción del discurso dominante de este CPP, pero que reflejan una concepción personal de la partera a cargo, no así la expresión de una política o cultura institucional sobre la atención médica de PEP en el hospital. El curso del hospital público, entonces, aparece como un espacio de circulación de información que cuestiona el modo hegemónico de atención obstétrica. La partera a cargo lo promociona como un "comodín" a mencionar al momento de la llegada a la internación, como una herramienta de poder antiintervencionismo ${ }^{95}$. Decir que hiciste el curso con ella y/o llegar con dilatación completa al hospital, son dos de las estrategias que ella comparte para disminuir la brecha.

A propósito, la descripción de algunas situaciones registradas en mi diario de campo da cuenta de esta incongruencia asistencial mencionada.

"Gabriela, la que había hablado bastante la vez pasada, cuenta que había tenido una experiencia fea con una médica de la guardia que no le respondió ninguna duda y sólo le decía "ajam". Se generó un espacio de charla en el que Sandra [la partera a cargo] habló de que el cuerpo debemos cuidarlo nosotras, que una parte de la responsabilidad la tiene el médico pero otra la mujer. Las instó a empoderarse, a cuidar su cuerpo, pedir el respeto. Varias veces dijo -en esta clase y las pasadas- que mencionen que hicieron el curso con ella, que la nombren, porque eso funciona a modo de comodín. Yo mencioné que Ixs médicxs tienen poder y que por eso nos da cosa cuestionarlos, y Sandra saltó muy fuerte a decir "iporque nosotros le dimos el poder!". Varias mujeres se armó un bullicio- decían que había que reclamar y cuestionar. "Los médicos son como nosotros, son personas, sin nosotros no están ahí" dice Sandra.

La mamá de Flor -la chica nueva- hizo el curso con Sandra en su embarazo y habló bastante de su experiencia. Sandra mencionaba su preocupación por la poca gente que hace el curso, porque de 3000 o 4000 partos anuales, solo muy pocas lo hacen, porque no derivan, no informan, no difunden. Esta mamá contó que el curso le sirvió para controlarse en las contracciones y pasarlas tranquila, y que notaba la diferencia con las otras mamas en trabajo de parto. Sandra apela al "efecto multiplicador" de los contenidos y enseñanzas que ella da, busca que esas cosas (las mujeres no son enfermas, somos dueñas de nuestro cuerpo, no hablar de dolor) les "prendan" a las mujeres y no solo las "aprendan" (en sus palabras) (...)

La charla giró entre qué lugar le damos a Ixs médicxs, Sandra dice "no le tiren el cuerpo al médico". Responsabilidad, compromiso, pedir información médica, hacernos cargo" (Diario de campo, 16/2/2017, curso hospital público).

\footnotetext{
${ }^{95}$ Sin embargo y contrario a lo que se podría interpretar, considera que el parto respetado es una moda, porque ella "siempre respetó".
} 
En la situación descripta es posible advertir la diferencia entre los contenidos vertidos en el curso y la atención que reciben en la guardia pero con un matiz particular: el compromiso por la propia salud y la responsabilización de las mujeres por su atención y sus procesos, puede suponer la desresponsabilización estatal, institucional y médica, como se dijo antes. El empoderamiento femenino puede entonces implicar como consecuencia no buscada, una total responsabilización de las usuarias que enmascara la culpabilización por la atención recibida. El límite es fino. La exigibilidad de los derechos sexuales y reproductivos no implica la ausencia estatal en su garantía y acceso.

Cuando me refiero a la transmisión de las normas institucionales como lo nonegociable que puede tender a buscar la obediencia, la descripción del itinerario asistencial y de lo que llamo la escena del parto son dos de los elementos que permiten identificarla. Como mencioné, uno de los objetivos de los CPP es "bajar la ansiedad" dando información. Saber qué pasará al llegar a la guardia detalladamente y quienes estarán en la sala de parto, resulta muy importante para las mujeres y sus acompañantes, que pueden así prever e imaginar cómo será el nacimiento, pero no pueden modificarlo (o no se les presenta esa opción). Este detalle del itinerario asistencial y de la escena del parto, lo desarrollaron sólo en una de las clases especiales del curso del hospital público y en el módulo obstétrico del hospital privado. Es importante mencionar que sí hay mayor detalle de lo que ocurre en el proceso de recepción de lxs recién nacidxs en todos los cursos, reproduciendo así la sobrevaloración del/ de la bebx en el binomio madre/hijx. Se trata de una apuesta por romper el velo de lo que pasa cuando la mujer entra a la institución y pasa a estar bajo su "jurisdicción".

La expresión de la tensión naturaleza /cultura como uno de los ejes que moldean todo lo que se dice sobre la atención médica de PEP en los CPP, aparece como la dicotomía entre fisiología e intervención médica. Sobre la apelación al proceso fisiológico ya destaqué algunas cuestiones que responden a este paradigma, y que fueron desarrolladas por la partera a cargo del curso del hospital público. La diferencia es que en los que dicta el gimnasio y el hospital privado aparece nominada como tal.

"Para pensar el parto fisiológico y los aspectos culturales que lo intervienen proponen problematizar la triada saber pujar/saber respirar/saber parir. El poder está en el saber. Y no hay saberes expertos específicos necesarios para el parto. La fisiología está en nuestra "naturaleza mamífera", nuestro rol de "mujeres como lobas"”' (Diario de campo, $8 / 3 / 2017$, curso gimnasio). 
"Sobre el trabajo de parto, el doctor llama a entregarse a que ocurra la naturaleza en su cuerpo, entregarse no al poder médico sino al proceso natural. Además contra la estandarización dice: "los tiempos del TP son inconstantes, cambian de mujer a mujer" (Diario de campo, 16/5/2017, curso hospital privado)

El curso de la clínica privada expone, a través de una serie de diapositivas, la convivencia de visiones fisiológicas e intervencionistas del PEP. Por ejemplo, presenta "tres intervenciones con las que la medicina se apropia del proceso fisiológico": la epidural, la episiotomía y la inducción. Si bien con esta carta de presentación y la elección del lenguaje parece que se desplegará una visión crítica del modelo hegemónico de atención obstétrica, a continuación se producen ciertas ambivalencias. Se establece que "poner la peri es una decisión médica pero la mujer tiene mucha voz y voto" y enseguida hace un listado de médicxs que, en la clínica, "no trabajan por peridural", es decir que no la aplican rutinariamente. También sostiene que "se le da una oportunidad al parto", como si fuera únicamente una decisión médica en el marco de una excepcionalidad, que quienes deben "conducir" el trabajo de parto son las parteras y que la inducción es una maniobra para "ponerle motor" al proceso dilatante y expulsivo. Esto me lleva a pensar en la concepción presente del cuerpo y del proceso como defectuoso, con total necesariedad de la intervención médica, en términos de, siguiendo la analogía, una metáfora mecánica que también permite pensar en la aceleración, el freno y el control total de los tiempos por un/a otrx.

Esto convive con la presentación crítica de las tres intervenciones prácticas señaladas y las ideas de que "la obstetricia es un trabajo de paciencia" y que "toda intervención médica tiene un riesgo" (iatrogenia). Es interesante ver que hay mayor conciencia y registro de las intervenciones prácticas pero aún no de las de carácter simbólico y de dominación que se plasman en la atención obstétrica. A veces estas últimas se asignan a profesionales individuales, mencionando su tendencia a ser de una u otra manera, pero no pudiéndolo ver como parte estructural del problema.

Entonces si bien existen tendencias a establecer que sí, la medicina ha trastocado el proceso fisiológico y que eso genera riesgos, la última palabra, la decisión, es puramente médica. La ambivalencia en el discurso nos permite dar cuenta de los grises entre los polos que mencionamos anteriormente. 


\subsubsection{TRES TÓPICOS CLAVES}

Uno de los efectos de la hegemonía es la apropiación acrítica de los mandatos del grupo de poder y su naturalización. En este sentido, considero que hay un par de dimensiones puntuales y cotidianas que reflejan esto, y que emergen como demandas de las mujeres, pero que es posible advertir o identificar como efecto de la socialización médica. Me refiero a que en la consulta por los elementos necesarios para llevar a la internación, la dificultad para transitar el miedo y dolor al parto, y el (ausente) modo de pensar las relaciones médicx-pacientes en los CPP, se puede advertir cómo se trabaja con el horizonte en la obediencia o en la emancipación de las mujeres.

\subsubsection{A) EL COMPONENTE EMOCIONAL}

Uno de los modos de problematizar las tendencias y cosmovisiones de los CPP es ver cómo se incluyen y abordan los aspectos emocionales de las mujeres y su entorno en el tránsito de todo el proceso perinatal. Me refiero a qué lugar y tratamiento se le da a las cuestiones de los miedos, en particular el miedo al dolor de parto, siendo que los miedos (por desconocimiento, por influencia social, por diversas razones) son parte clave de la experiencia de Ixs sujetxs en este aspecto de la vida. El hecho de que se los considere, magnimice, minimice o resuelvan como algunas de las opciones posibles, puede iluminar las prácticas y representaciones que se (re) producen en los cursos. Como vengo delineando, en el modo en que se viven, transitan y conciben estos aspectos podemos vislumbrar efectos de cuestiones macrosociales: la tendencia a la negación del dolor, la búsqueda del autocontrol de las emociones catalogadas como negativas, etc. ${ }^{96}$.

En la atención hegemónica (y por tanto defendida por profesionales, mujeres y varones) suelen resolverse estas cuestiones a partir de la administración de anestesias; la propuesta o elección de cesáreas "para no sentir nada"; la imposición de comportamientos de silencio y ocultamiento de expresiones ("cállate, no te quejes").

Uno de los objetivos a priori de los CPP es abordar estas cuestiones emocionales (información para bajar la ansiedad y los miedos) y por ello advertí durante las observaciones, tratamientos más "amigables" de estos temas. Al respecto retomo registros del hospital público, cuya coordinadora sostiene la importancia de considerar que "no somos úteros, no pensar en dolor sino en molestia", y del hospital privado,

\footnotetext{
${ }^{96}$ No ha sido profundamente abordado para esta tesis, pero sobre sociología del cuerpo y de las emociones recomiendo la lectura de Scribano (2012).
} 
donde el médico a cargo afirmó la importancia de pensar este "dolor con final feliz: el encuentro con su hijo".

"Una de las chicas (Cecilia, la que va a parir en un Sanatorio privado, que la semana pasada vino con su pareja) dijo que al principio ella le pidió a su médica que la mande a cesárea porque "no quería sentir nada" y que la doctora le dijo que ella la iba a convencer (de parto natural) y que de a poco se iba convenciendo. Que su idea era estar 20 hs en trabajo de parto y al momento de tener que pujar ya estar cansada y no poder. Ahí Sandra habló de una fuerza visceral que te sale de adentro. Hay algo de mística en esto, no todo es científico y racional" (Diario de campo, 9/2/2017, curso hospital público).

"Comienza a hablar y sugiere una dinámica participativa a raíz de la pregunta "¿qué sentimientos surgen sobre el TP-P?". Se dice miedo, ansiedad, incertidumbre, dolor. Retoma que "culturalmente y de manera inconsciente, las mujeres le transmiten a otras que el parto es horrible, doloroso". Se refiere a la expresión "es un parto"' (Diario de campo, 16/5/2017, curso hospital privado).

Lo interesante de ambos relatos es la referencia (directa o indirecta) a la construcción hegemónica social de un parto doloroso, terrible, explosivo que afecta las experiencias personales de las mujeres. Otra vez la tensión entre naturaleza, "preparadas para parir", y la cultura, que construye, legitima y potencia esos discursos. En este sentido, es relevante retomar a Schwartz (2016) quien sostiene que el dolor en el parto es el eje articulador de las experiencias (y expectativas) de las mujeres y que en este sentido, a su vez, "habilita la intervención médica" (p. 290) ${ }^{97}$ para su atravesamiento.

\subsubsection{B) ¿QUÉ LLEVO?}

Si "cómo sé que estoy en trabajo de parto" y "me da miedo el parto o el dolor" son las dos cuestiones principales y casi generales que emergen en los cursos, qué llevar al momento del parto ocupa el lugar restante en el podio.

En el curso del hospital público, colaboré tipeando, imprimiendo y distribuyendo entre Ixs presentes, la lista de "elementos necesarios para la internación en el hospital". Este elemento en sí constituye un instrumento por el cual se transmiten/imponen las reglas hospitalarias, y justamente por eso, analizar las diferencias que hay de estas listas en cada una de los ámbitos de atención, permite vislumbrar características que le

\footnotetext{
${ }^{97}$ Asimismo, establece "La relación entre dolor y parto resulta un eje organizador de la experiencia; ya sea porque simboliza la puerta de entrada al vínculo madre-hijo, como prueba de amor; ya sea por el temor a transitarlo, legitimando la intervención de la institución médica, a través de la peridural y la cesárea fundamentalmente” (Scharz, 2016, p. 185).
} 
imprimen a la atención del PEP. Por ejemplo, en el hospital público es en el único donde la lista incluye qué documentaciones hay que llevar en caso de que Ixs progenitorxs sean menores de edad, para conseguir el alta, y algunos elementos tales como almohadas o reproductores de video, para aportar al confort $u$ hotelería institucional. Lo distintivo de esta lista entonces es, además de lo legal, la referencia a insumos y carencias en la infraestructura, propias de nuestro servicio público de salud.

Para comparar, y a modo de ejemplo de las listas que proveen los otros CPP (o las otras instituciones), a continuación transcribo lo que sugiere el hospital privado a través de su "manual de maternidad".

“¿Qué tengo que llevar al momento de internarme? Para el bebé: Toallón, body, medias, batitas, ositos, pantalones con camperitas, mantita, gorro, accesorios de perfumería (pañales, lima para uñas, oleo calcáreo, gasas, alcohol). Para la mamá: Apósitos postparto, camisón, pantuflas. (En caso de cesárea su médico le indicará qué traer)" ("Manual de maternidad" del Hospital Privado).

La necesidad de contar con una lista de elementos necesarios para el nacimiento y la internación provista por profesionales médicxs, da cuenta del nivel de desconocimiento o descotidianización del evento perinatal, en tanto para otras internaciones no solemos preguntar y expresa una vez más la búsqueda por adaptarse a las exigencias institucionales.

\subsubsection{C) RELACIONES MÉDICX-PACIENTE}

El modo en que Ixs profesionales de la salud dictan el curso, los modos de relacionarse con las usuarias, de presentar su concepción de la atención, nos permite analizar (tangencial $\mathrm{O}$ indirectamente) las relaciones médicx-paciente presentes intercurso y extracurso. Sobre las primeras, en mis observaciones noté que el modo en que Ixs coordinadrxs médicxs del curso ejercen la construcción o transmisión del saber, revela en sí mismo el proceso de medicalización y autorización médica de los discursos. Se trata de la constatación del conocimiento autoritativo (Jordan, 1993) a través de lo "médicamente probado", "lo científico", "lo médico". Sin embargo esto convive con modos de relacionamientos más cercanos y afectivos.

"Sobre Sandra (la partera a cargo) no sé si es una postura armada su rol maternal y amoroso, pero funciona, llega, toca, convoca. No las trata de ignorantes, utiliza conceptos abstractos y teóricos con naturalidad, sin presuponer que no los entienden. Usa diminutivos todo el tiempo: ver si es infantilización o una forma de empatía" (Diario de campo, 13/2/2017, curso hospital público). 
Sobre las relaciones médicx-pacientes extracursos, en este espacio, al convertirse muchas veces en un espacio de catarsis, suelen mencionarse a veces cuestiones que hacen a la relación de las mujeres y sus parejas con su médicx obstetra. Lo emergente es que no se les da centralidad a estos aspectos. "Una de las mujeres (la que estaba sola) dijo que cambió tres veces de doctora y que con esta última se lleva "ahí", que son las dos muy secas" (Diario de campo, /9/2016, curso obra social). Considero que podría ser un objetivo interesante de los cursos empoderar a las mujeres para manejar la relación de otro modo, poder preguntar, cuestionar, proponer, interrogarse. Aunque sea un objetivo explicitado o pretendido, no he visto la concreción.

En algunos CPP, advertí que la atención se centra más en la figura de la mujer, sus responsabilidades y posibilidades sin cuestionar la "autoridad médica", que emerge como un "innegociable". En otros, como se mencionó, se llama a la construcción de un proceso de negociación, olvidando u omitiendo el fundamental diferencial de poder que asiste a las partes en la relación médicx-paciente.

"El doctor llama al consenso médico-paciente para elegir la posición para parir. Aconseja hablar con sus médicos de cabecera (no instituciones). "El médico obstetra está para asistir alguna complicación... el parto se hace solo". Se refiere a la "proeza obstétrica" irónicamente, contraponiéndolo a la no necesariedad" (Diario de campo, 16/5/2017, hospital privado).

Estos elementos (qué llevar al hospital, cómo se incorporan o no las emociones y las relaciones médicx-pacientes) describen disposiciones particulares que se despliegan en los cursos y cuyo análisis permite ir complejizando el estudio de los grises y tensiones entre los modelos de atención. Sostengo que en estos tres aspectos es posible advertir señales del objetivo empoderador o socializador para la obediencia en tanto motivan o promueven mayores o menores rasgos de autonomía para la decisión de las mujeres o de ajuste a las expectativas médicas e institucionales.

\subsubsection{ENFOQUE DE DERECHOS O REPRODUCCIÓN DE LA AUTORIDAD MÉDICA}

Si fuera posible dar una respuesta a la pregunta que encabeza este apartado, mencionaría que se ha ido advirtiendo que los CPP observados despliegan mayormente una tendencia hacia el empoderamiento, en una lógica procesual que entiende al embarazo, parto y puerperio en una continuidad de cuidados, que apela a la fisiología femenina como garante de nacimientos sanos sin necesariedad de intervenciones médicas de rutina. Ahora bien, aunque ese parece ser el horizonte de trabajo, los contenidos y las improntas de los cursos parecen responder a las concepciones de 
cada unx de Ixs profesionales a cargo, reproduciendo el personalismo en la atención obstétrica y en la garantía de derechos. Y como las posiciones médicas son ambivalentes y a veces contradictorias, tampoco es posible (ni es la intención de este trabajo) encerrar en categorías o etiquetas a los cursos según su carácter.

Sí es la intención, a partir de la pregunta que titula este capítulo, mencionar que los cursos, aunque se presenten como espacios que socializan y ponen en común información, tienen justamente el poder de utilizarla o dirigirla con determinados propósitos, a partir de los objetivos institucionales (o incluso macrosociales y culturales) de un sistema de salud que quiere garantizar la reproducción de la reproducción hegemónica. De hecho, la difusión de los derechos de las mujeres y su entorno al momento del nacimiento de sus hijxs y de todo el proceso perinatal, que por disposición estatal y legislativa debería realizarse en estos espacios y en otros al interior de las instituciones sanitarias, no se garantiza en términos generales. En lo específico, se mencionan la ley 25929 y los derechos sexuales y reproductivos en el curso del gimnasio (es importante recordar que el equipo a cargo está compuesto por profesionales militantes por el parto respetado) y en el del hospital privado (en donde el médico a cargo cerró su exposición en el módulo obstétrico enumerándolos). Este hospital además otorga a Ixs participantes un libro digital que establece las reglas hospitalarias, está casi totalmente centrado en el post-nacimiento y prolactancia y ahí menciona algunos derechos (aunque se podría concluir que un tanto limitados):

"La estadía en el Hospital. Durante tu estadía tenés derecho a recibir un trato amable y respetuoso. Recibir información por parte del personal acerca de los procedimientos que te van a realizar y elevar a la supervisora del piso cualquier sugerencia sobre la atención, tu opinión es muy importante para nosotros. Asimismo podés estar acompañada (por una sola persona) las 24 hs, recordá que el acompañante debe permanecer debidamente vestido" (Manual de maternidad, hospital privado).

En relación a cómo aparecen los derechos en los otros cursos, noté que se menciona la idea del parto respetado peyorativamente en el de la obra social, y muy poco en el hospital público y la clínica privada. El parto respetado sigue apareciendo disputado y construido como una moda, capricho clasista o innecesario.

Lo mencionado hasta aquí permite ir viendo de qué modos durante el embarazo se van desplegando diversos mecanismos que socializan a las mujeres y su entorno para la obediencia o la sumisión a las lógicas institucionales (la espera, el control de los tiempos, la necesariedad de la interpretación médica, entre otros). Aunque creo que en 
términos políticos debería trabajarse sobre la práctica profesional médica fuertemente, en el caso de los cursos dirigidos a Ixs usuarixs del sistema de salud, parece notarse que no logran generar en las mujeres una actitud activa sino que reproducen su rol de subordinación a la hegemonía médica, erigiéndose como un instrumento para generar obediencia al momento de la atención al parto a través del despliegue del detalle tanto de las normas institucionales como de las prácticas médicas que se "acostumbran" en esa institución, convirtiendo el acceso a la atención personalizada y garante de los derechos en una desviación de la norma y cultura institucional. Sostengo que cuando en los CPP se establece o enumera descriptiva e ingenuamente cuáles son las "costumbres en la atención médica de PEP" de tal o cual institución o profesional, se establece en realidad una normalidad o normatividad en la atención, que emerge como un innegociable/incuestionable y que, muchas veces, va contra los derechos sexuales y reproductivos. Prevalece, entonces, la dimensión institucional por sobre las dimensiones de la experiencia personal de las mujeres y su entorno; experiencia que incluye expectativas, deseos, miedos, saberes, además de derechos.

¿Qué empoderamiento real se puede garantizar si sigue primando por sobre el Estado de derecho y las legislaciones vigentes, la normativa institucional de sanatorios y hospitales, que rige, regla y uniformiza todos los PEP?

\subsection{El CASO ATíPICO: ENCUENTROS PRENATALES DEL “GRUPO DE PARTO DOMICILIARIO”}

Siguiendo la estructura del capítulo, presentaré ahora algunos elementos sobre el caso atípico que aquí denomino "grupo de parto domiciliario" (GPD) que aunque no excluye la posibilidad de acompañar/asistir nacimientos en instituciones con las que tiene convenio ${ }^{98}$, es el único espacio en la ciudad que ofrece un seguimiento del proceso perinatal con asistencia en domicilio. Asimismo, es atípico no sólo por el ámbito de atención que promulga, sino por el modelo de atención (fisiológico, no intervencionista, empoderador de las mujeres y su entorno) y por la relación médicxpaciente y la propuesta de atención: once encuentros durante el proceso de embarazo, parto y posparto, que integran la modalidad de curso de preparto con la de cuidados prenatales.

\footnotetext{
${ }^{98} \mathrm{El}$ convenio de este grupo de trabajo es parar asistir nacimientos en una clínica ubicada en una localidad vecina (Ensenada). Este hecho se debe a diversas expulsiones sufridas por el equipo médico de distintas instituciones platenses. El dato es relevante ya que la lejanía puede explicar o incentivar la elección del parto en domicilio: transitado el trabajo de parto en el hogar, es más factible por la distancia con la clínica que decidan concluir el proceso en casa.
} 


\subsection{A) CARACTERIZACIÓN DE LOS ENCUENTROS}

La estructura del ciclo de encuentros está muy organizada y trabaja en un doble registro: por un lado, acompaña el embarazo de las mujeres y sus parejas y se realizan actividades participativas de psicoprofilaxis; y, por otro lado, durante los encuentros se realizan las consultas prenatales con el doctor: registro del peso, presión, control y pedido de estudios y análisis.

El ciclo está comandado por cuatro profesionales principales y algunos que se suman para encuentros específicos: un médico obstetra, dos parteras y una profesora de educación física. El resto del equipo se completa con pediatras, psicóloga, médica generalista y otrxs profesionales vinculados al arte.

La propuesta computa 11 encuentros, de los cuales sólo accedí, por los tiempos de la investigación, a cuatro (marcados con *). Se realizan mensualmente y luego quincenal o semanalmente el último mes de embarazo. Duran entre 3 y 4 horas. Los ejes son: 1. Introducción; 2. Hábitos; 3. Arte; 4. Linaje materno; 5. Trabajo de parto y parto; 6. Corporal ${ }^{*}$; 7. Plan de parto; 8. Binomio madre-hijx (lactancia-crianza) ${ }^{*}$; 9. Música y canto; 10 . Despedida*; y 11. Posparto ${ }^{* 99}$. Sumados a estos 11 encuentros se realizan simultáneamente encuentros de "relatos de parto", en lo que parejas que han parido junto al equipo narran su experiencia.

Realicé el seguimiento del grupo "noviembre" (Ilamado así por las probables fechas de parto de las mujeres gestantes), compuesto por cinco parejas heterosexuales de menos de 30 años. Todas ellas viven alejadas del casco urbano de la ciudad (incluso una vive en una zona rural), lo que me resulta importante destacar ya que la distancia del lugar de los encuentros podría vislumbrar el interés y la importancia que le dan a este modelo de atención, elección por la cual se trasladan varios kilómetros. Asimismo explica que cuatro de las cinco parejas parieran en sus domicilios (alejadas del consultorio y de la clínica de referencia en Ensenada). La pareja restante dio a luz a mellizas, por lo cual se le realizó una cesárea institucional, a cargo del mismo equipo en la clínica referida.

El nivel de organización es tal que tienen organigramas y calendarios en la cocina de la casa que funciona como consultorio (en el centro de la ciudad) en donde se van sucediendo simultáneamente distintos momentos del itinerario de 11 encuentros

\footnotetext{
${ }^{99}$ Cuento con el material que se le comparte a lxs participantes para cada encuentro, que incluye pdfs por encuentro, música y videos. Es decir que además del trabajo presencial, se les otorga materiales para complementar el trabajo por fuera de los encuentros.
} 
según el grupo del mes que sea (por ahí se despide al grupo noviembre y se está realizando la misma semana el encuentro de plan de parto del grupo abril).

El grupo que acompaña el proceso de embarazo/parto y posparto, propone su continuidad en un grupo de crianza que proporciona acompañamiento y atención médica pediátrica con Ixs profesionales antes mencionadxs.

Las particularidades de este ciclo de encuentros son la interdisciplina, la participación en pareja de mujeres-madres y varones-padres, la comunicación interna de Ixs participantes (un grupo de whatsapp fomentado por la coordinación), el nivel socioeducativo de Ixs participantes (no necesariamente son profesionales pero sí poseen capitales culturales y simbólicos destacados) y un modelo participativo y democrático de circulación de la palabra. Además el uso del lenguaje (se habla de "cuidados" prenatales, no "controles") y otros elementos hacen a la coherencia con la propuesta de un abordaje fisiológico de los PEP. Lo distintivo también recae en contenidos y encuentros específicos (linaje materno, femenino, encuentro posparto y relatos de parto) y en metodologías de trabajo constructivistas.

\subsection{B) LOS TIEMPOS, LOS PROCESOS.}

Siguiendo la propuesta del capítulo, destaco el trabajo procesual e integral de este grupo de trabajo, ya que es el único curso que sigue y acompaña todo el proceso perinatal, incluido el posparto. Asimismo, en relación a la gestión de los tiempos, se subordina a la lógica fisiológica y de respeto a los tiempos "naturales" de cada mujer: no se establecen fechas de caducidad (del estilo "te esperamos hasta la semana 41"), sino que se respeta el desencadenamiento del trabajo de parto y los tiempos de cada uno de los partos. No hay partogramas universales estandarizados que conduzcan la atención, sólo la experiencia de acompañamientos y una constante actitud de expectación y espera.

En los relatos de parto que allí se exponen sobre nacimientos acompañados por estos grupos, la temporalidad adquiere un carácter fluido, espaciado, largo, por momentos sin memoria. En muchos momentos, los varones-padres que relatan la experiencia llenan los huecos de olvidos de las mujeres que no recuerdan cuánto tiempo pasó o en qué lugar de la casa se encontraban. Suele mencionarse también que la partera o el médico también descansan en algún lugar, o que dejan solas a la mujer o 
a la pareja. La espera en este modelo es de todxs, pero principalmente de Ixs profesionales acompañantes ${ }^{100}$.

Al igual que en los otros cursos, en éste también se establecieron recomendaciones de educación para la salud y cuestiones que hacen a los cuidados pre y post parto. Y asimismo también noté la poca atención al encuentro sobre lactancia que choca con las experiencias de dificultad que tuvieron tres de las cinco parejas en este tema, una vez ocurrido el nacimiento (dificultad de la toma, dolor, agrietamientos). El trabajo de campo me ha llevado a sostener que las "clases" de lactancia deberían tener mayor importancia ya que son de los principales problemas que aquejan a las mujeres en el posparto, aún cuando no sean parte de la demanda o inquietudes de ellas durante el PEP. Considero que la naturalización de la lactancia impide ver las posibles dificultades que tendrá y que efectivamente tiene en muchas mujeres, que enfocan su atención en la cuestión del parto.

"Sobre el encuentro de posparto: lactancia y crianza. Fue una "clase" larga en la que se mecharon cuestiones de lactancia, de crianza, mandatos, etc. El trabajo fue desmitificador y desprejuiciador. Se mostraron videos: uno de un bebé reptando al pecho de su mamá ni bien nace, otro de extracción manual de leche" (Diario de campo, 11/10/2017, curso parto domiciliario).

Entre las atipicidades de este espacio respecto a este tema común a todos (y con cierta recepción del "público" similar a otros) radica en la metodología de este encuentro, dictado particularmente por una psicóloga y una médica generalista especialista en puericultura. El trabajo grupal y de taller, con dinámica de juegos a través de "mitos" y su ratificación o rectificación; la apelación a saberes previos de las mujeres y a soportes audiovisuales, apuntan a un trabajo de abordaje integral de la lactancia.

\subsection{C) CONOCIMIENTO DEL PROPIO CUERPO}

Una de las particularidades de este abordaje, coherente con el enfoque fisiológico, es la concepción del cuerpo gestante como un cuerpo sano, y del proceso perinatal como un proceso no-patológico. Este punto de partida va decantando en distintas cuestiones, como por ejemplo el trabajo corporal de baile y desinhibición (descrito en el apartado metodológico). Asimismo, el ejercicio de variadas posturas y

\footnotetext{
100 Sobre la espera también destaco que en todos los encuentros siempre fueron lxs profesionales (y yo como observadora) quienes tuvimos que esperar hasta una hora a lxs asistentes del curso.
} 
posiciones para atravesar los trabajos de parto y parto, que también lo presencié en el curso del gimnasio, demuestran el lugar que se le da al cuerpo en este espacio.

"Durante una meditación anoté: "A las chicas les costaba sentirse cómodas en la posición decúbito dorsal, y eso me hizo pensar en las dificultades para parir en esa posición o, principalmente, atravesar el trabajo de parto así'”' (Diario de campo, 8/11/2017, curso parto domiciliario).

"Se muestran muchas posiciones para transitar el trabajo de parto y parto: sentadas, con sogas, con telas, apoyadas" (Diario de campo, 9/9/2017, curso parto domiciliario).

Pero, fundamentalmente, el abordaje contrahegemónico de este equipo es eliminar la mediación o el protagonismo médico en el conocimiento del propio cuerpo, a través de la auto-realización de controles médicos, por ejemplo tomarse la presión y llenar la propia historia clínica, por parte de las mujeres. Correr el velo de lo que pasa en el cuerpo y poner el saber médico a disposición de las mujeres para que conozcan lo que sucede, es una propuesta sutil en las acciones concretas, pero poderosa como horizonte. El sutil pero efectivo hecho de que el doctor "permita" (o mejor dicho, obligue, exija, en buenos términos) que las mujeres sean quienes llenan su historia clínica tiene varios efectos positivos: las vuelve dueñas y responsables de su salud, conocen sus datos, ven su evolución, conocen qué elementos se tienen en cuenta.

\subsection{D) SOCIALIZACIÓN PARA LA OBEDIENCIA O PARA LA AUTONOMÍA.}

Dado que participé de menos de la mitad de los encuentros, mucha de la información y la impronta de este curso la retomo del material documental que generó el equipo coordinador y que otorga a Ixs participantxs. Lo interesante es la apuesta por socializar y democratizar el acceso a información médica sobre la fisiología del proceso de embarazo, nacimiento, posparto y lactancia, que no se otorga ni en los centros de formación hegemónicos de IXs profesionales de la salud.

Así, por ejemplo, el punto de partida de este compilado de textos establece que "la mujer tiene una capacidad innata para atravesar sin complicaciones y sin ayuda por el proceso de embarazo, parto y crianza inicial", marcando la cancha sobre la consideración de la no-necesariedad exclusiva del saber experto médico para su asistencia o acompañamiento. Si algo propone este grupo, es el protagonismo exclusivo de la mujer en el proceso perinatal, por eso a continuación de lo mencionado enumera tres capacidades maternas claves: la intuición, la capacidad de parir y la capacidad de dar la teta como elementos de la "naturaleza" que sufren la intervención de la cultura a 
través del condicionamiento del funcionamiento fisiológico: la liberación de hormonas, básicamente. La consideración de estos condicionamientos culturales lleva a poner en el centro de la escena el aspecto emocional del proceso:

"Los estados emocionales maternos durante el embarazo, parto y crianza inicial son un elemento primordial que modifica la situación de salud de madre e hijo. Esto sucede porque durante este período de la vida los procesos fisiológicos que suceden en ambos están producidos por la activación de un sistema neuro-endócrino que puede inhibirse dependiendo de los estados emocionales maternos. Las emociones de la madre producen cambios hormonales que pueden facilitar o complicar estas etapas vitales. Es probable que cuidar los estados emocionales maternos sea más importante que cualquier otra medida que podamos tomar durante el embarazo, parto y crianza" (Material de texto, curso de parto domiciliario).

En otro de los textos incluidos se sostiene que "el parto no es de un modo particular", propiciando la atención personalizada y desaconsejando la universalización, estandarización y rutinización de la atención. "Su parto es normal, natural y perfecto para ella [cada mujer]". En consonancia, respecto a la posición del parto sostienen "Nadie tiene una posición correcta para parir, es tan individual como cada mujer y cada parto" y refieren a ciertas tendencias a arrodillarse o acuclillarse cuando las mujeres "no tienen nada culturalmente impreso". De todos modos el manual incluye la gráfica de 37 posiciones posibles entre verticales (de pie, sentada, en cuclillas, de rodillas, colgada), cuadrúpedas, asimétricas y alternativas a la postura obstétrica de litotomía, para atravesar el trabajo de parto y dar a luz.

Más allá de esta fuente secundaria y más allá de la argumentación desarrollada allí, algunas cuestiones observadas en los encuentros permiten marcar la tendencia del curso hacia un empoderamiento de las mujeres, en su capacidad de gestar y parir, y en el lugar secundario de Ixs profesionales médicxs, cuya función se reduce o limita a la asistencia o acompañamiento. El hecho de que "el curso" sea coordinado por profesionales "de civil", sin ambo, sentados en el piso al igual que el resto de Ixs asistentes, tiene importantes implicancias simbólicas ${ }^{101}$.

Asimismo, al tratarse de un equipo que acompaña partos generalmente domiciliarios, la institución a la que debería garantizarse "obediencia" sería en tal caso la institución médica, y dado que la convocatoria es a empoderarse en el propio proceso reproductivo y las propias capacidades femeninas-maternas, la respuesta ya está dada.

101 Aunque esto se repite de modo similar en el gimnasio, cuyos contenidos y abordajes son similares a los de este paradigma, tratándose de un grupo eminentemente profesional médico, se contrapone a los planteos por parte, por ejemplo, de la partera del hospital público para que yo vistiera una chaqueta blanca como ella, asi lxs asistentes podían "identificarme". 
"Incentivan la ruptura de mandatos como "no leche de formula", "no chupete", en privilegio de la calidad de vida" (Diario de campo, 18/12/2017, curso parto domiciliario).

"La participación de la psicóloga aportó mucho para desmitificar, romper mandatos, relajar, entender cuáles son exigencias sociales sobre lo que es ser madre y padre, sobre el colecho, el chupete, la teta, demás". (Diario de campo, 11/10/2017, curso parto domiciliario).

"Este grupo no sólo incentiva que los sujetos se hagan cargo de su salud llenando las historias clínicas, sino que al finalizar el proceso, se las entregan" (Diario de campo, 18/12/2017, curso parto domiciliario).

De todos modos y antes de pasar al cierre de este apartado, me parece relevante mencionar que hacia enero de 2018 (unas semanas después del último encuentro observado), circularon en redes sociales y en grupos ciber-activistas por el parto respetado en La Plata (Castrillo, 2018 a), declaraciones y denuncias de usuarias y participantes de este ciclo de encuentros (del "grupo" mayo 2017, es decir que iban a parir en esa época), sobre abandono de persona por parte del equipo profesional. Lo cierto es que a partir de una muerte perinatal ocurrida en abril, el equipo se distanció de la atención por unas semanas, y no asistió a las mujeres del "grupo mayo", que se sintieron abandonadas y estafadas. Sobre esto, dos reflexiones articuladas: la no necesariedad médica es aún una utopía (la excepcionalidad de la ausencia de Ixs profesionales no generó entendimiento o la posibilidad de ejercer la autonomía, sino denuncias) y mientras la garantía de un modelo de atención respetuoso y basado en la fisiología descanse sobre personalismos, se seguirán necesitando esXs profesionales individuales, generándose así un círculo vicioso.

\subsection{E) LO DISTINTIVO: ¿PARIR EN CASA?}

Como cierre del apartado, creo relevante destacar que la cuestión del ámbito de ocurrencia del nacimiento cuyo embarazo se acompaña en el ciclo de encuentros, contrario a lo que podía creerse, casi no se menciona en el desarrollo del curso, salvo en el encuentro específico sobre parto en casa. De todos modos sí encontré un amplio desarrollo del tema en el material de texto creado por el equipo. El punto de partida es el establecimiento de que la decisión del mejor lugar no es médica ni estatal (pública) sino privada, de la mujer: "No puede decidir la partera, doula o médico si la mujer puede tener o no a su bebé en casa, es la mujer la que debe decidir". Y agrega:

"El mejor lugar para tener el parto es un lugar en el que la mujer se sienta SEGURA. 
Debe ser un lugar seguro en el AFUERA de la mujer garantizando la proximidad de todos los recursos necesarios para responder a una situación de riesgo. Debe ser también un lugar seguro en el INTERIOR de la madre asegurando para ella, su bebé y su pareja tranquilidad, respeto, confianza, intimidad donde no se sienta observada, amenazada, invadida o infantilizada.

Cada pareja debe buscar el lugar que mejor garantice la seguridad de adentro y de afuera, en función de la propia experiencia, las expectativas y las posibilidades del entorno" (Material de texto escrito, generado y distribuido por el grupo de parto domiciliario, las mayúsculas son originales).

Este material agrega menciones a investigaciones y evidencias sobre los beneficios del parto domiciliario para Ixs recién nacidxs, para las mujeres y para el entorno, en tanto "la planificación de un parto en casa es una forma muy efectiva de mantener el proceso fisiológico del parto en condiciones normales y reducir el riesgo de complicaciones". También establece la importancia de los CPN y del trabajo conjunto con la pareja y con el equipo profesional para determinar las decisiones reproductivas.

Siguiendo una vez más con la estructura del capítulo, sin duda en "qué llevo" (o, en este caso, "qué tengo que tener"), la alternativa por el parto en casa despliega la mayor de sus atipicidades: por los insumos médicos que requiere y por la simpleza de otros materiales que exige.

"Elementos necesarios para el Parto Domiciliario

- Para el Parto: caloventor eléctrico con alargue; 1 Paquete de 20 saleas descartables; Gasa trozada 15x15 NO estéril (1/2 kg); Botellita de alcohol; Botellita de lodo povidona; Botellita de agua oxigenada 10\%; Balde limpio y Palangana; 1 bol o ensaladera de vidrio o cerámica; Espejo pequeño de 20 ó $30 \mathrm{~cm}$ de lado; Linterna y Velador; Bolsas de consorcio; Toallas y toallones.

- Para el Bebé: Mantita; Muda de ropa con gorro; Pañales RN; Oleo calcáreo y algodón.

- Para la Mamá: Varias Bombachas; 30 Apósitos Postparto NO estéril; Remera cómoda o musculosa; Frutas, helado de agua, hielo; Frutas secas" (Material de texto escrito, generado y distribuido por el grupo de parto domiciliario)

Dado que el foco está puesto en el modelo y no en el ámbito de atención, las cuestiones pasan más por la construcción de saberes en torno a la fisiología del embarazo y el parto, a la información médica y no médica al respecto y a la toma de decisiones informadas sobre diversas cuestiones.

Por ejemplo, en el encuentro sobre el plan de parto (y en el material escrito sobre el mismo) se establece un abanico amplio de cuestiones sobre las cuales hay que tomar decisiones ya que, como establece, "la última palabra es la tuya, ya que es tu cuerpo, tu bebé, tu nacimiento y tu decisión". Se trata de determinar cuestiones sobre el trabajo de parto, el parto, el alumbramiento y la recepción de Ixs recién nacidxs. Esto es, sobre la asistencia y atención médica, Ixs acompañantes del trabajo de parto, el uso o 
no de piletas, las técnicas de alivio del dolor elegidas, las cuestiones del pujo, posiciones, ambiente, manejo activo del alumbramiento, corte del cordón, reparación del periné si es necesario (por desgarro natural), diversas intervenciones médicas necesarias (por ejemplo cesárea), etc. La pregunta es: en el modelo hegemónico, el más extendido, ¿todas estas decisiones fueron cedidas o expropiadas por la medicina?

\subsection{A MODO DE CIERRE Y RECAPITULACIÓN: LAS EXPERIENCIAS CONCRETAS}

La posibilidad metodológica y teórica que me dio entrevistar a algunas de las mujeres con las que realicé los cursos posterior a sus partos, tiene la riqueza de permitir visibilizar qué evaluación realizan de dicho tránsito y de la información que obtuvieron. Esta riqueza radica en la corroboración de lo analizado en términos de que existe un desajuste entre los contenidos y las formas de los CPP (y el mensaje simbólico que transmiten las instituciones y Ixs profesionales sobre ellas, sus procesos y sus emociones) y lo que realmente ocurre desde que se "recibe el TP" en la institución o el/la profesional en el domicilio hasta el posparto inmediato.

Durante mi transito semietnográfico por el hospital público, no dejé de pensar que esas cuatro paredes en las que se daba el curso, eran la excepción y no la regla sobre la atención obstétrica pública. En la cantidad de expectativas fallidas, porque la atención personalizada (que aparece como un privilegio de clase en las experiencias analizadas) se reemplaza por un "te toca quien te toca" (tal como expresaron, entre otrxs, las psicólogas entrevistadas) en la recepción del TP, y por la falta de una política clara de humanización de la atención, lo que deviene en que casi-todo se ampara en la voluntad personalísima de cada profesional. Si el curso te enseña que el parto es tuyo, por ahí el que te toca, piensa que no. Y ese desajuste esconde la violación a derechos sexuales y reproductivos.

Consulté a algunxs de mis entrevistadxs sobre qué evaluación realizaban, pasada la experiencia del parto, de la información y el tránsito por los CPP: la forma, los contenidos, el público, etc. Retomo aquí un fragmento de entrevista al respecto.

“¿Te sirvió el curso?

Johana: Ni. Pero por una cuestión de que, no es que yo sé todo, obviamente es la primera vez, hijo primero, pero tengo una hermana que tiene 3 nenes. O sea, yo viví con mi hermana los embarazos y el post y el pre y el todo. Entonces como que, obviamente que cada uno tiene su experiencia para contar sus cosas pero eh, más o menos lo que me iban contando, había muchas cosas que estaban buenas que no lo sabés, o sea, "y bueno, ¿cuándo sé que voy a tener, cuándo va a nacer". "Te vas a dar cuenta". Bueno, yo qué sé (risas). Eso que te digan así, como "bueno, te vas a dar 
cuenta", no, no, tenés que vivirlo para decir "sí, sí, ya viene" porque te morís del dolor ¿no? Pero bueno, sí sirvió en un montón de cosas. A él le sirvió mucho porque él no estaba ni siquiera enterado de nada, no tiene en su familia, él es hijo único, entonces no tiene hermana, no tiene sobrina, no tiene como para decir "bueno, estoy un poco más empapado" en ese sentido. Pero, a mí me sirvió alguna que otra cosa, pero bueno a él le sirvió mucho más, creo yo (risas)" (Entrevista 17, Johana y Damián, parto en hospital privado, curso de preparto en obra social).

Este fragmento de la entrevista permite ver dos cosas. Primero cierta paradoja de la medicalización de los PEP: no se confía en que el propio cuerpo va a dar señales claras que van a poder interpretar sobre el comienzo del trabajo de parto, por ello "van a la medicina" y ésta "las vuelve a la intuición" con un "te vas a dar cuenta" que no despeja las dudas. Segundo, la importancia del "parto transmitido" de las mujeres de su familia, como universo de imaginarios y discursos que circulan, y el hecho de que el curso sirviera como cúmulo de saberes para su pareja, que no cuenta con esas experiencias femeninas 0 maternales cercanas. $Y$ en esta segunda parte es posible pensar un efecto secundario positivo de los cursos en tanto permiten informar a los varones-padres. Esta es la pareja en la que el varón tomaba nota, preguntaba y aprovechó el CPP como insumo de la información que la médica obstetra no les daba en las consultas prenatales. Por ello, se suma que los diferenciales de puntos de partida para mujeres y varones (por la simple socialización de género hegemónica) deben ser considerados a la hora de estimular aún más la participación de éstos últimos en esta clase de espacios.

Otras entrevistadas tuvieron opiniones diversas respecto a su experiencia con el curso de preparto: lo que esperaban y lo que sucedió (en términos positivos o negativos), las dificultades de horario o espacio que encontraron, lo que les aportó y lo que no, cómo utilizaron las "formulitas" para saber en qué momento de las contracciones acercarse a la guardia o la clínica o contactar al personal.

Sólo en el curso de preparto del grupo de parto domiciliario se consideró una reunión posparto en la que se les pidió a Ixs asistentes su evaluación sobre el mismo. En un contexto emotivo, con Ixs recién nacidxs presentes, hubo consenso en ese último encuentro sobre la importancia de lo ocurrido más en la atención del parto, el acompañamiento y asesoramiento personal, el consejo sobre posiciones y técnicas para atravesar los dolores de parto.

Las mujeres, en las charlas posparto, se hayan atendido donde haya sido, tienden a responsabilizarse y culparse por no lograr los partos a los que aspiran: hay 
cuestiones que sí puede pensarse responsabilidad suya (informarse, empoderarse) pero las principales les escapan: desde las cuestiones fisiológicas de su cuerpo hasta la presencia del Estado y el cumplimiento de las leyes, y la atención médica digna y respetuosa.

El curso de preparto emerge entonces como un espacio a veces de catarsis, a veces de acompañamiento y de conocimiento de herramientas centradas, sobre todo, en el momento del nacimiento. Se trata de espacios asistenciales-pedagógicos, como establecí anteriormente, que adquieren rasgos según los grupos e instituciones coordinadoras. La propuesta de cursos que empoderen a las mujeres en sus capacidades fisiológicas y promuevan un enfoque de derechos y género, aún requiere trabajo $^{102}$.

El objetivo de este capítulo ha sido mostrar que los embarazos sufren/son destinatarios de intervenciones médicas prácticas (controles prenatales, monitoreos, ecografías, tactos) y simbólicas (cursos, hábitos saludable, expectativas), que he decidido abordar y problematizar a partir del dispositivo de diversos cursos de psicoprofilaxis obstétrica. La propuesta fue atravesar el análisis de los cursos buscando saber si promueven la obediencia al modelo médico y sus normas y protocolos, o, por el contrario buscan generar espacios de autonomía de las mujeres, en el marco de un enfoque de género y derechos humanos, y una vuelta a la fisiología. El extenso desarrollo descriptivo y analítico al respecto, permite concluir que existen grises, tensiones, expectativas, metodologías y discursos diversos, pero que sigue primando una brecha entre lo que se dice en los cursos y lo que pasa en sala de partos, por la ausencia de líneas de trabajo generales que promuevan la atención obstétrica respetuosa de derechos de las mujeres. En este sentido, si, como me indicaron en algunas entrevistas, Ixs obstetras mencionan que las mujeres que hicieron el curso preguntan menos (¿y obedecen más?), diré que el objetivo de que cuestionen y no le tiren el cuerpo al/a la médicx no se cumple.

\footnotetext{
${ }^{102}$ Esta tensión también ha sido trabajada previamente, en tanto: "Los cursos de preparación para el parto también fueron cuestionados desde el análisis institucional que postula que la psicoprofilaxis obstétrica opera como ‘conjunto tecnológico’ en el cual la preparación implica una aceptación de las prácticas que se le realizan y no una capacitación que otorgue protagonismo a la mujer sobre su proceso de parto (Videla y Grieco, 1993: 258)" (Fornes, 2011, p. 143)
} 


\section{CAPÍtULO 5 \\ HACER (O ACOMPAÑAR) PARTOS \\ -INTERVENCIONES MÉDICAS EN LOS PROCESOS DE PARTO-}

\subsection{Presentación}

Los procesos de embarazo y parto se han construido como hechos médicos a nivel mundial y en nuestro país, desde el siglo XIX, cuando se dieron dos hechos conexos: la profesionalización de la atención, que pasó de parteras a "médicos"103, y la institucionalización del parto, que se trasladó del hogar y el contexto familiar hacia el hospital. El objetivo de estas dos ocurrencias estuvo ligado a disminuir las altas tasas de mortalidad materno-infantil, con la incorporación de principios como la asepsia, los controles prenatales y el seguimiento del trabajo de parto y posparto, entre otros, con el fin de establecer parámetros universales y estandarizados de normalidad, desviación, riesgo y alarma. Una de las principales críticas es que este complejo proceso de medicalización construye a los embarazos y partos como eventos sanitariohospitalarios, homogéneos, controlados y regulados por el personal de salud, con un aumento del uso de la tecnología entre sus intervenciones, concibiendo todos los PEP como de alto riesgo, exigentes así de la actuación médica intervencionista.

Este capítulo recorta una pregunta hacia el quehacer de médicas obstetras, parteras y otras agentes de salud en la atención de los PEP. La pregunta por las representaciones sobre diversos aspectos que re-construyen las profesionales de la atención obstétrica ${ }^{104}$ encuentra su importancia en su impacto y repercusión en la atención que dispensan, o, en otras palabras, porque "representaciones simbólicas que los profesionales relacionados con el proceso reproductivo poseen [repercuten] en las prácticas profesionales" (Arnau Sánchez y otros, 2012, p. 226). Se trata de representaciones de profesionales sanitarias que ocupan diversas posiciones en el campo profesional obstétrico: parteras, médicas obstetras, trabajadoras sociales, psicólogas, jefas de servicio de tocoginecologia de maternidades públicas y funcionarias

\footnotetext{
${ }^{103}$ La feminización del término "parteras" y la masculinización del término "médicos" es arbitraria e intencional: refiere tanto a la exclusión de las mujeres para ingresar a la universidad en tanto la imposibilidad de aquellas mujeres parteras de profesionalizarse en un primer momento y, principalmente, refiere a la masculinización del ejercicio del rol médico (Camacaro Cuevas, 2000; Pozzio, 2013)

${ }^{104}$ Justamente por el proceso de profesionalización que modificó la atención de los nacimientos hace más de un siglo, las entrevistadas cuentan con certificación académica para trabajar. Quedan fuera de esta investigación otro tipo de acompañantes no tituladxs (por ejemplo doulas).
} 
del gobierno kirchnerista del Ministerio de Salud de la Provincia ${ }^{105}$. Esta heterogeneidad (esquematizada en el cuadro 15) de profesionales, disciplinas y campos de actuación, no sólo representa una decisión metodológica en tanto criterio de selección de la muestra, sino que, principalmente, responde a la diversidad de agentes de salud que participan del campo obstétrico, lo (re)producen, cuestionan y describen.

Tal como muestra la siguiente tabla, se realizaron 12 entrevistas en profundidad a profesionales de la salud que participan/participaron de la atención de embarazos y partos en distintos ámbitos (público, privado y domicilio) y cuyas experiencias, prácticas y discursos permiten ir delineando y describiendo la situación concreta de los dos modelos de atención obstétrica que se han venido trabajando.

\section{CUADRO 15: ENTREVISTAS A PROFESIONALES DE LA SALUD OBSTÉTRICA}

\begin{tabular}{|c|c|c|c|c|c|c|}
\hline \multirow[t]{2}{*}{$\begin{array}{l}\text { Nominación } \\
\text { entrevista }^{106}\end{array}$} & \multirow[t]{2}{*}{ Profesión } & \multirow[t]{2}{*}{ Edad } & \multicolumn{3}{|c|}{$\begin{array}{l}\text { Actividad profesional desempeñada } \\
\text { en }\end{array}$} & \multirow[t]{2}{*}{$\begin{array}{l}\text { Fecha de } \\
\text { entrevista }\end{array}$} \\
\hline & & & $\begin{array}{l}\text { Maternidad } \\
\text { publica }^{107}\end{array}$ & $\begin{array}{l}\text { Clínica } \\
\text { privada }\end{array}$ & Domicilio & \\
\hline Bárbara & Partera & 32 & - & SI & SI & $30 / 3 / 2015$ \\
\hline \multicolumn{2}{|c|}{ Equipo de psicología de Maternidad } & $25-45$ & "A" & - & - & 20/2/2017 \\
\hline \multicolumn{2}{|c|}{ Equipo de trabajo social de Maternidad } & $28-30$ & "A" & - & - & $13 / 3 / 2017$ \\
\hline Rocío & $\begin{array}{l}\text { Médica } \\
\text { obstetra/tocoginecologa }\end{array}$ & 42 & "A" & SI & - & $10 / 04 / 2017$ \\
\hline Sandra & Partera & 57 & "A" & - & - & $1 / 2 / 2017$ \\
\hline Carla & Médica obstetra & 34 & "B" & $\mathrm{SI}$ & - & $4 / 9 / 2016$ \\
\hline Andrea & Neonatóloga - lactancia & 49 & "A" & $\mathrm{SI}$ & - & $24 / 1 / 2017$ \\
\hline Adela & $\begin{array}{l}\text { Médica obstetra - Jefa } \\
\text { de servicio de } \\
\text { tocoginecología }\end{array}$ & 56 & "A" & SI & - & $14 / 9 / 2015$ \\
\hline Alicia & $\begin{array}{l}\text { Médica obstetra - Jefa } \\
\text { de servicio de } \\
\text { tocoginecología }\end{array}$ & 47 & "B" & $\mathrm{SI}$ & - & $1 / 10 / 2015$ \\
\hline Marta & $\begin{array}{l}\text { Médica obstetra - Jefa } \\
\text { de servicio de } \\
\text { tocoginecología }\end{array}$ & 48 & "C" & SI & - & $30 / 9 / 2015$ \\
\hline Elina & Pediatra - Funcionaria & 52 & $\begin{array}{l}\text { Dirección de } \\
\text { MSPBA }\end{array}$ & aternidad & Infancia - & $10 / 9 / 2015$ \\
\hline Fernanda & $\begin{array}{l}\text { Neonatóloga - } \\
\text { Funcionaria }\end{array}$ & 49 & $\begin{array}{l}\text { Dirección de } \\
\text { MSPBA }\end{array}$ & aternidad & Infancia - & $6 / 8 / 2015$ \\
\hline
\end{tabular}

En este capítulo, entonces, analizo la atención de los PEP centrándome en la perspectiva de Ixs profesionales de la salud a cargo, en base a algunos tópicos que reconstruí en el trabajo de campo en relación a:

${ }^{105}$ Los discursos de estos dos últimos conjuntos de entrevistadas (jefas de servicio y funcionarias ministeriales) fueron mayormente utilizados en el capítulo 4.

${ }^{106}$ Los nombres de las entrevistadas fueron cambiados para mantener el anonimato.

${ }^{107}$ La ciudad de La Plata cuenta con 4 hospitales públicos de gestión provincial que cuentan con área de maternidad y atención obstétrica. He realizado trabajo de campo en tres, que aquí nomino como "A" (es la más grande, con 4500 partos anuales y atiende alto riesgo), "B" y "C", para mantener el anonimato. 
1. La construcción del habitus médico obstétrico hegemónico, como el aprendizaje de hacer partos: la reconstrucción de algunos eventos significativos en la formación médica y en la asistencia y la puesta en práctica de intervenciones clínicas y simbólicas.

2. El campo profesional obstétrico como campo de disputa alrededor de la humanización de la atención y lxs (re)productores de la atención hegemónica, intervencionista y medicalizante.

3. La otra obstetricia, la que propone acompañar partos y no intervenirlos: la reconstrucción de experiencias de profesionales a fin a este modelo de trabajo.

\subsection{CONSTRUCCIÓN DEL HABITUS MÉDICO OBSTÉTRICO: APRENDER A HACER PARTOS.}

El punto de partida para analizar las prácticas y representaciones que (re)producen las profesionales de la salud entrevistadas, es considerarlas como discursos que dicen, articulan, actúan y performan un hábitus médico. En este sentido, retomo los trabajos de Castro $(2009,2014)$ quien, con el objetivo de construir la violencia obstétrica como problema sociológico, propone estudiar las condiciones de posibilidad del autoritarismo médico, a través de aportes bourdianos (campo y habitus) y foucaultianos (tecnologías del yo, poder, control y vigilancia) ${ }^{108}$. Su postulado es que "a nivel de las interacciones microsociales [como son las relaciones médicx-paciente en la atención obstétrica] es posible rastrear relaciones de poder que resultan fundamentales por el papel que juegan en la producción y la reproducción de las relaciones de dominación" (Castro, 2014, p. 172).

${ }^{108}$ Bourdieu define a los campos como: “(...) espacios estructurados de posiciones (o de puestos) cuyas propiedades dependen de su posición en dichos espacios y pueden analizarse en forma independiente de las características de sus ocupantes -en parte determinados por ellas- (...) Un campo se define, entre otras formas, definiendo aquello que está en juego y los intereses específicos, que son irreductibles a lo que se encuentra en juego en otros campos o a sus intereses propios y que no percibirá alguien que no haya sido construido para entrar en ese campo (...) La estructura del campo es un estado de la relación de fuerzas entre los agentes o las instituciones que intervienen en la lucha de la distribución del capital específico que ha sido acumulado durante luchas anteriores y que orienta las estrategias ulteriores. Esta misma estructura, que se encuentra en la base de las estrategias dirigidas a transformarla, siempre está en juego: las luchas que ocurren en el campo ponen en acción al monopolio de la violencia legítima (autoridad específica) que es característico del campo considerado, esto es, en definitiva, la conservación o subversión de la estructura de la distribución del capital específico" (Bourdieu, 1990, p.2). Y al habitus como: "sistemas de disposiciones duraderas y transferibles, estructuras estructuradas predispuestas a funcionar como estructuras estructurantes, es decir, como principios generadores y organizadores de prácticas y de representaciones que pueden ser objetivamente adaptadas a su meta sin suponer el propósito consciente de ciertos fines ni el dominio expreso de las operaciones necesarias para alcanzarlos, objetivamente "reguladas" y "regulares" sin ser para nada el producto de la obediencia a determinadas reglas, y, por todo ello, colectivamente orquestadas sin ser el producto de la acción organizadora de un director de orquesta" (Bourdieu, 1991, p. 86) 
"El campo médico abarca el conjunto de instituciones y actores de la salud que, ubicados en diferentes posiciones, mantienen entre ellos relaciones de fuerza orientadas a conservar, adquirir o transformar esa forma de capital específico que consiste en la capacidad de imponer los esquemas dominantes de definición, percepción y apreciación de las materias propias de la agenda sanitaria, así como de la acción (política, comercial, científica, profesional) que deriva de ello. Así, junto con las instituciones de salud, son elementos centrales del campo médico las instituciones que forman los nuevos cuadros profesionales que eventualmente pasarán a ser parte del campo (las facultades de medicina y los hospitales de enseñanza), los agentes que operan estas instituciones, y los profesores y estudiantes de las especialidades médicas" (Castro, 2014, p. 173).

En su definición sobre el campo médico, Castro da cuenta de lo que aquí nomino como campo profesional heterogéneo (y será mejor caracterizado en la segunda parte de este capítulo). Su propuesta conceptual se complejiza al pensar cómo ese campo médico "produce (y es, simultáneamente, el producto de) una serie de subjetividades" (Castro, 2014, p. 173), de las que destaca el habitus médico.

"Éste es el conjunto de predisposiciones generativas que resultan de la incorporación (lo social hecho cuerpo) de las estructuras objetivas del campo médico. Tales predisposiciones las adquieren los profesionales de este campo -en primer lugar, los médicos - a través de la formación que reciben en la facultad de medicina y en los hospitales de enseñanza. Al mismo tiempo, dichas predisposiciones se recrean cotidianamente a través de su práctica profesional, y engendran todas las conductas "razonables" y de "sentido común" posibles en tanto profesionales. La coincidencia entre el campo médico y el habitus médico da lugar a un sentido práctico propio del campo, es decir, a una práctica cotidiana espontánea, casi intuitiva, preconsciente (debido a su determinación social de origen), que permite la realización permanente de conductas eficaces para los fines del campo" (Castro, 2014, p. 173-4).

Su postulación, que lo convierten en uno de los referentes teóricos de esta tesis, da un paso más en la problematización del concepto y propone como tesis que en las características de ese habitus pueden encontrarse las ontologías de "la relación autoritaria que los médicos propenden a establecer con las mujeres durante la atención del parto" (Castro, 2014, p. 174).

"Postulo que existe una vinculación estructural entre el conjunto de mensajes, enseñanzas, conminaciones, recriminaciones, clasificaciones, etiquetaciones, descalificaciones, regulaciones y jerarquizaciones (de clase, de género, etcétera), que los estudiantes de medicina y los médicos viven en carne propia o atestiguan de cerca durante los años de formación, y los rasgos autoritarios que eventualmente exhiben durante su práctica profesional y que encuentran su vehículo más propicio en el habitus médico. Se trata de "tecnologías del yo" (cuya relevancia no ha sido dimensionada adecuadamente), por cuanto constituyen prácticas pautadas a través de las cuales el campo médico se legitima y se reproduce" (Castro, 2014, p.174).

A continuación expongo y analizo mis hallazgos en relación a cómo ese habitus puede (y efectivamente hace) retomar/reproducir características de las tendencias típico 
ideales de atención obstétrica (intervencionista o respetuosa), considerando que diversos elementos de las trayectorias formativas y asistenciales, y también personales, de las profesionales entrevistadas, explican cómo es la atención obstétrica actual. Su historia imprime características peculiares a la asistencia que dispensan. Para ello será relevante también tener en cuenta el concepto de curriculum oculto que también desarrolla Castro, al que entiende como el conjunto de "procesos, presiones y restricciones", no siempre oficiales, que hacen a la formación médica, de las que él elige centrarse y problematizar tres que son claves y son emergentes en esta tesis también. Me refiero a los castigos y disciplinamientos corporales (y agrego psicológicos) que sufren Ixs médicxs en formación; la fuerza del orden de las jerarquías; y el disciplinamiento de género. El análisis de estas tres dimensiones del currículum oculto, reposan en su propuesta teórica metodológica para la construcción de la violencia obstétrica como problema sociológico, a la que pretendo abonar.

Una de las propuestas de la presente tesis es mostrar tendencias y no determinaciones, razón por la cual se plantean algunos cruces, grises y puentes entre los modelos (intervencionismo y medicalización versus humanización y fisiología). En ese sentido, es posible que con la reconstrucción de los itinerarios formativos y profesionales de las entrevistadas, sea posible advertir cómo aprendieron a hacer partos, esto es: la constatación de la vertiente hegemónica y medicalizada de la concepción y atención de los PEP.

En vías de establecer qué es hacer los partos, tal como propone este capítulo, en primer lugar describiré elementos que hacen la construcción del habitus médico de estas profesionales de la salud a partir de su experiencia formativa y asistencial. Elegí reconstruir este proceso de construcción de su rol a través de sus discursos sobre su experiencia profesional tanto en la formación como en la asistencia. Esto a través de la invitación realizada a las entrevistadas a narrar el primer y último parto en el que participaron (en general primero como "público" o expectadoras, en rol de alumnas y con actitud expectante; y finalmente interviniendo o atendiendo en relación al modelo al que adscriben); y la descripción o el detalle de las prácticas médicas que utilizan rutinariamente y cómo se componen (actorxs médicxs) las escenas del parto en la atención que dispensan. En otras palabras, en la reconstrucción cronológica es posible ir viendo cómo la estructura médica dominante que describe Castro se va estableciendo de tal modo en el quehacer profesional que se pasa de la actitud expectante a la acción intervencionista o de mando que exige el hacer partos. Considero que en su experiencia 
profesional, asistencial, formativa y docente, así como en su experiencia maternal -o noy como usuarias del sistema de salud, tanto en la narración cronológica como la visión crítica en retrospectiva, es posible encontrar y vislumbrar elementos que van dando solidez a su discurso en tanto responsables de la atención obstétrica.

\subsubsection{FORMACIÓN: HACER(SE) HACEEDORXS DE PARTOS}

Siguiendo la propuesta de Castro antes descripta, analizar algunos elementos de la formación que reciben quienes están a cargo de la atención obstétrica, permite reponer ontologías que explican cómo y por qué se pare y se nace de tal modo actualmente. Dado que la formación no es el foco de este trabajo y cuyo abordaje debiera realizarse en mayor profundidad y extensión, aquí se recogen algunos fragmentos de entrevista que se refieren a la elección de la carrera, el tránsito por la universidad y las primeras incursiones en la práctica médica.

Sobre la elección de la carrera, las entrevistadas refieren diversas trayectorias personales, familiares y académicas que no hacen al quid de la cuestión aquí analizado pero que pueden pincelar un poco su experiencia y su formación. Por ejemplo Bárbara, partera, cuenta que su objetivo era estudiar medicina pero al no lograr superar el examen eliminatorio de ingreso y al anoticiarse de que el curso de ingreso para la licenciatura en obstetricia "era más fácil" y "se podía pasar a Medicina en tercer año", tomó este atajo, aunque nunca realizó el pase ya que era un poco más dificultoso de lo que le habían mencionado. Lo interesante es que en este camino/atajo llevado adelante, ya hay simbólicamente algunos datos característicos de la profesión médica y afines. La partería aparece como una puerta trasera de entrada al mundo sanitario, reforzando su rol secundario en términos jerárquicos y de saber con médicxs. Asimismo parece que la obstetricia recibe el descarte de medicina, Ixs "médicxs frustradxs" (textual), porque no todxs pueden ser médicxs. Por último, y paradójicamente, las obstétricas son formadas por médicxs.

Carla y Rocío (ambas médicas obstetras) por su parte narran influencias personales y familiares en la elección de convertirse en estudiantes de medicina: la madre de la primera trabajaba en una obra social en el pueblo de Entre Ríos de la que es oriunda; y el padre de la segunda también "hace obstetricia" (en sus palabras). Ambas mencionan que una vez completado el tránsito por la formación básica en la universidad (dificultoso: una con dificultades para estudiar por falta de estrategias, la otra por una doble maternidad adolescente); la elección de la especialización en 
tocoginecología devino por cuestiones de "gusto". En este sentido, Carla mencionó en la entrevista que eligió esa especialidad luego de ver un cuello de útero y maravillarse (se le llenaron los ojos de lágrimas) y Rocío dijo haberla elegido porque combina sus gustos por la endocrinología, la cirugía y la atención de adolescentes.

Dado que no hice hincapié durante las indagaciones en la etapa universitaria, los discursos más interesantes se concentran en las innumerables tensiones, dificultades y puntos de quiebre en la formación práctica que reciben en los hospitales-escuelas. En ellos, las disputas suelen centrarse en la figura del/de la residente, quien parece tener (unánimemente en las entrevistas) el protagonismo absoluto en la atención de partos del sistema público, bajo la excusa de que "está aprendiendo".

"Me puse a hacer unas guardias ahí [en el hospital escuela - maternidad publica "A"], después me fui obviamente porque me peleé con todos los residentes y todo, porque es un maltrato constante. Mecánico, yo creo que más allá que sí se dan cuenta porque son gente, es mecánico el maltrato que tienen como poner oxitocina. No aguanté más y me fui. $\mathrm{Y}$ ahí me contacté con Marta [partera que asiste partos domiciliarios]" (Entrevista Bárbara, partera).

Para la entrevistada, la formación tradicional en el hospital, que (re)produce la jerarquía de Ixs médicxs, sean residentes o de planta, es decir, en formación o formadxs, se vuelve expulsora de algunxs sujetxs, por generar aprendizajes en contexto de violencia o maltrato, o por no admitir otras visiones o modos de trabajo.

"Vos laburás como te enseñan en la universidad. Y encima vas a hacer una práctica a un lugar donde hay parteras que son o no laburan o que cuando laburan intervienen" (Entrevista Bárbara, partera)

Sobre la formación, Bárbara permite ver cómo en las residencias médicas se replica la grieta parteras/médicxs, y quien tiene el poder de hacer los partos (que es el verdadero mérito) es el/la residente. Pareciera darse una disputa al interior de la jerarquía médica por apropiarse de los trabajos de parto, los partos, las mujeres, los cuerpos y los procesos reproductivos como material didáctico/pedagógico ${ }^{109}$.

\footnotetext{
109 Sobre esto, los estudios del campo se han pronunciado. "El cuerpo de la mujer, pierde su carácter de humano/a y pasa a ser un campo de estudio y de experimentación” (Camacaro Gómez, 2009, p. 223). "El conocimiento "autorizado" (científico) tiende a demandar una distancia frente a su objeto, por lo que los galenos acostumbran a ver a sus pacientes en términos de partes corporales que necesitan tratamiento (visión mecanicista que se presenta en la ciencia médica): Esta imagen de las tecnologías médicas es inculcada desde la misma formación de estos especialistas, ya que los textos obstétricos describen, por lo general, al cuerpo femenino en las labores de parto como si fuera una máquina de reproducción y el papel del médico se limita a supervisor o administrador; la madre se menciona muy poco y cuando ello sucede se hace de un modo básicamente fragmentario” (Cárdenes y Ugarte, 2002, p. 129)
} 
"No me pelearía con los residentes por los partos. Viste que ellos se pelean por los partos.

¿Residentes de qué? ¿De obstetricia? ${ }^{110}$

De obstetricia. Vos controlás, uno se mata por controlar el trabajo de parto porque en realidad lo que quiere es hacer el parto, hacer. Que es lo que nos pasaba en [el hospital escuela en el que se formó], te clavabas haciendo trabajo de parto para... y eso conmigo no tienen problema, porque no me interesa para nada el parto. Yo prefiero el acompañamiento. Obviamente sí, entrar al parto, sí, pero yo prefiero el acompañamiento. $Y$ prefiero estar con la mujer y después decirle al residente "che vení" y no me importa, entendés, no se pelearían conmigo por eso" (Entrevista Bárbara, partera).

Me pregunto si esta preferencia de Bárbara (partera) por el acompañamiento en trabajo de parto y la preferencia de Sandra (partera) por el puerperio, no responde en realidad a la pérdida de lugar en la atención de los nacimientos

Y aunque la partera se refiera al lugar privilegiado de Ixs residentes, a medida que se van considerando los testimonios recabados, se hace más tangible la presión de atender con la pistola de la jerarquía en la cabeza, más que la de la disciplina o del saber:

"Tenés dos jefes de guardia que son dos ginecológos, que ellos son los que deciden. ¿Por qué? Porque si pasa algo, el que se hace cargo de lo que pase son ellos. Entonces vos como residente no podés hacer lo que vos querés, tenés que responder a lo que el médico que se va a hacer cargo después es el que dice. Si dice "se hace asi", se hace así, y no se discute mucho.

¿Y en el hospital donde trabajás?

$Y$ ha ido cambiando bastante. En nuestro hospital es bastante diferente. Vos tenes en otros hospitales donde se dirigen de "usted" al médico de planta, donde no hay mucha relación con el médico de planta, en otras épocas ni siquiera lo conocías, no hablabas, nada, no le dirigías la palabra. Nosotros no. Ellos están de guardia con nosotros. Nosotros preguntamos a nuestro compañero residente superior y le preguntamos a ellos directamente. Cambió muchísimo, son todos ex residentes" (Entrevista Carla, médica obstetra).

Como se va estableciendo, las diversas figuras del campo obstétrico se van entrecruzando, y los roles se van superponiendo en la escena del parto. Dicha escena, en términos generales, suele estar encarnada por el/la médicx obstetra, el/la pediatra 0 neonatólogx, la partera y la/el enfermerx. En los hospitales-escuela, que en nuestra ciudad son los cuatro del sector público, y algunos del sector privado, esta escena se complejiza por la presencia a su vez de residentes de primer y segundo año (los últimos enseñan/ acompañan/ controlan a los primeros) tanto de obstetricia, que hacen los partos, como de neonatología, que reciben a Ixs recién nacidxs. Incluso pueden existir practicantes de partería y enfermería entre Ixs presentes. A esta multiplicidad de

${ }^{110} \mathrm{Mi}$ voz en los fragmentos de entrevista aparece diferenciada en cursiva y aparte. 
actorxs, en los casos en los que se garantiza el derecho al acompañamiento, deberá sumarse la presencia del varón-padre o de la compañía elegida por la parturienta ${ }^{111}$.

En las preguntas por la formación y en el relato de estas disputas, emerge constantemente la referencia a lo viejo, lo que pasaba, en términos del maltrato que se dispensaba. En este sentido, es relevante mencionar que la figura de la parturienta en estos discursos aparece como víctima de esa violencia obstétrica, y no tanto como la protagonista del evento.

"Vas guiando el trabajo de parto y es bastante intervenido, no como el parto respetado que está todo divino, que hay poca gente, que te van a esperar tus tiempos de parto. Acá es todo más, se va apurando. O sea, comparado como yo empecé la residencia, que este, escuchaba barbaridades, que las parteras decían "¡abrí las piernas, bien que te gustó y que las abrías!", esas barbaridades que se decían antes” (Entrevista Andrea, neonatóloga)

En general los itinerarios formativos y asistenciales reflejan más continuidades que rupturas. Esto es, la mayoría de las profesionales entrevistadas, refieren la pertenencia institucional a un hospital público y el tránsito por distintas etapas de la jerarquía. Tal es el caso de Rocío, quien también combina su actividad asistencial con la docente.

"Nunca estuve en otro hospital. O sea yo entré a la residencia en el 2002, hice los 4 años de la residencia, después fui jefa de residentes, después me quedé acá [en la maternidad pública] con una beca, después fui instructora de residentes que lo hacía en simultaneo mientras estaba con la beca acá, quedé como planta, después nada trabajé, trabajo en privado en otros lados. Estuve también, haciendo guardias de reemplazo por ahí en el hospital de [anonimizado, zona rural], en un hospital de [anonimizado, otra ciudad del conurbano], como que he ido a otros lados. Y otra de las cosas que hago soy jefa de trabajos prácticos en la facultad. En la cátedra de obstetricia, que también estoy desde el 2006. Terminé la residencia y empecé a dar clases en la facultad" (Entrevista Rocío, médica obstetra)

\footnotetext{
111 Camacaro Cuevas vincula esto a un proceso de falta de autocrítica: "De forma irrebatible, su imaginario no concibe a éstas como protagonistas del proceso, sino como sus objetos de trabajo. Así mismo, consideran que dicho procedimiento es válido porque sus maestros, los precursores de la obstetricia del siglo antepasado, así lo aprendieron y así lo enseñaron, ha sido un conocimiento heredado socialmente sin cuestionamiento ninguno. Al respecto el obstetra Carlos Burgos manifiesta: "Los obstetras oponen una notable resistencia a verificar la eficacia de las prácticas que caracterizan su disciplina. Y ésta suele ser como tantas otras una disciplina de opiniones, donde "la práctica aceptada" es a menudo un consenso desarrollado por una mayoría de profesionales en un determinado período y no siempre verificado por un método científico". (2001:6).Son evidentes las implicaciones que la racionalidad científica del modelo médico tiene en la conformación de la mentalidad del cuerpo médico, en tanto legitiman argumentos que se soportan solo en una visión reducida de la realidad, donde la fuerza de la jerarquía impide toda posibilidad de entender otra forma de relación humana. Parafraseando a Rigoberto Lanz podríamos decir que el discurso de la ciencia no es un modelo de producción de conocimiento, sino un criterio de autoridad para convalidar todas las formas de jerarquía” (Camacaro Cuevas, 2008b, p. 303).
} 
Finalmente, otra de las referencias a la formación en residencia se produce desde el rol de instructoras de una de estas mismas profesionales.

"En mi guardia trabajamos de esta manera ¿sí? Y por otro lado yo también lo entiendo, acá, como es un hospital escuela, ¿sí?, los residentes que van rotando, un día están conmigo pero al otro día no y a la otra semana tampoco, entonces tienen muchas influencias. Entonces uno tampoco se puede plantar y decir "no, acá eso no se hace". Porque también les tenes que dar lugar a ellos que ellos elijan el camino que más les gusta, el que les queda más cómodo, dentro de lo médicamente correcto ¿sí? Yo no los puedo dejar hacer cualquier locura porque a ellos se les antoja, pero como que ellos también tienen que experimentar qué es lo que a ellos les gusta más. Y yo no me puedo poner a discutir, en realidad no debo ponerme a discutir con otro profesional que tiene sus convicciones y su manera de trabajar por algo en particular, digamos. No me puedo meter en otra guardia y decir "no, ustedes tienen que hacerlo así porque para mí es la mejor manera". Yo traté de, a los residentes, mostrarles todas las opciones. O sea ahora hago lo mismo, cuando estamos en la guardia yo les muestro todas las opciones que hay para manejar, o sea "bueno esto pueden hacer tal cosa pero también pueden hacer lo otro", o sea trato que vean y después cada uno elige su camino, su manera de hacer el parto, su manera de atender a las pacientes. No somos todos iguales, pero yo trato de que, sobre todo para los chicos que están en formación, de que vean que hay otras maneras por ahí de hacerlo, que no es todo tan..." (Entrevista Rocío, médica obstetra, el destacado es mío).

Este fragmento testimonial aporta cuestiones que complejizan y permiten ver las tensiones y los grises entre los modelos de atención que se enseñan, aprenden y (re)producen en las residencias. Así, por un lado, como se menciona, al igual que lo que sucede en la atención, la adopción/puesta en práctica de una perspectiva más respetuosa o más intervencionista depende del/ de la instructor/a que toca. $Y$, en paralelo, se puede entrever que esta convivencia de diversas posturas, que en nuestra perspectiva implica ni más ni menos que el respeto o la violación a derechos humanos, sexuales y reproductivos de las mujeres, genera una reproducción del voluntarismo de Ixs médicxs en formación ("que ellos decidan cómo atender"), por la falta de una política institucional de atención que siga las leyes y normativas ministeriales vigentes. Por último, en relación a esto, destaco que aunque la responsabilidad de Ixs agentes de salud obstétrica es enumerar los derechos y alternativas de asistencia que tienen las mujeres (tal como establecen las normas), esta situación y prerrogativa no aparece relatada en ninguna de las entrevistas, pero sí el paradójico muestrario de opciones a Ixs médicxs. Se confirma así quién es protagonista de la escena del parto en el habitus dominante. Entonces, se le muestran alternativas a el/la residente y no a las mujeres, y se aprende y se experimenta sobre el cuerpo de ¡mujeres! En la atención en hospitales escuelas (que responden mayoritariamente al sector público, por ende es mayormente utilizada por sectores populares), son públicos tanto las instituciones como los cuerpos y 
las mujeres. Es clara la ausencia de una perspectiva, política o cultura organizacional integral con perspectiva de derechos y de género, que permitiría romper con el personalismo del/ de la "médicx amigable/respetuosx" y esta discrecionalidad médica a la hora de atender.

\subsubsection{PRIMEROS Y ÚltiMOS PARTOS: TRAYECTORIAS DE ATENCIÓN Y CONSTITUCIÓN DEL} HABITUS.

Tal como mencioné anteriormente, con la intención de captar elementos del quehacer profesional de las entrevistadas, las consulté por el primer y por el último parto en el que participaron, bajo el supuesto de que sería posible advertir el pasaje de espectadoras a encargadas de la atención en dicho relato.

Sobre los primeros partos, existe cierto consenso sobre el choque que les generó. A continuación transcribo un fragmento extenso de la entrevista con Bárbara que aporta algunas cuestiones importantes para el análisis, en tanto es posible ver experiencias claves en la constitución del habitus dominante, que marcan a fuego la trayectoria formativa y personal de las entrevistas.

"Fue asqueroso, inmundo, tuve que salir afuera, era una sala de parto inmunda, la mujer colgada, los pies atados ¿no? Que uno se da cuenta, con la cabeza coronando, yo después me doy cuenta que no había ni que decirle pujá, ni apretarle la panza. La enfermera, la estudiante, diez residentes, nosotros que éramos como tres o cuatro de obstetricia, los chicos de neonatología. Los chicos de neonatología que estaban estudiando partero, eh, o sea, pero estaban viendo el nacimiento, eh, nada.

¿Y algún familiar de ella había?

No, no, no (alargando las "o", en signo de obviedad). Se me empezaron a caer las lágrimas y me fui afuera y estaba la que era la partera de guardia, yo me senté pálida se ve y me dio un caramelo y me dijo "ya te vas a acostumbrar". Mucha, no sé, mucha sangre, horrible, horrible.

¿Era un parto vaginal?

Era un parto vaginal. Y nada, gracias a Dios, después me hicieron hacer otra guardia y no hubo parto. No vi nunca más un parto y después nos llevaban a hacer neonatología, viste, cuidado del recién nacido y al lado está la sala de parto, y yo no miraba por ejemplo. No, no. No me olvido más. Ponele que te diga que era una multípara, me acuerdo patente, porque se lo dejaron hacer a la residente... Yo digo debe ser normal que me descomponga y debe ser normal la situación" (Entrevista Bárbara, partera, el destacado es mío).

En este relato es posible advertir la multitudinaria sala de partos, las sensaciones físicas y emocionales de la partera, el hecho de que una partera formada le dice "ya te vas a acostumbrar": ¿a qué?, ¿a la sangre?, ¿al rol secundario? El agradecimiento a 
Dios por no ver más partos (siendo que esa era su vocación) y, finalmente, la autoexigencia o autopresión por naturalizar y normalizar esa escena tan contraria a la esperada.

El relato del primer parto que presenció Carla ${ }^{112}$ refiere a los efectos que causó no sobre su quehacer y futuro profesional sino sobre su posible experiencia como madre:

"Me acuerdo que el primer parto que fui fue en [un hospital escuela del conurbano] que para mí me pareció terrible el primer parto, que fui con una de mis mejores amigas de la carrera. Y me acuerdo que estábamos una de cada lado mirando el parto y que terminó el parto y nos miramos las dos así y dijimos "no paro ni en pedo, ni en pedo tengo un parto". Y me acuerdo de la impresión que me dio ver salir la placenta, que era algo que ni me esperaba... Registré el momento del parto, eh y la impresión y la sensación de decir "no tengo un parto ni en pedo" (risas). Olvidate. La sensación de dolor, de "ni loca"' (Entrevista Carla, medica obstetra).

Sumando a estas experiencias negativas ("inmundo", "terrible"), Sandra, la partera del hospital público, recuerda su primer parto como obstétrica en los siguientes términos: "me largaron un feto muerto". Esto se puede vincular con esos elementos que Castro describe del curriculum oculto: los castigos, la jerarquía y el pagar el derecho de piso. Sandra menciona que Ixs médicxs le dijeron "si quería trabajar" (la invitaban a participar) y que todxs (ellxs y la parturienta) sabían que se trataba de un feto muerto, excepto ella. Disciplinamiento médico-jerárquico inicial que implica, entre otras cosas, que quien decide cuánto entra a trabajar la partera es el equipo médico; y lo hará en circunstancias excepcionales, donde la destreza y la atención médica no son necesarias. ¿No será además que se vincula(ba) el acompañamiento de parteras con elementos afectivos y femeninos que podrían contener mejor a una parturienta en esas condiciones?

En paralelo, Andrea (neonatóloga) y Rocío (obstetra) narran experiencias de primeros partos en términos más positivos. Andrea participó antes que en la formación, en el parto de una amiga, y Rocío refiere una naturalización de estos eventos por vivir con un obstetra.

"El primer parto que vi lo vi en la facultad. La primera cesárea la vi con mi papá [obstetra]. El primer parto fue en la cursada, en el hospital [anonimizado, una maternidad de La Plata] cursaba yo obstetricia. A mí me gustaba mucho cuando cursé, la verdad que me gustó mucho la cursada porque eso nos permitía entrar a sala de

${ }^{112}$ Es interesante que al preguntarle por el primer parto, Carla relacionó con el primero que "hizo" (usó esta noción), y por ello afirmó "Sí me acuerdo, por ejemplo, la primer sutura que hice, una de las primeras que tengo registro, pero porque me acuerdo. [¿̇Sutura de episiotomia?] De desgarro vaginal. Pero porque me acuerdo que la que estaba al lado mio con mucha paciencia explicándome era una partera”. 
partos y ver y... nada, qué se yo, yo igual en la facultad era bastante así como preguntona y activa y quería saber cosas, entonces también aprovechaba la cursada. Me pareció como una curiosidad viste porque uno, pero... Lo que pasa es que yo en mi casa en realidad desde que nací se habla del parto como si fuera algo normal, porque mi viejo hacía partos, entonces nunca fue una ciencia oculta, de hecho mi papá nos hablaba claramente cómo eran, cómo se hacía un bebé, cómo nacía un bebé, por dónde nacía un bebé y yo ya había tenido hijos, aparte. Entonces no me resultó, qué se yo, nada, no me resultó traumático ni nada. Sí, por ejemplo, cuando empecé a hacer parto acá lo que a mí me, más me molestaba e incluso ahora también es el olor que tiene la sangre, no me gusta, es como.... y mirá que hago partos y partos y partos, pero tiene como, cuando sale la placenta yo le siento como un olor particular" (Entrevista Rocío, médica obstetra, el destacado es mío).

Aunque como entrevistadora no mencioné la idea del trauma, no deja de ser llamativo o relevante la referencia de Rocío, que creo responde a un sentido común entre colegas: el primer parto es traumático para la generalidad ${ }^{113}$.

Ahora bien, considero que el último parto asistido vislumbra el modelo y el modo de atención que dispensa cada profesional. Es el modelo asentado, el habitus consolidado, y es interesante ver cómo su relato (a diferencia de los que refieren al primer parto) es breve, conciso. En el primero se ve el quehacer y el modo de trabajo de otrxs profesionales, en el último se ve el propio.

"El último parto ¿institucional?"114

No, el que vos quieras. El último. ¿Esta semana tuviste algún parto?

$\mathrm{Si}$, un parto en la clínica. Mujer descontrolada, segundo bebé, con peridural, hacia muchísimo que no veía una mujer con peridural y, nada, un parto hermoso.

¿La pidió ella la peridural?

Sí, a gritos. Porque en realidad, yo creo que estuvo mal (...) [el médico] la vio en la consulta y le creó la ansiedad de por ejemplo revisarla, al pedo, en una consulta. 39 semanas y te reviso no sé para qué" (Entrevista Bárbara, partera).

La ansiedad creada por el médico, en este caso, es ejemplo de una intervención simbólica que da cuenta de la iatrogenia que he mencionado anteriormente, que determina la experiencia de la parturienta y desencadena el comienzo de la cascada de intervenciones y de la incertidumbre de la mujer. Bárbara relata las idas y vueltas de la mujer hasta internarse, por cumplir con los centímetros de dilatación que impone como norma la institución para admitir a la paciente. En este sentido la ansiedad por

${ }_{113}$ El diccionario define el trauma como un "choque o impresión emocional muy intensos causados por algún hecho o acontecimiento negativo que produce en el subconsciente a de una persona, una huella duradera que no puede o tarda en superar". Además la medicina habla de "traumatismo" para referirse a una lesión o daño. Y esto podemos vincularlo al currículum oculto que Castro incluye en el análisis del habitus médico autoritario.

${ }^{114}$ Barbara asiste partos domiciliarios además de los que acompaña en la clínica privada. 
vincularse a cuestiones temporales, también está muy presente en los relatos de mujeres, varones y profesionales.

Carla, Rocío, Sandra y Andrea, que trabajan en el sector público, refieren sus últimos partos en clínicas privadas. Esto tiene que ver con que la atención de partos en hospitales-escuelas está a cargo de Ixs residentes.

"El último parto fue en [clínica privada] hace un montón. Yo ahora estoy como jefa de residentes así que no hago asistencia en el hospital, pero el último que vi, fue en [clínica privada] que fue un golazo. Fue tres pujos contados y nació" (Entrevista Carla, médica obstetra).

' $Y$ el último fue anteanoche (risas). Pero no acá arriba [en la maternidad pública] sino en el hospital privado. Yo hago guardias en privado: en el hospital privado y en la clínica privada. Y el lunes a la madrugada, una y media de la madrugada, nació Magdalena en el Hospital Privado, un parto precioso también y la recibí yo, sí" (Entrevista Andrea, neonatóloga).

Sandra relata su último parto como obstétrica como un "parto que hice a una multípara, se hizo solo". Participó más como "acompañante de la paciente", se corrige, "no es paciente, es embarazada, no está enferma". Hace años dejó la sala de partos

"El último parto a ver ¿cuándo fue? Hace nada, unos días atrás. Un parto así muy eutócico, normal. Muy así como, poco traumático, con nada, tranquilo. Yo soy bastante tranquila para hacer los partos, no me gusta el griterío ni estar enloquecidos, entonces como que a mí me gusta, de hecho el enfermero me carga porque a mí me gustan con la luz apagada, no a oscuras, no con la luz prendida de arriba, sino alguna luz pero no la luz directo en la cara ni en la mía ni en la señora, porque en realidad yo no necesito la vista para atender el parto tengo las manos, entonces como, como es mucho por tacto y es más hacerte la imagen que mirar. Eh, obvio que cuando tengo que suturar y eso, no. Pero, nada este fue un parto sin episiotomía, sin peridural. Una chica que ya tenía 4, 3 partos así que hermoso el parto" (Entrevista Rocío, médica obstetra).

En estos relatos de los últimos partos aparecen menciones a tendencias más respetuosas de atención, marcando no sólo el cambio sociohistórico de la asistencia obstétrica, sino, principalmente, su quehacer profesional consolidado. Así, por ejemplo, hacen mención a cómo les gusta/acostumbran trabajar, a los posibilidades reales de atención (sólo en privado) y dan cuenta de una atención con parámetros más fisiológicos.

\subsubsection{LA ATENCIÓN DE TODOS LOS DÍAS: PUESTA EN PRÁCTICA DEL HABITUS}

Con el objetivo de conocer el habitus médico, no basta con abordar lo que dicen las entrevistadas, que difícilmente se autoproclamen como ejecutoras de una atención 
intervencionista, medicalizante o irrespetuosa, por el simple efecto de corrección política, sino que es necesario saber qué hacen. En otras palabras si en mi inserción de seis años en el campo he notado que está establecido que los índices de violencia obstétrica son muy altos y el diagnóstico de sobre-intervencionismo médico es indiscutible: ¿mis entrevistadas son la excepción o me están diciendo lo que quiero escuchar? En este apartado, pero principalmente en el siguiente, daré cuenta de cómo se ubica en "otros" esa acusación de atención no humanizada.

De todos modos, para poder abordar en qué consiste la atención hegemónica, consulté sobre las prácticas o intervenciones innecesarias que se aplican por rutina y que constituyen violencia obstétrica, según nuestra legislación. En el capítulo tres realicé un análisis de lo que refieren las jefas de servicio de maternidades públicas en tensión con lo que establece la OMS (desde 1985). En términos simples y a modo de pantallazo: deberían existir índices de 10-15\% de cesáreas (lo actual en La Plata es 30$40 \%$ en el sector público y $85 \%$ en el privado); $10 \%$ de episiotomías (por ejemplo los hospitales públicos realizan al $90 \%$ de las primerizas por una cuestión pedagógica, -de los privados no hay datos) y $10 \%$ de inducciones, cifra sumamente sobrepasada por la preeminencia del enfoque de riesgo y las fechas probables de parto acortadas, gestión de los tiempos reproductivos, etc. Asimismo, se desaconsejan el enema, el rasurado, kristeller, vía (suero) a todas las parturientas, inmovilidad, etc.

¿Cuáles son las técnicas de rutina?
Las, eh...
O intervenciones, no sé cómo le dicen

Ah, ¿en la clínica? Según el médico, suero, apenas entran, eh, tenemos un médico que pone antibiótico igual, por más que no tenga estreptococo, porque tuvo una vez en su vida un falso negativo... Eh, bueno, sí, suero, por las dudas que haga una hemorragia, por ejemplo. Si es multípara sí o sí un suero. Y después, no, monitor ahora nos obligan a hacer una tira de monitoreo... ¿Cuáles de esas hacés vos? ¿El monitoreo?

Yo hago monitoreo y si el médico pide le digo que le diga a la enfermera que ponga el suero, yo no (Entrevista Bárbara, partera)

Bárbara, quien asiste partos en el sector privado y en domicilio y mantiene una actitud crítica con el $\mathrm{MMH}$, nombra "episio, kristeller y alumbramiento"15 activo, manejado, dirigido, como las técnicas de rutina. Lo interesante es cómo el discurso

${ }_{115}$ Se refiere al corte entre la vagina y el ano (episiotomía), el empuje hecho por una persona sobre literalmente- la panza de la parturienta llevando al/a la bebe hacia "la salida" (maniobra de Kristeller, desaconsejada por la OMS hace mas de 40 años) y la extirpación manual de la placenta (alumbramiento activo). 
médico articula hegemónicamente estas intervenciones y establece justificaciones médico-clínicas pero también políticas para realizarlas.

"¿Cuál es la excusa de la episiotomía o la justificación? ¿Un desgarro conducido o quirúrgico para evitar un desgarro?

Sí, para evitar un desgarro mayor. Mmm, ahí no se está haciendo tanto. Ponele de 5 médicos que hay, 2 debe ser que son bastante cagones. Es miedo de ellos nada más.

¿Vos decís que la mayoría de las intervenciones tiene que ver con el miedo de los...?

¡Pf, olvídate, sí! ¿Vos te pensás que les molesta desgarrar a la mujer? No, les molesta que la mujer se desgarre y después les haga juicio, porque te lo dicen los médicos y, te lo dicen, se lo preguntas y te dicen "porque vos tenés que pensar que después vienen, te hacen quilombo". Sí, todo es miedo" (Entrevista Bárbara, partera)

Miedo al devenir fisiológico y miedo, principalmente, al reclamo: medicina defensiva $^{116}$. Lo interesante es que Bárbara narra que ella también traía miedos que tuvo que trabajar: por su propio miedo y rechazo al dolor, tendía a poner epidural y a anestesiar a las mujeres porque era ella quien no toleraba el dolor.

En otras profesionales noté resistencia a hablar de prácticas rutinarias, expresando cierto recelo a cuestionar el quehacer médico o a permitir que se opine sobre su formación o su saber. Al respecto suelen esgrimirse argumentos que defienden intervenciones porque criticarlas implicaría promover el descuido y el abandono de la atención sanitaria. De todos modos, por ejemplo Carla, sí se refiere a estas prácticas en términos de "exceso de intervención" médica y lo explica así:

"Exceso de intervención es desde poner un suero a una paciente que no tiene indicación, que son muy pocas las que tienen indicación. O sea a toda paciente que entra a un hospital en trabajo de parto ponerle un suero es un exceso. Poner oxitocina para corregir de entrada estrictamente cada una hora ir aumentándole el goteo, es un exceso. Hacer una inducción de un trabajo de parto en una paciente de 38 semanas, es un exceso. Hacer una cesárea que no tiene indicación, es un exceso.

¿Vos lo ves en la práctica diaria eso?

Todo lo que te estoy diciendo es algo que sucede (...) El tener a una paciente ayunada por las dudas que vaya a una cesárea después, también es un exceso. ¿Me entendés?" (Entrevista Carla, médica obstetra).

Por último, revisando su trayectoria asistencial, Sandra menciona que en el pasado rasuraba y hacia enemas, por lo que "no tiene vida" para pedirle perdón a esas mujeres pero ella "hacía lo que le decían". Menciona que por hacer mucha "kristeller para ayudar" ella misma se hizo mal por la fuerza ejercida.

\footnotetext{
${ }^{116} \mathrm{Al}$ respecto Magnone Aleman establece "La radicalización del enfoque de riesgos está muy relacionada a la medicina defensiva. Los médicos/as tratan de hacer la mayor cantidad de pruebas objetivas y dejar constancia de ellas, por las dudas si en el futuro se abre una demanda sobre su práctica médica. Rodríguez (2006) plantea que cuando se ejerce guiado por la defensa, las decisiones médicas no se sustentan en la evidencia científica o en la experiencia del médico; el objetivo principal es la protección ante un eventual futuro reclamo del paciente" (2013, p. 84).
} 
Claramente la pregunta por la rutina o protocolos de atención desencadenó respuestas que tienden a ubicar a "Ixs interventorxs" en otrxs. Esta ha sido una constante que vengo describiendo (y continuaré) en este capítulo, en tanto la intervención rutinizada y anexada en una cadena equivalencial a "innecesaria" o "acrítica" se convertido en un arma de acusación.

\subsubsection{DóNDE SE ATIENDE, CÓMO SE ATIENDE.}

Otro elemento que aporta características peculiares al campo y al habitus médico de Ixs profesionales implicadxs en la atención obstétrica, es el ámbito donde dispensan dicha asistencia. Al igual que en relación a las prácticas rutinarias, fue más fácil captar opiniones de las profesionales que no hacen referencia a su quehacer sino de Ixs otrxs.

Las condiciones de trabajo en el hospital público emergen constantemente como una apelación unánime e ineludible para explicar cómo se atiende/ pare/ nace en la actualidad en dicho sector. Una vez más la clase de las mujeres (el acceso al sistema de salud público o al de seguridad social) parece determinar/ condicionar la atención que se recibirá, el modo en que se gestionarán (o no) los tiempos fisiológicos de los nacimientos y el tipo de relación médicx-paciente que se puede generar.

"Cuando vos tenés por día, 3 partos por día, 4, 5, ponele 3 partos y 2 cesáreas, 5 promedio por día, vos laburás con un ritmo tranqui, o sea no tenés que estar con la sala de parto con gente esperando e ir organizando a ver en qué momento van a pariendo quiénes, qué sé que en otras clínicas pasa, o sea es tanta la demanda que tienen que ir coordinando de alguna forma. De esa forma usan oxitocina y van viendo a ver en qué momento lo hacen. Es un laburo parecido a lo que pasa en el hospital público del conurbano, ponele. ¿Está? Tenés muchísimos partos y tenés que organizarlo y coordinarlo. Y si vos los dejás a todos que evolucionen espontáneamente, se te hacen seis partos juntos, no tenés dónde hacerlos y es un caos. Entonces por eso es que se van coordinando. En la clínica privada donde trabajo no pasa eso, es chiquita, te permite laburar recontra tranqui y si yo tendría que atender el año que viene, trabajaría re tranquila ahí, porque sé que podés hacer la obstetricia que vos quieras. O sea, de hecho un médico reconocido (anonimizado) labura ahí recontra tranquilo. O sea la gente que labura tranqui, labura muy tranqui ahí. No tenés nadie que te meta presión por ningún lado y haces lo que querés tranquilo. Bien, no es que haces las cosas como querés, haces las cosas como corresponde" (Entrevista Carla, médica obstetra).

Esta gestión de los procesos de trabajo, y entonces de los procesos reproductivos y los cuerpos de las mujeres, parece traducirse en la atención y el trato que dispensan Ixs profesionales, porque como dijeron las trabajadoras sociales: "atendés como laburás".

"A veces uno desgraciadamente ve el mismo obstetra en privado y en público y no es el mismo trato, y eso no está bien. Sí, la diferencia cuando tiene que ver la plata y cuando tiene que ver el trato del hospital, que te trato mal porque sos no sé de otra raza, de 
otro país, no está bien. Yo trato con el mismo respeto a una mamá, yo trabajo en el privado, en la clínica más cara, con el mismo respeto a la mamá concheta que a la mamá..." (Entrevista Andrea, neonatóloga)

En el mismo sentido, Sandra se pregunta "¿por qué en el privado acariciás a una mujer y en el público no?". Critica a sus compañerxs por "dobles mensajes" que según ella generan "esquizofrenia". "La partera en el privado es Dios y acá no les servís". A la pregunta de cuál puede ser la causa de esto aduce un "problema moral" vinculado a la "viveza criolla" porque Ixs médicxs "no sé si quieren al paciente". Un problema moral por falta de registro del otro. Para ella la prioridad es la educación. Marton y Echazu (2010, p. 131) aportan otra mirada: "Si bien los/as médicos/as (...) pueden circular entre el sistema público y el privado, lo hacen modificando su bagaje de expertise al trasladarse de uno hacia otro".

Rocío arriesga una explicación similar: la diferencia de criterios del mismo profesional en el hospital y en la clínica ${ }^{117}$.

"Muchos de los que trabajan acá yo creo que vienen porque el público es un sueldo seguro para toda la vida, y no porque les guste la atención. Yo no discrimino entre lo que hago en público y lo que hago en privado en cuanto a cómo atiendo, qué estudios pido y todo. Sí reconozco que acá hay estudios que por ahí yo los pido y no se pueden hacer porque no hay disponibilidad. Pero mi manera de atender, mi manera de abordar un, es igual. O sea, yo sé que si tengo una hipertensa y le tengo que pedir esto, esto y esto, se lo voy a pedir acá o afuera. Le voy a pedir exactamente lo mismo. Pero qué se yo, se ven cosas acá que... Ha pasado, yo en una época me acuerdo, había un médico que no estaba a favor de la ligadura tubaria pero, eh, no estaba a favor para nada pero en privado ligaba las trompas, entonces vos decís "¿cómo es?, pongámonos de acuerdo". Si vos tenés un criterio, tenés un criterio acá y afuera, el mismo. Que podés tener matices porque la paciente no es el mismo tipo de paciente, eso es otra cosa, pero tu criterio no puede cambiar" (Entrevista Rocío, médica obstetra).

Entonces entre el sector público y el privado no solo varían las condiciones de trabajo de Ixs profesionales, sino que (y en relación) también varían ciertos criterios médicos/clínicos y morales/ideológicos que moldean su atención y la relación que establecen con Ixs pacientes ${ }^{118}$.

Finalmente, al hablar de ámbitos de atención y condicionantes económicos para la atención obstétrica, es necesario retomar las reflexiones de Carla sobre las presiones

\footnotetext{
${ }_{117}$ Rocío asi como Carla y Andrea, trabaja tanto en hospitales públicos como en clínicas privadas. No será posible saber si esto que refiere a lxs otrxs, lo replican ellas en su quehacer profesional.

118 Castro sostiene que es posible advertir diferencias en la atención de lxs profesinales entre ámbitos porque "en el caso de los hospitales privados, el habitus autoritario es mucho menos evidente: porque las características del campo son distintas, menos propicias para que los médicos puedan situarse, de manera automática, en la cúspide de todas las jerarquías (profesional, de clase, de género, de etnia, etcétera) potencialmente vigentes" (Castro, 2014, p. 192).
} 
institucionales combinadas con las preferencias personales de lxs médicxs para la realización masiva de cesáreas.

¿¿Es verdad el mito de que en los privados les conviene que haya cesáreas?

No. Mirá al obstetra, el único beneficio que le da la cesárea es que vos sabes en qué momento atendés a la paciente. Vos sabés que la atendés tal momento, tal día a tal hora y que lo que te pagan la cesárea te lleva una hora de laburo. El trabajo de parto no. El trabajo de parto te pagan lo mismo y te lleva 3 horas, 4 horas, depende el tiempo que vos estés hasta que nace ¿está? Ese es el único beneficio que yo veo para el médico hacer una cesárea y no un parto. Para la institución... yo te puedo hablar de lo que es la clínica en la que trabajo. Yo sé que no hay presiones en ese sentido. Que los que hacen cesáreas es porque no se fuman los trabajos de parto

O sea, ¿los cuchilleros ${ }^{119}$ existen?

Sí, obvio. El que hace un parto porque se le cae, en la jerga nuestra es eso. Porque no llegó a hacerle la cesárea. Hace un parto cuando se le cae sería.

¿En el público?

No, en el público no" (Entrevista Carla, médica obstetra)

En este verbatim, Carla permite ver cómo en la epidemia de cesáreas denunciada por la OMS hace décadas, inciden no sólo cuestiones económicas, culturales y de formación médica, sino también, y con un rol protagónico, la cuestión de los tiempos, la previsibilidad y el control del proceso. En relación a esto, Schwartz (2016) sostiene:

"la cesárea proporciona al médico la sensación de control total sobre el proceso del nacimiento y por eso es percibida como segura. A su vez, la sumisión de la paciente a la autoridad médica puede ser, en parte, atribuida al crecimiento tecnológico y a la creciente especialización de la biomedicina" (p. 194).

Siendo éstas algunas de las reflexiones sobre los ámbitos de atención institucionales (del sector público y privado), la cuestión del parto en casa es traída a escena por las entrevistadas como el otro espacio de nacimientos que está siendo escogido por algunas familias. La conceptualización que realizan sobre el parto domiciliario se asienta en elementos morales y punitivos en tanto se aleja del paradigma de institucionalización de los partos (y de riesgo obstétrico) promovido por el modelo médico hegemónico hace 200 años.

"Eso creo yo, que el parto domiciliario viene como respuesta a lo que no se respeta en la institución. Por eso te digo, es lo que se encontró como opción al parto en institución, a todo lo que no se respeta" (Entrevista Carla, médica obstetra)

Aunque se comprenda la elección del parto en casa como respuesta a la violencia obstétrica institucional, de todos modos su ponderación o valoración por parte de médicxs incluye cuestiones de incumbencia profesional, de condena moral, de irresponsabilidad, etc. Andrea (neonatóloga) cuenta el caso de una pareja (les dice

\footnotetext{
119 "Cuchilleros/as" o "carniceros/as" se le suele decir a lxs profesionales obstétricxs que tienen tendencia a realizar cesáreas innecesarias. La idea del cuchillo y la carnicería se vincula al acto quirúrgico.
} 
"criaturas") que tuvieron a su bebé en su casa y leyeron cosas en internet: disputa por la fuente de la información y por la falta de tutela, control, asistencia, en fin, presencia médica.

"Tampoco estoy de acuerdo con el parto en la casa sin obstetra, sin neonatólogo, sin ambulancia en la puerta. No, me parece un disparate absoluto. Ponés en riesgo dos vidas. Si vos querés hacer un parto en la casa respetado bueno que esté el obstetra, la partera y un neonatólogo con todo para reanimar por las dudas y con una ambulancia en la puerta, ahí sí, y con un lugar en alguna neo en algún sanatorio que tenga una cama disponible por si algo se complica. Ahí estamos bien. Pero esta cosa de "no, recibe la partera sola o el obstetra solo, ni siquiera llamamos al pediatra porque no hace falta", ninguna ambulancia, nada preparado, no, no, no, me parece una barbaridad" (Entrevista Andrea, neonatóloga).

La idea de "la ambulancia en la puerta" no solo refuerza el paradigma de riesgo reproductivo, del parto como evento explosivo y la primacía de la complicación que el modelo humanizado y fisiológico cuestionan, sino que también endilga a las familias que eligen este ámbito de atención cierta falta de solidaridad o respeto por Ixs otrxs. Esto es: si la ambulancia está en la puerta de tu casa, cumpliendo tu capricho/deseo/elección, no estará salvando alguna vida en un accidente de tránsito, un incendio, etc. Lo interesante es que estas profesionales no asisten partos en casa y allí se vislumbra una crítica que se sustenta en el enfoque de riesgo y el prejuicio: no hacen falta ambulancias en las puertas de las casas sin derivación con clínicas por si llega a ser necesario ${ }^{120}$. Bárbara que sí lo hace, narra en otros términos cómo fue su primer parto en casa.

"[La partera que la inició] me llevó a un parto en una casa me acuerdo, una casa de barro, impresionante, increíble, y ahí dije "pero, ¿cómo puede ser?". No, casi me muero. Es maravilloso. Sí, no, es una energía, es algo, no no sé, es inexplicable.

¿Pero podés hacer una comparación entre no sé...?

¿Entre eso y la clínica? Sí, no, es totalmente distinto. Ojo, una mujer empoderada, sí, empoderada, acompañada, puede llegar a parir en una clínica hormonalmente como en la casa. Sí, puede" (Entrevista Bárbara, partera).

El análisis del hábitus médico, entonces, incluye dimensiones sobre la formación, la asistencia, el quehacer profesional, las interrelaciones (atravesadas por jerarquías e incumbencias disciplinares, como mínimo) con colegas, disciplinamientos, reconocimientos y modos personales y otros colectivos de hacer partos. A continuación, desde una mayor abstracción, propongo la consideración de algunos procesos que sostienen dicho habitus y campo médico obstétrico.

${ }^{120} \mathrm{Y}$ al igual que sucede con las mujeres que llegan a las guardias con abortos voluntarios en curso, las mujeres que llegan posterior al intento de un parto en casa reciben el disciplinamiento y la violencia obstétrica acorde al castigo por salirse de la norma que establece el modelo médico hegemónico sobre cómo debemos parir/nacer. 


\subsubsection{PROCESOS QUE SUSTENTAN EL HABITUS MÉDICO Y EL HACER PARTOS.}

El trabajo de campo me ha ido permitiendo construir analíticamente algunos procesos y elementos que sustentan y permiten la reproducción de la reproducción hegemónica, y que son a su vez los puntos de quiebre y crítica de quienes profesan modelos más humanizados de atención.

Identifico, como mínimo, cuatro procesos interrelacionados que promueven, posibilitan y se reactualizan en el habitus médico obstétrico hegemónico eminentemente intervencionista, está amparado en el enfoque de riesgo y en la gestión institucional y clínico-farmacológica de los tiempos. Se trata de: a) la medicalización, de la vida cotidiana en general y del proceso perinatal en particular; b) el personalismo en la garantía o violación de los derechos sexuales y reproductivos; c) la protocolarización de la atención; y, d) la monopolización/ transferencia de los saberes sobre la reproducción.

\subsubsection{A) MEDICALIZACIÓN DE LA VIDA COTIDIANA ${ }^{121}$}

Sin duda uno de los procesos que ha garantizado (y propiciado) la construcción hegemónica del modelo de atención dominante ha sido la medicalización de la vida cotidiana en general y de la reproducción humana en particular. Este proceso es fundante de (y articula) los otros. Ya ha sido ampliamente desarrollado en el apartado conceptual, pero no puedo dejar de mencionarlo aquí, en tanto la apelación a la complicación (que sostiene y es sostenida por el enfoque de riesgo y la concepción del cuerpo defectuoso) y la urgencia/ imprevisibilidad y miedo aparecen fuertemente anexados al habitus y quehacer profesional obstétrico. Esto a su vez legitima la necesariedad de la intervención médica y por ello es clave la pregunta por la rutinización de las prácticas y la acción protocolorizada. Pero, básicamente, la medicalización garantiza que quienes tienen el dominio, el poder de decisión y la última palabra, sean Ixs referentes del campo médico.

\subsubsection{B) PERSONALISMO: NOMBRES PROPIOS EN LA GARANTÍA -O NO- DE DERECHOS.}

La ausencia de políticas, líneas de trabajo y consensos humanizadores sumados a la posición de poder y jerarquía médica, generan una doble tendencia: por un lado, el/la médicx obstetra es quien decide cómo se atiende ese PEP (y esto puede ser con

\footnotetext{
${ }^{121}$ Mucho de esto está desarrollado en el capítulo 1, cuando establecí la caja de herramientas conceptuales para pensar la sociología de la atención médica de embarazos y partos.
} 
tendencias más intervencionistas o más fisiológicas) en una actitud de control jurisdiccional y posesión de los procesos reproductivos de las mujeres. Por otro lado, y en relación a ello, el monopolio de la decisión y la falta de control y seguimiento a su quehacer profesional obstaculiza las estrategias de resistencia de las mujeres, su entorno y de aquellxs profesionales que buscan atender de modos humanizados.

Si la atención descansa en una voluntad personal médica y la hegemonía se alimenta de esa fragmentación de voluntades que legitiman el modelo dominante de atención, la emergencia de voces disidentes (aunque existe) se ve avasallada por la tendencia colectiva. Lxs medicxs amigables son pocxs y contadxs, reconocidxs socialmente (gracias al activismo), pero si la garantía de los derechos sexuales y reproductivos descansa sólo en estxs sujetxs, quien pierde es la gran cantidad de mujeres que gesta y pare cotidianamente. Entonces el personalismo también reproduce, como efecto colateral, la dependencia médica, aunque sea profesionales amigables.

Asimismo, en relación directa con esto, emerge la atención personalizada como un privilegio de clase: las mujeres que paren en el sistema público son "pacientes del servicio" (entrevista a equipo de psicología de maternidad "A"); en tanto quienes a partir del pago particular (como es el caso del equipo de atención domiciliaria) o portación de obra social pueden acceder a la asistencia en el sector privado, se garantizan la asistencia del/de la profesional de su elección, aunque eso no implica necesariamente que garanticen derechos.

La relación médicx-paciente, por tanto, se ve sujeta al capital socioeconómico de las mujeres, generando consecuencias negativas para ellas, para el establecimiento de una posible negociación con Ixs profesionales sobre sus deseos, necesidades y derechos en la atención. En el sector público, por ejemplo, según los relatos tanto de los equipos de salud como de las usuarias entrevistadas, "te toca quien te toca". Esto, además de poder significar una brecha con el modelo de atención del embarazo y de los cursos (como establecí en el capítulo precedente), reproduce la subordinación de las mujeres a la discrecionalidad médica y al azar de "caer en la guardia amigable" (como dicen Ixs nativxs). $\mathrm{Y}$ bien se sabe que aunque el $\mathrm{MMH}$ quiera hacernos creer que es posible, es difícil (sino imposible) provocar intencionalmente el desencadenamiento del trabajo de parto para coincidir con la guardia respetuosa (con el día de la semana en la 
que el/la profesional amigable está de guardia $)^{122}$. Entre este caso y el anterior vemos entonces los peligros del personalismo (sea el/la médicx respetuosx o no): no existen estrategias para hacer coincidir tu parto con las guardias a cargo de médicxs amigables $^{123}$ y asimismo, la dependencia a este tipo de profesionales refuerza la sumisión a la corporación médica y obstaculiza el empoderamiento.

Sumado a esto que sucede en el sector público, el personalismo como proceso tiene efectos en los otros ámbitos de atención. En el domiciliario, por ejemplo, la existencia en la ciudad de La Plata de sólo un equipo con médico obstetra y dos más con parteras a cargo que asisten en este ámbito, produce una total dependencia a ellxs para el logro de este tipo de nacimientos. Ya mencioné en el capítulo anterior que la situación de un hecho excepcional en mayo de 2017 (muerte perinatal) que produjo que dicho equipo no atienda por unas semanas, significó para las mujeres que habían contratado sus servicios un "abandono de persona" con la consecuente denuncia pública.

Por último, el personalismo tiene consecuencias en el ámbito privado: el cobro de extras o diferenciales, por sobre lo que cubre la obra social, a modo de cobro por la exclusividad y la atención personalizada. Asimismo, en entrevistas a mujeres y en charlas informales, se mencionó que algunxs profesionales en el sector privado cobran un plus por atender respetuosamente y por poner a disposición de la mujer "su equipo de trabajo" (parteras, pediatras, neonatólogxs especiales). Sí, se cobra por el acceso a un derecho enunciado en una ley. Se trata del reparto del parto respetado en relación al ingreso ${ }^{124}$.

Lo que discuto, a partir de este segundo proceso que sustenta el habitus médico, es que la relación médicx-paciente exclusiva (o la atención personalizada) que se erige como privilegio de clase, no sería necesaria si existiera el respeto de los derechos sexuales y reproductivos de las mujeres, y, en interrelación, si las mujeres estuvieran empoderadas en su capacidad para parir (respetada y fisiológicamente). En este

\footnotetext{
${ }^{122}$ Esta idea de guardias como espacios diferenciados, con características particulares, respondiendo a una $\mathrm{u}$ otra tendencia típico ideal, aparece en los testimonios de las profesionales: basta releer las palabras de Rocío sobre "su" guardia y las de lxs otrxs.

${ }_{123}$ Aunque el ciberactivismo generó mapas de guardias amigables de hospitales públicos por día de la semana, para tener la posibilidad de "caer" en una.

${ }^{124}$ En una ponencia inédita sobre atención de la hipertensión, Marin (2018) analiza las diferencias en la relación médicx-paciente en los ámbitos de atención y respecto a este eje advierte: "Esta mayor personalización de la atención en el ámbito privado requiere un mayor nivel de compromiso por parte del médico siendo que el paciente deposita un conjunto de demandas en la propia persona, y no en el servicio" (p. 14). Asimismo, establece que las tecnologías de comunicación masiva como el whatsapp también tienen un impacto en la relación médicx-paciente.
} 
situación utópica el/la médicx sería un accesorio intercambiable, un rol. ¿No radicará allí la razón por la cual la corporación médica hegemónica se asienta sobre una tendencia medicalizante que reproduce la necesariedad (y el protagonismo) de su intervención? La conclusión parece ser que las intervenciones dependen de Ixs médicxs, no de los partos ni de las mujeres ni sus derechos y necesidades.

\subsubsection{C) PROTOCOLARIZACIÓN Y BUROCRATIZACIÓN DE LA ATENCIÓN}

El habitus como producto y productor del campo médico, se encuentra atravesado por la atención protocolorizada, que aún no ha sido actualizada con la inclusión del enfoque de género y derechos sino que sólo se rige por criterios biomédicos y la alta preponderancia del enfoque de riesgo. Se trata de las normas que el propio campo construye para sí y no incluye el paradigma humanizador.

El "automatismo del cumplimiento de los protocolos" (Blázquez Rodríguez, 2009, p. 216) tiende a estandarizar la atención y, en consecuencia, a las mujeres y sus procesos reproductivos, negando una asistencia conforme a sus necesidades y deseos. Cuando es más importante seguir los protocolos (que no son neutrales, repito) antes que las demandas y necesidades de las parturientas, se está enseñando a residentes y reproduciendo al interior del campo médico que la atención que sigue los estándares de calidad de las instituciones médicas, es la que prima por sobre la subjetividad de las mujeres.

Montes Muñoz (2007) señala que la importancia del protocolo radica en que así como estandariza la atención, tiñe la acción profesional como meramente protocolar, no discutible, homogénea y justificada. Esta aparente neutralidad del quehacer profesional entra en tensión con la existencia de personalismos diversos en la atención. "Yo sigo el protocolo" es la excusa de aquel/la médicx obediente al habitus/ campo médico, que viola el derecho, por ejemplo, de la mujer a tener libre movilidad en su periodo dilatante o a pujar cuando lo desee.

Estos protocolos internos, con pretensión de cientificidad y neutralidad, son institucionales algunos y corporativos otros, y conviven. Una vez más, la búsqueda es que los procesos reproductivos de las mujeres se ajusten y adapten a esa normativa, ajena a la fisiología.

La pretendida infalibilidad del quehacer médico, porque está amparada en protocolos, se complementa con la medicina defensiva cuando falla: se presenta como única que sabe y cuando aparece el error médico, se presenta como humana. Se 
acomoda el discurso a partir de su potencial de ductilidad ${ }^{125}$. Esta nueva relación médicx-paciente en el marco de una medicina que se defiende del avance social y popular (aumento de juicios de mala praxis, de escraches en redes sociales a profesionales, de exigencias de cumplimiento de derechos) requiere un nuevo elemento de la burocratización de la atención para conservar su dominancia. El consentimiento informado aparece entonces como un dispositivo de poder y control por parte de profesionales e instituciones.

Este elemento no aparece mencionado en las entrevistas ni a profesionales ni a mujeres. Sin embargo, sí hay referencias a una nueva herramienta de resistencia, generada en los últimos años por la militancia por el parto respetado: el plan de parto. Este documento utilizado por mujeres (y sus parejas, si así lo desean) es una carta que se entrega tanto a Ixs profesionales que asistirán el parto como a la institución en donde ocurrirá, en la que se enumeran las elecciones de la mujer en relación a la atención del nacimiento de su hijx en consonancia con los derechos que la asisten por la ley 25.929, y respetando el margen de imprevisibilidad e incertidumbre que conlleva el proceso. Así, suelen establecer que quieren estar acompañadas por tal persona, que quieren poder tener libre movimiento en el trabajo de parto, que quieren elegir la posición para parir, que quieren que una vez nacidx su hijx se esperen unos minutos para el corte del cordón (en consonancia con los beneficios que esto imprime, probado científicamente), que no quieren ser separadxs durante la primera hora, etc. Lisa y llanamente: que quieren que se respeten sus derechos.

Esta estrategia (que se está popularizando) viene a parodiar la burocratización de la atención, a discutir el poder y el habitus médico y a poner en tensión la fuerza de los protocolos, con el amparo de las legislaciones vigentes. Lógicamente, suele recibirse con resistencia, burla y hasta con posteriores castigos a quienes los presentan: una parturienta entrevistada comentó que la "retaron" por haber publicado en redes sociales que no le habían atendido respetando el plan. Asimismo, en las instituciones privadas, donde los márgenes de negociación de las mujeres son mayores por la relación de exclusividad con el/la médicx, en los primeros años de sancionada la ley (2004), hubo dificultades para abordar esta herramienta, por la "libertad de empresa" que rige en estos ámbitos. La acción pedagógica feminista ha permitido que los planes de parto se

125 Otra tendencia es vincular el error médico a las mismas mujeres o a sus cuerpos defectuosos: "útero finito" o "cadera estrecha" son algunas de las excusas y justificaciones cotidianas tanto del error, la mala praxis como de la necesariedad de la intervención médica. 
erijan como una estrategia viable, válida y necesaria hasta que el respeto de los derechos sexuales y reproductivos sea parte de los protocolos de atención.

\subsubsection{D) TRANSFERENCIA (Y MONOPOLIZACIÓN MÉDICA) DE LOS SABERES SOBRE LA REPRODUCCIÓN}

Ya se ha analizado en esta tesis cómo históricamente el proceso de construcción de la hegemonía de la medicina occidental obstétrica ha implicado la expropiación de saberes femeninos y populares sobre los PEP, y la apropiación/ monopolización de los mismos por parte de la corporación médica. Detentar ese saber permite detentar el poder para su intervención. Dicha apropiación se ha complementado con la cientifización, neutralización y estandarización de esos saberes, articulación discursivapráctica que ha permitido la consolidación del poder médico en la atención de nacimientos $^{126}$.

"Así se rompe con un proceso histórico de acumulación y transmisión de saberes heredados de generación en generación. Esta pérdida allanó el camino para lo que Federici, basándose en Ehrenreich e English (2009), denomina "una nueva forma de cercamiento", y que refiere al progreso de la medicina profesional caracterizada, desde esos momentos preliminares, por el establecimiento de una frontera que hacía del conocimiento científico algo incuestionable, lejano y a la vez incomprensible para el pueblo" (Arguedaz Ramírez, 2014, p. 161).

Lo que aparece en el trabajo de campo es la confirmación de dicha tendencia a partir de la referencia a la "transferencia del saber" (noción aportada por una de las psicólogas entrevistadas) lo que implica un reforzamiento de la entrega y subordinación a la decisión médica. El habitus médico obstétrico, en tanto disposición para actuar, entonces, confirma que sabe hacer partos: que tiene la legitimidad (racional, legal pero también carismática y tradicional) para hacerlos, intervenirlos y conducirlos. Saber-hacer y poder-hacer son entonces dos elementos claves que articulan dicho habitus.

\subsection{EL CAMPO PROFESIONAL OBSTÉTRICO COMO CAMPO DE DISPUTA}

Si debiera demarcar un aspecto ineludible en el discurso de las entrevistadas, que subyace y tiene una gran carga simbólica a la hora de representar su labor profesional, es la nominación de la tarea obstétrica como hacer los partos. Y entonces allí caben las preguntas: ¿no son las mujeres gestantes -y lxs bebés por nacer- quienes hacen los partos? ¿Es lo mismo hacer el parto que parir? La normalización de este

\footnotetext{
${ }^{126}$ Sobre el proceso de desplazamiento de las parteras ver Cárdenes y Ugarte (2002).
} 
concepto que encierra en sí mismo una definición del quehacer profesional, deja por fuera todo tipo de posibilidad de un rol protagónico de la mujer gestante en su propio proceso reproductivo. Asimismo, la acción de "hacer el parto" conlleva una visión intervencionista del evento perinatal, en el cual no existe la posibilidad de estar expectante, acompañar, asistir, porque parecer ser que tal como expresa Erviti (2010), los profesionales se presentan como "actores obligados a intervenir", responsables de evaluar el riesgo y "de definir las acciones" (p. 10).

Considerando entonces, que el emblema de la atención hegemónica y medicalizada es este hacer los partos, núcleo de una actividad profesional formada para intervenir, patologizar y mirar los procesos con ojo clínico, resulta interesante la contradicción sustancial que hay entre este elemento indiscutible y la posición crítica de las entrevistadas con el modelo hegemónico de atención. La muletilla del hacer partos reviste un carácter fundamental en la centena de páginas de transcripción de entrevistas, en tanto es la confirmación constante de la dominancia de un modo de pensar y actuar profesionalmente, aunque el resto del discurso apunte a un cambio (como visibilicé en los capítulos precedentes). Rocío, médica obstetra, incluye en su cadena equivalencial hacer obstetricia (su papa "hacia obstetricia"), hacer partos (ella) y hacer nacer (el médico que atendió su nacimiento).

\subsection{1.“ELLOS”: REPRESENTACIONES SOBRE LA ATENCIÓN OBSTÉTRICA HEGEMÓNICA}

Ya mucho se ha dicho en las ciencias sociales sobre el proceso de identificación social que se construye a partir de la distinción "nosotros-ellos". En el marco de la atención médica, cuando se habla de relación médicx-paciente podría sostener que en los dos términos de la relación ya está configurado el par dicotómico, pero lo interesante es que hay subdivisiones al interior de cada uno, y sobresalen a cada paso del discurso de las profesionales.

Aunque se ha evidenciado histórica y socialmente la medicalización del parto y el exceso de intervencionismo, la casi totalidad de las entrevistadas se reconoce como opuesta y resistente a ese tipo de atención hegemónica. En otras palabras: ninguna se reconoce como (re)productora del modelo de atención medicalizado e intervencionista, y en este sentido me pregunté por quiénes sostienen el modelo. Las entrevistadas se refieren a los sostenedores en términos de un "ellos" construido en torno a un "otro" que es determinante en la atención obstétrica (jefas del servicio, o atención privada, o 
parteras, o residentes, u hospital escuela, según quién hable $)^{127}$. Un pasarse la bola por la responsabilidad de una atención que violenta a las mujeres, que concibe al proceso reproductivo como una patología a intervenir, que perjudica la salud reproductiva de la población.

¿Quiénes son ellos?

a) El ministerio-Estado en términos de las pésimas condiciones de trabajoinfraestructura de los hospitales, que son reales sin dudas, pero que condicionan que las jefas de servicio adopten una actitud defensiva ante la "bajada de línea hacia la humanización". Entonces de algún modo, el ministerio al no garantizar el modelo de atención que exige, terminaría garantizando la re-producción de la atención hegemónica intervencionista.

Al respecto en el capítulo sobre las políticas del parto, he registrado diversas opiniones de las jefas de servicio sobre la cuestión idiomática de la humanización de la atención, que refieren a un diagnóstico o punto de partida contrario al del Estado: no creen dispensar atención no respetuosa ni deshumanizada ${ }^{128}$.

Al respecto, las psicólogas entrevistadas mencionan "hay que ver qué condiciones hay para implementar algunas cosas (...) que es lo mismo que nos pasa con la ley de salud mental" y marcan la diferencia entre el discurso de la ley y el "trabajo en campo", confirmando la sospecha de una brecha entre la letra muerta y la realidad concreta: "atrás del escritorio está buenísimo, y otra cosa es cómo ponerla en la práctica" (Entrevista 14, equipo de psicología de maternidad pública). Con estas palabras, a su vez, marcan la distancia entre la gestión política con lo que sucede en la trinchera de la atención pública, una idea que se repite en la mayoría de las entrevistadas.

En este sentido, si se amplía la mirada hacia la producción de condiciones aptas para el cambio de la atención hacia un paradigma de derechos, es sumamente relevante la inclusión del Estado (principalmente el ministerio de salud) como actor clave en dos sentidos. Primero, como productor de políticas/normativas que promocionan y establecen el paradigma del parto respetado como horizonte de trabajo; y, segundo,

\footnotetext{
${ }^{127}$ La masculinización de los términos nosotros y ellos es arbitraria e intencional y respeta el lenguaje generizado que utilizan las entrevistadas.

${ }_{128} \mathrm{Al}$ respecto se ha dedicado un apartado en el capítulo 4, sobre las concepciones de la humanización de jefas de servicio.
} 
como obstaculizador de su realización concreta ${ }^{129}$. Sin nombramientos de cargos, sin mejoramiento en la infraestructura, sin capacitación y estímulo, pero, principalmente, sin el financiamiento y la voluntad política de producir un lineamiento general, predomina más el segundo rol que el primero.

"Hoy es una realidad también que a nivel general, digo hoy porque estamos situadas en hoy pero es un arrastre bastante grande, se trabaja con mucha precarización laboral, con mucha falta de recurso humano, de infraestructura, de insumos, eso es una realidad, digamos. Y obviamente la gente atiende como labura, ¿no?" (Entrevista Trabajadoras sociales, maternidad pública)

La asociación argumental entonces es: si el ellos estatal no transforma (o crea condiciones para transformar) la atención hegemónica intervencionista, la (re)produce y legitima.

b) Las guías y protocolos establecidos para el trabajo profesional, que aunque se presenten como promotores del cambio, reproducen principios del modo de atención cuestionado.

"A ver, partamos de la base de la bibliografía. Cuando vos vas a las guías del ministerio, de atención al trabajo de parto y parto (...) Ya te las plantea de que hay dos tipos de trabajo de parto: el conducido y el espontáneo. Vo fi, nada. $Y$ así como te lo plantea ahí, te lo plantea la bibliografía, entonces como que ya te tiran dos opciones de laburo. O sea, podés hacerlo de esta forma o poder hacerlo de esta otra. Hay instituciones en las cuales vos, por el exceso de trabajo, hay que hacerlo conducido, porque es un parto tras de otro que no está bien, o sea no está bien" (Entrevista Carla, médica obstetra)

c) Los sectores "viejos" y "anquilosados" de las maternidades, en general en puestos jerárquicos, que tienen dificultades emocionales y profesionales para el cambio.

"En general el detractor [del cambio de modelo de atención] es el que no quiere cambiar, el que no quiere cambiar, el que se aferra. $Y$ el detractor muchas veces se aferra, muchas veces las personas tienen miedo al cambio y no tienen mucha capacidad de cambio. Ahí ya cuando uno habla de personas sueltas, cuando vos analizas la curva del cambio siempre hay un grupo de personas que ya con esos no podés, tiene que ver con cuestiones individuales y personales. En medicina es muy fuerte el cambio. ¿Por qué? Porque si yo hice los partos toda mi vida y me fue bien, porque soy un buen profesional y los hice así como lo aprendí y me fue bien, para que yo cambié después de muchos años de una práctica y que me fue bien es muy difícil, porque no estás hablando de pintar o de arreglar, estás hablando de personas. La mayoría de la gente tiene buena voluntad, siempre está el loco, pero digamos, la mayoría tiene buena voluntad y nosotros trabajamos con eso. Entonces mucha gente tiene que estar muy firme, sobre todo, porque por ahí es gente grande, que basó toda

${ }^{129}$ Es importante mencionar en tal caso que el hecho de que no ya en la prevención sino en lo postfáctico (con la atención del parto-nacimiento ya realizada), el ministerio de salud de la Provincia de Buenos Aires aún no realiza sanciones administrativas ni de ningún tipo ni estableció un protocolo a tal fin: me refiero a las denuncias por violencia obstétrica. 
su vida en trabajar de una manera, vos le cambiás una estructura y algunos los desarticulás como persona, porque estructuraron su vida haciendo eso. $Y$ hoy vas y les decís que está todo mal. Entonces hay que hacer un trabajo muy fino, muy personalizado y muy de convencimiento. Es muy duro, vos le decís a alguien que tiene, no sé, 60 años "todo lo que hiciste está mal". E hizo eso toda la vida entonces no puede aceptar, tampoco lo hizo a propósito. Entonces hay toda una cosa del cambio" (Entrevista Fernanda, Directora de Maternidad Infancia en 2015, MSPBA)

"Tampoco puedo cambiar las prácticas del profesional porque este profesional está aferrado a lo que aprendió, porque a mí me da seguridad esto, si a mí me sacás de esta práctica yo entro en pánico, me angustio, no puedo y te voy a decir que no. O te voy a decir que sí, "ah qué linda la norma que me trajiste, qué linda" pero cuando te fuiste hago lo que yo sé porque es lo que a mí me da seguridad y, es más, es probable que me salga mejor. Siempre cuando haces algo con seguridad sale mejor. Cuando te digo seguridad es algo para analizar. Es cómo se siente esta persona, y a lo mejor esa seguridad es a un costo muy grande, de desconectarse. O sea vos pensá que hay todo un sistema médico, más avanzado y menos avanzado según las especialidades, quizás el núcleo más duro y más atrasado sea la obstetricia. El más terrible, yo tengo esa impresión" (Entrevista Elina, pediatra, funcionaria MSPBA)

Sumada a la visión de esas dos funcionarias ministeriales, una trabajadora del servicio social de la maternidad pública "A" lo describe de este modo:

"Es complejo el tema de pelearle a la hegemonía médica, digamos, más allá de que hoy no es lo mismo de que hace 30 años pero es difícil que una persona le pueda discutir al médico la información que decide darle. $O$ en la práctica que decide realizarle. Incluso para nosotras es complejo pelearles algo, decirles "no, me parece que estás equivocado", imaginate para las mujeres que llegan en una condición que es "necesito parir"' (Entrevista Trabajadoras sociales, maternidad pública)

Respecto a estos tres puntos, una primera referencia: la jerarquía médica en términos institucionales inter y extra hospital (Estado/ministerio - jefxs de servicio médicxs/equipos de salud) encierra diversas disputas. Una de ellas refiere a quién es el encargado de garantizar el cambio hacia la humanización. Para el Estado (en la voz de estxs funcionarixs) son Ixs médicxs, principalmente Ixs jefxs de servicio bajando una línea de trabajo humanizada. Para Ixs jefxs de servicio, primero tiene que actuar el Estado cambiando las condiciones de trabajo tanto en términos de recursos humanos como materiales y simbólicos. Finalmente, Ixs médicxs sostienen que el ministerio lanza normativas ambiguas y (aunque no haya citado fragmentos de entrevistas al respecto) sostienen que la principal traba son Ixs jefxs de servicio, que no bajan lineamientos, que obstaculizan el cambio y adhieren, de algún modo, con las funcionarias del ministerio, con que sus características generacionales son limitantes para garantizar el cambio.

d) La formación universitaria de grado y en la residencia. Si a los tres factores anteriores, se le agrega la cuestión de la formación, se puede ir viendo cómo la 
constitución de las disputas internas y el corpus de representaciones del campo profesional obstétrico va más allá de lo que sucede en una sala de partos. Con respecto a la formación de grado, existe un consenso en las entrevistadas respecto a que son preparadas para intervenir, enseñadas en la patología y que desconocen aspectos claves de la fisiología.

En relación a la formación en la residencia de obstetricia, es relevante mencionar que las tres maternidades en las que trabajé funcionan como hospital-escuela y esto lleva a una característica sobresaliente del sistema de salud obstétrico público de la ciudad: las mujeres usuarias son instrumentos pedagógicos para Ixs alumnxs residentes, que utilizan sus cuerpos para "aprender" técnicas como la episiotomía, la cesárea y el fórceps, entre otros. Asimismo, hablar de hospitales escuelas implica tener en cuenta que la escena del parto, como decidí nominar el acto de performance que se da al interior de la sala de partos, implica la actuación de diversxs agentes según jerarquía: residentes de primer año, residentes de segundo, médicxs de planta, parteras, enfermerxs, etc. $Y$, si en un mismo hospital hay residencia también de neonatología, como sucede en una de las maternidades en las que trabajé, se debe duplicar la presencia de personas en ese parto. Pero, y fundamentalmente, para la cuestión del campo profesional obstétrico, la situación hospital-escuela es relevante en tanto agrega toda otra porción de jerarquías, mandos, autoridades y modos de trabajo que se entrecruzan y contradicen. Al respeto, las argumentaciones de Castro (2014) sobre la generación del habitus médico autoritario en la etapa de formación médica, son sumamente relevantes.

"Es una batalla que hay que dar: formación universitaria, formación de la residencia. Ahora, la formación de la residencia es interesante, es un lugar de choque, porque vos vas a parar como residente a un servicio. ¿Quién manda en el servicio? El jefe. Pero a su vez pertenece a una residencia, con un jefe de residentes que negocia con el jefe [de servicio]. Entonces vos terminás formándote en la pelea, que está bueno, entre lo que vos estás estudiando y aprendiendo más moderno y a lo mejor el jefe que está aclerosado, que está coagulado en una práctica. Pero el problema es que vos te estás formando en un lugar que la práctica que vos quisieras hacer no la podés hacer. O sea nos ha pasado a todos" (Entrevista Elina, pediatra, funcionaria MSPBA)

"Ponele algunos te enseñan de una forma. Nosotros como residentes respondemos a lo que te indican los médicos de planta, algunos te dicen que hagas una cosa y algunos te dicen que hagas otra. Pero cuando vos haces esto que está mal siempre viene el otro y te dice eh "y pero por qué? Y pero por qué?". Después es difícil ir a cuestionarle al médico de planta, pero ellos lo saben. Ellos saben que durante nuestra formación nosotros respondemos a lo que nos dicen pero la idea es que cuando vos salís labures de la forma en que ellos te lo enseñan. ¿Entendés? Todas las cosas que criticaste no las hagas y la vas viendo" (Entrevista Carla, médica obstetra) 
Sobre esto es interesante resaltar el contexto contradictorio o ambiguo de formación: hay médicxs que te enseñan de forma intervencionista, hay otrxs médicxs que te enseñan a cuestionar eso, pero no podes hacerlo sino hasta que finalices la residencia. O sea que se encierra a Ixs residentes en un rol de acatamiento y obediencia combinado con una actitud crítica en silencio. Esta heterogeneidad de modos y formas de atención tienen el correlato de ser una ruleta rusa para el respeto de los derechos sexuales y reproductivos de las mujeres, que termina confinándose a una cuestión de azar: "en la guardia de los lunes hay gente piola" o "si te toca la guardia de los viernes, cagaste", se reproduce en los grupos de mujeres que militan por el parto respetado. La esquizofrenia del quehacer obstétrico es tal que en lugar de estandarizar la atención para asegurar el acceso a los derechos humanos y el cumplimiento de las necesidades de las mujeres gestantes-parturientas, se estandarizan y normalizan los procesos reproductivos, comportamientos y expectativas de ellas.

e) Las parteras ¿chivo expiatorio? El rol que ocupan "las parteras" como colectivo ("ellas") en el discurso de las entrevistadas, y, en asociación, en el campo obstétrico, es ambiguo: por un lado, para el ideal que exponen las funcionarias ministeriales (y se expresa en diversas guías nacionales e internacionales) es que ellas deberían ser la punta de lanza del cambio hacia la humanización, porque se supone que tienen una formación en el acompañamiento y en la fisiología del parto ${ }^{130}$. Por otro lado, para las que son miembros de los equipos de salud, suelen ser la expresión de la desidia y del no-trabajo, o, en paralelo, del trabajo intervencionista, con desgano. Sin duda, son el reservorio de muchos comportamientos esperados, resignadas al trabajo administrativo.

"Están muy acostumbradas [las parteras] a que la residencia labure. Años y años donde la residencia mueve la guardia y ellas actuaban o metían mano en el momento, tenía que desbordar todo demasiado como para que laburaran ellas, sino era rascarse la guardia entera (...) Las parteras más viejas, o sea el manejo que tienen es activo. $O$ sea ellas sacan chicos (chasquea los dedos), es eso. O sea, están acostumbradas, nosotros somos los que les ponemos el freno para que no rompan bolsa, para que no las hagan pujar antes de tiempo. Siempre aparte ellas tampoco tienen ninguna responsabilidad, ellas actúan en el parto o en el trabajo de parto pero ellas no tienen ninguna responsabilidad legal. Es el médico el que sale después, ¿me entendés? El médico es el responsable de un parto y de un trabajo de parto (...) Entonces, yo lo he visto, o sea... ellas se manejan con impunidad y hacen cualquier cosa. No todas, obvio, pero yo he visto cosas que... Sí, son la punta de lanza del cambio, no leen una

\footnotetext{
130 Sobre el quehacer obstétrico y las disputas profesionales de las parteras, recomiendo el trabajo de Gilligan y Salsa Cortizo (2016) en el cual concluyen: "las nociones de "acompañante" de un "proceso fisiológico", "normal”, el "respeto de los tiempos de la mujer”, exceden el papel de recurso de legitimidad moral. Estas nociones, encarnadas en prácticas cotidianas, conforman una estrategia política de creación de un "objeto" de intervención propio y de disputa por la autonomía profesional” (p. 15).
} 
miercole... No te leen nada, no leen nada, no lo leen. No leen, no leen, ponen suero, no leen (risas) (...) ¿Cuántas? ¿Cuántas de las parteras se fuman un trabajo de parto entero? ¿Cuántas? ¡No! Ellas cuanto más rápido se hace mejor” (Entrevista Carla, médica obstetra).

Carla expresa una visión más culpabilizadora de las parteras por la pérdida de su lugar ${ }^{131}$. En complemento, Andrea marca la tensión parteras-residentes como explicativa del relego de la tarea de las primeras, tendiendo su explicación a dividir responsabilidades.

"Acá como es un hospital escuela, en realidad el que está digamos, en la primera línea de fuego, es el residente de primer año haciendo el parto normal, que está todo bien, con el residente de 2do atrás y la partera dando vuelta. Acá la partera perdió un poco la figura de estar ahí tanto. Está, se encarga de la patita, de la huellita, de la partida de nacimiento... [¿Cómo más un rol administrativo?] Exactamente. Acá perdió, bastante" (Entrevista Andrea, neonatóloga).

Rocío (médica obstetra) describe más ampliamente esta relación tensa con las parteras, reproduciendo choques entre comportamientos esperados y reales.

\begin{abstract}
"Me quedé pensando eso que dijiste de la partera, ¿por qué acá no participa tanto?
Por... tradición (risas), no sé, porque no quieren, porque no sé, porque se acostumbraron a que como hay residentes

¿Y qué hacen?

Papeles. Llenan el certificado de nacimiento, llenan el libro. Pero es muy raro que estén revisando pacientes, que estén asistiendo pacientes. En la guardia que estoy yo particularmente sí, pero porque las dos que están con nosotras, primero que nosotros se lo permitimos, nosotros las participamos para que sepan, lo que hay y cuando necesitamos es "por favor vayan a ver tal paciente, revisamela, controlala, fijate" o "ha internado tal cosa, a esta hay que ir a controlarla". Nosotras las hacemos partícipes de la atención, pero en todas las guardias no pasa lo mismo. Entonces si vos no le das el lugar y encima te toca alguna que está cómoda con no tener el lugar, listo. El resultado es que no hacen nada. No hacen nada digo. Pero, lo que pasa es que se acostumbran. Alguna que está en el privado y acá, yo en el privado las veo más activas desde el punto de vista de la atención del paciente. Acá yo sé que si les pido que hagan un parto a esa misma partera, lo va a hacer. Que si le pido, pero se lo tengo que pedir, no le sale espontáneamente. Por ahí en privado, yo escribo los papeles y ellas están encima de la paciente. Igual acá escriben el papel, no te hacen la historia clínica. Lo que te escriben es el libro de partos, el certificado de nacimiento y la hoja de parto, que ahí pone los datos de la mamá, cómo fue el parto, datos del recién nacido, cuánto pesó, la edad gestacional, todas esas cosas. Pero no, no escriben la historia clínica, no bajan a la guardia... Antes lo hacían, mucho mucho antes de que yo ingresara, pero claro, al haber residentes ¿sí?, y como el residente de primero que está en, todos están en formación, entonces los chicos están mucho más, vos cuando sos residente como que querés estar en todos lados. Entonces eso un poquito fue desplazando la función, no la función, la actividad que tenía la partera, porque era preferible que en lugar de hacer el
\end{abstract}

131 "Estas evidencias históricas invitan a repensar la visión romántica sobre los partos atendidos por parteras en un ambiente femenino y doméstico, y a reconocer el papel que tuvieron las propias mujeres en la cesión de confianza y poder a los médicos. Como sostienen estos estudios, para escapar de la muerte y del dolor cedieron tanto que luego fue difícil revertir la situación (Kholer Riessman, 1998)” (Felitti, 2011a, p. 116). 
parto la partera que ya sabía, que ya había hecho no sé un montón de partos, le deje lugar al de primero que recién entró, que estaba aprendiendo. Entonces eh, bueno a muchas les ha quedado muy cómodo eso y lo aprovecharon y listo" (Entrevista Rocío, médica obstetra)

En este fragmento, Rocío describe cómo las tensiones, choques y superposiciones entre las incumbencias de distintxs actorxs del campo profesional obstétrico, han ido delineando el lugar (relegado a lo administrativo) de las parteras en la atención. Lo cierto es que puede advertirse cierto tono peyorativo o culpabilizador, pero en su mismo relato se pueden encontrar razones múltiples, asociadas al corrimiento de las parteras. De todos modos, reconoce distintos ámbitos de competencia, y piensa en el trabajo interdisciplinario o la complementariedad como horizonte de trabajo

"Yo creo que estaría bueno que participen porque se puede hacer, tienen una función distinta que la nuestra. Nosotros estamos formados más en lo médico y ellas están formadas más en lo que es psicoprofilaxis y ellas saben mucho más que nosotros, entonces como que tienen otras herramientas que nosotros no las tenemos, que estaría bueno complementar, lo de uno y lo de otros.

¿Y eso cómo se podría hacer? ¿Es una decisión política?

Sí, yo creo que eso depende del jefe de servicio que es el que tiene que establecer las pautas de cómo tiene que funcionar el servicio" (Entrevista Rocío, médica obstetra).

En paralelo, las parteras entrevistadas también reconocen que en el hospital público ocupan un rol menor, en la mayoría de los casos por haber cedido el espacio a Ixs médicxs, en otros por no haber podido sobrellevar la caza de brujas que se reactualiza diariamente. Es decir, por haber sido atravesadas por un discurso que deslegitima sus saberes y las somete o ubica por debajo o subordinadas a la decisión de Ixs médicxs formadxs o en formación. ¿Cómo van a ser las responsables del cambio hacia la humanización si los equipos médicos no las estiman, si no tienen lugar (porque lo han cedido o lo han perdido) en el campo profesional obstétrico?

"Pero la cuestión es que había muy pocos profesionales. Ponele, el más respetuoso que teníamos era [anonimizado, apellido de un doctor] y era uno. O sea... Después se empezaron a encaminar ¿Las parteras no son profesionales?

Sí, tratamos las parteras de encaminarnos pero ahí por más que nos pese, manda el médico. Ahí manda el médico". (Entrevista Bárbara, partera).

Otra partera, Sandra, menciona dos tipos de disputas interrelacionadas: a) disputas internas: menciona las diferencias jerárquicas y de conocimiento/experiencia con Ixs residentes y Ixs médicxs, en tanto sostiene que se manejan "criterios diferentes". b) Disputas jerárquicas: entre dirección, ministerio, gobernación. Cree que el ministerio y 
la dirección deben bajar lineamientos. La trabajadora social en paralelo sostiene "la corporación médica es un clan bastante particular, digamos, en sus modos de encarar, en sus modos de relacionarse con el resto, digamos, no sos médico y no sos nadie digamos".

Es importante remarcar que la construcción de un "ellos" en el discurso, en el que depositar las críticas, me ha permitido describir lo que otrxs autorxs ya han descripto para otros contextos (Pozzio, 2013), en torno a la heterogeneidad de posturas médicas frente a la humanización del parto y las tensiones entre la estructura institucional y la voluntad de profesionales, que ayuda a complejizar la mirada y evitar lecturas reduccionistas que Ixs ubican como Ixs "malxs de la película". Sin duda si en algunos casos me he encontrado con lo que denomino objetorxs de conciencia del parto respetado, deberemos incluir en la interpretación toda una serie de jerarquías médicas, políticas, económicas y socioculturales que las implican, y le dan un tinte diferencial a este campo profesional.

La respuesta a la pregunta sobre quiénes sostienen el modelo y, por ende, quiénes podrán modificarlo, debe tener en cuenta algunas de las claves que hemos descripto en forma provisoria y que es necesario seguir profundizando.

\subsection{LA OTRA OBSTETRICIA: ACOMPAÑAR PARTOS.}

$\mathrm{Si}$ hacer partos resume el quehacer profesional obstétrico con tendencias intervencionistas y medicalizantes, la alternativa y el trabajo de "la otra obstetricia" ${ }^{\text {"132, }}$, se aglutina en la idea de acompañarlos. Mientras que hacer implica conducir, corregir e intervenir los trabajos de parto y parto; acompañar implica mantener una actitud expectante, en confianza con el proceso fisiológico/ hormonal y el devenir natural y subjetivo del parto en cada mujer. No implica de ninguna manera negar la atención médica, sino invertir el dominio o protagonismo en la escena del parto (ahora centrada en la mujer que pare y el/la bebx que nace), y en la concepción del proceso perinatal no como evento médico sino como evento sexual e íntimo. Esta otra obstetricia implica, por tanto, no solo prácticas sino fundamentalmente representaciones diferentes del proceso, de las mujeres, de los cuerpos y del quehacer obstétrico/profesional en él.

\footnotetext{
132 "La otra obstetricia” es una expresión que utilizó en la entrevista la partera Bárbara para referirse al modelo de atención fisiológico y respetuoso.
} 
Lo destacable es que una vez más y respetando la línea propuesta por la tesis en torno a marcar los grises ente las tendencias, se comprueba que se trata de Ixs mismxs profesionales, que cinturean entre uno y otro modelo.

Partiendo entonces de las diversas representaciones que (re)produce esta otra obstetricia, retomo a Sandra (partera a cargo del curso hospital público), quien sostiene que cree "en las mujeres como protagonistas". No concibe la obstetricia sin psicología, porque "la mujer no es un útero, es una mente, cuerpo y espíritu" y tiene una "historia social, familiar, vecinal". En sintonía, Carla, médica obstetra, reconoce: "tengo una mirada bastante diferente de lo que es la medicina, la mujer y todo, choco un montón con la gente del servicio".

Esta otra obstetricia se opone a "la impunidad del ambo" o la naturalización del "ambo allá arriba", como dice Bárbara en referencia a la idea del status del rol médico más allá de la persona que lo encarna, y propone una atención cargada de afectividad, que re-piensa hasta las posiciones que se adoptan en la escena del parto.

"O sea tu rol es: durante el preparto, la preparación, el acompañamiento

Sí

En el parto ¿cuál sentís que es tu rol?

Acompañar a la mujer.

Acompañar a la mujer... ¿No estás en frente de ella? ¿Estás al costado?

No, sí, al frente de ella casi siempre está el médico. Salvo que no llegue, sí, estoy adelante. Sin guantes hasta que vea... Yo siento que, que si yo me pongo los guantes, igual eso también es bastante psicológico mío, que si yo estoy con una mujer acompañándola, no llega el médico, si yo me pongo el guante y la espero adelante, es otro rol el que estoy cumpliendo. Y se va a la mierda todo lo que estuvimos haciendo. Entonces trato de ponerme... No, vos no sabés lo que es cuando está por parir una chica o cómo te ponen los guantes. "iEh, vos que tenés una paja!". No, no tengo apuro, porque yo no pienso apretarle el periné como hacía en [el hospital escuela del Conurbano] para que salga, lo voy a dejar que salga cuando se le cante.

¿Pero cómo te manejas con los tiempos tuyos y los tiempos institucionales?

$\mathrm{Y}$, sí, es una lucha constante" (Entrevista Bárbara, partera) ${ }^{133}$

En este sentido, además, este modo de atención rompe con el modelo biomédico al articular un pluralismo de técnicas y recursos para el acompañamiento y el alivio del dolor de parto y posparto: la alopatía, la vertiente más espiritual (reiki, couching, biodanza, yoga, etc.), hierbas medicinales, tinturas madres, etc. De todos modos no propongo aquí una visión romantizada de la atención que se autodescribe como "respetuosa", porque incluso hasta quienes sostienen propuestas más

${ }^{133}$ Es interesante esa disquisición sobre ponerse delante o al lado de la parturienta, ya que "obstetricia" etimológicamente significa "poneerse enfrente". 
progresistas, pueden imponer y reforzar un ideal materno basado en la idea de instinto, la feminización de la crianza y otros elementos que potencian la maternalización de las mujeres.

En general, en el relato de las entrevistadas que adscriben a esta forma de trabajar y concebir los PEP ${ }^{134}$, los giros y quiebres (Camacaro Cuevas, 2008b ${ }^{135}$ ) con la forma aprendida, aparecen por la experiencia directa de "la otra obstetricia", que choca y se contrapone con el modelo hegemónico de atención en general aprendido en la etapa de formación.

"El hospital, te enseña, porque yo no me voy a quejar, la verdad que te enseña mucho, hay algunas mujeres que tienen patología, pero era terrible... Teníamos 20 partos y era ¡pujá, pujá, pujá! (a los gritos), atarle las piernas.... A mí me había tocado, es el día de hoy que se lo agradezco, justo era la presidenta del colegio en esa época, me había tocado de tutora a mí los miércoles y ella fue la que un día en un parto, agarró un grabadorcito, lo puso al lado de la mujer embarazada, apagó la luz y me hizo ver que era todo diferente. $Y$ ahí medio que dije se puede, pero no estuve como un año... es más hacía control prenatal y no me veía en una sala de parto (...) Fue como que quedó ahí y lo opacó todo lo otro después. Sí, lo opacó mal todo lo otro. Después leí ese libro me acuerdo en lo de una amiga y después la conocí a una partera y un médico obstetra que asisten partos domiciliarios" (Entrevista Bárbara, partera).

"Pero te pasa que de repente ves un obstetra con la mente abierta, que hace un parto así respetado y vos te enamorás, decís "yo quiero eso, no quiero estar esta carnicería que estoy viendo, quiero eso". Si vos no lo ves... Con el ejemplo, o sea para mí el ejemplo vale mucho más que 20 mil leyes. Está bien, tiene que haber una ley para que diga "esto que está haciendo está loca de respetar el parto está bien, no es un disparate", ¿entendes?" (Entrevista Andrea, neonatóloga).

Otra obstetricia, entonces que aparece como salida a un modo de trabajo asfixiante, violento o como excepcionalidad a la regla. $\mathrm{O}$ que, incluso como narra Carla, se ha establecido como espacio formativo en su historial, aunque en otras partes de la entrevista hace referencia a que el modelo médico hegemónico sigue presente en manos de la dirección del servicio y de la mayoría del servicio que se ha formado en el antiguo paradigma.

134 Todas las entrevistadas, por efecto de la corrección política de la que hablé antes o con cierto tono de realidad, se autoproclaman efectoras del modelo respetuoso de atención.

135 "Entre esos giros encontramos: un reconocimiento de su desconocimiento e inexperiencia en relación al parto vertical; la inquietud de buscar información al respecto; la posibilidad de que otras concepciones sobre el parto sean ventajosas; identificación de una práctica tradicional que niega lo fisiológico. Que los/as obstetras, mencionen haber oído otra posibilidad de acercarse a los procesos reproductivos de la mujer, era impensable hace solo unos años atrás, porque ese "haber oído" ya pone en entredicho su praxis como única verdad $(\ldots)$ [ Frente a la socialización médica que actua como una] socialización instructiva (...) haberse acercado a otras concepciones de los procesos reproductivos y de las mujeres como sujetas de derechos, interrumpió su lógica de saber dominante, y hoy pueden aportar argumentos biológicos, anatómicos y fisiológicos, para demostrar por qué el parto medicalizado impacta negativamente en la salud reproductiva de las mujeres" (Camacaro Cuevas, 2008b, p. 304-306) 
"Yo tengo la suerte de que en el hospital nuestro la formación es otra, o sea nosotros esperamos, esperamos y esperamos, controlamos todo el tiempo y vemos que no se nos vayan de esos tiempos estipulados que tenemos, pero nosotros esperamos. Mirá siempre durante la residencia ha habido como dos corrientes: los que laburaban de una forma y los que laburaban del otro. Cada vez se está yendo a la forma súper eutócica, $y$ en eso hemos tenido los que nos han formado y nos han machacado la cabeza, nos machacaron y todo el tiempo te ponen en juego "y pero ¿por qué? Y pero, ¿y por qué? Y pero ¿para qué?"." (Entrevista Carla, médica obstetra)

En otras palabras: la pedagogía del ejemplo como instrumento de multiplicación de la humanización en la atención y de deconstrucción de la práctica profesional puede ser un puntapié para el cambio o para la búsqueda de otros modos de trabajar ${ }^{136}$. En este sentido, el "ejemplo" emerge como un método pedagógico más eficaz que la confrontación con colegas, entre modelos de atención. "No, no, no me peleo. Demuestro con mi ejemplo como hay que tratar a la gente (...) Sí, con el buen ejemplo y con las caras demuestro muchas cosas por ahí" (Entrevista Andrea, neonatóloga). De hecho señala que para promover el cambio, más que una política que baja (a diferencia de lo que sostienen otras entrevistadas), "tiene que haber alguien totalmente entusiasmado", que esté comprometidx, que contagie a Ixs demás.

A este mapa heterogéneo de representaciones y posiciones sobre el quehacer profesional tensionado entre las dos tendencias, se suma Rocío (médica obstetra) que es crítica y marca cómo las acciones individuales de algunxs médicxs se ven también atrapadas en la falta de voluntad política de Ixs jefxs de servicio, o más bien, una voluntad política de desprecio a las trabajadoras ("descerebradas") y las pacientes ("unas hijas de puta"137). Esto quiere decir que incluso Ixs agentes de cambio deben ocupar posiciones de poder para replicarlo. Me mencionó que la formación médica también es paternalista. Entonces si la formación y la jefa del servicio son paternalistas, su rol voluntario de cambio se ve constantemente avasallado.

Lo común a sus relatos, es la autopercepción y la certeza de que se oponen al modelo dominante: "Nosotros sabemos que la obstetricia que nosotros hacemos es diferente" (Entrevista Carla, médica obstetra). Y el descubrimiento de esta otra obstetricia (al igual que el caso del relato del primer parto que presenció Carla, que retomé anteriormente), tiene impactos en la vida personal/ maternal de las mujeres

\footnotetext{
${ }^{136}$ En este punto, el personalismo en la atención que he criticado porque evidencia la falta de una política general, muestra su cara positiva.

137 Rocio narra que esas palabras textuales las expresó la jefa del servicio de tocoginecologia de la maternidad A.
} 
profesionales entrevistadas ${ }^{138}$, como sostiene Bárbara: "Yo cuando descubrí la otra obstetricia me morí por tener un hijo".

"Lo que a mí me gusta es, me di cuenta en el consultorio, es el acompañamiento. El parto es como la frutilla del postre" (Entrevista Bárbara, partera). Esta afirmación parece responder a la concepción del parto como un (micro) evento en el marco de un proceso general, pero me pregunto si en realidad no responde a cierta resignación (en tanto partera) del parto como incumbencia del/ de la profesional médicx y en la exclusión de las obstétricas de dicho momento. El acompañamiento se erige como la trinchera del quehacer profesional de las parteras y reafirma o se conforma con el rol que se le asigna en el sistema médico. ¿No reproduce de algún modo la fragmentación del proceso en distintas incumbencias particulares?

Lo central de esta otra obstetricia es el foco en el proceso fisiológico, en el devenir hormonal y, principalmente, en la reducción de las intervenciones médicas a las mínimas necesarias, para la atención de todos los PEP de bajo riesgo. Al respecto Carla, quien como encargada médica del CPP de la obra social ya señalaba su oposición al sobreintervencionismo recomendando realizarse los controles prenatales básico, es coherente con "esta misma idea de no intervenir" (en sus palabras) en la totalidad de su entrevista.

\begin{abstract}
"En relación a "la posible complicación": ¿es necesario que vos estés loca pensando "va a pasar algo, va a pasar algo"?

No, no. Sobre todo porque vos sabés, y eso es algo que a nosotros de forma fundamentalista nos lo han metido en la cabeza, vos sabés que cuanto menos intervención vos hagas, menos posibilidad de complicaciones tenés. Y eso es lo que te da la tranquilidad, eso es lo que te da la tranquilidad que si vos sabes que lo que haces es sentarte y mirarlo y cada una hora lo vas y lo controlás, incluso sabemos que si lo controlamos más espaciado también, no pasa nada, eh... vos con eso ya tenés la garantía de que las cosas te salgan bien. Que se pueden cagar en cualquier momento, se pueden cagar, obvio que sí, por más controlado que este el embarazo, eh, puede pasar. De hecho, a ver, cuál es la peor complicación que vos podés tener en un embarazo: un feto muerto (...) Es lo peor que te puede pasar. Pero son cosas que en un montón de casos no te podés anticipar, por más que vos hagas todo bien, esas cosas suceden y en los partos puede pasar lo mismo, pero no por eso vas a estar con cada uno de los partos pensando que te va a pasar algo grave. $Y$ el manejar el trabajo de parto tranqui, te da esa tranquilidad, o sea, te da esa tranquilidad de decir "yo sé que cuanto menos intervenga, mejor resultado, cuanto menos intervengo, mejor resultado"' (Entrevista Carla, médica obstetra, el destacado es propio).
\end{abstract}

\footnotetext{
${ }^{138}$ Carla contaba que luego de presenciar el primer parto en un hospital-escuela sintió que "ni loca” tenía un hijo.
} 
Reducir las intervenciones bajo la premisa de evitar la iatrogenia discute también simbólicamente el predominio del enfoque de riesgo y su expresión máxima: la apelación a la complicación.

"Si no tiene indicación, no se hace, porque nada es gratuito. O sea, después la mujer tiene una cicatriz, se le puede complicar, se le puede infectar, ¿para qué la vas a hacer si no tiene indicación? $Y$ así con todo. Pero bueno hemos tenido gente que nos ha taladrado de buena forma la cabeza y te entra. No es tan difícil igual, o sea es algo lógico lo que estamos planteando" (Entrevista Carla, médica obstetra).

En esto de la iatrogenia, provocado por el fantasma de la complicación (generado por el enfoque de riesgo obstétrico, garante de la medicalización del proceso) Andrea concuerda:

"Hay como una idea también de una complicación inminente que va a explotar todo, ¿no?

Sí, sí, sí y hay mucho

¿Y cuánto tiene de realidad eso?

No siempre, no siempre, y depende mucho también de que estás interviniendo, haciendo cosas, queriendo apurar algo que no tiene que apurarse y vos estas provocando también a veces la complicación" (Entrevista Andrea, neonatóloga)

\subsubsection{ESTRATEGIAS PARA GANARLE AL SISTEMA DESDE ADENTRO ${ }^{139}$}

Como su quehacer profesional, aunque distintivo, también está sometido a las normas institucionales dominantes, porque existe la atención respetuosa en instituciones $^{140}$, estas profesionales van generando, encontrando y compartiendo válvulas de escape o estrategias alternativas al modelo hegemónico.

"Las que estamos encaminadas en esto tratamos de ir contra la corriente, de denunciar cuando, en realidad soy yo la que más denuncia, hablo con las autoridades cuando hay algo que me parece que no está bueno" (Entrevista Bárbara, partera).

Algunos márgenes de maniobra con los que cuentan Ixs profesionales para escaparle a la hegemonía, son reunidos por Bárbara en algunos ejemplos prácticos. Internar con más centímetros de dilatación que lo que dice el protocolo (para promover que las mujeres atraviesen sus trabajos de parto en la comodidad de su hogar si así lo prefieren); hablarles de la ley o de sus derechos a las mujeres que llegan a la guardia; o llamar al/ a la médicx cuando lo crean conveniente, demostrando esto una ventaja del

\footnotetext{
139 Para pensar en las estrategias que le discuten desde afuera al sistema reinante en las instituciones, hay que pensar en el parto en casa.

${ }^{140}$ Circulan en las tribus ciberactivistas de mujeres los datos de contadxs obstetras que atienden bajo este paradigma en instituciones, porque como cité, por ejemplo, de Barbara "la mujer puede parir hormonalmente en instituciones".
} 
rol secundario o de "asistente", en tanto en qué momento se le da lugar a la intervención del/ de la médicx es un espacio de poder. De todos modos no puede evitar completamente las intervenciones médicas, por lo que la denuncia es un mecanismo postfáctico al que aluden.

"A las 12 de la noche la interno con 5 centímetros, protocolar. A los 4 centímetros, primigesta o segunda o tercera, lo que sea, se interna. Yo la he mandado a la casa con 4-5 centímetros, después de ver los partos en casa, eh.

O sea, vos también tenés esa libertad para manejarte con el protocolo, para hacer oídos sordos.

Sí, no se enteran, obvio.

Cuando decís "la revisé", ¿qué es "la revisé"? ¿qué le hacías?

La revisé, la tacté. Protocolarmente una mujer que viene con contracciones cada cinco minutos, le debés hacer un tacto. La revisé, sí, había modificado un montón el cuello todo, pero estaba para irse a la casa. Bueno, a las 12 la interné y como a las 2 de la mañana

Bueno, pero ahí no está el médico, estas vos.

Yo estoy todo el tiempo.

¿Y por qué me decís como que el médico es más importante?

No, porque el médico viene cuando ella está con 8 y ahí ya está, ¿entendés? Yo le puedo sugerir, "che, mirá, dejala", pero no. No baja, no baja, no baja

¿Vos sos la que decide cuándo llamarlo?

Claro, en realidad, cada médico tiene su, "a mi llamame cuando está con 8", "a mi llamame cuando está la cabeza ahí", "a mi llamame"... O sea, la preparación la hace la partera con la mamá, pero la cagada es que después el médico [dice en referencia al bebé] "es muy grande". Tenemos uno que le dice, tres o cuatro veces ya lo denuncié, que le dice a la mamá "es re grande, es re grande, no baja, no baja" y por ahí la mamá estaba pujando y le hace una cesárea. Y ahí yo ya ¿qué voy a hacer? Más que denunciarlo, descomponerme, calentarme" (Entrevista Bárbara, partera)

Destaco de este fragmento la alusión de Bárbara a que toma algunas decisiones "después de ver los partos en casa" y haber tenido la experiencia directa de ese modo de atención. Otra de las estrategias que dice tener para no seguir los lineamientos que son comunes en su lugar de trabajo y con los que ella no comulga, es declararse incompetente.

¿¿En la cesárea kristeller?

Sí. El otro día escuché un médico que dijo "en el $90 \%$ de las cesáreas se debe hacer kristeller". Y sí, porque si vos sacás un chico a las 37-38 semanas está acá arriba, necesitás empujarlo. Yo no. Yo les digo que no sé hacer (...) No, yo no, casi siempre lo hace el anestesista.

El anestesista, o sea alguien que no está preparado para hacerlo.

¡No, el anestesista es el más preparado! (con tono irónico).

Pero, fuera, ahora hablando en serio, no está preparado, nunca en su vida hizo un kristeller en la facultad.

No, en la facultad no, pero sabe que en las cesáreas lo hace él. Parto tenemos una que "llamala a Laura que es la que mejor kristeller hace", tiene un brazo largo así" (Entrevista Bárbara, partera) 
Junto a la incompetencia, Bárbara también se opone directamente a realizar algunas prácticas que considera innecesarias. Una especie de objeción de conciencia pero, en este caso, para no violar los derechos de las mujeres a una atención respetuosa de sus tiempos fisiológicos.

\begin{abstract}
"Porque, a ver, yo no lo puedo obligar a él [el médico] a que sea no intervencionista, porque lamentablemente es así

Pero él no te puede obligar a vos a ser intervencionista

No. Entonces, aprendí a que no tengo que pelear más ni tampoco agachar la cabeza y decir "bueno, en contra de mi voluntad voy a poner las 5 unidades". No, "vaya e indíqueselo". Entonces después la mamá te pregunta... No, mirá, yo confío en que las hormonas en un ambiente propicio son mejor que la oxitocina. Además las veo sufrir. Terriblemente las veo sufrir" (Entrevista Bárbara, partera)
\end{abstract}

Estas válvulas de escape que propone Bárbara se dan en la atención privada en el caso que ella narra. Respecto a lo que ocurre en el sistema público, ya se han mencionado las sugerencias de Sandra a llegar a la guardia transcurrida buena parte del trabajo de parto (para tener que estar menos tiempo internadas antes del momento efectivo del parto) o a mencionar que realizaron el CPP con ella, como comodines que podrían garantizar atenciones más respetuosas. En este mismo hospital en el que trabaja Sandra, las trabajadoras sociales establecen tejer redes con profesionales "amigables" o "progresistas" como esas "estrategias institucionales" que, aunque sean solo un parche a corto plazo, permiten ir estableciendo modos de trabajo con perspectiva de derecho y género.

De todos modos a veces las profesionales narran que despliegan estas estrategias y chocan con las demandas 0 deseos de las parturientas, en general socializadas en el modelo de atención dominante, como se ha mostrado en el capítulo 4.

"Pero por más que venga yo, revolucionaria, a romper todo, no. Por eso hay que tratar también hasta de mediar. Decirle "bueno, andá, tomate un mate y yo me quedo con ella". Y hasta que para, tenerla en cuclillas, hacerla caminar, apagarle la luz, irme... Ojo, el otro día quise apagar la luz y echar a una enfermera que estaba hablando, hablando, hablando y la mujer que está pariendo se enojó. "No, porque me distraigo". Entonces, para mí, hay que hacer toda una preparación.

Por eso el curso.

Sí" (Entrevista Bárbara, partera)

Al respecto narra la dificultad para romper con el discurso médico y sus influencias sobre las decisiones reproductivas de las mujeres, aunque señala que el CPP tendría un potencial transformador al respecto. 
"Ni tampoco, si vos tenés una mujer que llega a hacerse una cesárea, y "¿por qué te hacés una cesárea?" $Y$, porque el médico me dijo que era muy grande y por ahí no salía, y si no salía, se quedaba el hombro ¿no? Y bueno y la cabeza y bueno se mueren en el canal de parto. ¿Cómo haces en veinte minutos para arran-? No, no, no podés. Las mandan muy poco al curso de preparto..." (Entrevista Bárbara, partera)

De lo dicho emerge el diagnóstico común de varias entrevistadas sobre la importancia del empoderamiento femenino, de la responsabilización de las mujeres, no en términos de culpabilización sino por el propio conocimiento interno del sistema: no se ofrecen otras alternativas de atención, pero si las mujeres las exigen, las piden, se las dan, por el marco legal que coacciona. En mi consideración, en un proceso de transición de paradigmas asistenciales como el que estamos viviendo, donde lo nuevo no termina de nacer y lo viejo no termina de morir, la demanda "desde abajo" para el respeto de los derechos sexuales y reproductivos sigue siendo necesaria, aunque en lo posterior, debería ser parte inherente a la oferta de atención.

Esta otra obstetricia sustenta su quehacer en la concepción fisiológica del PEP. En este sentido, y buscando la creación de condiciones favorables para el devenir fisiológico (principalmente, la secreción de hormonas), estxs profesionales suelen intervenir no los cuerpos de las mujeres sino los espacios y salas de parto. Oscuridad, intimidad, calor, posibilidad de libre movimiento, reutilización de camillas y mantas en el piso: todos elementos necesarios para la liberación hormonal que gobierna los trabajos de parto y partos con este enfoque. Esa modificación de las condiciones (por ejemplo infrestructurales) comunes de atención, suelen conllevar sanciones a Ixs profesionales 0 la conformación de sus modos de asistencia como la excepción, Ixs distintxs, Ixs locxs. En el mejor de los casos, la sanción no pasa más allá de ser este tipo de nominación o etiquetamiento, que permite se siga realizando este tipo de asistencia y hasta multiplicando por el efecto ejemplificador antes mencionado.

Esta intervención espacial no responde a un capricho o moda: el modelo MSCF antes descripto, que gobierna la atención de PEP en nuestro país, supone la creación de estos espacios en las maternidades construidas desde cero. El ejemplo concreto en la provincia de Buenos Aires es el de la Maternidad de Moreno, donde se efectivizan las condiciones de intimidad, calor, oscuridad, silencio, acompañamiento y seguridad en las salas donde se transcurre por completo el trabajo de parto, el parto y posparto.

Esta concepción fisiológica no solo choca con la institucionalidad hegemónica que establece una asistencia medicalizante de los procesos reproductivos y con Ixs 
pares (profesionales de la salud) que (re)producen dicha atención, sino, fundamentalmente, con las mujeres y sus entornos, socializadxs en el $\mathrm{MMH}$. Como he venido describiendo, y se verá más detalladamente en el capítulo siguiente, la construcción de "un parto" hegemónico, a través de diversos instrumentos y dispositivos socioculturales, ha prendido de tal modo que su reproducción, por tratarse de un proceso hegemónico, viene garantizada por Ixs sujetos subalternizadxs: las mujeres. Por falta de deconstrucción, desconocimiento de derechos y de otras alternativas de atención; y, principalmente por la fuerte internalización de los mandatos médicohegemónicos (expandidos a su vez por la cultura de masas y el Estado), muchas mujeres siguen demandando la atención dominante: anestesiante, desconectada, aséptica, estandarizada, quirúrgica. $\mathrm{O}$, como dice la partera Bárbara, distraída, porque la distracción se opone a la conexión con el dolor, con el trabajo de parto, que son necesarios (o esperables) para el devenir fisiológico.

Sin embargo Ixs profesionales dicen resistir a cierto proceso de cuestionamiento de la hegemonía del discurso médico, visible en el caso de la atención de partos y nacimientos en el aumento de partos domiciliarios, de denuncias por violencia obstétrica, de visibilización en la agenda pública de estas cuestiones. Al respecto, la médica obstetra Rocío refiere:

"Las costumbres no son las mismas, los valores no son los mismos, entonces vos te tenes que adaptar, vos no podés hacer, seguir haciendo la medicina de hace 30 años atrás, porque está mal. Por más que medicamente digamos pero porque la relación con el paciente ya no es más, cambió, antes el médico era súper paternalista y lo que decía el doctor era palabra santa y hoy te tenes que sentar a conversar con el paciente y si te dice "yo no quiero" lo tenés que respetar. "Yo no quiero"' (Entrevista Rocío, médica obstetra)

Cambiaron los tiempos y los contextos, las legislaciones y la emergencia de esta otra obstetricia viene a confirmar la transición entre modelos asistenciales.

\subsection{A MODO DE CIERRE Y RECAPITULACIÓN: HACER PARTOS RESPETADOS}

No será posible discriminar si es por efecto de la corrección política o mera sinceridad que emerge como un elemento clave en las entrevistadas el parto respetado como una realidad que precede a los reclamos sociales en auge. Ya en el capítulo cuarto registré cómo se referían a ésto las jefas de servicios (marcando que no se trata de ninguna novedad, fingiendo demencia ante el sentido común que hay en el campo cobre el aumento del intervencionismo), pero tal como se analizó en este capítulo, las 
profesionales sostienen que "nosotrxs" hacemos parto respetado, son "ellos" quienes no lo hacen. Al respecto, Camacaro Cuevas (2009, p. 154) aporta una posible explicación:

"El estatus de paradigma incuestionable que le ha conferido a la obstetricia ser una disciplina médica, la cual a su vez asume las premisas del discurso científico, trae como consecuencia que todas las representaciones simbólicas, los dispositivos de significados de que se vale el discurso médico y sus disciplinas, les legitimen de una manera tan férrea, que producen un cuerpo médico con una ceguera total frente al impacto de la medicalización de la vida, la muerte, y su constante intrusión en los ciclos de la existencia humana".

"El pez no puede ver el agua en el que nada. Los asistentes del parto ya sean doctores, matronas o enfermeras, que tienen experiencia en parto únicamente en hospitales, con un intervencionismo elevado y medicalizado, no pueden ver el profundo efecto que sus intervenciones tienen en el parto (...) La mayoría de las personas que se dedican a asistir el parto desconocen qué es un parto no medicalizado. Toda la obstetricia moderna y literatura neonatal está basada esencialmente en la observación de un parto medicalizado" (Wagner, 2006, p. 598) ${ }^{141}$.

No está de más decir que no fue criterio para la construcción de esta muestra la búsqueda de profesionales "amigables", más bien todo lo contrario: la búsqueda tuvo como eje rector la heterogeneidad (de actorxs, de disciplinas, de posiciones en el campo). Pues bien, eso no parece significar diversidad de discursos: todxs Ixs profesionales indagadxs, tanto en las entrevistas como en charlas informales durante más de seis años de inserción en el campo, se pronuncian como reproductorxs de la tendencia fisiológica y humanista. Todxs "hacen" partos respetados, con la ambivalencia que esas cuatro palabras indican (hacer vinculado a intervenir, partos respetados vinculados a no hacerlo innecesariamente)

"Yo hago respetado siempre. Porque yo con la paciente digamos tengo en cuenta lo
que quiere la paciente. Si la paciente quiere la peri, porque la quiere, si se la puedo
hacer, se la hago. Si la paciente no quiere la peri porque no la quiere, porque no tiene
ganas, por lo que fuere, y se le puede no hacer, yo no se la hago. Lo mismo me pasa
con la episiotomía, con todas las prácticas, con la cesárea, con todo. De hecho hay
pacientes que por ahí no quieren tener parto porque no quieren, porque tienen miedo,
yo no las obligo a que tengan un parto. La que tiene una cesárea anterior, si quiere
tener un parto y está todo dado y está todo bien para que tenga un parto, va a tener un
parto. La que no quiere suero, no le pongo suero, siempre y cuando no sea necesario.
O sea, yo lo pauto, lo charlo primero. Entonces a mí me parece que el tema del parto
respetado como que se encasilla, que parto respetado es si no te dan suero, si no te
ponen anestesia, si no te eh, si te lo hacen en domicilio, y no es eso. Respetado para
mi es respetar lo que quiere la paciente dentro de lo médicamente posible y correcto, o
sea sin ponerla en riesgo (...)
Nosotros intentamos de ver y de hacer lo que cada paciente necesita, que es lo que me
parece que hay que hacer. O sea si vos necesitás más atención, te voy a dar más a
vos; si la otra necesita, no sé, que le cuelgue un suero porque se siente mejor con un
suero, le cuelgo un suero. A veces el trabajo, la cantidad que hay acá y la cantidad de

${ }^{141}$ Wagner fue director del área de salud de mujeres y niños de la OMS. 
personas que somos no te permite dedicarle todo el tiempo que necesitan a las pacientes. Yo por eso creo que ahí es importante que las parteras participen. Porque ahí la partera sentada charlando con la paciente y dándole contención y todo, porque por ahí incluso ni vinieron al curso de preparto, no saben lo que quieren, porque el problema es ese. No es que si nosotros hacemos o no hacemos lo que quieren ellas 0 el deseo que tengan, sino que ni siquiera saben. No saben lo que les va a pasar, no saben lo que es normal, entonces como que falta eso que por ahí el hospital no es el lugar indicado para impartir ese conocimiento. Porque los pacientes no se controlan todas acá" (Entrevista Rocío, médica obstetra)

El aporte de este fragmento radica en que la médica vincula el respeto al caso particular de cada usuaria (que es lo que establece la legislación vigente) y sostiene que existe un desconocimiento de las mujeres sobre qué desean o, mejor dicho, qué pueden desear. Sin embargo no vincula esto al monopolio/ expropiación de los saberes por parte de la clase médica ni al incumplimiento profesional de la tarea de presentar alternativas a las mujeres y propone de base una atención no intervencionista innecesariamente. Al respecto y en consonancia, Carla que al igual que Rocío es obstetra tanto en el ámbito público como en el privado, sostiene

\begin{abstract}
"La ley de parto respetado en realidad para mí no es respetar el parto eutócito fundamentalista. Para mí la ley de parto respetado es respetar la voluntad de la mujer al momento de parir. Si la mujer quiere una cesárea, parir por cesárea

Que sea una decisión informada.

Obvio. Lo que nosotros solemos hacer en el público, si ella quiere una cesárea, informada y consciente, si ella quiere una cesárea fantástico, parís por cesárea. Si la decisión es de un parto, buenisimo, ¿un parto cómo? ¿Querés esperar las 12 horas del trabajo de parto? Porque hay mujeres que no se lo bancan, hay mujeres que tuvieron dos o tres partos, que vos podes hacer un parto conducido, o sea, vos en la mujeres multíparas podés hacer un trabajo de parto conducido, que sabés que los riesgos no son los mismos que en una nulípara. Y la mujer en dos horas, tres horas tiene su parto. Y si es la elección de ella nosotros deberíamos hacer lo que la mujer quiere. Siempre y cuando no pongas en riesgo, las condiciones se den y esté bien informada y sepa bajo qué condiciones toma la decisión. Yo creo que el parto respetado es eso, respetar lo que quiera. Es respetar la decisión" (Entrevista Carla, médica obstetra).
\end{abstract}

Lo que he querido ir mostrando en el desarrollo de este capítulo son las tensiones, cruces y grises entre los modelos típico ideales de atención desde la perspectiva y experiencia de Ixs profesionales de la salud que se dedican al área obstétrica $^{142}$.

${ }_{142} \mathrm{Al}$ respecto de la convivencia de los modelos, retomo la reflexión de Arnau Sanchez y otros (2012, p. 229): "Como en todos los procesos de transformación que se llevan a cabo en los centros hospitalarios y en los que interviene una amplia red de actores, persiste cierta ambivalencia en la medida que coexisten roles y prácticas antiguas con el modelo emergente (Singleton y Mike, 1993: 257). No hemos caído en el error de pensar que el modelo biomédico es falso y que se debe erradicar. Es evidente que contendrá aspectos positivos que se deben mantener. El reto consiste en complementarlos para perfeccionar la práctica 
A modo de presentación de algunos resultados del trabajo de campo, me propus describir algunas características que surgen en las entrevistas a profesionales sanitarias de la atención de embarazos y partos que nos permiten dar cuenta de las disputas y tensiones internas del campo profesional obstétrico alrededor de su quehacer profesional y las relaciones con las tendencias típico-ideales construidas.

Si bien a priori había pensado que iba a escribir un capítulo titulado "Médicxs que hacen partos: reflexiones sobre la construcción social de la legitimidad de la atención médica intervencionista del nacimiento", lo que aquí se delineó en realidad fue la construcción de su cuestionamiento al interior mismo del campo médico. Esto es, en el trabajo de campo emergieron en realidad profesionales que cinturean, resisten y se mueven entre un modelo y otro. ¿Se puede hablar, entonces de una crisis hegemónica o de rearticulación de la atención obstétrica? Aunque sería imposible dar una respuesta concluyente, sí puede decirse que para que eso efectivamente suceda es necesario que la atención (y su regulación en protocolos y normas institucionales y corporativas médicas) se ajuste a un único lineamiento coincidente con el enfoque de derechos y de género. La evidencia científica y la decisión política internacional y ministerial local están consolidadas hace más de una década (y más de cuatro en otros casos). Partiendo, como mínimo, de la voluntad política de jefas de servicios y de encargadxs de guardia, de generar mecanismos de revisión, autocrítica y actualización de atención obstétrica que dispensan.

"El problema más grave que tiene este servicio sabés cuál es, que todos nosotros los que trabajamos en el servicio nunca tenemos reuniones para charlar sobre el manejo del servicio, sobre cómo se hacen las cosas, sobre lo que está bien, lo que podemos mejorar, lo que tenemos que cambiar. Entonces si desde los jefes no hablan eso, nosotros entre nosotros no podemos hacer nada. Osea, porque yo puedo manejarlo en mi guardia con mis compañeras de guardias, o sea, no sé, mi compañera que está todos los lunes conmigo, las dos parteras que están conmigo todos los lunes, nosotras cuatro y los residentes que ya nos conocen cómo trabajamos. Pero yo no puedo decirle al del martes, al del miércoles, al del jueves, al del viernes. No es mi responsabilidad y creo que hay gente que es la responsabilidad, y que la responsabilidad es revisar qué es lo que se puede mejorar, ver nosotros que estamos en la trinchera trabajando preguntarnos qué se puede mejorar, qué cosas habría que cambiar. Pero como no pasa eso, hay muchas cosas que se podrían hacer mejor y no pasa. A mí me han acusado de ser muy académica, muy lectora y muy estudiosa, y que las cosas se hicieron de una manera por mucho tiempo y que para qué cambiarlas si hasta ahora... Bueno, porque lo nuevo dice que hay que probar otra cosa, que se hace de otra manera, que lo adecuado... Y me mandaron del hospital "dejá de leer tanto" (risas)" (Entrevista Rocío, médica obstetra).

asistencial que se le ofrece a la mujer en el proceso reproductivo. Y es que no comulgamos con la utopía de pensar que en la sociedad actual, a diferencia de la tradicional, se pueda implantar el parto domiciliario". 
Tal como visibiliza este fragmento de entrevista con Rocío, Ixs profesionales sanitarixs exigen, necesitan y valoran lineamiento aggiornados y acordes a la política de humanización de los PEP. 


\title{
Capítulo 6 \\ Parir (O tener cesárea) \\ -INTERVENCIONES MÉdICAS EN LOS PROCESOS DE PARTO-
}

\begin{abstract}
"El parto es sólo un momento fisiológico y cultural de un proceso continuo cuyo comienzo es tan arbitrario como su fin" (Jordan, 1993, p. 54 en Sadler, 2004, p. 1).

"El parto es un proceso fisiológico que, de no presentar complicaciones, puede ocurrir sin ningún tipo de intervención. Resulta paradójico que en un proceso donde la mujer parturienta es la natural protagonista, y en el cual lo mejor que puede hacerse es no intervenir y dejar que transcurra por sí solo, nos encontremos en un sistema de atención altamente intervencionista en el que las mujeres son pasivas pacientes que deben ayudar y cooperar con el personal médico, que es dueño del proceso. Es en este sentido que planteamos que la atención biomédica del parto en la actualidad es una poderosa metáfora de la opresión que el sistema patriarcal ejerce sobre las vidas femeninas, lo cual es a su vez símbolo de la supresión de todas las maneras de conocer no hegemónicas" (Sadler, 2004, p. 29).
\end{abstract}

\subsection{Presentación}

Luego de analizar, proponer y problematizar los marcos conceptuales y contextuales que permiten estudiar la atención médica de los PEP, se analizaron las experiencias concretas de los cursos de preparto y de la perspectiva de Ixs profesionales obstétricxs, para dar paso finalmente al análisis de un conjunto de nacimientos, desde la perspectiva de Ixs madres y padres. Así, en este capítulo, se realiza un abordaje micro social de experiencias de atención de embarazos y partos retomando la perspectiva de un grupo de mujeres-madres y varones-padres. Siguiendo el criterio rector de esta tesis que ha sido la búsqueda de la heterogeneidad, se reconstruyen experiencias de distintos modelos y ámbitos de atención.

En las experiencias de las mujeres-madres y los varones-padres es posible advertir la diversidad de itinerarios asistenciales, idas y vueltas, contradicciones, decisiones informadas (y no tanto), vínculos con el activismo. Heterogeneidad de experiencias de atención obstétrica que a su vez descansa en las diferencias de género, edad, instituciones de ocurrencia de los nacimientos y perfil socioeconómico de Ixs sujetxs, entre otros. Asimismo en las experiencias es posible ver cómo los partos transmitidos que traen, conocen, resignifican y moldean su actividad estas mujeres, influyen en ellas. O, en palabras de Gilligan (2017), se trata de "experiencias que, sin duda, se hallan atravesadas por una serie de respuestas que podemos ver en acción en 
el marco de la atención médica y que se constituyen en una fuente significativa de sentidos" (p. 4).

En particular se realizará el análisis de las experiencias construidas en siete entrevistas en profundidad que narran 10 nacimientos (una mujer narra el nacimiento de sus tres hijxs y otra de sus dos hijos). En los cuadros 16 y 17 se presenta un resumen de dichos casos. Se trata de 8 partos institucionales (4 en el sector privado y 4 en el sector público) y 2 partos domiciliarios. En ellos nacieron 6 niños y 4 niñas mediante 4 cesáreas (dos en público y dos en privado) y 6 partos vaginales. Esta muestra no busca ser representativa de los índices locales, provinciales, nacionales e internacionales de nacimientos, sólo responde a los criterios de heterogeneidad y saturación de la muestra que constituye esta investigación.

Aunque compartimentar y fragmentar una experiencia tan densa y fluida como es el proceso perinatal es difícil, se tomó la decisión analítica de ir tras ello con vistas a presentar un análisis sociológico de esta experiencia ${ }^{143}$. A partir de estos casos ocurridos en la ciudad de La Plata entre 2013 y 2017, se analizan los itinerarios asistenciales y los relatos de partos y el ejercicio de la ciudadanía reproductiva de mujeres-madres y se reconstruyen las particularidades de la participación de los varones-padres en el proceso. Finalmente se presenta un apartado dispuesto a problematizar cómo a partir de sus propias experiencias de atención médica de sus PEP, algunas mujeres politizan su parto y emergen movimientos de activismo por el parto respetado y contra la violencia obstétrica. En este apartado, discutiré qué violaciones a los derechos sexuales y reproductivos (establecidos en la ley de parto respetado) es posible advertir que se dieron en los relatos de los casos analizados.

143 "Lázare y Fons (2016) sostienen que el discurso biomédico ha estructurado el proceso procreativo en 3 etapas, promoviendo una visión parcializada del proceso que sólo visualiza al feto/embrión y no incorpora el nivel experiencial de las mujeres. Por el contrario, el análisis del proceso procreativo a través de las narrativas de las mujeres, revela contenidos y sentidos diversos: experiencias, significaciones y representaciones sobre el cuerpo, el lugar de la conciencia, las emociones y los procesos fisiológicos, el nacimiento, el vínculo con el bebé, los cuidados, la intersección con los discursos expertos y las prácticas biomédicas" (García Presas y otras, 2018, p. 3). 
CUADRO 16: ENTREVISTAS EN PROFUNDIDAD A MUJERES-MADRES Y VARONES-PADRES ${ }^{144}$

\begin{tabular}{|c|c|c|c|c|c|}
\hline Entrevista & Fecha & Propio nacimiento & Perfil socioeconómico & Hijo(s)/ tipo (s) de parto (s) & Ámbito \\
\hline $\begin{array}{l}\text { 1. Natalia (34) y } \\
\text { Lito (36) }\end{array}$ & $25 / 01 / 15$ & $\begin{array}{l}\text { Cesárea vertical } \\
\text { Clínica privada } \\
\text { "Traumático" }\end{array}$ & $\begin{array}{l}\text { Universitarixs. } \\
\text { Comerciantes ligados al } \\
\text { turismo. }\end{array}$ & $\begin{array}{l}\text { Niña. } \\
\text { Parto Vaginal. } \\
\text { "Muy lindo" }\end{array}$ & Clínica Privada \\
\hline \multirow[t]{3}{*}{ 2. Sabrina (25) } & \multirow[t]{3}{*}{$03 / 02 / 17$} & \multirow[t]{3}{*}{$\begin{array}{l}\text { Parto vaginal } \\
\text { Hospital privado } \\
\text { Episiotomía y epidural }\end{array}$} & \multirow[t]{3}{*}{$\begin{array}{l}\text { Ella ama de casa. } \\
\text { El primer papá albañil. }\end{array}$} & $\begin{array}{l}\text { Niña A (20 años). } \\
\text { Cesárea. } \\
\text { "Traumático" }\end{array}$ & Hospital Privado \\
\hline & & & & $\begin{array}{l}\text { Niña B (22 años) } \\
\text { Cesárea. } \\
\text { "Tranquila" }\end{array}$ & Hospital Público \\
\hline & & & & $\begin{array}{l}\text { Niño C (24 años) } \\
\text { Cesárea. }\end{array}$ & Hospital Público \\
\hline \multirow[t]{2}{*}{$\begin{array}{l}\text { 3. Valeria (23) y } \\
\text { Santiago (23) }\end{array}$} & \multirow[t]{2}{*}{$14 / 02 / 17$} & \multirow[t]{2}{*}{$\begin{array}{l}\text { Parto vaginal } \\
\text { "Complicado" } \\
\text { Un mes neonatología }\end{array}$} & \multirow[t]{2}{*}{$\begin{array}{l}\text { Ella ama de casa. } \\
\text { Él empleado en } \\
\text { panadería. }\end{array}$} & $\begin{array}{l}\text { Niño A (19 años) } \\
\text { Parto Vaginal } \\
\text { "Caótico" }\end{array}$ & Hospital Público \\
\hline & & & & $\begin{array}{l}\text { Niño B (23 años) } \\
\text { Parto Vaginal }\end{array}$ & Hospital Público \\
\hline $\begin{array}{l}\text { 4. Johana (33) y } \\
\text { Damián (34) }\end{array}$ & $4 / 09 / 2017$ & - & $\begin{array}{l}\text { Universitarixs. } \\
\text { Profesorxs. }\end{array}$ & $\begin{array}{l}\text { Niño. } \\
\text { Cesárea. }\end{array}$ & Hospital Privado \\
\hline $\begin{array}{l}\text { 5. Mariana (36) y } \\
\text { Leandro (38) }\end{array}$ & $27 / 09 / 2017$ & $\begin{array}{l}\text { Parto vaginal } \\
\text { Hospital publico } \\
\text { "Lo peor que le pasó } \\
\text { en la vida" }\end{array}$ & $\begin{array}{l}\text { Universitarixs. } \\
\text { Bioquímicxs. }\end{array}$ & $\begin{array}{l}\text { Niña. } \\
\text { Parto vaginal. }\end{array}$ & Hospital Privado \\
\hline $\begin{array}{l}\text { 6. Anabel (27) y } \\
\text { Dimitri (29) }\end{array}$ & $06 / 03 / 2019$ & $\begin{array}{l}\text { Cesárea } \\
\text { y neonatología } \\
\text { "protocolar" } \\
\end{array}$ & $\begin{array}{l}\text { Emprendedorxs, } \\
\text { trabajos part-time en } \\
\text { negocios familiares. }\end{array}$ & $\begin{array}{l}\text { Niño } \\
\text { Parto vaginal }\end{array}$ & Domicilio. \\
\hline $\begin{array}{l}\text { 7. Emilia () y } \\
\text { Marco () }\end{array}$ & $09 / 03 / 2019$ & Parto vaginal & Comerciantes. & $\begin{array}{l}\text { Niño } \\
\text { Parto Vaginal }\end{array}$ & Domicilio. \\
\hline
\end{tabular}

${ }^{144}$ La orientación de este cuadro y el siguiente tiene el fin de marcar la linealidad de cada proceso en particular, a modo de resumen de cada caso, la orientación inversa que permite comparar caso por caso no fue posible por una cuestión de diseño. 
CUADRO 17: RESUMEN DE INTERVENCIONES MÉDICAS EN LOS PROCESOS DE EMBARAZO Y PARTO DE LOS NACIMIENTOS RELATOS

\begin{tabular}{|c|c|c|c|}
\hline Entrevista & Itinerario (s) & Estudios referidos en EMBARAZO (IME) & Prácticas en PARTO (IMP) \\
\hline $\begin{array}{l}\text { 1. Natalia } \\
\text { (34) y Lito } \\
\text { (36) }\end{array}$ & $\begin{array}{l}\text { Dos obstetras: la primera de la obra social, la } \\
\text { descarta y se queda con un obstetra varón } \\
\text { recomendado por amigxs. }\end{array}$ & $\begin{array}{l}\text {-3 ecografías en todo el embarazo (médico "no pro- } \\
\text { ecografías") } \\
\text {-Sangre, glucosa, presión. } \\
\text {-Por fuera: ecografía 4d. }\end{array}$ & $\begin{array}{l}\text {-Tacto (con Hamilton) } \\
\text {-Goteo con oxitocina } \\
\text {-Litotomía } \\
\text {-Piernas atadas } \\
\text {-Episiotomía } \\
\text {-Prohibición de beber }\end{array}$ \\
\hline \multirow[t]{3}{*}{$\begin{array}{l}\text { 2. Sabrina } \\
\text { (25) }\end{array}$} & $\begin{array}{l}\text { Niña "A" / Hospital Privado: elección de institución por } \\
\text { cercanía y por conocimiento familiar, elección fortuita } \\
\text { de médico. }\end{array}$ & -Algunos, no refiere en mayor profundidad. & $\begin{array}{l}\text {-Monitoreo constante } \\
\text {-Litotomía en trabajo de parto } \\
\text {-Tactos repetidos (residentes) } \\
\text { - Hamilton. } \\
\text {-Ayuno } \\
\text {-Vía con antibiótico. } \\
\text {-Horario límite para dilatar. } \\
\text {-Peridural } \\
\text {-Anestesia }\end{array}$ \\
\hline & $\begin{array}{l}\text { Niña "B" / Cambio a Hospital Público (ya no tenía más } \\
\text { obra social). Controles en salita (CAPS) de la } \\
\text { periferia platense correspondiente por área } \\
\text { programática. Último mes controles en hospital }\end{array}$ & -Solo 3 ecografías, refiere haber sido más "light". & $\begin{array}{l}\text {-Fecha límite para desencadenamiento de trabajo } \\
\text { de parto. } \\
\text {-Litotomía en trabajo de parto. } \\
\text {-Cesárea programada por pasar las } 40 \text { semanas } \\
\text { de gestación. }\end{array}$ \\
\hline & Niño "C" / Hospital Público. Controles en salita. & $\begin{array}{l}\text {-Refiere que por haber perdido dos embarazos } \\
\text { previos se hizo muchos estudios "por su cuenta" } \\
\text { (fuera de los que cubre el servicio público): } \\
\text { ecografías, traslucencia nucal, scan morfológico, } \\
\text { análisis de hormona HCG cuantitativa. }\end{array}$ & $\begin{array}{l}\text {-Fecha límite para desencadenamiento de trabajo } \\
\text { de parto. } \\
\text {-Cesárea programada por pasar las } 40 \text { semanas } \\
\text { de gestación. }\end{array}$ \\
\hline $\begin{array}{l}\text { 3. Valeria } \\
\text { (23) y } \\
\text { Santiago } \\
\text { (23) }\end{array}$ & $\begin{array}{l}\text { Niño "A" / Hospital Público. Controles en salita } \\
\text { correspondiente por área programática }\end{array}$ & $\begin{array}{l}-2 \text { ecografías indicadas por médica de salita y } \\
\text { cubiertas por el servicio público. } \\
-3 \text { ecografías hechas por su cuenta, pagadas en } \\
\text { forma particular. }\end{array}$ & $\begin{array}{l}\text {-Tactos repetidos (residentes) } \\
\text {-Goteo con oxitocina } \\
\text {-Análisis de sangre } \\
\text {-Epidural (contra su voluntad) } \\
\text {-Rotura de bolsa (dolor) } \\
\text {-Sonda para orinar (dolor) } \\
\text {-Catéter (dolor) } \\
\text {-Litotomía en trabajo de parto y parto } \\
\text {-Kristeller } \\
\text {-Episiotomía } \\
\text {-Fórceps }\end{array}$ \\
\hline
\end{tabular}




\begin{tabular}{|c|c|c|c|}
\hline & $\begin{array}{l}\text { Niño "B" / Hospital Público. Controles en salita } \\
\text { correspondiente por área programática. Derivación a } \\
\text { atención hospitalaria por patologías: anemia, } \\
\text { celiaquía y dolores articulares. }\end{array}$ & Cambió de ginecoobstetra en la salita. & $\begin{array}{l}\text {-Litotomía. } \\
\text {-Kristeller }\end{array}$ \\
\hline $\begin{array}{l}\text { 4. Johana } \\
\text { (33) y } \\
\text { Damián } \\
\text { (34) }\end{array}$ & $\begin{array}{l}\text { Hospital Privado. Atención con la ginecóloga "de } \\
\text { siempre" que además es obstetra. Atención en } \\
\text { consultorio externo, privado (beneficio de la menor } \\
\text { espera). }\end{array}$ & $\begin{array}{l}\text {-Ecografía particular para confirmar embarazo: saco. } \\
-5 \text { ecografías. }\end{array}$ & $\begin{array}{l}\text {-Tactos } \\
\text {-Goteo con oxitocina } \\
\text {-Litotomía en trabajo de parto } \\
\text {-Peridural } \\
\text {-Cesárea (atada). }\end{array}$ \\
\hline $\begin{array}{l}\text { 5. Mariana } \\
\text { (36) y } \\
\text { Leandro } \\
\text { (38) }\end{array}$ & $\begin{array}{l}\text { Hospital Privado. Cambia } 3 \text { veces de obstetra. A la } \\
\text { primera va por recomendación de su ginecóloga (se } \\
\text { equivoca y pide turno con otra). No le gusta el trato. A } \\
\text { la segunda va por cartilla de obra social. Al verla } \\
\text { mayor en edad y en peso, busca otra. Finalmente va } \\
\text { a una por recomendación de amigas y se queda con } \\
\text { esa. }\end{array}$ & $\begin{array}{l}\text {-Confirmación por examen propio (son bioquímicos y } \\
\text { él trabaja en laboratorio). } \\
\text {-La doctora tiene tendencia a hacer los menos } \\
\text { estudios posibles (por ejemplo, análisis de sangre } \\
\text { cada } 3 \text { meses). } \\
\text {-Por su cuenta realizan análisis de sangre seguidos, } \\
\text { urocultivos, estreptococo, etc. }\end{array}$ & $\begin{array}{l}\text {-Vía con antibiótico (la pide ella) } \\
\text {-Tactos repetidos } \\
\text {-Hamilton } \\
\text {-Sospecha que junto con el reliveran le pusieron } \\
\text { oxitocina (por el aceleramiento de la dilatación } \\
\text { posterior). } \\
\text {-Litotomía } \\
\text {-Piernas atadas } \\
\text {-Episiotomía y problemas con los puntos en el } \\
\text { posparto. } \\
\text {-Autokristeller. }\end{array}$ \\
\hline $\begin{array}{l}\text { 6. Anabel } \\
\text { (27) y } \\
\text { Dimitri (29) }\end{array}$ & $\begin{array}{l}\text { Grupo de parto domiciliario como primera y única } \\
\text { opción, al cual conocen por amigxs. }\end{array}$ & $\begin{array}{l}\text { Ecografías y analíticas básicas, perfil no- } \\
\text { intervencionista. }\end{array}$ & $\begin{array}{l}\text {-No hay referencia a prácticas externas durante el } \\
\text { parto. Sólo un tacto avanzado el período dilatante } \\
\text { y fue a pedido suyo. }\end{array}$ \\
\hline $\begin{array}{l}\text { 7. Emilia () } \\
\text { y Marco () }\end{array}$ & $\begin{array}{l}\text { Grupo de parto domiciliario como primera y única } \\
\text { opción. }\end{array}$ & $\begin{array}{l}\text { Ecografías y analíticas básicas, perfil no- } \\
\text { intervencionista. Pasadas las } 41 \text { semanas de } \\
\text { gestación sin desencadenamiento del trabajo de } \\
\text { parto se realiza un ecodoppler para conocer estado } \\
\text { fetal. }\end{array}$ & $\begin{array}{l}\text {-No hay referencia a prácticas externas durante el } \\
\text { parto. }\end{array}$ \\
\hline
\end{tabular}




\section{2. PARIR/TENER CESÁREA Y PONER EL CUERPO: VISIÓN DE LAS MUJERES-MADRES}

Todas las entrevistas realizadas en esta tesis comenzaron con la inquietud sobre qué saben Ixs sujetxs de su propio nacimiento ${ }^{145}$. Uno de los supuestos particulares en relación a las mujeres-madres entrevistadas fue que los relatos que recibieron, en general de boca de sus madres, sobre cómo fueron dadas a luz, impactó de distintos modos sobre sus expectativas, deseos y vivencias en torno a parir a sus hijxs. A este tipo de historias y relatos generacionales incluyo en lo que denominó como "parto transmitido", retomando las palabras de una jefa del servicio de tocoginecología de una maternidad de la ciudad.

Los relatos que las mujeres entrevistadas recibieron de sus propios nacimientos suelen ser negativos. Tres de ellas referenciaron haber nacido por partos "naturales" (es decir, vaginales) pero traumáticos, dolorosos, complicados. Una de ellas contó haber nacido por una "cesárea vertical", muy dolorosa para su madre.

"De mi nacimiento yo sé que fue parto normal, como todo lo que es la normalización de mi mamá de lo que es el trabajo obstétrico, súper intervenido, episiotomía, con anestesia" (Sabrina).

Las vivencias de sus madres se utilizan a lo largo de los relatos de parto reseñados como referencias para distanciarse o acercarse en su propia experiencia. Los partos transmitidos están compuestos por las narrativas maternas y, también, por las experiencias cercanas de amigxs, vecinxs y compañerxs de trabajo. $\mathrm{Y}$, sin duda alguna, por los imaginarios que construyen los medios masivos de comunicación y las industrias culturales. Así, por ejemplo, es relevante y notoria la referencia a las películas y a los partos que transmite Hollywood y la TV nacional como un referente conceptual muy significativo para comparar con la propia experiencia.

\footnotetext{
"Vos decís "voy a tener un bebé peladito" como, no sé, las películas. No, era una cosa peluda así" (Natalia y Lito).

"Llamamos un remis, me dice "nos van a mandar de nuevo, porque estás re tranquila" [lo imita con voz quejosa]. "Yo estoy tranquila, pero las contracciones las tengo cada 5 minutos" (risas), así que agarramos, fuimos en el remis, me agarró una contracción cuando estábamos entrando, me llevaron en sillas de ruedas, fue como de película. Y ya después me dejaron ahí en preparto" (Sabrina, primer parto)

"No me imaginaba mucho cómo era el momento de las instancias ya finales, cuándo tomar en consideración que era, que podía ser algo determinante como para salir corriendo o no. Entonces viste que por ahí uno tiene información de las películas, ese tipo de cosa que rompen bolsa y qué se yo" (Damián)
}

\footnotetext{
145 Esto me llevó incluso a realizarle una entrevista a mi madre sobre mi nacimiento, donde obtuve respuestas muy interesantes.
} 
En este marco interpretativo tan heterogéneo pero tan cercano, se construyen las historias y los relatos sobre las experiencias de PEP que analizaré a continuación.

\subsection{A. EMBARAZO: ITINERARIO ASISTENCIAL ${ }^{146}$.}

De los 10 embarazos, se encontró que sólo cuatro de ellos fueron buscados: de éstos, tres son segundas y terceras gestas. El caso distintivo fue el de Mariana, primeriza, quien mencionó que su hija fue "buscada, planeada, planificada con fecha, horario". La pregunta por la planificación del embarazo se basó en la idea de que la búsqueda (o no) del/de la hijx podía afectar el modo en el que las mujeres transitaran los procesos perinatales, lo dispuestas o no que estarían a ciertas intervenciones médicas o lo informadas o no que se sintieron. Lo paradójico es que la única mujer (Mariana) que mencionó haber planificado la gestación, refirió que el tránsito del embarazo fue "lo peor" de su vida, que significó un gran disgusto. Por lo que podría decirse que la planificación no parece condicionar positivamente las sensaciones y las emociones que pueden sentir una vez conseguido.

Del mismo modo, aquellas mujeres-madres primerizas que "se sorprendieron" con la noticia del embarazo, parecen haber resuelto el shock inicial una vez decidido continuar con el mismo. Por ende, en los casos en los que el embarazo no fue planificado, sí concluyó siendo deseado, y se argumentó que probablemente existía un deseo inconsciente (como modo de explicar las fallas en los métodos anticonceptivos utilizados).

"No. A ver, no la buscamos conscientemente de decir bueno, la fecha, no. Pero yo creo que inconscientemente la buscamos porque no nos cuidábamos bien, como es la responsabilidad de mayores, así que evidentemente" (Natalia y Lito).

Respecto a la confirmación del embarazo, como se mostró en el capítulo 4, en torno a la mediación médica del conocimiento del propio cuerpo, la mayoría de las mujeres refieren haberse hecho el test de embarazo que se compra en las farmacias, pero haber obtenido la confirmación con analíticas de laboratorio. Un caso particular se dio en la pareja de Mariana y Leandro, en la que, siendo ambos bioquímicos, la confirmación la realizó él extrayéndole sangre y analizándola en el laboratorio en el que trabajaba. Esta peculiaridad marcó el tránsito del embarazo: realizaron diversos estudios por fuera o con mayor frecuencia de los indicados por su obstetra con tendencia anti-intervencionista (es decir, prescriptora de los estudios mínimos necesarios).

${ }^{146}$ Aunque este capítulo se centre en las experiencias de parto, parto de contar el itinerario asistencial porque, como se viene postulando, es durante este entramado que se van internalizando ciertas pautas e ideas que serán centrales al momento de la atención y el tránsito del parto. 


\title{
- ELECCIÓN DEL/DE LA MÉDICX Y DE LA INSTITUCIÓN. RELACIÓN MÉDICX-PACIENTE
}

Respecto a la elección de Ixs profesionales obstétricxs y de las instituciones, la cercanía geográfica y las referencias de conocidxs suelen ser el punto de partida. Después aparecen otros elementos que hacen al descarte o a la continuidad con tales médicxs. Por ejemplo el maltrato, la deshumanización o la no respuesta a las preguntas de las mujeres y sus parejas, suele ser un elemento para descartarlxs y buscar otrxs. Del mismo modo la cercanía, la recomendación de conocidxs, la confianza, el trato especial y la conexión o química con él o ella, hacen a su elección como profesional de cabecera.

\begin{abstract}
"Me hice un evatest con mi pareja. Bueno, ahí me enteré que estaba embarazada, fui a la obra social, porque yo no tenía idea cómo se manejaba, no tenía conocidos acá. Me saqué turno con una obstetra que era como una carnicera, que te trataba, como si te estuviera vendiendo un pedazo de carne. Por ejemplo, quería que tomara unos óvulos que descubrí que estaban contraindicados para embarazos hasta tres meses. ¿Viste cuando vos sentís que no...?" (Natalia y Lito, privado)

"Yo me empecé a controlar ahí [en el hospital privado] porque había pedido un turno para ir a hacer el primer control del embarazo, me lo tomaron mal y me hicieron turno para ecografía y yo no tenía orden, nada. Hablé con el doctor y me dijo "bueno, yo la ecografía te la hago igual", entonces ahí fue como que le tuve cierta confianza al médico de que no me iba a dejar a pata. No lo conocía. No tenía ninguna recomendación ni nada y ahí es como que yo dije "bueno él no me va a dejar a pata por más que no tenga la orden, por más que esto, por más que lo otro". Y fui a ese hospital porque era el que me quedaba más cerca de mi casa, me tomaba el colectivo 307 y estaba ahí enseguida y me empecé a atender ahí porque sabía que era el que más rápido iba a llegar. Porque bueno, es el que conocía además, porque ahí tuvo mi mamá a mi último hermano, así que bueno, yo conocía ese lugar, me quedaba dentro de todo cerca. No conocía otras clínicas" (Sabrina, primer parto, privado).
\end{abstract}

Para su segundo y tercer parto, Sabrina concurre a un hospital público de la ciudad, al consultarle por el cambio de efector, menciona:

"Fuimos primero ahí para hacerme los controles, ya no tenía obra social, había cumplido los 21 así que fuimos ahí, me dijeron "para venirte a atender, tenés que ir a la salita, hacer tal cosa, tal otra, si no tenés derivación no te podemos atender". Así que tuve que ir, atenderme en la salita" (Sabrina, segundo parto, público).

Como se viene mencionando, la "elección" (y las comillas tienen que ver con que no siempre es una verdadera elección entre distintas opciones) de Ixs profesionales obstétricxs o de las instituciones sanitarias, resulta de la combinación de una serie de elementos. Lo interesante es que no se da de una vez y para siempre. Algunas entrevistadas mencionan cambios de médicxs al no sentirse cómodas, respetadas, contenidas.

"Mi ginecóloga de siempre, que ya no hacía más partos, me dice "yo las mando a tres personas de confianza mía" y me dice, me conoce hace mucho tiempo, desde que 
vine a estudiar acá a La Plata que me atiendo con ella y me dice "tu perfil es para tal persona" y yo perdí el papel y me acordaba de dónde atendían, llamé por teléfono y cuando me dijo "bueno, yo quiero un turno", me dijo el primer nombre y yo dije "ah, sí, es esa" y no, no era esa. Era la otra. Y yo saqué el turno con la que ella me dijo que no vaya, porque era como que, ella sentía que a mí no me iba a gustar. Y no me gustó (...) Yo saqué turno y fui y no me gustó y no sabía qué hacer, viste. No sabía qué hacer, no me gustó, muy plana. Fuimos los dos. A él tampoco le gustó y él es poco quisquilloso, viste, él "está todo bien", viste, todos los varones. Sí, como que no nos dio bola, pero visto después, digo "bueno, está bien" porque a las dos-tres semanas de embarazo ¿qué podés pretender? Como que la ví muy... como que "está todo bien", bueno, no me contestaba preguntas, como "bueno, eso lo vemos más adelante". No, si te lo estoy preguntando es porque lo quiero saber. Muy pum para abajo, ¿entendes? Claro, no sabía qué hacer. Entonces agarré la cartilla de la prepaga y saqué otra, porque yo me tenía que sacar las dudas" (Mariana, privado)

Mariana pasa por tres obstetras hasta quedarse con quien finalmente atendió su parto. A la primera fue por (una equivocación en) la recomendación de su ginecóloga, a la segunda por la cartilla de la medicina prepaga y a la última por recomendación de unas compañeras de trabajo de Leandro.

La elección de la atención obstétrica está condicionada por varios factores, pero uno de los más determinantes es el perfil socioeconómico de las mujeres, que en el caso del acceso a la salud, se vislumbra en la posesión o no de obra social o medicina prepaga o la utilización de los servicios públicos de salud (que en los casos analizados se vinculó a mujeres de sectores populares sin trabajos registrados). Así, la elección de Ixs médicxs se limita al sector privado, y la institución, en el caso de los públicos, se vincula a la jurisdicción del área programática, por lo que tampoco constituye una decisión entre opciones.

Elegir a tal médicx o tal clínica/hospital implica conocer, aceptar y ajustarse a sus reglas del juego. En este sentido, las entrevistadas mencionan que existe un modo de trabajo particular a cada profesional, que "es así" e indiscutible. Así, por ejemplo, la mención a cómo conforman sus equipos de trabajo algunxs profesionales en el sector privado con parteras y pediatras, a veces implica el cobro de un diferenciado de dinero que no se cuestiona.

"No trabajan con parteras ellos. Trabajan con su equipo de trabajo ahí, que es lo que yo te decía que no nos había dado el número de teléfono, viste. Yo digo "si me pasa algo ¿cómo te enteras?, o sea ¿a quién consulto?". Ella lo que me decía que, efectivamente fue así, me decía "fijate que vos vas a ir a la parte de guardia y en la guardia te va a atender fulana, mengana o sultana que estén ahí y ellas se comunican enseguida conmigo y yo les digo qué tienen que hacer" (Johana, privado).

"Ella se manejaba con un par de parteras que ellas daban el curso y te lo cobraban, en el Español. Después me entero que te cobraban ese combo de curso más la atención que vos tuvieras en el parto ellas, las parteras te cobraban eso. Ella nunca me nombró nada, claro porque ella está afuera de eso, viste. 2500 me cobraron, sin hacer el curso.

Ah, ¿si hubieses hecho el curso y la atención 2500? 
Claro, 2500 pesos. Que me enteré después de tener al bebé, pero de pedo porque le dije "¿no te debemos nada?", por metiche, por decir, no me dijo nada, nunca me dijo nada y yo ya sabía de otras personas que les habían cobrado hasta respirar, hasta la médica les había cobrado, entonces dije "yo voy a preguntar por las dudas" porque viste (...) A partir de la semana 36 la partera ya me empezó a monitorear. Sí porque ella te acompaña hasta 10 minutos antes de que salga el bebé. Yo eso nunca lo supe hasta el momento. Sí, los últimos minutos y el broche de oro es la obstetra. Que viene, se cambia, pum, y ahí está" (Mariana, privado).

Emerge entonces que aunque elijan a tal médicx y se realicen toda la atención perinatal con él/ella, lo que sucede en el parto incluye a otrxs profesionales que las mujeres suelen desconocer hasta unas semanas antes del nacimiento. Lo cierto es que "trabajar (o no) con parteras" suele ser un elemento que varía entre Ixs obstetras de la ciudad. El hecho de, además de la exclusividad del/la médicx, asegurarse la exclusividad de una partera, suele implicar el pago de un diferenciado (no reconocido por la obra social) que las mujeres y los varones conocen recién en el momento el parto, si es que no lo consultan antes. De este modo conocer el modus operandi particular de cada médicx suele ser un motivo de angustia e incertidumbre por parte de Ixs sujetxs.

Sobre la relación que durante el embarazo se establece con dichxs profesionales, hay distintas versiones. En este punto es clave la disputa por la información que se comparte, y allí aparece la apelación a internet y a grupos activistas virtuales para saciar la demanda de saberes que Ixs profesionales ni los cursos de preparto cubren. Esto aparece en distintos momentos del proceso perinatal.

Uno de los elementos que vertebran la relación médicx-paciente y la atención obstétrica durante el embarazo, es la indicación y realización de estudios y controles médicos. En este punto encuentro una convivencia, a veces complementaria y a veces contradictoria, entre los estudios, consejos de medicación y pautas de estilo de vida que sugieren/ordenan/propones Ixs profesionales y los que eligen y hacen hasta por fuera las mujeres y sus parejas. Sobre esto último se destaca la realización de ecografías $4 \mathrm{~d}$ que, como ya comenté previamente, no aportan información médica y responden más a una lógica mercantilista de la medicina.

"Me hice la 4d, por un tema de que yo la quería ver y quería quedarme tranquila, por un tema de verla nomás.

¿Y eso te lo cubre la obra social?

No, no, la $4 d$ no te la cubre. Es más, la $4 d$ es súper comercial, te venden la foto con el video, para los familiares, el llaverito. Y muy muy comercial. Llegas y el doctor hace como una actuación porque después te filman ese video. Horrible ese video. Yo quería la ecografía viendo la cara del bebé, nada más. Y no, te dicen "no, tenes el combo con el llavero". Súper comercial, no conozco otra, seguro hay otra que tenga que ver más con la parte médica que con la parte comercial pero yo no lo encontré" (Natalia y Lito, privado). 
Del mismo modo, por fuera las mujeres suelen realizar estudios para compensar la tendencia desmedicalizadora de algunxs profesionales obstétricxs, como en el caso de Mariana y Leandro, Ixs bioquímicxs, o para palear la baja cobertura que ofrece el sistema público. Por ejemplo, tanto Valeria como Sabrina realizaron muchos estudios por fuera de lo que cubría el sector público. Así, Valeria mencionó que se hizo ecografías aparte de las que le realizaban en el hospital porque lo que le entregaban eran solo informes textuales, sin imágenes, elemento muy valorado en el tránsito del embarazo. También Sabrina mencionó que durante el embarazo de su tercer hijo se realizó muchos estudios invasivos para conocer el estado de salud fetal, dado que había perdido dos embarazos previamente y necesitaba adquirir seguridad. Ninguna de estas analíticas fueron realizadas en el servicio público en el que ellas se atendían.

Respecto a la medicación no hubo muchos detalles en relación al uso de vitaminas o suplementos. Y sorprendió el hecho de que las mujeres no mencionaran el establecimiento de pautas de estilo de vida, porque suele ser común en las conversaciones de mujeres o en los relatos de partos disponibles en internet, la referencia a profesionales que sólo controlan el peso y suelen "retarlas" por engordar, no comer bien, no dejar la sal. De hecho entre las entrevistadas una mencionó que en sus tres embarazos fumó y que nunca ocultó este hecho a sus médicxs, por lo que la mencionada estandarización de los estilos de vida y del emprendedorismo moral médico parece flexibilizarse en varios casos.

\section{- PLANIFICACIÓN DEL PARTO: ARENA DE NEGOCIACIONES CON MÉdICXS E INSTITUCIONES}

Aquí aparece una de las riquezas de la indagación empírica: vislumbrar lo negociable y lo no-negociable que se impone en la relación médicx-paciente en torno a los partos que desean y por derecho les asiste a las mujeres y sus parejas. Me refiero a "lo negociable" como aquello que piden las mujeres y es escuchado/tenido en cuenta; y "lo no-negociable" como aquellos modus operandi de Ixs médicxs y las instituciones que tienden a no tener en cuenta las necesidades, deseos y derechos de las mujeres. En este sentido, aquí se podrán identificar las influencias de los partos transmitidos culturalmente.

"Quería que fuera un parto natural, es más, ¿viste esas cosas que dicen las viejas?, que había escuchado que dormir del lado izquierdo hace que tengas parto natural, bueno, yo dormí todo el embarazo del lado izquierdo. Y no, yo siempre quise parto natural. Y cuando llegue al parto, después tuve muchas horas de TP y yo pensé, a amigas mías les había pasado que habían tenido un día de TP y después cesárea y dije no, o sea, si va a hacer sufrir al bebe y voy a terminar en una cesárea hacemela ahora. Pero, pero yo siempre quise natural sí. 
Vos, cuando te acercaste a este médico, ¿qué fue lo primero que hablaron: cómo iba a ser el parto o cómo iba a ser el embarazo?

Yo le dije lo del parto y me dijo "para eso hay tiempo para hablarlo". Y hablamos del embarazo básicamente, de lo que se podía engordar, de lo que no, de lo que le hacía bien al bebé, de lo que no. Y yo... no sé cómo explicarte, el médico yo lo tomo como que está todo bien en un algún punto obviamente es el médico, te indica algunas cosas, y otras yo pienso que deben ser naturales. Eso es a lo que yo te digo que es instinto y cuerpo. Porque yo lo sentí así y lo siento ahora con mi segunda bebé y la pediatra y es lo mismo. En algunas cosas está todo bien pero en otras es lo que siento yo como madre.

O sea, ¿vos sentiste que había cosas que él te indicaba y vos no tenías ganas de hacer?

Sí, no. Por ejemplo una cosa básica que él me decía, que me acuerdo siempre, "las madres se toquetean la panza todo el tiempo y eso no está bien porque se incentiva el parto". Y yo, no sé, puede ser que sea así, pero vos te dan ganas de tocarte la panza. Las madres no van toqueteándose la panza porque sí, te dan ganas de tocarte la panza, y bueno, yo me la toqueteaba igual (...) Y el tema que ni bien la sacaran me la dejen en brazos.

¿Eso de dónde lo sacaste? ¿Se te ocurrió o estuviste estudiando, leyendo o alguien te dijo?

No, el tema ese sí, lo leí. Y más que nada porque es así, porque yo veía en el campo que lo primero que hacen los terneros es ir y prenderse a la teta de la vaca, o sea que es lo más normal" (Natalia y Lito, privado).

En este primer verbatim aparecen algunos elementos que permiten pensar cómo la tensión naturaleza-cultura atraviesa el objeto de estudio. En su caso, el relato materno de un parto vaginal traumático no hizo mella en sus expectativas y deseos. En cambio el contacto con vacas y terneros por su crianza en el campo se convirtió en una referencia constante en su forma de pensar y relatar "lo natural" (y por tanto constituyente de su parto transmitido). Asimismo se va viendo cómo la relación médicx-paciente se va construyendo con acuerdos y desacuerdos con determinados temas, más o menos triviales. Finalmente aparecen referencias a ideas que las mujeres leen, conocen y escuchan por fuera y las toman como elementos que quieren que sean respetados en su atención obstétrica.

Respecto a esto último, varias de las entrevistadas mencionan cuáles fueron sus propios "no negociables", aquellas cuestiones que plantearon a su médicx o en las consultas prenatales.

"Y me empecé a atender con él. Hubo un montón de muestras de que él no iba a ser respetuoso conmigo que yo en ese momento como era chica no me di cuenta. Cuando yo hablé con él de que yo quería un parto normal sin episiotomía, sin anestesia, o sea, yo desde la primera sabía que quería un parto totalmente natural, en el que yo me sintiera cómoda y, y sintiera mi cuerpo en todo momento, que no me pusieran oxitocina

¿Y vos esas ideas de dónde las sacabas?

$\mathrm{Y}$ cuando estuve leyendo sobre partos y todo, estuve viendo videos de partos en el agua y todas esas cosas, sabía que era algo acá prácticamente inalcanzable, más en mi situación económica en ese momento y dije "bueno voy a tratar que sea lo más natural posible, lo más respetado dentro de la institución".

¿Y cuáles eran las muestras de él de que no te iba a respetar? ¿En las consultas?

$\mathrm{Y}$, un poco como que se me cagaba de risa. Cuando yo le decía "no, mirá, yo no quiero tener episiotomía, no quiero que me pongan oxitocina, no quiero que me pongan epidural, no quiero que me pongan nada, quiero que me dejen tranquila, que 
mi cuerpo haga su trabajo. Es lo que había hablado yo con él. Y bueno medio que me miraba y me decía "bueno, eso se ve en el momento" y que se yo y como que me tomaba el pelo, ¿entendes?" (Sabrina, primer parto, privado).

El relato de Sabrina refiere al de una paciente informada que conoce la jerga y el modo de trabajo de la obstetricia intervencionista, y busca una relación más "democrática" o menos asimétrica con el médico. De hecho cuando hace mención a que sabía que el médico no sería "respetuoso" no se refiere al trato sino a sus derechos y al modelo de atención. Cuando enumera las intervenciones que quería evitar, son justamente las que su madre atravesó en su nacimiento, lo que confirma cierta influencia de este parto transmitido. De todos modos y más allá de estas negociaciones, su primera beba nació por cesárea y ella sospecha que se debió a la salida del médico por vacaciones. Para su segunda bebé, siguió buscando e incluso reforzó su búsqueda de una atención más respetuosa.

"Para la segunda yo quería intentar un parto después de cesárea. Se llevaron 18 meses. Desde el hospital, cuando yo dije que yo quería tratar de tener un parto natural, me dijeron "bueno, podés tratar de tener un parto natural pero si se desencadena antes de las 40 semanas, sino te programamos cesárea". O sea que me pusieron una fecha límite, que la mayoría de los bebés no nacen ni antes ni a las 40 semanas, nacen después" (Sabrina, segundo parto, público).

Esta cuestión de los tiempos es nodal en la atención obstétrica tal como se ha venido demostrando en esta tesis. $Y$ en el caso de la cesárea previa, encierra una disputa particular, a la que Sabrina también hace mención en la entrevista, reforzando su rol de paciente informada. Con esto me refiero a la condena de la cesárea previa que supone que los partos posteriores a una cesárea, deberán ser sí o sí por cesárea, por el riesgo (otra vez) de rotura de la herida en el útero. Este mito obstétrico (sólo alimentado por el miedo profesional) ha sido cuestionado por la $\mathrm{OMS}^{147}$ y estableció que lo más saludable y menos riesgoso sería que el período intergenésico sea de 18 meses o 2 años. En este saber disputado se para Sabrina para exigir la posibilidad de pasar por un parto vaginal. $\mathrm{Y}$ allí una nueva utilización de los tiempos como instrumento de poder: te esperan hasta la semana 40, como si el desencadenamiento del trabajo de parto fuera voluntario. Y, en conjunto, el conocimiento "externo" de Sabrina, acerca de que los partos pueden ocurrir hasta la semana 42 y seguir considerándose de bajo riesgo.

Asimismo en el testimonio de Sabrina aparece cierto cambio en la respuesta de Ixs profesionales a sus inquietudes si se trata del ámbito privado (primer parto) o público (segundo y tercero). Pareciera que en la maternidad pública tiene un mayor margen de negociación, sumado a su proceso de información y empoderamiento.

${ }_{147} \mathrm{Al}$ respecto, recomiendo el informe de la OMS sobre las tasas de cesáreas disponible en https://www.who.int/reproductivehealth/publications/maternal perinatal health/cs-statement/es/ 
"La mayoría te programan a la 38 con la cesárea previa, en el hospital público bueno, lo que yo pude hablar, era si yo podía tener un parto normal. Y para mí en ese momento que me dijeran que me esperaban hasta la 40 ya era un golazo, porque en cualquier lado me iban a programar a la 38 , porque tenía una cesárea de no mucho tiempo. Así que bueno, con eso me quedé tranquila y nunca me puse a pensar que era poco el tiempo que me esperaban, que si me hubieran esperado más yo a mi segunda hija la podía parir tal como hubiera podido parir a la primera si no me apuraban. Con él (tercer parto) yo ya estaba completamente encaminada para un parto normal, iba a hacer todo el trabajo de parto en casa, llegar por guardia, ya cuando sintiera la sensación de pujo. Me había informado un montón, estaba en el grupo de parto vaginal después de cesárea, había hablado, teníamos un grupo de contención en whatsapp con mamás de todos lados, hasta de Chile, que esperábamos para las mismas fechas. Mi plan era hacer todo el trabajo de parto que pudiera y si me tocaba justo un día que estaba la doctora $X$ [anonimizado] en la maternidad $\mathrm{Y}$ o el doctor $\mathrm{P}$ en el hospital $\mathrm{T}$, me iba a alguno de esos dos porque eran médicos en los que yo tenía confianza que iba a poder ir a parir" (Sabrina, segundo y tercer parto, público).

El relato de cómo Sabrina fue proyectando y planificando cada uno de sus tres partos es sumamente rico en tanto muestra la tensión de posiciones de saber-poder en la relación médicx-paciente y la tensión con las normas institucionales. Es interesante ver cómo la posibilidad del diálogo se va chocando con los resultados no queridos (los nacimientos terminan siendo por cesárea), lo que la lleva a ir pensando nuevas estrategias. Para el último parto planifica entonces casi no tener contacto con la institución y acercarse a alguna "guardia amigable" de alguna de las maternidades públicas de la ciudad. Con "guardia amigable" el activismo por el parto respetado se refiere a los espacios de atención de determinadxs médicxs fisiológicxs/respetuosxs en determinados hospitales públicos en determinados días de la semana: el conocimiento de cuándo funcionan estas guardias es difundido por los grupos militantes. Finalmente por una patología Sabrina queda internada en la maternidad donde tuvo a su segunda hija y relata cómo pudo conseguir que se le respeten algunos derechos (aunque a nivel institucional fueran considerados privilegios 0 excepciones). Sabiendo que no iba a poder cumplir su deseo de parir por vía vaginal, se concentró en exigir que la dejaran entrar acompañada y que la recepción del recién nacido fuera en el marco del modelo humanizado.

"Yo le dije [a la jefa de servicio de la maternidad pública] "yo lo único que quiero es que, como sea que mi hijo nazca, mi marido esté al lado mío o mi marido pueda al menos, no sé, ver cómo mi bebé nace filmado, algo". Me dice "bueno, adentro no puede entrar al quirófano, porque es un quirófano de emergencia" [la maternidad estaba en refacciones], porque estaban justo remodelando. El quirófano era así hasta esa mesa, era una cosa re chiquitita, así que bueno, cuando entré ahí me di cuenta que era cierto, que era imposible meter un alma más ahí adentro, eh (...) No me adelantaron la cesárea, me dijeron "si vos estás acá internada y empieza el trabajo de parto, vos tenés que ir a cesárea" me dicen. Por las dos cesáreas anteriores y por protocolo del hospital. Les pedí que esperen para cortar el cordón, que me dejen estar un ratito con él antes de que se lo lleven y que cuando él saliera estuviera con el papa. Además, bueno, también sabía sobre la ley... Yo le dije "si a mí no me van a respetar el derecho mío de estar acompañada en la internación por mi pareja y de estar casi todo el tiempo que sea posible con mi hijo, yo no me voy a quedar acá". Y 
se lo dije y lloraba. "Si yo no puedo estar, si mi pareja no puede ver cómo nace mi hijo, yo no me quiero quedar acá". Así que por eso fue que lo filmaron, porque no había posibilidad de que él entrara al quirófano y yo exigí que él se pudiera quedar a cuidarme porque yo no tenía ninguna mujer que se pudiera quedar conmigo (...) No, sala conjunta no, fue una sala privada" (Sabrina, tercer parto, público).

Lxs tres hijxs de Sabrina nacieron por cesárea, pero en cada caso se fue desplegando y desarrollando un rol más combativo. Asimismo, en su trayectoria se visibilizan algunas diferencias y similitudes entre los ámbitos de atención institucional.

En la planificación de los partos, el ser primeriza o multípara, parece ser importante, por el capital de la experiencia. Por ello, en sus segundos partos, ya sabiendo de qué se trata, las mujeres coinciden en utilizar la estrategia de atrasar lo más posible la llegada a la institución.

"[Para el segundo bebé, del que está embarazada en la entrevista] quiero esperar, y estar relajada, lo más que pueda, comer tranquila, tomar, darme un baño y salir. No como esa vez que... O tratar de descansar lo más que pueda. Y hoy estoy más tranquila, sé que va a ser otra cosa, por ahí controlar todo lo que no pude controlar con el primero, pero que era más chica, que no tenía ni idea, porque no estaba mi hermana que era la que iba a manejar la batuta" (Valeria, segundo parto).

En este verbatim además de lo señalado anteriormente aparece un elemento clave en torno al diagnóstico de autoresponsabilización o autoculpabilización que hacen las mujeres si sus partos no fueron como esperaban. Tener poca información parece clave en las valoraciones negativas que tienen de sus experiencias, pero esa falta de información se vincula en la argumentación a una cuestión personal y no se la ve como un elemento clave de reproducción del $\mathrm{MMH}$. $\mathrm{Y}$ de todos modos acabo de mostrar cómo una paciente sobreinformada atraviesa tres cesáreas que, en su opinión, fueron innecesarias.

En la planificación del parto, de todos modos, no todas las mujeres se asientan en un paradigma anti-intervencionista total. Algunas incluyen el pedido de prácticas como la epidural o la aplicación de antibióticos.

"Johana: Siempre fue pensado el parto en base a parto natural. Había la posibilidad de la cesárea pero no, no contábamos con eso. Y en cuanto a la epidural, yo la iba a querer.

¿Lo hablaste eso en algún momento o no?

Johana: Sí, lo hablé con una consulta porque me habían dicho que se cobra aparte, no sé qué, y entonces yo le digo "si yo la tengo que planificar", le dije, "decime y yo ya la tramito". "No", me dice, "vos quedate tranquila". Bueno, listo.

Damián: Sí, había que sacarle un poco la información... Yo en momento medio me calenté porque parecía que si vos no le planteabas las cosas o sea si vos ya no venias con las preguntas, no se anticipaba la ginecóloga de ella. Entonces no es que te decía "no, va a pasar tal cosa, va a pasar tal otra". No, ella respondía en función de lo que vos le preguntabas, si vos no le preguntabas nada, no respondía nada y por ahí vos ni te enterabas lo que pasaba" (Johana y Damián, privado) 
"Yo sabía qué parto quería y le dije a Leandro [su pareja]. Le dijimos a la obstetra y "sí, sí, sí" y después no fue.

¿Qué parto querías?

No esa locura de cero intervención, me parece una estupidez, para mí me parece una estupidez porque te pasa algo y qué carajo hacés. Y no creo en la, porque de hecho yo le pedí ya que me ponga la vía [de antibiótico]

¿Pero qué cosas dijiste "esto no puede faltar" o "esto no te lo negocio"?

La posición de parir. El sillón o la silla, donde me iban a depositar, para mí era lo fundamental. Y me dijo "sí, sí". Porque por la gravedad tiene que ser así. Que Leo estuviera, obviamente. No pactaba no estar.

¿En algún momento ella te habló de cesárea o algo por el estilo?

Nunca. Sí, nunca lo hablamos de cesárea o parto natural, todo fue natural, todo se hablaba como natural" (Mariana, privado).

En estos dos verbatims aparece no sólo que en la planificación del parto las mujeres pueden incluir ciertas prácticas clínicas (aun sin saber si las van a necesitar), sino también cómo se multiplica ésto de Ixs profesionales respondiendo sin mucha certeza. Aunque esto puede interpretarse coherente con la incertidumbre propia del proceso de nacimiento, hay casos donde implican violaciones a los derechos sexuales y reproductivos de las mujeres, por lo que adquiere otro cariz. No permitir el acompañamiento del varón-padre (como en el caso de Johana y Damián) o la elección de la posición para parir (como en el de Mariana y Leandro) son algunos de los ejemplos en lo que la brecha entre el deseo y lo que efectivamente pasó, tiene un significado distinto que solo el no cumplir un capricho.

A través de estos fragmentos de entrevistas quise mostrar cómo las mujeres van construyendo qué parto desean (con la influencia de los partos transmitidos por madres, hermanas, amigas, medios, etc.), cómo lo comunican y cómo lo reciben sus médicxs, y en este proceso de negociación se tensionan las posiciones asimétricas en la relación médicx-paciente. Asimismo, se pueden vislumbrar cómo se cuestionan, legitiman, exigen y negocian ciertas prácticas y representaciones sobre los PEP y su atención.

Antes de analizar los relatos de parto, dos últimos elementos sobre el itinerario asistencial y las vivencias durante el embarazo. Primero, el aspecto emocional que aparece tensionado entre el deber ser/el ideal y la realidad. Esto es, el tránsito del embarazo ha sido romantizado durante muchos años respondiendo al ideal maternal que atraviesa a las mujeres ${ }^{148}$. En este sentido, en los últimos tiempos emergieron

\footnotetext{
148 Retomo a Espinosa Pérez (2006, p. 310-311) quien sostiene que: "La maternidad ha sido eje de la construcción de los roles de género" y retoma a Martínez (s/f) quien sostiene "El ideal social de género femenino que comparte nuestra cultura occidental es el ideal maternal, en tanto la reproducción del ejercicio de la maternidad es la base de la reproducción de la situación de las mujeres y de su responsabilidad en la esfera doméstica. El hecho de que las mujeres ejerzan la maternidad es un rasgo fundamental del sistema género sexual, ya que produce una determinada ideología sobre las capacidades y la naturaleza de las mujeres y el dominio masculino. Las mujeres como esposas y madres, contribuyen a la reproducción física y psicológica de los trabajadores masculinos y maternizan a hijas que a su vez,
} 
relatos menos azucarados y más realistas sobre lo que implica poner el cuerpo durante, mínimo, dos años, para traer vida.

¿El embarazo fue la etapa soñada esa que dicen para vos?

No. No entiendo qué significa (...) Lo peor que me pasó. Es decir, me han pasado pocas cosas evidentemente pero no, no me gusta estar embarazada. Si lo pienso, no me gusta estar embarazada (...) Pesada, no podía hacer nada, paralítica (...) Me cansaba como las mejores (...) No es un estado, bueno, a esto voy de lo que me hablaba, nos hablaba mi mamá, que para ella estar embarazada era feo y el parto era horrible, viste, y ahora te digo "sí, tiene razón, tiene razón". Y recién ahora ponele hace dos meses estoy bien, físicamente, digo "bueno volví casi a ser la misma, casi". Pero si ponés en la balanza, viste, embarazo, posparto y todo lo que te queda es como, casi, fácil año y medio, dos para, año y medio, dos te lleva" (Mariana, privado).

Y en segundo lugar, los tránsitos de las mujeres y sus parejas por los cursos de preparto, a los que suelen valorar negativamente, tal como muestran los siguientes verbatims.

"[Curso de preparto] no hice, pero porque no quise hacerlo.

¿Te lo recomendó tu médico?

El me dijo “¿vas a hacer curso de preparto?”, yo le dije “¿es sumamente necesario? Yo no lo quiero hacer", y le expliqué las razones por las que no quería hacerlo que son las mismas que te estoy diciendo, porque hay que llegar más natural y menos, más relajado, algo que es del cuerpo humano y que se yo. Y me dijo "no, no es necesario, vos cuando llegue el momento del parto respirar vas a respirar normalmente, eso que aprendés a respirar es una mentira" y no, no lo hice" (Natalia y Lito, privado).

\begin{abstract}
"¿Hiciste curso de preparto?
El único que me dieron de preparto ahí en el hospital privado era, vos ibas con tu pareja, te decían todas las cosas que te iban a hacer y si ibas a cesárea que no podía entrar el marido, si hacías esto, si hacías el otro

¿Una charla un día?

Claro, eso solo fue mi curso de preparto, así que bueno (risas) no tuve mucha preparación

¿Pero fuiste con él?

Claro, fuimos con él. Después me dice "pero vinimos al pedo, al final lo único que te dijeron es que si te hacen cesárea yo no puedo entrar" [lo imita con voz quejosa] y es cierto, fue así. Fue como para hablarme de los protocolos de ellos nomás" (Sabrina, primer parto, privado).
\end{abstract}

"No me sirvió mucho. No porque lo que me sirvió fueron las tres palabras que me dijo la partera cuando empecé el trabajo de parto. Tres palabras. "Vos tenés que hacer esto, esto y esto". Así. Y me pareció como que el curso no fue muy claro, muy claro en el sentid de esa parte. La parte que vos vas a buscar. ¿Qué tengo que hacer cuando estoy pariendo? Vos vas a un curso a buscar qué tengo que hacer (...) A mí lo que me alivió más de ir es saber lo que le pasaba a las otras, a ver si yo era la extraña o si a las otras chicas les pasaba lo mismo (...) Y a Leo no le gustó por ejemplo que lo indaguen mucho" (Mariana, privado)

En mi tránsito etnográfico por los CPP (desarrollado en el capítulo 4) participé

de los que realizaron Sabrina (hospital privado) y Mariana (obra social). Es interesante la referencia a que se trata de un espacio que te aleja de lo natural, como refiere Natalia, a que solo sirve para comunicar los protocolos institucionales de atención, sin

cuando llegan a ser mujeres, ejercen la maternidad". Al respecto, son interesantes las disquisiciones de Castilla (2011) sobre el "instinto materno" y la maternidad como constitutiva de la identidad femenina. 
admitir negociación (como concluye Sabrina) y que en la práctica no les aportan herramientas concretas a las mujeres para parir. Si la responsabilidad de que la planificación de los partos falle radica en la falta de información de las mujeres (según ellas interpretan) los CPP aparecen en sus relatos como espacios que no sirvieron ni aportaron mucho y reprodujeron o potenciaron dicha desinformación. La pregunta que surge es ¿quién decide, controla y regula los contenidos de los cursos? La respuesta no incluye a Ixs decisorxs institucionales, ni organismos gubernamentales ni sociedades médicas. Los contenidos y formatos descansan en quienes los dictan. No se rinde cuenta a los equipos obstétricos ni los servicios tocoginecológicos y eso aumenta la brecha entre el curso y la atención dispensada.

Tal como se expresó en esta tesis, analizar los itinerarios asistenciales que transitan las mujeres desde y durante el embarazo, permite ir describiendo cómo es la atención obstétrica, cómo se presenta, concibe, legitima o cuestiona. De qué modos durante las 40 semanas que en promedio dura un embarazo, las mujeres van internalizando (o no) la visión médica de los PEP y la atención médica que requieren.

\subsection{B. PARIR Y RELATARLO PARA ANALIZARLO SOCIOLÓGICAMENTE}

De los 10 nacimientos referenciados en las entrevistas, 6 fueron por parto vaginal y 4 por cesárea. Los vaginales ocurrieron dos en privado, dos en público y dos en domicilio. Las cesáreas relevadas ocurrieron dos en el ámbito privado y dos en el ámbito público. Claramente esto no es representativo de las cifras generales por ciudad, provincia y país y no da cuenta de la epidemia de cesáreas que denuncia la OMS hace años (1985). De todos modos, si tomáramos esta muestra de diez casos fuera de contexto, se estaría igualmente superando el índice aconsejado de sólo 10 a $15 \%$ de cesáreas sobre el total de nacimientos.

En este marco, la búsqueda de la presente tesis es mostrar, problematizar y analizar la heterogeneidad que hoy es posible encontrar en la atención obstétrica de la ciudad. Para ello, retomaré del mejor modo posible algunos fragmentos de las relatos de los partos de sus hijxs que construyen mujeres madres y varones padres. Cuando digo "del mejor modo posible" me refiero a la dificultad intrínseca de resumir, fragmentar y analizar la narrativa de un proceso tan intenso, fluctuante, fluido, de sufrimiento, dolor, miedo y emoción, como es un nacimiento. Por esta carga y por no ser relevante a los fines de la tesis, no reproduciré los relatos en su totalidad. Iré mechando verbatims y fragmentos de entrevistas a las cuales leí y analicé a partir del marco teórico desarrollado en el primer capítulo. Este análisis se presentará en tres 
ejes: la referencia a las intervenciones médicas, el dolor y el vínculo con Ixs médicxs; la evaluación que realizan del parto y de su asistencia las mujeres; y, finalmente, algunas lecturas posibles a los diferenciales entre ámbitos y modelos de atención obstétrica. Los relatos de parto de los diez nacimientos que se (re)construyeron con las entrevistas en profundidad a mujeres madres y varones padres son extensos, intensos, viscerales, dramáticos. No incluirlos completamente y fragmentarlos es una decisión analítica a los fines de la presente tesis, por ello en este apartado retomaré sólo algunos aspectos que hacen a la atención médica de dichos procesos y a sus experiencias sobre la misma.

Un primer aspecto a destacar es el primer contacto con el/la profesional o la institución una vez desencadenado el trabajo de parto.

"Busqué en internet qué era romper bolsa. No sabíamos. Me seguía saliendo algo, yo digo "acá rompí bolsa". Lo llamé y me dijo que vaya a la clínica, ni bien llegué a la clínica estaba, no, no, o sea él me dijo "yo en un rato voy". Cuando yo llegué estaba la partera de él y me dijo "estás teniendo una contracción", me miró la panza y me dice "tenes una contracción". Y yo no entendía nada, no me dolía nada. Y cuando me hizo tacto se terminó de romper la bolsa, me dijo "bueno hoy la tenés, sí o sí, por parto natural, por cesárea o como sea porque rompiste bolsa y es un parto en seco". Me dio la orden de internación, me interné, me puse el camisón. Vino una enfermera a hacerme el goteo, porque me tenía que inducir el parto, yo no tenía contracciones. Había roto bolsa pero no tenía contracciones. Y ahí llegó el obstetra, me dijo "bueno, si vos no dilatás en dos horas, cesárea, sino bueno, vamos a tratar de que dilates" porque él sabía que yo quería parto natural y empecé a dilatar, ponele a las cuatro horas fue ahí que yo le dije "si ves que no, sácamela y ya está" porque no la quería hacer sufrir. Porque tampoco, a ver, yo quería parto natural, quería todo eso, pero tampoco por empecinarme con algo... Me dijo "no, estás dilatando re bien sino yo te lo diría", aparte él me decía "mirá, me hiciste levantar un sábado a la madrugada ahora te la bancás" me decía. Siempre él, también, muy lindo. Muy de que estaba todo bien" (Natalia y Lito, privado).

Elegí este verbatim entre los diez relatos porque incluye algunos aspectos claves. Así, por ejemplo, la búsqueda en internet de qué es romper bolsa, qué es el tapón mucoso o cada cuánto son las contracciones de trabajo de parto, aparece en varias entrevistas, revelando los diversos modos en los que Ixs sujetxs acceden a la información médica. Asimismo, Natalia narra la llegada a la clínica, que incluye una bienvenida con ciertas intervenciones de rutina y menciona con humor el contacto con el médico y la partera, y da cuenta de cómo transita estos primeros momentos.

Los relatos suelen mezclar menciones simultáneas e interconectadas a los aspectos fisiológicos del parto y a las intervenciones médicas ajenas al mismo. E dolor es un aglutinador de estos carriles, en tanto puede ser consecuencia de uno $u$ otro.

"Bueno, el día que tuve la primera contracción eran las diez de la noche, sentí como un dolor menstrual normal, para mí es re normal, a mí me duele muchísimo. Y fue como "qué raro, no me pasa hace nueve meses" (risas).Y me toqué la panza y me di 
cuenta que estaba dura y dije "es una contracción", bueno, tranqui, no pasa nada, yo hasta ese momento le tenía miedo, más allá de que yo quería todo natural y todo, tenía miedo del momento del parto, de no sentirme lista o de tener mucho dolor, y cuando tuve esa primera contracción fue como que me dio una paz, saber que iba a ser algo tan, tan familiar para mí el dolor. A mí me pusieron un monitoreo constante, me hicieron quedar acostada, el trabajo de parto se frenó ahí. Me dijeron "mirá, no estás dilatando", vino el obstetra mío, que fue la primera vez que vino, me controló él, porque me habían estado controlando todos residentes. Y vinieron no sé 4 o 5 veces me hicieron tacto

¿Esto todo la madrugada o ya estamos hablando de la mañana del otro día?

Y desde las 3 de la mañana que yo llegué ahí, hasta la 1 y 10 que nació la nena, ponele que serían las 12 y algo cuando me dijeron que yo ya no estaba haciendo bien el trabajo de parto" (Sabrina, primer parto, privado).

El devenir fisiológico del proceso de parto supone ciertas condiciones para la secreción de las hormonas necesarias para progresar. El relato de Sabrina sobre el freno de su trabajo de parto al ingresar al hospital y recibir toda esa serie de restricciones e intervenciones y someterse a las normas médicas y hospitalarias, se corresponde con lo que sucede con cualquier proceso hormonal y fisiológico como el parto: se frena ante las órdenes, la luz, la presencia de otrxs ${ }^{149}$. La culpabilización que sostiene que ella no estaba realizando correctamente el trabajo de parto es contradictoria con la serie de condiciones que la institución altera para que se despliegue la secreción de hormonas: la prohibición de moverse, los tactos a repetición y el contexto hospitalario.

Después de esta sentencia médica, Sabrina recibió la indicación de ir a cesárea y entró al quirófano llorando, como muchas de las mujeres que he conocido en este trabajo de campo. Sin embargo, la reacción a la misma indicación en Johana es diferente.

"Yo ahí ya vomitaba más, estaba re descompuesta, me dolía mucho la panza. Horrible porque no sabía qué era de todo lo que me dolía. Empecé a caminar a caminar, no podía ni acostarme ni sentarme. Me acostaba, me sentaba, me paraba, no sabía cómo ponerme. Me pusieron el goteo, me hicieron de nuevo el tacto. 2 centímetros de dilatación. Nada, nada. "Caminá". Bueno, "ya vino la doctora", ponele 7 y media de la mañana. Ella se comunicaba con la chica que me estaba atendiendo, eh y le decía "fijate, bueno hacele tal cosa, bueno hacele tal otra". Y volvió a venir a las 10 y me dice "¿caminaste?" y las enfermeras le dijeron "si, caminó", porque yo estaba tirada, no, no, no quería nada, nada. Volvió a venir a las 12 y ahí le dije "por favor, sacámelo, como sea pero sacámelo". Porque estaba muy dolorida. Y además estaba desde las 3 de la mañana, súper cansada, eso es algo que me dijo ella "mirá te clavaste en 2 centímetros de dilatación con el goteo, eh, estás muy cansada, no llegás al parto, vamos a tener que ir a cesárea". Yo dije "¡bueno!" le dije yo (riendo). No me interesaba, o sea "sacalo como sea, no sé abrime así, en 4 pedazos, no me importa". En ese momento.

¿No te pusiste mal, no te entristeciste?

¡No, no, para nada! Porque nunca, nunca lo idealicé al parto” (Johana, privado).

${ }^{149}$ Pensar en alcanzar un orgasmo o poder defecar en la guardia de un hospital, a la luz de mucha gente, son buenos ejemplos para entender este argumento. 
Es visible cómo la tolerancia y gestión del dolor son elementos claves de la narración de los trabajos de parto. Es importante, de todos modos, distinguir el dolor "natural" o fisiológico (propio del proceso) y el dolor iatrogénico (resultante de las intervenciones médicas, como el goteo con oxitocina). La gestión de los dolores también difiere tanto como sus causas: la inmovilidad o la prohibición de gemir, llorar o gritar sin dudas impiden una gestión más fisiológica del dolor ${ }^{150}$. Pero la institución tiene una solución: la oferta constante de analgesia y anestesia epidural.

"En un momento me largo a llorar y les digo que, que me dolía mucho, que hasta se me ocurrió decirles que quería una cesárea, que era más rápido y me dicen "no, mami", tienen razón, porque a la vez les dije "no, no, igual no quiero". Y ella me dice "te podemos dar la peridural", me dice. Le digo "no, no la quiero", porque no la quería realmente y me dice "pero mami si vas a estar más tranquila, te va a doler menos, confía en mí". Le digo "¿vos tenés hijos?”. "No”, me dijo. “¿Entonces cómo sabés?” le digo, y se empezaron a reír todos los médicos. "Porque estudié" me dice. Y yo los miraba porque yo no estaba riéndome, viste, para mí era re preocupante toda la situación" (Valeria, primer parto, público)

"De hecho yo recuerdo que en el parto era continuamente "¿querés la peridural? ¿querés la peridural?". "No, no, no", así. Yo me acuerdo que decía "si es este dolor me la banco" porque sinceramente el dolor son 3 segundos que te bancás, que te morís y después revivís, así, te morís y revivís.

¿En la sala de parto te ofrecían la peridural?

Sí, sí, me decían "estás a tiempo todavía". "No" les decía yo, porque yo tenía mucho pánico, ah, me habían explicado que la peridural en ese lugar te ponen una cánula y te van pasando la anestesia por cánula. O sea la cánula en la columna y te la van pasando. ¡Te dejan la cánula, vos tenés que estar sentada en la cánula! y yo dije "no, eso no me lo hacen"' (Mariana, privado).

Hay mujeres que eligen transitar sus procesos de parto de forma menos intervencionista, por distintos factores, como se ve en los dos fragmentos presentados. Las razones por las cuales se ofrece (tanto en el ámbito público como en el privado) la anestesia podrían descansar en las presiones internas de Ixs anestesiólogxs para no perder servicios/usuarixs o por la mayor dirigencia que pueden tener Ixs profesionales sobre los procesos de parto de mujeres anestesiadas. En cualquier caso, se trata de la preeminencia de necesidades e ideas médicas por sobre las de las mujeres, e, incluso por la construcción médica de las necesidades maternas. Intervenciones innecesarias que, además de aumentar los costos económicos de la atención médica, vulneran derechos.

\section{- EL QUE QUISE Y EL QUE TUVE: EVALUACIONES DE LOS PARTOS EN VOZ DE LAS MUJERES}

${ }_{150} \mathrm{Al}$ respecto, retomo a Gilligan (2017, p. 9) quien a su vez retoma a Tornquist: "Si partimos de la concepción de que las manifestaciones de las emociones son construcciones culturales, percibimos que, también en la institución hospitalaria, diferentes concepciones de dolor están en disputa (...) Sin embargo esta concepción de la dolencia en cuanto expresión sociocultural (...) no es compartida por la biomedicina, que tiende a subrayar las manifestaciones orgánicas, universaless y cuantificables..." (Tornquist, 2003,p. 423, traducción de la autora) 
Una vez analizadas algunas cuestiones aisladas que hacen a la intervención médica del parto, presentaré algunas de las evaluaciones generales que realizaron las mujeres sobre su experiencia de parto y la atención obstétrica recibida. Para ello, en primer lugar, recogí algunas evaluaciones que hicieron sobre la experiencia en general.

\begin{abstract}
"Y no sé qué explicarte... se te parte el cuerpo en dos, es como que, ya está, no sé. A mi yo me acuerdo y se me pone la piel de gallina, porque me encantó, fue algo re lindo, te juro que fue re lindo. Por eso le dije a Lito "qué tonto de que te comiste todo lo peor conmigo y te perdiste lo más lindo". Eh, sí porque a mí me encantó eso... es lo que te digo, yo me acuerdo y se me pone la piel de gallina" (Natalia y Lito, privado).
\end{abstract}

Las referencias positivas escasean, contradiciendo o yendo en la dirección opuesta a cierta lectura acrítica que se daba en los relatos. Esto es, mientras que en la mayor parte del relato no mencionaban con desagrado o cuestionamiento muchas de las intervenciones y situaciones que iban narrando, al preguntar por la totalidad del evento, la mayoría de las evaluaciones fueron negativas o, por lo menos, con críticas fundadas. La pregunta sobre la evaluación fue realizada indirectamente, ya que pregunté qué cambiarían de su experiencia, y como realicé la pregunta al finalizar la entrevista, considero que el hecho de haber recorrido puntillosamente todo el PEP, las intervenciones médicas y las relaciones con Ixs profesionales sanitarixs, generó que hubiera mayores elementos en la evaluación. Estas valoraciones negativas suelen descansar en que vinculan su experiencia con su falta de información, autoresponsabilizándose.

"Fue cesárea, bueno con ciertas excusas que en ese momento para mi eran muy válidas porque yo no tenía la información que tengo ahora y era muy chica. Fue cesárea, me dijeron que era porque estaba de cara y no dilataba y porque durante las contracciones le bajaban los latidos, que de eso yo después me di cuenta que era normal, porque bajaban y volvían a subir. Lo que pienso es que por más que yo en ese momento no lo sabía, me siento una boluda por no haber sabido que me estaban mintiendo en la cara y que el sistema se manejaba de esa manera, y yo con toda mi inocencia de que iban a buscar lo mejor para mí en vez de lo mejor para ellos. Eso es lo que a mí me duele en cuanto a mí misma. Pero yo sé que no fue culpa mía. O sea, aunque yo podría haber estado parada de otra manera si hubiera tenido la información" (Sabrina, primer parto, privado)

"Y esa es mi historia con el nene. O sea, hoy en día no tendría episiotomía, no tendría epidural y no dejaría por ahí tanto manoseo y tanta cosa que, que a mí me, me hacía, la verdad que me hacía sentir re chiquitita, re desprotegida me sentía re desprotegida. Está bien, te genera esa necesidad de estar acompañada un parto, pero me sentí re desprotegida por, primero porque me dijeron "si no te gusta mami... este es un hospital escuela" y eso me hizo sentir desprotegida" (Valeria, primer parto, público).

"Cuando terminé de parir dije "no tengo nunca más un chico si no es cesárea". Así. En el momento que te cae la ficha que estás sola ahí, porque a mí me dejaron sola, dije "nunca más, la próxima pido cesárea". Pero después siendo consciente de lo que implica la cesárea, una operación, el postoperatorio, que el posparto de tener natural no es lindo tampoco, pero bueno" (Mariana, privado). 
La soledad, la desprotección, las prácticas invasivas, el dolor iatrogénico y la (des)información médica son algunos de los elementos que aparecen en sus relatos. La información emerge como un elemento central de disputa en la atención médica de los PEP y la posibilidad o el derecho de exigir otra atención, como una herramienta desconocida o difícil de ejercer. La posición subalterna que impide u obstaculiza demandas frente al personal de salud no es algo que afecte sólo a las mujeres sino que también se da en los vínculos con los varones, tal como se visibiliza en el siguiente relato

"Damián: A mí me hubiera gustado entrar en la sala. No sé si me lo hubiera bancado finalmente pero bueno por ahí sí, porque yo me impresiono con el tema de la sangre y todo, probablemente no hubiera sido fácil. Pero me hubiera quedado del otro lado agarrándola (...). Yo igual me caliento y soy re combativo cuando me enoja la situación. Pero es como que en ese momento listo ya está, es lo que dice el médico, bueno que salga todo bien. Vamos, listo, ya está. No da para empezar a decir "no, pero quiero entrar igual", no es como que querés que salga todo bien y que viste, y mucho depende el médico, también, entonces es como que... no sé, viste, deseás que esté todo bien. Pero esas cosas las cambiaría, si fuera posible

Johana: Sí yo en un momento hasta pensé, digo bueno, por ahí si hay otro embarazo más hacerlo en otro lugar donde él pueda entrar, qué se yo. Yo, es mi doctora de toda la vida. Él me venía y me decía "no, porque a mí no me gusta". "Yo lo lamento que no te gusta, a mí me atiende desde que tiene, desde que tengo 18 años". Ella, porque yo siempre tuve un problema, ella enseguida me lo resolvió siempre.

Damián: $\mathrm{Na}$, a mí no me gustaba esa última parte sobretodo, cuando veía que no me daba información y yo no conocía nada, me parecía que me faltaba información, que no estaba, viste, a veces lees cosas en internet y qué se yo, y entonces iba y le decía "¿y esto? y tal cosa y tal otra" y se limitaba a responder eso y como... "no, va a estar todo bien, va a estar todo bien". Sí, ya sé, Dios quiera que esté todo bien, pero yo quiero saber qué pasaría si tal cosa. Tampoco no obsesivo" (Johana y Damián, privado).

\section{- DifERENCIALES DE ÁmBitos de ATENCIÓN}

Uno de los elementos que es posible analizar a partir de los relatos de Ixs entrevistadxs, es la diversidad de experiencias en los distintos ámbitos de atención. Por ejemplo la diversidad de tratos en la misma institución, la importancia del derecho a la intimidad (en público y privado), la burocratización y el pago por asistencia, y la (im)posibilidad de parir en casa por cuestiones económicas y de vivienda.

En este marco primero analizaré algunas particularidades que emergen en la atención en instituciones de salud privadas. Ya se ha mencionado en capítulos previos que en este subsector se dan ciertos privilegios vinculados a, por ejemplo, la exclusividad de la asistencia de un/a profesional (trato personalizado), aunque ese privilegio de clase conlleva muchas veces una contrapartida de dinero.

"El tipo este [el obstetra] te cobra un extra por armar el equipo, por atenderte en todo momento, todo. Un extra que nada por lo que es. La atención es sumamente superior a lo que yo vi, al lado mío pasaron embarazadas que las atendieron como vacas, peor 
(...) Sí, este médico, no sé si en todos los médicos es igual pero este médico me dijo, no me acuerdo ni cuánto era, "te cobro un plus para armarte el equipo, no con médicos que te tocan de guardia ni nada", sino él te arma un plus el equipo de él. La partera y la pediatra. "Te armo el equipo cuándo sea, cuando esté" y a disposición el día que sea" (Natalia y Lito, privado).

El cobro de diferenciados no suele ser explicitado durante las consultas prenatales y no suele quedar claro bajo qué conceptos se realiza. Algunas mujeres mencionan que eso cubriría la atención de las parteras, y otras que en realidad lo que se paga es la disponibilidad total del equipo médico. Lo relevante es que a veces dichos equipos suelen mencionar que el plus se cobra para garantizar una atención respetuosa, tal como indica la ley 25.929 de parto respetado. ¿Se paga para que garanticen derechos? ¿El dinero separa a Ixs violentadxs (atención por guardia) y a Ixs respetadxs (equipo personalizado) dentro de una institución?

En este sentido emerge como clave en los discursos de muchas entrevistadas la posibilidad de acceder a habitaciones VIP, en las que no comparten hospedaje posparto con otras mujeres. Acceder a ellas depende de la medicina prepaga con la que se cuenta o del pago particular de un monto elevado ${ }^{151}$. Otra vez, el dinero genera diferencias al interior de Ixs usuarixs del servicio privado de salud. En este caso hablaríamos de cierto privilegio en la hotelería, pero cuando el dinero hace variar la atención médica, la cuestión toma otro cariz. Así, Natalia menciona como una de las críticas a su experiencia en la clínica privada, el hecho de compartir habitación con otra mujer que se encontraba en un momento distinto del proceso de parto suyo: primero una ya puérpera, y cuando ella ya había parido, una en pleno trabajo de parto. Vincula el derecho a la intimidad como un aspecto a respetar y entabla una lectura comparativa con la atención pública.

"Me parece que tiene que ver con la concepción del parto como que es una operación o como que es algo más de la medicina y no como que es algo que es tu momento, lo tenés que disfrutar. A ver, te estoy diciendo esto, es como una chetada lo que estoy diciendo también, porque yo sé que hay hospitales que te ponen diez mujeres juntas y que parís, pero, no sé, a ese respeto voy yo. El respeto de ese momento. De ese momento que estaría genial que vos y tu pareja o el que quieras estar, que sé que en otros lugares es así..." (Natalia y Lito, privado).

Por último, además del trato personalizado y la hotelería, la posibilidad que brinda la asistencia privada de elegir, se da el privilegio de la gestión de los tiempos, tendientes a reducir las horas de espera.

"Ella me atendía en el hospital privado pero yo me estaba atendiendo en otro lugar donde ella atiende donde hay menos gente, otro consultorio ajeno del hospital. No tenés tanta espera. Yo me seguí atendiendo con ella en ese lugar y ahí ella misma tiene ahí un lugar donde te hacen la ecografía, o sea, el ecógrafo. Tiene todo.

${ }^{151}$ En mayo de 2019 la habitación VIP del sanatorio más grande la ciudad (con más nacimientos) costaba 10.000 pesos más IVA por noche. 
Entonces nos empezamos a atender ahí. Todos los controles todos lo meses" (Johana y Damián, privado).

Al analizar, por otro lado, algunas diferenciales en la atención pública, bastaría con describir la negativa de la anterior. No hay relación exclusiva con un/a obstetra, no hay posibilidad de cambiar o elegir las condiciones de hotelería ni de gestionar los tiempos de espera. Sin embargo, emergen algunas peculiaridades que son leídas en términos positivos por las mujeres: la gratuidad y el excelente nivel médico, entre otros. El caso de Sabrina es muy interesante porque atravesó el pasaje del sector privado al público y por ello pudo hacer una lectura comparativa.

"Ir a parir al hospital público, ¿te generaba algún prejuicio, algo?

No, por ahí me daba cosa la gente que andaba en el hospital. No estaba acostumbrada, más allá de que no es que soy careta, ni nada. He estado con gente de todos los palos. Pero me cruzaba con gente muy ignorante... gente que iba, no sé, con diez chicos a tener uno más y... no sé, para mí era raro, o sea, no estaba acostumbrada. Más allá de que he tenido amigos, o sea, con mucho, con poco, amigos que se criaron en la calle y todo. No estaba acostumbrada a ver ese tipo de familias. Claro, no, de los médicos no tenía ningún problema" (Sabrina, segundo parto, público)

Se destaca en este verbatim que los prejuicios o sensaciones de Sabrina se dirigen a la población usuaria del servicio público y no tanto a la atención o a Ixs profesionales que allí atienden. De hecho encuentra en la aparente desventaja de no tener obstetra de cabecera, una oportunidad.

"No, en el público te atiende el que está.

¿Y eso te generaba alguna incertidumbre o no?

No, no, me sentía tranquila de que si por ahí un doctor me decía "tal cosa no se puede", por ahí con otro sí se podía" (Sabrina, segundo parto, público)

Lo interesante es que Sabrina experimentó que no importa dónde sino cómo se pare, nace y atiende.

"No a mí no me importaba dónde fuera a parir, yo lo que quería era que me traten bien y que mi bebé nazca de la forma más natural posible, en todos los casos siempre quise lo mismo.

$Y$ en tu experiencia, ¿hubo alguna diferencia importante?

Yo me sentí mucho más tranquila y mucho más contenida yendo a una cesárea que yo ya sabía que estaba programada para ese día y siendo que todos me trataron con mucho respeto, o sea, me sentí mucho más respetada en el Hospital público que en el Hospital privado. En todo momento mientras a mí me operaban, yo tenía al anestesista al lado mío agarrándome la mano, acompañándome ahí" (Sabrina, segundo y tercer parto, público).

Por último, retomo la experiencia de Valeria quien marca una diferencia interna también en el sector público y dice que en la salita (primer nivel de atención) le responden más que en el hospital y de todos modos sostiene "yo me siento como en casa en el hospital público, en Maternidad". Agrega otra dificultad de la atención pública: que las ecografías que les dan ahí no tienen imágenes, solo informes, por eso se hacen otras de modo particular, para poder "ver" y tener la imagen, tal como 
mencioné. Por último, en su relato, articula un diferencial con el tercer ámbito posible de atención: el domicilio.

"Mi idea en realidad desde un principio era tenerlo acá en casa, pero sale 15 mil pesos y es una plata que yo tranquilamente... yo quería bueno eso, lo podría haber juntado por ahí desde un principio pero me pareció como un gasto... como si puedo ir y hacerlo gratis, está bien es otra cosa, después me puse a pensar "¿qué hago? tengo que correr la mesa, está mi abuelo", porque vive mi abuelo acá, "el nene", el nene no me molesta pero él piensa que sale por el pupo y no le voy a discutir, porque él no es que..." (Valeria, segundo parto, público).

Lo cierto es que al analizar las experiencias de las mujeres es importante contextualizarla en el ámbito de atención, que a la vez suele ser expresión de su perfil socioeconómico, de los partos transmitidos que traen (de hecho al elegir clínica $u$ hospital mencionan las experiencias de sus conocidxs), de las experiencias que construyen y cómo conciben los PEP. Esto no quiere decir que se pueda (ni se busque) esencializar las poblaciones usuarias de los distintos ámbitos de atención obstétrica. Se trata de marcar o subrayar algunas regularidades que se corroboran con relatos de partos disponibles en internet o el conocimiento adquirido en los años de trabajo de campo ${ }^{152}$.

Aunque se analizará en un apartado especial el parto domiciliario, se puede comenzar a concluir que si bien el ideal de la política de humanización implicaría que realmente no importe dónde parir, porque se estandarizaría/universalizaría una atención obstétrica respetuosa de los derechos y necesidades de las mujeres, en la actualidad existen diferencias que impactan en las experiencias de ellas y los varonespadres. Lo distintivo es que si el sentido común ha establecido que acceder a los privilegios de la atención privada podría garantizar el respeto de los deseos y derechos y buenas experiencias de atención de PEP, en la práctica hay matices, ventajas y desventajas en los distintos ámbitos.

En esta tesis, entonces, se puede corroborar que de manera paradójica no importa dónde parir: en todos los ámbitos conviven distintos modelos de atención, distintas expresiones de violencia obstétrica y las relaciones médicx-pacientes adquieren características más o menos respetuosas o asimétricas ${ }^{153}$.

Relatados y evaluados los nacimientos de los casos incluidos en esta investigación, Ixs entrevistadxs dieron detalles de su experiencia de crianza, lactancia

\footnotetext{
${ }^{152}$ Gloria Comesaña (citada por Camacaro Cuevas, 2008b, p. 100) sostiene que en la atención pública las mujeres "pagan con el dolor de sus cuerpos el pertenecer a las clases desposeiad de un país subdesarrollado".

153 Sobre diversas desigualdades que atraviesan la atención médica de los PEP y sus experiencias, he realizado una aproximación en Castrillo (2017).
} 
y cuidados en el posparto. La decisión de no extenderme en este punto responde al recorte analítico propuesto, pero sin dudas se trata de esferas de la vida profundamente medicalizadas y atravesadas por una diversidad de mandatos que suelen movilizar a las mujeres. Esta tesis se concentró en los mandatos y normatividades que atraviesan en la atención de sus PEP.

\title{
6.2.C. Ciudadanía(S) REPROductiva(S) ENTRE MODELOS OBStÉTRICOS
}

El objetivo de este apartado es ofrecer, en un nivel mayor de abstracción, nuevas vías de problematización de los casos analizados en torno a tres ejes: las relaciones médicx-paciente, los roles o tipos de pacientes (las obedientes y las rebeldes) y los grises y puentes tendibles entre dichos tipos. La pregunta que está detrás es de qué modos, las mujeres madres y los varones padres ejercen su ciudadanía reproductiva, entendida como la "capacidad de las mujeres de apropiarse, ejercer y defender sus derechos en materia de salud sexual y reproductiva" (Castro y Erviti, 2015, p. 40) ${ }^{154}$. En este sentido,

\begin{abstract}
"Una perspectiva de derechos implica la capacidad de las mujeres de apropiarse, ejercer y defender sus derechos en materia de salud sexual y reproductiva. Entre ellos se incluye su capacidad de reclamar una atención médica libre de autoritarismos y atropellos, por parte de los servicios de salud. <Al hacerlo así, se introduce en escena a las usuarias de los servicios en tanto ciudadanas, y se deja de lado la perspectiva médica que, al construirlas como pacientes, históricamente las ha ubicado en la parte más baja de un sistema jerarquizado dentro del cual han sido clasificadas ante todo como objetas pasivas de los servicios, de las que se espera ante todo su colaboración y su acatamiento a las órdenes médicas>(Castro, 2010:56)" (Magnone Aleman, 2014, p. 2).
\end{abstract}

- RELACIONES MÉdicX-PACIENTE hegemÓNICAS Y MUJERES OBJETO DE LA PRÁCTICA MÉDICA

El modo en que profesionales, mujeres-madres y varones-padres se enfrentan a un parto es diferente en muchas cosas, pero principalmente en la excepcionalidad o cotidianeidad del evento: algunas mujeres sólo parirán una vez en su vida, en cambio Ixs profesionales ven ese mismo nacimiento como uno de una serie de "nueve" en ese día (cadena de montaje). La diferencia en la óptica, naturalización, miedo y compromiso emocional es determinante. Unxs quieren terminar, otrxs no saben por dónde empezar. Unxs saben por práctica rutinaria. En el mismo sentido, para cada mujer su parto es tan único y trascendental que exigen a veces pleitesías que desconocen de coyunturas, pero lo común es escuchar que sus necesidades son más simples y se enfocan en la necesidad de contención, información y tiempo.

154 Al respecto de los estudios sobre ciudadanía, salud, sexualidad y derechos sexuales y (no) reproductivos es ineludible el trabajo de Brown (2007, 2014, 2015). 
Los relatos de partos de las mujeres madres y varones padres comienzan días previos al desencadenamiento del trabajo de parto, rotura de bolsa, dolores o la llegada de la fecha límite impuesta por el/la médicx o institución. Para Ixs profesionales el parto suele comenzar recién cuando "reciben" el trabajo de parto. De esto suelen encargarse parteras de guardia, que realizan un símil triage ${ }^{155}$ y se establece el protocolo a seguir: internación o diagnóstico de falsa alarma (y vuelta a casa). Una vez que las mujeres se internan aparece todo un itinerario de intervenciones médicas, como se viene reconstruyendo, que pueden concluir con un parto o una cesárea.

Los partos pueden ser nominados como vaginales (en relación al canal de salida), instrumentales (con ayuda de instrumentos o intervenciones, como los fórceps), naturales o respetados. La cesáreas pueden ser intraparto (decididas una vez desencadenado el trabajo de parto y todo el proceso hormonal necesario para la madre y el/la recién nacidx), programadas (por el/la médicx), electiva (programada por la mujer), innecesaria (cuando la indicación no responde a razones médicas fehacientes), inducidas (resultantes del goteo de oxitocina y la no espera del proceso de dilatación) o respetada ${ }^{156}$. La variedad de las nominaciones, producidas por distintxs actorxs del campo obstétrico en disputa, responde al foco desde el que se los define.

A partir de las entrevistas realizadas, es posible reconstruir el itinerario asistencial obstétrico de un grupo de mujeres. Principalmente puesto el énfasis en analizar las intervenciones médicas que van marcando dicha trayectoria. Entre las intervenciones analizadas, la de mayor visibilidad es la cesárea. Es la fuente de 4 de los 10 nacimientos aquí considerados. Tres de ellos corresponden a una misma mujer, Sabrina, cuya primera cesárea se volvió una condena (innecesaria, amparada en mitos obstétricos) para sus siguientes hijxs. En su relato se ve que muchas veces la cesárea no aparece como elemento de lo posible en las expectativas que las mujeres tienen del parto de sus hijxs ${ }^{157}$.

"Y, a mi cuando me dijo que si no hacia la cesárea en ese momento después me iba a tener que hacer una de urgencia, ahí me dio miedo que le pase algo a mi hija, yo no sabía, en ese momento no tenía ni la más mínima idea (...) Yo lloré, no lloré nunca en la vida como lloré ese día desde que me dieron el papel para firmar, mi mamá me dijo "bueno, hacelo, es por el bien de tu hija", qué se yo. Bueno, agarré me puse a llorar, me llevaron al quirófano llorando, entré en pánico, en el quirófano yo entré en pánico,

\footnotetext{
${ }^{155}$ Con triage me refiero a la evaluación de la gravedad de la situación de salud y de la atención médica necesaria.

${ }_{156}$ Magnone Aleman (2014, p. 6) suma la idea de la "cesarea diáctica" como aquella "realizada por necesidad del residente de ginecología para completar su aprendizaje".

157 Ya se reprodujo que la cuarta cesárea incluida en esta tesis es la de Johana quien mencionó que, justamente por "no haber idealizado el parto", no sufrió la indicación de dicha operación quirúrgica.
} 
lloraba y no podía dejar de temblar, me querían poner la anestesia y yo no, me tocaban y yo gritaba porque no, me sentía violada, esa es la palabra, sentía que me habían robado algo que yo venía planeando durante toda la vida, que era una idea de poder parir yo a mis hijos como mi abuela parió a mi mamá y a mis tías, y como mi mamá nos parió a todos. Era esa idea de que me la iban a sacar a mi hija, que no la iba a poder tener yo. Y fue, fue, una cosa terrible. Me tocaba el anestesista la espalda y yo ya gritaba como si me hubieran pinchado" (Sabrina, primer parto).

Más allá de la cesárea, que puede ser la parte más visible, existen otras intervenciones más naturalizadas que van engrosando el itinerario asistencial. Por ejemplo, el ayuno obligado y la prohibición de beber agua. Más allá de que viola la recomendación de la OMS (hecho sobre el que la ley no se expresa, pero entiendo que lo incluye la idea de evitar prácticas innecesarias), ¿cuál puede ser la razón médica o institucional? Si bien se sabe coloquialmente que en caso de recibir una anestesia, puede provocar vómitos, se trataría de una estandarización más que se adelanta a los hechos. ¿Tiene una razón médica o se vincula a la cuestión pretendidamente aséptica, pura y sagrada del parto? El vómito y la defecación, presentes en la mayoría de los partos naturales, ¿incomodan la labor médica? ¿Se prefiere la sed y la descompostura por hambre de las mujeres antes que pedir colaboración al área de limpieza de la institución? Destaco esta mínima intervención, presentada como una prohibición, porque constituye uno de los indicadores de la mala experiencia que más se menciona en las entrevistas. Lo mismo sucede con la prohibición de moverse y la soledad. Se trata de elementos que tienden a desnaturalizar y descotidianizar el proceso de parto y a quitarle poder de gestión del dolor y del proceso en sí a las mujeres.

Asimismo respecto al dolor, se asiste a una disputa de expectativas del dolor legítimo. Siendo que tanto la concepción como el tratamiento del dolor son construcciones sociales, en los distintos relatos se ve cómo las mujeres cuentan que les ofrecían, aun contra su voluntad, la administración de anestesia. De todos modos a partir de la bibliografía y mi inserción en campo, he podido constatar que el uso y administración de anestesia (sea rutinario, masivo o excepcional) es contextual y, en algún sentido, político y no necesariamente encuentra diferencias entre los ámbitos de atención. Hay mayor cantidad de testimonios de mujeres a las que se les pone anestesia, lo que las hace perder protagonismo y control de sensaciones y pujos, en el sector privado; mientras que suele mencionarse que en la asistencia pública, por falta de insumos, las mujeres no pueden acceder a la analgesia cuando lo requieren (el tristemente famoso: "si te gustó, báncatela").

Otra de las intervenciones médicas que aparecen en los relatos de las entrevistadas se vincula a la disputa sobre la (im)posición para parir. Sólo Mariana parece tener en cuenta en su planificación del parto esta cuestión y en su experiencia 
se vulnera su derecho a elegirla, y termina pariendo acostada y con las piernas atadas. Y aquí la pregunta que lleva a la reflexión es por qué parimos acostadas, o, como se sostiene desde el activismo, por qué nos acostaron para parir, denotando el ejercicio de poder que ello implica. Parimos en litotomía para mayor comodidad médica, en caso de (reproduciendo la ideología del riesgo obstétrico) necesitar practicar una cesárea de urgencia. Solo una relación de poder asimétrica podría explicar que hace 200 años nacemos y las mujeres paren yendo en contra de la ley de gravedad.

"Muchas de las dificultades obstétricas se producen porque los equipos de salud no dan la menor certeza racional a los sentidos, reprimen sus instintos y controlan las expresiones del cuerpo. La percepción sensorial de las mujeres que están en trabajo de parto y sus necesidades de movilidad corporal no son tenidas en cuenta. El poder simbólico del mandato médico es tan fuerte que la mayoría de las mujeres pierden la noción intuitiva sobre qué tipo de posiciones las favorecería" (Magnone Alemán, 2013, p.83).

Esto último también radica en cierta visión médica dominante, culturalmente internalizada, que concibe a las mujeres madres como ayudantes-colaboradoras de, primero, el/la bebé ("lo ayudan a nacer/salir") y, segundo, de Ixs profesionales de la salud, no interfiriendo para que ellxs realicen "bien" su trabajo.

Finalmente una de las intervenciones médicas más invisibilizadas se vincula a la (des)información, elemento central de disputa en el campo de la atención de los PEP. Lo que he podido advertir es que hay una distinción central entre dar información, una acción de carácter universal y estandarizado, e informar, con mayor direccionalidad personal. En esta carencia se erige la emergencia de grupos activistas en redes sociales, charlas, talleres y conferencias que, por fuera de la institucionalidad médica, trabajan difundiendo datos, derechos e información para romper con los mitos obstétricos que suelen dificultar la experiencia de partos más placenteros y respetuosos. Por ello, es lógico advertir que la información puede ser utilizada, producida y gestionada tanto para el empoderamiento como para generar mayor obediencia y sumisión al MMH. Lo cierto es que los contextos de producción de la información médica también son variables y responden a relaciones de poder, por lo que la circulación de dichos mitos tendientes a garantizar la necesidad de la intervención médica seguirá creciendo sino se inaugura un proceso de mayor democratización de dicha información.

Antes de pasar a una posible tipificación de las mujeres en las relaciones médicx-paciente obstétricas, retomo dos casos para subrayar algunos elementos de análisis. 
Valeria parió a sus dos hijos en un hospital público de la ciudad. En su relato ensambla y asimila los términos "obstetra" (médicx) con "obstétrica" (partera), dándole el mismo nivel de jerarquía a todxs Ixs que la atienden. En lo cronológico, cuenta como proeza, y para asignarle naturalidad al proceso, lo que hicieron con Santiago antes de entrar en trabajo de parto: caminar, ir, venir, subir escaleras. En su relato se ve cómo el trabajo de parto y el parto tienen que ajustarse a las normas hospitalarias y no al revés: tiene que esperar tres horas para llegar a los $4 \mathrm{~cm}$ de dilatación que le permiten la admisión en el hospital. "Vas a estar lista" le dicen quienes no le permiten el ingreso y no parece importar lo que ella siente (dolor, miedo, ansiedad, incertidumbre). Asimismo en su narración se vivencia cómo los tactos se vuelven una tortura para ella, generándole mucho dolor por la posición en la que le ponen una "chata" y su problema de espalda. Pone en juego la estrategia, propuesta por su hermana, de evitar que la toquen "los practicantes", pero al expresarlo le dicen que ese es un hospital escuela, y si no le gusta, puede retirarse. Esa es la tortura que debe soportar si quiere recibir atención: ser tocada por varixs residentes en una posición y mediante una maniobra que le genera mucho dolor, por los parámetros dominantes en el proceso de enseñanza/aprendizaje de la profesión médica, no suya ni de su proceso ${ }^{158}$. Ella sostiene que ante esto no dijo "nada", en referencia a no hacer escándalo. ¿Expresar que le duele no es suficiente? Se confirma que parirás con dolor, sea fisiológico o infringido.

Valeria es una paciente que revisa y critica las intervenciones médicas que se realizaron sobre su PEP: fórceps, kristeller, rotura de bolsa, sonda, tactos, suero y epidural. Sostiene que "se dejó en el primer parto pero ya no" (al momento de la primera entrevista estaba embarazada de su segundo hijo).

Otro momento que ella narra como de cierta disputa con Ixs profesionales es el hecho de tener que estar desnuda por la sala de internación colectiva, frente a personal sanitario y de limpieza, para ir al baño. Reflexiona que ningunx de esxs médicxs se pasearía desnudx en público, por lo que es posible vislumbrar el proceso por el cual se rebaja la categoría de persona-sujeto a la de paciente-objeto sin emociones, decoro o pudor. Se encuentra tan naturalizada esta cuestión que cuando exige ser tapada le dicen que cubrirla y dejarla orinar en privado es un privilegio o beneficio. Finalmente destaco que en los intercambios con Ixs profesionales en un momento Valeria, quien se siente incomprendida en su dolor, cuestiona si quien la ${ }^{158}$ Durante las residencias, lxs estudiantes realizan diversas prácticas en grupos numerosos y sobre las
mujeres que paren en el sistema público: tactos, episiotomías, suturas, fórceps, etc. 
dirige es madre, disputando entonces si la fuente del saber o conocimiento autorizado proviene del estudio o de la experiencia.

A modo de ejemplo de un caso que ocurre en el sector privado retomo algunos elementos claves de la experiencia de Johana. En primer lugar es interesante que su mayor inquietud durante el embarazo era que no contaba con el número telefónico de la doctora, para contactarla al momento del desencadenamiento del trabajo de parto. Esto remite a las desigualdades de clase propias de nuestra sociedad en tanto la atención exclusiva de un/a profesional es un elemento que no se da en el ámbito de la salud pública. ¿Se trata de un privilegio de clase o, por el contrario, implica una mayor dependencia en la relación médicx-paciente? Aquí vuelvo a postular lo que he desarrollado en el marco conceptual: si la atención estandarizada fuera humanizada y respetuosa de los derechos y necesidades de las mujeres, no sería necesario contar con un/a profesional personalizadx.

El caso de Johana y Damián también resultó diferencial en tanto en la planificación del parto, realizan consultas en torno al costo y cobro de prácticas. No aparece en su relato la dimensión de los deseos y derechos, y durante la entrevista emerge la crítica al control de la información que realizó la obstetra y que no les permitió conocer alternativas. De hecho ella quería tramitar de antemano la analgesia peridural sin saber si la iba a necesitar, reproduciendo de algún modo la antelación médica y la necesidad de control. De hecho sostienen que se entregaron al parto y "que sea lo que sea", no exigieron nada particular y en realidad parece ser que se entregaron a la discrecionalidad médica de su profesional de cabecera. La narración de cómo vive el trabajo de parto en su cuerpo es súper intensa: descompuesta, dolorida, sin saber qué hacer. La falta de guía se incrementa con que a modo de orden o consejo su doctora le indica caminar, por intermedio de una profesional de menor rango y por vía telefónica. Cuando aparece evalúa la obediencia de la paciente a sus órdenes (“¿caminaste?”) sin interrogar sus necesidades y deseos. Johana cuenta que después de nueve horas de trabajo de parto termina pidiéndole a la obstetra "sacámelo". Se confunde en el relato porque después menciona que fue la obstetra quien le dijo que "estás muy cansada, no llegás a parto, vamos a cesárea" y ella aceptó. ¿Ella pidió la cesárea pero la doctora se arroga la decisión o fue una indicación médica pero ella la aceptó de tal modo que en su discurso parece que ella misma la pidió?

Finalmente su caso permite analizar cuestiones en torno a la cesárea. Primero, el hecho de que la atravesó sola y no sintió "nada", aunque esperaba sentir algo. 
Cuando en la entrevista Damián reflexiona sobre las cesáreas por negocio, ella se apura a justificar que la suya "fue a último momento" y que la doctora le dijo "yo intenté esperar lo más que pude". La mención a la decisión médica en primera persona no es casual: la decisión no parece contemplar a la parturienta. Por último, aún sin haber planificado un/a segundx hijx, esta cesárea la condena: ya internalizó la sentencia médica mítica de la imposibilidad de un parto vaginal después de cesárea. La epidemia de cesáreas, entonces, emerge como la marca o herida médica en los úteros de la sociedad.

\section{- MuJERES, PACIENTES, OBEDIENTES Y REBELDES ${ }^{159}$}

En los casos analizados, pocos pero profundos, es posible discriminar actitudes, roles y prácticas de las mujeres que permitirían ubicarlas (solo analíticamente y no de modo exhaustivo ni excluyente) en dos tipos de paciente: obedientes o rebeldes. Esto es, ante la indicación/intervención médica hay acciones de obediencia o estrategias de resistencia, activas o sutiles. Al respecto, es imposible no retomar algunos de los aportes de Magnone Aleman en relación a cómo se produce y asegura la obediencia (o la rebeldía) a estos mandatos médicos.

"El poder simbólico que detenta el campo médico en nuestra sociedad hace que tanto dominantes como dominados compartan la creencia de que en el marco de una buena atención es necesario entregarse a los mandatos médicos sin cuestionar al detentor de ese saber específico" (Magnone Aleman, 2011, p. 12).

"En términos de tendencias sociales, en vez de apoyar el asombroso proceso humano de parir lo estamos sustituyendo por el poder de la medicina y la tecnología de anestesiar, cortar, sacar y coser. En este escenario se requiere de cuerpos obedientes que se sometan a una racionalidad superior, en donde no existe la posibilidad de integrar el saber racional con el saber instintivo y corporal" (Magnone Aleman, 2013, p. 90).

Uno de los primeros elementos que vislumbré que hacen a la "obediencia" es que al acatar y legitimar las normas institucionales médicas, se acatan, legitiman y esperan las sanciones ante los comportamientos que las cuestionan. En otras palabras, son constantes las referencias a "me dolía pero no daba decir nada", "no iba a hacer escándalo", "debe ser así el modo de trabajo". Aunque reconozcan, perciban o intuyan que la atención, Ixs profesionales o la institución está siendo deficitaria o vulnerando derechos, no quieren pagar el costo, socialmente internalizado, de quejarse.

\footnotetext{
${ }^{159}$ Considero importante señalar que esta es una construcción analítica propia y no tiene que ver con las representaciones que lxs profesionales médicxs hacen de las mujeres. Lo que la mayoría de los trabajos han encontrado (con centralidad en el de Erviti, 2010) es que dichos profesionales suelen nominar a estas mujeres que aquí pienso como "rebeldes" en términos de "no cooperadoras" o "desobedientes".
} 
Junto a dicha internalización, es evidente cómo se ha admitido y aceptado el lenguaje médico (con diminutivos para mencionar ciertas intervenciones), la concepción del riesgo reproductivo, la masificación de mitos obstétricos, la condena de la primera cesárea por ejemplo, y, principalmente, la predominancia de una sociedad desconectada, controladora, previsora y acartonada. En la era de la pastilla y de la inmediatez, se ha extendido la idea de "no sentir nada" durante el nacimiento de Ixs hijxs, el miedo al dolor, la evitación de la experiencia y la desconfianza en el cuerpo. Si hemos internalizado la condena del "parirás con dolor" en el universo simbólico de los partos transmitidos por la familia, Ixs amigxs, las películas, y si le tenemos miedo a dicho posible sufrimiento, la obediencia al mandato y la tecnología médico-científica parece ser la solución más viable.

En este sentido la demanda de cesáreas electivas por parte de las mujeres que han recibido relatos trágicos y dramáticos de los nacimientos (funcionales al $\mathrm{MMH}$ y al "parirás con dolor") está más presente en las clases medias y medias altas, en vínculo con las posibilidades de atención privada y cierta interseccionalidad en las socializaciones de clase y género. Las mujeres de clases populares están influidas mayormente por partos transmitidos vaginales, coincidentes con los índices obstétricos de la atención pública, y por la necesidad de recuperación rápida y cierta docilidad de los cuerpos para la reincorporación al trabajo. Emerge entonces que la clase impone los privilegios de descanso, licencia, contratos en blanco, por lo que las mujeres de sectores más bajos no suelen contar con estos márgenes de maniobra. Así, en los relatos es posible advertir ciertas estrías de clase (Marton y Echazu, 2010) que marcan sus experiencias, las relaciones médicx-pacientes que entablan y los modos de significar y transmitir esas experiencias

"Obedecer", entonces, puede ser resultado de la internalización de los mandatos e ideas presentes en el $\mathrm{MMH}$ y las dificultades para cuestionar e impugnar al menos algunos elementos o ejes centrales de la perspectiva médica. Obediencia por desinformación, como narra Sabrina:

"Dentro de todo, yo creo que si no hubiera tenido nadie presionándome y hubiera tenido la información que tengo en este momento, yo agarraba y le decía "tengo 3 de dilatación, me voy a mi casa", entendés, y volvía ya cuando sintiera que se me estaba por salir. Pero bueno, en ese momento no tenía la misma información. Tenía bastante información pero no tenía la información más específica. No tenía la información por ahí de ciertas cosas que te dicen y que no son en realidad. Yo no sabía que con 3 de dilatación no era necesario que te internen, no sabía que podía estar lo más tranquila haciendo el trabajo de parto en mi casa y que no le iba a pasar nada a mi bebé, ese tipo de cosas no estaba informada, no había encontrado ese tipo de información, son cosas que yo aprendí después" (Sabrina, primer parto). 
Si la obediencia se asienta, entre otras cosas, en el hecho de no contar con cierta información, no democratizada por los sectores de poder médicos, no es elegida o asumida sino consecuencia de diversos mecanismos de poder. En este sentido, al iniciar un proceso de desconstrucción, las mujeres comienzan a rebelarse contra el $\mathrm{MMH}$, a partir de diversas estrategias.

Por otro lado y sólo respondiendo a una construcción analítica maniquea y arbitraria, advertí que frente a las que obedecen, legitiman o no cuestionan, algunas mujeres adquieren actitudes "rebeldes" en la relación médicx-paciente ${ }^{160}$. Esto es, en otros relatos aparecen detalladas algunas válvulas de escape a la dominancia de un modelo que interpretan como intervencionista y ajeno a un proceso fisiológico y natural. Probablemente la mayor y más literal válvula de escape sea el parto domiciliario, sobre el que me detendré unos apartados más adelante. Pero en estos relatos de partos institucionales, se mencionan ciertos espacios de autonomía para tener partos respetados o acceder a una atención que tenga en cuenta sus deseos y necesidades ${ }^{161}$. Así, por ejemplo, refieren atravesar el trabajo de parto en el hogar; cambiar las fechas de última menstruación para que en el cálculo de la fecha probable de parto se retrase y se acerque más a la semana 40, 41 o 42 de gestación; y decir que sienten las piernas (o sea, que se ha ido el efecto de la anestesia epidural postcesárea) para poder tener a Ixs bebxs en la habitación con ellas. Estas estrategias permitirían cierto autocontrol o autogestión de los tiempos, porque el tiempo y la información emergen como dos de los capitales de disputa centrales en la atención obstétrica. Asimismo, asumirse como "la rebelde" o "la loca" en muchos casos las empodera y exige a las instituciones y Ixs profesionales a ceder algunas prerrogativas: dejar que entre el/la acompañante a sala de parto, esperar para cortar el cordón umbilical, etc.

En este sentido, por ejemplo, Mariana menciona críticamente que lo que no le gustó es "que la dirigieran" y que, según le contó una enfermera, se mostró rebelde y hasta dio órdenes:

\footnotetext{
160 "Se advierte que la mujer pierde su lugar de ciudadana, dado que se produce el desvanecimiento del lugar de sujeto de derechos, quedándose sin voz. La paciente reclama y exige, pero los efectores de salud desoyen sus requerimientos, que además se ajustan a lo que debería ser la actuación efectiva de los médicos/as y enfermeros/as. Se produce una dialéctica que Cháneton y Oberti (2003) conceptualizan como un yo frente a un plural. El yo de la mujer embarazada frente al plural de la corporación médica y sus preceptos institucionalizados que conciben el cuerpo femenino como posesión, como cuerpo dócil y disciplinado" (Colanzi, 2014, p. 11)

${ }^{161}$ Es importante, de todos modos, recordar que, como sostiene Felitti, el mandato del parirás con dolor fue ejemplificador para todas las mujeres que se rebelaron y fueron tras su deseo.“'Multiplicaré los sufrimientos de tus embarazos; darás a luz a tus hijos con dolor. Sentirás atracción por tu marido y él te Dominará' (Génesis, 3:16) fue el castigo a Eva por su desobediencia y en ella, a todas las féminas" (Felitti, 2011a, p. 115).
} 
"Me quedo con la enfermera, yo estaba ahí sola y me empezó a charlar de su vida y en un momento se reía y me dice "¿sabés de qué me río?", me dice, "es la primera vez que yo veo un parto así". Le digo "¿por qué?". Me dice "nunca la paciente le da órdenes a los médicos y vos les dabas órdenes". Y le digo "¿qué? no sé". "Sí, hasta me pegaste una patada y me acomodaste el hombro, yo tenía un dolor de hombro bárbaro y me pegaste una patada". No sé en qué momento, seguramente cuando me ataron. "Me pegaste una patada acá y ahora no me duele más". Tal vez por ahí me lo decía para distender, pero, bueno... Lo que yo recuerdo es que cuando me venía la contracción le decía "ahora" como que estén atentas y hacia la fuerza; y después paraba. Ella me decía que esa orden de hacer la fuerza generalmente te la dan ellas, que ellas te ordenan hacer la fuerza. Y yo aparentemente hacía al revés" (Mariana, privado).

Según rememora, ella gestionó algunas situaciones de dolor y hasta sintió que le hacía bien empujar a la beba con sus manos para ayudarla a descender en el canal de parto. Este hecho en el que ella interviene/acompaña su proceso, fue sancionado por Ixs profesionales en sala de parto, y ella hizo caso omiso.

Asimismo en su relato refiere que en su transcurso ella pudo ver que es un proceso eminentemente animal, en el que se fue guiando por su intuición sobre cómo ir transitando los dolores ${ }^{162}$. En este punto me pregunto si no será que algunas mujeres adjetivan sus partos como "animales" porque los partos humanos se han convertido en institucionalizados, medicalizados e intervenidos, cuasi animaladas. El punto de tensión entre naturaleza y cultura representa cierta encerrona: criticar la mamiferización de las mujeres y de los PEP es también necesario desde la sociología de la atención médica de embarazos y partos que propongo, en tanto se trata de hechos sociales, culturales e históricos.

Sabrina, en el recuento de cada uno de sus tres partos, valora la importancia de los procesos de aprendizaje e información para zanjar violaciones a derechos, en un constante proceso de construcción de empoderamiento y autonomía, aun cuando eso implicó enfrentarse a su madre, a quien define como pro-sistema.

"Estaba mi mamá en ese momento y vino el médico y me dijo adelante de ella que
debía ir a cesárea. Ella me miró como diciendo "si no aceptás sos una hija de puta, es
lo que tenés que hacer por tu hija". Por más que hubiera estado informada en ese
momento y hubiera querido discutirle al doctor o no sé, tratar de que las cosas sean
de otra manera, si mi mamá hubiera estado ahí, hubiera terminado en cesárea igual.
Es así porque mi mamá es muy del sistema. Si viene el médico y le dice "si no te
sacás un ojo te vas a morir", por más que no tenga nada en el ojo, ella va para que se
lo saquen" (Sabrina, primer parto, privado). Lo que emerge en los relatos de "las rebeldes" es que muchas veces piden que se tengan en cuenta sus particularidades frente a la estandarización médica y exponen las brechas entre los partos planificados y los partos reales. De todos modos, aunque

${ }_{162}$ Magnone Aleman sostiene que "el sistema pasa por alto el dolor y pretende cuerpos dóciles esperando ser intervenidos. El poder simbólico del mandato médico es tan fuerte que la mayoría de las mujeres pierden la noción intuitiva de qué tipo de posiciones las favorecerían en el trabajo de parto y parto" (2011, p. 10). 
se rebelen en pequeñas cosas, no dejan de estar sometidas a normas médicas e institucionales por lo que mencionan reajustes constantes a la normatividad.

Se trata, entonces, de prácticas que se entrecruzan más que polos o modelos de pacientes. Por ello, aunque presenté a "la obediente" y "la rebelde", son solo categorizaciones analíticas, ya que en lo concreto se visibilizan una serie de cruces y tensiones. Cada mujer asume en sí misma actitudes más obedientes y más rebeldes frente a distintos hechos e indicaciones. Es interesante que en todos los casos "en las explicaciones y relatos que las mujeres hacen de su salud reproductiva, en general utilizan el lenguaje médico (simplificado) es decir, toman ese set de procedimientos y explicaciones como el legítimo y lo usan como propio" (Sadler, 2003, p. 101).

"Las mujeres internalizan en mayor o menor medida las normas impuestas como naturales y las aceptan, pasando a ser cómplices de su propia subordinación. En este contexto, son muy pocas las mujeres que cuentan con las herramientas para reaccionar a la imposición del conocimiento biomédico durante la atención, e incluso teniéndolas, muchas veces no se atreven a opinar o intervenir en el curso de los eventos por temor a las represalias" (Sadler, 2004, p. 29).

Por ejemplo, Sabrina aparece como una "paciente" hiperinformada, cuyo uso del lenguaje la posiciona en otro nivel de conocimientos, al hablar de las técnicas específicas y hasta las recomendaciones de los organismos internacionales. En el mismo sentido, en ella convive una expresión de pluralismo médico muy interesante, ya que en su último embarazo, a partir de la pérdida de dos previos, aplica un excesivo uso de la tecnología "para ver si está todo bien" con el bebé. Hay partes de su relato donde la fuente ineludible de certezas es su sentir y su intuición y en otros casos recurre a la invasión de la tecnomedicina. Parece ser que, si bien, el paradigma médico del cuerpo defectuoso no afectó su visión acerca de la posibilidad de parir, no surtió el mismo efecto en su capacidad de gestar. Por último, en su caso, durante la entrevista noté que el niño tenía un collarcito de ámbar, que ella me explicó que sirve para tratar procesos inflamatorios, como la salida de los dientes. Los grises develan la imbricación de distintos saberes y yuxtaposiciones elásticas en relación a situaciones diferentes, que combinan aproximaciones biomédicas y aproximaciones alternativas. Por ejemplo, aunque hiper-estudió a su bebé durante el proceso de embarazo, ahora apela a un instrumento no biomédico para la cura de padecimientos.

En paralelo, por ejemplo, aunque es aparentemente "rebelde", Valeria justifica el no acompañamiento de varones en la internación posparto, porque sostiene que puede ser "peligroso" y potencia así la feminización de los cuidados. 
He podido advertir en mi extenso trabajo de campo que el nivel de tolerancia, obediencia o rebeldía al intervencionismo médico suele estar determinado por la paridad (si las mujeres son primerizas o ya madres), las condiciones en las que se dio el embarazo (si fue buscado, si se consiguió por fertilización ${ }^{163}$ ), si hubo anteriores pérdidas de embarazo (lo que suele producir una internalización de la idea de cuerpo defectuoso), el nivel de contacto con la medicina biomédica, entre otros. Lo interesante es que en un mismo nacimiento es posible ver vestigios de obediencia y de rebeldía, de legitimidad y cuestionamiento, lo que marca que estamos frente a un proceso de transición entre modelos, que el MMH comienza a hacer más visibles sus grietas ${ }^{164} \mathrm{y}$ es por ellas que pueden colarse los espacios de autonomía de las mujeres para conseguir parir como desean. Al respecto, Mitjavila (1998) sostiene que

"el poder de la medicina para colonizar la vida social suele experimentar tanto la simultaneidad como la alternancia de los componentes legitimidad y dependencia, tratándose de configuraciones variables de acuerdo a los contextos involucrados. Cada una de esas situaciones proporciona condiciones favorables para los procesos medicalizadores aunque impliquen estrategias y alcances diferenciados. La autoridad implicaría pues, una relación de tensión entre dependencia y legitimidad" (p. 33).

En el hallazgo de estos puentes y entrecruzamientos entre obediencia y rebeldía, o dependencia y legitimidad, o más aún, entre tipologías y modelos alrededor de la atención médica obstétrica descansa el aporte de la presente tesis.

En este sub-apartado se buscó mostrar distintas formas que asumen los ejercicios de ciudadanía reproductiva de mujeres madres. Al vincular las experiencias concretas de atención y relación con profesionales e instituciones sanitarias con derechos ciudadanos, es posible advertir la lectura sociológica del proceso y de la atención médica de los PEP. En tal sentido, comparto la conclusión a la que arriban Gainza et al (2013), respecto a la "ciudadanía empobrecida" como el modelo al que responden las prácticas obstétricas:

${ }_{163}$ He advertido que aquellas mujeres y varones que consiguieron concebir a partir de tecnologías reproductivas tienen, por un lado, mayor confianza en la técnica médica y, por otro, mayor necesidad de control médico del nacimiento, por lo alejado que estuvo todo el proceso del devenir fisiológico o natural, y por el miedo de perderlo.

164 Tal como estableció Menéndez, el MMH está en crisis desde los 60, aunque rearticula constantemente su hegemonía. Laplacette y Vignau (2008, p. 59) retoman la argumentación de Belmartino al respecto: "Cinco son los rasgos que intervienen en la crisis del modelo médico hegemónico: 1) Tiene una concepción de la salud individual y biológica, descontextualizada social e históricamente. 2) Es un modelo tecnocrático fundado en la idea de que el desarrollo científico y tecnológico conduce al bienestar, que en los hechos se traduce en un monopolio del saber que utiliza un lenguaje definido previamente como científico, lo que produce relaciones asimétricas y pasividad en las personas. 3) Es medicalizante, ya que la medicina invade la totalidad de las prácticas sociales y refuerza su función de control al definir la desviación como enfermedad. 4) Aumenta la iatrogenia, con consecuencias sociales correlativas. 5) No es igualitario, ya que el acceso a las prácticas en condiciones de excelencia está asociado a la disponibilidad de tecnología, a la cual no acceden no sólo importantes conjuntos sociales, sino también profesionales médicos que no cuentan con las posibilidades de disponer de los recursos ni de las especializaciones (Belmartino, 1987)”. 
"Las mujeres - independientemente de su situación socioeconómica, nivel educativo, etc. - no son concebidas como ciudadanas con derechos plenos, ya que su libertad reproductiva y su capacidad de experimentar los partos en función de sus cuerpos y sexualidades no son tomadas en cuenta. El sistema de salud decide por ellas, no se les informa ni se les pregunta sobre las intervenciones realizadas sobre sus propios cuerpos. No se les permite practicar una ciudadanía activa que implique el reconocimiento de otras opciones, como, por ejemplo, respecto de las alternativas que hay para la realización de un parto, la reivindicación de la diversidad y la subjetividad, la confianza en las decisiones de cada una estrictamente relacionadas con sus propias necesidades y trayectorias de vida" (p. 190).

En lo general, en este primer apartado del capítulo se analizaron las experiencias, representaciones, sentidos y prácticas que un grupo de mujeres madres (re)producen alrededor de sus embarazos y partos. A continuación desarrollaré las particulares representaciones de los sujetos, partícipes necesarios del proceso perinatal que, sin embargo, han sido históricamente relegados: los varones-padres.

\section{3. ACOMPAÑAR: EXPERIENCIAS DE VARONES-PADRES.}

He establecido, en la construcción de los antecedentes y el área de vacancia de la presente tesis, que era un interés central incluir a los varones-padres en los estudios sobre la atención médica de los PEP. En este sentido, he realizado entrevistas duales (cuyas características principales desarrollé en el capítulo metodológico) y tanto a través de sus reflexiones como de las de sus compañeras he podido establecer algunas regularidades y particularidades en sus experiencias.

El contexto en el que problematizo dichas experiencias es en el de cierta crisis en los modelos tradicionales de paternidad, lo que Castilla (2011) ha caracterizado como "un nuevo mapa vincular entre hombres/mujeres, madres/padres" (p. 261) vinculado a los cambios socioeconómicos instaurados en los setenta. Esto es, las paternidades hegemónicas se vinculan al modelo de masculinidad hegemónica de no afectividad y la institución médica se comporta como un dispositivo central en su reproducción y en la instauración de roles específicos (y estereotipados) masculinos y femeninos ${ }^{165}$. De este modo, por ejemplo, la feminización de los cuidados en la internación puerperal, supone que los varones-padres desconocen qué hacer 0 prefieren no involucrarse en las primeras horas de Ixs recién nacidxs. Las licencias por

\footnotetext{
165 Sadler lo explica así: "Las identidades masculinas se ordenan en relaciones de dominio y/o de subordinación con referencia al modelo hegemónico, como plantea Connell (1995). En el modelo de masculinidad hegemónica los varones son por lo general descritos como seres promiscuos, sexualmente agresivos, arriesgados, descomprometidos con su propio entorno reproductivo, privados repetidamente de la libre y espontánea expresión de sus sentimientos de felicidad, angustia, dolor o miedo y del establecimiento de relaciones afectivamente cercanas y comprometidas con los demás (Amuchastegui 1996). Por ejemplo, el padre descrito en el contexto del patriarcado es un hombre distante emocionalmente de sus hijos/as, quien supone que la crianza y cuidado de éstos/as es tarea y responsabilidad femenina” (Sadler, 2007, p. 439).
} 
paternidad (de entre 2 y 15 días para los trabajadores formales) potencian esta construcción simbólica del padre proveedor, desconectada de los cuidados y sin deseo de participar.

"Se registra la emergencia de un nuevo mandato moral que se resume en dos grandes demandas: diálogo horizontal entre padres e hijos / as y mayor participación del padre en la crianza de los hijos. Estos cambios en los mandatos del padre se relacionan con las tensiones y transformaciones en el ámbito económico, social y cultural que caracterizan el pasaje de las sociedades jerárquicas hacia las modernas. Así, la paternidad, al mismo tiempo que un eje en la vida de los varones, es un campo donde se redefine la identidad masculina hegemónica" (Fuller, 2000, p. 430 en De Keijzer, 2001, p. 12).

En los relatos de parto, la totalidad de las mujeres entrevistadas mencionó que en sus propios nacimientos sus padres no estuvieron presentes, ya sea porque "no se usaba", "no se podía", "ni lo pensaban". Parece ser que estamos ante un cambio generacional porque sus compañeros, novios o esposos sí desean, piensan y pueden (tal como establece la ley de parto respetado) entrar y participar en los nacimientos de sus hijxs, sea parto vaginal o cesárea. De todos modos su participación no se reduce a la presencia física, sino que implica acuerdos y desacuerdos con las mujeres madres sobre la relación médicx-paciente, la información necesaria para adquirir seguridad para transitar el proceso, las mejores instituciones y formas de transitar y abordar el PEP. Al final de cuenta "mi cuerpo, mi decisión" termina determinando qué opinión prima. Porque lo que he advertido es que muchas veces hay tensiones internas en la pareja sobre la tendencia más intervencionista o más fisiológica con la que abordan y buscan atender su proceso. $Y$ muchas veces sus compañeros y sus familias (re)producen y refuerzan los mandatos del $\mathrm{MMH}$, por ejemplo reforzando la importancia del feto en el binomio madre/hijx ("lo importante es que el/la nenx esté bien"), invisibilizando las experiencias, emociones y vivencias de las protagonistas del proceso. Autorxs como Erviti (2010) van más allá y señalan que los varones-padres pueden ser "cómplices" de Ixs profesionales hegemónicxs.

"La presencia del varón, desde su posición de dominio en la pareja, se construye como el trasmisor de las órdenes del médico y controlador de la mujer, y desde esta visión, colabora también en la expropiación del protagonismo de la mujer y en la minimización de su participación: "lo único que tienes que hacer es colaborar". La entrada del varón se construye como una forma de complicidad con el médico para controlar a la mujer" (p. 17).

En paralelo, la autora sostiene que dicha conceptualización responde a un "orden corporal hegemónico" que ha producido que "socialmente los varones sean conceptualizados como agentes que obstaculizan o facilitan la atención pero no como agentes co-activos, corresponsales y copartícipes en la misma" (Erviti, 2010, p. 19). Al respecto, en mi caso de estudio, ya he mencionado en algunas citas del capítulo 3 
sobre la idea de "maternidad centrada en la familia", que entre varixs profesionales es dominante la idea de que no hay condiciones edilicias para el acompañamiento, y que los varones-padres entorpecen el trabajo, por lo que se podría concluir que también son vulnerados sus derechos en la atención perinatal. La pregunta es si, en lugar de Ixs residentes $u$ otrxs profesionales, no debería ser prioridad que ingresara a quirófano o sala de parto el padre, ya que se trata del nacimiento de su hijx. El protagonismo del evento, cuando se viola este derecho, vuelve a enfocarse en las necesidades de la institución médica y Ixs profesionales formadxs y en formación. La propuesta de este apartado es iluminar, justamente, la experiencia de estos sujetos apartados y problematizarla a la luz de lo que se viene desarrollando en la tesis.

"La manera en que se permite la participación del padre varía entre los hospitales, y hay servicios donde aún no es permitida. En la gran mayoría de los casos en que participa, lo hace sólo en el período expulsivo del parto. Aunque sea un breve momento, y sólo la culminación de un proceso, en los testimonios de los varones comprobamos que esta participación produce fuertes cuestionamientos en sus definiciones de lo que significa ser hombre y ser padre. Diversos relatos de padres apuntan a un reconocimiento de que los hombres también se emocionan, y podemos agregar, también se pueden emocionar. El parto es un momento tan impresionante, que los autoriza para demostrar sus emociones; este permiso para expresarse, que se contradice con las definiciones de la masculinidad hegemónica, los lleva en ocasiones a reflexionar sobre su relación con su mujer e hijos/as" (Sadler, 2004, p. 13-14)

Sobre la participación durante el embarazo y el control prenatal, se advierte que el hecho de ser un espectador secundario aporta características especiales. Así, con Damián, compañero de Johana, hemos podido reflexionar sobre distintos momentos de su participación en el proceso perinatal y el modo de conectarse con su hijo durante la gestación, con el diferencial de no poner el cuerpo.

"Es una cosa que no es tan física y esas participaciones que vos mínimas, por más mínimas que sean, estar dos minutitos en la ecografía y qué se yo, te

Te conectan

Son fundamentales, yo trataba de ir. Creo que no perdí ninguna, o no sé, por ahí alguna consulta (...) En realidad para nosotros es como que, digamos, durante gran parte del tiempo que vos estás en tu laburo haciendo tus cosas es como que, nada, viste. Yo veía y venia para acá y ver el embarazo y más que nada después cuando se empezó a mover" (Damián)

Así, en los relatos del embarazo he advertido que algunos varones aportan presencia y acompañamiento, a modo de una participación pasiva y que otros asumen roles de cuestionamiento a Ixs profesionales por ejemplo, o de dirigencia a partir de sus propios saberes biomédicos. Al respecto dos casos paradigmáticos. Primero Leandro, quien, por su profesión de bioquímico, no sólo confirmó el embarazo en su propio laboratorio sino que, a entender de su pareja, "participó por demás en el embarazo". No tanto por presenciar los CPN (por tema de horarios sólo presenció un 
par de consultas y ecografías) sino por el "control" que ejercía en su casa sobre estilos de vida y estudios que él consideraba que ella debía cumplimentar.

"Me volvió loca, loca, loca, todos los nueve meses loca porque él al saber (...) Me quería meter adentro de una burbuja pero porque él es así, yo siempre les decía, le explicaba a la gente que no entendía su obsesión: al estudiar bioquímica, él sabe tantas cosas que te pueden pasar, que está sobreinformado y viste, no le tenés que dar bola pero bueno él sí le daba bola" (Mariana y Leandro, privado).

Por su parte Damián que sí tuvo asistencia perfecta a las consultas prenatales, presenta (en la entrevista) una disputa constante con la información que les daba (o no) la obstetra.

"Yo me daba cuenta de que en realidad había que ir a preguntarle. Yo no tenía nada de información y cada vez que leía algo o me enteraba por alguien que escuchaba qué se yo, iba y le preguntaba. Entonces quedaba más como el que interrogaba más era yo, ella en general no preguntaba mucho, pero a mí me pasa eso. Que era corto al tema, porque yo tampoco me imaginaba cómo iba a ser la situación, si iba a poder presenciarlo yo, si no, cómo, en qué modalidad tenía el hospital. Y nunca nos dijo nada de todo eso" (Damián).

He mencionado que esta cuestión no fue valorada negativamente por Johana, tal vez porque por los partos transmitidos que "traía", es decir, por las experiencias de sus amigxs y familiares, sabía todo lo que ella consideraba que tenía que saber, así que no notaba esta carencia.

Lo que sí queda claro respecto al rol de las varones-padres durante el embarazo, es que la instancia de la ecografía es central para ellos en tanto les permite ver/espiar/corroborar mediante la tecnología médica, lo que las mujeres sienten en su propio cuerpo todos los días.

De todos modos, los relatos de las experiencias de los varones en la atención médica de los PEP se centran más en el momento del parto y el contacto con su hijx. Aquí aparece cierto rasgo general: la ansiedad, el miedo y la incertidumbre que los lleva a ser ellos, muchas veces, los que deciden durante el trabajo de parto, tomar contacto con Ixs profesionales o la institución.

"Si no era por Leo, yo lo tenía en mi casa, por ejemplo. Porque para mí eso no era trabajo de parto lo que tenía (...) Leandro me dijo "no, nos vamos". Yo no quería, no quería ir porque no quería sufrir el viaje desde allá hasta acá otra vez porque me hacía mal. Y "no, esto no es", yo estaba con que esto no era, porque uno piensa en las novelas, en las películas, viste que se descosen ahí del dolor, y yo "no, esto no es"(...) Al entrar al hospital a mí me dejaron sola con una enfermera y ella. A Leo enseguida lo mandaron a hacer papeles, lo volaron, a hacer papeles, a traer la ropita del bebé" (Mariana, privado)

"Rompí bolsa, le avisé a Lito, Lito estaba re asustado, yo no, yo estaba re contenta, no sé cómo explicarte, como que yo estaba segura de que iba a ser algo lindo (...) Me dijo "déjate de joder, basta de peinarte, no vas a una fiesta" (...) él quería ir ya" (Natalia y Lito, privado) 
En paralelo, Valeria también relató que su marido fue quien le insistió por ir al hospital. A él le dicen que se vaya y ella queda internada sola, entonces él cuenta que se fue porque le dijeron que faltaban como 5 horas y que "sí, sí, estaba re asustado, más cuando me llamaron me volví loco", porque finalmente su hijo nació media hora después de que él se fue a descansar, siguiendo el consejo/indicación médica. "No, llegué transformado. ¿Sabés cómo empecé a buscar la doctora que me dijo que venga a la 1, no? Quería cagarla a trompadas" (Santiago).

De los nacimientos analizados, solo uno fue presenciado por el padre (el caso de Mariana y Leandro, quien en esta tesis es relatado sólo por ella porque él no pudo asistir a la entrevista). Del resto, sólo Lito (pareja de Natalia) se negó a entrar.

"Ahí me llevaron a la sala de preparto, de parto, que fue cuando el obstetra decía "dale, cambiate y entrá" y Lito "no, no me animo, no me animo" y él le insistía y en un momento dije "bueno, ya está, llevame a mí, dejalo, no le obligues también, flaco"” (Natalia y Lito, privado).

Durante el trabajo de campo y tal vez por la transición generacional que no termina de establecer, disputar y (re)construir los roles de los varones-padres en el PEP, noté cierta sobreprotección con las sensaciones, miedos e impresionabilidades de ellos, que no se contemplan por igual con las mujeres. Ellas ponen el cuerpo, sufren el dolor, hacen fuerza, pero ellos son objeto de cuidado y compasión porque "les da cosa entrar". ¿No es una expresión más de desigualdad de género o de cierto micromachismo? ¿Incluso de cierta esencialización de género? ¿No es hora de exigirles que participen activamente sosteniendo, acompañando y presenciando el nacimiento de sus hijxs? Qué "se hagan machos" o que lloren, pero que dejen de recibir el privilegio de elegir no comprometerse ni experimentar "la impresión" de conocer que sus hijxs nacen con sangre, que las vaginas y úteros de sus compañeras traen vida, con todo lo que eso implica. La idea no es generar nuevas normatividades o mandatos, sino proponer una reflexión con perspectiva de género del sobre-cuidado de las emociones de los varones-padres durante los partos, cuando las de las mujeres suelen estar censuradas, invisibilizadas o prohibidas.

Más allá de quienes no quieren entrar, abundan en esta investigación los casos de padres que quisieron y no pudieron por la normativa institucional (que viola la ley 25.959). Así, la prohibición de entrar a sala de parto o quirófano, aparece como un punto de quiebre en la experiencia de los varones-padres.

"Él no entendía nada, él estaba ahí para acompañarme (...) Cuando me dijeron que él no iba a poder entrar... creo que ahí fue también todo, todo el clic, entendés, de que no quería eso, de que me estaban sacando algo importante que era estar con mi pareja y recibir a nuestra hija juntos. Cuando le dije que él no iba a poder entrar, él dijo "lo importante es que la nena esté bien, no te preocupes porque yo voy a estar afuera, yo la voy a estar esperando" y bueno, dentro de todo me calmó. Pero bueno 
igual cuando me llevaron y me alejaron de él, fue como que, me volvió todo y volví a llorar, entré llorando en el quirófano, pero bueno dentro de todo, yo creo que si no hubiera tenido nadie presionándome y hubiera tenido la información que tengo en este momento, yo agarraba y le decía "tengo 3 de dilatación, me voy a mi casa", entendés, y volvía ya cuando sintiera que se me estaba por salir" (Sabrina, primer parto, privado).

En este caso el padre de la primera hija de Sabrina las abandonó (y por ende no participó de la entrevista), por lo que el relato de su participación viene desde su vivencia y lo que provocó en ella esta soledad. Quien sí lo narra en primera persona es Damián, a quien no lo dejan ingresas a la cesárea, en el mismo hospital privado donde parió Sabrina.

¿¿Pudiste entrar a la cesárea?

No, no, no. No sabíamos. Yo pensé que sí, que podía entrar. Me enteré ahí en el momento de que no iba a poder entrar. O sea que me dijeron "no, hasta acá, llegás hasta acá". Y en esa situación no me daba para armar lío ni nada. Yo quería entrar. Pero bueno este, entendí que si era tipo así, digamos, por cesárea no, y si hubiera sido parto natural sí, quizás. Pero bueno... no sé. Fue como una opción que no me dieron. No fue una elección mía" (Damián)

Nuevamente, el análisis de la vulneración de sus derechos la vincula a su propia desinformación y no a la responsabilidad de la institución de garantizárselos.

En estos relatos, la situación de espera es la general en los varones padres una vez ingresadas sus compañeras a quirófano o sala de parto.

¿Y vos estabas asustado?

Sí, yo estaba nervioso más que asustado. Ella estaba tranquila, después cuando llegó, con el tacto, todo, ahí se le fue toda la tranquilidad.

¿Y por qué no entraste? ¿Te acordas? ¿Pensaste que te ibas a sentir mal?

No, porque en realidad, sí, pensé que me iba a impresionar, viste con la sangre y todo eso. Dije "me voy a impresionar". Y no sé si no era peor el preparto pero bueno, qué se yo, uno nunca sabe.

$Y$ ¿el dolor? ¿Cómo viviste vos que ella sintiera dolor y eso?

$Y$, es como que te pone nervioso, porque vos sufrís también a la par, porque ella está sufriendo y vos sufrís a la par pero bueno, tenés al obstetra que te va explicando el porqué de la situación. A mí me hablaba afuera, no me hablaba adentro de la habitación, me hablaba afuera y me iba explicando el tema de la dilatación, si iba dilatando, si no, porqué, dice "yo sé que es doloroso dilatar y demás, y el tacto, pero bueno, dice, si yo estoy haciendo esto es porque considero que puede ser por parto natural, para mí sería más fácil hacer una cesárea, pero si puede nacer por parto natural para qué vamos a hacer una cesárea" (Lito, privado).

En este fragmento de la experiencia de este varón-padre destacan cómo transita una experiencia que sucede en el cuerpo de su compañera, cuáles son las emociones que va atravesando $y$, en un hecho que interesa especialmente a la tesis, el diálogo de dos varones (un médico y un compañero/padre) sobre lo que sucede en el proceso de Natalia, con información que, como pude recabar en la entrevista, a ella no se le daba. Esa invisibilización de la mujer que pare también es un hecho a destacar si consideramos la interseccionalidad de género que atraviesa a la atención obstétrica. 
En la situación de espera (elegida, como el caso de Lito; o impuesta, como el de Damián y otros incluidos en este estudio), algunos se sienten nerviosos y otros, como Lito, se quedan tranquilos por "la confianza que le tenía al médico", a veces acompañados de familiares. De todos modos la institución tiene preparado un rol para ellos: el rol administrativo, la realización de trámites de internación, etc. Asimismo, las mujeres les asignan una función: realizar un seguimiento a Ixs recién nacidxs y no perderlxs de vista. Al respecto Mariana mencionó "eso fue una orden mía: 'aunque te la quieran llevar a otro cuarto que vos no la veas, vos tenés que estar al lado, te prohibo... porque digo, yo no voy a estar".

En este sentido, el relato de Damián sobre el primer contacto con su hijo da cuenta de bastantes elementos para analizar.

"El primer contacto que tuve con él no fue muy lindo. Por como lo organizan en el hospital. Porque yo lo vi en la incubadora pasando por un pasillo ¿entendes? Ese fue mi primer contacto, la primera vez que lo veo a él, lo veo a través de una incubadora, que incluso pensé que le había pasado algo, porque como, asocie con que "uh, lo metieron en la incubadora, pasó algo, se complicó". Y lo primero que le dije al médico que estaba ahí y me dice "no, no, salió todo fenómeno, salió todo fenómeno, mirá, está bárbaro". Me dejaron verlo un segundo así a través el vidrio. Y pasó así, derechito y después [lo llevaron] para Neo, donde lo pesan, viste. Y tardó, ponele 20 minutos pero para mí fue... estar atrás de una puerta esperando, ahí, en qué momento me dejaban pasar para verlo, para tenerlo. Bueno, para mí fue eterno. Porque aparte más que nada la falta de información. Eso fue muy feo del hospital. Después está todo fenómeno, pero esa parte es como que no... Es algo que no te lo esperás. Si las cosas están habladas de antes, "mirá la cosa va a ser así, vos lo vas a ver en pasillo, te lo van a pasar en una incubadora", bueno okey. Ya sabés, está en vos después..." (Damián).

Es evidente que él necesitaba anticipación, información y saber cómo iban a ser las $\operatorname{cosas}^{166}$, y en esta carencia se asienta para criticar durante toda la entrevista a la obstetra de cabecera, como he venido ejemplificando. Por ello, lo inesperado aparece como negativo, fuente de temor y hasta de cierta imposibilidad de ejercer la patria potestad sobre su propio hijo. En ese momento, el recién nacido es patrimonio de la institución médica, hasta que se anima a romper ciertas reglas institucionales implícitas y entrar en neonatología para conocerlo.

"Yo me metí ahí en la neonatología sin que me dijeran nada, vi que abrieron la puerta así que me metí porque ya me estaban hinchando mucho las bolas, la verdad, porque no sabía qué pasaba. Están los chiquitos que nacieron con bajo peso. Y me quedé ahí un ratito y un padre me dice "mirá que podés abrir" me dice, porque tienen como unas trabitas las incubadoras. Ahí lo saqué, me quedé con él, viste. Sí, lo agarré, después cuando vino la enfermera me dijo "nada de fotos". Había un cartel que decía "no celulares" y eso. Después una vez que me quedé con él, tranquilo, sentado, tenía el celular acá en el bolsillo y me saqué una selfie, una foto, la primer foto que tenemos juntos (...) Aparte me había hinchado muchos las bolas, hablando lisa y llanamente, el hecho de haberlo visto pasar en un pasillo no me gustó para nada.

${ }^{166}$ Durante todo el relato, Damian muestra cómo pensaba que ya era el parto porque el proceso se ajustaba a las normas médicas (la fórmula de contracciones/minuto). Su necesidad de control y de anticipación permean toda la experiencia y la negativizan. 
Porque era como que "acá está tu hijo" y te digo la verdad lo primero que asocié es que pasó algo, que no puedo verlo, tocarlo, agarrarlo. Y no, estaba todo fenómeno. Se ve que es así el método. Porque entre quirófano y neo hay como un pasillo que los conecta. En ese pasillo lo vi por primera vez" (Damián).

En la experiencia de los varones-padres, por tanto, es posible ver actitudes de obediencia y rebeldía al $\mathrm{MMH}$, de grises y puentes como en los casos reseñados de las mujeres madres. En su experiencias se combinan la legitimidad: se ve que "es así" el método, no "hace lio" por no entrar a cesárea, conoce a su hijo en un pasillo; con cierto cuestionamiento: rompiendo las reglas hospitalarias y colándose en neo y sacando al bebé de la incubadora, de algún modo se venga del primer encuentro que tuvo con su hijo. Se considera "combativo" pero cree que exigir presenciar el nacimiento de su hijo era "armar lio". "En ese momento es lo que dice el doctor" y así justifica no haber resistido. Ese momento él siente vulnerabilidad total, urgencia, miedo, desconocimiento.

Antes de concluir, es interesante considerar que la/s institución/es médica/s (como concepto y como espacios concretos) generan y (re)producen ideologías de género (Blázquez Rodríguez, 2009) tanto para mujeres-madres como para los varones-padres. A ellos, por ejemplo, no solo los sobreprotegen en su impresionabilidad, sino que los construyen como sujetos hipersexualizados a quienes "les devuelven" vaginas más angostas (aunque en algunos casos, como el de Mariana, la salud reproductiva afectó su posterior salud sexual por mala praxis en la sutura de la episiotomía).

En la participación de los varones-padres, entonces, es posible advertir la incidencia de modelos de atención y su rebeldía o acatamiento, tal como en el caso de las mujeres. A veces ellos tienen vínculos con Ixs profesionales que chocan o son distintos a los que tienen sus compañeras. Es visible también que el parto transmitido hegemónico también hace mella en ellos: tienen miedo a entrar al parto y no saben bien cuál es su rol, tal vez porque está en proceso de construcción por los cambios generacionales mencionados antes. Incluso en la relación médicx-acompañante de la paciente, se puede renovar o tensionar el pacto patriarcal entre varones-padres, profesionales e instituciones médicas. Al respecto, elijo cerrar este apartado con una referencia que expuso Damián durante la entrevista, en la que se abrió un proceso de deconstrucción para él.

"Ahora cómo puede ser, vos fijate los porcentajes que decías vos ¿no?, es decir 7 de cada 10 mujeres no podrían tener parto vaginal, o sea no podrían dar a luz, ¿cómo sería? ¿Cómo llegó la humanidad hasta este momento?" (Damián).

En esta idea, Damián comienza a encontrarte las grietas al paradigma del cuerpo femenino defectuoso que propone el modelo hegemónico obstétrico, que es el 
que refuerza la necesariedad de la intervención médica, trastorna los protagonismos en el parto y no permiten que padres afectivos, como él, presencien los nacimientos de sus hijxs.

\subsection{El CASO ATíPICO: PARIR EN CASA}

Parir y nacer en casa ha sido uno de esos hechos cotidianos atravesados de lleno por la medicalización del PEP. La hospitalización de los partos y la profesionalización de su atención han hecho que históricamente se abandonara esta práctica y, al mismo tiempo, ha producido que se volviera a establecer en forma de demanda de algunos grupos en la actualidad. La medicalización e institucionalización de los nacimientos ha sido la explicación de su abandono y es actualmente la explicación de que se vuelva a elegir este ámbito de atención. En palabras de Ramírez (2015, p.10): "el parto en casa planificado, es una modalidad ancestral, que en la actualidad ha sido retomada por gestantes mayormente informadas". La opción del parto en casa responde, por tanto, a un modelo obstétrico ligado al aumento del intervencionismo médico en el ámbito hospitalario y por ello considero que discute ambas cuestiones: modelo y ámbito de atención. Se vincula a la búsqueda de parir con placer, en un marco de derechos y de respeto del proceso fisiológico y de las necesidades de las mujeres y Ixs recién nacidxs. Por tanto, como sostiene Fornes (2011) "el parto domiciliario no habla solamente de decisiones individuales, nos habla de cómo está llevándose adelante la atención de la mayoría de los partos en la Argentina" (p.149). Esta autora ha analizado en profundidad el parto en casa en Argentina $^{167}$ y lo analiza a través de las dicotomías naturaleza-cultura y públicoprivado. Al respecto de esto último vincula el parto domiciliario a una estrategia politizadora del mismo y sostiene que

"a pesar de que esta alternativa expresaría una vuelta a la domestico, la cadena de experiencias y deliberaciones que recorre traducen en acción política algo que nace de una decisión privada(...) Su vida privada se traduce en una acción política que está denunciando la exclusión de garantías públicas a sus derechos basadas en el género como desigual social" (p. 142).

La mayoría de Ixs estudiosxs del parto en casa (Ramírez, 2015; Fornes, 2011, Saraceno, 2018, Lorenzo, 2013) apuntan a esta conceptualización de la elección de este modo de parir como una elección política, en tanto se trata de "una de las respuestas de la mujer ante un sistema que no tiene en cuenta sus sentimientos y

${ }_{167}$ Valeria Fornes defendió su tesis de maestría sobre parto en casa mientras yo cerraba este trabajo, por lo que no pude acceder al documento completo publicado. Sin dudas, su trabajo es de referencia ineludible para estos estudios en la Argentina contemporánea. 
necesidades íntimas, la transcendencia del momento del nacimiento y el bienestar del recién nacido" (Fernández Del Castillo, 2006, citado por Fornes, 2011, p. 145).

"El acto de elegir un parto en casa, en el contexto de atención tecnocrática, podría responder a un acto de empoderamiento de mujeres y parejas que toman la decisión de participar, elegir e informarse sobre sus procesos (...) ven en la casa un territorio donde pueden actuar con mayor independencia y acorde a un paradigma holista y humanista de atención del parto y nacimiento. La casa permite a las mujeres recuperar la autonomía de su cuerpo, mente y espíritu, moverse libremente y decidir responsablemente" (Ramírez, 2015, p. 16).

Tal como desarrollé en el capítulo 4 en referencia al curso de preparto del grupo de parto domiciliario y en el capítulo 5 en relación a la otra obstetricia, es relevante retomar en este capítulo las experiencias concretas de mujeres-madres y varones-padres que eligieron y planificaron dar a luz a sus hijxs en su casa. Para ello, realicé dos entrevistas en profundidad a dos parejas con quienes transité dicho curso de preparto: Anabel y Dimitri y Emilia y Marco, que tuvieron en noviembre/diciembre de 2017 a dos niños. A los fines de simplificar la exposición, expondré algunos elementos de la experiencia de Ixs primerxs, en tanto las experiencias han sido muy similares y sería redundante presentar ambos casos.

Para contextualizar es importante describir que en la ciudad de La Plata solo hay un equipo completo que asiste partos en casa, compuesto por un médico obstetra, tres parteras, dos pediatras y otrxs profesionales adhoc (psicóloga, puericultora, etc.). Asimismo, un grupo de parteras también ofrece la opción pero no cuenta con la infraestructura o logística de ese grupo respecto a disponibilidad de médicxs pediatras y obstetras y vínculo con una clínica u hospital de la localidad vecina de Ensenada. A grupo que acompaña el parto en casa (GPC, de aquí en adelante) se lo conoce por el apellido del médico obstetra que coordina el equipo, y aquí ya es posible advertir un rasgo de hegemonía o jerarquía vertical que traspasa las fronteras de los modelos/ámbitos de atención.

Continuando con el esquema del capítulo, en los dos casos analizados, las parejas, compuestas por sujetxs heterosexuales, de clase media-alta, ligados a actividades culturales y emprendedoras de la ciudad, llegan al GPC como primera y única opción al enterarse de que están esperando su primer/a hijx, no buscadx. Conocen el GPC por amigxs o conocidxs o por sus ámbitos de sociabilidad "hippies". Al tratarse de una prestación médica no reconocida por las obras sociales, la atención del grupo superaba en 2017 (cuando ocurrieron los nacimientos analizados) los 30 mil pesos (entre los controles prenatales y la asistencia del parto). Una de mis inquietudes fue cómo valorizaban esta inversión, siendo que contaban con obra social para poder 
parir en instituciones ${ }^{168}$. Anabel y Dimitri sostuvieron que tenían una plata ahorrada y usaron eso, y Emilia ahorró el dinero de seis meses de su trabajo como niñera para poder pagarlo.

"A mí me parecía mucho más valioso toda esa atención personalizada y el parto en casa... A ver no iba a terminar en un hospital por la plata, como que no me parecía exponerme a eso por una cuestión de plata" (Anabel, domicilio).

La cuestión económica para estxs sujetxs no es superior a la búsqueda de garantizarse partos placenteros y respetuosos de sus derechos, deseos y necesidades. $Y$ de diversos modos encuentran el modo para costearlo. Hay que decir que ambas parejas viven en casas prestadas por sus familiares, por lo que no pagan alquiler. De todos modos cuando les consulté qué se cubría con ese pago, al igual que en los casos de partos institucionales, no tenían mucha certeza:

"Anabel: No había mucha claridad con respecto a eso. Un día lo explicaron pero nos parecía que lo podían haber explicado más al principio, no más al final. Pero bueno nosotros estábamos re entregados a eso, sabíamos que no iba a ser barato, que iba a ser medio caro, y bueno.

Creo que eso paga el obstetra, la partera y el pediatra

Anabel: Sí, esas tres cosas

Dimitri: Y la disponibilidad de ellos en el momento exacto, en la hora justa" (Anabel y Dimitri, domicilio).

Aquí entonces es posible ver algunas similaridades con la atención privada: el personalismo y el pago por la disponibilidad.

Respecto al itinerario asistencial durante el embarazo, el GPC promueve los estudios básicos y deja a libre demanda de Ixs usuarixs la demanda de otros análisis. Dimitri lo conceptualiza como una "política no intervencionista" y describe lo que le dejó la primera entrevista con el médico coordinador del grupo

"Diciéndote "vos tenés que parir, o sea yo no voy a hacer que vos paras, vos vas a parir". Como dejándole en claro también eso, como que depende de vos parís, como su política no intervencionista. Y como que eso me gustó también, como eso dándole ese poder también a la mujer" (Dimitri, domicilio)

Sobre la decisión de parir en casa, aparece como un elemento que va variando entre fijo a flexible a lo largo del relato y del itinerario asistencial. Por ejemplo Emilia, al llegar a su semana 41 de gestación empieza a considerar la posibilidad de parir en la clínica, y al enterarse de que se había cortado el convenio con su obra social, comienza a pensar en parir en el hospital público donde atiende el médico coordinador del GPC. De todos modos, a diferencia de lo que creía, el ámbito de ocurrencia del nacimiento no es lo que aparece como carta de presentación al interior del equipo, sino la atención desde otro modelo. De hecho, lo conversan con Ixs usuarixs:

${ }^{168}$ Es importante establecer que si los partos con el GPC no ocurren en el domicilio, sino que se dan en la clínica de referencia, allí sí lo cubre la obra social de lxs sujetxs. 
"También eso igual me parecía bien, que ellos te decían "vos querés tu parto en tu casa pero pensá que eventualmente podés tener que ir a la clínica por una complicación o algo así que prepará el bolso también para la clínica y lo del parto se va a ver cuando sea el parto". Que también depende de algo más a veces que de lo que uno desea. Entonces bueno, está bien que uno elija como se lo imagina" (Anabel, domicilio)

De todos modos optar por este GPC implica justamente, tener ese horizonte del parto domiciliario.

"¿Y cuándo deciden parto en casa?

Anabel: Ya cuando empecé a ir a lo de [nombre del médico] o sea como que yo sabía que quería parto en casa pero no sabía si ellos como que iban a poder o no porque como que no se hablaba. Tampoco como que lo pregunté mucho porque entendí que era la mejor opción que tenía estar con ellos porque como fuera iba a estar bien, confié en eso aunque yo igual prefería el parto en casa, pero bueno si no se podía o ellos no podían era como que ya me excedía digamos.

¿Y por qué ellos no iban a poder?

Anabel: Lo del parto en casa dependía de no sé qué, como que no era seguro, era como... Pero a nosotros nunca nos lo dijeron eso al final. Lo del pediatra lo dijeron, pero no me acuerdo bien. Como que había una especie de confusión con respecto a eso, como que no quedaba del todo claro

Dimitri: Como que si te caía tal día tenías que, para que esté el pediatra, tenías que ir ahí al hospital.

Anabel: Claro, y como que ellos hacían el hincapié igual como que lo importante era que fuera un parto respetado.

No importaba el ámbito

Anabel: Claro, de ultima iba a la clínica y bueno, o sea lo único que veía como más garrón era comerme el viaje en el medio del parto, pero tampoco estábamos tan lejos. No lo prefería pero no me parecía tan mala opción tampoco, digamos" (Anabel y Dimitri, domicilio).

En resumen, la elección de este grupo asistencial es similar a las que mostré anteriormente en el capítulo, y requiere el sopesamiento de factores económicos, culturales e ideológicos. Asimismo, al igual que en aquellos casos, al elegir a este equipo se aceptan "sus reglas del juego" y es posible también ver cierta "entrega" o "subordinación" a dicha oferta obstétrica. Claramente los márgenes de acción son mayores, hay una mayor democratización del saber, el enfoque es fisiológico totalmente, pero la socialización médica lleva a mantener esa relación de "dependencia" o confianza casi plena en el/la profesional médicx.

De todos modos es en el relato del parto donde se advierte la diferencia y un completo protagonismo de las mujeres y sus procesos fisiológicos, intuitivos, emocionales, sensoriales. Los dos relatos de los nacimientos son fluidos y refieren los cambios temporales por la luz, la oscuridad, la llegada de alguien, y no ya por los tiempos externos/institucionales o la realización de alguna práctica clínica. La autogestión del dolor y del proceso y su narración son sumamente intensas, imposibles de describir en una tesis.

"Me acuerdo que puse telas en las ventanas porque me molestaba la luz, estaba con la pelota esa gigante, jugaba un poco ahí. Me movía básicamente, hacía unos 
movimientos rítmicos, que me ayudaba, y vocalizaba también y eso como que me ayudaba a ir pasando" (Anabel, domicilio).

Anabel y Emilia toman la primera persona y narran cómo iban transitando espacios de la casa, de su cuerpo, de sus emociones durante el período de trabajo de parto. Se pierden en las referencias temporales, pero recuerdan algunas vivencias corporales trascendentales. No saben cuánto tiempo pasó entre una y otra fase del período del parto. No hacen tanta mención al dolor sino que se sorprenden por algunas expresiones y sensaciones corporales que desconocían:

"Y nada esos gritos fueron una gran sorpresa para mí también porque... o sea conocer la dimensión de ese poder, viste, muy, o sea nunca en tu vida jamás gritás tanto, entendés. Es la primera vez que gritás (se emociona) (...) Los pujos son como que vienen solos. Venían solos o sea no era algo que yo decidía pujar, por eso también después de esa experiencia me parece re absurdo eso de "pujá, pujá", viste. Esa figura del que te dice cuándo tenés que pujar, pero bueno igual entiendo que supongo que si te ponen anestesia debe ser diferente (...) No, no, muy fuerte. Y yo sentía esa cosa que encima que estaba sentada ahí y sentía esa verticalidad, como una fuerza que me bajaba y que me subía a la vez. Y nada y ahí nació" (Anabel, domicilio).

La referencia a la fuerza y al poder es constante. Se hace cuerpo, carne, se experimenta. Y no solo por las mujeres, sino por quienes están alrededor. De hecho al mencionarme que la partera que asistió el parto nunca le realizó un tacto, le consulté:

"¿Y cómo se dio cuenta que estaba por nacer?

A: Y por los gritos, por la intensidad de lo que se veía que estaba viviendo. Porque como que si estás en una, estás como gritando, como que se te ve en el cuerpo" (Anabel, domicilio).

Del mismo modo, estas experiencias son particulares en los varones-padres.

Dimitri narró muy conmovido cómo fue esta experiencia para él:

"Dimitri: Era como una ansiedad increíble por la emoción digamos de la situación, pero o sea fue la mejor noche de mi vida, la mejor noche de mi vida, una buena trasnochada. Y estaba que, me acercaba a Ani pero yo sabía que ella por ahí no me necesitaba exactamente a mí entonces como que le preguntaba por ahí algo, si necesitaba agua, le acercaba un poco de agua. Pero por ahí me decía "tapá ahí, hay mucha luz", yo trataba como de ir cubriendo cuestiones

Anabel: Yo estaba en un estado como muy molesto, todo me molestaba.

Dimitri: Pero más que nada como que la dejé a la partera que haga, yo, o sea estaba como mirando. Yo estaba re atento y dispuesto a colaborar con la situación

¿Tenías miedo?

Dimitri: Tenía confianza y fe también de que es lo natural y que si estaba todo bien, iba a ser así, que además era nuestra voluntad también, entonces nada, era algo que ya se había hablado, había voluntad, había intención, había ganas, entonces, ya está, también eso me daba un poco más de tranquilidad, ¿no? Pero siempre en algún recoveco de la mente se esconden esos fantasmitas que, bueno uno trata de ahuyentarlos. Había una linda magia en la noche, la casa estaba con las velas y estaba todo muy dado, yo te veía también muy cómoda en la situación, como con el baño, la pieza, con la partera. Te veía circulando bien" (Anabel y Dimitri, domicilio). 
En los partos en casa los varones-padres, además, tienen un arsenal mayor de funciones: desde sostenedores de las mujeres en la posición en la que elijan parir, hasta ser quienes reciban a Ixs recién nacidxs y corten el cordón.

Las experiencias de estos partos en casa se entroncan en trayectorias de vida de jóvenes ligados al ecologismo (sus hijxs usan pañales de tela, ellas usan la copa menstrual, son recicladores), de alimentación naturista, críticos de la biomedicina, anticonsumismo, crianza con apego, lactancia a demanda. Sin duda se trata de experiencias excepcionales: no hay datos oficiales de los partos en casa, y de hecho el modelo del parto domiciliario está desaconsejado desde las carteras de salud y las sociedades médicas argentinas ${ }^{169}$. Se supone que los partos planificados domicilios irían entre el 1 y el $3 \%$ de los nacimientos ocurridos en el país, con diferencias regionales, por supuesto.

Entonces, ¿es un caso atípico? Algunos elementos considerados permiten responder afirmativamente a esta pregunta. En primer lugar, es visible una mayor democratización del saber y del poder de decisión en la relación médicx-paciente, en la que las parteras tienen mayor protagonismo (en el acompañamiento y sostén) que en la atención institucional. Esto es visible, por ejemplo, en los controles prenatales participativos, en las indicaciones de pocos estudios, evitando así la medicalización innecesaria. En segundo lugar, es un caso atípico en tanto es un signo de distinción para muchas mujeres y familias en general, en lo económico, político, cultural, feminista. Esto es, existe cierto síntoma de época que vincula el progresismo y la evolución a la búsqueda espiritual y la "vuelta" a lo natural, lo fisiológico: en la alimentación, la cura de enfermedades, las formas de crianza y, por supuesto, los modos de parir y nacer. Estos discursos del new age en algunos casos se articulan con discursos feministas acerca de la sumisión institucional de las mujeres, de reencontrar el poder de parir innato/inherentemente femenino y en tono al lema "por el derecho a decidir sobre mi propio cuerpo". Felitti y Abdala (2018) hacen un extenso trabajo sobre este "giro subjetivo" y la búsqueda de la "maternidad holista" vinculada al actual movimiento por el parto humanizado. En este sentido, el parto en casa, que no equivale a parto humanizado, emerge como el exterior constitutivo de la obstetricia institucionalizada, a la manera de Laclau $^{170}$. Por último, el parto en casa es un caso atípico en tanto discute no sólo el ámbito de atención sino también el modelo. La vuelta, entonces, es a discutir las dos ocurrencias históricas que promovieron a la

\footnotetext{
169 Sobre las pronunciaciones de SOGIBA y FASGO al respecto del parto domiciliario recomiendo la visita a sus sitios webs.

${ }^{170}$ Los partos (cuerpos) abyectos son aquellos partos sobre los que se construye la hegemonía, por ello, por ejemplo, el parto en casa aparece como exterior constitutivo.
} 
hegemonización del modelo intervencionista, que he desarrollado en el capítulo primero: la hospitalización y la profesionalización de la atención de los nacimientos de fines del siglo XIX. Se trata de parir en casa, acompañadxs por parteras y de manera fisiológica, sin intervenciones médicas innecesarias y sin la medicalización tanto de la concepción como del abordaje de los partos, con los beneficios de la tecnología médica del siglo XXI en caso de ser necesarios.

Y sin embargo, como todo en esta tesis, es posible advertir ciertos grises en cada una de las experiencias. Por ello, existen algunos aspectos (menores, sin duda) que no permiten afirmar que se trate de un caso atípico: existen tensiones en las relaciones médicx-pacientes; se reproduce la "entrega" a Ixs profesionales; en los casos referidos, el obstetra participa en los últimos cinco minutos del período expulsivo (tal como en el caso que narra Mariana en la atención privada) a modo de "la frutilla del postre" y es posible advertir algunas zonas oscuras en la información burocrática que se les da a las mujeres y sus familias sobre los cobros, por ejemplo.

En este apartado quise recoger una de las tendencias actuales ligadas a la asistencia al PEP en la ciudad. Si bien es minoritario en cantidad, es resonante en cuanto a lo cualitativo: las experiencias de parto en casa son intensas, fluidas, trascendentales, y muestran que en el mismo tiempo histórico conviven distintas formas de parir, de sentir los cuerpos gestantes y parturientos, de dar a luz a nuestrxs hijxs.

\subsection{VIOLENCIA OBSTÉTRICA: EL NACIMIENTO DEL ACTIVISMO POR EL PARTO RESPETADO}

Una sociología de la atención medica de embarazos y partos no puede dejar por fuera las disputas de poder que se dan alrededor del campo obstétrico. Por ello, esta tesis propone cerrar un ciclo volviendo al inicio: considerando la construcción de la violencia obstétrica como problema público y el rol del activismo por el parto respetado en dicho proceso. Para ello, problematizaré, en primer lugar, las vulneraciones a los derechos sexuales y reproductivos de las mujeres madres en su atención obstétrica que se hicieron visibles en el trabajo de campo que estructura la tesis, para, en segundo lugar, delinear algunas dimensiones de análisis de dicho activismo.

\subsection{A. VIOLACIONES A DERECHOS EN LOS CASOS ANALIZADOS}

Cuando comencé, hace seis años, a gestar esta tesis, me propuse analizar la violencia obstétrica (VO): experiencias, expresiones concretas, posibles causas, posibles prevenciones. Hacía sólo cuatro años que se la había establecido como un 
tipo de violencia contra las mujeres y solo seis años habían pasado desde la primera definición legal que generó la ley orgánica contra la violencia hacia las mujeres de Venezuela. En la academia no se hablaba mucho de este concepto, pero era un campo de estudios en ebullición. En distintas lecturas a mi proyecto de investigación en un grupo de investigación del que formé parte, recibí ciertas reticencias y el consejo de no centrarme en la VO, sino que emerja en la indagación como un hallazgo, como un punto de llegada. Por ello repensé mi propuesta de análisis y pude encontrar que el núcleo conceptual de las intervenciones médicas en los PEP me permitía explicar no sólo la VO sino también la tensión entre modelos de atención, las prácticas y representaciones médicas y sociales respecto a los nacimientos, los extremos y los grises. En ese marco, nunca abandoné la búsqueda por analizar, pensar y producir herramientas para comprender y prevenir una modalidad de violencia sumamente naturalizada e invisibilizada. Si no hubiera tenido esta vía paralela e interconectada durante la investigación, mi punto de llegada habría sido que no existe la VO.

Sí. Ninguna de mis entrevistadas se reconoció como víctima de VO, ni tampoco Ixs profesionales de la salud visibilizaron situaciones en las que se ejerciera este tipo de violencia. Lo que emerge es que la VO no es aún una categoría social apropiada subjetivamente. El desafío que se me presentó entonces fue: ¿es parte de nuestra tarea como investigadorxs señalar violaciones a los derechos que las mujeres tienen por ley, aunque ellas no hayan significado tales situaciones como VO? ¿Soy yo la que debe juzgar si lo que vivieron fue VO?

La respuesta a esa inquietud es una decisión arbitraria: si la dimensión subjetiva no emergió entre las entrevistas vinculada a definir ciertas situaciones como VO o a sí mismas como víctimas, lo que es posible (y preciso, desde mi posición) es analizar los hechos desde una perspectiva de derechos y género. Esto es, analizar qué necesidades, deseos y derechos de las mujeres (establecidos por la ley de parto respetado) violan distintos momentos de la atención perinatal, podría ir delineando qué expresiones asume la VO para el caso de estudio. Esto porque la interconexión entre leyes 25.929 y 26.485 establece que la sola vulneración de alguno de los derechos en el proceso de parto, implica violencia obstétrica. El hecho de que las mujeres no hayan identificado ciertas situaciones como violentas y en ocasiones las hayan justificado o se hayan autoinculpado por ellas, no es más que la confirmación de su naturalización e invisibilización. Y además confirma que determinadas intervenciones médicas en los PEP, tanto prácticas como simbólicas, pueden adquirir diversos significados para diversxs actorxs. Al respecto, tres estudios del campo han encontrado los mismos escollos y han dado posibles explicaciones: 
"Las "pacientes" internalizan las normas del sistema hegemónico haciéndolas propias, y transformándose en cómplices de su propia subordinación, participando así de una forma de dominación que se instituye a través de la adhesión que el dominado se siente obligado a conceder al dominador. Esto ocurre cuando no se dispone de otros esquemas de percepción y apreciación del mundo que aquellos que comparte con el dominador. O cuando se dispone de otros esquemas, pero quedan subsumidos bajo la supremacía del paradigma hegemónico que goza del poder" (Sadler, 2004, p. 21)

"El trato deshumanizado se interpreta como conductas individuales de Ixs profesionales y no como prácticas institucionalizadas que merecen revisión y crítica. Cuando se reconocen como violentas las prácticas de atención del parto, estas prácticas aparecen como efectos inevitables de las deficiencias en la infraestructura hospitalaria" (Arosteguy y otras, 2017, p. 4).

"Nuestras entrevistadas, no se reconocen sujetas de derechos y por lo tanto, se inscriben en un discurso que las mutila, sin tener argumentos como rebatirlo, enfrentarlo, dar la cara o poder decir que no" (Camacaro Gómez, 2009, p. 223).

La propuesta es destacar de cada entrevista algunos pasajes que me permiten ejemplificar las vulneraciones a los derechos humanos de las mujeres en su proceso de parto. Natalia menciona que lo único que cambiaría de su atención es el hecho de haber estado atada de pies, en unos estribos, en posición de litotomía (boca arriba).

'Lo único que no me gustó, pero también es un señor grande, qué se yo, lo único que no me gustó es que me ataron las piernas. Eso fue lo único que no me gustó. Sí, porque sentía que se me acalambraban las piernas. Como que eso es poco natural. Parir natural sería, yo he escuchado de parir sentada o en cuclillas o de otras maneras. Pero, a ver, en este caso, me encantaría eso pero también como tengo tanta confianza con el obstetra y me gusta tanto, resigno algunas cosas" (Natalia y Lito, privado).

En este caso se está violando el derecho a elegir la posición para parir y el derecho a un parto natural (ambos consagrados en la ley de referencia). Pero lo que es más rico aún de analizar es la justificación que encuentra ella tanto en la edad como en la confianza que tiene con el profesional, para "bancarse" esta situación. Señalando esas justificaciones no quiero culpabilizar a las mujeres sino mostrar cómo se despliegan mecanismos de este tipo de violencia simbólica. Esto se recrudece cuando Natalia significa como negativa esta experiencia pero en otro lapso de la entrevista narra un hecho que para ella pasa desapercibido pero que ha sido denunciado como una expresión de violencia sexual dentro de la VO:

"Aparte él me cargaba "sos de campo, sos fuerte" o cosas así. Viste, aparte después él me cargaba y me decía "te la estoy cosiendo..." porque me hizo un punto, "te la estoy dejando divina para el pelado [Lito]", o sea me hacía, como chiste en ese momento, yo calculo que era también para distraerme mientras veían si la llevaban a neo o no, que en realidad enseguida, la sacaron y dijeron "no, no va a neo, está divina, está re, es re grandota"' (Natalia y Lito).

"El punto para el marido", nombre que le puso la militancia, implica achicar el tamaño de la vagina en el momento de la sutura de la episiotomía. Intervención, la episiotomía, que responde a una epidemia intervencionista que también ha sido 
denunciada por la OMS y que resulta de la posición litotómica para parir, que no permite el trabajo de los músculos del suelo pélvico y del miedo profesional al desgarro natural. La desexualización del parto al convertirlo histórica y simbólicamente en un acto médico, se rompe al resexualizar la vagina una vez ocurrido el nacimiento, presentada como un nuevo pacto patriarcal entre varones: el/la obstetra y la pareja. El regalo del/la doctor/a al papá del/la bebx: el cuerpo virgen, como si aquí no hubiera pasado nada, de su mujer, para aumentar el placer sexual de él.

En este caso y en varios aparece la que denomino la versión sutil de la VO, vinculada a las aparentemente necesarias y criteriosas intervenciones médicas, que son más difíciles de significar como violaciones a derechos humanos, por tener supuestas justificaciones clínicas. Así el caso de Sabrina, cuyo relato extenso e intenso describe con riqueza el tránsito de la atención obstétrica.

"Cuando me dejaron quieta, era como que yo sentía el dolor pero no sentía mi cuerpo trabajar. Sentía el dolor pero no se me ponía la panza dura. Así que estaba con el monitoreo y que se yo, me dicen "mirá cuando tenés contracciones al bebé le bajan los latidos", me vino a decir el doctor, que vino, me controló en ese momento y me dijo, me tiró el chamuyo ese viste, "me parece que tu bebé está de cara", que eso es algo que por lo general te das cuenta cuando hay más dilatación y llegás a tocar la cara al bebé (...) En uno de los tactos me despegan membranas, sin pedirme permiso, sin avisarme, sin nada, sentí mucho dolor y vi que sacó la mano llena de sangre y fue como "qué me hiciste". Me dice "no, mirá, es para ayudarte a que dilates más" y eso creo que también, el sentirme invadida, y que me causen dolor, entendés, innecesario y todo fue como que, eso me frenó un montón, porque estaba con miedo, no me sentía cómoda dentro del hospital. En mi casa estuve 5 o 6 horas con contracciones y dilaté hasta 3 , llegué al hospital y se me frenó todo, porque me sentía totalmente incómoda. No, no, no podía, tenía miedo, me tocaban, venían, me pusieron suero con el antibiótico porque tenía estrepto positivo, me hicieron quedar quieta, ahí me frenaron todo (...) No me dejaron ni siquiera levantarme a hacer pis, porque tenía que estar acostada por el monitoreo, siendo que el monitoreo en todo momento estaba marcando positivo y que estaba todo bien. No me dejaron tomar agua, no me dejaron nada, era como que estaba desde un primer momento totalmente armado el tema de que yo terminara yendo a una cesárea (...) No, no tenía ningún problema. Lo único que decía en la historia clínica mía era que se había frenado el trabajo de parto y que había deflexión que es cuando tienen la cabeza doblada. De cara es cuando está así con la cabeza para abajo y no puede encajar la cabeza para salir por el canal de parto. Cuando a mí me hacen la cesárea, sea como para sacarme, como para sacarme un poco el ensimismamiento ese de creerle todo al médico, a mi hija le hacen un tajito acá horizontal. Si ella hubiera estado de cara, no importa a qué altura, hubiera estado vertical. Entonces a mí eso me dice que la nena no estuvo en ningún momento de cara, eh, salí muy enojada de que hayan lastimado a mi hija, encima el doctor me echaba la culpa a mi diciéndome "no, porque estuviste muchas horas con trabajo de parto", siendo que estuve, no sé, 12 como mucho, y que hay mujeres que están días y días, "estuviste muchas horas con trabajo de parto y tu útero estaba muy finito". O sea como culpándome a mí o a cómo había trabajado mi cuerpo (...) Nunca tomando él la responsabilidad de lo que había pasado" (Sabrina, primer parto, privado).

Sabrina narra que sufrió muchas de las intervenciones clínicas desaconsejadas por las normativas nacionales e internacionales y los protocolos de atención, tal como se expresó en el capítulo 3. Así, la falta de libertad de movimiento, la prohibición de beber, el monitoreo continuo, los tactos repetidos, la separación de membranas sin su 
consentimiento y la información de razones para la cesárea que se basan en un cuerpo defectuoso, se articulan para no respetarle el derecho y el deseo de un parto natural. A lo largo del relato, ella va esbozando la sospecha (que construye en retrospectiva) de que en este primer parto fue "todo armado" para que ella fuera a cesárea porque coincidía con las vacaciones del doctor y el día de la madre. Las consecuencias no se reducen al nacimiento de su primer hijo sino que se convierte en una condena de cesáreas ad eternum para ella. Asimismo, un apartado especial para la iatrogenia resultante de estas intervenciones médicas: el dolor infringido aparece vinculado al miedo y a la interrupción del trabajo de parto.

El caso de Valeria es abrumador en términos de la cantidad de intervenciones innecesarias a la que es sometida: tactos repetidos, suero con episiotomía, epidural compulsiva, kristeller, fórceps, sonda, catéter. Retomo algunos fragmentos de su relato que sirven para complejizar el análisis.

"Le dije [a la médica de guardia] "lo único, te puedo pedir por favor que no me hagan tacto todos porque realmente me duele ¿Y cómo lo tomaron?

Mal. Me dijeron "mirá mami, este es un hospital escuela, si no te gusta...". Así me dijeron, viste. Y le dije "porque me duele", viste, no le dije nada. Yo creo que si hoy me dicen así "si no te gusta", listo "no me gusta", me levanto y me voy, me iré a otro, no sé. Pero queda en ella, porque ellos te anotan todo ahí, si me pasa algo a mí o a mi hijo. Y, entonces agarró y me hicieron tacto" (Valeria, primer parto, público).

Uno de los derechos consagrados en la ley 25929 establece que las mujeres pueden negarse a ser objetos de estudio. La brecha con la situación real es grande: las cuatro maternidades públicas de la ciudad de La Plata son hospitales-escuelas donde funcionan las residencias de tocoginecología, neonatología y licenciatura en obstetricia (partería) de la Universidad local. Tal como queda establecido en el relato de Valeria, este derecho es sistemáticamente vulnerado, y la posibilidad de negarse a ser objeto de las prácticas de Ixs estudiantes, por el dolor que le implica que una docena de ellxs ingresen sus dedos en su vagina y utilicen su cuerpo como sustrato pedagógico, se convierte en un tiro por la culata: si te negás, perdés la atención.

"Me llevaron allá arriba y me pusieron suero que yo les pregunté qué era y que era para mantenerme hidratada me dijeron, sigo pensando que es eso, pero hasta el día de hoy me dicen que debe haber sido oxitocina, porque, a ver, me generó más dolor, viste, contracciones. Yo estaba sola, viste, ahí arriba, encima fui la última en ese día en tener, entonces no había nadie más" (Valeria, primer parto, público)

Valeria lee la experiencia de su primer parto a partir de datos que tuvo después: la inducción con oxitocina sintética con el fin de acelerar el progreso del trabajo de parto, suele generar que las contracciones se vuelvan muy dolorosas (lo que activa la cascada de intervenciones: la necesidad de analgesia epidural, por 
ejemplo $)^{171}$. Y en paralelo sospecha que sin su consentimiento, lo que viola el derecho a la información establecido por la ley de referencia, le "pusieron" esa hormona sintética para acelerar el proceso porque era la última que quedaba por parir en el día. Esto se conoce en el campo como "limpiar la guardia", lo que implica no dejarle a Ixs profesionales que ingresan en el cambio de turno, trabajos de parto en progreso y así evitar cargarlxs de trabajo. Allí, una vez más, prima el modus operandi institucionalmédico por sobre las necesidades y derechos de las mujeres.

En el tránsito de su trabajo de parto, en la internación, Valeria sufrió violaciones a sus derechos a la intimidad y privacidad constituyendo esto, desde la lectura objetiva y normativa, VO, sin tratarse de la aplicación de intervenciones prácticas sino simbólicas.

"Hace frio ahí arriba. Y... entonces en un momento me agarran ganas de hacer pis, "me hago pis" le digo, y me dice "sacate todo mami, no tengas vergüenza", me dice, yo estaba con un corpiño nada más y abajo yo estaba en pelotas, horrible porque estaban los de limpieza (...) Entonces se me vinieron todos los médicos a hablar, a joder entre ellos, en la pieza, había algunos tirados en la cama de al lado y me preguntan cómo estaba y yo les digo que me dolía. En un momento pido ir al baño y me dicen "sí, anda, hace en la chata", me dice. "En la chata no me gusta, no puedo y no me sale" le digo "y menos si hay gente mirando". Y me dice "bueno, qué caprichosa", me dice, "andá que así en diagonal tenés el baño", me dice. Entonces yo le digo que estaba desnuda, no iba a ir, porque estaban los de limpieza, todo, entonces me dice "iay, mami!", me dice, "la verdad que esto que estoy haciendo por vos no lo hicimos por ninguno", y me da la manta así, la sabana, me tapa y me dice "no te vayas a sentar en el inodoro, mami, por favor". Mirá que no me voy a sentar en el inodoro con el peso del nene, voy a estar parada...." (Valeria, primer parto, público).

Destaca que Valeria logra oponerse más fuertemente a estas situaciones que no implican decisiones y prácticas clínicas, sino que ella puede interpretar como malos tratos aunque intenten disuadirla de que es un capricho o privilegio de trato especial. Otra vez su cuerpo aparece objetivado desde la institución médica, por lo que cubrir su desnudez aparece como un beneficio. El relato, en el que ella no se piensa ni presenta como víctima de violencia, sino más bien de algunas situaciones que no le gustaron, continúa con otras intervenciones médicas que le realizan sin su consentimiento, mostrando un absoluto control médico del proceso.

"Cuando me llevan a la sala y me dicen "vamos que el anestesista se va y te quedás sin anestesia", me dice. "No, no quiero" le digo. "Dale mami vas a ver que va a ser mejor". Bueh, no sé cómo terminamos yendo a la sala de parto. Y, me llevan allá, me sientan, me ayudan a sentarme porque es re alta la cama, y me preparan todo y me dan la peridural. Encima yo no la quería pero bueno, me la dieron. $Y$ te hacen sentar así y apretar toda la panza, encima yo soy cortita de torso, y el peso del bebé, me habían roto bolsa, antes. $Y$ me acuerdo que me rompieron la bolsa, que sentí todo, cuando cayó todo el líquido. Y me pusieron una sonda y yo le dije "yo ya fui a hacer

\footnotetext{
${ }^{171}$ Camacaro Cuevas (2009, p. 157-158) narra un ejemplo de esta cascada o cadena de intervenciones y sostiene que se justifica porque "Esa concatenación de eventos medicalizados y patologizados asegura la eficacia del trabajo profesional y un "guardarse las espaldas" frente a cualquier emergencia ocasional, todo ello, por encima de la salud reproductiva y sicológica de las mujeres”.
} 
pis, no quiero", me pusieron una sonda igual, que me acuerdo que eso sí que me re dolió (...) realmente no, no era necesario, si yo ya había ido a hacer pis hacía 10 minutos, 20. Me pasaron la sonda, me hizo hacer pis, me re dolió me acuerdo, me pusieron la chata igual, me fui, me pusieron la peridural, me dejaron el catéter acá adherido, viste, abajo y uno hasta acá arriba" (Valeria, primer parto, público).

Finalmente, en el período expulsivo, Valeria cuenta que le realizan la maniobra de kristeller, desaconsejada por las normativas y protocolos. Lo significativo de su relato es la presencia constante del dolor, no el fisiológico o propio del proceso, sino el iatrogénico, provocado por las intervenciones médicas.

"Y yo hacía fuerza con el cuerpo, entendés. Y me decía "no, mami, así no, respirá tranquila" y de a ratos, te juro que parecía re drogada, porque de a ratos me dormía, me iba y me despertaba de nuevo y me decía "mami, no te duermas, dale, empujá, pujá", me decía. Y como a la larga, no me acuerdo en qué momento, viene una y me empieza a empujar el nene así y que cuando yo recién estaba tomando aire y entendiendo cómo era porque sentía como que me salía, y la doctora me decía "sale y entra, mami", me dice, "sale y entra, fijate que si empujás un poquito más va a salir enseguida". Bueno, para este entonces se me, me aprieta, me corta, mirá mi torso, tengo la cadera acá y las costillas acá yo, o sea soy así de cortita de torso, y me apretaba acá, el peso del nene porque ya no tenía ni líquido amniótico y me hacía doler. Y me cortaba la respiración, entonces yo le digo, la empujo y le digo "pará porque no puedo así" le digo. Y me dice "ay, bueno mami, pero tiene que salir ese bebé"' (Valeria, primer parto, público).

Tal como se mencionó anteriormente, Valeria refirió sentirse "desprotegida" en todo su proceso de parto y planificó que no dejaría que se realizaran ciertas intervenciones para su segundo hijo. Lo interesante es que esta actitud defensiva sigue reproduciendo la idea de que cada mujer es responsable y/o culpable de lo que le ocurra en su parto, y no permite ver que se trata de una estructura mayor en la que, en el caso de salud pública, el Estado y los organismos de formación médica tienen responsabilidad $^{172}$.

En los casos de Johana y Mariana, que parieron en dos hospitales privados distintos de la ciudad, registré otro tipo de violaciones a sus derechos humanos, sexuales y reproductivos. Básicamente, a Damián no lo dejaron entrar a la cesárea violando el derecho de Johana a tener el acompañamiento de la persona de su elección. Ellxs fueron padres a fines de 2016, cuando la ley ya llevaba doce años

172 "Una lectura del mundo desde la que es posible descalificar, ridiculizándolas primero, y llamándolas a la norma después, las expresiones de dolor de las mujeres a las que están atendiendo. Estamos frente a un campo médico en el que opera una estructura de poder tal que es capaz de invertir el mundo, esto es, de describir las cosas que ocurren dentro de éste de una manera por completo opuesta a las evidencias fácticas, y de imponer dicha descripción a todos los actores involucrados. En efecto, bien vistas las cosas, una mujer que pare es la protagonista del nacimiento de su bebé, y son los médicos y el personal de salud que la asisten los que están ahí para cooperar con ella. Que dicho personal encuentre natural describir a las mujeres en términos de más o menos cooperadoras no demuestra sino la capacidad performativa de los agentes dominantes del campo médico y del discurso que esgrimen.19 Esta jerarquía en funcionamiento puede llevar la interacción entre médicos y mujeres en trabajo de parto a niveles de autoritarismo más graves” (Castro, 2014, p. 185). 
sancionada y uno reglamentada. Él explicitó que habría querido entrar pero no se lo permitieron y él creyó que eso estaba "bien", que así se hacían las cosas allí. Por su parte, Mariana relata por lo menos cinco situaciones que, desde una mirada externa y centrada en lo normativo-objetivo, constituirían VO. Por un lado, la cuestión de la posición para parir, que fue distinta a la pactada previamente, incluyendo las piernas atadas, lo que la incomodaba aún más.

"Y cuando veo la camilla, no era lo que me habían dicho, era una camilla común que solamente se bajaba, la parte de las piernas se bajaba, no era anatómica. Y me quiero atar las piernas, les dije que no. Porque no, era, no podía hacer fuerza. Cuando probé, en la posición que me querían, que era totalmente horizontal pero con las piernas arriba, no podía hacer fuerza. Les decía "yo necesito agarrarme de algo porque no puedo". No podía, no era lo mismo. De hecho me agarré de la camilla y me puse... no estaba cómoda, nunca estuve cómoda" (Mariana, privado).

Asimismo la prohibición de beber y tomar no solo va contra las recomendaciones de la OMS sino que también vulnera su derecho a un parto natural sin intervenciones.

"Me faltaba, hacía mucho calor, viste que te prenden unas lámparas para el bebé, unas lámparas infrarrojas que den calor, y yo estaba... me ahogaba. No tenía aire, estaba muerta de calor, quería agua, porque viste de la adrenalina se me secaba la boca, era toda una pasta que tenía en la boca, quería agua, me decían que agua no podía tomar, que es mentira, podés tomar agua. Me dieron una gasa mojada, un asco, pero bueno. Y como a mí me faltaba el aire y tenía tanto calor lo hacía a Leo tirarme oxígeno con una manguerita, que yo me acuerdo que me tiraba de lejos y en un momento le agarro la manguera así y me empecé a manguerear porque estaba ahogada, que no podía respirar" (Mariana, privado).

Finalmente Mariana menciona dos intervenciones que dos profesionales (enfermera y obstetra, respectivamente) realizaron sobre su cuerpo, con supuestas justificaciones clínicas que le generaron mucho dolor. En primer lugar, una enfermera retuerce sus pezones bajo la excusa de que ello era lo que impedía una fluida lactancia las primeras horas. Con los días y consultando puericulturas, Mariana pudo leer que eso era parte de uno de los mitos alrededor de la lactancia: todos los pezones de todas las mujeres pueden dar leche. En segundo lugar, Mariana cuenta que fue víctima de una episiotomía "por prevención", que en los círculos activistas ya ha empezado a considerarse la mutilación genital de occidente. Se trata de la epidemia de episiotomías, que cuando son a priori sin relación con el nacimiento concreto, responden a un modus operandi de trabajo médico, estandarizado y sin atender al cuerpo y al parto de cada mujer en particular. Un desgarro controlado (con el objetivo explícito de facilitar la sutura médica) "por las dudas" de que ocurra un desgarro natural. La violación al derecho a un parto natural sin intervenciones innecesarias se vuelve mayor cuando responde a un modo sistemático de Ixs profesionales y no registra ni evalúa en qué mujeres es necesaria dicha intervención. 
"No, la hace por prevención. Ella ya me lo había dicho. "Mirá por prevención yo hago la episiotomía, antes que te desgarres y que yo tenga que coser más, yo te la hago". Hasta ahora me caga la vida, hasta hoy me caga la vida. Yo no soy la misma. No soy la misma, ¿entendés? Y eso es terrible. Es una frustración que te agarra, terrible (...) Creo que el día antes que la ví, el día antes de esto me dijo "mirá yo hago la episiotomía por prevención", no sé qué. Bueno, dije, ¿ahora me voy a empezar a hacer la loca?. ¿"No, no la quiero" o "no, me voy con otra"? ¿Qué iba a hacer en ese momento? Ya estaba. Lo peor del mundo. Lo peor. Lo peor porque la re sufrís después" (Mariana, privado)

¿Es mi trabajo como socióloga señalar las violaciones a los derechos sexuales y reproductivos que vislumbro en los relatos de parto de Ixs entrevistadxs, cuando ellxs no se identifican como víctimas de ninguna violencia? La respuesta a esta pregunta se encuentra en las páginas previas. Considero que la brecha entre la mirada objetiva o normativa y la subjetiva de este tipo de vulneraciones responde al momento de transición del proceso de construcción de la VO como problema público. Este año la ley que establece que las violaciones a los derechos de las mujeres en sus partos constituyen modalidades de violencia contra las mujeres, cumple diez años. Es sabido que los tiempos sociales y los tiempos legales no siempre son simultáneos. Tal vez en este desfasaje se encuentren las razones de por qué en esta tesis no habría VO, si la hubiera encarado como pensaba inicialmente.

\begin{abstract}
"Una delimitación y comprensión más acabada de la violencia obstétrica requiere que se consideren las prácticas y ordenamientos institucionales que se encuentran invisibilizados y no son reconocidos como formas de violencia. Para dar cuenta de la complejidad de este fenómeno, fue necesario reconocer una multiplicidad de dispositivos relacionados con el funcionamiento del sistema de salud, el diseño de políticas públicas, el modo de relación entre el equipo de salud y el público hospitalario, las relaciones jerárquicas de poder dentro de las instituciones de salud, las desigualdades en el acceso al conocimiento, el estatus social y cultural de Ixs diversxs actorxs y la cultura institucional" (Arosteguy y otras, 2017, p. 5).
\end{abstract}

En este marco de extensión y consolidación de un modelo de atención obstétrica que sistemáticamente vulnera los derechos, deseos y necesidades de las mujeres en el proceso perinatal, un actor ha emergido como clave en el proceso de construcción social de la VO como problema público: el activismo por el parto respetado. Dado que el análisis del activismo en sí implicaría una tesis aparte, la propuesta es cerrar este capítulo analizando cómo las experiencias de atención obstétrica de las mujeres en algunos casos se politizan y se convierten en herramientas para cuestionar, denunciar y cambiar la obstetricia hegemónica. 


\subsection{B. ACTIVISTAS POR EL PARTO RESPETADO: ¿EMANCIPACIÓN O NUEVAS}

NORMATIVIDADES?

Como afirmé ante, creo que una tesis doctoral en ciencias sociales sobre la atención médica de embarazos y partos no sería sociológica si no incluyera un análisis completo de las relaciones de poder que se dan en el campo analizado. En este sentido, para el campo obstétrico ha sido central en Argentina el activismo por el parto respetado que, por ejemplo, consiguió el tratamiento de un proyecto y la sanción de una ley en $2004^{173}$. Fuimos las activistas (y este cambio en el sujeto hablante es intencional) quienes conseguimos que se reglamentara en 2015. Y somos quienes trabajamos en su difusión.

Distintxs autorxs han analizado la conformación y las dinámicas propias del movimiento por la humanización del parto en relación a formas novedosas de participación ciudadana, de reivindicación de derechos sexuales y reproductivos y deseos y necesidades postergadas históricamente, de vínculos tensos con el feminismo y de prácticas emancipadas de autocuidado (Felitti, 2011; Felitti y Abdala, 2018, García Presas y otras, 2018; Schwartz, 2010a; Rich, 1986; Jerez 2015a, Fornes, 2010). En resumen, "lo que está en juego es el significado del parto como un evento social" Jerez (2015a, p.11), por lo tanto disputado, construido, atravesado por múltiples dimensiones de desigualdad. Tal vez una de las caracterizaciones más acabadas de estos grupos activistas sea la de Valeria Fornes (2010) quien sostiene:

"La coexistencia entre lo instintivo y lo cultural, lo universal y lo particular, lo reproductivo y la productivo tensan la posibilidad de un colectivo identitario que refuerce la pertenencia desde bases unívocas aunque relativamente se comparta un horizonte común. Una reivindicación de la mujer como mamífero coexiste con la de demanda como sujeto de derechos, una postura maternalista del instinto comparte el espacio con una feminista que politiza el cuerpo, una experiencia gratificante de parto domiciliario se superpone a una de violencia o maltrato en una institución (...) Todas comparten la condición genérica de ser potenciales y efectivas reproductoras biológicas (dar vida) y sociales (dar cuidado) pero sólo pasan de la serie al grupo si experimentan en carne propia, o a través de un vínculo, situaciones que se relacionan con lo bello o lo terrible de una situación de parto-nacimiento. En el primer caso por la experiencia placentera de un nacimiento respetado en un entorno cálido y afectuoso, la cual se percibe que debería ser universal y un "derecho de todas". En el segundo, porque la experiencia traumática del maltrato se eleva como prevención y denuncia para "que a nadie más le pase"'” (p. 8-9).

En este marco, el activismo por el parto respetado asume dos dimensiones complementarias: la prevención de la VO, a través de la visibilización de los derechos sexuales y reproductivos de las mujeres en su atención perinatal y la deconstrucción de los mitos obstétricos; y la denuncia de dicha violencia, a partir de la

${ }^{173}$ La ley fue resultado de la conjunción de los proyectos de la asociación activista "Dando a Luz" y del entonces ministro de salud nacional González García. 
democratización de espacios, contactos y trámites de querella. Asimismo, estas acciones militantes se dan por un lado, en el entorno material, con charlas, talleres, paneles, sobre todo en fechas claves del año: en la Semana Mundial del Parto Respetado (en mayo), para el día de la mujer (en marzo), para el día de la eliminación contra las violencias a las mujeres (en noviembre). Y, por otro lado, tiene una fuerte presencia en el entorno virtual, asumiendo la forma que analicé como un modo de ciberactivismo feminista (Castrillo, 2018a) y la potencia política de los relatos de parto.

Al respecto, en los últimos años han proliferado en las redes sociales, en diversas plataformas virtuales, foros y páginas webs, espacios de publicación de relatos de embarazos y partos de mujeres de todo el mundo. En Argentina en la red social Facebook, actualmente, hay más de una decena de grupos y páginas que se centran en publicitar las experiencias femeninas de estos procesos, en el marco de un ciberactivismo feminista que apunta a generar conciencia y empoderamiento femenino, aportar información de médicos y centros de salud, consejos, técnicas alternativas de manejo de problemas clínicos, etc. Estos grupos actúan a modo de una gran tribu virtual de mujeres, en el marco del despliegue de una sororidad femenina (Lagarde, 2012) ${ }^{174}$. Es de relevancia analizar los sentidos asignados por Ixs sujetxs a las intervenciones médicas atravesándolos por factores como la clase, el género y la edad, entre otros. Respecto a este último elemento, el factor generacional es clave: se trata de mujeres jóvenes que en su vida cotidiana han incorporado las redes sociales como espacio de publicidad de todo tipo de experiencias. ¿Por qué el embarazo y el parto van a recibir distinto tratamiento? En general, en su rol de madres, son parte de una grupalidad mayor de mujeres que integran grupos y foros virtuales respecto a temas de salud, de sexualidad y de crianza (escolaridad y lactancia, principalmente). Sostengo que publicitando sus experiencias a través de la escritura de relatos, las politizan. Así, el activismo por el parto respetado en las redes sociales, actúa como tribu virtual de empoderamiento en tanto se promueve la publicación de experiencias con el fin de que otras mujeres las retomen a la hora de pensar sus partos. Es relevante mencionar que entre las ciberactivistas se habla de "relatos de partos", pero éstos también incluyen las experiencias de embarazo, posparto y lactancia. El hecho de que se permita y fomente la mención de Ixs profesionales y las instituciones en las que ocurrieron los nacimientos, es variable entre los grupos/páginas de Facebook, ya que en la mayoría está vetado con motivos defensivos y previsores de acciones de éstos, en el marco del despliegue de una medicina defensiva.

${ }^{174}$ Adrienne Rich (1986) ya daba cuenta de estas historias de parto, sosteniendo que "éstas nunca fueron meras anécdotas, sino testimonios a través de los cuales la negligencia y el abuso de las mujeres por parte del sistema de salud podían ser sustanciados" (Rich, 1986:1) con fines políticos y de transformación social. 
Teniendo en cuenta la diversidad de las formas y modalidades que asume este activismo, para cerrar, se propone dar una vuelta y volver al punto de partida: la construcción de la agenda pública y académica alrededor de la atención de PEP ha sido potenciada por cierto sector de la militancia feminista a partir de la denuncia de la violencia obstétrica. Por ello aquí propongo una lectura crítica de este activismo, describiendo cómo muchas veces estas propuestas militantes tienden a la maternalización de las mujeres, encerrándolas en el ámbito privado, viciando de mandatos (lactancia a demanda, crianza con apego, colecho, partos naturales "mamíferos") el maternaje, lejos del deseo y el derecho a decidir.

Esto es, por un lado, tal como se pregunta Jerez (2015) en torno a qué partos merecen ser humanizados, hay una interseccionalidad de clase, género y edad en el activismo y en el reparto del parto respetado que proponen. Por ello, si la única propuesta de algunos grupos más radicalizados es abolir la hospitalización de los partos, no se estaría incluyendo a aquellas mujeres que por condiciones de vivienda y hacinamiento y por la no disponibilidad del dinero para pagar la atención particular, no quieren/pueden parir en casa.

Lo que emerge, viendo las interacciones en los grupos, asistiendo a charlas, talleres y diversas actividades, es que hay algunos grupos activistas que promueven un único modelo de parto respetado como válido: en casa, vaginal, fisiológico, sin anestesia. Por lo que, retomando a Butler (1993) propongo una crítica a este feminismo (o fundamentalismo) que se asienta en el dualismo sexo-género, naturaleza-cultura y que regula, normativiza, excluye y piensa una sola mujer o, en un este caso, un solo parto respetado. $Y$ que, lo que es peor, tiende a culpabilizar y responsabilizar a las mujeres por los partos que tuvieron. “¿Por qué te dejaste?” se lee constantemente en los comentarios a los relatos de mujeres que cuentan felices que acaban de tener a sus hijxs por cesárea o inducidas o con epidural. ¿Estamos ante una paradójica performatividad del género en la que se reiteran las normas que impone, ahora, un nuevo ideal maternal, esta vez establecido por un grupo activista "fundamentalista"?

Así, frente a aquél activismo emancipador que consiguió las leyes actuales, y que hoy mismo actúa con la idea de que el parto respetado es justamente ese, el que respeta las decisiones informadas y derechos de las mujeres (fueran los que fueran valorizados por cada una), existe cierto movimiento que genera nuevas normatividades. Esto es, a veces ciertos grupos activistas generan mandatos tan fuertes como los que discuten: imposición de la lactancia, apego, colecho, amor material instintivo, feminización de la crianza, la falta de autonomía laboral. Se trata de una trampa del discurso de la maternidad amorosa, que genera otra encerrona a las 
mujeres que no pueden/quieren cumplir con esas expectativas/exigencias. Se sale de una encerrona (la del $\mathrm{MMH}$ ) y se entra en otra (la de las maternidades impuestas amorosas). Así, se sigue potenciando la maternalización de las mujeres (Blázquez Rodríguez, 2009 y Nari, 2005) y su confinamiento al ámbito privado en un ejemplo claro de lo que la humorista Charo López ha denominado "mamasplaning" (parodiando la crítica al mansplaning patriarcal) y Mafalda nombró como "comando paramaternal". Maternidades normativizadas que continúan quitando el poder de decisión y autonomía a las mujeres que paren, crían y maternan como pueden, quieren, desean. Una vez más, se trata de romper las polarizaciones y los tipos extremos para pensar los grises de las experiencias concretas.

\subsection{A MODO DE CIERRE Y RECAPITULACIÓN}

El aporte de este capítulo radica en completar la reconstrucción de actorxs, relaciones, representaciones y estrategias que se ponen en tensión con la disputa/transición/crisis de modelos de atención médica. En este sentido, las voces de las mujeres adquiere una doble importancia: como mujeres madres, sus experiencias de embarazos y partos, permiten vislumbrar dicha disputa encarnada en el cuerpo; como activistas por el parto respetado, tienen la relevancia de haber motorizado el cambio y cuestionamiento a los modelos de atención obstétrica.

¿Por qué trabajar con relatos de parto? Porque a raíz de las regularidades y particularidades que exponen, en forma de textos acabados con la intención de comunicar públicamente sentimientos y experiencias, será posible caracterizar las significaciones de un grupo de mujeres sobre las intervenciones médicas que se dieron en sus embarazos y partos, al tiempo que se podrán "desentrañar las representaciones y prácticas médicas relativas a la mujer y la forma en que éstas la viven en carne propia" (Fornes, 2009, p. 2). Este trabajo con las experiencias subjetivas de las mujeres "permite reconstruir los derroteros por los que circulan como sujetos sociales problematizando la trama que van tejiendo sus itinerarios, los significados que éstas les atribuyen y haciendo visible lo genérico de este proceso" (Fornes, 2009, p. 4) $)^{175}$. El objetivo de este capítulo, entonces, ha sido retomar los relatos a nivel micro de la atención médica de los PEP. El aporte principal ha sido el de tender puentes entre los modelos de atención obstétrica a partir de las experiencias de

\footnotetext{
${ }^{175}$ Todo esto enmarcado en el consejo metodológico de Menéndez (2009) que promueve que la identificación y análisis de las formas de atención debería iniciarse a través de la descripción de lo que hacen, usan y dicen lxs sujetxs y grupos sociales para atender sus padecimientos (en este caso, sus partos), y no a partir de lo que afirmen los curadores biomédicos, tradicionales o alternativos ya que de este modo, "siguiendo la carrera del enfermo" es posible identificar la mayoría de las formas de atención que intervienen en un contexto determinado.
} 
mujeres-madres y varones-padres y encontrar tensiones entre el cuestionamiento y la legitimidad a la hegemonía del intervencionismo. Así, se reconstruyeron los itinerarios asistenciales durante el embarazo: la elección de Ixs profesionales y las instituciones de atención, los controles y estudios prenatales y las vivencias del periodo gestacional. Respecto al parto, se analizaron sus evaluaciones y sus relatos en torno a las intervenciones médicas, al dolor y a los diferenciales entre los ámbitos privados y públicos. En paralelo se analizaron los roles que asumieron las mujeres y los varones frente a la atención obstétrica. Finalmente se problematizó el activismo por el parto respetado, retomando las vulneraciones a los derechos sexuales y reproductivos que, en los casos analizados, pueden etiquetarse como violencia obstétrica, desde la mirada legal/objetiva.

El objetivo ha sido cubrir el amplio espectro de actorxs, experiencias, sentidos, representaciones, prácticas, expectativas y emociones que hacen al heterogéneo campo de la atención médica de embarazos y partos en la ciudad. 


\section{CONCLUSIONES}

\section{GRISES Y PUENTES EN LAS EXPERIENCIAS DE ATENCIÓN DE EMBARAZOS Y PARTOS}

A partir de una investigación con perspectiva de género y derechos humanos, se han descripto y problematizado experiencias de mujeres-madres, varones-padres y profesionales de la salud obstétrica de la ciudad de La Plata para el período 20132019 sobre la atención médica de embarazos y partos. La propuesta conceptual ha sido construir una sociología de dicha atención a partir de la construcción analítica típico ideal de modelos de atención, y la consecuente deconstrucción a partir del establecimiento de matices, transiciones y puentes entre las intervenciones médicas que son el núcleo.

Dichas intervenciones médicas han ido atravesando y guiando la tesis. En el capítulo 1 mostré cómo emergen como categoría de análisis sociológico y su construcción en relación al campo de estudios emergente, para conformar una sociología de la atención médica de embarazos y partos. Para ello propuse una caja de herramientas conceptuales para estudiar la atención hegemónica (hegemonía médica; saber experto; medicalización y patologización; enfoque de riesgo reproductivo; tecnología, producción y tiempos; y mecanismos de dominación y desautorización) y la atención alternativa/humanizada (enfoque fisiológico; democratización del saber médico; centralidad del saber femenino e intuitivo; criterio médico: necesidad y particularidad; y enfoque de derechos humanos y género). Y en este esquema las intervenciones componen las transiciones y grises entre los polos modélicos.

En el capítulo 2 presenté de qué modo me propuse estudiar el objeto con un sustento empírico, relevando experiencias actuales y heterogéneas para un caso particular. Asimismo presenté un ejercicio de reflexividad respecto a la negociación de roles en el campo y las tensiones entre militancia y academia.

En el capítulo 3 mostré cómo esas intervenciones fueron objeto de políticas públicas que las recomiendan o desaconsejan en relación al respeto o violación de derechos humanos, sexuales y reproductivos. Propuse pensar la política de humanización de la atención de partos en un círculo interrelacionado entre prácticas

médicas y derechos humanos. Asimismo describí algunos elementos de la implementación de dicha política en las maternidades públicas de la ciudad. 
En el capítulo 4 problematicé cómo se va construyendo su legitimidad y acatamiento entre las mujeres y sus acompañantes, en la socialización específica de los cursos de preparto. Para ello presenté la constitución de algunos elementos que se van desplegando en la socialización médica que se da en este espacio y en el tránsito del embarazo: expropiación del control de los tiempos y de las certezas físicas sobre los procesos (necesariedad de la mediación médica).

En el capítulo 5 mostré cómo durante los años de formación médica se construye un habitus médico hegemónico (el "saber hacer partos"), reproductor del modelo intervencionista, basado en una monopolización del saber, la burocratización de la atención, la medicalización de la vida cotidiana y el personalismo. Asimismo, presenté las disputas internas al campo profesional obstétrico. Finalmente, describí cómo emergen estrategias de disputa al modelo hegemónico, como la puesta en práctica de "otra obstetricia".

En el capítulo 6 presenté y leí críticamente las intervenciones en acción, en experiencias encarnadas de atención médica de partos, a través de los relatos de mujeres-madres y varones-padres. Finalmente, establecí cómo a partir de las intervenciones médicas y de una sociología de la atención médica de PEP es posible estudiar la problemática de la violencia obstétrica y del activismo por el parto respetado.

En general en esta tesis construí y deconstruí tipologías o modelos extremos analíticos por su finalidad heurística: me ha permitido encasillar pero a su vez mostrar desplazamientos de acciones, actorxs, representaciones, sentidos.

A modo de cierre de esta tesis, retomaré las principales conclusiones y luego presentaré las posibles líneas de indagación futura y de intervención social que emergen del trabajo aquí realizado.

$\checkmark$ He podido establecer que existe una tríada explicativa del proceso creciente de intervencionismo médico en los PEP: se trata de la combinación entre la concepción defectuosa del cuerpo femenino y de los procesos fisiológicos, la profundización de los procesos de medicalización y patologización y la construcción de la necesariedad de la intervención médica. En este marco y asimismo, la intervención simbólica del PEP (que implica su construcción como hecho médico a partir de su dessexualización, estandarización, uniformización, pacientización, infantilización, control, vigilancia, normativización, cosificación y reinado del paradigma de riesgo reproductivo) garantiza, permite, produce y exige su 
intervención práctica. Se trata de la eficacia simbólica de las representaciones incorporadas sobre el PEP y su asistencia. Los tres procesos mencionados encuentran eje en la consolidación del paradigma del riesgo obstétrico, que reproduce un encadenamiento secuencial desde la primera etiqueta de riesgo:

Las intervenciones médicas en los PEP, núcleo de esta tesis, permiten la flexibilidad necesaria para entender las disputas y tensiones en tanto soportan distintas significaciones por parte de Ixs sujetxs. Por ello las intervenciones por sí mismas no constituyen la expresión acabada de un modelo de atención, sino que es necesario conocer cómo la experimentaron Ixs sujetxs, contextualizarla. Nacer por cesárea no implica necesariamente que se trate de un evento de violencia obstétrica, por la existencia de criterios de acción y sentidos asignados, y un parto vaginal tampoco implica que se trate de un parto respetado. Lxs sujetxs implicadxs y sus acciones tienden puentes entre esos modelos, y en una misma experiencia conviven prácticas y representaciones aparentemente contradictorias entre sí.

$\checkmark$ El cuerpo gestante emerge como un territorio que soporta procesos de control y apropiación/colonización médica y a su vez de estrategias de resistencia y empoderamiento. Como sostiene Pizza (2005) "el cuerpo es el terreno de un conflicto de hegemonías" (p. 26). Un territorio atravesado por distintos factores de desigualdad, sobre todo la clase, en tanto son las mujeres pobres que asisten al sector público las que soportan intervenciones médicas didácticas en sus cuerpos, en pos de la formación médica.

$\checkmark$ En el proceso de embarazo, específicamente, se establece una pedagogía que tiende a formar a las mujeres para el evento del parto en términos de obediencia y sumisión. Frente a ésta las mujeres pueden desplegar estrategias de resistencia. El curso prenatal emerge como una acción pedagógica, que puede pensarse no sólo educativa a los fines del parto sino que opera como escuela para subsumirse a los mandatos de las instituciones médicas y generar la obediencia esperada (Erviti, 2010). Estos mandatos incluyen también las disuasiones médicas para la toma de decisiones reproductivas, que implican a las mujeres como "pacientes cautivas" del saber médico experto.

$\checkmark$ Respecto a cómo se enteraron que estaban embarazadas, sólo es destacable aquí aquella situación que evidencia la medicalización del proceso de embarazo: las 
mujeres requieren la certeza médica (certificada por un/x profesional o por un estudio: ecografía, análisis de sangre) de lo que sucede en su cuerpo. Además de ello, el contacto con el/la profesional que las asistirá está permeado por múltiples factores: por ejemplo, la imposibilidad de elegirlo por las restricciones que imponen las obras sociales; por las experiencias previas, esto es, el hecho de que en general Ixs médicxs no "permiten" partos vaginales posteriores a cesáreas previas; porque Ixs ginecólogxs que las atendieron desde siempre "ya no hacen partos" y los derivan a otrxs obstetras.

$\checkmark$ En el proceso de parto se ponen en práctica las principales intervenciones médicas y por ello considero el parto como un momento en el que se rearticula la dominancia médica o se rompe para siempre la obediencia al mandato biomédico.

$\checkmark$ Que los bebes son grandes, que las caderas son chicas. Este tipo de discursos médicos apuntan a construir cuerpos femeninos defectuosos, incapaces de cumplir con la función biológica del parto. Riesgo, cesárea, información que en un portavoz del conocimiento autorizado parece científicamente probada y neutral. La táctica del miedo (Erviti, 2010) por la posible muerte del/ de la hijx y la responsabilidad de la mujer por ello, permite justificar ciertas intervenciones médicas aceleratorias del parto. Es destacable además cómo la propia experiencia médica y ciertos curriculums ocultos de las instituciones, se superponen a la evidencia científica probada, y termina dependiendo de una voluntad y una práctica profesional subjetiva el tratamiento del embarazo y parto. Se repiten en los relatos referencias a que tal doctor/a es "pro-cesárea", "pro-inducción" o que "siempre aplica la epidural". Esto remite a etiquetas que construyen las mujeres en base a cómo perciben la atención de sus partos y se vincula a la idea de que no es el proceso de parto de cada mujer el que prima en la atención, sino cierta estandarización que, además, no es homogénea: varía según el saber experiencial médico, la institución en la que ocurra el parto, el momento del año (es conocido el aumento de tasas de cesáreas e inducción durante los fines de semana y la época de fiestas).

$\checkmark$ Las experiencias de atención pero sobretodo las relaciones médicx-paciente varían según los ámbitos de atención, aunque en todos ellos hay expresiones de intervencionismo, humanización y matices. Así, por ejemplo, en la atención pública el no personalismo en el vínculo con Ixs profesionales tiene pros y contras, y es evidente que cada guardia o médicx pone en acción cierta discrecionalidad sobre el modelo de atención que se dispensa en "su área de acción". La falta de líneas de trabajo estandarizadas que cumplan con las normativas explica la brecha. En la 
sociología de la atención médica de embarazos y partos es necesario hacer jugar ambos elementos: ámbito y modelo de atención.

$\checkmark \quad$ La participación de los varones-padres en el PEP está asistiendo a un proceso de cambio hacia un "controvertido enfoque del padre con derechos propios en el ámbito sanitario, superando la lógica del espectador o acompañante de la mujer embarazada" (Maroto Navarro y otros, 2009, p. 268). Aún es necesario trabajar en los lugares que las instituciones y los equipos les permiten ocupar y en los que ellos construyen para sí.

$\checkmark$ Considero que estamos en un proceso de transición entre modelos de atención obstétrica, en el que se cuestiona la reproducción de la reproducción hegemónica. Cierta crisis hegemónica o de rearticulación de la atención de embarazos y partos, donde lo viejo no termina de morir y lo nuevo no termina de nacer. Aún no hay una apropiación subjetiva y colectiva de la violencia obstétrica como una forma de violencia contra las mujeres, y su naturalización e invisibilización es el germen de su reproducción. Y en paralelo, la emergencia y consolidación del activismo por el parto respetado y la construcción de un entramado de normativas con enfoque de derechos humanos y género van hacía una nueva dirección. En ese marco en esta tesis busqué mostrar cómo en el mismo contexto es posible conocer experiencias en las que se legitima y al mismo tiempo se cuestiona el parto hegemónico transmitido (doloroso, traumático, acostadas, solas) y se instauran otros discursos y nuevos partos transmitidos. He buscado mostrar la existencia de formas hegemónicas y alternativas de representaciones y prácticas sobre parto/ dolor/ riesgo/ relación médicx-paciente; y ciertas articulaciones y disputas médicas entre modelos de atención: Ixs profesionales de la salud también resisten el MMH. Se trata de una disputa hegemónica que implica a una multiplicidad de actorxs: Estado, universidades, sociedades médicas, colegios obstétricos, movimientos sociales, ciudadanxs, medios de comunicación, movimientos feministas.

$\checkmark$ El modo en que se dan las intervenciones médicas refleja coordenadas del modelo médico hegemónico actual ( $y$ de imperativos sociales de clase, género, raciales) que imperan en la medicalización. En este sentido, sobresalen algunas características, como son el control de los procesos biológicos, la búsqueda de la inmediatez, la construcción social negativa del dolor y la responsabilización de las mujeres sobre las consecuencias iatrogénicas de las intervenciones. Las consecuencias simbólicas de las intervenciones médicas en general se refieren a la 
relación médicx-paciente, a ese entramado de creencias, representaciones y asignaciones de roles. De este modo es visible que, en términos generales, el corpus de intervenciones médicas es percibido como algo distinto a la relación inmediata con el/la médicx que asiste el propio proceso de embarazo y parto. Distinto en tanto algunas mujeres separan la actividad del/la médicx de ciertas intervenciones que se realizaron - ¿en impersonal?- y, en algún punto, reifican o dan una gran entidad a los designios de la naturaleza, del clima humano, de las circunstancias y del "sistema" sin visibilizar ni construir una relación causal directa entre la experiencia y el tipo de atención recibida por tal o cual profesional, ni su propia agencia. De hecho se asume que hay mujeres que sufren maltratos o son víctimas de prácticas rutinarias innecesarias, pero no se vincula ese "dato de la realidad" con la experiencia subjetiva.

Considero, siguiendo Erviti (2010), que en las construcciones discursivas de Ixs sujetxs emerge un entramado complejo de creencias, mitos y dispositivos sociales y que, en general, "la existencia de dispositivos sociales de asignación y acatamiento de los cuidados y la responsabilidad ante los embarazos [y partos] se despliega en las interacciones de los médicos con las mujeres en la atención del parto" (Erviti, 2010:9). A partir de estas relaciones médicx-pacientes y de las intervenciones médicas que se realizan en su marco, es desde donde se construyen las experiencias y los sentidos asignados. Destaco que en el análisis de las experiencias y los sentidos asignados por las mujeres-madres a las intervenciones médicas es necesario tener en cuenta ciertas estrías de clase y trayectorias militantes y de empoderamiento que permean el discurso, que suele valorar positivamente la relación con el/la profesional, autorresponsabilizarse de lo nologrado, aunque la experiencia general sea considerada como negativa. Es interesante, entonces, ver dónde ubican los distintos sentidos; qué significantes hegemónicos se discuten o se apropian y destacar el carácter intrínsecamente legitimador y a la vez destituyente, resistente, crítico de las prácticas y representaciones.

"Hacer partos y parir" busca representar esa disputa por el protagonismo de la escena de los nacimientos. ¿Quiénes son Ixs sujetxs centrales? ¿Lxs que "hacen" (intervienen) el parto o las que paren? ¿Lxs que empujan o las que pujan? La búsqueda es por analizar las construcciones socioculturales sobre el rol protagónico en la escena del parto/obstétrica. Lo que está detrás del título de esta tesis es la vuelta al protagonismo total de las mujeres en sus procesos de embarazo y parto, porque 
¿quiénes son Ixs que hacen el parto? Son las propias mujeres y Ixs niñxs por nacer quienes realizan el trabajo de parto. La naturalización de esta confusión sobre hacer partos, expresada en la pregunta común a las puérperas sobre "quién te hizo el parto", implica la normalización no sólo de un protagonismo cambiado de la escena del parto sino de todo el arsenal de relaciones médicx-pacientes, indicaciones, intervenciones y mandatos que se mostraron en esta tesis. Si después de leerla, solo una persona comienza a preguntar "quién te asistió/acompañó/atendió en el parto", parte del trabajo de deconstrucción sociocultural habrá comenzado.

\section{>LINEAS DE INDAGACIÓN FUTURA}

Destaco cuatro líneas de indagación futura, bien porque emergieron en la tesis como problemáticas no consideradas o bien por ciertas decisiones de recorte del objeto de estudio que las dejaron por fuera. En primer lugar, y probablemente como constitutivo de mis investigaciones postdoctorales, la cuestión de la formación médica aparece como un elemento muy rico en cuanto a brechas, tensiones, disputas. Desde la formación de grado y la inexistencia del enfoque fisiológico como núcleo de la enseñanza de la obstetricia y la ausencia de la perspectiva de derechos humanos y género hasta los años de residencia en hospitales, donde se consolidan y naturalizan muchas de las principales formas de violencia obstétrica.

En segundo lugar y como un emergente del campo, la consolidación de todo un campo de disputa con la biomedicina por los cuidados puerperales y de Ixs recién nacidxs, pero en particular la cuestión de la lactancia materna ${ }^{176}$. En la práctica concreta de muchas congéneres "dar la teta" es la parte más difícil, engorrosa, dolorosa e invisibilizada de la práctica de maternar y a la vez la más naturalizada y edulcorada. Analizar ese núcleo oscuro alrededor de las expectativas y las realidades de amamantar me parece muy interesante y relevante

En tercer lugar y como efecto del recorte del objeto de estudio y de Ixs actorxs incluidxs en el estudio, discutir el modelo clásico de familia heteroparental e incluir parejas homoparentales, co-maternidades, co-paternidades, monoparentalidades y otros formatos familiares, sería sumamente fructífero $^{177}$, para conocer diversas experiencias de atención médica de los PEP.

\footnotetext{
${ }^{176}$ Schwartz (2010) da unas primeras coordenadas para pensar ese objeto: "el amamantamiento es un proceso complejo que demanda un determinado aprendizaje y un contexto social favorable. La lactancia materna es una práctica socialmente construida; los mitos y significados acerca de ella dependen de intereses histórico sociales (Almeida, 1999)” (p.100).

${ }^{177}$ En esta área los trabajos de Schwartz (2016) y Trupa (2015) son guían ineludibles.
} 
Finalmente, creo sumamente fértiles los debates en torno al activismo por el parto respetado, los cruces entre clase y género y, en particular, la disputas sobre los modelos de maternidad y maternaje que proponen.

La descripción de estas cuatro líneas no excluye la emergencia de otras posibilidades de trabajo futuro.

\section{> PROPUESTAS DE CAMBIO/INTERVENCIÓN}

Tal como se ha ido vislumbrando en el desarrollo de la tesis, la imbricación entre sociología y militancia o entre academia y activismo signó este trabajo. A modo de una investigación-acción, mientras desarrollaba mi tesis, me consolidaba como una divulgadora de los derechos del parto en "el campo" y mucho de ese rol fue construido a partir de la realización de esta tesis. Por ello y a modo de propuesta y de "devolución social", presento algunas posibles estrategias concretar para disminuir la brecha entre las normativas y el horizonte humanizador y la real atención de embarazos y partos. Porque como bien aprendimos, no se trata solo de comprender la realidad, sino también de transformarla.

El eje de esta propuesta transformadora es, imitando la línea de trabajo del activismo, comprometerse paralelamente en la difusión y apropiación de los derechos tanto como en la prevención y erradicación de la VO. En este sentido, en primer lugar considero que el parto respetado como derecho articulador de un conjunto de derechos sexuales y reproductivos, debería ser parte de los contenidos de la Educación Sexual Integral, que a su vez debería estar ya en acción en todos los niveles educativos. De este modo se trabajaría colectiva y estructuralmente en la deconstrucción del parto hegemónico transmitido y podríamos construir otras formas de pensar, vivenciar, sentir, demandar y desear transitar los embarazos y partos, ligados al placer, al goce y a los derechos que nos asisten y a enfoques fisiológicos, más cercanos a lo sexual y femenino, que a lo médico-institucional.

En segundo lugar, construir nuevos sentidos en lo específico de los cursos de preparto. Una de las decisiones metodológicas que tomé al cerrar mi trabajo de campo en cada uno de los cursos, fue dar una devolución a su equipo coordinador, con miras a proponer algunas (humildes) opiniones o posibilidades de mejora, sobre todo en las dinámicas de participación del público (por mi experiencia personal en dictado de talleres y prácticas de educación popular). Esta decisión de dar devoluciones se originó tanto en mi propia necesidad como en la demanda de quienes dictan los cursos por conocer la perspectiva de una veedora externa. Las devoluciones (presentadas por escrito en persona o vía digital) se centraron en dos dimensiones: cambios en las formas (llevarlo a un formato taller, de democratización de saberes y de mayor 
participación de Ixs asistentes) y cambios o incorporaciones en los contenidos de los cursos. Sobre esto último, resalté que hay tres cuestiones que deberían profundizarse y/o incluirse. Primero y principal, la dimensión de la ley y los derechos de las mujeres y varones en el proceso de conocimiento. Es una obligación legal y estatal como agentes de salud. Segundo, el trabajo sobre las relaciones con Ixs médicxs que asisten sus PEP: trabajar en la deconstrucción de la autoridad médica, en la negociación, en la posibilidad de elegir. Tercero y fundamental, problematizar qué lugar se les da a los varones-padres desde y en los CPP. En algunos se los sobreprotege, en otros se los obliga a participar, en otros se le dan herramientas, en otros ni se los incluye. Mi propuesta, que se vincula con la inquietud política y cognitiva en torno a la participación de los varones-padres en los PEP, es la de asignar el rol de el que recuerda los acuerdos, las necesidades y deseos de su mujer en el momento del parto, de máxima vulnerabilidad y desconexión con el entorno. Esto es, como propugna el enfoque fisiológico del parto, durante el periodo del trabajo de parto al alumbramiento, la mujer, si se respetan sus mecanismos hormonales, irá descendiendo en el estado de conciencia. La estimulación con preguntas o la actitud defensiva ante la posible violación de derechos (que no la dejen entrar acompañada a la sala de parto, que le realicen intervenciones innecesarias, que la obliguen a atravesar el trabajo de parto y nacimiento en una posición no elegida, etc.) activa el neo córtex, lo que no permite la secreción de las hormonas del parto y rompe con la fisiología del proceso. Si quien se encarga de responder, garantizar los deseos y necesidades y establecer los vínculos con Ixs otrxs de la escena del parto es el varón padre (o quien acompañe, claro está, aquí me refiero a parejas heterosexuales) como el ser racional, que además ayuda en el sostén físico y emocional de su compañera, encontraría un espacio de participación activa y de involucramiento y vinculo parental.

En tercer lugar, es un requisito ineludible la intervención en los contenidos de las facultades de ciencias médicas hacia paradigmas respetuosos de los derechos humanos. De todos modos la revisión de las prácticas médicas es condición necesaria pero no suficiente para la humanización: es necesario garantizar derechos. Por ello es necesario que los protocolos de atención médicos e institucionales se adapten a las normativas humanizadoras. Los derechos de las mujeres no pueden estar supeditados a convicciones, maneras de trabajar, experiencias e influencias de Ixs profesionales. Amparar el respeto de los derechos en voluntades o discrecionalidades va contra la posibilidad de construir institucionalidad. Actualmente siguen primando los nombres propios en la garantía de derechos y de humanización y se sigue consolidando la triada de excusas para no respetarlos (infraestructura / voluntad política / formación), en tanto la práctica médica se encuentra atada al contexto y las condiciones de 
producción. Por ello, claramente, la prioridad por el parto respetado debería ser una política de Estado global e integral. Entiendo que en un país gobernado por una corporación que suprime el Ministerio de Salud, las posibilidades de cambio deberán ampararse más en los trabajos de los movimientos activistas feministas y los trabajos de divulgación de derechos, para garantizar su apropiación subjetiva.

El cambio hacia la humanización es multidireccional: de arriba hacia abajo (el Estado interviniendo en la actividad profesional, garantizando derechos a Ixs ciudadanxs) y de abajo hacia arriba, a través de la construcción de la agenda pública y política amparada en la exigibilidad de los derechos. También es horizontal, entre mujeres, entre varones, entre generaciones, en un gran ejercicio de deconstrucción sobre cómo nacimos y cómo parimos, y como queremos y podemos parir y nacer. La apuesta es por construir nuevos partos culturalmente hegemónicos, que consideren las necesidades y derechos de las mujeres y sus familias en el proceso perinatal.

La propuesta de esta tesis ha sido construir saberes situados (Femenias y Soza Rossi, 2011) sobre cómo se nace y se pare en la actualidad y cómo Ixs sujetxs experimentan la atención médica de dichos PEP. Mientras escribía esta tesis (20132019), nacieron casi 80.000 personas en la ciudad de La Plata ${ }^{178}$. Es posible decir que la mayoría de esos nacimientos se dieron en el marco de un modelo asistencial intervencionista, en el que primaron los criterios y necesidades médicas, que tienden a patologizar el proceso, sobre los derechos y deseos de las mujeres y sus familias. La apuesta es porque cada vez más el porcentaje de nacimientos placenteros, respetuosos y fisiológicos crezca.

178 Siguiendo los datos de la DEIS que establecen un promedio de 13500 nacimientos anuales para la ciudad desde 2013, realicé un calculo aproximado a fines ilustrativos. 


\section{REFERENCIAS BIBLIOGRÁFICAS ${ }^{179}$}

ALIAGA, P. (2012) Violencia y resistencia: La maternidad dentro de un contexto biomédico. En Red Chilena contra la Violencia Doméstica y Sexual (coord.) Mujeres y violencia: Silencio y Resistencias. Chile.

ALONSO, L., \& BENITO, L. (1998) La mirada cualitativa en sociología: una aproximación interpretativa (Vol. 218). España. Ed: Fundamentos.

ÁLVAREZ, S. (2011) Haciéndose hombre en la calle y en la escuela. La construcción social de la masculinidad en los andes colombianos en Rifiotis, T. y Castelnuovo N. (coord.), Antropología, violencia y justicia. Repensando matrices de sociabilidad contemporánea en el campo del género y de la familia. Buenos Aires. Ed: Antropofagía.

ARANGO, F., GÓMEZ, J., \& ZULETA, J. (2005) Uso de prácticas clínicas durante el embarazo, parto, puerperio y recién nacido, en hospitales públicos de Manizales-Colombia. Revista Colombiana de Obstetricia y Ginecología, 56(4), 271-280.

ARGUEDAZ RAMÍREZ, J. (2014), La violencia obstétrica: propuesta conceptual a partir de la experiencia costarricense. Cuadernos Intercambio sobre Centroamérica y el Caribe Vol. 11, No. 1 Enero-Junio (2014), pp. 155-180 -ISSN: 1659-4940

ARIZA, M. y DE OLIVEIRA, O. (2000) Contribuciones de la perspectiva de género a la sociología de la población en Latinoamérica. Trabajo preparado para el panel "Repensando la Sociología Latinoamericana", XXII International Congress, Latin American Sociological Association (LASA), Miami, marzo 16-18, 2000.

ARNAU SÁNCHEZ, J., MARTÍNEZ ROCHE, M. E., NICOLAS VIGUERAS, M.D., BAS PEÑA, E., MORALES LÓPEZ, R., y ÁLVAREZ MUNÁRRIZ, L. (2012). Los conceptos del parto normal, natural y humanizado. El caso del area I de salud de la región de Murcia. AlBR. Revista de Antropología Iberoamericana, 7 (Mayo-Agosto) ISSN 1695-9752

AROSTEGUY, J., CANEVARI, C., RIGHETTI, N., y VALLEJOS, C. (2017) Violencia obstétrica: un desafio para la salud pública. Trabajo presentado para las XIII Jornadas Nacionales de Historia de las Mujeres, UBA y UNQUI, Julio 2017.

ARVELO ARREGUI, L., (2004) Maternidad, paternidad y género. Otras Miradas. 2004, 4 (diciembre). ISSN 1317-5904

BÁEZ, A., \& SCHIAVONI, L. (2009) Entre el" trato" y el" contrato": percepciones de las usuarias acerca de los servicios de atención obstétrica. VII Jornadas Nacionales de Debate Interdisciplinario en Salud y Población, 5(6).

BARANCHUK, N., (2009) Humanización de la atención perinatal. Revista del Hospital Materno Infantil Ramón Sardá, 19. ISSN 1514-9838

BELLI, L. (2013) La violencia obstétrica: otra forma de violación a los derechos humanos. Revista Redbioética/UNESCO, Año 4, 1 (7): 25-34, Enero - Junio 2013 ISSN 2077-9445

BIERNAT, C. y RAMACCIOTTI, K. (2013) Crecer y multiplicarse. La política sanitaria maternoinfantil. Argentina 1900-1960. Argentina, Ed: Biblos.

BIERNAT, C. y RAMACCIOTTI, K. (2014) Síntesis del libro "Crecer y multiplicarse". Estudios Comparados de América Latina, GESHAL. Mesa redonda sobrelíneas de investigación comparativas entre las políticas sociales de Argentina y Brasil.

BLÁZQUEZ RODRÍGUEZ, M. (2009) Ideologías y prácticas de género en la atención sanitaria del embarazo, parto y puerperio: el caso del área 12 de la Comunidad de Madrid. Universitat Rovira i Virgili.

BLÁZQUEZ RODRÍGUEZ, M., (2005) Aproximación a la antropología de la reproducción. AIBR. Revista de Antropología Iberoamericana, 42. Julio-Agosto 2005. ISSN 1578-9705.

BLÁZQUEZ RODRÍGUEZ, M., (2008) Una etnografía en la atención sanitaria. En Romani, O., Larrea, C., y Fernández, J., (coord.) Antropología de la medicina, metodologías e interdisciplinariedad: de las teorías a las prácticas académicas y profesionales. España. Ed: Donostia, Ankulegi Antropologia Elkartea. ISBN-13: 978-84-691-4953-9.

BOCCO, G., BUFFA, S., CASTRO, M., FERRUCCI, S., GÓMEZ, M., \& LEDESMA, N. (2012) Procesos Socioculturales y dinámicas de género. Anuario de Investigaciones de la Facultad de Psicología, 1(1). 331-340 ISSN 1853-0354.

BOICHUK, L. (2012), La maternidad como acto político. Disponible en: http://www.80grados.net/la-maternidad-como-acto-politico/

${ }^{179}$ Realizadas según la “Guía para citas y referencias de Publicaciones de la FaHCE” de 2017. 
BOTELLO, N. (2003) El espacio de la violencia: un modelo de interpretación social. Sociológica, 18(52), 119-145.

BOURDIEU, P. (2007a) Campo del poder y reproducción social: elementos para un análisis de la dinámica de las clases. Córdoba, Ferreyra Editor.

BOURDIEU, P. (2007b [1991]) El sentido práctico. Madrid, Taurus.

BOURDIEU, P. (1990). Algunas propiedades de los campos. Sociología y cultura, 11, 52-65.

BOURDIEU, P. (2000) La dominación masculina. Editorial Anagrama. Barcelona.

BROWN, J. (2007) Mujeres y ciudadanía: de la diferencia sexual como diferencia política. Kairos: Revista de temas sociales, (19), 1.

BROWN, J. L. (2014) Ideas, opiniones y conocimientos sobre derechos (no) reproductivos y sexuales. In I Jornadas de Género y Diversidad Sexual (GEDIS)(La Plata, 2014).

BROWN, J. L. (2015) Sentidos sobre derechos, salud y sexualidad en Argentina. Un estudio exploratorio. Question, 1(48), 325-340.

BURGO, P. (s/f) Litotomia en el parto, una práctica cuestionable. Disponible en: http://www.holistika.net/parto_natural/parto_medicalizado/la_postura_de_litotomia_acostada-_es_la_mas_comoda_y_digna_para_la_mujer.asp

BUTLER, J. (1993). 2002. Cuerpos que importan. Sobre los límites materiales y discursivos del "sexo.

CÁCERES-MANRIQUE, F., MOLINA-MARÍN, G., (2010) Inequidades sociales en atención materna. Revista Colombiana de Obstetricia y Ginecología, 61. ISSN 0034-7434

CAMACARO CUEVAS, M. y CAMACARO GÓMEZ, M. (2010) Un cuerpo mutilado a la orden de otro. Salus Online. Volumen 13 - Sup. 1 Año 2009-2010. Pp 57-65.

CAMACARO CUEVAS, M. (2000) Experiencia del parto. Proceso de la mujer o acto médico. Universidad de Carabobo.

CAMACARO CUEVAS, M. (2008a) La construcción discursiva médico-obstétrica en el proceso reproductivo de las mujeres. Revista Ensayo y error, Año XVII, № 35. Caracas, 2008, pp. 95-115. ISNN 1315-2149.

CAMACARO CUEVAS, M. (2008b) Dos sentencias masculinas: parirás con dolor... parirás acostada. En: Delgado de Smith y González, (comp.) Mujeres en el mundo. Migración, género, trabajo, historia, arte y política. Laboratorio de investigación en estudios del trabajo. (LAINET). Facultad de Ciencias Económicas y Sociales. Universidad de Carabobo. Valencia, Venezuela.

CAMACARO CUEVAS, M. (2009) Patologizando lo natural, naturalizando lo patológico. Improntas de la praxis obstétrica. Revista Venezolana de Estudios de La Mujer Caracas. Enero/Junio 2009 - VOL. 14 / N 32

CAMACARO CUEVAS, M. (2016) La atención respetada del parto/nacimiento será una política pública en ciernes... inconclusa... o una quimera...? Revista venezolana de estudios de la mujer, 21(47), 150-161.

CAMACARO GÓMEZ, M. (2009) Histerectomia: una práctica médica entre la profilaxis y la castración. En Delgado de Smith y González (coord.) Mujeres en el Mundo: Ciencia, género, migraciones, arte, lenguaje y familia. Laboratorio de Investigación en Estudios del Trabajo (LAINET) Facultad de Ciencias Económicas y Sociales. Universidad de Carabobo. Venezuela.

CAMPERO, L. (2007) Problemas, políticas y acciones para mejorar la salud reproductiva. Salud Pública de México. 2007, 49 ISSN 0036-3634

CAMPOS FLORES, J., ÁlVAREZ, J., GARCíA, P., NEMER, C., ESTIÚ, M.C., ROJAS, M., (2007). Parto vaginal después de una cesárea. Revista del Hospital Materno Infantil Ramón Sardá 2007, 26. ISSN 1514-9838

CANELLOTTO, A., y LUCHTEMBERG, E., (coord.) (2008). Medicalización y sociedad. Lecturas críticas sobre un fenómeno en expansión. Argentina: Observatorio Argentino de Drogas (SEDRONAR)

CANEVARI BLEDEL, C. (2011). Cuerpos enajenados: experiencias de mujeres en una maternidad pública. Argentina. Barco Edita.

CANEVARI BLEDEL, C. (2016) El marco legal de la violencia obstétrica: derechos y reveses. El marco legal de la violencia obstétrica: derechos y reveses. Jornadas Salud y Población. ISSN № 978- 950-29-1322-3

CARDENES, G. C., \& BARQUERO, M. U. (2002) La mujer frente a las tecnologías médicas: Problemas éticos en el proceso del parto. Revista de filosofía de la Universidad de Costa Rica, 40(100), 125-132. 
CARDUS I FONT, L. (2015). Miedo al parto y narrativas intergeneracionales: Una aproximación desde la antropología. Dilemata, (18), 129-145.

CASTAÑEDA ABACAL, I. (2014) El marco teórico en la investigación en salud con enfoque de género. Revista Cubana de Salud Pública. 2014;40 (2):249-257

CASTILLA, M. V. (2011) Miradas maternas de la paternidad. En Felitti, K.(ed.). Madre no hay una sola: experiencias de maternidad en Argentina. Fundación Centro de Integración, Communicación, Cultura y Sociedad-CICCUS.

CASTRILLO, B. (2018a) Relatos de parto: dispositivos de ciberactivismo feminista hacia una ciudadanía reproductiva. Prácticas de oficio. Volumen 1, Número 21. Junio 2018 Diciembre 2018. ISSN 1851-6076

CASTRILLO, B. (2018b) Derechos de mujeres y prácticas médicas. Humanización de la atención médica de partos. En Ortale, S. y Rausky, E. (comp.) Políticas sociales, desigualdades y vulnerabilidades. Prosecretaría de Gestion Editorial y Difusión - FaHCE, La Plata, Argentina. 978-950-34-1641-9

CASTRILLO, B. y SALSA CORTIZO, V. (2018) La partería bonaerense en el campo legislativo: entre recomendaciones internacionales y escenarios locales. Trabajo presentado a las $V^{\circ}$ Jornadas CINIG de Estudios de Género y Feminismos y III - Congreso Internacional de Identidades. IdIHCS (UNLP/CONICET) FaHCE /UNLP.

CASTRILLO, B. (2017) 'Yo no puedo parir en casa porque tengo piso de tierra'. Desigualdades sociales en la atención médica de embarazos y partos, y en las demandas políticas por el parto respetado. Trabajo presentado al IV Seminario Internacional Desigualdad y Movilidad Social en América Latina. La Plata, junio de 2017.

CASTRILLO, B. (2016a) Dime quién lo define y te diré si es violento. Reflexiones sobre la violencia obstétrica. Sexualidad, Salud y Sociedad-Revista Latinoamericana, (24), 43-68. ISSN 1984-6487.

CASTRILLO, B. (2016b) Análisis de la atención médica de embarazos y partos: aportes conceptuales. II Jornadas de Género y Diversidad Sexual de la Facultad de Trabajo Social de la UNLP. La Plata, octubre de 2016.

CASTRILLO, B. (2016c) Gobierno de embarazos y partos: las guías de procedimientos de los Ministerios de Salud nacional y provincial. Trabajo presentado en las XII Jornadas Nacionales de Debate Interdisciplinario en Salud y Población; Buenos Aires, agosto de 2016. Área de Salud y Población, Instituto de Investigaciones Gino Germani, Facultad de Ciencias Sociales, Universidad de Buenos Aires. ISSN: 978-950-29-1322-3

CASTRILLO, B. (2016d) De partos y derechos en el camino hacia la humanización. Trabajo presentado en las VIII Jornadas de Investigación en Antropología Social Santiago Wallace; Buenos Aires, 27 al 29 de julio de 2016; Facultad de Filosofía y Letras Universidad de Buenos Aires. ISSN 1850-1834

CASTRILLO, B. (2015a) Parir en casa, parir en el hospital. Algunas dimensiones para el análisis de los lugares del parto. Geograficando, 11 (2), diciembre 2015. La Plata, Argentina. ISSN 2346-898X.

CASTRILLO, B. (2015b) Intervenciones médicas en los procesos de embarazo y parto: Reflexiones conceptuales y análisis de relatos de partos de la ciudad de La Plata. Trabajo presentado en XI Jornadas de Sociología de la UBA, 13 al 17 de julio de 2015, Ciudad Autónoma de Buenos Aires, Argentina.

CASTRILLO, B. (2014a) Un recorrido por los modos de estudiar intervención médica en el parto. I Jornadas de Género y Diversidad Sexual, Área de Género y Diversidad Sexual, Facultad de Trabajo Social de la UNLP. ISBN: 978-950-34-1154-4

CASTRILLO, B. (2014b) La perspectiva de género en el estudio de la intervención médica en el parto. I Congreso de Investigación Cualitativa en Ciencias Sociales / I Post Congreso ICQI, International Institute of Qualitative Inquiry, University of Illinois. Universidad Siglo 21, Córdoba, Argentina. ISSN 1851-4790.

CASTRO, R. \& BRONFMAN, M. (1993) Teoría feminista y sociología médica: bases para una discusión. Cadernos de Saúde Pública, 9(3), 375-394.

CASTRO, R. (2014) Génesis y práctica del habitus médico autoritario en México. Revista Mexicana de Sociología 76,núm. 2 (abril-junio, 2014): 167-197. México, D.F. ISSN: 01882503/14/07602-01

CASTRO, R. (2011). Teoría social y salud. CRIM. Buenos Aires. Ed. Lugar.

CASTRO, R., \& ERVITI, J. (2015) Sociología de la práctica médica autoritaria. Violencia obstétrica, anticoncepción inducida y derechos reproductivos. México: UNAM, CRiM 
CASTRO, R., \& ERVITI, J. (2014) 25 años de investigación sobre violencia obstétrica en México. Revista Conamed, 19(1), 37-42.

CASTRO, R., \& LÓPEZ, A. (2010) Poder médico y ciudadanía: el conflicto social de los profesionales de la salud con los derechos reproductivos en América Latina. Montevideo: Universidad de la República; México: UNAM, CRiM.

CASTRO, R., BRONFMAN, M., y LOYA, M. (1991) Embarazo y parto entre la tradición y la modernidad: el caso de Ocuituco. Estudios Sociológicos IX: 27 (1991).

CHECA, S., (2006) ¿De qué hablamos cuando hablamos de derecho a una maternidad libre de riesgos? Revista del Hospital Materno Infantil Ramón Sardá 2006, 25. ISSN 1514-9838

CHECA, S. (2000) La perspectiva de género en la humanización de la atención perinatal. Revista del Hospital Materno Infantil Ramón Sardá, 19(4).

CHECA, S., \& ROSENBERG, M. (1998). Sobre Derechos Reproductivos y su relación con la violencia social. En Izaguirre, I. y Aguiar, E. (coord.) Violencia Social y Derechos Humanos. Buenos Aires. Eudeba.

CHIAROTTI, S., JURADO, M. G., AUCÍA, A., \& ARMINCHIARDI, S. (2003) Con todo al aire. Reporte de derechos humanos sobre la atención en salud reproductiva en hospitales públicos. INSEGNAR/CLADEM.

COLANZI, I. (2014) De brujas y parteras: disciplinamiento y violencia obstétrica. In VIII Jornadas de Sociología de la UNLP. La Plata.

COLOMBET TROVAR, C., (2008) La protección social de la maternidad en Cuba y Venezuela: un estudio comparado. Observatorio Laboral Revista Venezolana, 1 (Enero-Junio).ISSN 1856-9099

CONRAD, P. (1982) Sobre la medicalización de la anormalidad y el control social. En: Psiquiatría Crítica. La política de salud mental. Barcelona, Ed: Crítica.

CONTRERAS-PULACHE, H., MORI-QUISPE, E., \& LAM-FIGUEROA, N. (2011). EI Blues Materno. Contextualización, definición y presentación de un instrumento de evaluación. Revista Peruana de Epidemiología, 15(2).

COWEN, P. (2016) Régimen de lactancia y mortalidad infantil en el siglo XIX porteño. Notas para su estudio. In IX Jornadas de Sociología de la UNLP 5 al 7 de diciembre de 2016 Ensenada, Argentina. UNLP.

DAVIS-FLOYD, R. (2009) Perspectivas antropológicas del parto y el nacimiento humano. Buenos Aires: Editorial Creavida.

DAVIS-FLOYD, R. (2004) Birth as an American rite of passage: With a new preface. Univ of California Press.

DAVIS-FLOYD, R. (2001) The technocratic, humanistic, and holistic paradigms of childbirth. International Journal of Gynecology \& Obstetrics, 75(S1).

DAVIS-FLOYD, R., (1994) El modelo tecnocrático en medicina en Del medico al sanador. Buenos Aires: Creavida, 23-60.

DAVIS-FLOYD, R. \& SARGENT, C. F. (1997) Childbirth and authoritative knowledge: Crosscultural perspectives. Univ of California Press.

DE BARBIERI, T. (1993) Sobre la categoría género: una introducción teórico metodológica. Debates en Sociologia no 18. UNAM. México. Pp 145-169.

DE BERNARDI, J. (2013) El parto publicado. El uso de las redes sociales como herramienta de denunca de violencia obstétrica. Ponencia presentada al XXIX Congreso ALAS Chile.

DE KEIJZER, B. (2001) Los hombres ante la salud sexual y reproductiva: una relación contradictoria. Bronfman M, Denmac C. Salud reproductiva: Temas y debates. México: Instituto Nacional de Salud Reproductiva.

DIPIETRANTONIO y otros (2007) Programa maternidades centradas en la familia. Revista del Hospital Materno Infantil Ramón Sardá 2007, 26. ISSN 1514-9838

EHRENREICH, B., \& ENGLISH, D. (1981) Brujas, parteras y enfermeras. Una historia de sanadoras. Buenos Aires. Ediciones la mariposa y la iguana.

ELIAS, N. (1998). Ensayo teórico sobre las relaciones entre establecidos y marginados. La civilización de los padres y otros ensayos, 79-138.

ERVITI J., CASTRO, R., y SOSA, I. (2006) Las luchas clasificatorias en torno al aborto: el caso de los médicos en hospitales públicos de México. Estudios Sociológicos, vol. XXIV, núm. 72, pp. 637-665.

ERVITI, J. (2010). Construcción de los objetos profesionales, orden corporal y desigualdad social. Una reflexión en torno a las interacciones médicos-usuarias de servicios ginecológicos. En Castro, R. y López Gómez, A. (ed.). Poder médico y ciudadanía: el conflicto social de los profesionales de la salud con los derechos reproductivos en 
América Latina: avances y desafíos en la investigación regional. Montevideo: Universidad de la República; México: UNAM, CRIM.

ESCURIET, R., PUEYO, M., BIESCAS, H., ESPIGA, I., COLLS, C., SANDERS, M., \& RUBIO, V. O. (2014). La atención al parto en diferentes países de la Organización para la Cooperación y el Desarrollo Económico (OCDE). Matronas profesión, (2), 62-70. España.

ESPINOSA PÉREZ, B., (2006) El lenguaje jurídico ante la transformación de un mito. Vniversitas 2006, (julio-diciembre).

ESTEBAN, M. L., (2001) El género como categoría analítica. Revisiones y aplicaciones a la salud. Perspectivas de género en salud. Fundamentos científicos y socioprofesionales de diferencias sexuales no previstas. Miqueo, Consuelo.

FACIO, A. (2009). Metodología para el análisis de género del fenómeno legal. En Ávila Santamaría, R.; Salgado, J. \& Valladares, L. (Comps.) El género en el derecho. Ensayos críticos. 1 Ed. Quito: Ministerio de Justicia y Derechos Humanos.

FARIAS, J. (2013). Desnaturalizar para volver a lo natural. En Comunicar Igualdad.

FELITTI, K. \& ABDALA, L., (2018), El parto humanizado en la Argentina: activismos, espiritualidades y derechos. En Laako, H. y Sánchez Ramirez, G. (eds.) Partería en América Latina. Diferentes territorios, las mismas batallas. San Cristobal de las Casas, Chiapas, México (ECOSUR), 2018, pp.95-121

FELITTI, K. (2012) Nuevas formas de atención del parto en la argentina de los años sesenta y setenta: debates y experiencias. En Pérez E, Toscano J, Flecha C, Guil A, Macias A, Pinero M. Congreso Iberoamericano de Ciencia, Tecnología y genero (Vol. 31).

FELITTI, K. (2011a) Parirás sin dolor: poder médico, género y política en las nuevas formas de atención del parto en la Argentina (1960-1980). História, Ciências, SaúdeManguinhos, 18.

FELITTI, K. (coord.) (2011b) Madre no hay una sola. Experiencias de maternidad en la Argentina. Buenos Aires: Ciccus.

FEMENÍAS, M. L., \& SOSA ROSSI, P. (2011) Saberes situados, teorías trashumantes. Facultad de Humanidades y Ciencias de la Educación, CINIG-IdHCS-CONICET.

FERNÁNDEZ DEL CASTILLO, I. F. (2006). La revolución del nacimiento: partos respetados, nacimientos más seguros. Grupo Editorial Norma.

FERNÁNDEZ SACASAS, J. A. (2011) Controversias en torno a la medicina basada en evidencias. Revista Habanera de Ciencias Médicas, 10(3), 339-347.

FORNES, V. (2011) Parirás con poder...(pero en tu casa). El parto domiciliario como experiencia política contemporánea. En Felitti (coord.) Madre no hay una sola. Experiencias de maternidad en Argentina. Ed. CICCUS, Buenos Aires, 133-154.

FORNES, L. (2010) Entre el instinto y el derecho. Representaciones de la maternidad en la humanización del parto. VI Jornadas de Antropología Social, Facultad de Filosofia y Letras, Universidad de Buenos Aires.

FORNES, L. (2009) Cuerpos, cicatrices y poder: una mirada antropológica sobre la violencia de género en el parto. I Congreso Interdisciplinario sobre Género y Sociedad, Universidad Nacional de Córdoba.

FOUCAULT, M. (2003) El nacimiento de la clínica: una arqueología de la mirada médica. Siglo $X X I$.

FREIDSON, E. (1978) La profesión médica. Barcelona. Edit. Península.

GAINZA, P. P., LABASTIE, M., \& MAGNONE ALEMAN, N. (2013). La atención contemporánea del parto: jaque a la perspectiva de derechos humanos. ULÚA. Revista de Historia, Sociedad y Cultura, (22).

GALLIANO, D. (2007), Historia de la ginecología y obstetricia. Servicio de Obstetricia y GinecologíaHospital Universitario. Documento de estudio para residentes.

GARCÍA, L. (2009) Cuerpo y narrativa: una aproximación etnográfica al proceso de atención del embarazo, parto y puerperio de mujeres viviendo con VIH en Ciudad de Buenos Aires. Horizontes Antropológicos, Porto Alegre, ano 15, n. 32, p. 247-272, jul./dez. 2009

GARCÍA FERNÁNDEZ, T. (2014) De la palabra a la carne, cuerpo femenino y maternidad. I Jornadas de Género y Diversidad Sexual, Facultad de Trabajo Social, Universidad Nacional de La Plata, Argentina.

GARCÍA JORDÁ, D., \& DÍAZ BERNAL, Z. (2010) Perspectiva antropológica y de género en el análisis de la atención al embarazo, parto y puerperio. Revista cubana de salud pública, 36, 330-336.

GARCIA PRESAS, A. L., GONZÀLEZ, M. F., MATTIOLI, M., y MARANO ROUDE, M. (2018). "Ni solas, ni locas". Narrativas de activistas por el parto respetado en Entre Rios. Trabajo 
presentado a III Jornadas de Gènero y Diversidad Sexual de la Facultad de Trabajo Social, UNLP.

GARCIA ZEFERINO, E., CADENA, D., \& PEÑA, M. (2016) Humanismo durante la atención del trabajo de parto. Revista Conamed, 15(3). México. ISSN 1405-6704

GARCÍA-JORDÁ, D., DÍAZ-BERNAL, Z., ACOSTA ÁLAMO, M., (2012) El nacimiento en Cuba: análisis de la experiencia del parto medicalizado desde una perspectiva antropológica. Ciência \& Saúde Coletiva 2012, 17 (Julio). ISSN 1413-8123

GARRIGA ZUCAL, J. (2010) "Se lo merecen" Definiciones morales del uso de la fuerza física entre los miembros de la policía Bonaerense. Cuadernos de Antropología social, № 32 , Pp 75.94

GARRIGA ZUCAL, J. y NOEL, G. (2010) Notas para una definición antropológica de la violencia: un debate en curso. Publicar en Antropología y en ciencias sociales, Buenos Aires.

GEERTZ, C. (1987) Descripción densa: hacia una teoría interpretativa de la cultura. La interpretación de las culturas, 19-40.

GENOlet, A., LeRA, C., SChOENFELD, Z., GUERRIERA, I., BOlCATtO, S., (2009). Trayectorias de vida y prácticas maternales en contextos de pobreza. Ciencia, Docencia y Tecnología 2009, XX (Mayo). ISSN 0327-5566

GIARRACCA, N., \& Bidaseca, K. (2001) Ensamblando las voces: los actores en el texto sociológico. Metodologías cualitativas en ciencias sociales, Biblos, Buenos Aires.

GIBERTI, E. (2003) El poder hegemónico del médico en situación de embarazos y partos. Primer Congreso Nacional de Partería - La Plata 29 de octubre 03

GILLIGAN, C. (2017) El malentendido de la maternidad reciente. Encuentros y desencuentros entre mujeres y trabajadores de un servicio de obstetricia. Trabajo presentado para las XIII Jornadas Nacionales de Historia de las Mujeres, UBA y UNQUI, Julio 2017.

GILLIGAN, C., \& SALSA CORTIZO, M. V. (2016) Entre el acompañamiento y la producción de un campo disciplinar: Una mirada antropológica acerca del ejercicio profesional de las obstétricas. In IX Jornadas de Sociología de la UNLP 5 al 7 de diciembre de 2016 Ensenada, Argentina. Universidad Nacional de La Plata. Facultad de Humanidades y Ciencias de la Educación. Departamento de Sociología.

GOBERNA TRICAS, M. (2012) Autonomía, heteronomía y vulnerabilidad en el proceso de parto. ENE. Revista de Enfermería. Abr. 2012; 6(1): 71-78

GÓMES HOYOS, D., (2007) Nuevas normas sobre protección a la maternidad. Díkaion 2007, 21 (noviembre). ISSN 0120-8942

GÓMEZ DE LA CÁMARA, A. (2003) La medicina basada en evidencias científicas: mito o realidad de la variabilidad de la práctica clínica y su repercusión en los resultados en salud. In Anales del Sistema Sanitario de Navarra (Vol. 26, No. 1, pp. 11-26). Gobierno de Navarra. Departamento de Salud.

GÓNZALES MONTES, S. (2003) Los oficios de la maternidad Una mirada desde la antropología médica. Desacatos 2003, (invierno). ISSN 1405-9274

GONZÁLEZ, M., DIEZ, M., JIMÉNEZ, I., MORGADO, B., (2008) Maternidad a solas por elección: primera aproximación. Anuario de Psicología 2008, 39 (Abril). ISSN 0066-5126

GRACIA, D. (2009) Medicina basada en la evidencia: aspectos éticos. Revista Bioética, 8(1).

GRIMBERG, M. (2003) Narrativas del cuerpo. Experiencia cotidiana y género en personas que viven con VIH. Cuadernos de antropología social, (17).

GRIMBERG, M., (1995) Teorías, propuestas y prácticas sociales. Problemas teóricometodológicos en antropología y salud". En Alvarez, M. y Barreda, V. (comps.) Cultura, salud y enfermedad. Temas en antropología médica. pp.31-50. Buenos Aires: Instituto Nacional de Antropología y Pensamiento Latinoamericano.

GROSBERG, L. (2006) Stuart Hall sobre raza y racismo: estudios culturales y la práctica del contextualismo. Tabula Rasa, (5).

GUPTA, A., \& FERGUSON, J. (2008). Más allá de la "cultura": espacio, identidad y las políticas de la diferencia. Antípoda. Revista de Antropología y Arqueología, (7), 233-256.

HALL, S. (2003) Introducción: ¿quién necesita identidad?. Cuestiones de identidad cultural, 1339.

HASICIC, C. (2012) Paternidades adolescentes: hacia una conceptualización y sistematización en América Latina y Argentina. En VII Jornadas de Sociología de la UNLP 5 al 7 de diciembre de 2012 La Plata, Argentina. Argentina en el escenario latinoamericano actual: Debates desde las ciencias sociales. Universidad Nacional de La Plata. Facultad de Humanidades y Ciencias de la Educación. Departamento de Sociología. 
HASICIC, C. (2018) Jóvenes y cuidado: un análisis sobre las prácticas de crianza y cuidado de padres varones de un barrio popular del Gran La Plata (Argentina). Polis (Santiago), 17(50), 91-109.

HERNÁNDEZ GARRE, J. M., \& ECHEVARRíA PÉREZ, P. (2016) Sociología del parto. Conflictos asistenciales en el marco del" paradigma tecnocrático'”. Revista Internacional de Sociología, 74(1), 025.

HERNÁNDEZ GARRE, J. M., \& ECHEVARRÍA PÉREZ, P. (2015) El nacimiento hospitalario e intervencionista: un rito de paso hacia la maternidad. Revista de Antropología Iberoamericana, 10.

HERNÁNDEZ GARRE, J. M., \& ECHEVARRÍA PÉREZ, P. (2014) La parte negada del parto institucionalizado: explorando sus bases antropológicas. Revista de Dialectología y Tradiciones Populares, 69.

HUAMÁN BERRÍOS, J. E. (2004) Historia de la obstetricia ensayo sobre algunas ideas de la obstetricia. Perú, Huancayo, 23-28.

HURTADO LA ROSA, R., (2006) Adecuación cultural para la atención del parto. Chacarera (No. 33 jul 2006). Lima. Ed. Centro de la Mujer Peruana Flora Tristán.

ILLICH, I. (1978) Némesis médica: la expropiación de la salud. México: Joaquín Mortiz.

ISLA, A. y MIGUEZ, D. (2003) Introducción. En Isla, A. y Miguez, D. (Coord.) (2003). Heridas Urbanas. Violencia delictiva y transformaciones sociales en los noventa. Buenos Aires. Editorial de las ciencias.

JEREZ, C. (2015a) Paradojas de la "Humanización" del parto:¿ Qué partos merecen ser "empoderados". XI Jornadas de Sociología, Buenos Aires, Argentina. Universidad de Buenos Aires. Facultad de Ciencias Sociales.

JEREZ, C. (2015b) Partos 'humanizados', clase y género en la crítica a la violencia hacia las mujeres en los partos. Tesis de Licenciatura en Ciencias Antropológicas. UBA.

JEREZ, C., (2014a) "Partos empoderados": clase y género en la crítica a la violencia hacia las mujeres en los partos. XI Congreso Argentino de Antropología Social. Rosario, Argentina.

JEREZ, C. (2014b) Clase y género en las propuestas de la "Humanización" del parto: Un análisis desde la Antropología feminista. Zona Franca n²3. Universidad Nacional de Rosario.

JIMENO, M. (2005) Narrando la violencia. Relatos de pasión y muerte. Anuario de Estudios en Antropología Social, Año 1, № 1, pp 55-67.

LAGARDE, M. (2012) El feminismo en mi vida. México: Instituto de las Mujeres del Distrito Federal.

LAPLACETTE, G., y VIGNAU, L., (2008) Medicalización de la salud. En Cannellotto, A., \& Luchtenberg, E. (2008). Medicalización y sociedad. Lecturas críticas sobre un fenómeno en expansión. Argentina: Observatorio Argentino de Drogas (SEDRONAR).

LARGUÍA, M., (2000) Proyecto maternidades centradas en la familia. Revista del Hospital Materno Infantil Ramón Sardá. 2000, 19. > ISSN 1514-9838

LEDESMA PRIETTO, N. (2014). La maternidad consciente y voluntaria como estrategia para la emancipación sexual femenina. Cuadernos de $H$ ldeas, 8.

LEDESMA PRIETTO, N. (2012a). Apuntes sobre la eugenesia y la libertad sexual en el discurso de dos médicos anarquistas. Argentina, 1930-1940. Nomadías, (16), ág-75.

LEDESMA PRIETTO, Nadia. (2012b). Reseña Chaneton, July y Vacarezza, Nayla (2011). La intemperie y lo intempestivo. Experiencias del aborto voluntario en el relato de mujeres y varones. En Mora (B. Aires). Vol. 18 no. 2 Ciudad Autónoma de Buenos Aires dic. 2012.

LEFEBVRE, H. (1991) The production of space (Vol. 142). Oxford: Blackwell.

LEVANDOWSKI, D. C., MARIN, A. H., DA SILVA PEREIRA, C., \& MENDES, M. G. (2015) ¡Llegó la hora! Expectativas y experiencias de parto de adolescentes embarazadas. Revista de Psicología, 33(2), 333-361.

LINS RIBEIRO, G., (1989) Descotidianizar. Extrañamiento y conciencia práctica, un ensayo sobre la perspectiva antropológica. En Cuadernos de Antropología Social, Sección Antropología Social, Instituto de Ciencias Antropológicas, Facultad de Filosofía y LetrasUBA, Vol. 2, №. 1, 1989, pp. 65-69.

LÓPEZ GÓMEZ, A. (2016) Tensiones entre lo (i) legal y lo (i) legítimo en las prácticas de profesionales de la salud frente a mujeres en situación de aborto. Salud colectiva, 12, 2339. 
LORENZO, C. (2013). Es un parto: indagaciones en torno a la construcción de un derecho. VII Jornadas de Jóvenes Investigadores. Instituto de Investigaciones Gino Germani, Facultad de Ciencias Sociales, Universidad de Buenos Aires, Buenos Aires.

MAGNONE ALEMAN, N. (2014) El derecho a elegir dónde, cómo y con quién parir vs las políticas de salud: consecuencias sobre las mujeres que paren del proceso de regionalización de las maternidades. Jornadas Feministas de UdelaR.

MAGNONE ALEMAN, N., (2013) Modelos contemporáneos de asistencia al parto: Cuerpos respetados, mujeres que se potencian. Revista Latinoamericana de Estudios sobre Cuerpos, Emociones y Sociedad №12. Año 5. Agosto 2013 - Noviembre 2013. Argentina. ISSN: 1852-8759. pp. 79-92.

MAGNONE ALEMAN, N., (2011) Derechos sexuales y reproductivos en tensión: intervencionismo y violencia obstétrica. $X$ Jornadas de Investigación de la Facultad de Ciencias Sociales, UdelaR, Montevideo, 13-14 de setiembre de 2011

MAGNONE ALEMAN, N. (2010). Derechos y poderes en el parto: una mirada desde la perspectiva de Humanización (Doctoral dissertation, Tesis de la Maestría en Sociología. Facultad de Ciencias Sociales, Universidad de la República).

MARCÚS, J., (2006) Ser madre en los sectores populares: una aproximación al sentido que las mujeres le otorgan a la maternidad. Revista Argentina de Sociología. 2006, 4 (noviembre-diciembre). ISSN 1667-9261

MARIN, L. (2018) La relación médico/paciente en el abordaje de padecimientos crónicos. La construcción del paciente y del tratamiento de la enfermedad en el ejercicio de la práctica médica. X Jornadas de Sociologia de la UNLP, diciembre 2018.

MAROTO NAVARRO, G., CASTAÑO LÓPEZ, E., CALVENTE, G., DEL MAR, M., HIDALGO RUZZANTE, N., \& RODRÍGUEZ, I. (2009). Paternidad y servicios de salud. Estudio cualitativo de las experiencias y expectativas de los hombres hacia la atención sanitaria del embarazo, parto y posparto de sus parejas. RevEsp Salud Pública 2009; 83: 267-278 N. ${ }^{\circ} 2$ - Marzo-Abril 2009.

MARTON, B. y ECHAZÚ, M. (2010) La violencia simbólica en la consulta médica: la naturalización de la díada madre-hijo y la promoción compulsiva de la lactancia materna. Sexualidad, Salud y Sociedad - Revista Latinoamericana (5) ISSN 1984-6487

MAXWELL, J. (1996). Qualitative Research Design. An Interactive Approach. Sage Publications. Traducción Alicia Itatí Palermo.

MEDINA, G. (2010) Violencia obstétrica. Cap 4 en Informe de "Omisión y diferencia. Derechos Reproductivos en México". Grupo de información en reproducción elegida. http://informe.gire.org.mx/bibliografia.html

MENDEZ-GONZALEZ, R. M. y CERVERA-MONTEJANO, M., (2002) Comparación de la atención del parto normal en los sistemas hospitalario y tradicional. Salud pública Méx [online]. 2002, vol.44, n.2, pp. 129-136. ISSN 0036-3634.

MENÉNDEZ, E. (2009) De sujetos, saberes y estructuras. Introducción al enfoque relacional en el estudio de la salud colectiva. Argentina. Edit. Lugar.

MENÉNDEZ, E. (1992) Morir de alcohol. Saber y hegemonía médica. México. Edit. Alianza.

MENÉNDEZ, E. (1988) Modelo médico hegemónico y atención primaria. Segundas jornadas de atención primaria de la salud, 30, 451-464.

MERINO, L. y FORNES, V., (2008) Gestar y parir espacios de género. Un abordaje cultural sobre la palabra, la experiencia y el poder en los modelos de parto. Trabajo final del curso de posgrado. Construcción de proyectos en Ciencias Sociales. Investigación cualitativa, acción social y gestión cultural. CAICYT- CONICET.

MíGUEZ, D. (2002) Inscripta en la piel y en el alma: cuerpo e identidad en profesionales, pentecostales y jóvenes delincuentes. Religiâo e Sociedade, 22(1).

MINISTERIO DE SALUD DE LA NACIÓN - DIRECCIÓN NACIONAL DE MATERNIDAD E INFANCIA (2012) "Guía para la atención del parto normal en maternidades centradas en la familia".

MINISTERIO DE SALUD DE LA NACIÓN, UNICEF, MATERNIDAD SARDÁ Y FUNDACIÓN NEONATOLÓGICA (2011)."Maternidad Segura y Centrada en la Familia [MSCF] con enfoque intercultural: conceptualización e implementación del modelo".

MINISTERIO DE SALUD DE LA PROVINCIA DE BUENOS AIRES (2012). "Guía de procedimientos para el control del embarazo y la atención del parto y puerperio de bajo riesgo". Ministerio de Salud de la Provincia de Buenos Aires. 2012.

MISERES, V. (2018) "El parto es tuyo": testimonio, maternidad y política en dos documentales sobre violencia obstétrica. Letras femeninas, 43(2), 134-146. 
MITJAVILA, M. (1998) El saber médico y la medicalización del espacio social. Documento de Trabajo DTS. Montevideo, Facultad de Ciencias Sociales.

MONTES MUÑOZ, M. J. (2008) Cuerpos gestantes y orden social. Discursos y prácticas en el Embarazo. Index de Enfermería ISSN 1132-1296. V.17 n.1 Granada ene.-mar. 2008

MONTES MUÑOZ, M. J. (2007). Las culturas del nacimiento. Representaciones y prácticas de las mujeres gestantes, comadronas y médicos. Universitat Rovira i Virgili.

MUÑOS SELLES, A. y GOBERNA TRICAS, L. (2012) Oferta formativa en terapias alternativas y complementarias para la asistencia al parto. Revista Matronas Profesión 2012; 13(2): 50-54

NARI, M. M. (2004) Políticas de maternidad y maternalismo político: Buenos Aires, 1890-1940. Buenos Aires: Editorial Biblos.

NOVICK, S., (1993) Mujer, Estado y Políticas Sociales. Centro editor de América Latina S. A. ISBN: $950-25-2413-6$

ODENT, M. (2011) El nacimiento en la era del plástico. Buenos Aires. Editorial creavida.

ORGANIZACIÓN MUNDIAL DE LA SALUD (1985) Recomendaciones de la OMS sobre el Nacimiento. Declaración de Fortaleza 1985 Tecnología apropiada para el parto. En Lancet 1985; 2:436-437. Traducción ACPAM

ORTALE, M. S., \& SANTOS, J. A. (2014) Crianza. Un estudio de los patrones de criana en hogares del partido de La Plata. Buenos Aires. Ed. Elaleph.com.

ORTALE, S. (2008) Los programas de salud sexual y reproductiva y la maternidad adolescente en el partido de La Plata. Discusiones a la luz de los derechos humanos y el enfoque de género. IX Congreso Argentino de Antropología Social. Facultad de Humanidades y Ciencias Sociales - Universidad Nacional de Misiones, Posadas.

ORTEGA CALVO, M. \& CAYUELA DOMÍNGUEZ, A. (2002) Medicina basada en la evidencia: una crítica filosófica sobre su aplicación en atención primaria. Revista Española de Salud Pública, 76, 115-120.

PAGNAMENTO, L.; WEINGAST, D.; HASICIC, C.; CASTRILLO, B.; CANEVA, H.; SPECOGNA, M. (2016) Proceso salud-enfermedad-atención desde una perspectiva de género: una propuesta conceptual para su análisis. Ponencia colectiva del Proyecto PPID, presentada a las IX Jornadas de Sociologia de la UNLP. La Plata, diciembre de 2016.

PALOMAR VEREA, C., (2005) Maternidad: Historia y Cultura. Revista de Estudios de Género. La ventana 2005. ISSN 1405-9436

PELCASTRE, B., VILLEGAS, N., DE LEÓN, V., DÍAZ, A., ORTEGA, D., SANTILLANA, M., \& DE LOS ÁNGELES MEJÍA, J. (2005) Embarazo, parto y puerperio: creencias y prácticas de parteras en San Luis Potosí, México. Revista Escuela de Enfermeria USP 2005; 39(4):375-82.

PESTAÑA, J., \& GARCÍA, F. V. (Eds) (2006) Pierre Bourdieu y la filosofía. Editorial Montesinos.

PICHOT, M. (2017) El recetario de la violencia obstétrica. Buenos Aires. Ed. Madreselva.

PINTO, V., (2007) Madres e hijos en los 90: Las representaciones sociales de la maternidad en la revista Para Ti. Opción 2007, 23 (mayo-agosto). ISSN 1012-1587

PIZZA, G. (2005) Antonio Gramsci y la antropología médica contemporánea. Hegemonía y capacidad de actuar. Revista de Antropología Social, 14.

PORTO, A. A. S., DA COSTA, L. P., \& VELLOSO, N. A. (2015). Humanização da assistência ao parto natural: uma revisão integrativa. CIÊNCIA \& TECNOLOGIA, 1(1), 12-19.

POSSO QUICENO, J., (2010) Las transformaciones del significado y la vivencia de la maternidad, en mujeres negras, indígenas y mestizas del suroccidente colombiano. Revista Sociedad y Economía, núm. 18, 2010, pp. 59-84. Universidad del Valle. Cali, Colombia

POZZIO, M. (2016) La gineco-obstetricia en México: entre el "parto humanizado" y la violencia obstetrica. Revista Estudos Feministas, 24(1), 101-117.

POZZIO, M. (2014) "El hecho de que sean más mujeres, no garantiza nada": feminización y experiencias de las mujeres en la ginecobstetricia en México. Salud colectiva, 10, 325337.

POZZIO, M. (2013) Una propuesta de "Parto Humanizado", los discursos de los actores y el lugar (incómodo) de las mujeres médicas en el mismo. In VII Jornadas Santiago Wallace de Investigación en Antropología Social. Sección de Antropología Social. Instituto de Ciencias Antropológicas. Facultad de Filosofía y Letras, UBA.

POZZIO, M. (2011) Madres, mujeres y amantes. Buenos Aires, Editorial Antropofagia.

PUJADAS RÍOS, X., OVIEDO RODRÍGUEZ, R., MONTERO TORRES, F., PINEDA, J. F., (2011) Humanización del parto en la medicina de excelencia. MediSur 2011, 9. 
RAMACCIOTTI, K. I., CANNELLOTTO, A., \& LUCHTENBERG, E. (2008) Las instituciones sanitarias en la Argentina: Entre el clamor de las urgencias sociales y la planificación. Buenos Aires: Observatorio Argentino de Drogas (SEDRONAR), Universidad Nacional de General San Martín, Programa Mundos Contemporáneos.

RAMIREZ, C. (2015) Parto en casa planificado con asistencia profesional: recuperando el protagonismo, Tesis de grado de antropología social dirigida por Sadler. Chile.

RIBOT, L. (2010) De mujeres y de partos: en la búsqued del trono perdido. La Plata.

RIBOT, L., HASPERUE, R., Y SOSA, A. C. (2016) Relatos Paridos. Cada nacimiento es una historia. Buenos Aires: Acercándonos ediciones.

RICH, A., \& BARTOLOMÉ, M. B. (1996) Nacemos de mujer: la maternidad como experiencia e institución. Cátedra. Madrid.

RICHES, D. 1988. El fenómeno de la violencia. Madrid. Pirámide.

RIVAS, L. (1994) La subjetividad: opaco objeto de conocimiento.

RODRIGAÑEZ BUSTOS, C. (2007) Pariremos con placer. Apuntes sobre la recuperación del útero espástico y la energía sexual femenina. Buenos Aires. Ed la mariposa y la iguana.

ROMERIO, M. N., DÍAZ, M. C., (2001) La maternidad como conflicto. Una expresión de inequidad social y de género. Colombia Médica 2001, 32. ISSN 0120-8322

ROMERO MARCHESINI, N. (2018) Claves para pensar la dimensión temporal en el marco de trayectorias terapéuticas. X Jornadas de Sociologia de la UNLP. Diciembre 2018.

SADLER, M. \& DÍAZ, SOL (2017). Historia ilustrada de un embarazo. Santiago de Chile.Ed. Catalonia.

SADLER, M. (2007) "Los hombres también se emocionan": hacia la construcción de masculinidades presentes. Revista Gaceta Universitaria de Psiquiatria, 2007; 3; 4: 437449.

SADLER, M. (2004) Así me nacieron a mi hija. Aportes antropológicos para el análisis de la atención biomédica del parto hospitalario. En Sadler, Acuña y Obach, Nacer, Educar, Sanar; Miradas desde la Antropología del Género. Colección Género,Cultura y Sociedad, Cátedra UNESCO Género. Catalonia, 2004, Santiago de Chile,pp. 15-66.

SADLER, M. (2003). Así me nacieron mi hija. Aportes antropológicos para el análisis de la atención biomédica del parto hospitalario [Tesis]. Santiago: Universidad de Chile.

SCHRAIBER, L. (2015). Acción técnica y acción moral en los profesionales de la salud. Poder médico y ciudadanía: El conflicto social de los profesionales de la salud con los derechos reproductivos en América Latina. Montevideo: Facultad de Psicología, Universidad de la República.

SCHWARZ, P. (2016) Maternidades en verbo: identidades, cuerpos, estrategias, negociaciones: mujeres heterosexuales y lesbianas frente a los desafíos de maternar. Buenos Aires. Editorial Biblos.

SCHWARZ, P., (2010a) Construcción de la maternidad en el encuentro de la institución médico ginecológica con mujeres de clase media de la ciudad de Buenos Aires. Sexualidad, Salud y Sociedad - Revista Latinoamericana 2010, (Diciembre).

SCHWARZ, P., (2010b) La maternidad tomada. Ginecólogos, obstetras y mujeres en interacción. Discursos yprácticas en la clase media. En: Argumentos (no. 11 2010) Estudios sobre sexualidades y salud reproductiva. Buenos Aires.

SCOTT, J. W. (1999). La experiencia como prueba. N. Carbonell y M. Torras (Comp.), Feminismos Literarios, 77-112.

SCRIBANO, A. (2012) Sociología de los cuerpos/emociones. Revista Latinoamericana de Estudios sobre Cuerpos, Emociones y Sociedad, 3(10), 93-113.

SEGATO, R. (2004). Territorio, Soberanía y crímenes de Segundo Estado: La escritura en el cuerpo de las Mujeres Asesinadas en Ciudad Juárez. Brasilia Departamento de Antropología Universidad de Brasilia.

SEGATO, R. (2003) Las estructuras elementales de la violencia. Prometeo- Universidad Nacional de Quilmes, Bernal.

SIMIAO, D. (2011) Las dueñas de la palabara: género, justicia y la invención de la violencia domestíca en Timor Oriental. En Rifiotis, T. y Castelnuovo N., Antropología, violencia y justicia. Repensando matrices de sociabilidad contemporánea en el campo del género y de la familia. Bs. As., Antropofagía.

SPECOGNA, M. (2016) Nacer y Parir en la provincia de Buenos Aires. Dispositivos normativos de la atención del parto. In IX Jornadas de Sociología de la UNLP 5 al 7 de diciembre de 2016 Ensenada, Argentina. Universidad Nacional de La Plata. Facultad de Humanidades y Ciencias de la Educación. Departamento de Sociología. 
STAKE, R. E. (1998) Investigación con estudio de casos. Ediciones Morata.

SUAREZ, H. J. (2008) Pierre Bourdieu: político y científico. Estudios Sociológicos, 433-449.

SVAMPA, M. (2008). Notas provisorias sobre la sociología, el saber académico y el compromiso intelectual. Gérard Althabe, Entre varios mundos, Buenos Aires, Prometeo.

TABAK, G. (2014) Corporalidades transformadas: Embarazo, parto y puerperio. In VIII Jornadas de Sociología de la UNLP 3 al 5 de diciembre de 2014 Ensenada, Argentina. Universidad Nacional de La Plata. Facultad de Humanidades y Ciencias de la Educación. Departamento de Sociología

TERÁN, P., CASTELLANOS, C., GONZÁlEZ BLANCO, M., \& RAMOS, D. (2013) Violencia obstétrica: percepción de las usuarias. Revista Obstetricia Ginecologia Venezuela. 2013;73(3):171-180

TRUPA, N. S. (2015) Apropiación subjetiva de derechos sexuales y reproductivos de familias comaternales, usuarias de Nuevas Tecnologías Reproductivas, del Área Metropolitana de Buenos Aires (Tesis de Maestría en Sociología de la Cultura y Análisis Cultural, Instituto de Altos Estudios Sociales--Universidad Nacional de San Martín. Mimeo).

VALLES, M. S. (2000). Técnicas cualitativas de investigación social. Sintesis Editorial.

VALLS LLOBET, C. (2009). Mujeres, salud y poder. Feminismos. Cátedra Ediciones.

VELAZQUEZ, M. (2004), La paternidad en el proyecto de vida de algunos varones de la Ciudad de México. En MNEME, Revista de Humanidades. Publicação do Departamento de História e Geografia da Universidade Federal do Rio Grande do Norte Centro de Ensino Superior do Seridó - Campus de Caicó. V. 05. N. 11, jul./set. de 2004. - Semestral

VIDELA, M. (2010) Maternidad: mito y realidad. Buenos Aires. Ed. Koyatùn..

VILLANUEVA EGAN, L. (2010) El maltrato en las salas de parto: reflexiones de un ginecoobstetra. Revista CONAMED. Volumen 15, número 3, julio-septiembre 2010, pp. 147-151. México. ISSN 1405-6704

VILLEGAS POLJAK, A., (2009) La violencia obstétrica y la esterilización forzada frente al discurso médico. Revista Venezolana de Estudios de la Mujer. Caracas. Enero/Junio 2009 - VOL. 14 / N 32

VOLTAS BARÓ, D., (2008) La mujer-madre, un valor que renace. Cuadernos de Bioética 2008, XIX (Sept-Diciembre). ISSN 1132-1989

WAGNER, M., (2006). El cuidado maternal en España 2006: La necesidad de humanizar el parto. Medicina naturista, (10), 120-132.

WILLIAMS, R. (1997 [1980]) Marxismo y literatura. Barcelona. Ed. Península. 